\title{
Carboxylate-Assisted Ruthenium-Catalyzed Direct C-H Bond Functionalizations
}

\author{
Dissertation \\ for the award of the degree \\ "Doctor rerum naturalium" (Dr. rer. nat.) \\ of the Georg-August-Universität Göttingen
}

within the doctoral program of chemistry

of the Georg-August University School of Science (GAUSS)

submitted by

Lianhui Wang

from Puyang (China)

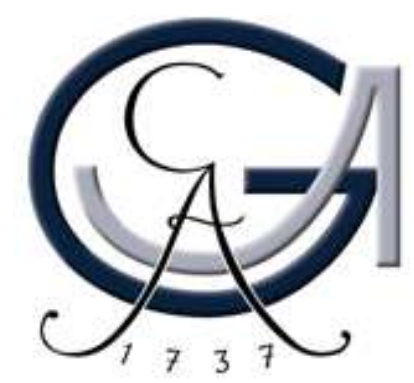

Göttingen, 2014 



\section{Thesis Committee}

Prof. Dr. L. Ackermann, Institute of Organic and Biomolecular Chemistry

Prof. Dr. D. Stalke, Institute of Inorganic Chemistry

\section{Members of the Examination Board}

Reviewer: Prof. Dr. L. Ackermann, Institute of Organic and Biomolecular Chemistry

Second Reviewer: Prof. Dr. D. Stalke, Institute of Inorganic Chemistry

\section{Further members of the Examination Board}

Prof. Dr. K. Koszinowski, Institute of Organic and Biomolecular Chemistry

Prof. Dr. F. Meyer, Institute of Inorganic Chemistry

Prof. Dr. G. Clever, Institute of Inorganic Chemistry

Dr. A. Breder, Institute of Organic and Biomolecular Chemistry

Date of the oral examination: February $26^{\text {th }}, 2014$ 



\section{CONTENTS}

1 Introduction

1.1 Metal-Catalyzed Direct C-H Bond Functionalizations...................................

1.1.1 Metal-Catalyzed Direct C-H Bond Functionalizations: An Overview.........................1

1.1.2 Mechanisms for Transition-Metal-Catalyzed C-H Bond Metalation.........................2

1.1.3 Carboxylate-Assisted Ruthenium-Catalyzed Direct C-H Bond Functionalizations..............3

1.2 Ruthenium-Catalyzed Alkyne Annulations by $\mathrm{C}-\mathrm{H} / \mathrm{Het}-\mathrm{H}$ Bond Functionalizations............7

1.3 Ruthenium-Catalyzed Direct Oxidative Alkenylation of Arenes............................14

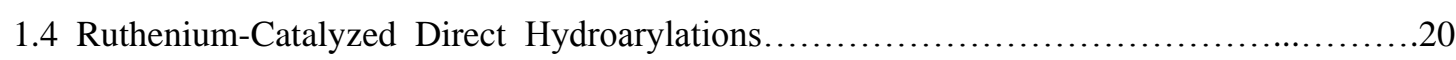

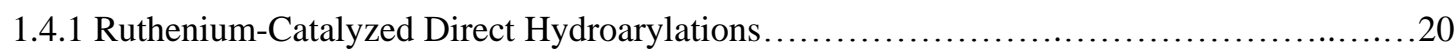

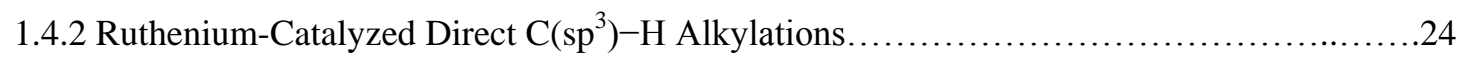

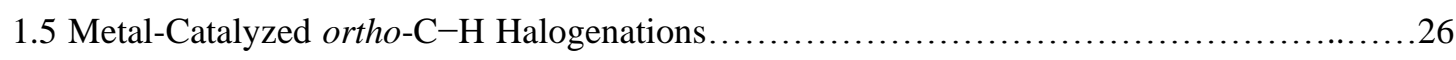

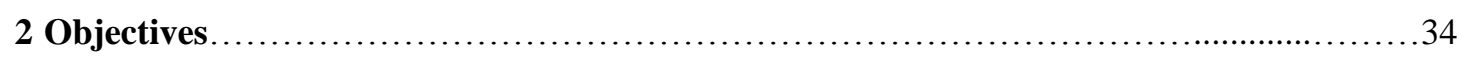

3 Ruthenium-Catalyzed Oxidative Annulation of Alkynes Through C-H/N-H Bond

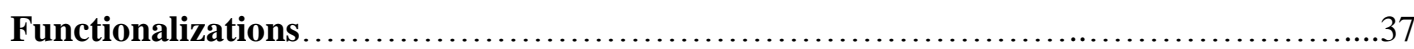

3.1 Ruthenium-Catalyzed Aerobic Oxidative Annulation of Alkynes with 2-Aryl-Substituted

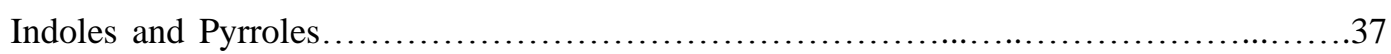

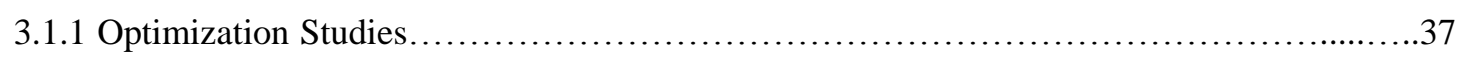

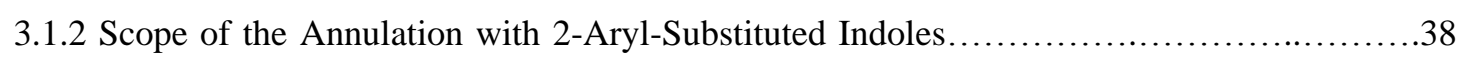

3.1.3 Scope of the Annulation with 2-Aryl-Substituted Pyrroles.............................40

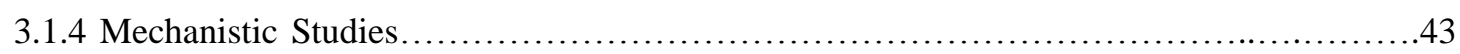

3.1.4.1 Inter- and Intramolercular Competition Experiments....................................43

3.1.4.2 Reactions with Isotopically Labelled Solvents.........................................44

3.1.5 Proposed Catalytic Cycle...............................................................4 44

3.2 Ruthenium-Catalyzed Oxidative Annulation of Alkynes with Enamines for Pyrrole

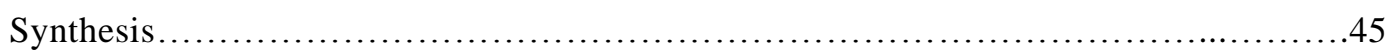

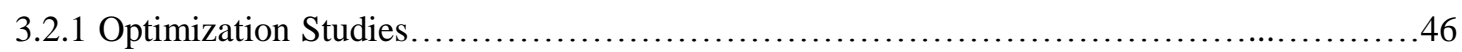

3.2.2 Scope of the Oxidative Pyrrole Synthesis........................................ 47

3.2.3 Ruthenium(II)-Catalyzed Aerobic Oxidative Pyrrole Synthesis.............................50

3.2.4 Mechanistic Studies.................................................................... 50

3.2.4.1 Intermolecular Competition Experiments...........................................50

3.2.4.2 Reactions in Isotopically Labelled Solvents.......................................52

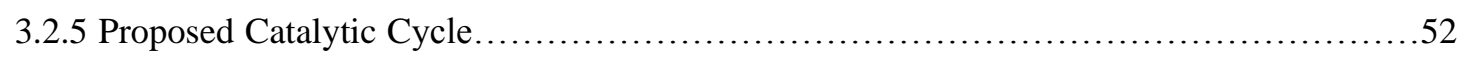

4 Ruthenium-Catalyzed Oxidative C-H Alkenylations..................................5

4.1 Ruthenium-Catalyzed Oxidative C-H Alkenylations of Anilides.............................54

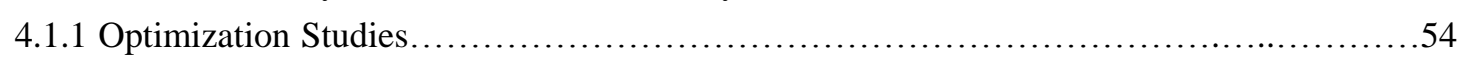

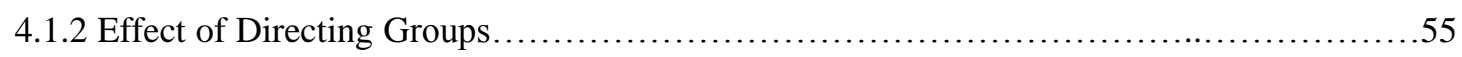

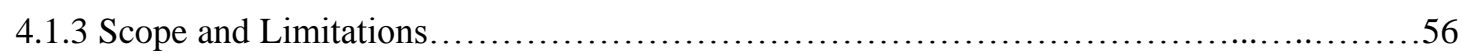

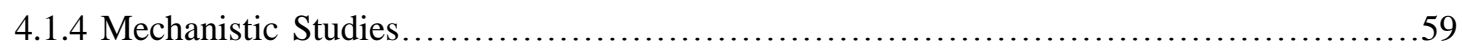

4.1.4.1 Intermolercular Competition Experiments.................................................59

4.1.4.2 Reactions in Isotopically Labelled Solvents........................................59

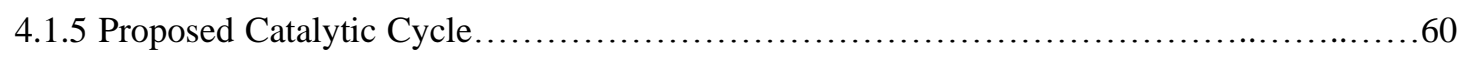

4.2 Ruthenium-Catalyzed Oxidative C-H Alkenylations of Benzamides.........................61 
5 Ruthenium(II)-Catalyzed C( $\left.\mathbf{s p}^{3}\right)-\mathbf{H} \boldsymbol{\alpha}$-Alkylation of Pyrrolidines with Alkenes...........63

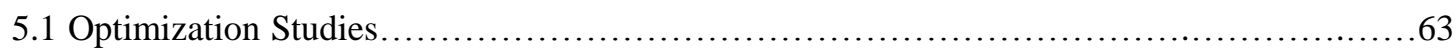

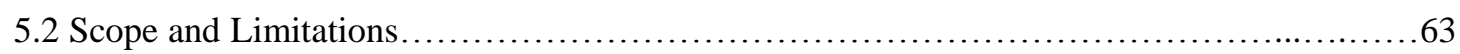

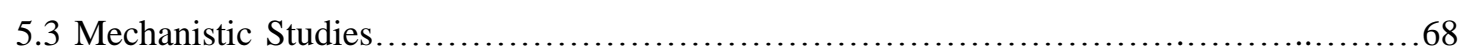

5.3.1 Reactions in the Presence of Radical Scavengers ....................................68

5.3.2 Reactions in Isotopically Labelled Reagents..................................6

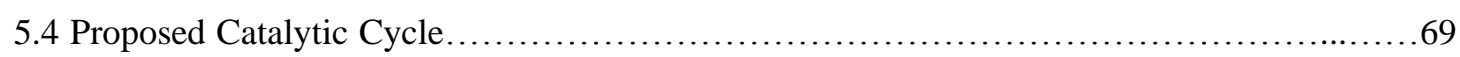

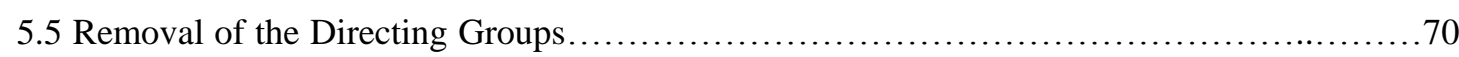

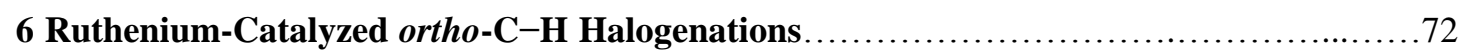

6.1 Preliminary Studies with Ruthenium(II)-Catalysis.................................... 72

6.1.1 ortho-Halogenations of Electron-Rich Arenes...................................... 72

6.1.2 ortho-Halogenations of Electron-Deficient Arenes..................................... 73

6.2 Ruthenium(0)-Catalyzed ortho-C-H Halogenations of Benzamides.........................74

6.2 .1 Optimization Studies...................................................... 75

6.2.2 Scope of the Ruthenium(0)-Catalyzed ortho- $\mathrm{C}-\mathrm{H}$ halogenations .........................77

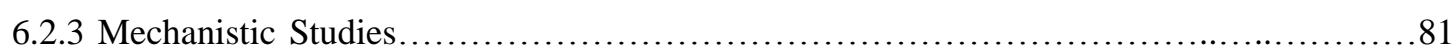

6.2.3.1 Reactions in the Presence of Radical Scavengers.................................. 81

6.2.3.2 Reactions in Isotopically Labelled Reagents..................................82

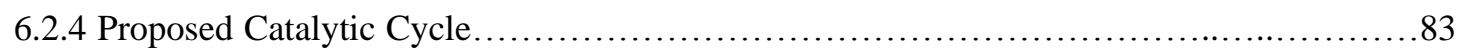

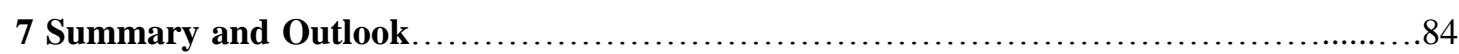

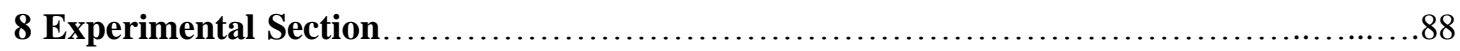

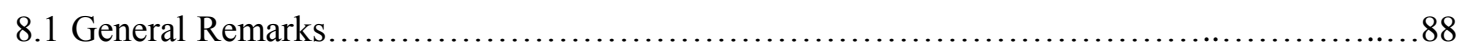

8.2 Synthesis of Starting Materials ................................................... 89

8.3 General Procedures......................................................... 90

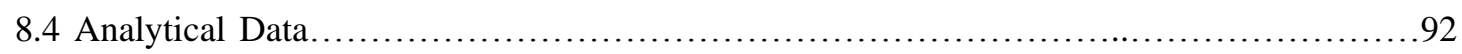

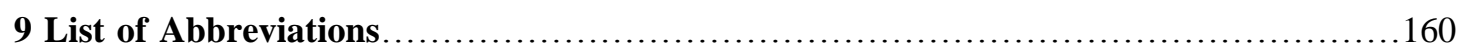

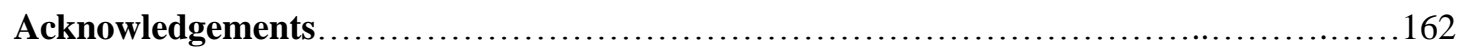

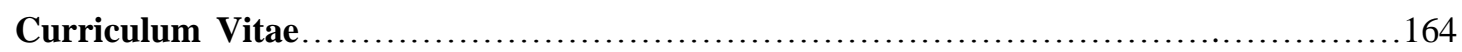




\section{Introduction}

\subsection{Metal-Catalyzed Direct C-H Bond Functionalizations}

\subsubsection{Metal-Catalyzed Direct C-H Bond Functionalizations: An Overview}

The catalytic functionalization of unreactive $\mathrm{C}-\mathrm{H}$ bonds represents one of the most powerful tools for sustainable syntheses and for opening new routes to pharmaceuticals and natural products. ${ }^{1,2}$ These methods are economically attractive alternatives to conventional cross-coupling reactions (Scheme 1). ${ }^{3,4}$ For instance, the prefunctionalized organometallics or main-group element arylating reagents $2\left(\mathrm{M}=\mathrm{MgX}, \mathrm{ZnX}, \mathrm{BR}_{2}, \mathrm{SnR}_{3}, \mathrm{SiR}_{3}\right.$, etc.) are often sensitive to air or are relatively expensive, and their preparation from the corresponding arenes $\mathbf{1}$ usually involves a number of synthetic operations (Scheme 1a). ${ }^{3 a}$ In contrast, direct $\mathrm{C}-\mathrm{H}$ bond activations such as the direct arylation reactions represent an environmentally and economically more attractive strategy,

(a) conventional cross-coupling

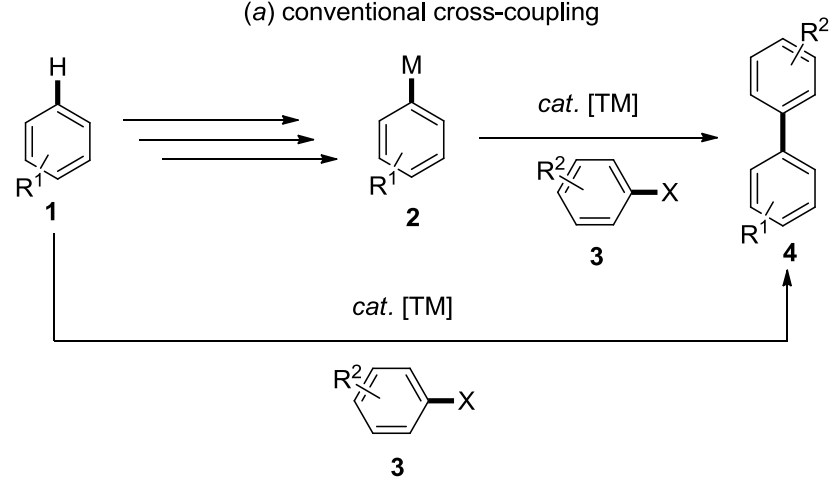

(b) direct arylation

Scheme 1 Conventional cross-coupling (a) versus direct arylation (b)

1 For recent reviews on C-H functionalizations in organic synthesis, see: (a) D. Y.-K. Chen, S. W. Youn, Chem.Eur. J. 2012, 18, 9452-9474; (b) W. R. Gutekunst, P. S. Baran, Chem. Soc. Rev. 2011, 40, 1976-1991; (c) L. McMurray, F. O'Hara, M. J. Gaunt, Chem. Soc. Rev. 2011, 40, 1885-1898.

2 (a) J. Yamaguchi, A. D. Yamaguchi, K. Itami, Angew. Chem. Int. Ed. 2012, 51, 8960-9009; (c) Modern Heterocyclic Chemistry; J. Alvarez-Builla, J. J. Vaquero, J. Barluenga, Eds.; Wiley-VCH: Weinheim, Germany, 2011.

3 (a) Modern Arylation Methods; L. Ackermann, Ed.; Wiley-VCH: Weinheim, Germany, 2009; For recent reviews on conventional cross-coupling reactions, see: (b) C. C. C. Johansson Seechurn, M. O. Kitching, T. J. Colacot, V. Snieckus, Angew. Chem. Int. Ed. 2012, 51, 5062-5085; (c) Chem. Soc. Rev. 2011, 40, Special Issue 10 "Cross coupling reactions in organic synthesis", pp 4877-5208; (d) B. M. Rosen, K. W. Quasdorf, D. A. Wilson, N. Zhang, A.-M. Resmerita, N. K. Garg, V. Percec, Chem. Rev. 2011, 111, 1346-1416; (e) G. Cahiez, A. Moyeux, A. Chem. Rev. 2010, 110, 1435-1462.

4 For representative general reviews on $\mathrm{C}-\mathrm{H}$ bond functionalizations, see: (a) K. M. Engle, J.-Q. Yu, J. Org. Chem. 2013, 78, 8927-8955; (b) J. J. Mousseau, A. B. Charrette, Acc. Chem. Res. 2013, 46, 412-424; (c) N. Kuhl, M. N. Hopkinson, J. Wencel-Delord, F. Glorius, Angew. Chem. Int. Ed. 2012, 51, 10236-10254; (d) C. S. Yeung, V. M. Dong, Chem. Rev. 2011, 111, 1215-1292; (e) D. A. Colby, R. G. Bergman, J. A. Ellman, Chem. Rev. 2010, 110, 624-655; (f) I. A. I. Mkhalid, J. H. Barnard, T. B. Marder, J. M. Murphy, J. F. Hartwig, Chem. Rev. 2010, 110, 890-931; (g) P. Sehnal, R. J. K. Taylor, I. J. S. Fairlamb, Chem. Rev. 2010, 110, 824-889; (h) M. C. Willis, Chem. Rev. 2010, 110, 725-748; (i) G. E. Dobereiner, R. H. Crabtree, Chem. Rev. 2010, 110, 681-703; (j) P. Thansandote, M. Lautens, Chem. -Eur. J. 2009, 15, 5874-5883; (k) L. Ackermann, R. Vicente, A. R. Kapdi, Angew. Chem. Int. Ed. 2009, 48, 9792-9826; (1) L.-C. Campeau, D. R. Stuart, K. Fagnou, Aldrichim. Acta 2007, 40, 35-41; (m) D. Alberico, M. E. Scott, M. Lautens, Chem. Rev. 2007, 107, 174-238; (n) R. G. Bergman, Nature 2007, 446, 391-393; (o) K. Godula, D. Sames, Science 2006, 312, 67-72 and references cited therein. 
which are not only advantageous with respect to the overall minimization of byproduct formation, but also allow for a streamlining of organic syntheses (Scheme 1b). ${ }^{3 \mathrm{a}, 4 \mathrm{k}, 5}$

Early studies in the catalytic functionalization of unreactive $\mathrm{C}-\mathrm{H}$ bonds were largely directed toward the challenging $\mathrm{C}-\mathrm{H}$ bond activation of methane. ${ }^{6}$ However, during the past two decades, intensive research efforts have led to the development of $\mathrm{C}-\mathrm{H}$ bond functionalizations ${ }^{4}$ with increasingly viable metal catalysts to improve the atom economy and more importantly the step-economy of organic syntheses. ${ }^{5}$ By far, a large variety of transition-metal catalysts have set the stage for efficient chemo-, site-, and enantioselective $\mathrm{C}-\mathrm{H}$ bond functionalizations. ${ }^{1,4}$

\subsubsection{Mechanisms for Transition-Metal-Catalyzed C-H Bond Metalation}

Key to the success to the direct $\mathrm{C}-\mathrm{H}$ bond functionalizations was generally a detailed mechanistic understanding of the elementary $\mathrm{C}-\mathrm{H}$ bond metalation step. Traditionally, three different modes of action were primarily considered for $\mathrm{C}-\mathrm{H}$ bond metalations, ${ }^{7}$ namely, (i) oxidative addition with electron-rich late transition metals, (ii) $\sigma$-bond metathesis with early transition metals, and (iii) electrophilic activation with electron-deficient late transition metals (Scheme 2).

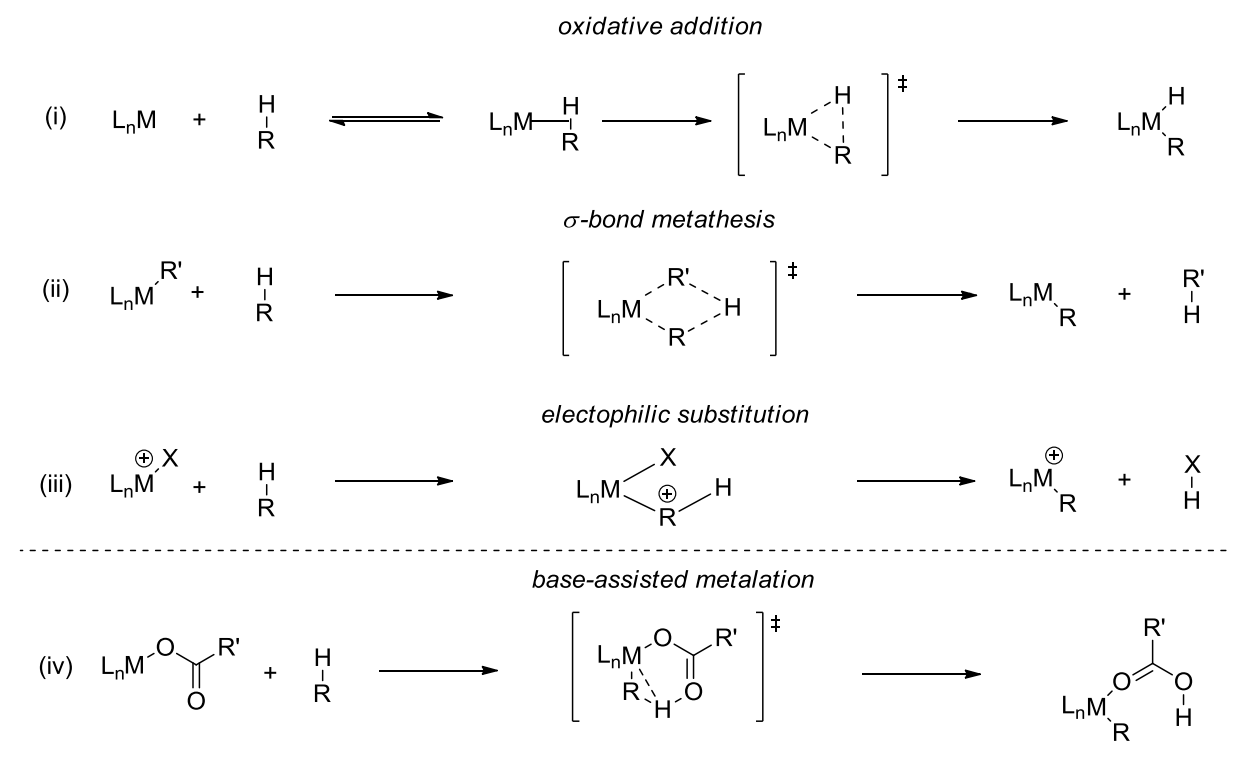

Scheme 2 Mechanisms for $\mathrm{C}-\mathrm{H}$ bond metalation

However, studies in the past years also indicated the existence of a continuum of electrophilic, ambiphilic, and nucleophilic interactions as well as base-assisted metalation reactions. ${ }^{8}$ As early as 1970s, the Shaw group ${ }^{9 a}$ observed the beneficial effect exerted by $\mathrm{NaOAc}$ for stoichiometric

5 (a) P. A. Wender, V. A. Verma, T. J. Paxton, T, H. Pillow, Acc. Chem. Res. 2008, 41, 40-49; (b) B. M. Trost, Acc. Chem. Res. 2002, 35, 695-705; (c) B. M. Trost, Science 1991, 254, 1471-1477.

6 (a) B. G. Hashiguchi, S. M. Bischof, M. M. Konnick, R. A. Periana, Acc. Chem. Res. 2012, 45, 885-898; (b) H. Schwarz, Angew. Chem. Int. Ed. 2011, 50, 10096-10115; (c) S. J. Blanksby, G. B. Ellison, Acc. Chem. Res. 2003, 36, 255-263.

7 For selected reviews on mechanistic aspects of $\mathrm{C}-\mathrm{H}$ bond functionalizations, see: (a) D. Balcells, E. Clot, O. Eisenstein, Chem. Rev. 2010, 110, 749-823; (b) M. Lersch, M. Tilset, Chem. Rev. 2005, 105, 2471-2526; (c) V. Ritleng, C. Sirlin, M. Pfeffer, Chem. Rev. 2002, 102, 1731-1770 and references cited therein.

8 L. Ackermann, Chem. Rev. 2011, 111, 1315-1345.

9 (a) J. C. Gaunt, B. L. Shaw, J. Organomet. Chem. 1975, 102, 511-516; (b) V. I. Sokolov, L. L. Troitskaya, O. A. Reutov, J. Organomet. Chem. 1979, 182, 537-546. 
cyclometalation reactions (Scheme 3). Thus, detailed experimental and computational analysis by Davies and coworkers ${ }^{10}$ provided strong evidence for this novel $\mathrm{C}-\mathrm{H}$ bond metalation mechanisms relying on the assistance of a bifunctional ligand bearing an additional Lewis-basic heteroatom or most prominently carboxylates (Scheme 2, iv).

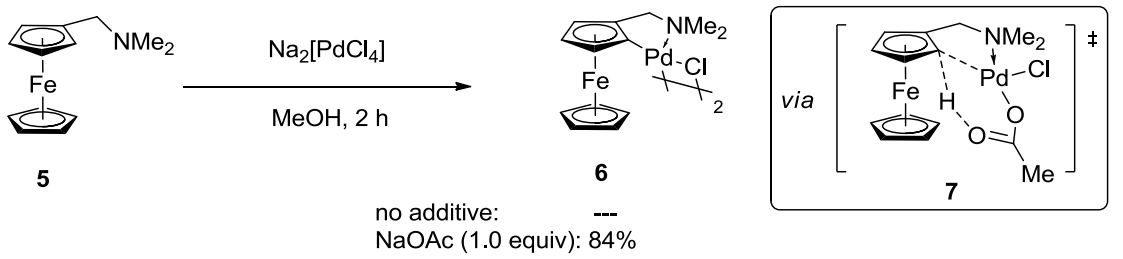

Scheme 3 Stoichiometric acetate-mediated cyclometalation

This novel insight into metalations has thus served as stimulus for the development of $\mathrm{C}-\mathrm{H}$ bond transformations based on cocatalytic amounts of carboxylates. ${ }^{8}$ To differentiate this type of base-assisted metalations mechanistically, new concepts have recently been introduced (Scheme 4). It has been proposed that a bidentate base is operating by the concerted-metalation-deprotonation pathway $(\mathrm{CMD})^{11}$ or by the ambiphilic metal-ligand activation (AMLA) mechanism, ${ }^{12}$ both of which favor a six-membered transition state. Theoretical calculation ${ }^{13}$ disclose that the metal-acetate complexes have an ambiphilic character due to an intramolecular electrophilic activation of a $\mathrm{C}-\mathrm{H}$ bond followed by deprotonation with an internal base. On the other hand, the mode of action of monodentate anionic ligands has been explored by the research groups of Oxgaard and Goddard as well as Gunnoe. ${ }^{14}$ DFT-studies favor an internal electrophilic substitution (IES) prior to traditional $\sigma$-bond metathesis.

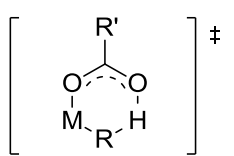

CMD

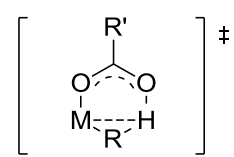

AMLA

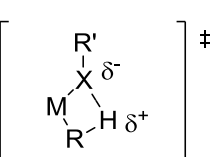

IES

Scheme 4 Proposed transition states during $\mathrm{C}-\mathrm{H}$ bond metalations

\subsubsection{Carboxylate-Assisted Ruthenium-Catalyzed Direct C-H Bond Functionalizations}

The contributions for $\mathrm{C}-\mathrm{H}$ bond functionalization brought by palladium catalysts ${ }^{1,4}$ have motivated the search for less expensive, active ruthenium catalysts. ${ }^{15}$ Notably, the pioneering

10 D. L. Davies, O. Al-Duaij, J. Fawcett, M. Giardiello, S. T. Hilton, D. R. Russell, Dalton Trans. 2003, 41324138 and references cited therein.

11 D. Lapointe, K. Fagnou, Chem. Lett. 2010, 39, 1118-1126.

12 (a) Y. Boutadla, D. L. Davies, S. A. Macgregor, A. I. Poblador-Bahamonde, Dalton Trans. 2009, 5820-5831; (b) Y. Boutadla, D. L. Davies, S. A. Macgregor, A. I. Poblador-Bahamonde, Dalton Trans. 2009, 5887-5893.

13 D. H. Ess, S. M. Bischof, J. Oxgaard, R. A. Periana, W. A. Goddard, III, Organometallics 2008, 27, 64406445.

14 (a) J. Oxgaard, W. J. Trenn, III, R. J. Nielsen, R. A. Periana, W. A. Goddard, III, Organometallics 2007, 26, 1565-1567; (b) D. Conner, K. N. Jayaprakash, T. R. Cundari, T. B. Gunnoe, Organometallics 2004, 23, 2724 2733; (c) a review: J. R. Webb, T. BolaÇo, T. B. Gunnoe, ChemSusChem. 2011, 4, 37-49.

15 February 2014, http://taxfreegold.co.uk/precious metalpricesusdollars.html: prices of gold, platinum, rhodium, iridium, palladium and ruthenium: \$1244, \$1377, \$1053, \$400, \$705, and \$56 US per troy ounce, respectively. 
studies on ruthenium-catalyzed direct hydroarylations of alkenes by Lewis ${ }^{16}$ as well as Murai ${ }^{17}$ highlighted the potential of efficient ruthenium catalysis for site-selective reactions of $\mathrm{C}-\mathrm{H}$ bonds onto $\mathrm{C}-\mathrm{C}$ and $\mathrm{C}-\mathrm{Het}$ multiple bonds (see Chapter 1.4).

The subsequent intensive search for easy-to-prepare and more stable ruthenium(II) catalysts during the following decades resulted in the discovery efficient ruthenium catalysts, milder reaction conditions and new ruthenium-catalyzed reactions, as was demonstrated by Oi and Inoue in 2001 (Scheme 5). ${ }^{18}$ However, essential progress in ruthenium-catalyzed direct arylations of arenes with aryl halides was achieved employing ruthenium complexes in situ derived from phosphine- ${ }^{19}$ or $N$-heterocyclic carbene ${ }^{20}$ (NHC) ligands. Notably, all of these reactions required the use of highly polar $N$-methylpyrrolidinone (NMP) as solvent, which led to catalytic systems with lower robustness, ${ }^{21}$ particularly when being applied to more challenging substrate combinations.

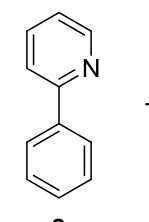

8

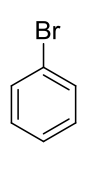

$3 \mathbf{a}$

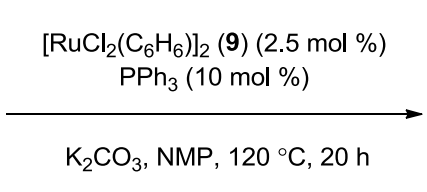

$\mathrm{PhBr}$ (1.0 equiv), $\mathrm{K}_{2} \mathrm{CO}_{3}$ (2.0 equiv) $\mathrm{PhBr}$ (3.0 equiv), $\mathrm{K}_{2} \mathrm{CO}_{3}$ (6.0 equiv)

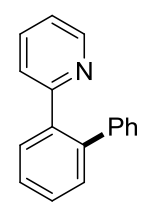

10

$71 \%$

0

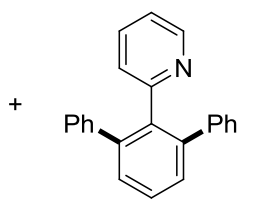

11

$11 \%$

$77 \%$

Scheme 5 Ruthenium-catalyzed direct arylation with aryl halides by Oi and Inoue

Until 2008, carboxylates have not been used as efficient cocatalytic additives in ruthenium-catalyzed $\mathrm{C}-\mathrm{H}$ bond functionalizations. Primary studies from the Ackermann group highlighted a significant reaction rate acceleration applying bifunctional secondary phosphine oxides (SPO) preligand ${ }^{22}$ in ruthenium-catalyzed direct arylations with organic electrophiles. ${ }^{23}$ Concerning the catalysis working mode ${ }^{23}$ a base assistance with an intermediacy of the five-membered transition state $\mathbf{1 2}$ was proposed to be the decisive feature (Figure 1). Analogously, further studies from the same group showed that bifunctional ligands, especially carboxylates, were expected to give rise to six-membered transition state $\mathbf{1 3}$ (Figure 1). ${ }^{8}$

16 L. N. Lewis, J. F. Smith, J. Am. Chem. Soc. 1986, 108, 2728-2735.

17 S. Murai, F. Kakiuchi, S. Sekine, Y. Tanaka, A. Kamatani, M. Sonoda, N. Chatani, Nature 1993, 366, 529531.

18 (a) S. Oi, S. Fukita, N. Hirata, N. Watanuki, S. Miyano, Y. Inoue, Org. Lett. 2001, 3, 2579-2581; (b) S. Oi, Y. Ogino, S. Fukita, Y. Inoue, Org. Lett. 2002, 4, 1783-1785.

19 L. Ackermann, R. Vicente, Top. Curr. Chem. 2010, 292, 211-229.

20 (a) W. A. Herrmann, Angew. Chem. Int. Ed. 2002, 41, 1290-1309; (b) D. Bourissou, O. Guerret, F. P. Gabbaie, G. Bertrand, Chem. Rev. 2000, 100, 39-92; (c) N-Heterocyclic Carbenes in Synthesis; S. P. Nolan, Ed.; Wiley-VCH: Weinheim, Germany, 2006.

21 S. G. Ouellet, A. Roy, C. Molinaro, R. Angelaud, J.-F., P. D. O'Shea, I. W. Davies, J. Org. Chem. 2011, 76, 1436-1439.

22 (a) L. Ackermann, Isr. J. Chem. 2010, 50, 652-663; (b) L. Ackermann, Synthesis 2006, 1557-1571.

23 (a) L. Ackermann, Org. Lett. 2005, 7, 3123-3125; (b) L. Ackermann, A. Althammer, R. Born, Angew. Chem. Int. Ed. 2006, 45, 2619-2622; (c) L. Ackermann, R. Born, P. Álvarez-Bercedo, Angew. Chem. Int. Ed. 2007, 46, 6364-6367. 


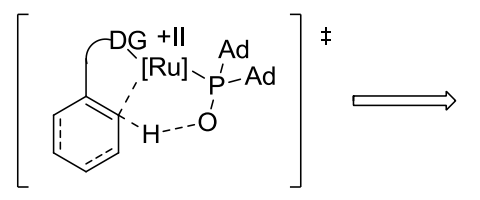

12

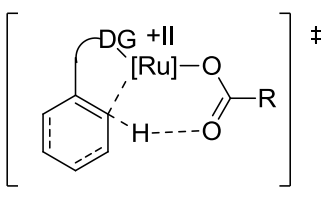

13

Figure 1 Proposed transition states for base-assisted ruthenations

Hence, the Ackermann group investigated the order of efficacy for various cocatalytic additives in direct arylations using toluene as inert solvent and $N$-aryl-substitued 1,2,3-triazoles $\mathbf{1 4}$ as substrates (Scheme 6). ${ }^{24}$ Herein, complexes of previously used ligands, such as NHC precursors or tertiary phosphines, demonstrated only poor activity. On the contrary, bifunctional sterically hindered SPO preligand (1-Ad) ${ }_{2} \mathrm{P}(\mathrm{O}) \mathrm{H}$ enabled more efficient catalysis. Further screening showed that acids were superior, with optimal results being obtained with sterically congested $\mathrm{MesCO}_{2} \mathrm{H}$.

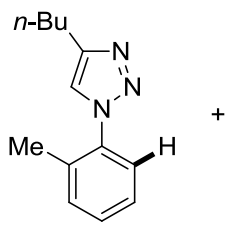

14

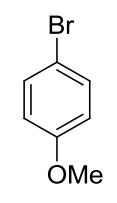

3b

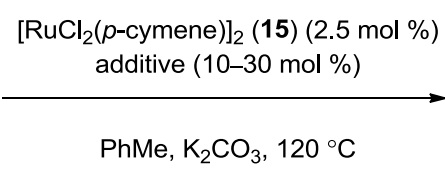

$\mathrm{PhMe}, \mathrm{K}_{2} \mathrm{CO}_{3}, 120^{\circ} \mathrm{C}$

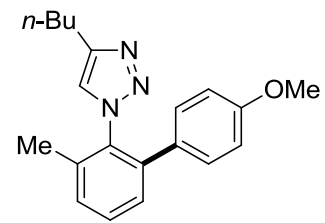

16

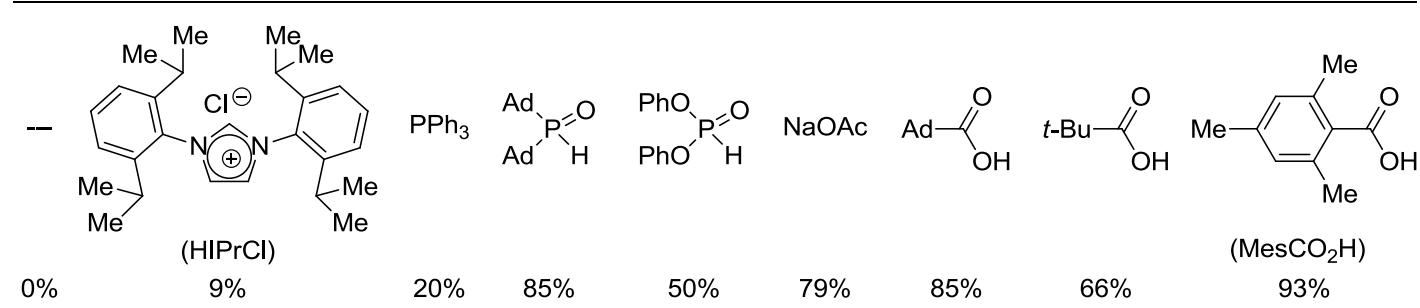

Scheme 6 Cocatalytic additives in the ruthenium-catalyzed direct arylation

The subsequent intensive mechanistic studies ${ }^{24,25}$ disclosed the ruthenium(II)-catalyzed direct arylations to involve initial $\mathrm{C}-\mathrm{H}$ bond activations via carboxylate-assisted and thus deprotonative ruthenations via the transition state $\mathbf{1 9}$ (Scheme 7).

24 L. Ackermann, R. Vicente, A. Althammer, Org. Lett. 2008, 10, 2299-2302.

25 L. Ackermann, R. Vicente, H. K. Potukuchi, V. Pirovano, Org. Lett. 2010, 12, 5032-5035. 


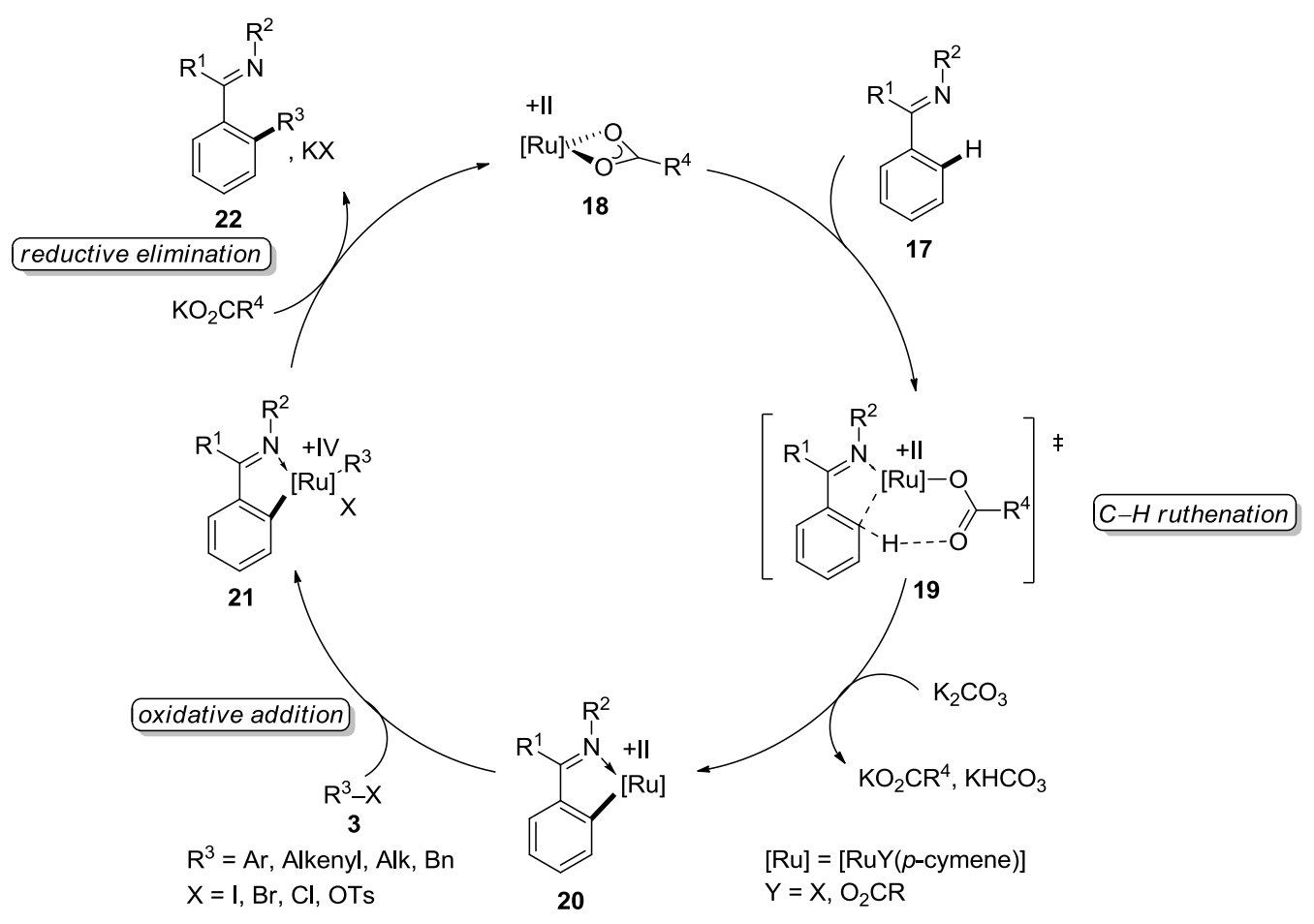

Scheme 7 Proposed mechanism for direct arylations and alkylations by carboxylate assistance

To address the mechanistic understanding, a ruthenium(II) biscarboxylate complex 23 was prepared (Scheme 8a). ${ }^{25}$ Notably, the well-defined complex $\mathbf{2 3}$ displayed a broad substrate scope in that various arenes were directly functionalized with (Het) $\mathrm{ArCl}$ in a highly regioselective fashion (Scheme $8 b){ }^{25}$
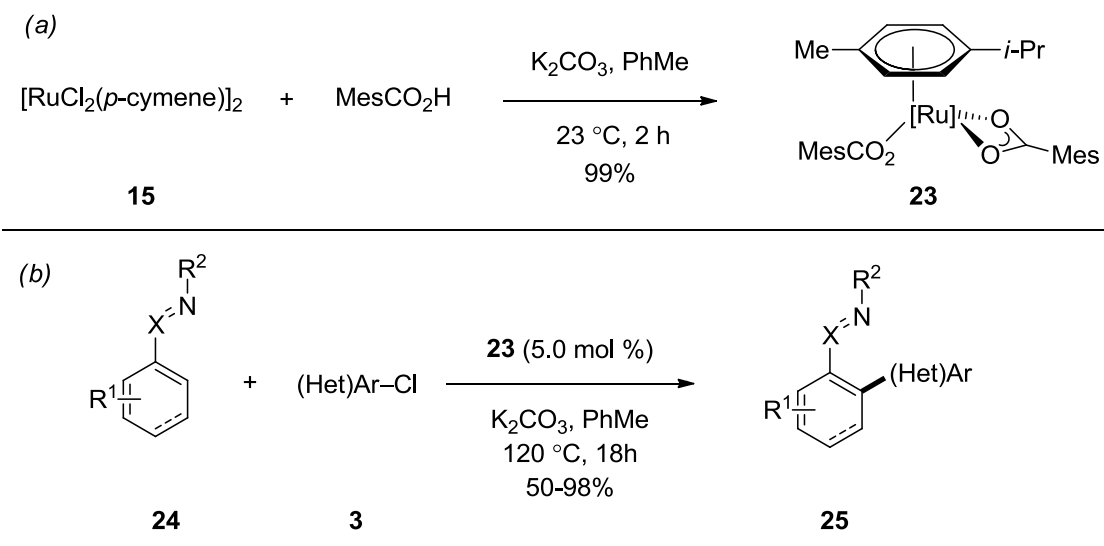

Scheme 8 Direct arylations catalyzed by ruthenium(II) biscarboxylate 23

On the basis of experimental findings in ruthenium-catalyzed direct arylations (Scheme 9, 27) as well as alkylations ( 28 and $\mathbf{2 9}$ ), ${ }^{4 k, 8,19,22,26}$ the Ackermann group intensively examined carboxylates as effective cocatalytic additives in ruthenium-catalyzed $\mathrm{C}-\mathrm{H}$ bond functionalizations, such as

26 For selected reviews on ruthenium-catalyzed C-H bond functionalization, see also: (a) B. Li, P. H. Dixneuf, Chem. Soc. Rev. 2013, 42, 5744-5767; (b) P. B. Arockiam, C. Bruneau, P. H. Dixneuf, Chem. Rev. 2012, 112, 5879-5918; (c) L. Ackermann, Pure Appl. Chem. 2010, 82, 1403-1413; (d) L. Ackermann, Chem. Commun. 2010, 46, 4866-4877; (e) L. Ackermann, Synlett 2007, 507-526. 
hydroarylations with alkenes $(\mathbf{3 0}),{ }^{27}$ as well as oxidative $\mathrm{C}-\mathrm{C}(\mathbf{3 2}$ and $\mathbf{3 3}),{ }^{28,29} \mathrm{C}-\mathrm{O}(\mathbf{3 4})^{30}$ and $\mathrm{C}-\mathrm{N}(\mathbf{3 5})^{30}$ bond formations (Scheme 9). This thesis herein focuses on carboxylate-assisted ruthenium-catalyzed oxidative $\mathrm{C}-\mathrm{H}$ bond functionalizations $(\mathbf{3 2}$ and $\mathbf{3 3})$ and $\mathrm{C}\left(\mathrm{sp}^{3}\right)-\mathrm{H}$ alkylations (31) with alkenes as well as direct ortho-C-Hal bond formations (36), which will be described in details in the following Chapters.

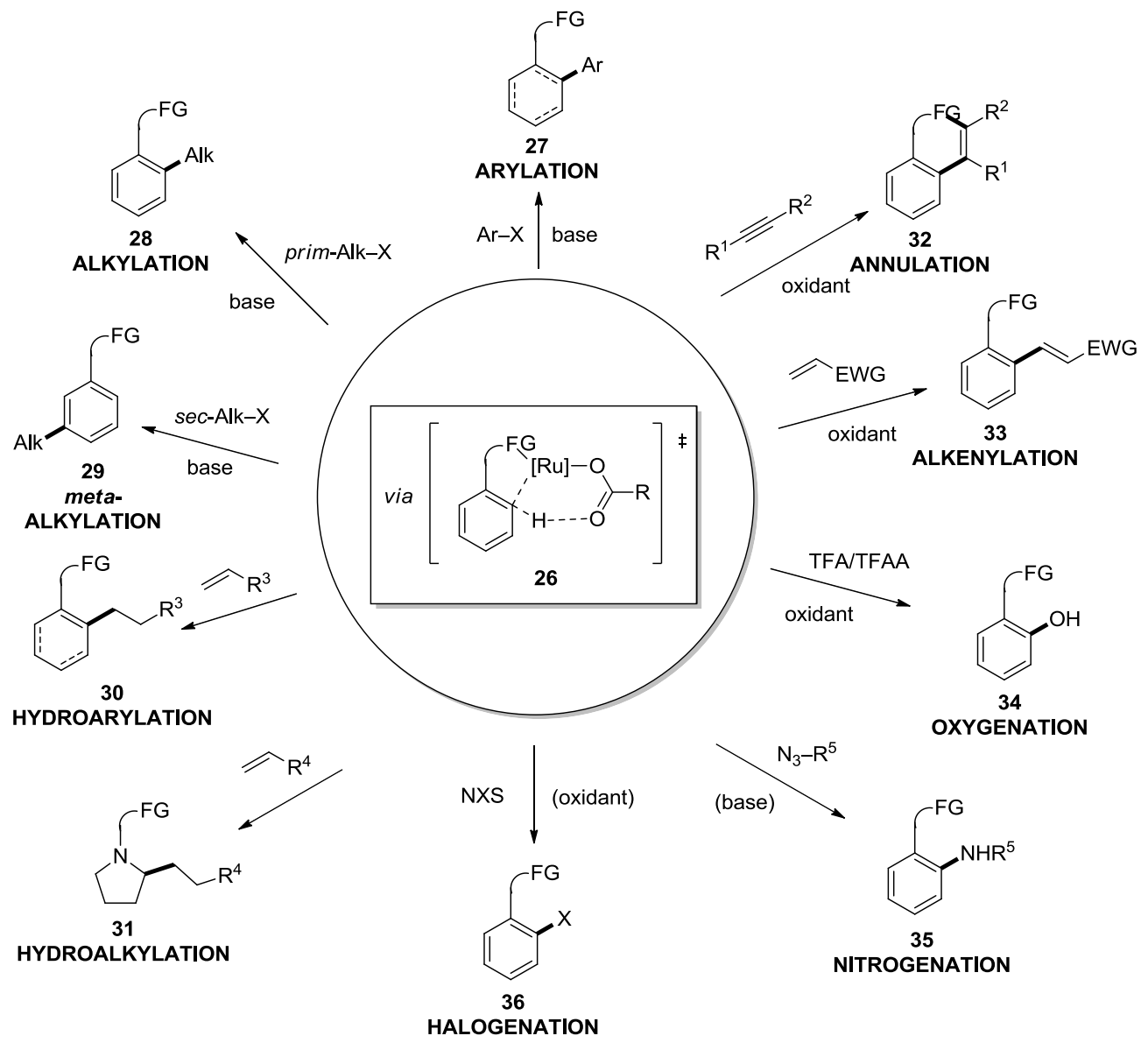

Scheme 9 Carboxylate-assisted ruthenium-catalyzed direct $\mathrm{C}-\mathrm{H}$ bond functionalizations

\subsection{Ruthenium-Catalyzed Alkyne Annulations by $\mathrm{C}-\mathrm{H} / \mathrm{Het}-\mathrm{H}$ Bond Functionalizations}

Proceeding with the previously reported experimental results on direct arylations, the Ackermann group first tested carboxylates as cocatalytic additives for ruthenium-catalyzed oxidative $\mathrm{C}-\mathrm{H}$ bond functionalizations, ${ }^{28,29}$ a research area that had thus far largely been dominated by the use of

27 Selected reviews: (a) J. R. Andreatta, B. A. McKeown, T. B. Gunnoe, J. Organomet. Chem. 2011, 696, 305 315; (b) N. A. Foley, J. P. Lee, Z. Ke, T. B. Gunnoe, T. R. Cundari, Acc. Chem. Res. 2009, 42, 585-597; (c) F. Kakiuchi, Top. Organomet. Chem. 2007, 24, 1-33; (d) C. Nevado, A. M. Echavarren, Synthesis 2005, 167-182; (e) F. Kakiuchi, N. Chatani, Adv. Synth. Catal. 2003, 345, 1077-1101; (f) C. Jia, T. Kitamura, Y. Fujiwara, Acc. Chem. Res. 2001, 34, 633-639.

28 L. Ackermann, Acc. Chem. Res. 2014, 47, 281-295.

29 S. I. Kozhushkov, L. Ackermann, Chem. Sci. 2013, 4, 886-896.

30 V. S. Thirunavukkarasu, S. I. Kozhushkov, L. Ackermann, Chem. Commun. 2014, 50, 29-39.

$$
\text { - } 7 \text { - }
$$


more expensive palladium $^{31}$ or rhodium complexes. $^{32}$

Considering the importance for step-economical syntheses of bioactive heterocycles, Ackermann and coworkers hence set out to develop ruthenium-catalyzed oxidative annulations of alkynes 38 through $\mathrm{C}-\mathrm{H}$ and $\mathrm{N}-\mathrm{H}$ bond cleavages for isoquinolones 39 synthesis (Scheme 10). ${ }^{33}$ Notably, preliminary studies ${ }^{33 a}$ revealed $\left[\mathrm{RuCl}_{2}(p \text {-cymene })\right]_{2}$ (15) to be optimal among a variety of ruthenium complexes, while $\mathrm{Cu}(\mathrm{OAc})_{2} \cdot \mathrm{H}_{2} \mathrm{O}$ was found to be the terminal oxidant of choice. ${ }^{33 \mathrm{a}}$ The optimized ruthenium(II) catalyst $\mathbf{1 5}$ proved to be tolerant to valuable electrophilic functional groups, and was found to be applicable to benzamides $\mathbf{3 7}$ with different substituents on nitrogen atom. Furthermore, the annulation process proceeded with excellent regioselectivity with unsymmetrical internal alkynes. ${ }^{33}$

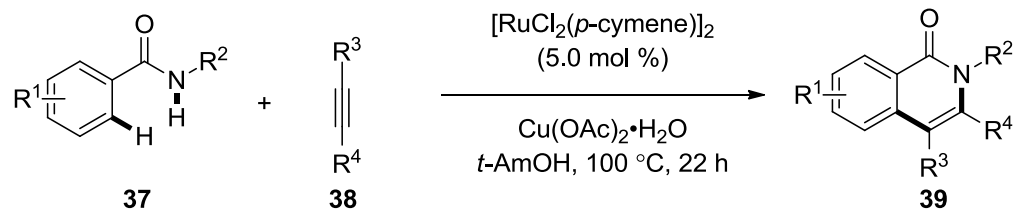

Scheme 10 Ruthenium-catalyzed oxidative annulation via $\mathrm{C}-\mathrm{H} / \mathrm{N}-\mathrm{H}$ bond cleavage

Based on mechanistic studies, the ruthenium(II)-catalyzed oxidative annulation was proposed to proceed by an initial carboruthenation via acetate-assisted $\mathrm{C}-\mathrm{H}$ bond cleavage, ${ }^{8,28}$ followed by migratory insertion, $\mathrm{C}-\mathrm{N}$ bond-forming reductive elimination, and final reoxidation of the ruthenium(0) intermediate (Scheme 11). ${ }^{33 a}$ Additional support for this proposed mechanism was recently provided through the independent synthesis and isolation of key intermediates by the groups of Li and Wang as well as Dixneuf. ${ }^{34}$

31 A review on palladium-catalyzed oxidative annulation of alkynes: C. Zhu, R. Wang, J. R. Falck, Chem. Asian J. 2012, 7, 1502-1514 and references cited therein.

32 Selected reviews on rhodium-catalyzed oxidative annulation of alkynes: (a) G. Song, F. Wang, X. Li, Chem. Soc. Rev. 2012, 41, 3651-3678; (b) F. W. Patureau, J. Wencel-Delord, F. Glorius, Aldrichimica Acta 2012, 45, 31-41; (c) T. Satoh, M. Miura, Chem.-Eur. J. 2010, 16, 11212-11222 and references cited therein.

33 (a) L. Ackermann, A. V. Lygin, N. Hofmann, Angew. Chem. Int. Ed. 2011, 50, 6379-6382; (b) M. Deponti, S. I. Kozhushkov, D. S. Yufit, L. Ackermann, Org. Biomol. Chem. 2013, 11, 142-148.

34 (a) B. Li, H. Feng, N. Wang, J. Ma, H. Song, S. Xu, B. Wang, Chem. -Eur. J. 2012, 18, 12873-12879; (b) B. Li, T. Roisnel, C. Darcel, P. H. Dixneuf, Dalton Trans. 2012, 41, 10934-10937. 


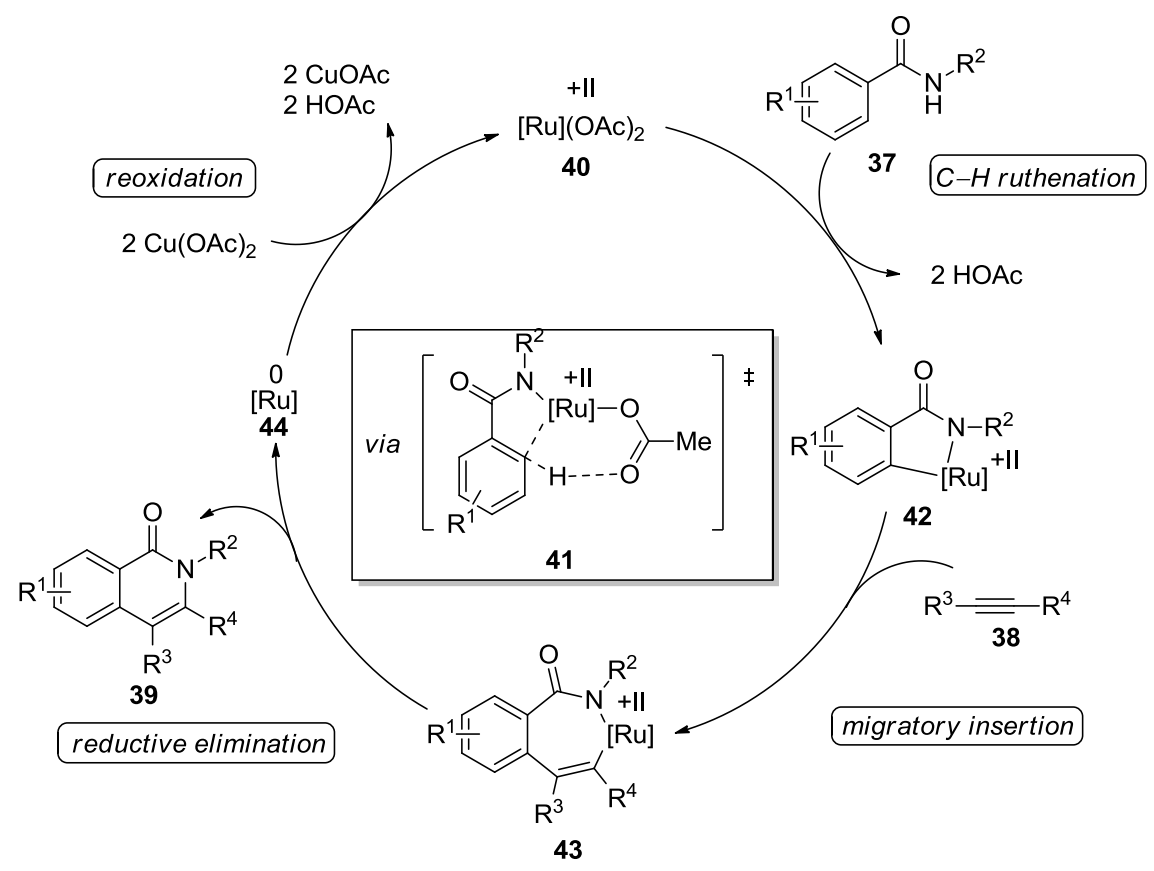

Scheme 11 Catalytic cycle for ruthenium-catalyzed oxidative annulation of alkynes

Subsequently, acrylamides $\mathbf{4 5}$ turned out to be competent substrates through alkenylic $\mathrm{C}-\mathrm{H}$ bond activation with the same ruthenium(II) catalytic system (Scheme 12). Likewise, $\mathrm{Cu}(\mathrm{OAc})_{2} \cdot \mathrm{H}_{2} \mathrm{O}$ as the oxidant led to the most efficient transformation, again being indicative of acetate assistance. ${ }^{35}$

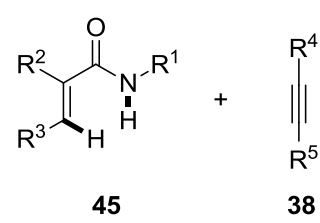

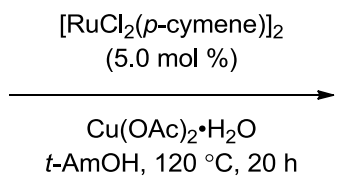

38

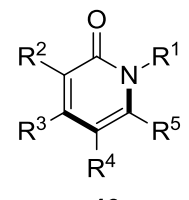

46

Scheme 12 Ruthenium-catalyzed synthesis of 2-pyridones 46

Recently, Jeganmohan developed a route to isoquinolones 49 through ruthenium-catalyzed aerobic oxidative cyclization of (hetero)aromatic nitriles 47 with alkynes (Scheme 13). ${ }^{36}$ Mechanistic studies showed an acetamide intermediate $\mathbf{4 8}$ was generated with $\mathrm{AcOH}$ in the presence of $\mathrm{Cu}(\mathrm{OAc})_{2} \cdot \mathrm{H}_{2} \mathrm{O}$ prior to oxidative annulation with alkynes.

35 L. Ackermann, A. V. Lygin, N. Hofmann, Org. Lett. 2011, 13, 3278-3281.

36 M. C. Reddy, R. Manikandan, M. Jeganmohan, Chem. Commun., 2013, 49, 6060-6062. 


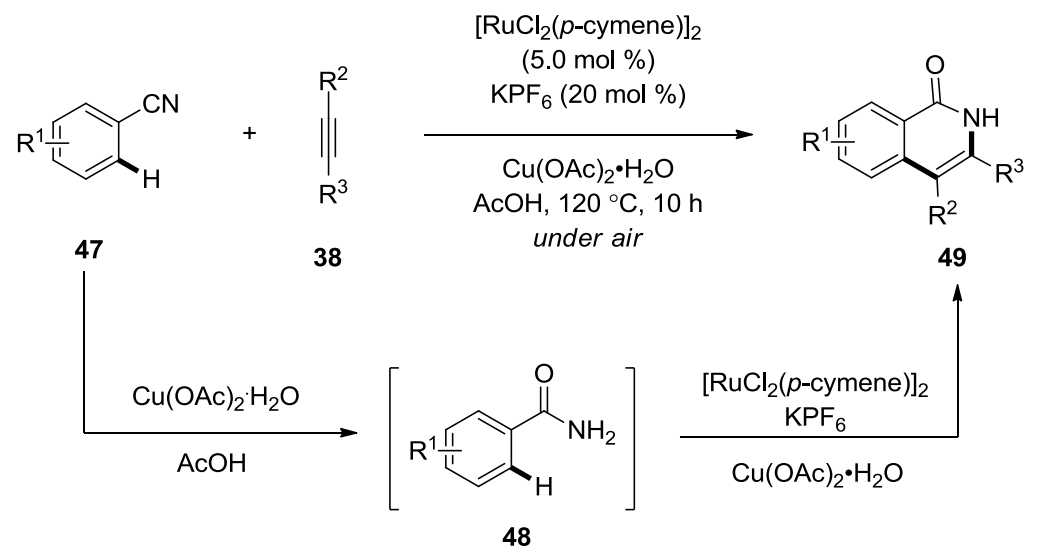

Scheme 13 Ruthenium-catalyzed oxidative cyclization of aromatic nitriles $\mathbf{4 7}$ with alkynes 38

The $\mathrm{C}-\mathrm{H} / \mathrm{N}-\mathrm{H}$ bond functionalization strategy was not restricted to arenes bearing electron-withdrawing directing groups. Indeed, the cationic ruthenium(II) complexes derived from $\mathrm{KPF}_{6}$ facilitated oxidative $\mathrm{C}-\mathrm{H}$ bond functionalizations with electron-rich anilines $\mathbf{5 0}$ through acetate assistance (Scheme 14). ${ }^{37 a}$ A notable feature of this protocol was represented by the use of substrates bearing easily removable directing groups. ${ }^{38}$ The $\mathrm{C}-\mathrm{H} / \mathrm{N}-\mathrm{H}$ bond cleavages occurred most efficiently in water as a green reaction medium and provided general access to indole derivatives $\mathbf{5 1}$.

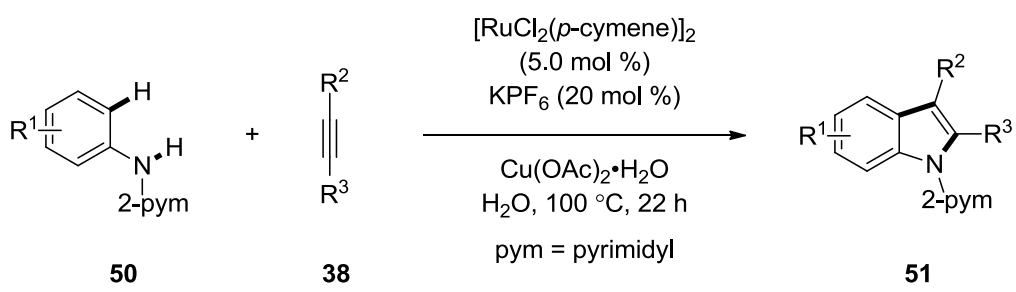

Scheme 14 Oxidative annulation with electron-rich anilines $\mathbf{5 0}$ bearing a removable directing group

Furthermore, Ackermann and coworkers found the cationic ruthenium(II) complexes derived from $\mathrm{AgSbF}_{6}$ additives allowed for highly efficient oxidative annulations of aryl- and alkyl-substituted alkynes $\mathbf{3 8}$ by 5 -aryl-1H-pyrazoles $\mathbf{5 2}$ under aerobic conditions (Scheme 15). ${ }^{39}$

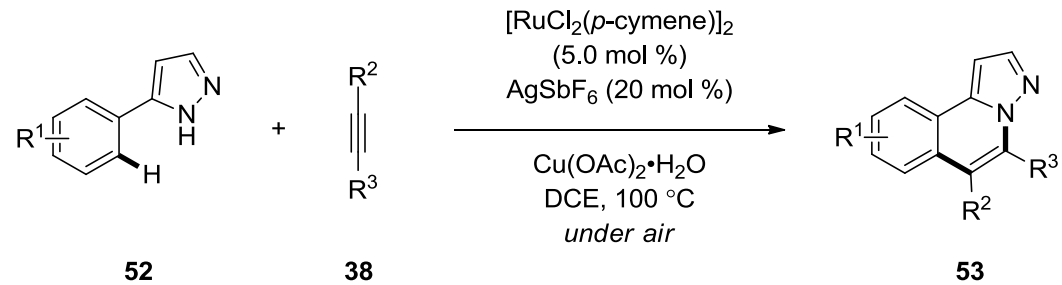

Scheme 15 Oxidative annulation of alkynes $\mathbf{3 8}$ by 5 -aryl- $1 H$-pyrazoles $\mathbf{5 2}$

37 (a) L. Ackermann, A. V. Lygin, Org. Lett. 2012, 14, 764-767; (b) for nickel-catalyzed alkyne annulation by anilines, see: W. Song, L. Ackermann, Chem. Commun. 2013, 49, 6638-6640.

38 Representative reviews on removable directing groups: (a) C. Wang, Y. Huang, Synlett 2013, 24, 145-149; (b)

G. Rousseau, B. Breit, Angew. Chem. Int. Ed. 2011, 50, 2450-2494.

39 W. Ma, K. Graczyk, L. Ackermann, Org. Lett. 2012, 14, 6318-6321. 
Very recently, the same group developed a ruthenium-catalyzed oxidative annulation of alkynes by ketimines $\mathbf{5 4}$ to furnish exo-methylene-1,2-dihydroisoquinolines $\mathbf{5 5}$. Particularly, carboxylate-assisted ruthenium(II) catalysis proved to be key to success for the synthesis of diversely decorated products in high yields (Scheme 16). ${ }^{40}$

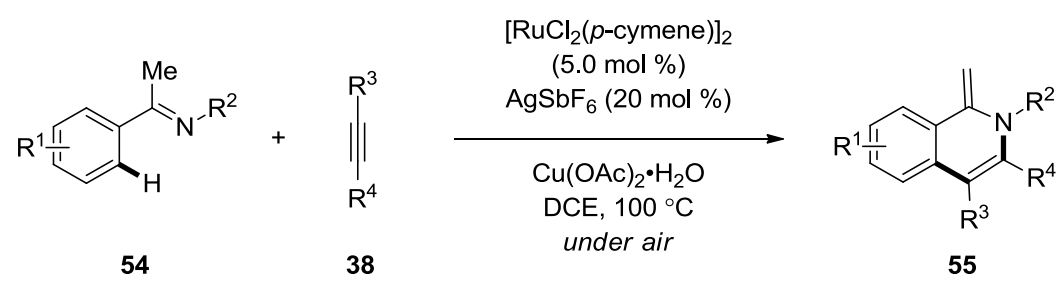

Scheme 16 Oxidative annulation of alkynes 38 by ketimines 54

Besides this, oxidative annulations of alkynes 38 through $\mathrm{C}-\mathrm{H} / \mathrm{O}-\mathrm{H}$ bond cleavages were independently achieved with ruthenium(II) complexes by the research groups of Ackermann and Jaganmohan (Scheme 17). ${ }^{41,42}$ Likewise, a cationic ruthenium(II) catalyst derived from $\mathrm{KPF}_{6}$ or $\mathrm{AgSbF}_{6}$ was employed for the synthesis of isocoumarins $\mathbf{5 7}$ through oxidative annulations of alkynes by (hetero)aromatic acids 56. Detailed optimization studies revealed acetates to be crucial additives and provided support for a kinetically relevant $\mathrm{C}-\mathrm{H}$ bond ruthenation. ${ }^{41}$

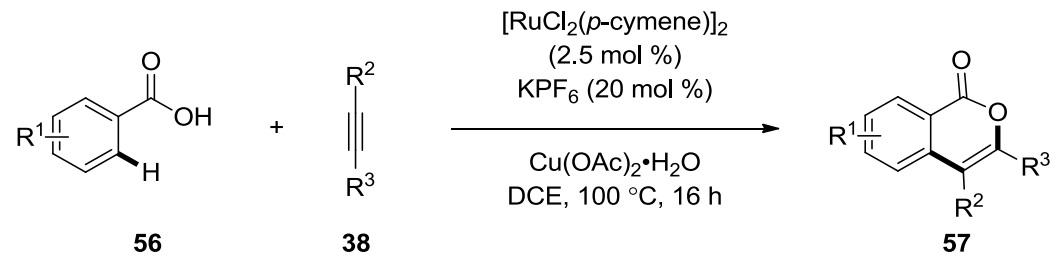

Scheme 17 Synthesis of isocoumarins 57 by Ackermann

Moreover, acetate assistance was found to be key to success for ruthenium(II)-catalyzed oxidative alkyne annulations with hydroxyl groups. ${ }^{43}$ Thus, hydroxyl-assisted $\mathrm{C}-\mathrm{H}$ bond functionalizations provided step-economical access to diversely decorated fluorescent coumarins $\mathbf{5 9}$ and quinolin-2-ones 61, respectively (Scheme 18).

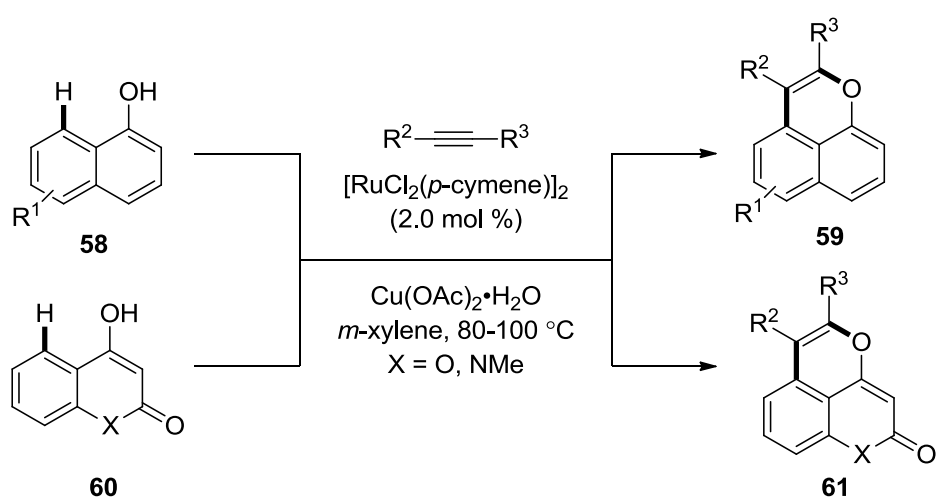

Scheme 18 Hydroxyl-directed alkyne annulations

40 J. Li, L. Ackermann, Tetrahedron 2014, 70, doi: 10.1016/j.tet.2013.10.003.

41 L. Ackermann, J. Pospech, K. Graczyk, K. Rauch, Org. Lett. 2012, 14, 930-933.

42 R. K. Chinnagolla, M. Jeganmohan, Chem. Commun. 2012, 48, 2030-2032.

43 V. S. Thirunavukkarasu, M. Donati, L. Ackermann, Org. Lett. 2012, 14, 3416-3419. 
Along with the rapid development on $\mathrm{C}-\mathrm{H} / \mathrm{N}-\mathrm{H}$ and $\mathrm{C}-\mathrm{H} / \mathrm{O}-\mathrm{H}$ bond functionalizations, Lee developed the first ruthenium-catalyzed oxidative cyclization of phosphonic acid monoesters or phosphinic acids 62 with alkynes for the synthesis of phosphaisocoumarins 63 under aerobic conditions. A variety of arylphosphonic acid monoesters as well as arylphosphinic acids bearing electron-donating and -withdrawing groups were efficiently converted under aerobic reaction conditions (Scheme 19). ${ }^{44}$

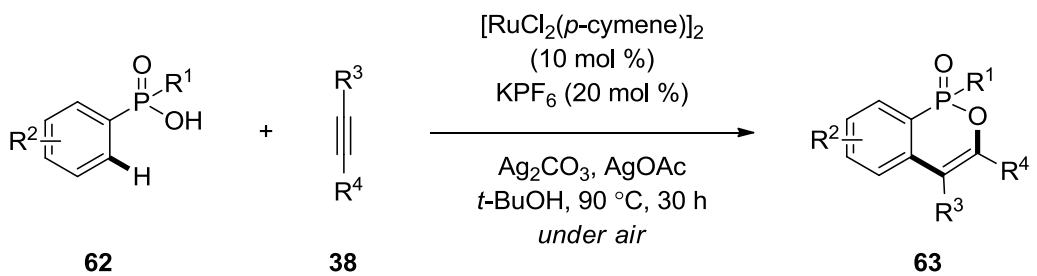

Scheme 19 Ruthenium-catalyzed annulation of alkynes 38 with phosphonic acid derivatives 62

Furthermore, Jeganmohan developed a highly regioselective ruthenium-catalyzed cyclization of aromatic ketones $\mathbf{6 4}$ with alkynes. This methodology offers a simple and mild method for the synthesis of indenols $\mathbf{6 5}$ and benzofulvenes $\mathbf{6 6}$ in a highly regioselective manner. Herein, the amount of silver salt determined the nature of the product: In the presence of $8 \mathrm{~mol} \%$ of $^{\mathrm{AgSbF}_{6}}$ favored the formation of indenols $\mathbf{6 5}$ (Scheme 20, left), whereas with $20 \mathrm{~mol} \%$ of $\mathrm{AgSbF}_{6}$ benzofulvenes $\mathbf{6 6}$ were obtained (Scheme 20, right). ${ }^{45}$

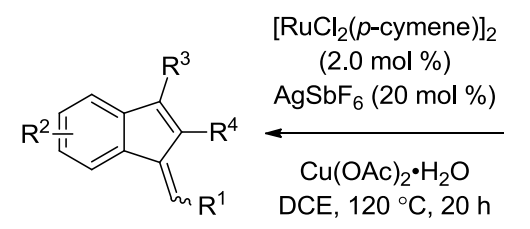

65

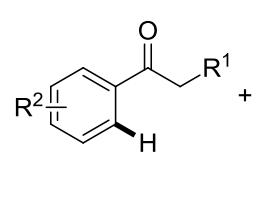

64

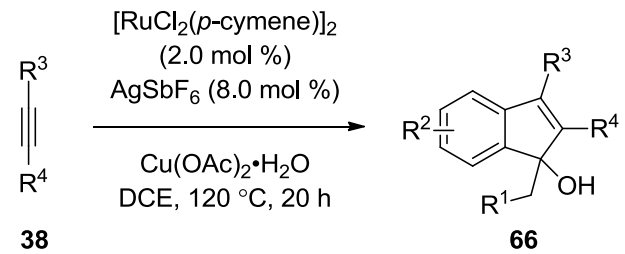

38

Scheme 20 Ketone-directed alkyne annulations

Lam recently reported a catalytic alkyne oxidative annulation by 2-aryl-1,3-dicarbonyl compounds 67 involving the (formal) functionalization of $\mathrm{C}\left(\mathrm{sp}^{3}\right)-\mathrm{H}$ bond and $\mathrm{C}\left(\mathrm{sp}^{2}-\mathrm{H}\right)$ bond (Scheme 21a). Notably, this ruthenium-catalyzed process led to the synthesis of indenes $\mathbf{6 9}$ with the formation of an all-carbon quaternary center. ${ }^{46 a}$ In analogy, Luan's intermolecular annulation reactions of 1-aryl-2-naphthols $\mathbf{7 0}$ with alkynes proceeded efficiently in the presence of the same ruthenium catalyst to generate spirocyclic compounds $\mathbf{7 1}$ by sequential cleavage of the $\mathrm{C}\left(\mathrm{sp}^{2}\right)-\mathrm{H}$ bond, migratory insertion of the alkyne, and dearomatization of the naphthyl ring (Scheme 21b). ${ }^{47}$

44 Y. Park, I. Jeon, S. Shin, J. Min, P. H. Lee, J. Org. Chem. 2013, 78, 10209-10220.

45 R. K. Chinnagolla, M. Jeganmohan, Eur. J. Org. Chem. 2012, 417-423.

46 (a) S. R. Chidipudi, I. Khan, H. W. Lam, Angew. Chem. Int. Ed. 2012, 51, 12115-12119; (b) for similar research with palladium catalysis, see: J. D. Dooley, S. R. Chidipudi, H. W. Lam, J. Am. Chem. Soc. 2013, 135, 10829-10836.

47 J. Nan, Z. Zuo, L. Luo, L. Bai, H. Zheng, Y. Yuan, J. Liu, X. Luan, Y. Wang, J. Am. Chem. Soc. 2013, 135, 17306-17309. 
a)

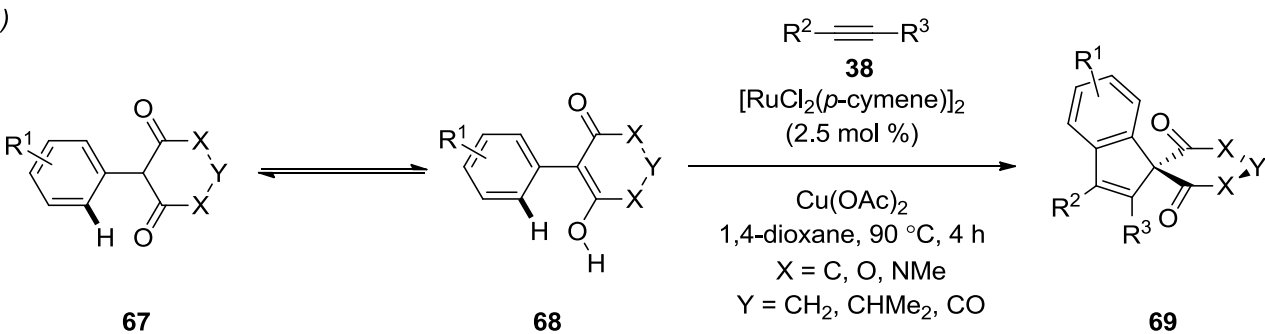

b)

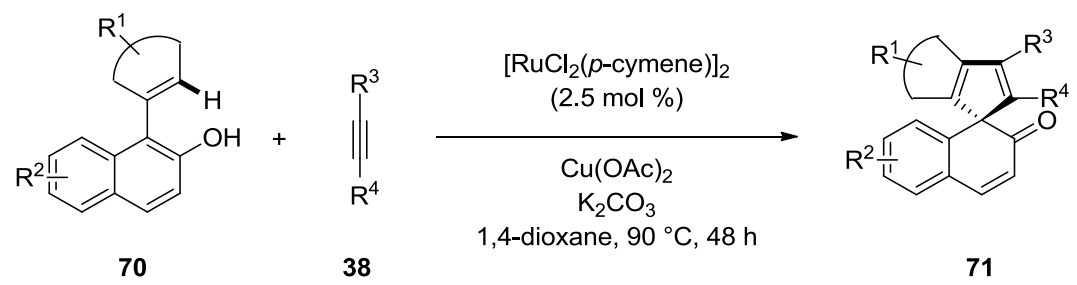

Scheme 21 Ruthenium-catalyzed carbocycles by (formal) $\mathrm{C}\left(\mathrm{sp}^{3}\right)-\mathrm{H} / \mathrm{C}\left(\mathrm{sp}^{2}\right)-\mathrm{H}$ bond cleavage

However, the success of the above-discussed ruthenium(II)-catalyzed annulations always relied on the use of an external oxidant in stoichiometric or cocatalytic amounts (vide supra). Thus, $\mathrm{Cu}(\mathrm{OAc})_{2} \cdot \mathrm{H}_{2} \mathrm{O}$ proved to be essential for these transformations, since it not only acted as the (co)oxidant but also served as the source of acetate for the carboxylate-assisted $\mathrm{C}-\mathrm{H}$ bond activation step. Conversely, an alternative strategy was viable through the use of substrates bearing $\mathrm{N}-\mathrm{O}$ bonds as "internal" 48 oxidants.

Herein, $\mathrm{N}$-methoxybenzamides and free hydroxamic acid $\mathbf{7 2}$ were utilized by Ackermann and Fenner for highly selective syntheses of isoquinolones 49 in the absence of an external oxidant under notably mild reaction conditions (Scheme 22). ${ }^{49}$ Remarkably, cocatalytic amounts of carboxylates were found to be indispensable for achieving efficient $\mathrm{C}-\mathrm{H}$ bond functionalizations, with optimal results being accomplished with $\mathrm{KO}_{2} \mathrm{CMes}$ as the co-catalyst and $\mathrm{H}_{2} \mathrm{O}$ as the reaction medium. ${ }^{49}$ Meanwhile, an alternative protocol by $\mathrm{Li}$ and Wang employed $\mathrm{NaOAc}$ as the additive in $\mathrm{MeOH}$ as the solvent, ${ }^{50}$ which was also rationalized in terms of acetate-assisted $\mathrm{C}-\mathrm{H}$ bond ruthenation.

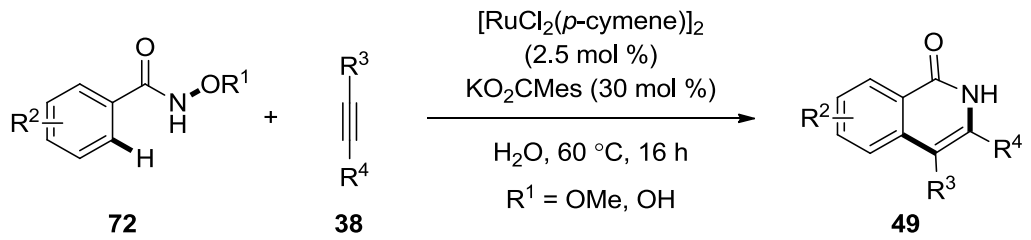

Scheme 22 Synthesis of isoquinolones 49 by $\mathrm{C}-\mathrm{H} / \mathrm{N}-\mathrm{O}$ bond cleavages

In analogy, this "internal" oxidant approach set the stage for an extension to the synthesis of isoquinolines 74 (Scheme 23). ${ }^{51,52}$ Thus, ketoximes $\mathbf{7 3}$ were selectively converted, with base

48 F. W. Patureau, F. Glorius, Angew. Chem., Int. Ed. 2011, 50, 1977-1979.

49 L. Ackermann, S. Fenner, Org. Lett. 2011, 13, 6548-6551.

50 B. Li, H. Feng, S. Xu, B. Wang, Chem. -Eur. J. 2011, 17, 12573-12577.

51 C. Kornhaaß, J. Li, L. Ackermann, J. Org. Chem. 2012, 77, 9190-9198.

52 (a) R. K. Chinnagolla, S. Pimparkar, M. Jeganmohan, Org. Lett. 2012, 14, 3032-3035; (b) see also: K. Parthasarathy, N. Senthilkumar, J. Jayakumar, C.-H. Cheng, Org. Lett. 2012, 14, 3478-3481; (c) P. Villuendas, E. P. Urriobeitia, J. Org. Chem. 2013, 78, 5254-5263. 
assistance proving to be essential for the dehydrative alkyne annulation to occur in an efficient manner. $^{51}$

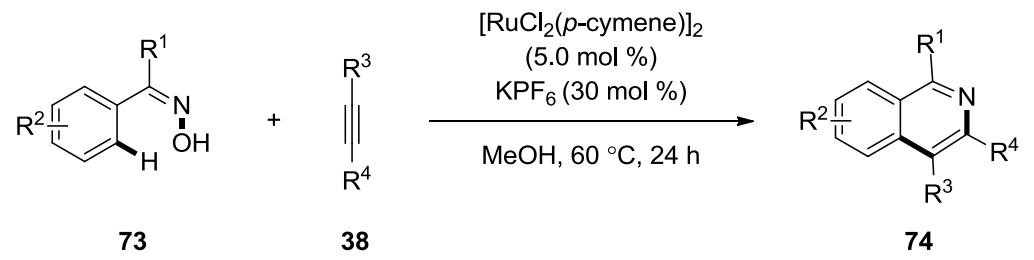

Scheme 23 Synthesis of isoquinolines $\mathbf{7 4}$ by dehydrative alkyne annulations

\subsection{Ruthenium-Catalyzed Direct Oxidative Alkenylation of Arenes}

Styrene derivatives are useful intermediates in synthetic organic chemistry and represent key structural motifs in natural products as well as in medicinal chemistry. ${ }^{53}$ Conventional transition metal-catalyzed cross-coupling reactions, ${ }^{3}$ such as the Mizoroki-Heck reaction, ${ }^{54}$ have matured to being reliable tools for the preparation of styrene derivatives (Scheme 24a). Besides, alkenylation via transmetallation employing stoichiometric amounts of palladium chloride and organomercury, -tin, or -lead arenes in lieu of aryl halides were also reported (Scheme 24b). ${ }^{3,54}$ However, the Mizoroki-Heck reaction is accompanied by the formation of a stoichiometric amount of potentially hazardous halide salt and transmetallation reactions always require organometallic nucleophilic reagents, which are, however, often not commercially available or are relatively expensive.

In contrast, the catalytic oxidative dehydrogenative alkenylation via a twofold $\mathrm{C}-\mathrm{H}$ bond activation approach, as initially demonstrated by Fujiwara and Moritani ${ }^{55}$ presents a powerful tool for the synthesis of styrene derivatives (Scheme 24c). ${ }^{56}$ Importantly, this approach is not only advantageous with respect to the overall minimization of byproduct formation (atom-economy), ${ }^{5 \mathrm{~b}, \mathrm{c}}$ but also allows for significantly reducing the number of required reaction steps (step-economy). ${ }^{5 \mathrm{a}}$ Subsequently, a variety of synthetically useful protocols for palladium-catalyzed direct oxidative couplings between arenes and alkenes have been achieved by inter alia Miura and Satoh, as well as $\mathrm{Yu} .{ }^{56}$ Efficient and selective rhodium catalysts have also been developed in recent years. ${ }^{32}$

53 (a) M. Sova, Mini-Rev. Med. Chem. 2012, 12, 749-767; (b) B. S. Siddiqui, H. Aslan, S. Begus, S. T. Ali, Nat. Prod. Res. 2007, 21, 736-741.

54 The Mizoroki-Heck Reaction, M. Oestreich, ed.; Wiley, Chichester, 2009.

55 (a) I. Moritani, Y. Fujiwara, Tetrahedron Lett. 1967, 8, 1119-1122; (b) Y. Fujiwara, I. Moritani, M. Matsuda, Tetrahedron 1968, 24, 4819-4824.

56 Reviews: (a) L. Zhou, W. Lu, Chem. -Eur. J. 2014, 20, 634-642; (b) J. Le Bras, J. Muzart, Chem. Rev. 2011, 111, 1170-1214; (c) B. Karimi, H. Behzadnia, D. Elhamifar, P. F. Akhavan, F. K. Esfahani, Synthesis 2010, 1399-1427; (d) M. Wasa, K. M. Engle, J.-Q. Yu, Isr. J. Chem. 2010, 50, 605-616. 


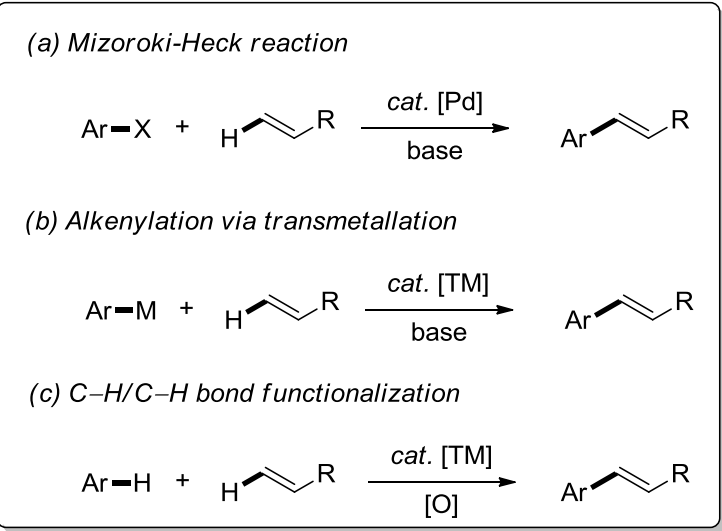

Scheme 24 Strategies for streamlining of styrene synthesis

However, less expensive ruthenium complexes have only recently been exploited as catalysts for oxidative $\mathrm{C}-\mathrm{H}$ bond alkenylations on arenes, starting from the work by Milstein and coworkers in 2001 (Scheme 25). ${ }^{57}$ According to this protocol, styrene derivatives 77 were obtained from substituted arenes 75. Unfortunately, major limitations of this protocol were represented by the low reactivity of unactivated alkenes as well as the poor site-selectivities with substituted arenes.
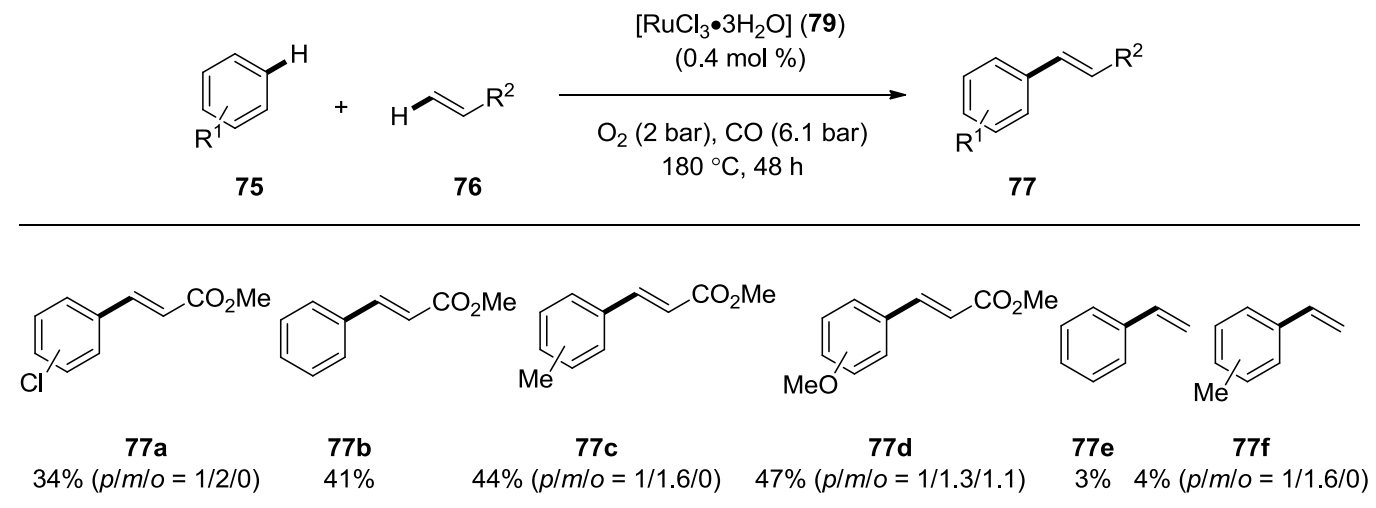

Scheme 25 Ruthenium-catalyzed direct alkenylations with simple arenes $\mathbf{7 5}$

The low selectivities observed in reactions of simple arenes were successfully addressed with the aid of Lewis-basic functional groups. Thus, a cationic ruthenium hydride complex $\mathbf{8 0}$ enabled highly site-selective oxidative $\mathrm{C}-\mathrm{H}$ bond alkenylations of benzamides 78 (Scheme 26), as described by Yi and coworkers. ${ }^{58 a}$ Since an external oxidant was not employed, an excess of the alkene $\mathbf{7 9}$ as well as the newly formed alkenylated benzamide $\mathbf{8 1}$ served as the hydrogen scavenger. Therefore, the products $\mathbf{8 1}$ were unfortunately contaminated with hydrogenated benzamides 82 .

57 H. Weissman, X. Song, D. Milstein, J. Am. Chem. Soc. 2001, 123, 337-338.

58 (a) K.-H. Kwon, D. W. Lee, C. S. Yi, Organometallics 2010, 29, 5748-5750; (b) C. S. Yi, D. W. Lee, Organometallics 2009, 28, 4266-4268. 


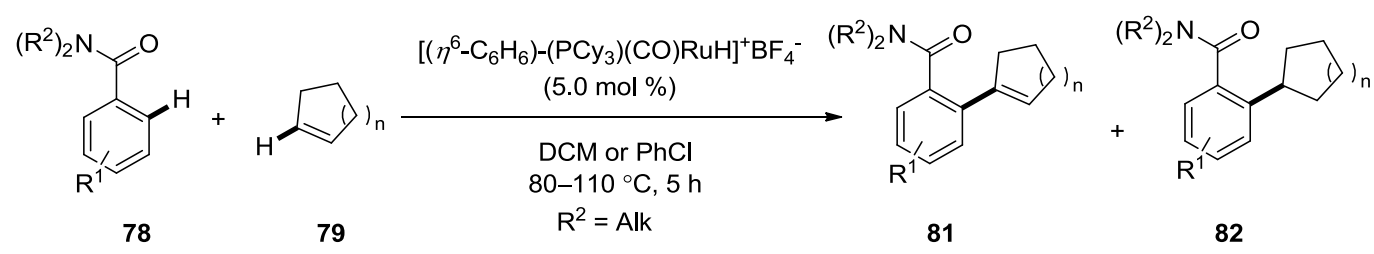

Scheme 26 Direct oxidative alkenylation of benzamides $\mathbf{7 8}$ with unactivated alkenes $\mathbf{7 9}$

The major breakthrough on the ruthenium-catalyzed oxidative alkenylaltions with directing groups was achieved by inter alia Ackermann as well as Miura and Satoh in recent years. ${ }^{29}$

In 2011, Ackermann and Pospech disclosed the ruthenium(II)-catalyzed oxidative $\mathrm{C}-\mathrm{H}$ bond alkenylation of benzoic acids $\mathbf{5 6}$ to smoothly proceed in water with $\mathrm{Cu}(\mathrm{OAc})_{2} \cdot \mathrm{H}_{2} \mathrm{O}$ as the oxidant (Scheme 27). ${ }^{59}$ Yet, the expected alkenylated benzoic acids 84 were not isolated, but the alkenylation products $\mathbf{8 4}$ immediately underwent a subsequent intramolecular oxa-Michael reaction, affording isobenzofuran-1(3H)-ones $\mathbf{8 5}$ in high yields. Experimental studies with isotopically labelled substrates suggested a kinetically relevant $\mathrm{C}-\mathrm{H}$ bond ruthenation through acetate assistance in the transition state. ${ }^{59}$<smiles>O=C(O)c1cc[R]cc1</smiles><smiles>[R]C=CC</smiles>

76

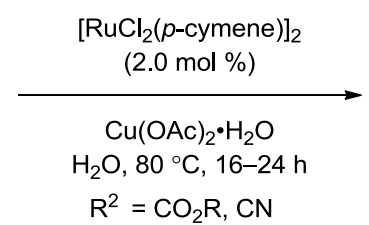

$\mathrm{R}^{2}=\mathrm{CO}_{2} \mathrm{R}, \mathrm{CN}$

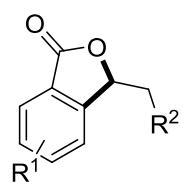

85

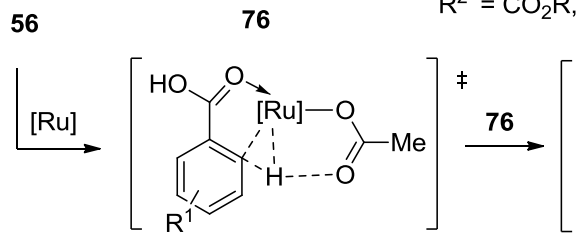

83

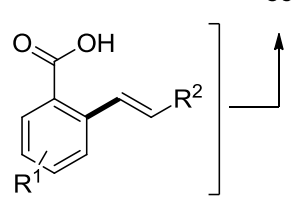

84

Scheme 27 Ruthenium-catalyzed oxidative alkenylation of benzoic acids $\mathbf{5 6}$ in water

Satoh and Miura reported on the use of a cationic ruthenium catalyst, in situ generated from $\left[\mathrm{RuCl}_{2}(p \text {-cymene) }]_{2}\right.$ and $\mathrm{AgSbF}_{6}$, for oxidative alkenylations of benzamides 78 (Scheme 28). ${ }^{60 \mathrm{a}}$ Notably, the reaction did not proceed in the absence of $\mathrm{AgSbF}_{6}$. Besides, Loh developed a ruthenium catalytic system with $\mathrm{KPF}_{6}$ as the efficient additive for the direct cross-coupling of acrylamides with electron-deficient alkenes forming $(Z, E)$-dienamides. ${ }^{60 \mathrm{~b}}$

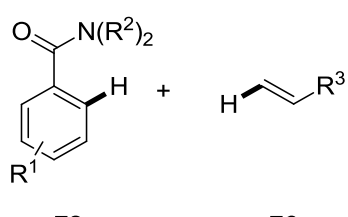

78

76

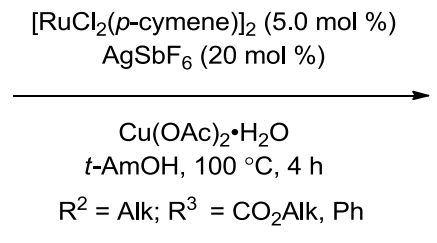

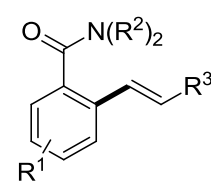

86

Scheme 28 Ruthenium-catalyzed oxidative alkenylation of benzamides $\mathbf{7 8}$ with $\mathrm{AgSbF}_{6}$ as the additive

Alternatively, ruthenium-catalyzed $\mathrm{C}-\mathrm{H}$ bond alkenylations can also be realized with

59 L. Ackermann, J. Pospech, Org. Lett. 2011, 13, 4153-4155.

60 (a) Y. Hashimoto, T. Ortloff, K. Hirano, T. Satoh, C. Bolm, M. Miura, Chem. Lett. 2012, 41, 151-153; (b) J. Zhang, T.-P. Loh, Chem. Commun. 2012, 48, 11232-11234; (c) for a ruthenium-catalyzed amide directed ortho-C-H alkylation, see: J. Qi, L. Huang, Z. Wang, H. Jiang, Org. Biomol. Chem. 2013, 11, 8009-8013. 
pre-functionalized starting materials bearing an "internal" oxidizing directing group. ${ }^{48}$ Notably, the reactions with acrylates $\mathbf{7 6}$ resulted in $\mathrm{C}-\mathrm{H}$ bond alkenylations of methoxybenzamides $\mathbf{7 2}$, affording olefinated benzamides 87 (Scheme 29). ${ }^{61}$

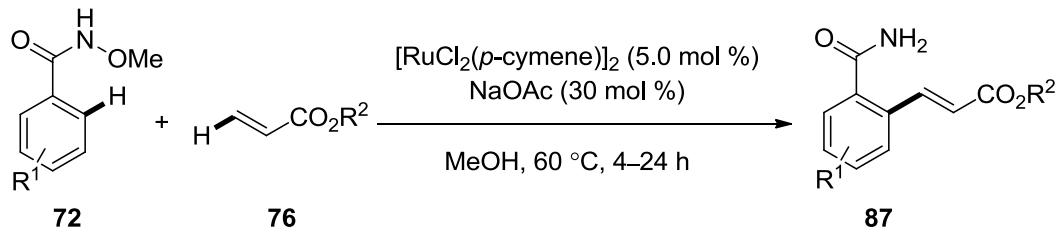

Scheme 29 Ruthenium-catalyzed $\mathrm{C}-\mathrm{H}$ bond alkenylation with an "internal" oxidazing directing group

With the success of chelation-assisted alkenylations on benzamides, analogous ruthenium-catalyzed oxidative functionalizations of weakly coordinating esters has until recently proven elusive. The research groups of Ackermann ${ }^{62}$ and Jeganmohan ${ }^{63}$ disclosed reaction conditions for the versatile oxidative direct functionalization of aromatic esters $\mathbf{8 8}$ (Scheme 30). Thus, a catalytic system comprising $\left[\mathrm{RuCl}_{2}(p \text {-cymene })\right]_{2}, \mathrm{AgSbF}_{6}$ and cocatalytic amounts of $\mathrm{Cu}(\mathrm{OAc})_{2} \cdot \mathrm{H}_{2} \mathrm{O}$ utilizing air as the ideal terminal oxidant allowed for efficient aerobic $\mathrm{C}-\mathrm{H}$ bond alkenylations in a highly site-selective fashion. ${ }^{62}$

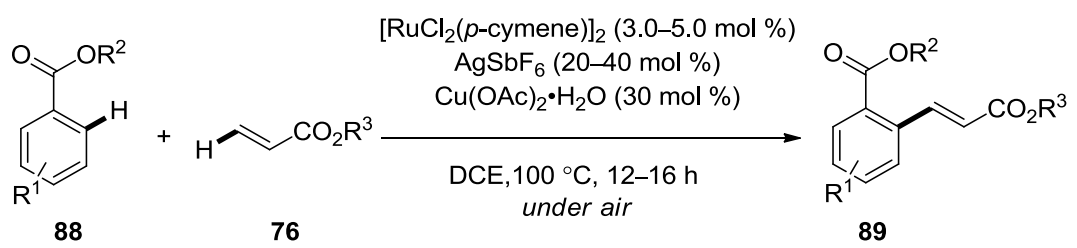

Scheme 30 Ruthenium-catalyzed oxidative alkenylations of weakly coordinating aromatic esters $\mathbf{8 8}$

This catalytic system was also found to be effective for alkenylations of aromatic ketones and benzaldehydes 90 (Scheme 31). ${ }^{64,65}$ Thus, the ruthenium-catalyzed $\mathrm{C}-\mathrm{H}$ bond functionalization provided alkenylated products $\mathbf{9 1}$ in moderate to good yields with acrylates and styrenes.

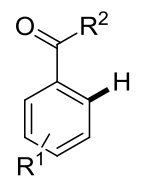

90
$\left[\mathrm{RuCl}_{2}(p \text {-cymene })\right]_{2}(2.0-3.0 \mathrm{~mol} \%)$ $\mathrm{AgSbF}_{6}(10-20 \mathrm{~mol} \%)$

$\mathrm{Cu}(\mathrm{OAc})_{2} \cdot \mathrm{H}_{2} \mathrm{O}(30-50 \mathrm{~mol} \%)$<smiles>[R]OC(=O)/C=C\C</smiles>

DCE, $100^{\circ} \mathrm{C}, 12-16 \mathrm{~h}$

under air

76

$\mathrm{R}^{2}=\mathrm{H}$, Alk; $\mathrm{R}^{3}=\mathrm{H}$, Alk, Ar<smiles>[R]OC(=O)C=Cc1c[R]#ccc1C([R])=O</smiles>

91

Scheme 31 Ruthenium-catalyzed oxidative alkenylation of phenones and benzaldhydes 90

Moreover, the ruthenium catalytic system enabled oxidative alkenylations of electron-rich aryl carbamates 92 with weakly coordinating and removable directing groups ${ }^{38}$ in a chemo- and

61 B. Li, J. Ma, N. Wang, H. Feng, S. Xu, B. Wang, Org. Lett. 2012, 14, 736-739.

62 K. Graczyk, W. Ma, L. Ackermann, Org. Lett. 2012, 14, 4110-4113.

63 K. Padala, S. Pimparkar, P. Madasamy, M. Jeganmohan, Chem. Commun. 2012, 48, 7140-7142.

64 K. Padala, M. Jeganmohan, Org. Lett. 2011, 13, 6144-6147.

65 K. Padala, M. Jeganmohan, Org. Lett. 2012, 14, 1134-1137. 
site-selective fashion, affording diversely decorated phenol derivatives 93 (Scheme 32 ). ${ }^{6 \mathrm{a}}$

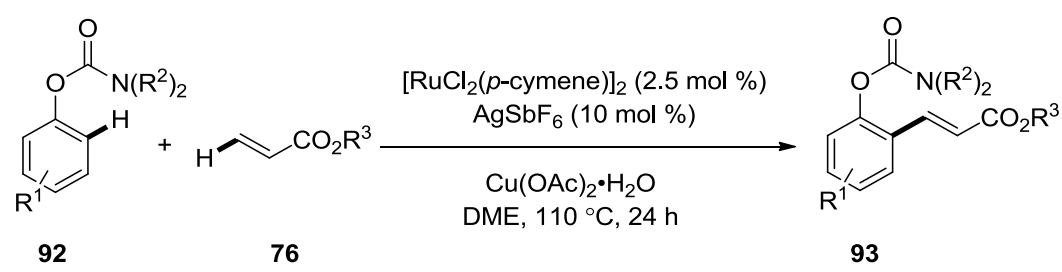

Scheme 32 Ruthenium-catalyzed oxidative alkenylation of aryl carbamates $\mathbf{9 2}$

Recently, the ruthenium(II)-promoted oxidative alkenylations of phenols 94 bearing easily cleavable directing groups ${ }^{38}$ was reported (Scheme 33). ${ }^{67}$ The double $\mathrm{C}-\mathrm{H}$ functionalization process proceeded with excellent chemo-, site-, and diastereoselectivities in an aerobic fashion.

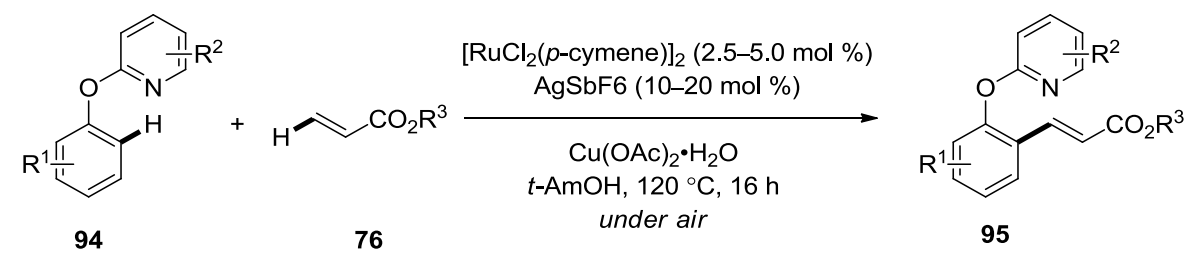

Scheme 33 Ruthenium(II)-catalyzed C-H alkenylations of arenes 94 with removable directing groups

Besides, Dixneuf and Bruneau reported on ruthenium-catalyzed oxidative alkenylation of $N$-phenylpyrazole (96) with acrylates and acrylamides (Scheme 34) ${ }^{68}$ Unfortunately, in many cases the products 97 were contaminated with by-products 98 generated through dehydrogenative homocoupling of substrates 96 .

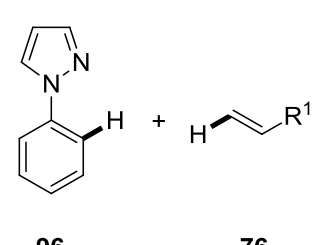

96

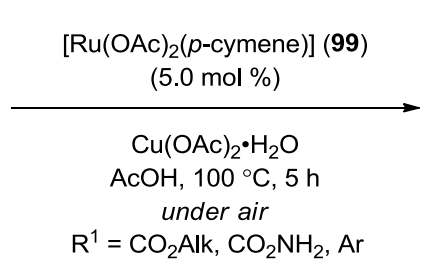

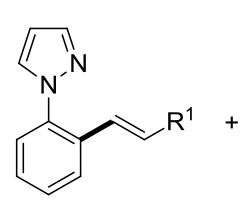

97

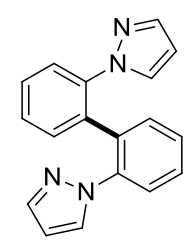

98

Scheme 34 Ruthenium-catalyzed oxidative alkenylation of $N$-phenylpyrazole 96

However, employing $\left[\mathrm{RuCl}_{2}(p \text {-cymene })\right]_{2}$ complex instead of the above mentioned $\left[\mathrm{Ru}(\mathrm{OAc})_{2}(p\right.$-cymene $\left.)\right]$ analog, along with a higher loading of $\mathrm{Cu}(\mathrm{OAc})_{2} \cdot \mathrm{H}_{2} \mathrm{O}$, efficiently suppressed the competitive homocoupling reaction. ${ }^{69}$ Hence, alkenylations of 2-phenylazoles 100 with $\left[\mathrm{RuCl}_{2}(p \text {-cymene })\right]_{2}$ in $t-\mathrm{AmOH}$ as the solvent was achieved, albeit with a significantly lower yields (Scheme 35). ${ }^{60 \mathrm{a}}$

66 (a) J. Li, C. Kornhaaß, L. Ackermann, Chem. Commun. 2012, 48, 11343-11345; (b) for subsequent report: M. C. Reddy, M. Jeganmohan, Eur. J. Org. Chem. 2013, 1150-1157; (c) B. Li, J. Ma, Y. Liang, N. Wang, S. Xu, H. Song, B. Wang, Eur. J. Org. Chem. 2013, 1950-1962; (d) for hydroalkenylation of alkynes, see: M. C. Reddy, M. Jeganmohan, Chem. Commun. 2013, 49, 481-483.

67 W. Ma, L. Ackermann, Chem.-Eur. J. 2013, 19, 13925-13928.

68 P. B. Arockiam, C. Fischmeister, C. Bruneau, P. H. Dixneuf, Green Chem. 2011, 13, 3075-3078.

69 Y. Hashimoto, T. Ueyama, T. Fukutani, K. Hirano, T. Satoh, M. Miura, Chem. Lett. 2011, 40, 1165-1166. 


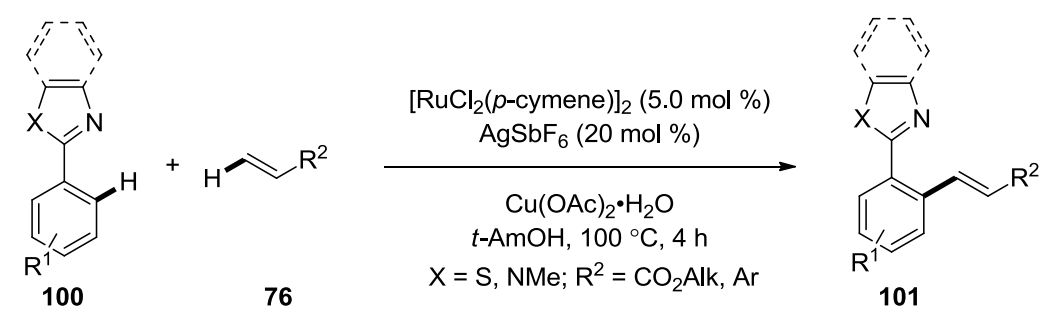

Scheme 35 Ruthenium-catalyzed oxidative alkenylation of 2-phenylazoles $\mathbf{1 0 0}$

Furthermore, monoalkenylations of aromatic $\mathrm{C}-\mathrm{H}$ bonds directed by an oxazoline group were found by the same group to take place efficiently using $\left[\mathrm{RuCl}_{2}(p \text {-cymene })\right]_{2}$ along with rac-BNPAN (104) as an efficient ligand (Scheme 36). ${ }^{70}$<smiles>[R]C=C[CH-]c1c[R]#ccc1C1=NCC([R])=C1</smiles>

102

76

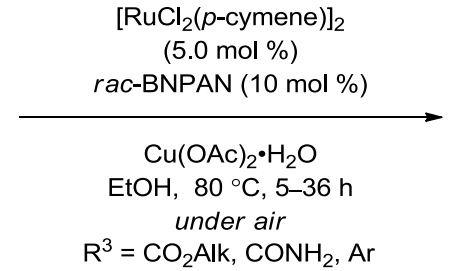

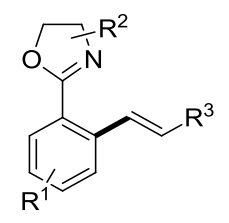

103

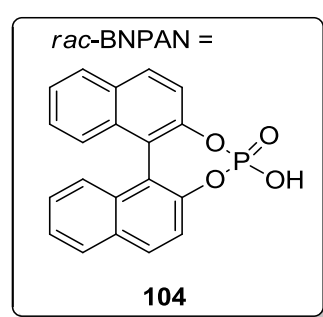

Scheme 36 Ruthenium-catalyzed oxidative alkenylation of 2-phenyloxazolines 102

Essentially, ruthenium-catalyzed alkenylations of heteroarenes 105 with various directing groups were achieved with the catalytic systems described above, albeit with different catalytic efficacies. ${ }^{71,72}$ The experimental results are summarized in Scheme 37 and highlight various esters, benzamides, aldehydes and carbamates could be employed for chemo- and site-selective ruthenium-catalyzed twofold $\mathrm{C}-\mathrm{H}$ bond functionalizations.

70 B. Li, K. Devaraj, C. Darcel, P. Dixneuf, Green Chem. 2012, 14, 2706-2709.

71 T. Ueyama, S. Mochida, T. Fukutani, K. Hirano, T. Satoh, M. Miura, Org. Lett. 2011, 13, 706-708.

72 (a) B. Li, J. Ma, W. Xie, H. Song, S. Xu, B. Wang, J. Org. Chem. 2013, 78, 9345-9353; (b) L.-Q. Zhang, S. Yang, X. Huang, J. You, F. Sodirectng, Chem. Commun. 2013, 49, 8830-8832. 


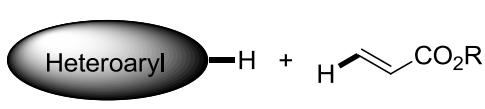

105

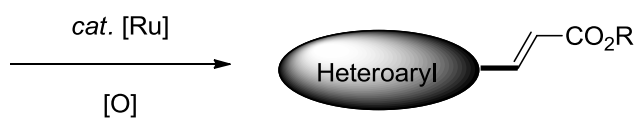

106

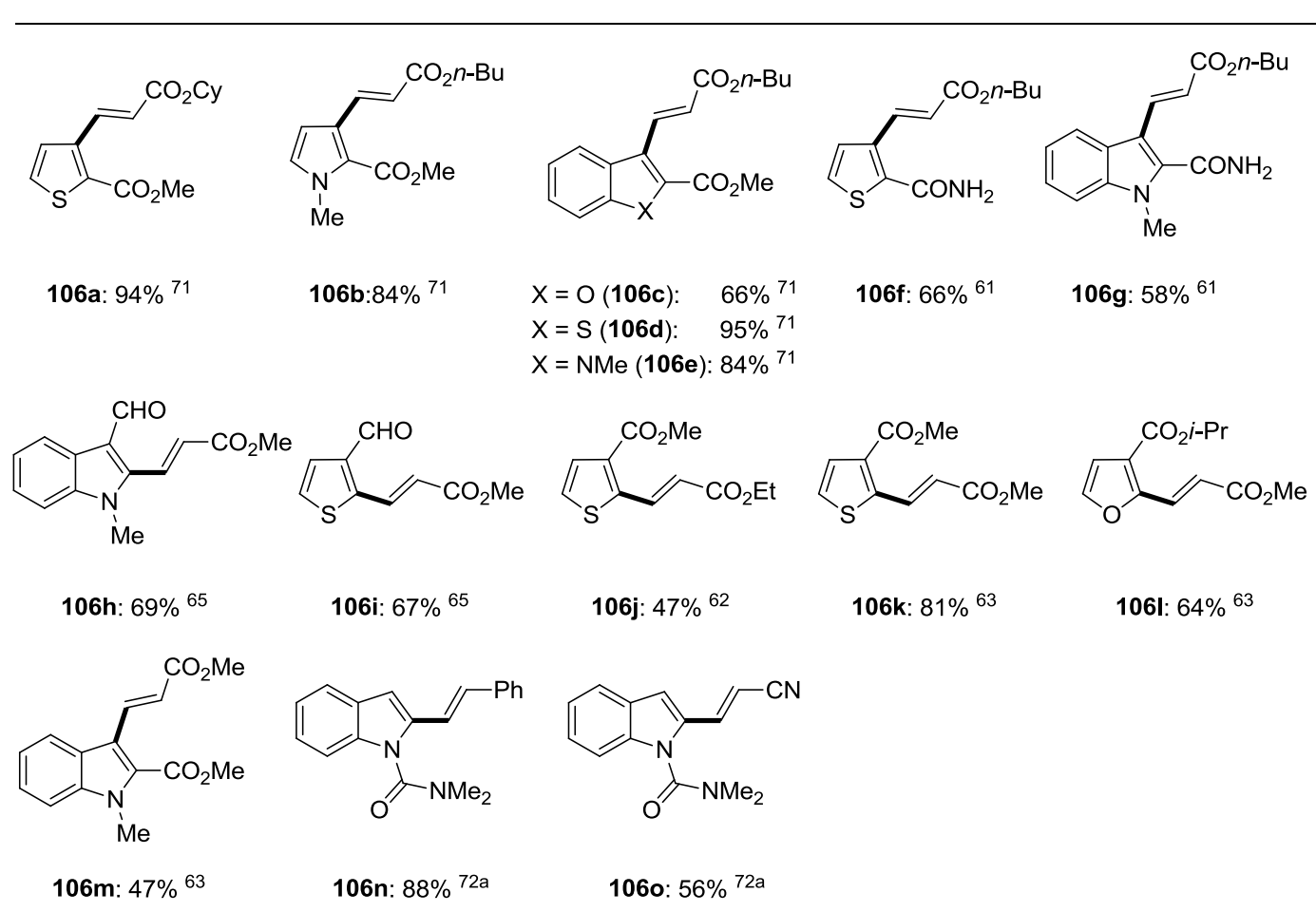

Scheme 37 Ruthenium-catalyzed oxidative alkenylation of substituted heteroarenes

\subsection{Ruthenium-Catalyzed Direct Hydroarylations}

\subsubsection{Ruthenium-Catalyzed Direct Hydroarylations}

As discussed above, the oxidative direct functionalization with unreactive $\mathrm{C}-\mathrm{H}$ bonds is a powerful tool for the construction of $\mathrm{C}-\mathrm{C}$ bonds in a step-economical fashion. On the other hand, the prospects to develop metal-catalyzed hydroarylation reactions are alternatively attractive due to their perfect atom economy, with notable progress being accomplished with versatile ruthenium catalysts. $^{27}$

As early as 1986, Lewis reported the first ortho-selective hydroarylation of phenol (107) with alkenes catalyzed by the ortho-metalated ruthenium complex $\mathbf{1 1 0}$ (Scheme 38). ${ }^{16}$

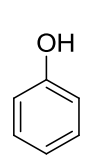

107

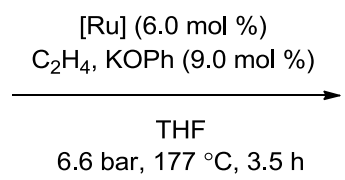

6.6 bar, $177^{\circ} \mathrm{C}, 3.5 \mathrm{~h}$<smiles>CCc1ccccc1O</smiles>

108: $13 \%$<smiles>CCc1cccc(CC)c1O</smiles>

109: $75 \%$

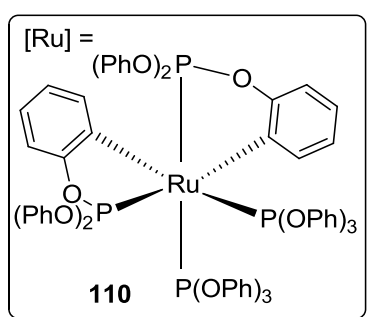

Scheme 38 Ruthenium-catalyzed direct $\mathrm{C}-\mathrm{H}$ alkylation by Lewis

However, a major breakthrough in the ruthenium-catalyzed directed hydroarylations was achieved by Murai in 1993 (Scheme 39). ${ }^{17}$ According to this protocol, chelation-assistance resulted in 
highly site-selective $\mathrm{C}-\mathrm{H}$ bond cleavage, leading to addition of aromatic ketone $\mathbf{9 0}$ to alkenes $\mathbf{1 1 1}$ with a $\mathrm{C}-\mathrm{C}$ bond formation. ${ }^{17}$

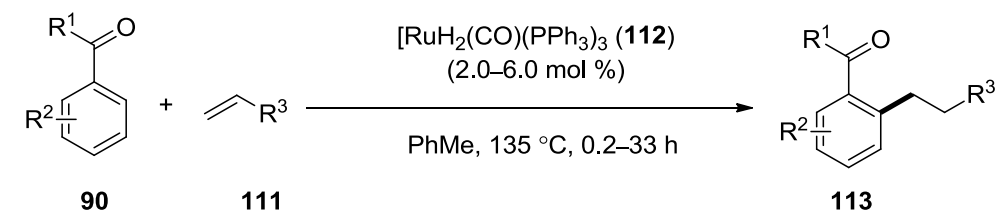

Scheme 39 Ruthenium-catalyzed direct $\mathrm{C}-\mathrm{H}$ alkylation by Murai

Intensive mechanistic studies ${ }^{73,74}$ on the Murai reaction showed that the initial formation of intermediate 117 via transition state 116, subsequent coordination of alkene $\mathbf{1 1 1}$ and migratory insertion to the $\mathrm{Ru}-\mathrm{H}$ bond are reversible (Scheme 40). Finally, reductive elimination of complex $\mathbf{1 1 9}$ delivers the target product $\mathbf{1 1 3}$ and regenerates the active ruthenium species 114. Besides, isotopically labelled experiment with substrates suggested that a branched species 119' is also probably formed, which, however, seems not to undergo reductive elimination, since no corresponding branched product was obtained. ${ }^{74}$ Further studies ${ }^{75}$ showed that the $\mathrm{C}-\mathrm{C}$ bond formation is the rate determining step.

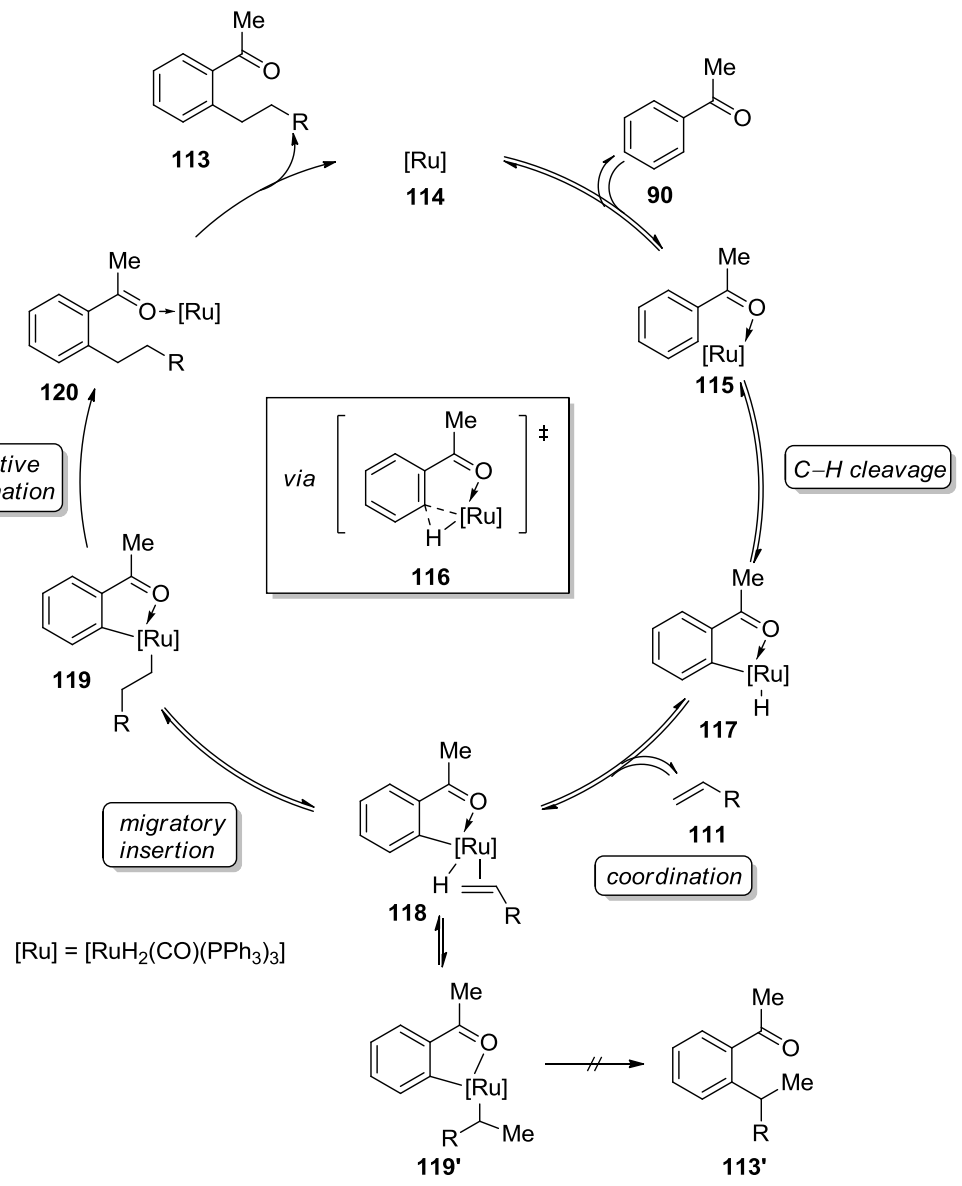

Scheme 40 Catalytic cycle for the Murai reaction

73 F. Kakiuchi, H. Ohtaki, M. Sonoda, N. Chatani, S. Murai, Chem. Lett. 2001, 918-919.

74 F. Kakiuchi, T. Kochi, E. Mizushima, S. Murai, J. Am. Chem. Soc. 2010, 132, 17741-17750.

75 (a) F. Kakiuchi, T. Sato, T. Tsujimoto, M. Yamauchi, N. Chatani, S. Murai, Chem. Lett. 1998, 1053-1054; (b) T. Matsubara, N. Koga, D. G. Musaev, K. Morokuma, J. Am. Chem. Soc. 1998, 120, 12692-12693; (c) T. Matsubara, N. Koga, D. G. Musaev, K. Morokuma, Organometallics 2000, 19, 2318-2329. 
In the following years, ${ }^{76}$ Murai and coworkers extended the application of hydroarylations including replacement of the terminal alkenes $\mathbf{1 1 1}$ by acetylenes ${ }^{77}$ and the use of esters, ${ }^{78}$ imines, ${ }^{79}$ oxazoline $^{80}$ and aldehydes ${ }^{81}$ as efficient directing groups. Coinciding with Murai's alkylations of cyclic and acyclic $\alpha, \beta$-enones, ${ }^{82}$ Trost successfully applied the precatalyst $\left[\mathrm{RuH}_{2}(\mathrm{CO})\left(\mathrm{PPh}_{3}\right)_{3}\right](\mathbf{1 1 4})$ to the alkylation of acrylic acid esters. ${ }^{83}$

However, a major disadvantage of Murai's protocol is the air sensitivity of catalyst $\left[\mathrm{RuH}_{2}(\mathrm{CO})\left(\mathrm{PPh}_{3}\right)_{3}\right](\mathbf{1 1 4})$. This promoted Darses and Genet to develop a new hydroarylating system through the elegant in situ formation of catalyst $\left[\mathrm{RuH}_{2}\left(\mathrm{PPh}_{3}\right)_{4}\right]$ (121) from $\left[\mathrm{RuCl}_{2}(p \text {-cymene) }]_{2}(\mathbf{1 5})\right.$ and sodium formate, in association with a phosphine ligand (Scheme 41). ${ }^{84}$ This novel system showed high activity in the ortho-hydroarylations of tetralone and acetophenone $\mathbf{1 2 2}$ with active alkenes, such as vinylsilane and styrene derivatives $\mathbf{1 1 1}$ (Scheme 41). ${ }^{84,85}$

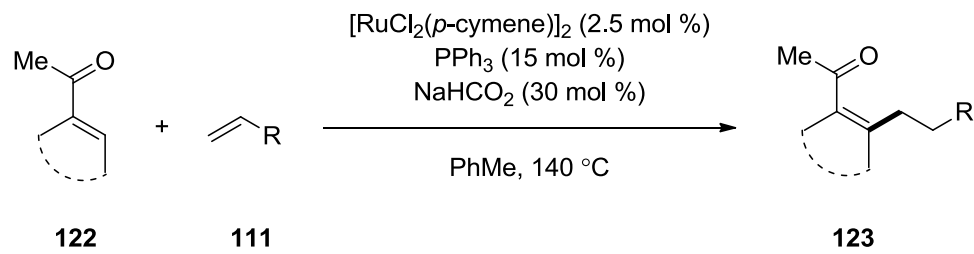

Scheme 41 Ruthenium-catalyzed direct $\mathrm{C}-\mathrm{H}$ alkylation by Genet and Darses

Besides, Ackermann and coworkers achieved the hydroarylation of highly strained methylenecyclopropanes 124 by the combination of $\left[\mathrm{RuCl}_{2}(\mathrm{cod})\right]_{\mathrm{n}}(\mathbf{1 2 5})$ and XPhos, which furnished anti-Markovnikov products $\mathbf{1 2 6}$ with complete conservation of all cyclopropane rings (Scheme 42). ${ }^{86}$

76 (a) F. Kakiuchi, T. Kochi, Synthesis 2008, 3013-3039; (b) F. Kakiuchi, S. Murai, Acc. Chem. Res. 2002, 35, 826-834; (c) S. Murai, F. Kakiuchi, S. Sekine, Y. Tanaka, A. Kamatani, M. Sonoda, N. Chatani, Pure Appl. Chem. 1994, 66, 1527-1534; (d) S. Murai, N. Chatani, F. Kakiuchi, Pure Appl. Chem. 1997, 69, 589-594; (e) M. Sonoda, F. Kakiuchi, N. Chatani, S. Murai, Bull. Chem. Soc. Jpn. 1997, 70, 3117-3128.

77 F. Kakiuchi, Y. Yamamoto, N. Chatani, S. Murai, Chem. Lett. 1995, 681-682.

78 M. Sonoda, F. Kakiuchi, A. Kamatani, N. Chatani, S. Murai, Chem. Lett. 1996, 109-110.

79 F. Kakiuchi, M. Yamauchi, N. Chatani, S. Murai, Chem. Lett. 1996, 111-112.

80 F. Kakiuchi, T. Sato, M. Yamauchi, N. Chatani, S. Murai, Chem. Lett. 1999, 19-20.

81 F. Kakiuchi, T. Sato, K. Igi, N. Chatani, S. Murai, Chem. Lett. 2001, 386-387.

82 (a) F. Kakiuchi, Y. Tanaka, T. Sato, N. Chatani, S. Murai, Chem. Lett. 1995, 679-680; (b) T. Sato, F. Kakiuchi, N. Chatani, S. Murai, Chem. Lett. 1998, 893-894.

83 B. M. Trost, K. Imi, I. W. Davies, J. Am. Chem. Soc. 1995, 117, 5371-5372.

84 (a) R. Martinez, R. Chevalier, S. Darses, J.-P. Genet, Angew. Chem. Int. Ed. 2006, 45, 8232-8235; (b) R. Martinez, M.-O. Simon, R. Chevalier, C. Pautigny, J.-P. Genet, S. Darses, J. Am. Chem. Soc. 2009, 131, 78877895.

85 (a) R. Martinez, J.-P. Genet, S. Darses, Chem. Commun. 2008, 3855-3857; (b) M.-O. Simon, R. Martinez, J.-P. Genet, S. Darses, Adv. Synth. Catal. 2009, 351, 153-157; (c) M.-O. Simon, R. Martinez, J.-P. Genet, S. Darses, J. Org. Chem. 2009, 75, 208-210; (d) M.-O. Simon, J.-P. Genet, S. Darses, Org. Lett. 2010, 12, 3038-3041; (e) M.-O. Simon, G. Ung, S. Darses, Adv. Synth. Catal. 2011, 353, 1045-1048; (c) M.-O. Simon, S. Darses, J. Org. Chem. 2013, 78, 9981-9985.

86 (a) S. I. Kozhushkov, D. S. Yufit, L. Ackermann, Org. Lett. 2008, 10, 3409-3412; (b) L. Ackermann, S. I. Kozhushkov, D. S. Yufit, Chem. -Eur. J. 2012, 18, 12068-12077. 


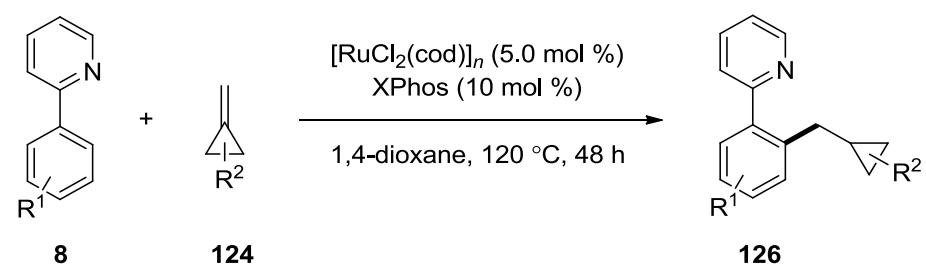

Scheme 42 Ruthenium-catalyzed hydroarylation of methylenecyclopropanes

Despite notable advances in the oxidative $\mathrm{C}-\mathrm{H}$ bond functionalizations, ${ }^{8}$ metal carboxylates were as of yet not exploited as cocatalytic additives for ruthenium-catalyzed hydroarylations. Very recently, Ackermann and co-workers reported on highly efficient carboxylate-assisted ruthenium-catalyzed hydroarylations of unactivated alkenes $\mathbf{1 1 1}$ and of methylenecyclopropanes 124 employing various (hetero)arenes 17 with ample scope (Scheme 43). ${ }^{87}$

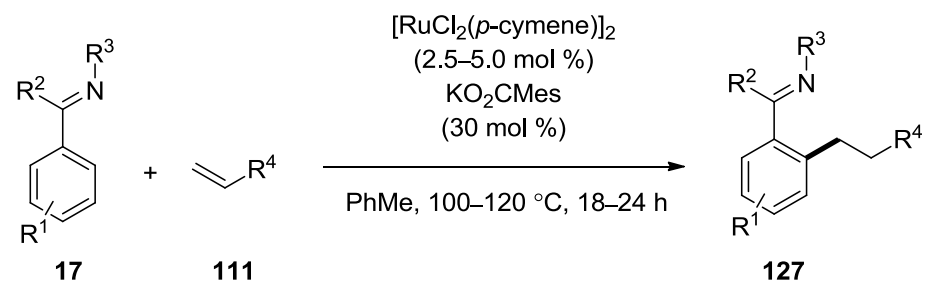

Scheme 43 Carboxylate-assisted ruthenium-catalyzed hydroarylations

Ruthenium-catalyzed hydroarylations of aromatic amides 129 with various $\alpha, \beta$-unsaturated ketones 130 using a removable 8-aminoquinoline bidentate directing group ${ }^{38,88}$ has been recently developed by Chatani (Scheme 44). ${ }^{89}$ This methodology represented the first efficient utilization of active enones in the ortho-directed ruthenium-catalyzed addition of $\mathrm{C}-\mathrm{H}$ bonds to $\mathrm{C}-\mathrm{C}$ double bonds.

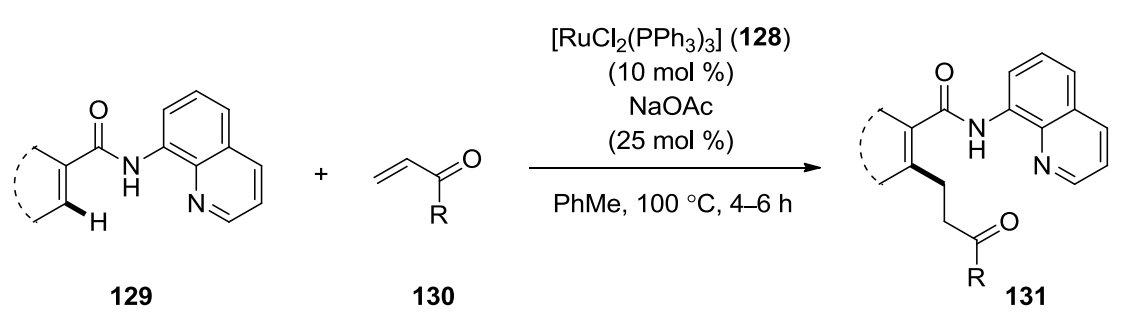

Scheme 44 Ruthenium-catalyzed ortho-hydroarylation with $\alpha, \beta$-unsaturated ketones

Along with the obvious progress in the ruthenium-catalyzed chelation-assisted hydroarylations, Nakamura and Yoshikai independently reported on the first examples of cobalt-catalyzed

87 (a) M. Schinkel, I. Marek, L. Ackermann, Angew. Chem. Int. Ed. 2013, 52, 3977-3980; (b) M. Schinkel, J. Wallbaum, S. I. Kozhushkov, I. Marek, L. Ackermann, Org. Lett. 2013, 15, 4482-4484.

88 A recent review on catalytic functionalization of $\mathrm{C}\left(\mathrm{sp}^{2}\right)-\mathrm{H}$ and $\mathrm{C}\left(\mathrm{sp}^{3}\right)-\mathrm{H}$ bonds by using bidentate directing groups: G. Rouquet, N. Chatani, Angew. Chem. Int. Ed. 2013, 52, 11726-11743.

89 (a) G. Rouquet, N. Chatani, Chem. Sci. 2013, 4, 2201-2208; selected examples of Rh(I) catalysis: (b) L. Yang, B. Qian, H. Huang, Chem. -Eur. J. 2012, 18, 9511-9515; (b) L. Yang, C. A. Correia, C.-J. Li, Org. Biomol. Chem. 2011, 9, 7176-7179; (c) S.-G. Lim, J.-A. Ahn, C.-H. Jun, Org. Lett. 2004, 6, 4687-4690. 
hydroarylation of terminal alkenes ${ }^{90,91}$ and internal alkynes ${ }^{92}$ using ketimines, $N$-methyl amide and pyridine as directing groups. However, the employment of this catalytic system was limited by low tolerance of many important functional groups. Besides, the first manganese-catalyzed hydroarylation of terminal alkynes was recently reported. ${ }^{93}$

\subsubsection{Ruthenium-Catalyzed Direct $\mathrm{C}\left(\mathrm{sp}^{3}\right)-\mathrm{H}$ Alkylations}

In contrast to the direct transformations of $\mathrm{C}\left(\mathrm{sp}^{2}\right)-\mathrm{H}$ bonds, catalytic alkylations with alkenes involving the cleavage of the $\mathrm{C}\left(\mathrm{sp}^{3}\right)-\mathrm{H}$ bonds ${ }^{94}$ have unfortunately thus far met with limited success. In 1998, Jun achieved the first chelation-assisted $\mathrm{C}\left(\mathrm{sp}^{3}\right)-\mathrm{H}$ alkylation on benzylamines 133 employing $\mathrm{Ru}_{3}(\mathrm{CO})_{12}(\mathbf{1 3 2})$. However, only benzylic $\mathrm{C}-\mathrm{H}$ bonds enabled addition to alkenes $\mathbf{1 3 4}$ under these conditions (Scheme 45). ${ }^{95}$<smiles>[R]c1ccc(CNc2ncccc2C)cc1</smiles>

133

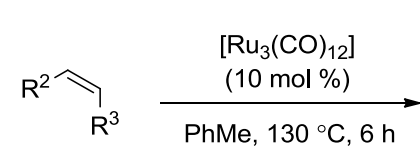

134

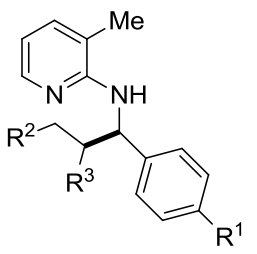

135

Scheme 45 Ruthenium-catalyzed hydroalkylation of benzylamines 133 with alkenes 134

Promoted by the success of rhodium-catalyzed $\alpha$-carbonylation of $\mathrm{C}\left(\mathrm{sp}^{3}\right)-\mathrm{H}$ bonds to cyclic amino and amido groups, ${ }^{96}$ Murai, Kakiuchi and Chatani observed that $\mathrm{Ru}_{3}(\mathrm{CO})_{12}(\mathbf{1 3 2})$ enabled the addition of $\mathrm{C}\left(\mathrm{sp}^{3}\right)-\mathrm{H}$ bond across the alkene bond to give the corresponding alkylated products $\mathbf{1 3 7}$ (Scheme 46). ${ }^{97}$ Intensive studies showed that the reactivity was improved using iso-propanol as the solvent. Various alkenes, including terminal, internal and cyclic alkenes, proved to be suitable applying this protocol, and the substrates were successfully extended to five-, six- and seven-membered rings.

90 L. Ilies, Q. Chen, X. Zeng, E. Nakamura, J. Am. Chem. Soc. 2011, 133, 5219-5223.

91 (a) K. Gao, N. Yoshikai, Angew. Chem. Int. Ed. 2011, 50, 6888-6892; (b) K. Gao, N. Yoshikai, J. Am. Chem. Soc. 2011, 133, 400-402. See also: (c) W. Song, L. Ackermann, Angew. Chem. Int. Ed. 2012, 51, 8251-8254.

92 K. Gao, P.-S. Lee, T. Fujita, N. Yoshikai, J. Am. Chem. Soc. 2010, 132, 12249-12251.

93 B. Zhou, H. Chen, C. Wang, J. Am. Chem. Soc. 2013, 135, 1264-1267.

94 For selected reviews on $\mathrm{C}\left(\mathrm{sp}^{3}\right)-\mathrm{H}$ bond transformations, see: (a) S. A. Girard, T. Knauber, C.-J. Li, Angew. Chem. Int. Ed. 2014, 53, 74-100; (b) H. Li, B.-J. Li, Z.-J. Shi, Catal. Sci. Technol. 2011, 1, 191; (c) O. Baudoin, Chem. Soc. Rev. 2011, 40, 4902; (d) M. Wasa, K. M. Engle, J.-Q. Yu, Isr. J. Chem. 2010, 50, 605; (e) R. Jazzar, J. Hitce, A. Renaudat, J. Sofack-Kreutzer, O. Baudoin, Chem. -Eur. J. 2010, 16, 2654.

95 C.-H. Jun, D.-C. Hwang, S.-J. Na, Chem. Commun. 1998, 1405-1406.

96 (a) N. Chatani, T. Asaumi, T. Ikeda, S. Yorimitsu, Y. Ishii, F. Kakiuchi, S. Murai, J. Am. Chem. Soc. 2000, 122, 12882-12883; (b) Y. Ishii, N. Chatani, F. Kakiuchi, S. Murai, Organometallics 1997, 16, 3615-3622; (c) Y. Ishii, N. Chatani, F. Kakiuchi, S. Murai, Tetrahedron Lett. 1997, 38, 7565-7568.

97 N. Chatani, T. Asaumi, S. Yorimitsu, T. Ikeda, F. Kakiuchi, S. Murai, J. Am. Chem. Soc. 2001, 123, 10935110941. 


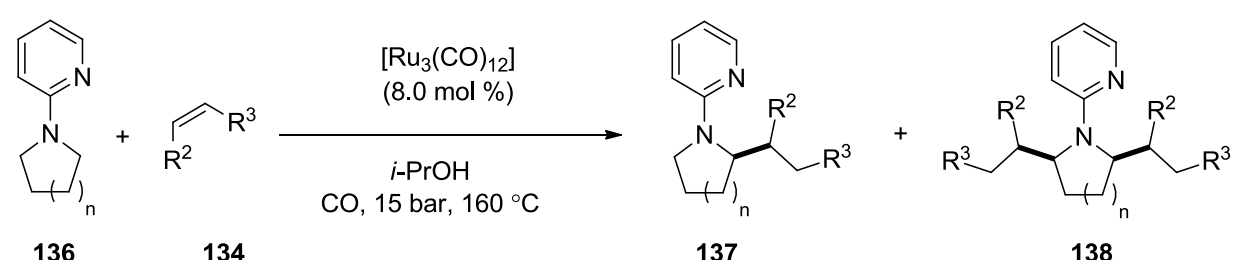

Scheme 46 Ruthenium-catalyzed alkylation of cyclic amines 136 with alkenes 134

The reaction mechanism proposed for Murai's $\mathrm{C}\left(\mathrm{sp}^{3}\right)-\mathrm{H}$ alkylation was similar to the mechanisms of $\mathrm{C}\left(\mathrm{sp}^{2}\right)-\mathrm{H}$ bond functionalizations discussed above (Scheme 47$){ }^{73-75,98}$ First, coordination of substrate 136 to ruthenium provides complex 140, in which the $\mathrm{C}-\mathrm{H}$ bond undergoes cleavage to give a $\mathrm{Ru}-\mathrm{H}$ complex 141. Subsequently, coordination of alkene $\mathbf{1 3 4}$ and its migratory insertion furnishes the $\mathrm{Ru}$-alkyl complex $\mathbf{1 4 3}$, from which reductive elimination affords the final product 137, with the active ruthenium complex being regenerate.

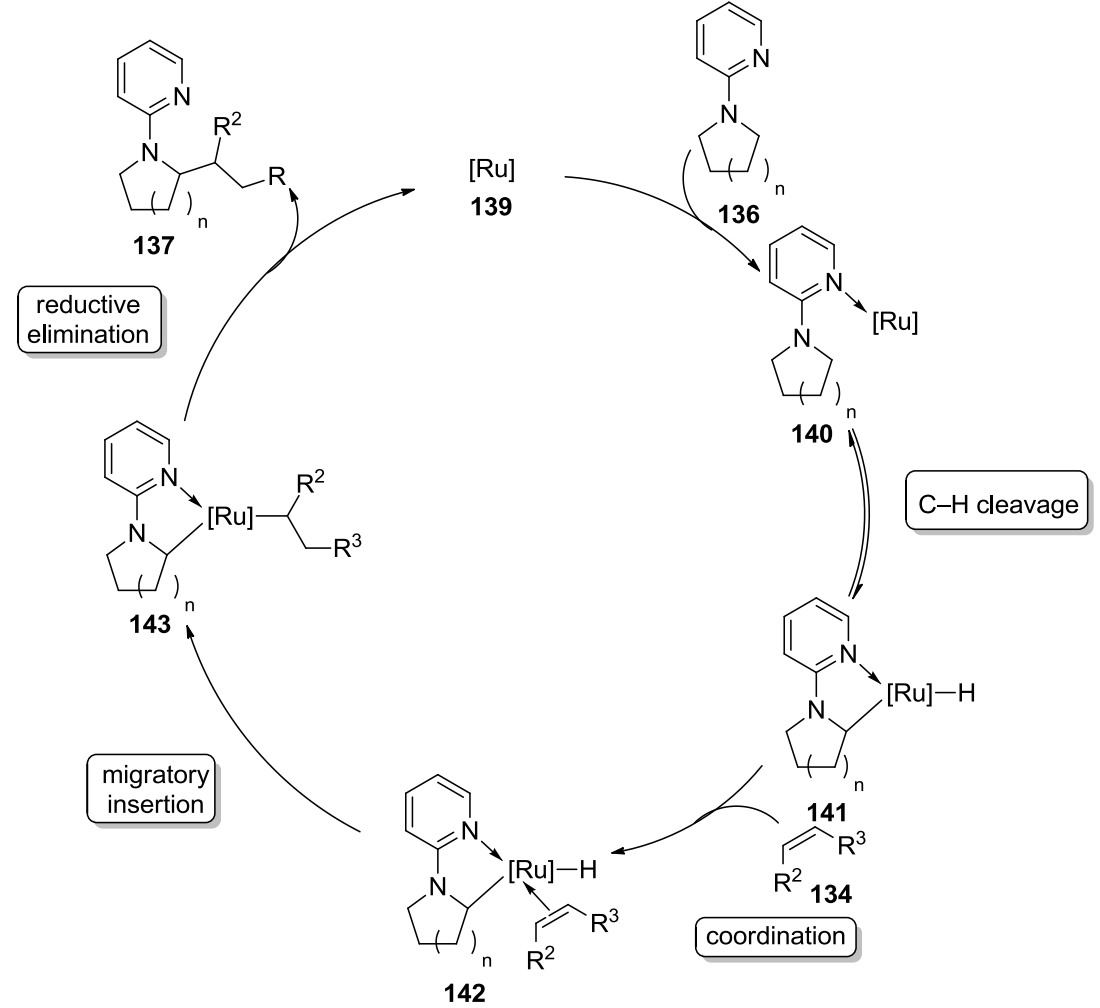

Scheme 47 Proposed mechanism for the ruthenium-catalyzed hydroalkylation

Very recently, Maes reported a ruthenium(0)-catalyzed $\alpha$-alkylation and -arylation of piperidines 144 with terminal alkenes 111a. ${ }^{99}$ Control experiments showed the carboxylic acid can efficiently increase the catalyst activation and longevity, along with that the alcohol reduces the side reactions (Scheme 48). ${ }^{99}$

98 Analogous mechanism with Iridium catalysis: (a) E. Clot, J. Chen, D.-H. Lee, S. Y. Sung, L. N. Appelhans, J. W. Faller, R. H. Crabtree, O. Eisenstein, J. Am. Chem. Soc. 2004, 126, 8795-8804; (b) D.-H. Lee, J. Chen, J. W. Faller, R. H. Crabtree, Chem. Commun. 2001, 213-214.

99 (a) S. D. Bergman, T. E. Storr, H. Prokopcová, K. Aelvoet, G. Diels, L. Meerpoel, B. U. W. Maes, Chem. -Eur. J. 2012, 18, 10393-10398; (b) A. Peschiulli, V. Smout, T. E. Storr, E. A. Mitchell, Z. Eliáš, W. Herrebout, D. Berthelot, L. Meerpoel, B. U. W. Maes, Chem.-Eur. J. 2013, 19, 10378-10387. 


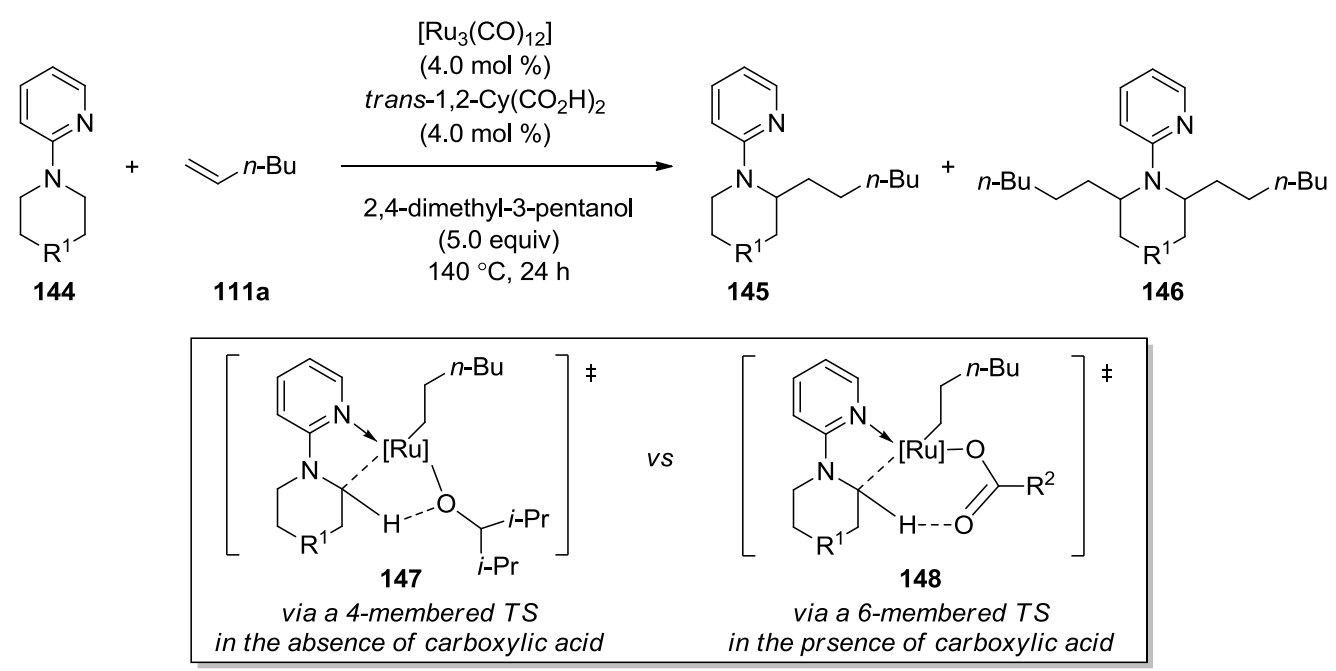

Scheme 48 Ruthenium-catalyzed alkylation of amines in the presence of carboxylate acid

Besides, using the ruthenium-hydride complex 150, Yi showed that the alkylation of cyclic amines 149 without additional directing group can be achieved by invoking the dehydrogenation of amine and subsequent $\alpha-\mathrm{C}-\mathrm{H}$ imine bond activation/alkene insertion sequence (Scheme 49). ${ }^{100}$

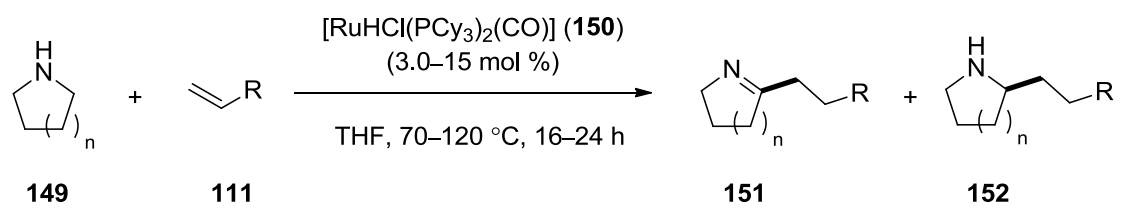

Scheme 49 Ruthenium-catalyzed alkylation of unprotected cyclic amines with alkenes

\subsection{Metal-Catalyzed ortho-C-H Halogenations}

Aromatic halides are key intermediates in organic synthesis, and have been broadly utilized for natural products synthesis, material sciences and medicinal chemistry. ${ }^{101}$ As a consequence, the development of efficient and selective methods for their syntheses continues to be of prime importance. Conventionally, the most useful strategies for their synthesis rely on the electrophilic aromatic substitution $\left(\mathrm{S}_{\mathrm{E}}{ }^{\mathrm{Ar}}\right)$, the Sandmeyer reaction or the directed ortho-lithiation approach (Scheme $50 \mathrm{a}-\mathrm{c}$ ). ${ }^{102}$ Unfortunately, these methods face considerable limitations, including tedious and/or hazardous reaction procedures, poor site selectivities, and harsh reaction conditions, resulting in low chemo-selectivities. In recent years, metal-catalyzed $\mathrm{C}-\mathrm{H}$ activation has emerged as an increasingly viable tool for $\mathrm{C}-\mathrm{X}$ bond formations (Scheme $50 \mathrm{~d}$ ). ${ }^{4}$ In this context, methods for the palladium-catalyzed chelation-assisted direct $\mathrm{C}-\mathrm{H}$ bond functionalization with

100 C. S. Yi, S. Y. Yun, I. A. Guzei, Organometallics 2004, 23, 5392-5395.

101 Selected reviews: (a) S. Johansson, C. C. Carin, M. O. Kitching, T. J. Colacot, V. Snieckus, Angew. Chem. Int. Ed. 2012, 51, 5062-5085; (b) G. Evano, N. Blanchard, M. Toumi, Chem. Rev. 2008, 108, 3054-3131; (c) K. C. Nicolaou, P. G. Bulger, D. Sarlah, Angew. Chem. Int. Ed. 2005, 44, 4442-4489; (d) P. Knochel, W. Dohle, N. Gommermann, F. F. Kneisel, F. Kopp, T. Korn, I. Sapountzis, V. A. Vu, Angew. Chem. Int. Ed. 2003, 42, 4302-4320 and cited references.

102 (a) Y. L. Janin, Chem. Rev. 2012, 112, 3924-3958; (b) S. D. Roughley, A. M. Jordan, J. Med. Chem. 2011, 54, 3451-3479; (c) A. Podgorsek, M. Zupan, J. Iskra, Angew. Chem. Int. Ed. 2009, 48, 8424-8450; (d) E. B. Merkushev, Synthesis 1988, 923-937; (e) E. J.-G. Anctil, V. Snieckus, in Metal-Catalyzed Cross-Coupling Reactions; A. de Meijere, F. Diederich, eds.; Wiley-VCH: Weinheim, Germany, 2004, pp761-814. 
electrophilic halogenating reagents have been developed by several groups. ${ }^{103}$

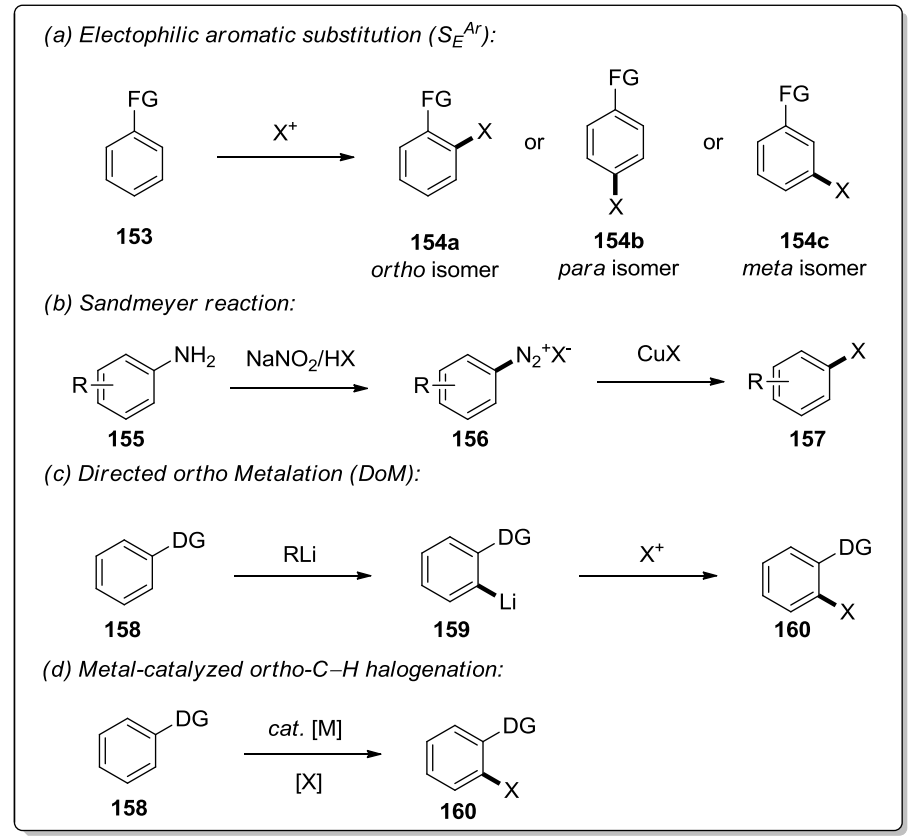

Scheme 50 Conventional approaches for halogenation reactions

An early report on palladium catalysis involved the ortho-halogenation of azobenzene 161 with $\mathrm{X}_{2}$ (Scheme 51), ${ }^{104}$ which afforded a mixture of mono-, di-, tri-, and tetra-halogenated products. While this work elegantly demonstrated the viability of such transformations, the requirement for $\mathrm{X}_{2}$ as the oxidant limited its widespread application in organic synthesis.<smiles>c1ccc(/N=N/c2ccccc2)cc1</smiles>

161

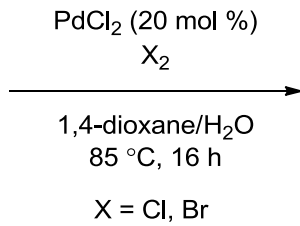

$\mathrm{X}=\mathrm{Cl}, \mathrm{Br}$

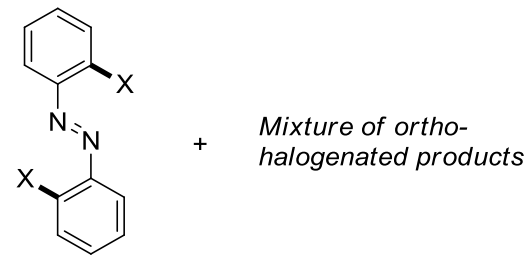

162

Scheme 51 Pd-catalyzed direct ortho-halogenation of azobenzene 161

In 2005, Yu and coworkers reported an auxiliary approach for the chemo- and stereo- selective ambient-temperature iodination of methyl groups with oxazoline as directing group (Table 1, entry 1). This protocol has also been successfully applied to the activation of cyclopropanes $(\mathrm{C}-\mathrm{H}$ bond $\beta$ to the carboxy group) and arenes $\left(\mathrm{C}-\mathrm{H}\right.$ bond $\gamma$ to the carboxy group) ${ }^{105 a, b}$ Furthermore, they developed ortho-iodination and bromination of arene carboxylic acids 56 with Suárez reagents

103 Reviews: (a) T. W. Lyons, M. S. Sanford, Chem. Rev. 2010, 110, 1147-1169; (b) S. R. Neufeldt, M. S. Sanford, Acc. Chem. Res. 2012, 45, 936-946.

104 D. R. Fahey, J. Organomet. Chem. 1971, 27, 283-292.

105 (a) R. Giri, X. Chen, J.-Q. Yu, Angew. Chem. Int. Ed. 2005, 44, 2112-2115; (b) R. Giri, X. Chen, X.-S. Hao, J.-J. Li, J. Liang, Z.-P. Fan, J.-Q. Yu, Tetrahedron Asym. 2005, 16, 3502-3505; (c) T.-S. Mei, R. Giri, N. Maugel, J.-Q. Yu, Angew. Chem. Int. Ed. 2008, 47, 5215-5219; (d) T.-S. Mei, D.-H. Wang, J.-Q. Yu, Org. Lett. 2010, 12, 3140-3143; (e) J.-J. Li, T.-S. Mei, J.-Q. Yu, Angew. Chem. Int. Ed. 2008, 47, 6452-6455; (f) X.-C. Wang, Y. Hu, S. Bonacorsi, Y. Hong, R. Burrell, J.-Q. Yu, J. Am. Chem. Soc. 2013, 135, 10326-10329; (g) L. Chu, X.-C. Wang, C. E. Moore, A. L. Rheingold, J.-Q. Yu, J. Am. Chem. Soc. 2013, 135, 16344-16347. 
(XOAc) as the halogen source as well as the terminal oxidant (entries $2-3){ }^{105 c}$ In this case, mechanistic study shows that employment of the large tetraalkylammonium cation can efficiently prevent the formation of dihalogenated product. ${ }^{105 \mathrm{c}}$ In 2010, this group extended this protocol to phenylacetic acid 167 (entry 4) ${ }^{105 \mathrm{~d}}$ as well as triflamide (NHTf) directing groups (entry 5). ${ }^{105 e}$ Very recently, palladium-catalyzed ortho-C-H iodination directed by a weakly coordinating amide auxiliary (171) using $I_{2}$ as the sole oxidant was developed (entry 6). ${ }^{105 f}$ This reaction is compatible with a wide range of heterocycles including pyridines, imidazoles, oxazoles, thiazoles, isoxazoles, and pyrazoles. Furthermore, a similar protocol realized the enantioselective $\mathrm{C}-\mathrm{H}$ iodination reaction using a mono- $N$-benzoyl-protected amino acid for the synthesis of chiral diarylmethylamines 174 (entry 7). ${ }^{105 g}$

Table 1 Palladium-catalyzed direct $\mathrm{C}-\mathrm{H}$ halogenations reported by the Yu group

\begin{tabular}{|c|c|c|c|c|}
\hline Entry & Substrate & Product & Conditions & Ref. \\
\hline 1 & & & $\begin{array}{l}\mathrm{I}_{2}(1.0 \text { equiv }), \mathrm{Pd}(\mathrm{OAc})_{2}(10 \mathrm{~mol} \%), \\
\mathrm{PhI}(\mathrm{OAc})_{2}(1.0 \text { equiv }), \mathrm{CH}_{2} \mathrm{Cl}_{2}, 24{ }^{\circ} \mathrm{C}, \\
48-72 \mathrm{~h} .\end{array}$ & $105 \mathrm{a}$ \\
\hline 2 & 56 & 165 & $\begin{array}{l}\text { IOAc }(2.0 \text { equiv }), \operatorname{Pd}(\mathrm{OAc})_{2}(5.0 \mathrm{~mol} \%) \text {, } \\
\text { DCE, } 76^{\circ} \mathrm{C}, 2 \mathrm{~h} .\end{array}$ & $105 \mathrm{c}$ \\
\hline 3 & 56 & 166 & $\begin{array}{l}\mathrm{IOAc}(4.0 \text { equiv }), \operatorname{Pd}(\mathrm{OAc})_{2}(5.0 \mathrm{~mol} \%) \\
\mathrm{Bu}_{4} \mathrm{NX}(1.5 \text { equiv }), \mathrm{DCE}, 100{ }^{\circ} \mathrm{C}, 24 \mathrm{~h}\end{array}$ & $105 \mathrm{c}$ \\
\hline 4 & 167 & 168 & $\begin{array}{l}\mathrm{I}_{2}(0.75 \text { equiv }), \mathrm{Pd}(\mathrm{OAc})_{2}(10 \mathrm{~mol} \%) \text {, } \\
\mathrm{PhI}(\mathrm{OAc})_{2}(0.75 \text { equiv }), \mathrm{DMF}, 60{ }^{\circ} \mathrm{C}, 24 \mathrm{~h} \text {, } \\
\text { no light. }\end{array}$ & $105 \mathrm{~d}$ \\
\hline 5 & 169 & 170 & $\begin{array}{l}\mathrm{I}_{2}(2.0 \text { equiv }), \mathrm{Pd}(\mathrm{OAc})_{2}(10 \mathrm{~mol} \%) \\
\mathrm{PhI}(\mathrm{OAc})_{2}(2.0 \text { equiv }), \mathrm{NaHCO}_{3}(2.0 \text { equiv }) \\
\mathrm{DMF}, 130^{\circ} \mathrm{C}, 72 \mathrm{~h} .\end{array}$ & $105 \mathrm{e}$ \\
\hline 6 & 171 & 172 & $\begin{array}{l}\mathrm{I}_{2}(2.5 \text { equiv }), \mathrm{Pd}(\mathrm{OAc})_{2}(2.0 \mathrm{~mol} \%), \mathrm{CsOAc} \\
(1.2 \text { equiv }), \mathrm{NaHCO}_{3}(1.0 \text { equiv }), 4 \AA \\
\text { molecular sieves, } t \text { - } \mathrm{AmOH} / \mathrm{DMF}(1: 1) \\
65^{\circ} \mathrm{C}, 20 \mathrm{~h} .\end{array}$ & $105 \mathrm{f}$ \\
\hline 7 & 173 & 174 & $\begin{array}{l}\mathrm{I}_{2}(2.5 \text { equiv }), \mathrm{Pd}(\mathrm{OAc})_{2}(10 \mathrm{~mol} \%), \\
\text { Bz-Leu-OH }(40 \mathrm{~mol} \%), \mathrm{CsOAc} \\
\text { (3.0 equiv), } \mathrm{Na}_{2} \mathrm{CO}_{3}(3.0 \text { equiv), DMSO } \\
\text { (15 equiv), } t-\mathrm{AmOH}, 30{ }^{\circ} \mathrm{C} \text {, air, } 48 \mathrm{~h} .\end{array}$ & $105 \mathrm{~g}$ \\
\hline
\end{tabular}

Meanwhile, distinct contributions arose also from the Sanford group. In 2004, Sanford and coworkers disclosed a highly regio- and chemo-selective palladium-catalyzed ortho-halogenation on benzo[h]quinolone (175), using NCS or NBS in place of $\mathrm{PhI}(\mathrm{OAc})_{2}$ as the stoichiometric 
oxidant. ${ }^{106 a}$ These transformations have been subsequently applied to a wide array of substrates and can provide products that are complementary to those obtained via conventional electrophilic aromatic substitution $\left(\mathrm{S}_{\mathrm{E}}{ }^{\mathrm{Ar}}\right)$ reactions. ${ }^{106 \mathrm{~b}}$ Further studies showed that the nature of the directing group and the substitution pattern on the arene ring of the substrate both led to different reactivity profiles, and often different and complementary products in the presence and absence of the catalyst (Scheme 52). ${ }^{106 \mathrm{c}}$ In other words, arene $\mathrm{C}-\mathrm{H}$ functionalization with an electrophilic oxidant can occurred by either a palladium-catalyzed pathway or an uncatalyzed electrophilic aromatic substitution $\left(\mathrm{S}_{\mathrm{E}}^{\mathrm{Ar}}\right)$. In certain cases, these two pathways afforded different and complementary site selectivity. For example, the halogenation of electron-rich oxime ether 176 (which selectively affords $\mathbf{1 7 8}$ in the absence of Pd and $\mathbf{1 7 7}$ under Pd catalysis), pyrazole $\mathbf{9 6}$ (forming 179 and 180, respectively), and quinolone 181 (generating 182 and 183) (Scheme 52). ${ }^{106 c-d}$<smiles>CO/N=C(\C)c1ccc(OC)cc1Br</smiles>

177

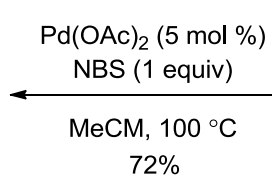

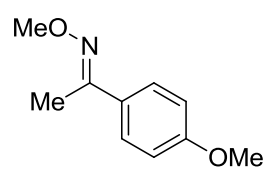

176

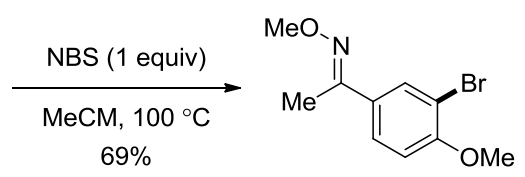

178

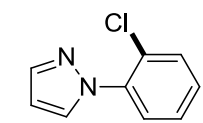

179

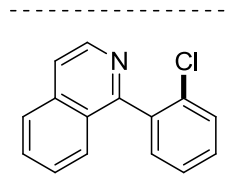

182

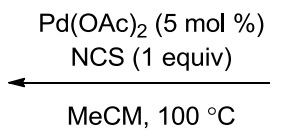

$58 \%$

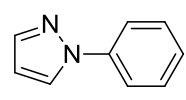

96

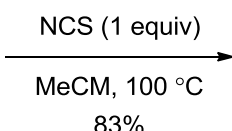

$83 \%$

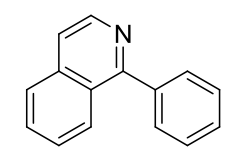

181

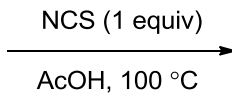

$56 \%$

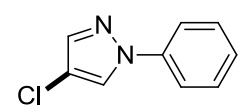

180

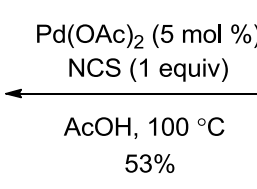

$53 \%$

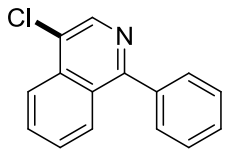

183

Scheme 52 Complementary site selectivity of halogenation in the presence and absence of palladium catalyst

Along with Yu's and Sanford's independent work, Shi reported a highly regioselective C-H functionalization/halogenation of acetanilides 184 catalyzed by $\mathrm{Pd}(\mathrm{OAc})_{2}$ and $\mathrm{Cu}(\mathrm{OAc})_{2}$ with $\mathrm{CuX}_{2}$ as the halogen source (Scheme 53). ${ }^{107 \mathrm{a}}$<smiles>CC(C)(C)Nc1ccc(NC(=O)O)cc1</smiles>

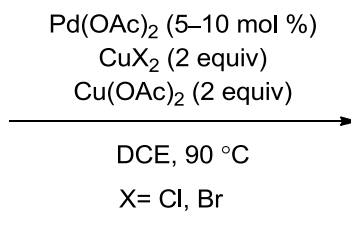

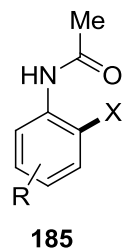

Scheme 53 Palladium-catalyzed $\mathrm{C}-\mathrm{H}$ halogenation of acetanilides 184 with $\mathrm{CuX}_{2}$ as the halogen source

106 (a) A. R. Dick, K. L. Hull, M. S. Sanford, J. Am. Chem. Soc. 2004, 126, 2300-2301; (b) D. Kalyani, A. R. Dick, W. Q. Anani, M. S. Sanford, Org. Lett. 2006, 8, 2523-2526; (c) D. Kalyani, A. R. Dick, W. Q. Anani, M. S. Sanford, Tetrahedron 2006, 62,11483-11498; (d) S. R. Whitfield, M. S. Sanford, J. Am. Chem. Soc. 2007, 129, 15142-15143.

107 (a) X. Wan, Z. Ma, B. Li, K. Zhang, S. Cao, S. Zhang, Z. Shi, J. Am. Chem. Soc. 2006, 128, 7416-7417; for similar research, see: (b) R. B. Bedford, J. U. Engelhart, M. F. Haddow, C. J. Mitchell, R. L. Webster, Dalton Trans. 2010, 39, 10464-10472; (c) B. Song, X. Zheng, J. Mo, B. Xu, Adv. Synth. Catal. 2010, 352, 329-335; (d) X. Zheng, B. Song, G. Li, B. Liu, H. Deng, B. Xu, Tetrahedron Lett. 2010, 52, 6641-6645; (e) X. Zhao, E. Dimitrijević, V. M. Dong, J. Am. Chem. Soc. 2009, 131, 3466-3467. 
In 2011, Bedford achieved a facile palladium-catalyzed ortho-selective bromination and chlorination of anilides $\mathbf{1 8 6}$ under aerobic conditions at ambient temperature with $N$-halosuccinimides (NXS) as the halogen source (Scheme 54a). ${ }^{108 a}$ Mechanistic studies showed that $p$-toluenesulfonic acid (PTSA) plays a key role in the catalytic process. Following this report, analogous work was achieved with varieties of directing groups in the presence of PTSA as efficient additive. ${ }^{109}$ Likewise, Rao very recently reported a palladium-catalyzed regioand chemoselective chlorination for the facile synthesis of aromatic chlorides $\mathbf{1 8 9}$. The reaction demonstrates excellent reactivity, good functional-group tolerance, and high yields. Control experiment showed that $\mathrm{TfOH}$ could accelerate the halogenation efficiently and that a co-oxidant was necessary (Scheme 54b). ${ }^{108 b, c}$

a) Bedford's work

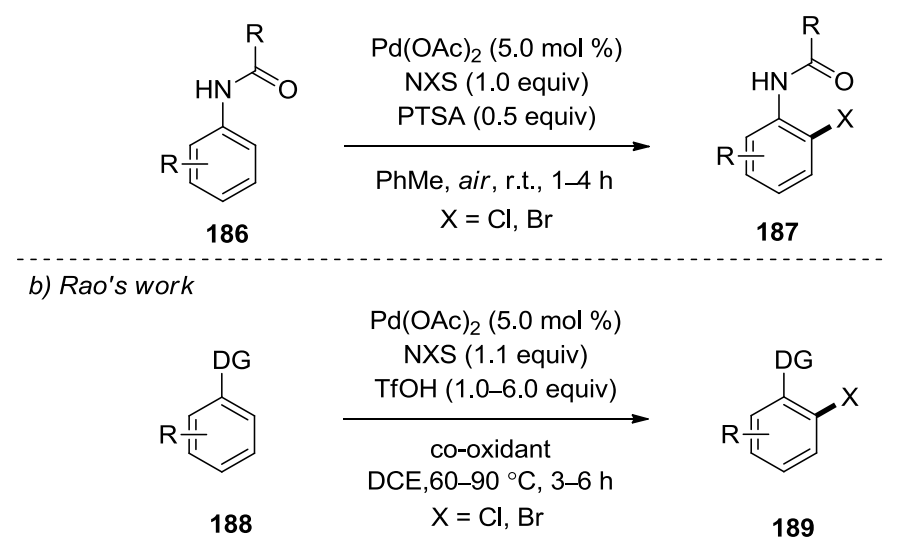

Scheme 54 Palladium-catalyzed $\mathrm{C}-\mathrm{H}$ halogenation in the presence of acid additives

Meanwhile, Gevorgyan developed an efficient strategy for the synthesis of 1,2-ambiphilic aromatic and heteroannulated aromatic synthons (Scheme 55). ${ }^{110}$ This method featured installation of the removable/modifiable PyDipSi directing group on haloarenes and subsequent palladium-catalyzed directed ortho-halogenation reaction to give the ortho-halogenated PyDipSi-arene derivatives 191. The synthetic usefulness of these 1,2-ambiphilic building blocks was demonstrated in a variety of transformations, involving reactions on both nucleophilic aryl silane and electrophilic aryl iodide moieties.

108 (a) R. B. Bedford, M. F. Haddow, C. J. Mitchell, R. L. Webster, Angew. Chem. Int. Ed. 2011, 50, 5524-5527; (b) X. Sun, G. Shan, Y. Sun, Y. Rao, Angew. Chem. Int. Ed. 2013, 52, 4440-4444; (c) X. Sun, Y. Sun, C. Zhang, Y. Rao, Chem. Commun. 2014, 50, 1262-1264.

109 (a) B. Du, X. Jiang, P. Sun, J. Org. Chem. 2013, 78, 2786-2791; (b) P. Sadhu, S. K. Alla, T. Punniyamurthy, J. Org. Chem. 2013, 78, 6104-6111; (c) A. John, K. M. Nicholas, J. Org. Chem. 2012, 77, 5600-5605; (d) X.-T. Ma, S.-K. Tian, Adv. Synth. Catal. 2013, 355, 337-340; (e) E. Dubost, C. Fossey, T. Cailly, S. Rault, F. Fabis, J. Org. Chem. 2011, 76, 6414-6420.

110 (a) A. S. Dudnik, N. Chernyak, C. Huang, V. Gevorgyan, Angew. Chem. Int. Ed. 2010, 49, 8729-8732; (b) D. Sarkar, F. S. Melkonyan, A. V. Gulevich, V. Gevorgyan, Angew. Chem. Int. Ed. 2013, 52, 10800-10804. 


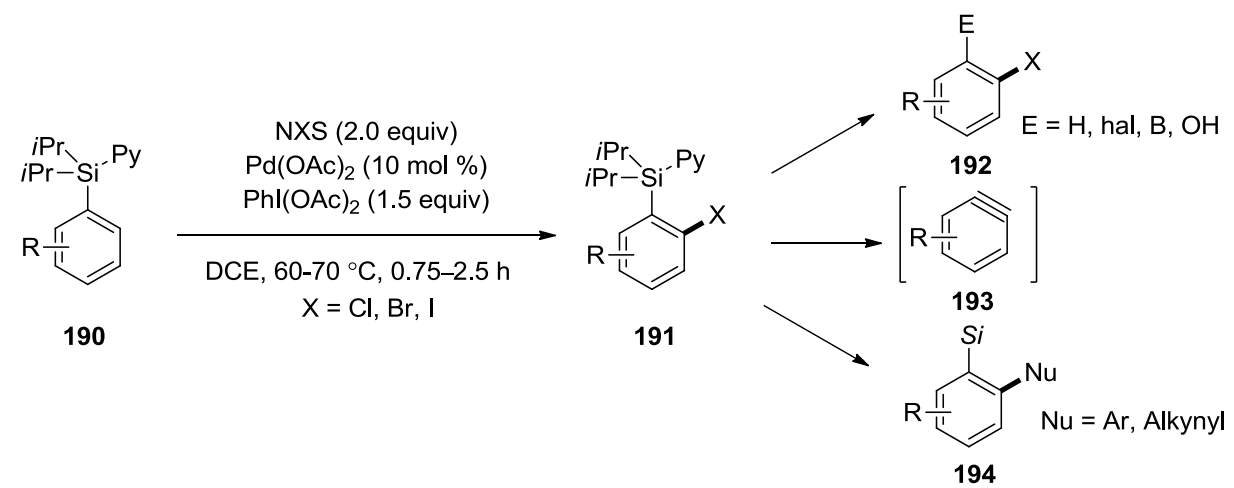

Scheme 55 Palladium-catalyzed ortho-halogenation of aryl silanes 190

Distinguished from the above protocols, Kakiuchi described a new strategy for catalytic halogenation of $\mathrm{C}-\mathrm{H}$ bonds by means of electrochemical oxidation. Herein, combination of palladium-catalyzed aromatic $\mathrm{C}-\mathrm{H}$ bond cleavage and halogenation with electrochemically generated halonium ions enables highly efficient, selective halogenations of aromatic compounds 195 in a green-sustainable manner (Scheme 56). ${ }^{111}$<smiles>c1ccc(-c2ncccn2)cc1</smiles>

195

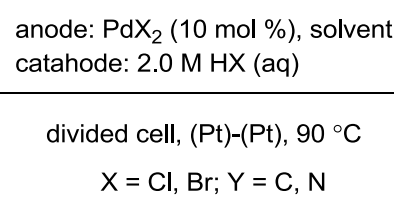

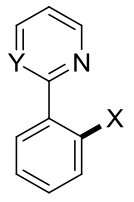

196

Scheme 56 Palladium-catalyzed regioselective halogenantion via electrochemical oxidation

In addition to palladium-catalyzed halogenation protocols, versatile copper-catalyzed/promoted ortho-halogenation strategies have also been applied to arenes. These reactions were usually directed by pyridyl or related heteroaryl directing groups along with employment of a proper halogen source (Table 2). ${ }^{112}$

${ }^{111}$ F. Kakiuchi, T. Kochi, H. Mutsutani, N. Kobayashi, S. Urano, M. Sato, S. Nishiyama, T. Tanabe, J. Am. Chem. Soc. 2009, 131, 11310-11311.

112 (a) X. Chen, X. S. Hao, C. E. Goodhue, J.-Q. Yu, J. Am. Chem. Soc. 2006, 128, 6790-6791; (b) W. Wang, C. Pan, F. Chen, J. Chen, Chem. Commun. 2011, 47, 3978-3980; (c) S. Mo, Y. Zhu, Z. Shen, Org. Biomol. Chem. 2013, 11, 2756-2760; (d) B. Urones, Á. M. Martínez, N. Rodríguez, R. G. Arrayás, J. C. Carretero, Chem. Commun. 2013, 49, 11044-11046; (e) Z.-J. Du, L.-X. Gao, Y.-J. Lin, F.-S. Han, ChemCatChem 2014, 6, $123-126$. 
Table 2 Copper-catalyzed direct $\mathrm{C}-\mathrm{H}$ halogenations



Furthermore, $\left[\mathrm{RhCp}^{*} \mathrm{Cl}_{2}\right]_{2}(\mathbf{2 0 1})^{32}$ was very recently demonstrated to be a competent catalyst for the halogenation of aromatic $\mathrm{C}-\mathrm{H}$ bonds in arenes 202, as reported by Glorius (Scheme 57 ). ${ }^{113 \mathrm{a}} \mathrm{In}$ addition, this protocol was realized for the iodination and bromination of vinylic $\mathrm{C}-\mathrm{H}$ bonds which provides a variety of (Z)-haloacrylic acid derivatives. ${ }^{113 \mathrm{~b}}$

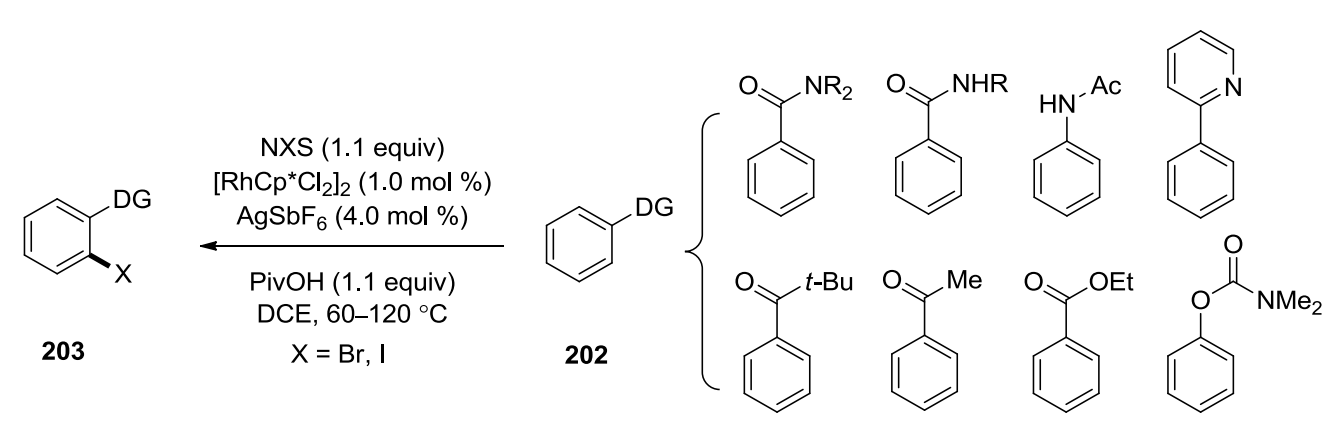

Scheme 57 Rh(III)-catalyzed ortho-halogenations

113 (a) N. Schröder, J. Wencel-Delord, F. Glorius, J. Am. Chem. Soc. 2012, 134, 8298-8301; (b) N. Kuhl, N. Schröder, F. Glorius, Org. Lett. 2013, 15, 3860-3863. 
Recently, Jeganmohan reported an intramolecular halogenation of $O$-methylbenzohydroximoyl halides 204 in the presence of the widely used ruthenium complex $\left[\mathrm{RuCl}_{2}(p \text {-cymene })\right]_{2}(\mathbf{1 5})^{26-30}$ along with diphenylacetylene (38a) as the ligand, yielding substituted halo aromatic nitriles under base- and oxidant-free conditions (Scheme 58). ${ }^{114}$

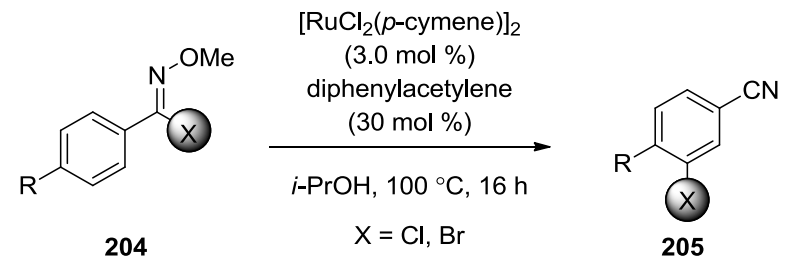

Scheme 58 Ruthenium-catalyzed intramolecular halogenations

114 R. K. Chinnagolla, S. Pimparkar, M. Jeganmohan, Chem. Commun. 2013, 49, 3146-3148. 


\section{Objectives}

During the past decade, remarkable progress in organometallic chemistry has set the stage for the development of increasingly viable metal catalysts for $\mathrm{C}-\mathrm{H}$ bond activation reactions. Among these methods, oxidative $\mathrm{C}-\mathrm{H}$ bond functionalizations are particularly attractive because they avoid the use of prefunctionalized starting materials. ${ }^{4}$ Among such protocols, oxidative annulations that involve sequential $\mathrm{C}-\mathrm{H}$ and heteroatom $-\mathrm{H}$ bond cleavages allow for the modular assembly of regioselectively decorated heterocycles. ${ }^{28-32}$ While other researchers have devised palladium $^{31}$ or rhodium ${ }^{32}$ complexes for oxidative alkyne annulations, our group has focused on the application of significantly less expensive, yet highly selective ruthenium complexes in recent years. ${ }^{28}$

Carboxylate-assisted oxidative annulations of alkynes by benzamides employing ruthenium catalysts were only disclosed in $2011 .{ }^{33}$ Unfortunately, these ruthenium-catalyzed transformations were as of yet restricted to the use of superstoichiometric amounts of copper(II) or silver(I) salts as the sacrificial oxidants, thereby leading to the formation of stoichiometric amounts of undesired heavy metal by-products. ${ }^{115}$ During our studies on ruthenium-catalyzed oxidative $\mathrm{C}-\mathrm{H}$ bond functionalizations with substituted pyrroles, we focused on developing carboxylate-assisted ruthenium-catalyzed oxidative annulations with air as an ideal oxidant (Scheme 59). Thereby, we established a novel access to pyrrolo[2,1-a] isoquinolines 209, which are indispensable structural motifs of inter alia bioactive lamellarine alkaloid. ${ }^{116}$ An additional asset of our ruthenium-catalyzed process is represented by its complementary scope and chemoselectivity as compared to the previously reported rhodium-catalyzed transformation that was found by Miura and coworkers. ${ }^{117}$

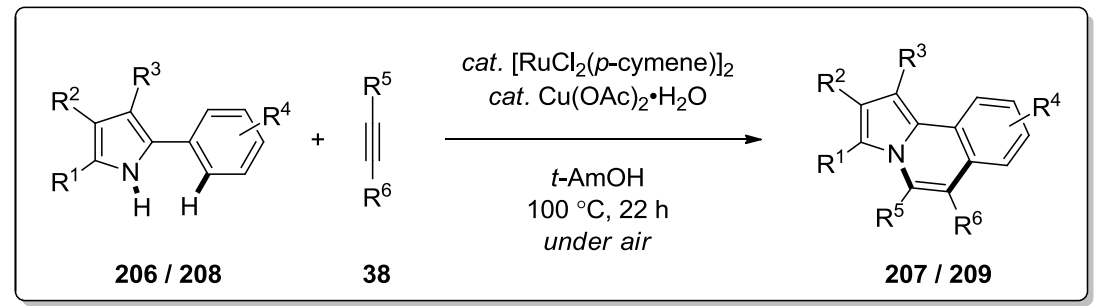

Scheme 59 Ruthenium-catalyzed aerobic oxidative annulation with substituted pyrroles

The recent years witnessed a rapid development of the ruthenium-catalyzed oxidative $\mathrm{C}-\mathrm{H} / \mathrm{N}-\mathrm{H}$ bond functionalizations. ${ }^{28}$ However, these $\mathrm{C}-\mathrm{H} / \mathrm{N}-\mathrm{H}$ bond functionalizations were hitherto restricted to electron-deficient Michael acceptors decorated with electron-withdrawing carbonyl groups. Herein, we wanted to devise a new protocol that could achieve the ruthenium-catalyzed oxidative alkyne annulations with challenging electron-rich alkenes $\mathbf{2 1 0}$ for an expedient pyrrole synthesis, which was also accomplished in an aerobic manner with air as the ideal terminal oxidant (Scheme 60).

\footnotetext{
115 Notably, ruthenium-catalyzed oxidative alkyne annulations with air as ideal oxidant were also achieved during the preparation of this thesis, see ref. 36, 39, 40 and 44 .

116 T. Fukuda, F. Ishibashi, M. Iwao, Heterocycles 2011, 83, 491-529.

117 K. Morimoto, K. Hirano, T. Satoh, M. Miura, Org. Lett. 2010, 12, 2068-2071.
} 


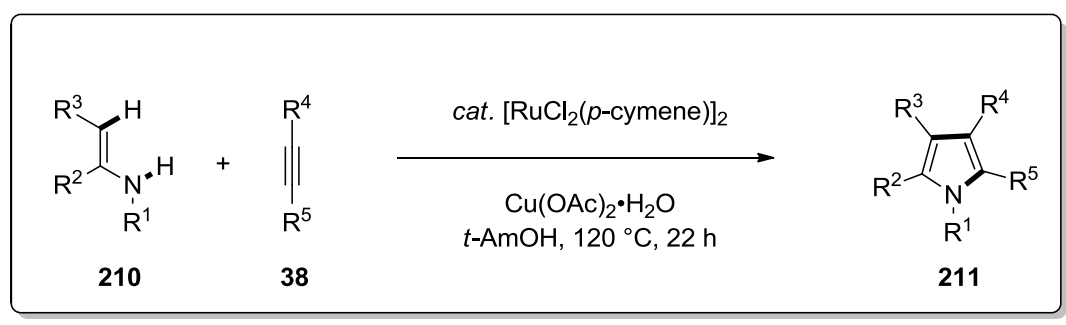

Scheme 60 Ruthenium(II)-catalyzed oxidative pyrrole synthesis

Along with the rapidly developing oxidative annulation with alkynes, significant progress has been accomplished in direct alkenylations through twofold $\mathrm{C}-\mathrm{H}$ bond functionalization of arenes and heteroarenes employing ruthenium catalysts. ${ }^{29}$ Herein, we were interested in the use of $\left[\mathrm{RuCl}_{2}(p \text {-cymene })\right]_{2}$ and $\mathrm{KPF}_{6}$ for efficient oxidative alkenylations of electron-rich anilides $2 \mathbf{2 1 2}$ in water as a green solvent (Scheme 61). Notably, this reaction also proved to be applicable to electron-deficient (hetero)aromatic amides 214. Mechanistic studies showed that the transformations of these two types of substrates displayed different rate-limiting steps, with an irreversible $\mathrm{C}-\mathrm{H}$ bond metalation in the case of oxidative alkenylations with benzamides 214 .

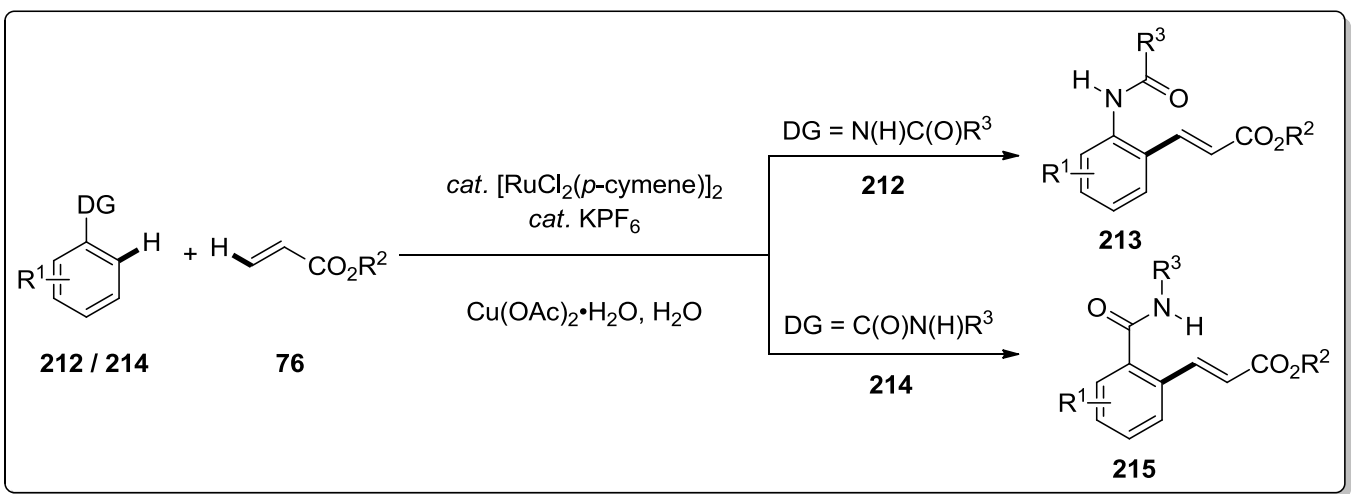

Scheme 61 Ruthenium-catalyzed oxidative $\mathrm{C}-\mathrm{H}$ alkenylations of anilides 212 and benzamides 214 in water

Despite the progress in the ruthenium-catalyzed $\mathrm{C}\left(\mathrm{sp}^{3}\right)-\mathrm{H}$ alkylations with unactivated alkenes in the past years, all protocols were restricted to $\mathrm{Ru}_{3}(\mathrm{CO})_{12}$ catalyst under relatively harsh reaction conditions and with high catalyst loadings. Thus, we became attached by developing a general procedure for ruthenium-catalyzed $\mathrm{C}\left(\mathrm{sp}^{3}\right)-\mathrm{H}$ alkylations of unactivated alkenes $\mathbf{1 1 1}$ with pyrrolidines 216 employing ruthenium(II) catalyst. Complementing to the above-discussed oxidative protocols, this procedure would be a new powerful tool to construct $\mathrm{C}-\mathrm{C}$ bonds. Furthermore, the pyridyl directing group can easily be removed to furnish the corresponding $(\mathrm{NH})$-free cyclic amines 218 (Scheme 62).

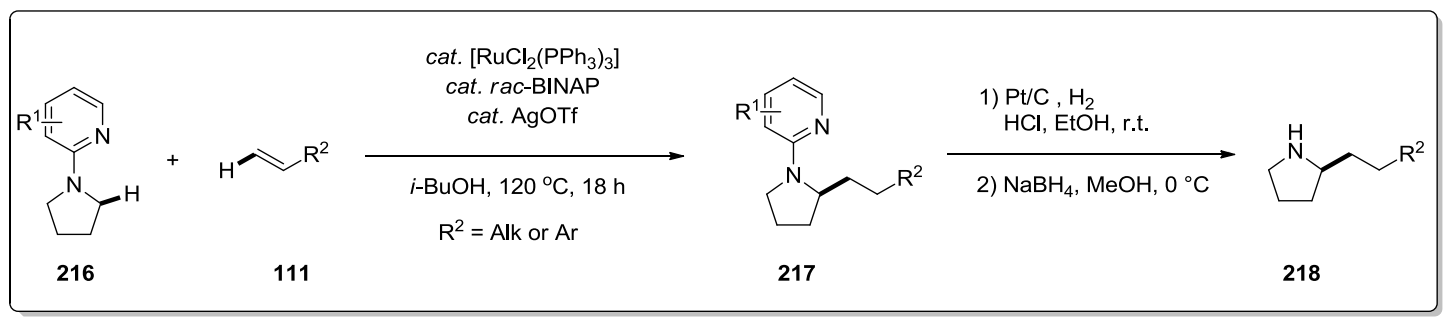

Scheme 62 Ruthenium(II)-catalyzed direct $\mathrm{C}\left(\mathrm{sp}^{3}\right)-\mathrm{H}$ bond alkylations with alkenes $\mathbf{1 1 1}$ 
In addition to the $\mathrm{C}-\mathrm{C}$ bond formations, ruthenium complexes have been identified as powerful catalysts for the oxidative transformation of otherwise unreactive $\mathrm{C}-\mathrm{H}$ bonds into $\mathrm{C}-\mathrm{O}$ and $\mathrm{C}-\mathrm{N}$ bonds. ${ }^{30}$ In strict contrast, ruthenium-catalyzed intermolecular ${ }^{114} \mathrm{C}-\mathrm{Hal}$ bond forming processes were unfortunately thus far not available. As a consequence, we became intrigued by a catalytic system comprising of $\left[\mathrm{Ru}_{3}(\mathrm{CO})_{12}\right]$ and $\mathrm{AgO}_{2} \mathrm{CAd}$ for first ruthenium-catalyzed intermolecular brominations and iodinations of electron-rich and electron-deficient benzamides 219 using $\mathrm{N}$-halosuccinimides as halogen source (Scheme 63).

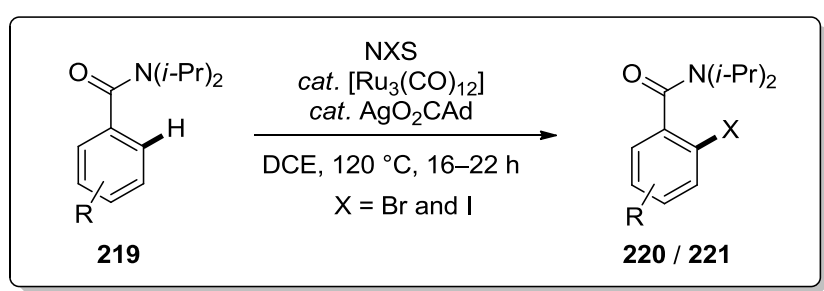

Scheme 63 Ruthenium-catalyzed direct ortho-halogenations 


\section{Ruthenium-Catalyzed Oxidative Annulation of Alkynes Through $\mathbf{C}-\mathbf{H} / \mathbf{N}-\mathbf{H}$ Bond Functionalizations}

\subsection{Ruthenium-Catalyzed Aerobic Oxidative Annulation of Alkynes with 2-Aryl-Substituted Indoles and Pyrroles}

As indicated in Chapter 1.2, transition metal-catalyzed oxidative annulations that involve sequential $\mathrm{C}-\mathrm{H}$ and heteroatom $-\mathrm{H}$ bond cleavages allow for the modular assembly of regioselectively decorated heterocycles. ${ }^{31,32}$ Publications on carboxylate-assisted oxidative annulations of alkynes employing less expensive, yet highly selective ruthenium catalysts, ${ }^{26,28-30}$ appeared only since the pionnering work in $2011 .^{33 a}$ Unfortunately, these transformations were as of yet restricted to the use of superstoichiometric amounts of copper(II) or silver(I) salts as the sacrificial oxidants. We established a novel access to pyrrolo[2,1-a]isoquinolines 207 through ruthenium-catalyzed oxidative $\mathrm{C}-\mathrm{H}$ bond functionalizations with cocatalytic amounts of $\mathrm{Cu}(\mathrm{OAc})_{2} \cdot \mathrm{H}_{2} \mathrm{O}$ under an atmosphere of ambient air. ${ }^{118}$

\subsubsection{Optimization Studies}

At the outset of our studies, we explored representative oxidants and additives for the envisioned ruthenium-catalyzed annulation of tolane (38a) by indole $206 \mathbf{a}$ (Table 3). Thus, the $\mathrm{C}-\mathrm{H} / \mathrm{N}-\mathrm{H}$ bond functionalization was achieved with $\left[\mathrm{RuCl}_{2}(p \text {-cymene })\right]_{2}$ and stoichiometric amounts of $\mathrm{Cu}(\mathrm{OAc})_{2} \cdot \mathrm{H}_{2} \mathrm{O}$ as the terminal oxidant (entries 1-3). Interestingly, catalytic amounts of $\mathrm{Cu}(\mathrm{OAc})_{2} \cdot \mathrm{H}_{2} \mathrm{O}$ were found to be sufficient, provided that reactions were conducted under an atmosphere of air (entry 4). Furthermore, the use of cocatalytic additive $\mathrm{KPF}_{6}$ that forms cationic ruthenium(II) catalyst did not improve the catalytic activity (entry 5). ${ }^{119}$ While reactions with $\mathrm{CuBr}_{2}$ as the co-oxidant did not furnish the desired product (entry 6), cocatalytic amounts of metal acetates restored the catalytic efficacy (entries 7-10), thus providing strong evidence for carboxylate-assisted aerobic oxidations. ${ }^{8}$

118 L. Ackermann, L. Wang, A. V. Lygin, Chem. Sci. 2012, 3, 177-180.

119 (a) S. Fernández, M. Pfeffer, V. Ritleng, C. Sirlin, Organometallics 1999, 18, 2390-2394; (b) M. A. Bennett, A. K. Smith, J. Chem. Soc., Dalton Trans. 1974, 233-241. 
Table 3 Optimization of oxidative annulation with indole 206a ${ }^{a}$

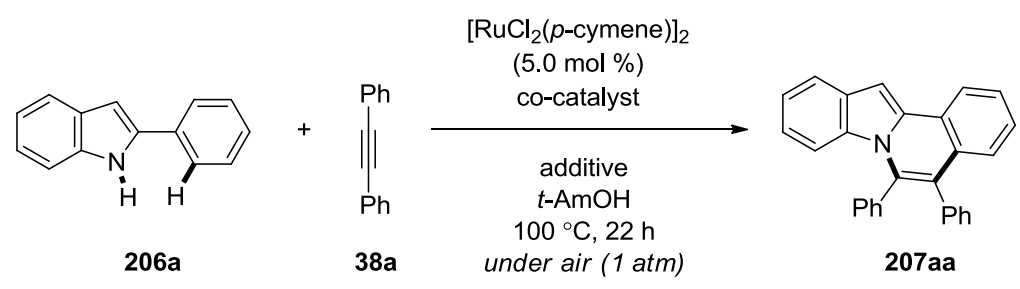

\begin{tabular}{|c|c|c|c|}
\hline Entry & Co-catalyst (mol \%) & Additive (mol \%) & 207aa $(\%)$ \\
\hline 1 & - & - & $<5^{b}$ \\
\hline 2 & $\mathrm{Cu}(\mathrm{OAc})_{2} \cdot \mathrm{H}_{2} \mathrm{O}(200)$ & - & $84^{c}$ \\
\hline 3 & $\mathrm{Cu}(\mathrm{OAc})_{2} \cdot \mathrm{H}_{2} \mathrm{O}(10)$ & - & $21^{c}$ \\
\hline 4 & $\mathrm{Cu}(\mathrm{OAc})_{2} \cdot \mathrm{H}_{2} \mathrm{O}(10)$ & - & 82 \\
\hline 5 & $\mathrm{Cu}(\mathrm{OAc})_{2} \cdot \mathrm{H}_{2} \mathrm{O}(10)$ & $\mathrm{KPF}_{6}(20)$ & 84 \\
\hline 6 & $\mathrm{CuBr}_{2}(10)$ & - & $<5^{b}$ \\
\hline 7 & $\mathrm{CuBr}_{2}(10)$ & $\mathrm{KPF}_{6}(20)$ & $<5^{b}$ \\
\hline 8 & $\mathrm{CuBr}_{2}(10)$ & $\mathrm{LiOAc} \cdot \mathrm{H}_{2} \mathrm{O}(20)$ & $16^{b}$ \\
\hline 9 & $\mathrm{CuBr}_{2}(10)$ & $\mathrm{NaOAc}(20)$ & 51 \\
\hline 10 & $\mathrm{CuBr}_{2}(10)$ & CsOAc (20) & 50 \\
\hline
\end{tabular}

\subsubsection{Scope of the Annulation with 2-Aryl-Substituted Indoles}

With an optimized catalytic system in hand, we explored the scope of this ruthenium-catalyzed aerobic oxidative annulation of alkynes 38 by indoles 206 (Table 4). Notably, the aerobic annulation proved to be broadly applicable, and occurred chemoselectively at the $\mathrm{N}-\mathrm{H}$ functionality of indoles 206. Valuable functional groups, such as fluoro, bromo, nitro or ester substituents, were well tolerated by the catalytic system. Electron-deficient heteroarenes 206 were efficiently converted, generally furnishing moderate to high isolated yields (entries 1-3 and 5-8). Unfortunately, electron-rich heteroarenes 206e and 206k (entries 4 and 10) as well as substrates 206j and 206m (entries 9 and 12) gave low conversion. However, improved yields were obtained when switching to stoichiometric amounts of the terminal oxidant $\mathrm{Cu}(\mathrm{OAc})_{2} \cdot \mathrm{H}_{2} \mathrm{O}$. On the other hand, the aerobic annulation tolerated decorated tolane derivatives 38 as well (entries 13-14). ${ }^{118}$ Likewise, dichlorotolane 38c delivered the desired annulated product 207 in good yield with stoichiometric amounts of $\mathrm{Cu}(\mathrm{OAc})_{2} \cdot \mathrm{H}_{2} \mathrm{O}$ (entry 14). 
Table 4 Aerobic oxidative annulation of alkynes $\mathbf{3 8}$ with indoles $\mathbf{2 0 6}^{a}$

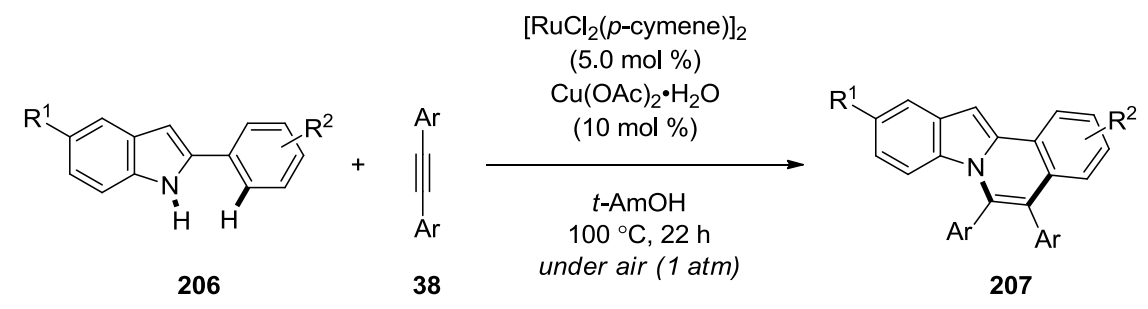

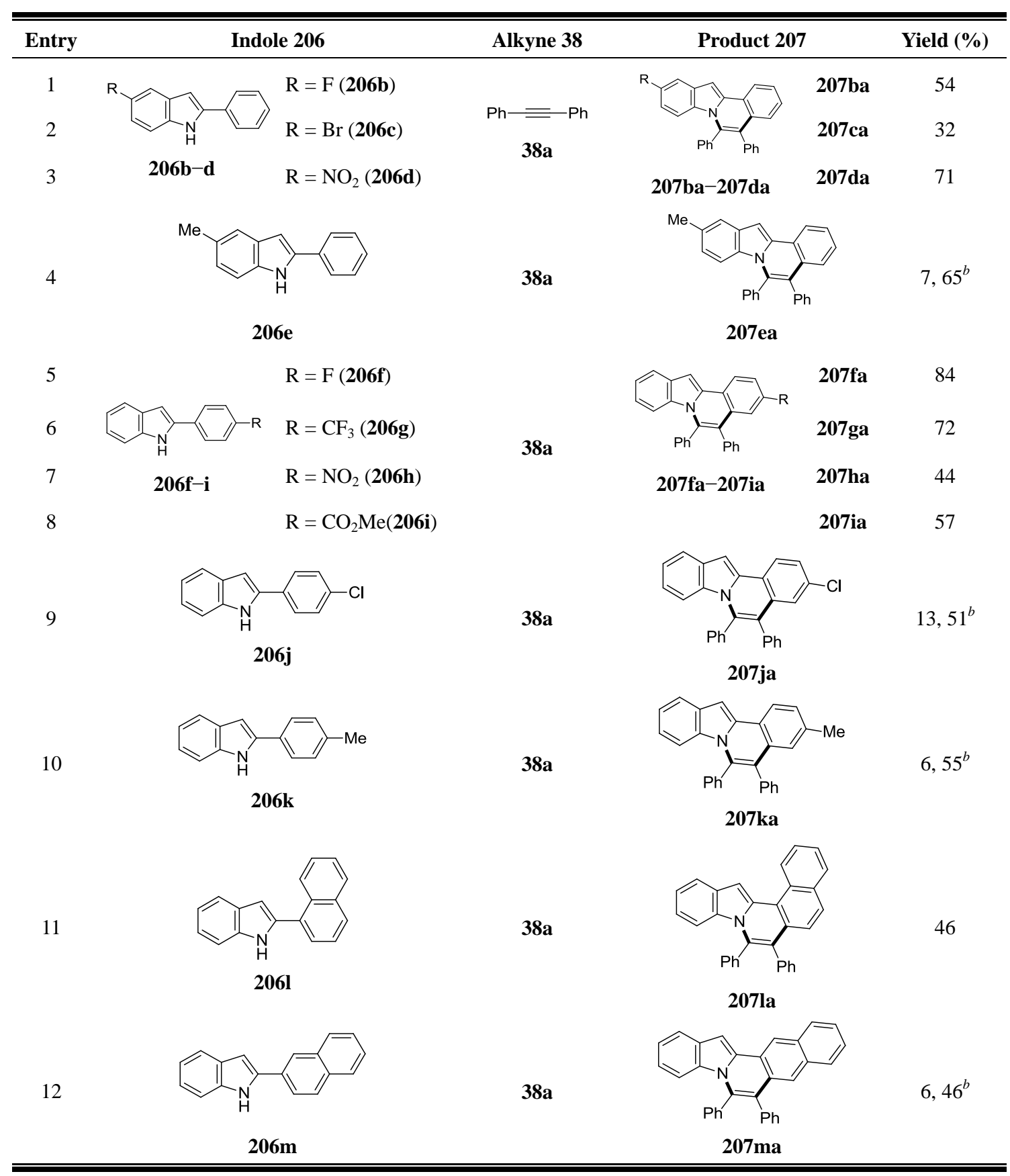


Table 4 (continued)

Entry Indole 206

${ }^{a}$ Reaction conditions: $206(0.5 \mathrm{mmol}), 38(1.0 \mathrm{mmol}),\left[\mathrm{RuCl}_{2}(p \text {-cymene })\right]_{2}(5.0 \mathrm{~mol} \%), \mathrm{Cu}(\mathrm{OAc})_{2} \cdot \mathrm{H}_{2} \mathrm{O}(10$ mol \%), $t$-AmOH $(2.0 \mathrm{~mL}), 100{ }^{\circ} \mathrm{C}, 22 \mathrm{~h}$, under air $(1 \mathrm{~atm})$; isolated yields. ${ }^{b} \mathrm{Cu}(\mathrm{OAc})_{2} \cdot \mathrm{H}_{2} \mathrm{O}(1.0 \mathrm{mmol})$, under $\mathrm{N}_{2}$.

\subsubsection{Scope of the Annulation with 2-Aryl-Substituted Pyrroles}

Importantly, the ruthenium catalysis was not restricted to the use of 2-aryl-substituted indoles 206, but also allowed for the first metal-catalyzed oxidative annulations with pyrroles 208 (Table 5). The remarkable chemoselectivity of the catalytic system enabled the preparation of substituted pyrrolo[2,1-a] isoquinolines 209 in a highly regioselective fashion (entries 1-4), a structural motif found among others in the biologically active lamellarine alkaloids. ${ }^{115}$ Likewise, the ruthenium system proved tolerant of various electrophilic functional groups, such as esters, cyano or enolizable ketones (entries 1-4), although 5-methylpyrrole derivative 208e failed to deliver the desired product (entry 5). Electron-rich as well as electron-deficient tolanes 38 were efficiently converted, with the latter furnishing higher isolated yields (entry 6). ${ }^{118}$

Table 5 Aerobic oxidative annulation with pyrroles $\mathbf{2 0 8}^{a}$

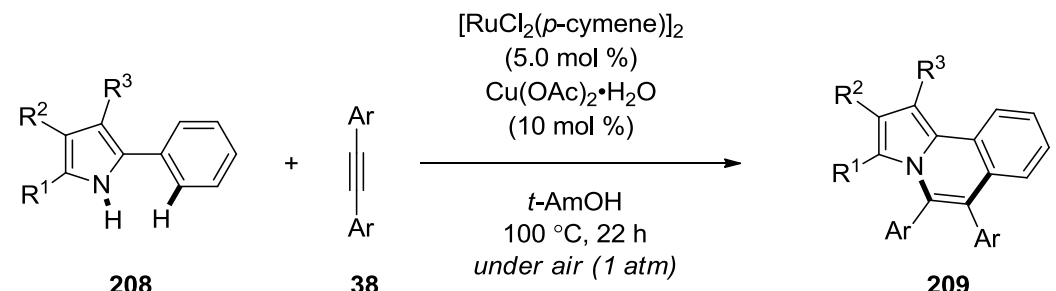

\begin{tabular}{|c|c|c|c|c|}
\hline Entry & Pyrrole 208 & Alkyne 38 & Product 209 & Yield (\%) \\
\hline 1 & 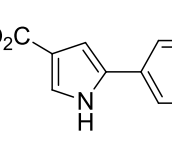 & $\begin{array}{c}\mathrm{Ph}=-\mathrm{Ph} \\
\text { 38a }\end{array}$ & $\mathrm{Ph}^{\prime}$ & 93 \\
\hline & $208 a$ & & 209aa & \\
\hline
\end{tabular}


Table 5 (continued)

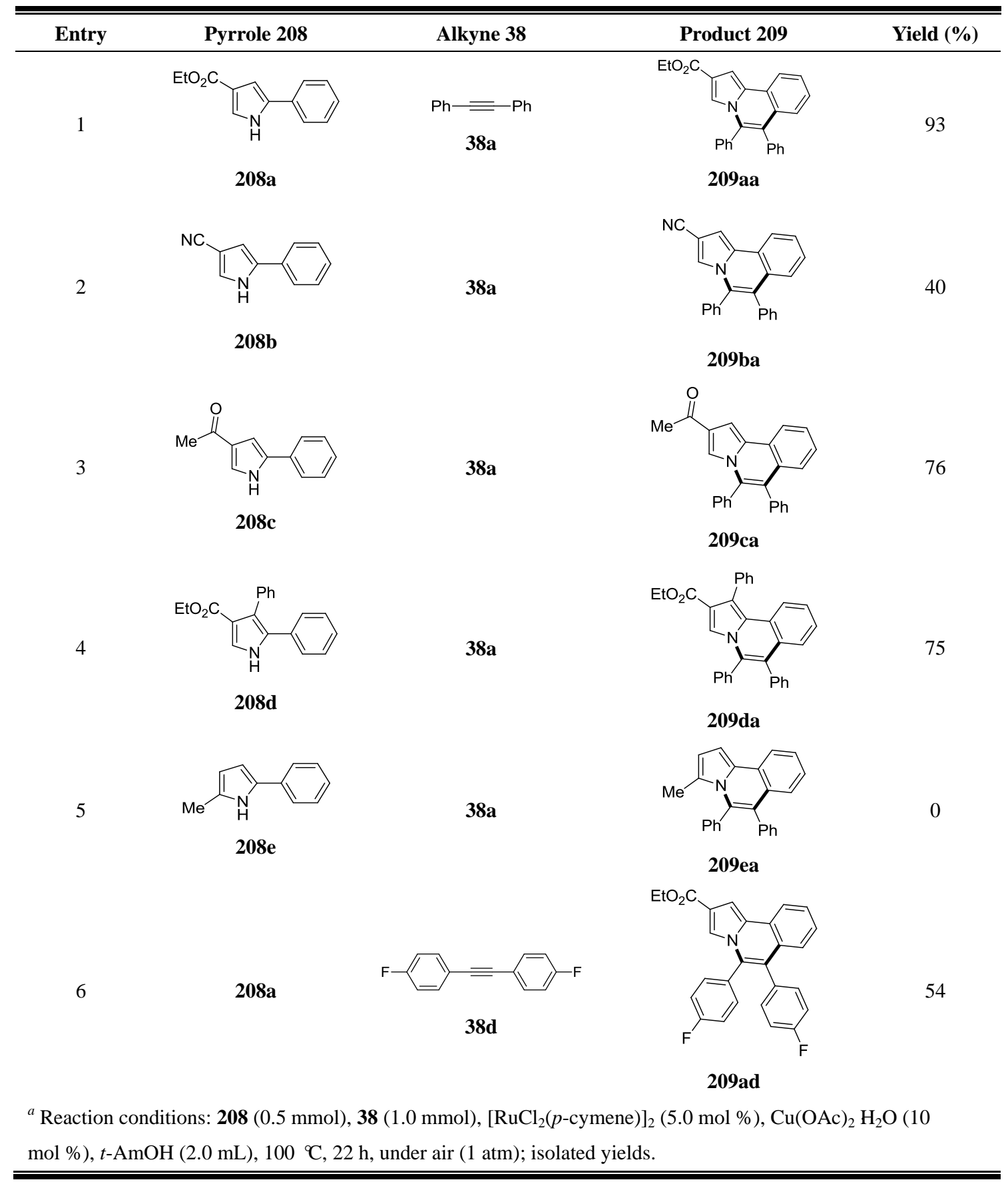

Further, the aerobic ruthenium-catalyzed annulation displayed an improved chemoselectivity as compared to the reported rhodium-catalyzed process. ${ }^{117}$ For instance, alkyl-substituted alkynes 38 gave access to the desired products without the formation of structural isomers (Table 6). Hence, the annulated heteroarenes $\mathbf{2 0 9}$ were isolated in high yields with slightly increased loadings of $\mathrm{Cu}(\mathrm{OAc})_{2} \cdot \mathrm{H}_{2} \mathrm{O}$ (entry 1 vs entry 2), while the related rhodium catalysis was shown to deliver a mixture of products. ${ }^{117}$ The selective transformation of $n$-alkyl-substituted alkynes $\mathbf{3 8}$ also enabled aerobic oxidative annulations with unsymmetrically-substituted alkynes $\mathbf{3 8 g}$ and $\mathbf{3 8 h}$, which proceeded with synthetically useful regiocontrol (entries 6-8). 
Table 6 Aerobic oxidative annulation with pyrroles $\mathbf{2 0 8}^{a}$

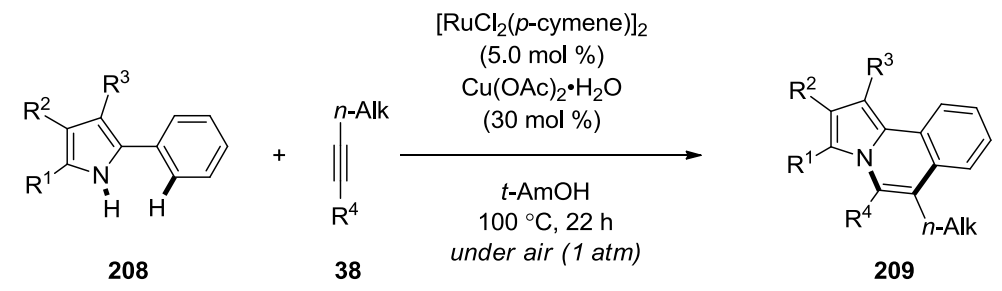

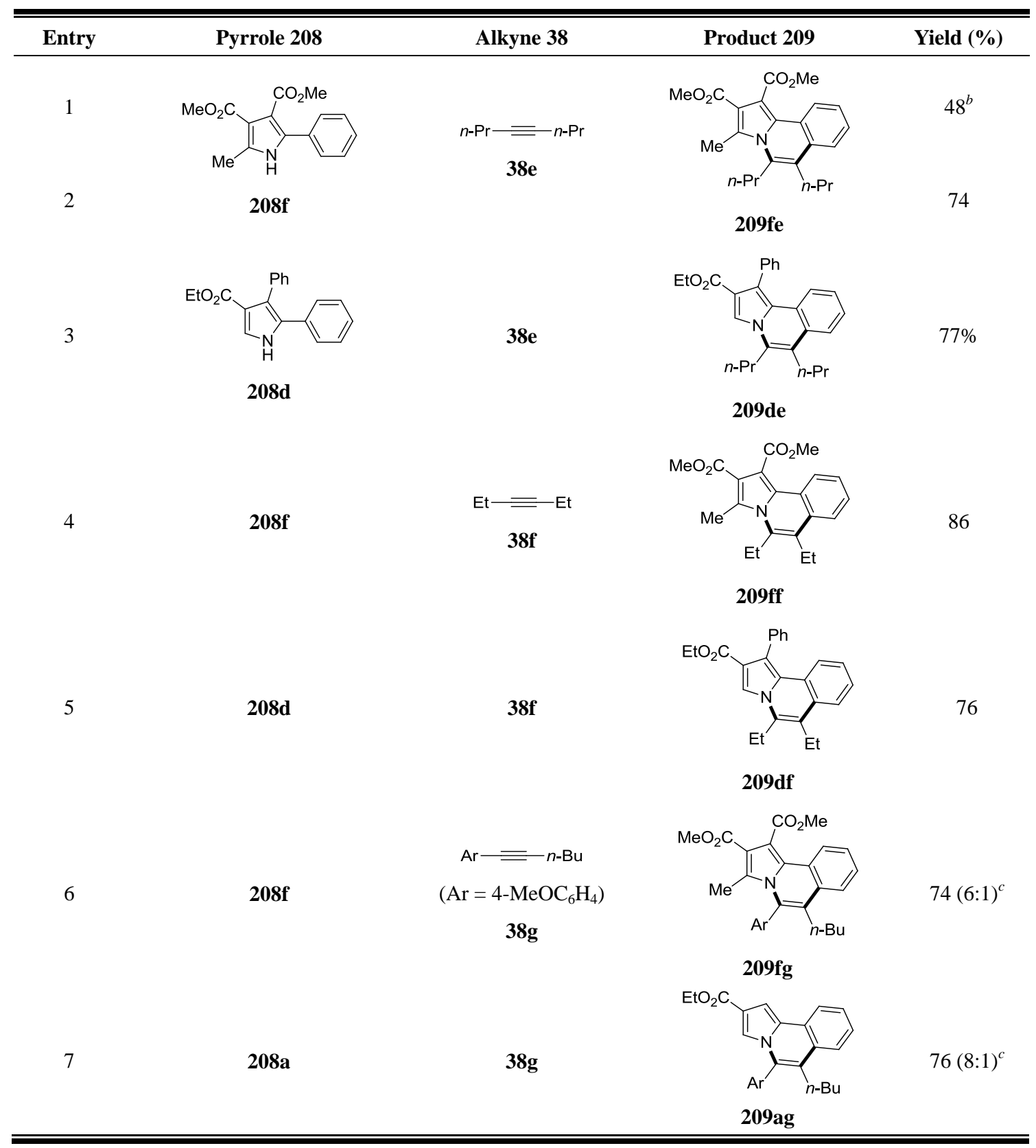

(continued) 
Table 6 (continued)

\begin{tabular}{lccc}
\hline \hline Entry & Pyrrole 208 & Alkyne 38 & Yield (\%) \\
8 & $\mathbf{2 0 8 a}$ & Product 209
\end{tabular}

\subsubsection{Mechanistic Studies}

\subsubsection{Inter- and Intramolercular Competition Experiments}

Considering the unique selectivity and outstanding efficacy of our ruthenium catalyst, we became interested in understanding its mode of action. For this purpose, intermolecular competition experiments with indoles 206b and 2060 were performed and selectively yielded fluoro-substituted indole 207ba as the sole product (Scheme 64a). Furthermore, electron-deficient alkyne 38b was preferentially reacted with indole 206a under the optimized reaction conditions (Scheme 64b).

(a)
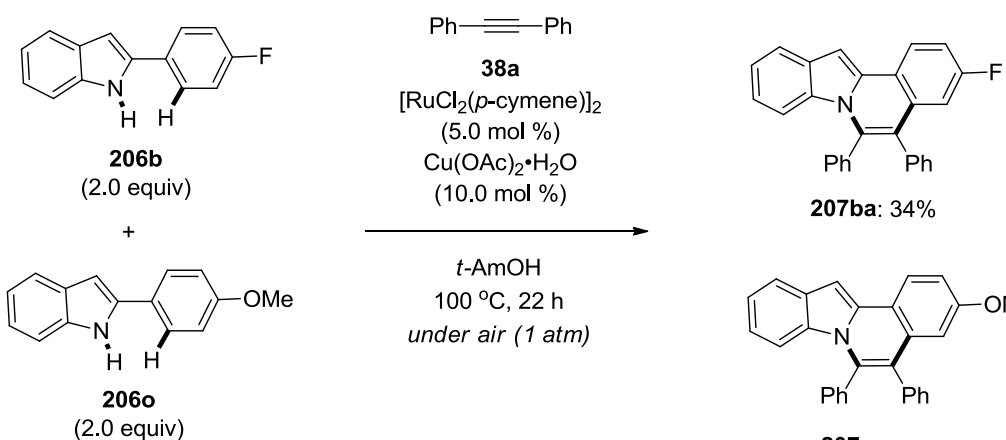

207ba: $34 \%$
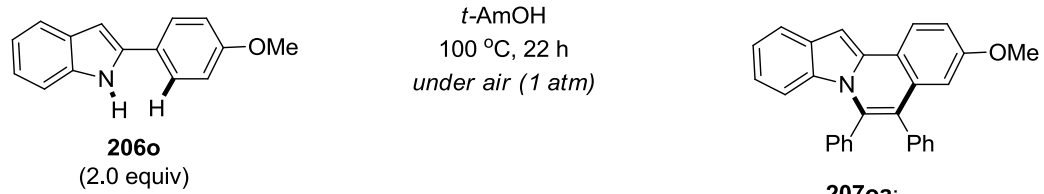

207oa: ---

(b)
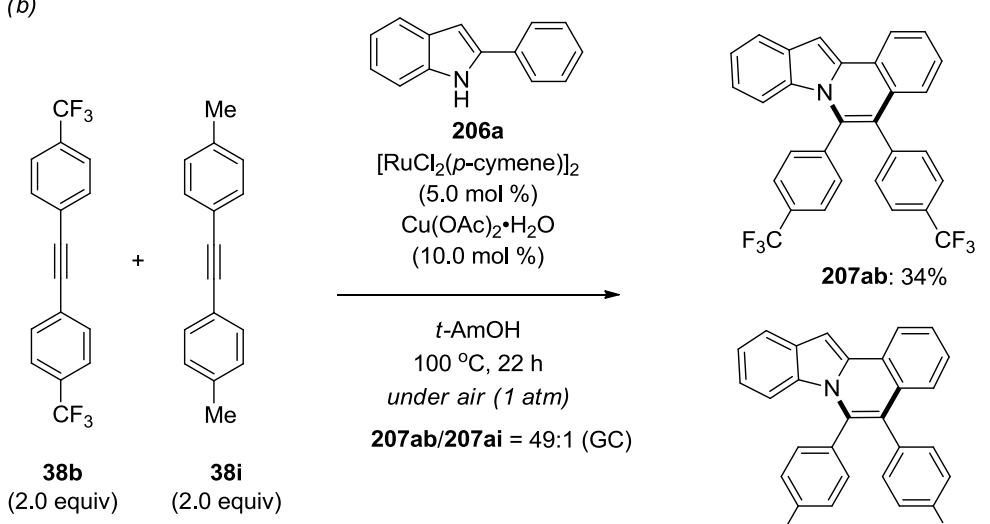

207ab: $34 \%$

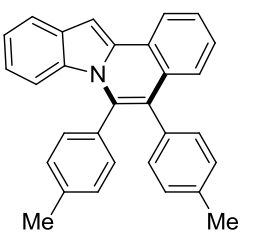

207ai: ---

Scheme 64 Intermolecular competition experiments 
Additionally, an intramolecular competition experiment with meta-fluoro-substituted indole 206p predominantly gave isomer 207'pa (Scheme 65), which can be rationalized with a deprotonative ruthenation manifold. ${ }^{7 \mathrm{c}, 8,120}$

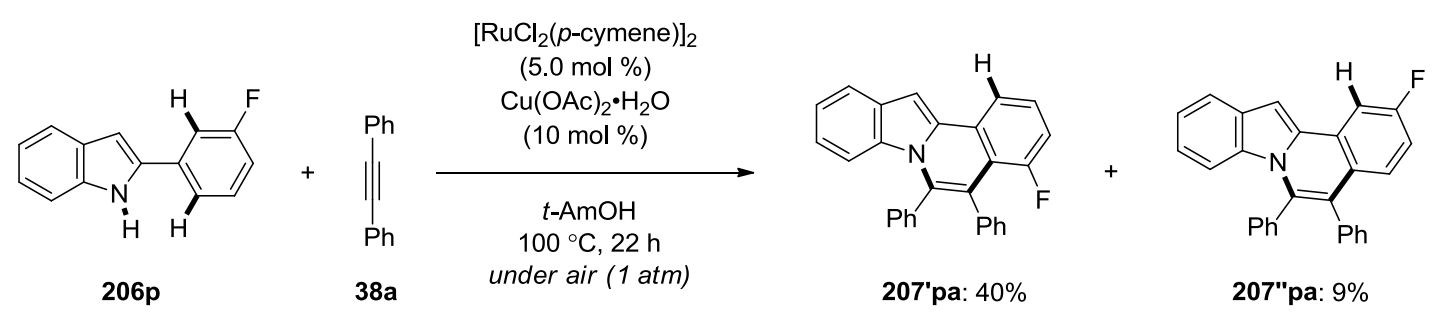

Scheme 65 Annulation with meta-fluorophenyl-substituted indole 206p

\subsubsection{Reactions in Isotopically Labelled Solvents}

Furthermore, no significant H/D scrambling was observed in the oxidative annulations with indole substrate 206d in $[\mathrm{D}]_{4}-\mathrm{MeOH}$ under otherwise identical reaction conditions (Scheme 66). These results can be rationalized in terms of an irreversible carboxylate-assisted $\mathrm{C}-\mathrm{H}$ bond metalation step with the ruthenium complex (Scheme 67).

(a)
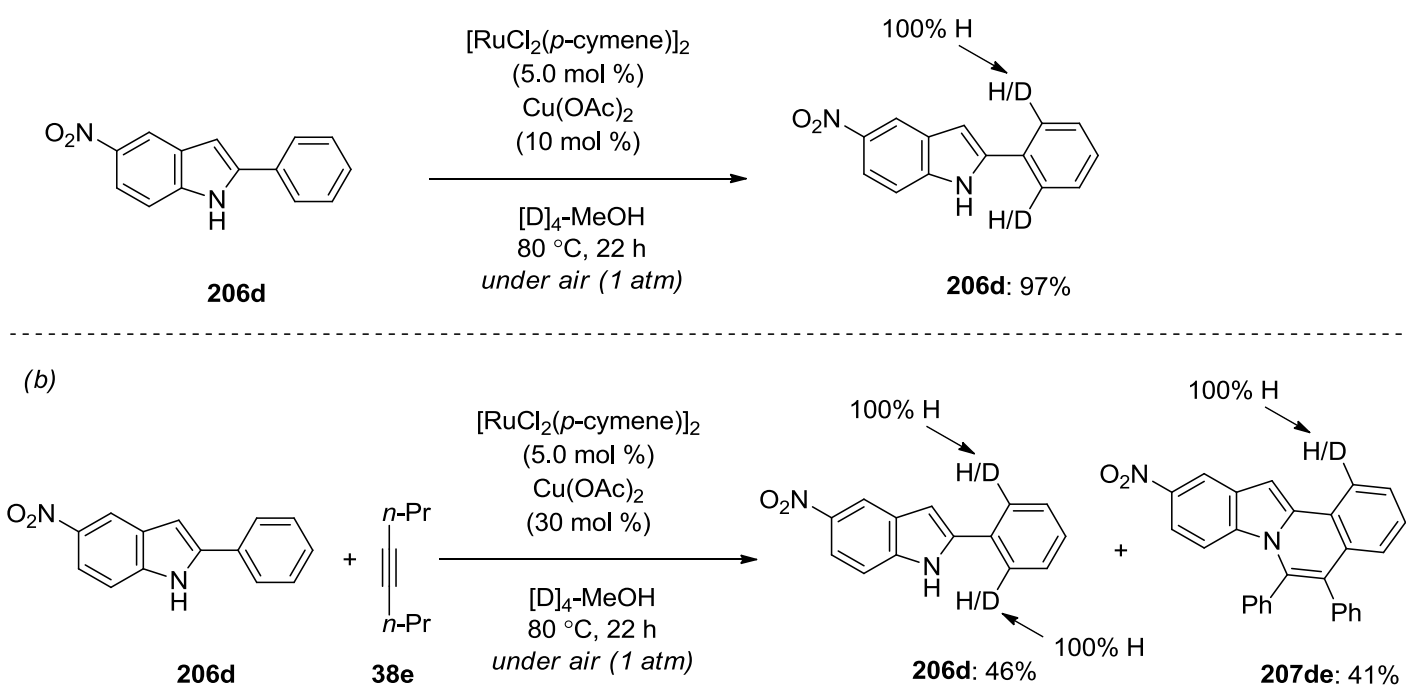

Scheme 66 Aerobic oxidative annulation in $[\mathrm{D}]_{4}-\mathrm{MeOH}$

\subsubsection{Proposed Catalytic Cycle}

Based on our experimental mechanistic studies, the following catalytic cycle for the ruthenium(II)-catalyzed aerobic oxidative annulation is proposed (Scheme 67). ${ }^{28}$ Initially, the ruthenium-dimer is expected to form an acetate complex 222, similar to those observed in the ruthenium-catalyzed carboxylate-assisted direct arylation. ${ }^{8}$ Subsequently, N-H bond ruthenation of free $\mathrm{N}-\mathrm{H}$ group followed by irreversible $\mathrm{C}-\mathrm{H}$ bond metalation via a key transition state $\mathbf{2 2 3}$ with a loss of two molecules of acetic acid affords ruthenacycle 224 . Coordination of alkyne 38 and regioselective migratory insertion delivers seven-membered ruthenacycle $\mathbf{2 2 5}$ as a key intermediate. Finally, the intermediate 225 releases the desired product 207 or 209 through

120 2-Aryl-substituted indoles bearing electron-donating groups on the aryl moiety led to low conversion. 
reductive elimination, which is followed by reoxidation of the resulting ruthenium( $(0)$ species core $\mathbf{2 2 6}$ by the copper (II)-acetate.

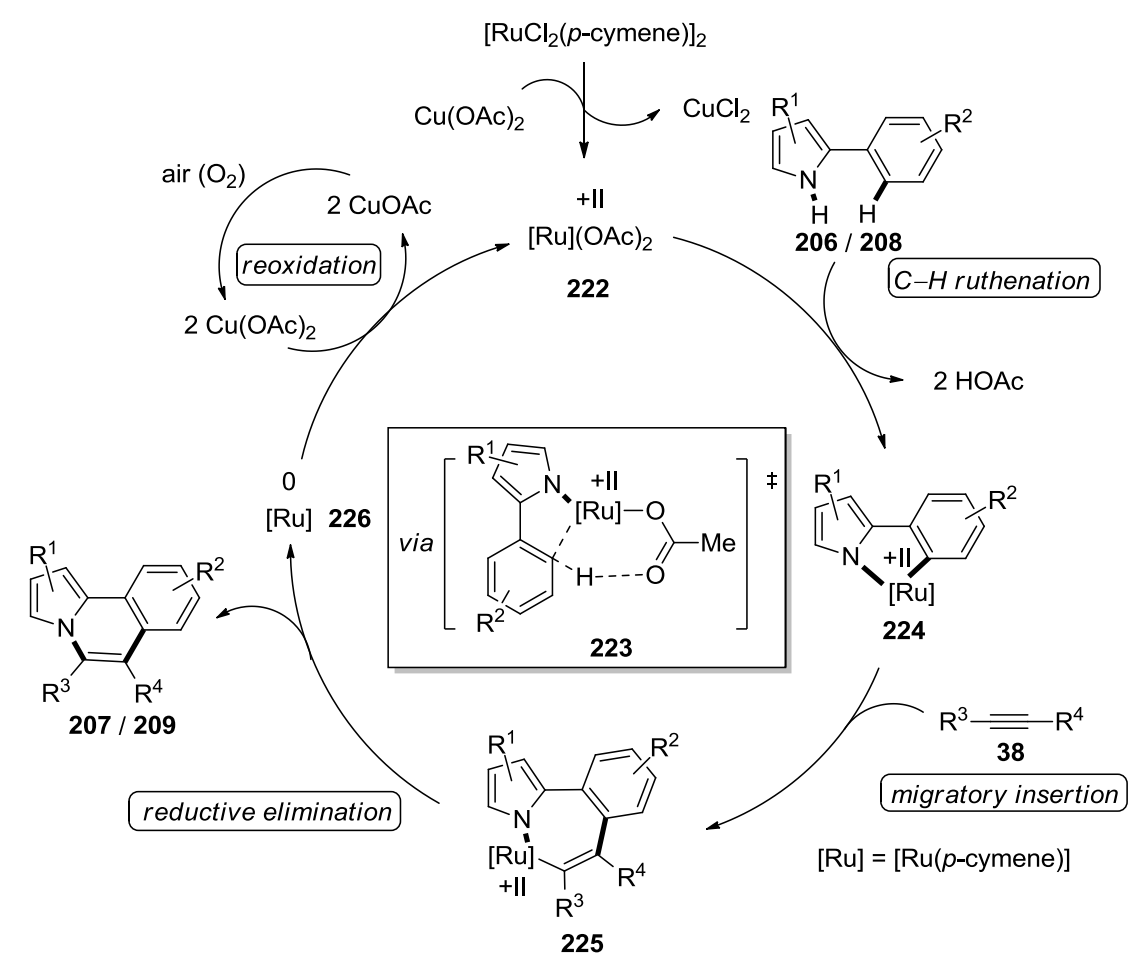

Scheme 67 Proposed catalytic cycle for the aerobic oxidative alkyne annulations

\subsection{Ruthenium-Catalyzed Oxidative Annulation of Alkynes with Enamines for Pyrrole Synthesis}

Pyrroles are among the most abundant heterocycles and represent indispensable structural motifs in bioactive natural products or material sciences. ${ }^{121 \mathrm{a}, \mathrm{b}}$ Therefore, there is a continued strong demand for methods that give broad access to this important heteroaromatic scaffold after the pioneering Knorr-pyrrole synthesis. ${ }^{121 \mathrm{c}, \mathrm{d}}$ Among these methods, transition-metal-catalyzed $\mathrm{C}-\mathrm{H}$ bond functionalization strategy for the pyrrole synthesis provides a more atom-economical approach and thus receives much recent attention. ${ }^{2}$

The seminal work by the research groups of Glorius ${ }^{122}$ as well as Stuart and Fagnou ${ }^{123}$ have revealed novel syntheses of polysubstituted pyrroles through rhodium(III)-catalyzed $\mathrm{C}-\mathrm{H}$ activation of enamines followed by the cyclization with an internal alkyne. Unfortunately, the high costs of the required rhodium(III) catalyst were identified as a limitation of this approach. ${ }^{15}$ The past three years witness a rapid development of the ruthenium-catalyzed oxidative $\mathrm{C}-\mathrm{H} / \mathrm{N}-\mathrm{H}$ bond functionalizations. ${ }^{28}$ However, these protocols were restricted to alkenes activated with electron-withdrawing carbonyl groups. To overcome these restrictions, we hence became intrigued

121 (a) V. Estevés, M. Villacampa, J. C. Menendéz, Chem. Soc. Rev. 2010, 39, 4402-4421, and references cited therein; (b) D. S. Bhakuni, D. S. Rawat, Bioactive Marine Natural Products, Springer: New York, 2005; (c) C. Paal, Ber. Dtsch. Chem. Ges. 1885, 18, 367-371; (d) A. Hantzch, Ber. Dtsch. Chem. Ges. 1890, 23, 14741476.

122 S. Rakshit, F. W. Patureau, F. Glorius, J. Am. Chem. Soc. 2010, 132, 9585-9587.

123 (a) M. P. Huestis, L. Chan, D. R. Stuart, K. Fagnou, Angew. Chem. Int. Ed. 2011, 50, 1338-1341; (b) D. R. Stuart, P. Alsabeh, M. Kuhn, K. Fagnou, J. Am. Chem. Soc. 2010, 132, 18326-18339. 
by developing a new ruthenium(II)-catalyzed oxidative alkyne annulations with challenging electron-rich alkenes for the pyrrole synthesis. ${ }^{124,125}$

\subsubsection{Optimization Studies}

We commenced our studies by probing oxidative annulations with differently $N$-substituted enamines 210 (Scheme 68). Among starting materials 210 bearing a variety of functional substituents, such as Boc, Ts, acetyl, solely the $N$-acetylated substrate delivered the product 211aa in a satisfactory yield of $70 \%$, while the corresponding trifluoroacetylated starting material led to the $N H$-free product 212aa, albeit in low yield (15\%).

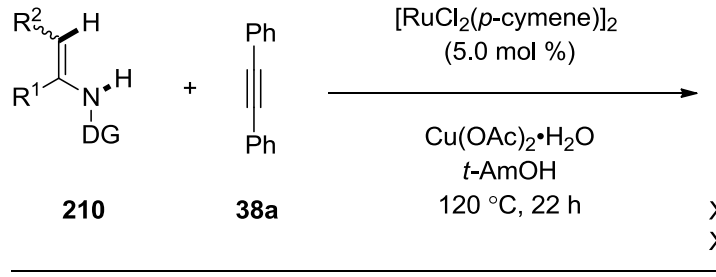

$\mathrm{MeO}_{2} \mathrm{C} \overbrace{\substack{1 \\ \text { Boc }}}^{* \mathrm{H}}$<smiles>COC(=O)/C=C\N([AsH3])[AsH3]</smiles>

$0 \%$<smiles>COC(=Cc1ccccc1)NC(=O)c1ccccc1</smiles>

$0 \%$
$0 \%$<smiles>[R]c1c(P)c([R])n([X])c1[R]</smiles>

$X=D G: 211 a a$ $X=H:$ 212aa<smiles>CC(=O)c1cc(-c2ccccc2)c(-c2ccccc2)[nH]1</smiles>

212aa: $15 \%$

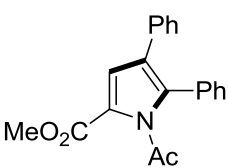

$\mathrm{Ac}$ $70 \%$

Scheme 68 Ruthenium(II)-catalyzed oxidative pyrrole synthesis

Thereafter, we tested the influence of reaction conditions on the activaty of the ruthenium(II) catalyst (Table 7). In the absence of either the ruthenium complex or the copper oxidant, the desired product 211 aa was not formed (entries 1 and 2). Likewise, the use of cocatalytic additive $\mathrm{KPF}_{6}$ that forms cationic ruthenium(II) catalyst did not improve the catalytic activity (entries 3-5), ${ }^{118}$ whereas the replacement with $\mathrm{AgSbF}_{6}$ led to 211aa in $39 \%$ yield, along with the formation of $\mathrm{NH}$-free product 212aa in $19 \%$ yield (entry 6). Further, a series of solvents, including DCE, $\mathrm{H}_{2} \mathrm{O}$, DMF, NMP, PhMe, DMA and $t$-AmOH (entries 3-11), were tested and disclosed the latter to be the most efficient one. Moreover, the use of $\mathrm{CuBr}_{2}$ instead of $\mathrm{Cu}(\mathrm{OAc})_{2} \cdot \mathrm{H}_{2} \mathrm{O}^{8}$ as the sacrificial oxidant did not deliver the desired product 211aa (entries 12-14). Besides, the complex $\mathrm{RuCl}_{3} \cdot \mathrm{xH}_{2} \mathrm{O}$ applied instead of $\left[\mathrm{RuCl}_{2}(p \text {-cymene })\right]_{2}$ displayed no catalytic activity in the pyrrole synthesis (entry 15).

124 L. Wang, L. Ackermann, Org. Lett. 2013, 15, 176-179.

${ }^{125}$ For similar subsequent reports on ruthenium(II)-catalyzed pyrrole synthesis, see: (a) B. Li, N. Wang, Y. Liang, S. Xu, B. Wang, Org. Lett. 2013, 15, 136-139; (b) K. Murugan, S.-T. Liu, Tetrahedron Lett. 2013, 54, 26082611; for recent palladium-catalyzed oxidative substituted pyrrole synthesis, see: (c) M.-N. Zhao, Z.-H. Ren, Y.-Y. Wang, Z.-H. Guan, Org. Lett. 2014, 16, 608-611. 
Table 7 Optimization study for the oxidative pyrrole synthesis ${ }^{a}$

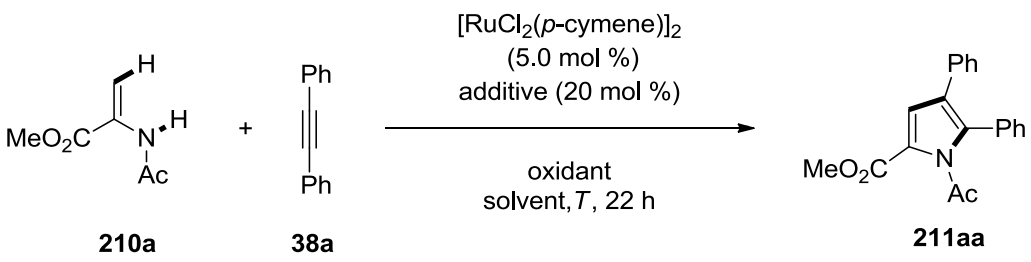

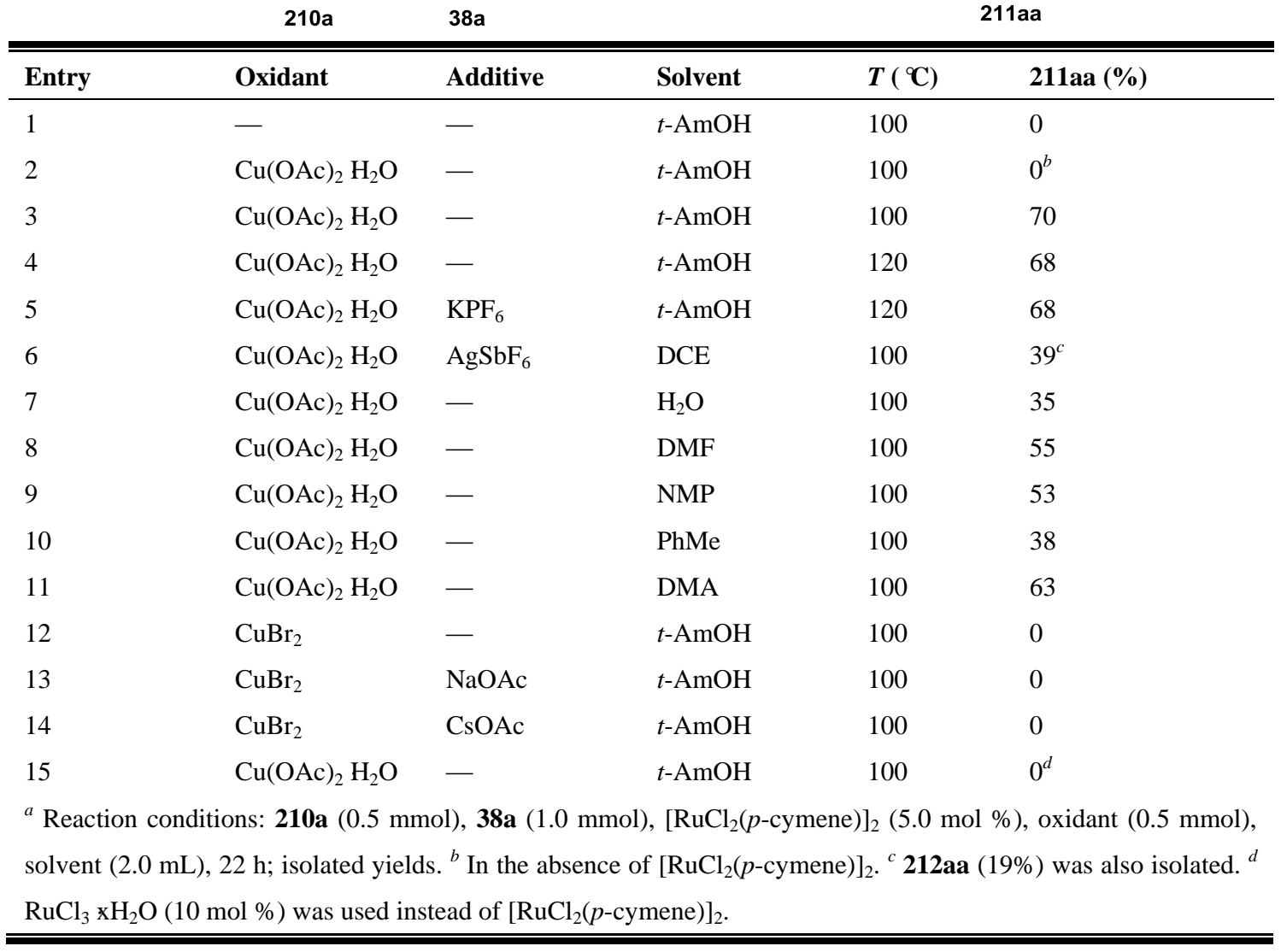

\subsubsection{Scope of the Oxidative Pyrrole Synthesis}

To evaluate the scope of the optimized ruthenium(II) catalyst, we tested its versatility in oxidative annulations of tolane (38a) utilizing representative enamines $\mathbf{2 1 0}$ (Table 8). We were delighted to observe that numerous useful electrophilic functional groups were well tolerated, including ester, vinyl, bromo, cyano, and nitro substituents. Substrates 210d and 210e with a ketone moiety or without an additional substituent, respectively, provided only low conversion under the optimized reaction conditions (entries 3 and 4). Transformations of 1-aryl-substituted enamines (entries 6-15) proceeded very smoothly in most cases. However, electron-rich methyl and methoxy (entries 12, 13) as well as cyclopropyl groups only delivered the target product in low yields, while more sterically congested substrate 210p was efficiently converted to product 211pa (entry 15). Moreover, 1-heteroaryl-substituted substrates 210q and 210r furnished the desired pyrroles 211q and 211ra as well (entries 16 and 17), albeit in lower yields. In the latter case, the $\mathrm{NH}$-free pyrrole 212ra was formed in a comparable yield, and the substrate 210s afforded analogous compound 212sa as a sole product in moderate yield (entry 18). 
Table 8 Oxidative annulation of tolane (38a) by enamides $\mathbf{2 1 0}^{a}$

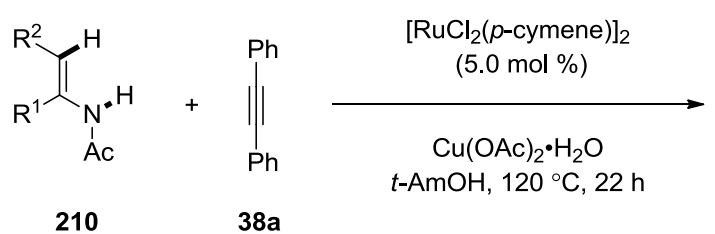

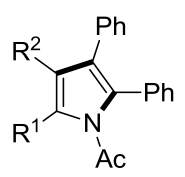

211

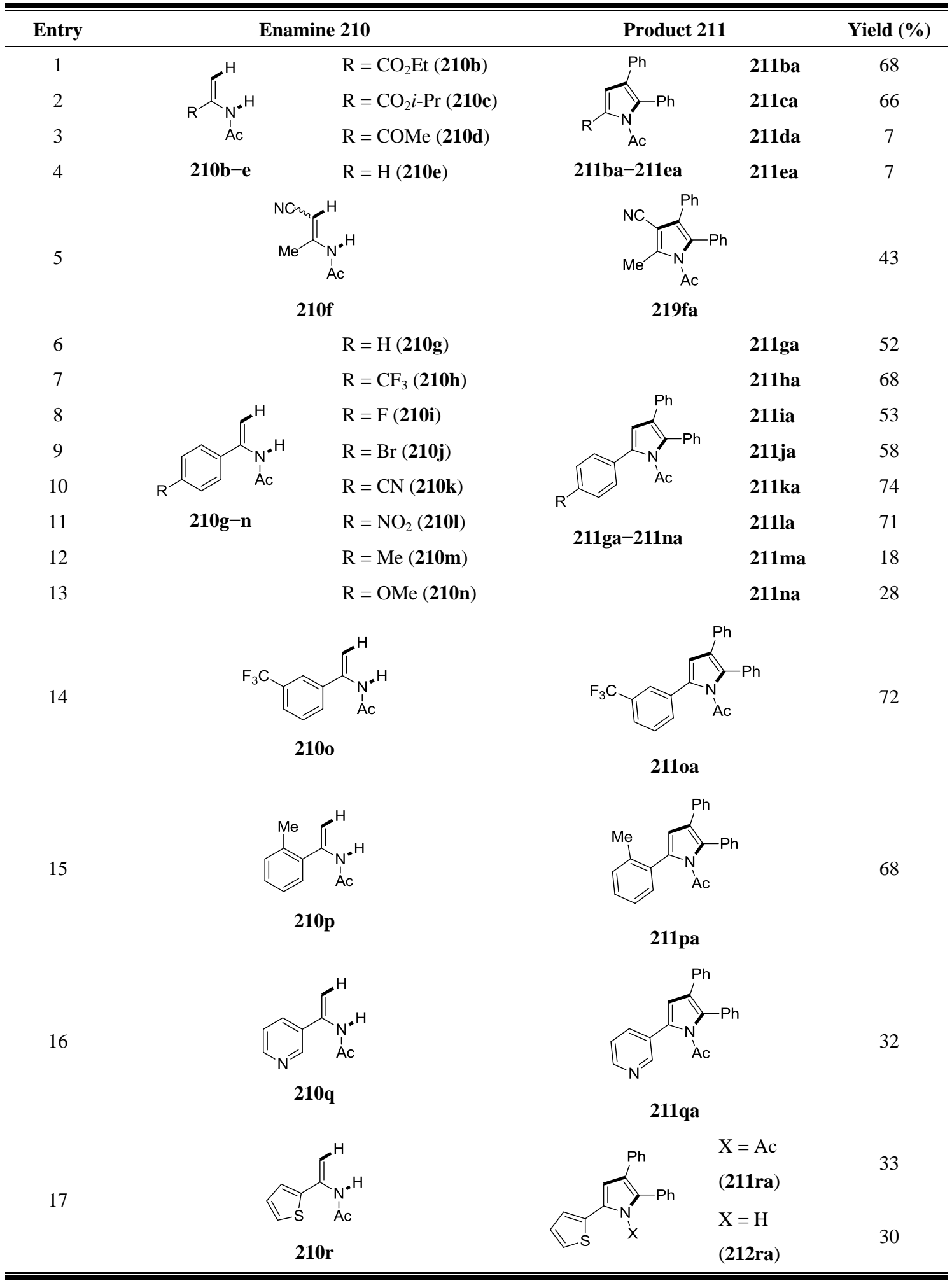


Table 8 (continued)

\begin{tabular}{l}
\hline Entry \\
\hline Enamine 210
\end{tabular}

Thereafter, we probed different tolane derivatives $\mathbf{3 8}$ in the oxidative pyrrole synthesis (Table 9). The optimized ruthenium catalyst proved to be tolerant of functional groups in the para-, metaand ortho-position of tolane (entries 1-8), but was not restricted to aryl alkynes 38. Dialkyl-substituted substrates 38e and 38f delivered the desired products 211ae and 211af, respectively, in high yields (entries 9 and 10). Notably, oxidative annulations of unsymmetrical alkynes 38h and 380 occurred with synthetically useful levels of regiocontrol, furnishing exclusively the products 211lh, 211ah and 211ao (entries 11-13). This selectivity pattern is in good agreement with the previously observed one for a related indole synthesis. ${ }^{37}$

Table 9 Oxidative annulation of alkynes 38 by enamines $\mathbf{2 1 0}^{a}$

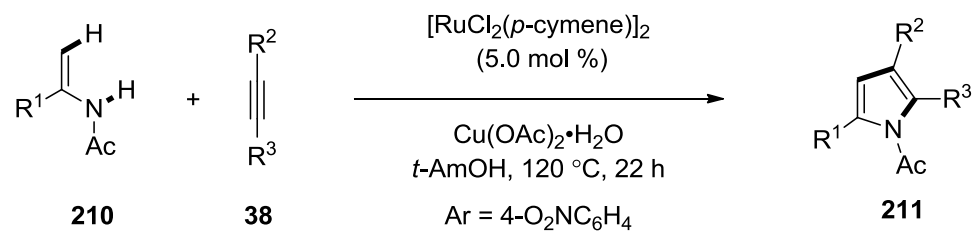

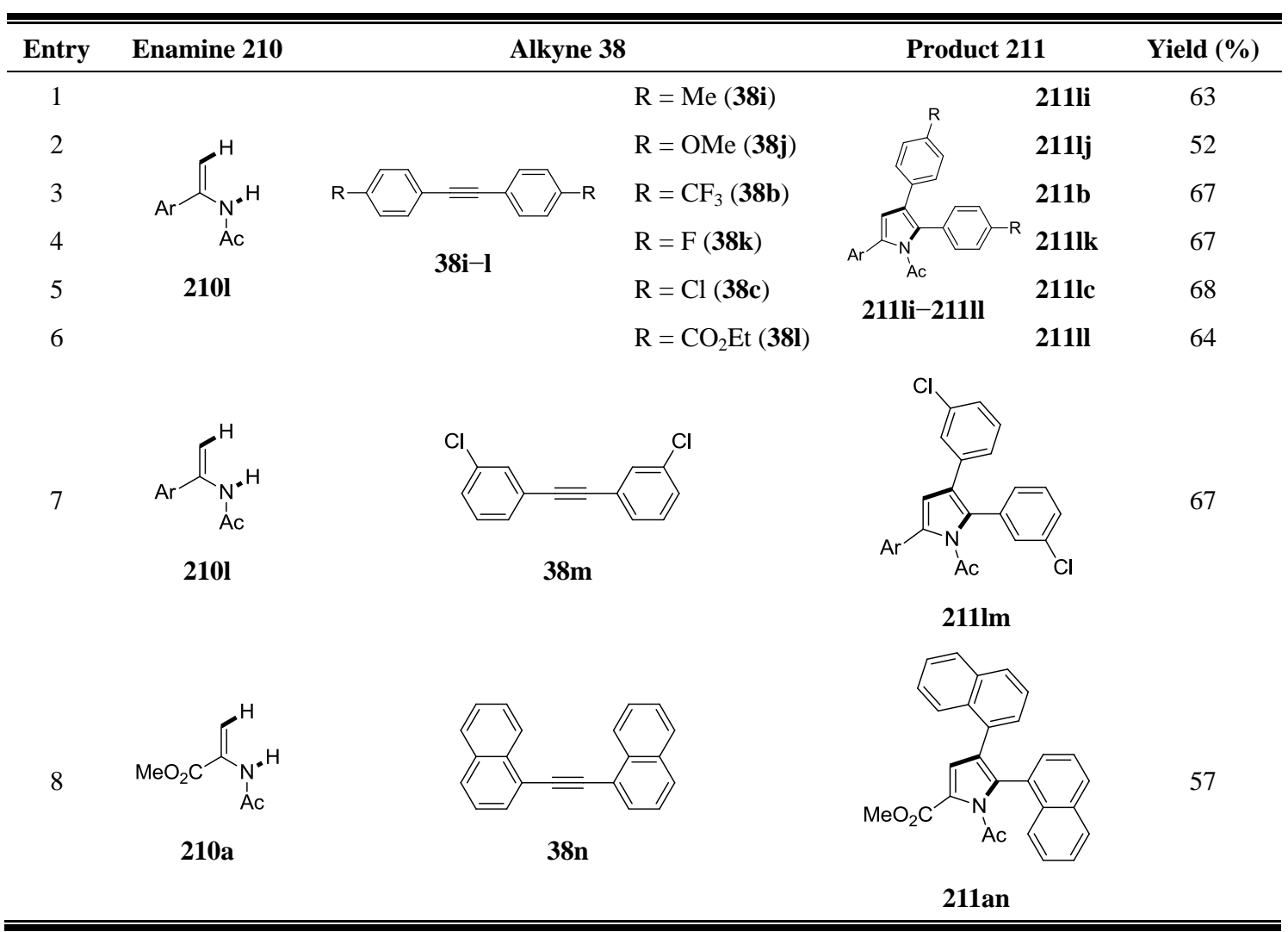

(continued) 
Table 9 (continued)

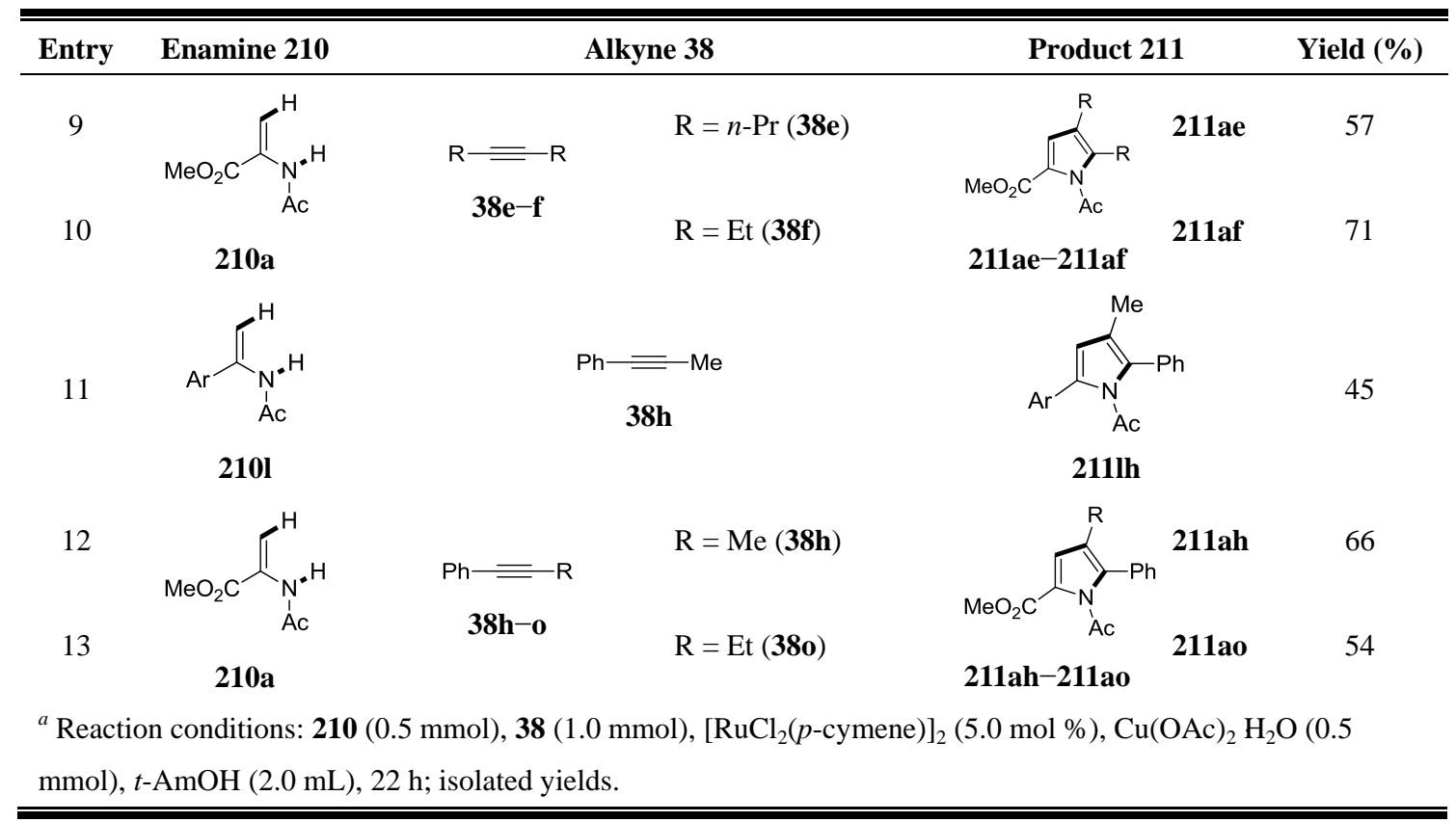

\subsubsection{Ruthenium(II)-Catalyzed Aerobic Oxidative Pyrrole Synthesis}

We were pleased that the $\mathrm{C}-\mathrm{H} / \mathrm{N}-\mathrm{H}$ bond functionalization was also achieved in an aerobic fashion employing cocatalytic amounts of $\mathrm{Cu}(\mathrm{OAc})_{2} \cdot \mathrm{H}_{2} \mathrm{O}$ under an ambient atmosphere of air as the ideal oxidant (Scheme 69).

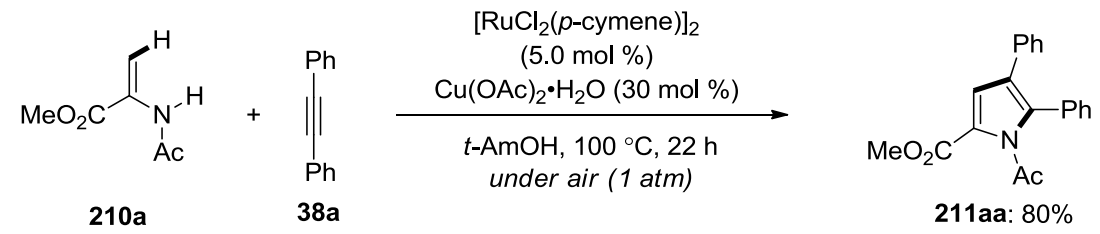

Scheme 69 Aerobic oxidative $\mathrm{C}-\mathrm{H} / \mathrm{N}-\mathrm{H}$ bond functionalization under ambient air

\subsubsection{Mechanistic Studies}

\subsubsection{Intermolecular Competition Experiments}

Given the remarkable catalytic activity of the ruthenium(II) catalyst, we became interested in elucidating the mechanistic aspects of this transformation. We conducted intermolecular competition experiments with alkynes $\mathbf{3 8}$, which revealed more electron-rich alkyne $\mathbf{3 8 j}$ to react preferentially (Scheme 70). 


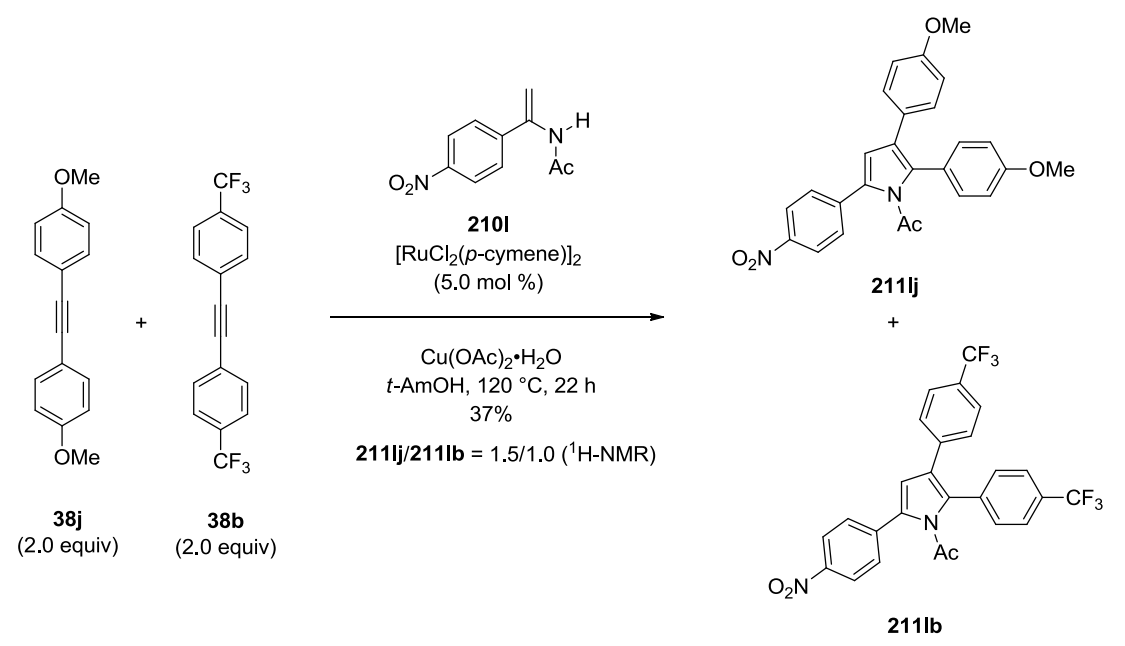

Scheme 70 Intermolecular competition between alkynes $\mathbf{3 8}$

Additionally, competition experiments with differently 2-aryl-substituted enamines 210 highlighted electron-donating substituents on the aryl moiety to be beneficial (Scheme 71).
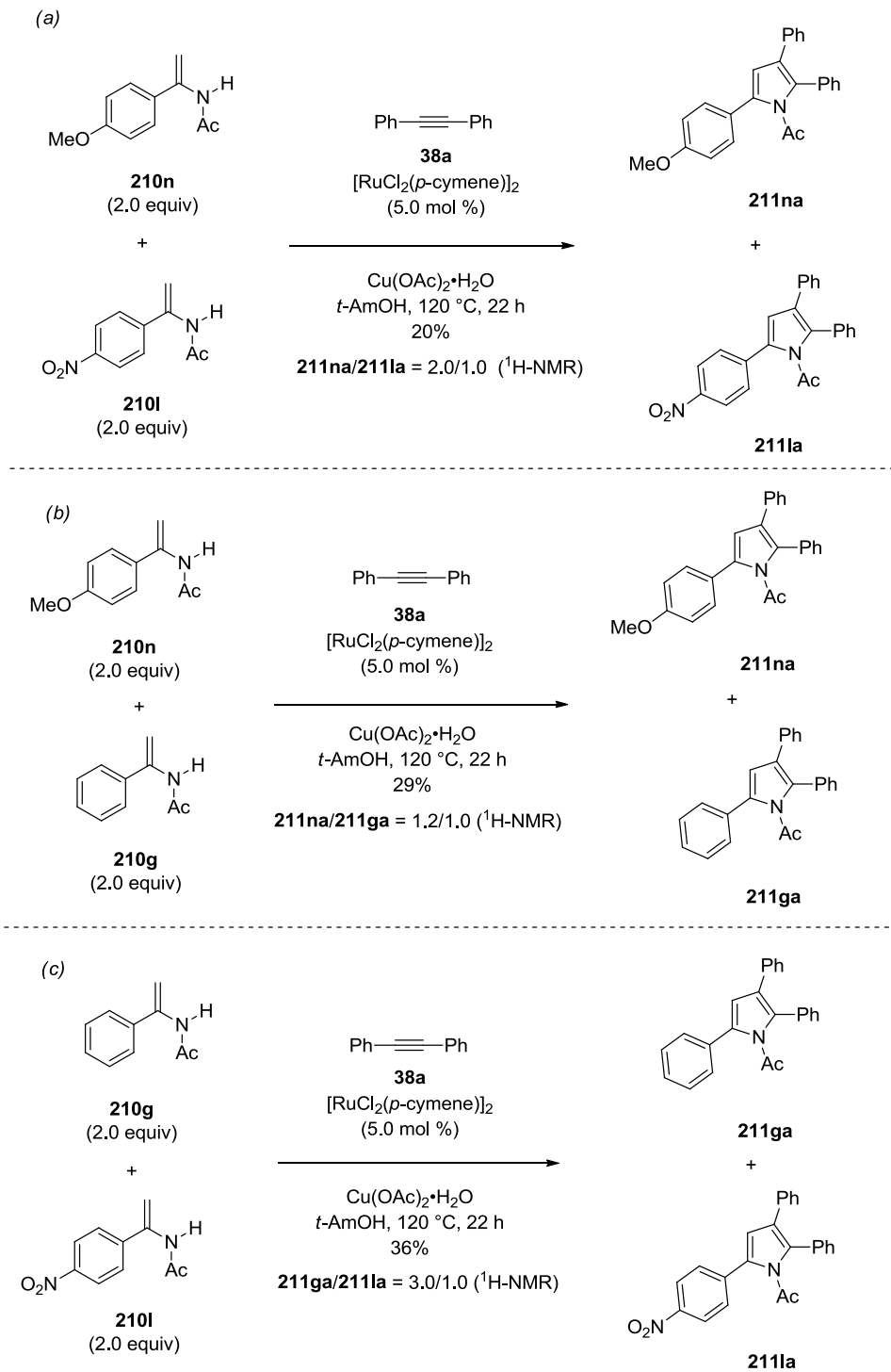

Scheme 71 Intermolecular competition between enamines 210 


\subsubsection{Reactions in Isotopically Labelled Solvents}

Oxidative annulations in isotopically labeled solvent $[\mathrm{D}]_{4}-\mathrm{MeOH}$ unraveled the $\mathrm{C}-\mathrm{H}$ bond activation on enamines $\mathbf{2 1 0}$ to be reversible in nature (Scheme 72a). Yet, the H/D scrambling was not observed in the presence of alkyne 38e under otherwise identical reaction conditions (Scheme $72 \mathrm{~b})$. These results can be rationalized in terms of an alkyne-coordinated ruthenium complex undergoing an irreversible $\mathrm{C}-\mathrm{H}$ bond metalation step.

(a)<smiles>C=C(NC)NC(=O)c1ccc([N+](=O)[O-])cc1</smiles>

2101

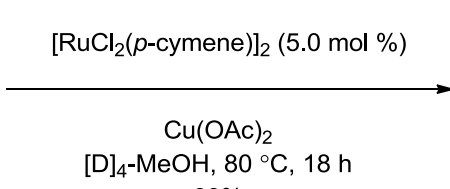

$60 \%$

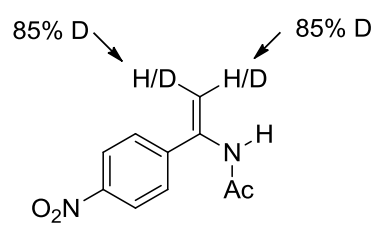

$[D]_{n}-2101$

(b)<smiles>[CH]N(NC(=O)c1ccc([N+](=O)[O-])cc1)C(=C)c1ccc([N+](=O)[O-])cc1</smiles>

Scheme 72 Oxidative annulations in $[\mathrm{D}]_{4}-\mathrm{MeOH}$

\subsubsection{Proposed Catalytic Cycle}

Based on the above discussed experiments and on the known mechanisms of transition-metal-catalyzed oxidative annulation reactions, ${ }^{28}$ a plausible catalytic cycle for the ruthenium(II)-catalyzed pyrrole synthesis is proposed (Scheme 73). Initially, the ruthenium-dimer reacts with $\mathrm{Cu}(\mathrm{OAc})_{2} \cdot \mathrm{H}_{2} \mathrm{O}$ to form an acetate-ligated species 227 , which is subsequently coordinated by $\mathbf{2 1 0}$ via the amide oxygen to generate complex 228. Then an alkyne-coordinate ruthenium complex undergoes an irreversible $\mathrm{C}-\mathrm{H}$ bond metalation step to deliver a six-membered ruthenacycle $\mathbf{2 3 0}$ with concomitant formation of acetic acid via an acetate-assisted transition state 229. Regioselectively migratory insertion into the $\mathrm{Ru}-\mathrm{C}$ bond and cleavage of $\mathrm{N}-\mathrm{H}$ bond furnish a six-membered ruthenacycle intermediate 231. Subsequently, the oxidative coupling of the $\mathrm{C}-\mathrm{N}$ bond takes place to form the pyrrole product $\mathbf{2 1 1}$ with the reduction of the ruthenium core from ruthenium(II) to ruthenium(0). Finally, the ruthenium(0) species 232 undergoes oxidation to regenerate the active ruthenium(II) complex with the aid of the copper oxidant. 


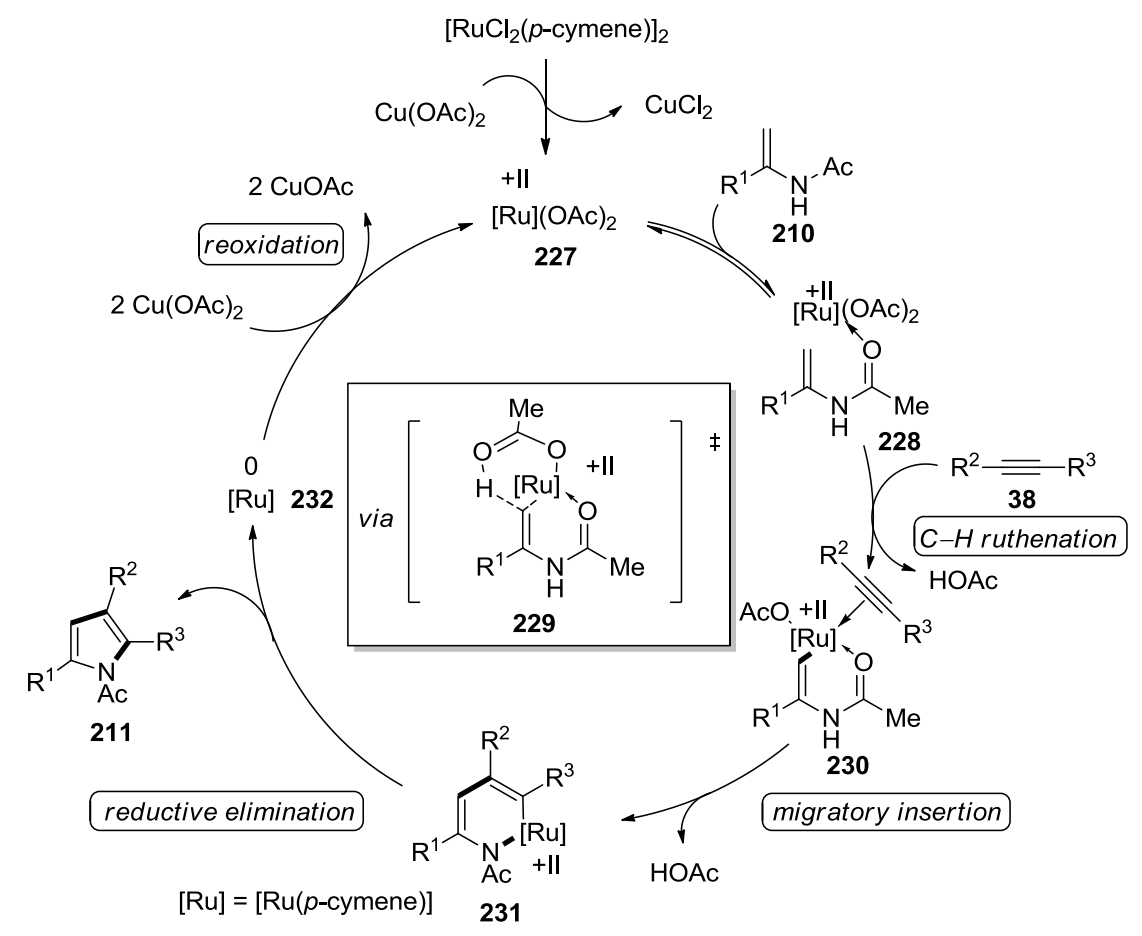

Scheme 73 Proposed catalytic cycle for the pyrrole synthesis 


\section{Ruthenium-Catalyzed Oxidative C-H Alkenylations}

\subsection{Ruthenium-Catalyzed Oxidative C-H Alkenylations of Anilides}

Along with the rapid developing oxidative annulations of alkynes, ${ }^{28}$ significant progress has been accomplished in direct oxidative alkenylations of (hetero)arenes via twofold $\mathrm{C}-\mathrm{H}$ bond cleavages employing ruthenium catalysts. ${ }^{29}$ However, ruthenium-catalyzed direct oxidative alkenylations continue to be limited to (hetero)arenes bearing electron-withdrawing directing groups. ${ }^{126}$ Given the importance of anilines as key intermediates for the preparation of bioactive compounds and functional materials, ${ }^{127}$ we set out to develop the first ruthenium-catalyzed oxidative olefinations with electron-rich anilines. ${ }^{128}$

\subsubsection{Optimization Studies}

At the outset of our studies, we optimized reaction conditions for the oxidative alkenylation of acetanilide 212a with alkene 76a in water (Table 10). In the absence of an additive, only trace amounts of the desired product 213aa were formed (entries 1 and 2). However, high catalytic efficiency was ensured by a complex generated in situ from $\left[\mathrm{RuCl}_{2}(p \text {-cymene) }]_{2}\right.$ and cocatalytic amounts of $\mathrm{KPF}_{6}$ (entries 3-9), reaction conditions previously established for the generation of cationic ruthenium(II) complexes. ${ }^{119}$ An aerobic oxidative alkenylation with cocatalytic amounts of $\mathrm{Cu}(\mathrm{OAc})_{2} \cdot \mathrm{H}_{2} \mathrm{O}$ was viable, albeit with reduced efficacy (entry 10 ). Further, the use of silver(I) salts as terminal oxidants provided less satisfactory results but indicated a strong dependence of the catalyst's performance on the presence of acetates (entries 11 and 12). ${ }^{8}$

Table 10 Optimization of alkenylation with acetanilide $\mathbf{2 1 2 \mathbf { a } ^ { a }}$

\begin{tabular}{|c|c|c|c|c|c|}
\hline \multirow[b]{2}{*}{ Entry } & $212 a$ & $6 a$ & $\begin{array}{c}\underset{\left[\mathrm{RuCl}_{2}(p \text {-cymene })\right]_{2}}{\text { additive }} \\
\underset{\text { oxidant }}{\mathrm{H}_{2} \mathrm{O}, 120{ }^{\circ} \mathrm{C}, 20 \mathrm{~h}}\end{array}$ & 213aa & $-\mathrm{CO}_{2} \mathrm{Et}$ \\
\hline & {$\left[\operatorname{RuCl}_{2}(p \text {-cymene })\right]_{2}(\mathrm{~mol} \%)$} & Oxidan & (equiv) & Additive (mol \%) & 213aa $(\%)$ \\
\hline 1 & - & $\mathrm{Cu}(\mathrm{OA}$ & )$_{2} \cdot \mathrm{H}_{2} \mathrm{O}(1.0)$ & $\mathrm{KPF}_{6}(10)$ & 0 \\
\hline 2 & 2.5 & $\mathrm{Cu}(\mathrm{OA}$ & )$_{2} \cdot \mathrm{H}_{2} \mathrm{O}(1.0)$ & - & $2^{b}$ \\
\hline 3 & 1.0 & $\mathrm{Cu}(\mathrm{OA}$ & )$_{2} \cdot \mathrm{H}_{2} \mathrm{O}(1.0)$ & $\mathrm{KPF}_{6}(5)$ & $43^{b}$ \\
\hline 4 & 2.5 & $\mathrm{Cu}(\mathrm{OA}$ & )$_{2} \cdot \mathrm{H}_{2} \mathrm{O}(1.0)$ & $\mathrm{AgSbF}_{6}(10)$ & 54 \\
\hline 5 & 2.5 & $\mathrm{Cu}(\mathrm{OA}$ & )$_{2} \cdot \mathrm{H}_{2} \mathrm{O}(1.0)$ & $\mathrm{KPF}_{6}(10)$ & 87 \\
\hline 6 & 2.5 & $\mathrm{Cu}(\mathrm{OA}$ & )$_{2} \cdot \mathrm{H}_{2} \mathrm{O}(1.0)$ & $\mathrm{KPF}_{6}(5)$ & 76 \\
\hline 7 & 2.5 & $\mathrm{Cu}(\mathrm{OA}$ & )$_{2} \cdot \mathrm{H}_{2} \mathrm{O}(2.0)$ & $\mathrm{KPF}_{6}(10)$ & 84 \\
\hline 8 & 5.0 & $\mathrm{Cu}(\mathrm{OA}$ & )$_{2} \cdot \mathrm{H}_{2} \mathrm{O}(1.0)$ & $\mathrm{KPF}_{6}(20)$ & 86 \\
\hline
\end{tabular}

(continued)

\footnotetext{
${ }^{126}$ For the recent reports on ruthenium-catalyzed oxidative olefinations with electron-rich arenes appeared during the preparation of this thesis, see ref. 66 and 67.

127 Amino Group Chemistry; A. Ricci, Ed.; Wiley-VCH: Weinheim, 2008.

${ }^{128}$ L. Ackermann, L. Wang, R. Wolfram, A. V. Lygin, Org. Lett. 2012, 14, 728-731.
} 
Table 10 (continued)

\begin{tabular}{|c|c|c|c|c|}
\hline Entry & {$\left[\operatorname{RuCl}_{2}(p \text {-cymene })\right]_{2}(\mathrm{~mol} \%)$} & Oxidant (equiv) & Additive (mol \%) & 213aa $(\%)$ \\
\hline 9 & 2.5 & $\mathrm{Cu}(\mathrm{OAc})_{2} \cdot \mathrm{H}_{2} \mathrm{O}(1.0)$ & $\mathrm{KPF}_{6}(10)$ & $77^{c}$ \\
\hline 10 & 2.5 & $\mathrm{Cu}(\mathrm{OAc})_{2} \cdot \mathrm{H}_{2} \mathrm{O}(0.05)$ & $\mathrm{KPF}_{6}(10)$ & $48^{b, c, d}$ \\
\hline 11 & 2.5 & $\mathrm{Ag}_{2} \mathrm{CO}_{3}(1.0)$ & $\mathrm{KPF}_{6}(10)$ & 0 \\
\hline 12 & 2.5 & $\operatorname{AgOAc}(1.0)$ & $\mathrm{KPF}_{6}(10)$ & $40^{b}$ \\
\hline
\end{tabular}

Notably, the replacement of water by organic solvents, such as $t$-AmOH and DMF, led to lower-yielding reactions (Table 11, entries 2-6). Hence, the reaction mixture was biphasic, which suggested that the reaction occured "on" water, rather than "in water". ${ }^{129}$ However, addition of surfactants, such as Triton X-100, surprisingly delivered the alkenylated product in similar yield in $\mathrm{H}_{2} \mathrm{O}$ (entry 7 vs entry 1).

Table 11 Influence of solvent on the alkenylation with acetanilide $212 \mathbf{a}^{a}$

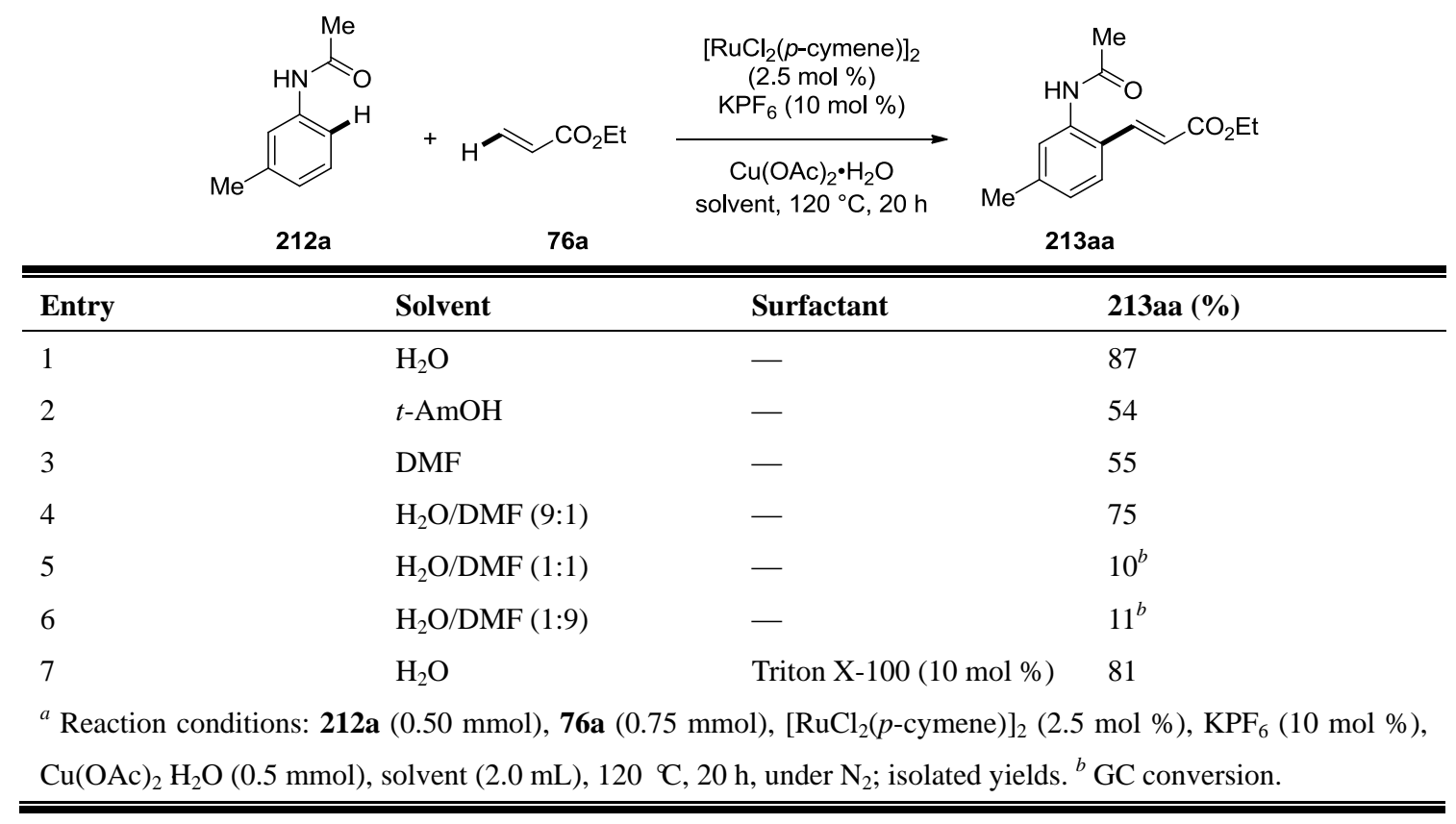

\subsubsection{Effect of Directing Groups}

Furthermore, we probed the ruthenium-catalyzed oxidative alkenylation with differently $\mathrm{N}$-substituted substrates 212 (Scheme 74). Among a variety of starting materials 212, $\mathrm{N}$-phenylacetamide (212d) delivered the product 213da in best yield in $\mathrm{H}_{2} \mathrm{O}(68 \%)$, while the corresponding $N, N$-disubstituted substrate $212 f$ led to the target product $\mathbf{2 1 3 f a}$ with a low conversion $(15 \%)$.

${ }^{129}$ For recent reviews on transition-metal-catalyzed coupling reactions in or on water, see: (a) M.-O. Simon, C.-J. Li, Chem. Soc. Rev. 2012, 41, 1415-1427; (b) C.-J. Li, Acc. Chem. Res. 2010, 43, 581-590; (c) B. H. Lipshutz, A. R. Abela, Z. V. Boskovic, T. Nishikata, C. Duplais, A. Krasovskiy, Top. Catal. 2010, 53, 985-990; (d) R. N. Butler, A. G. Coyne, Chem. Rev. 2010, 110, 6302-6337. 


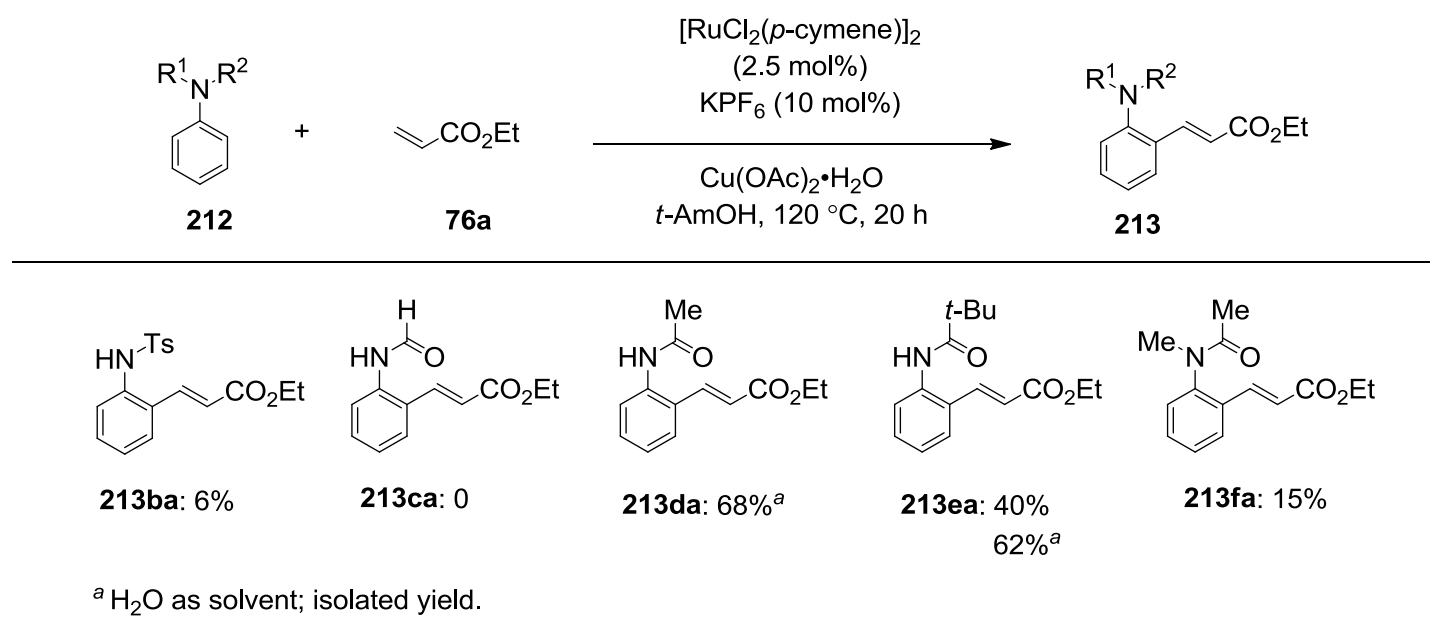

Scheme 74 Ruthenium(II)-catalyzed oxidative alkenylations

\subsubsection{Scope and Limitations}

With the optimized catalytic system in hand, we explored the scope in the ruthenium-catalyzed oxidative alkenylation of anilides $\mathbf{2 1 2}$ (Table 12). Thus, the catalytic $\mathrm{C}-\mathrm{H}$ bond functionalization in water allowed for the efficient conversion of para-substituted substrates $212 \mathbf{g}-\mathbf{i}$ via chemoselective monoalkenylations (entries 1-5). Intramolecular competition experiments with meta-substituted anilides $\mathbf{2 1 2}$ site selectively delivered the products $\mathbf{2 1 3}$ through alkenylation in position C-6, likely due to steric interactions (entries 6-10). Notably, this reactivity pattern was not observed when using meta-fluoro-substituted anilide $\mathbf{2 1 2} \mathbf{m}$ (entry 11), as was previously noted for ruthenium-catalyzed $\mathrm{C}-\mathrm{H}$ bond functionalization with organic electrophiles. ${ }^{24}$ Unfortunately, ortho-substituted substrate 212n delivered the alkenylated product 213na in only $41 \%$ conversion (entry 13). However, hydroarylation of alkenes surprisingly occurred with methy vinyl ketone (76c), yielding the corresponding alkylated product $213 a c$ in $31 \%$ yield (entry 12). ${ }^{130}$

Table 12 Oxidative alkenylations with anilides $\mathbf{2 1 2}^{a}$

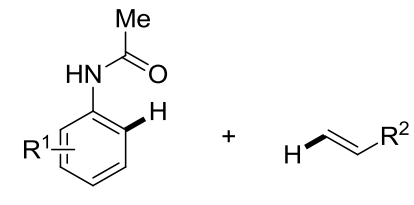

212

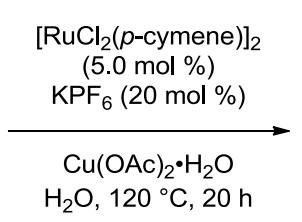

$\mathrm{H}_{2} \mathrm{O}, 120^{\circ} \mathrm{C}, 20 \mathrm{~h}$

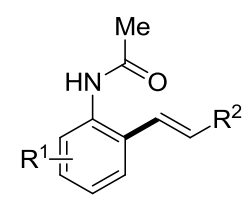

213

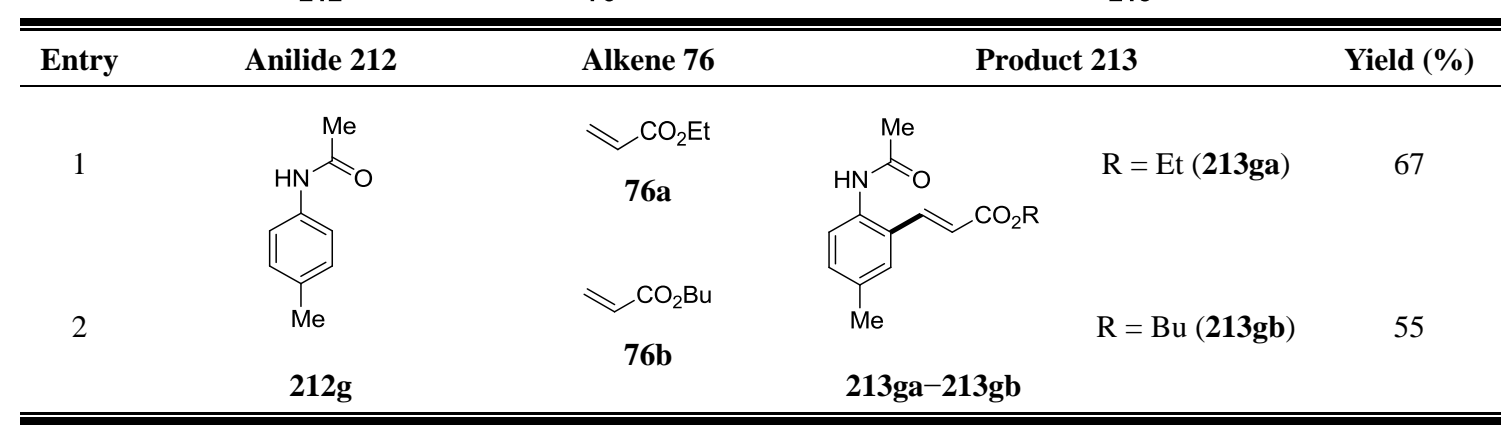

(continued)

${ }^{130}$ For a similar subsequent example, see: L. Huang, Q. Wang, J. Qi, X. Wu, K. Huang, H. Jiang, Chem. Sci. 2013, 4, 2665-2669. 
Table 12 (continued)

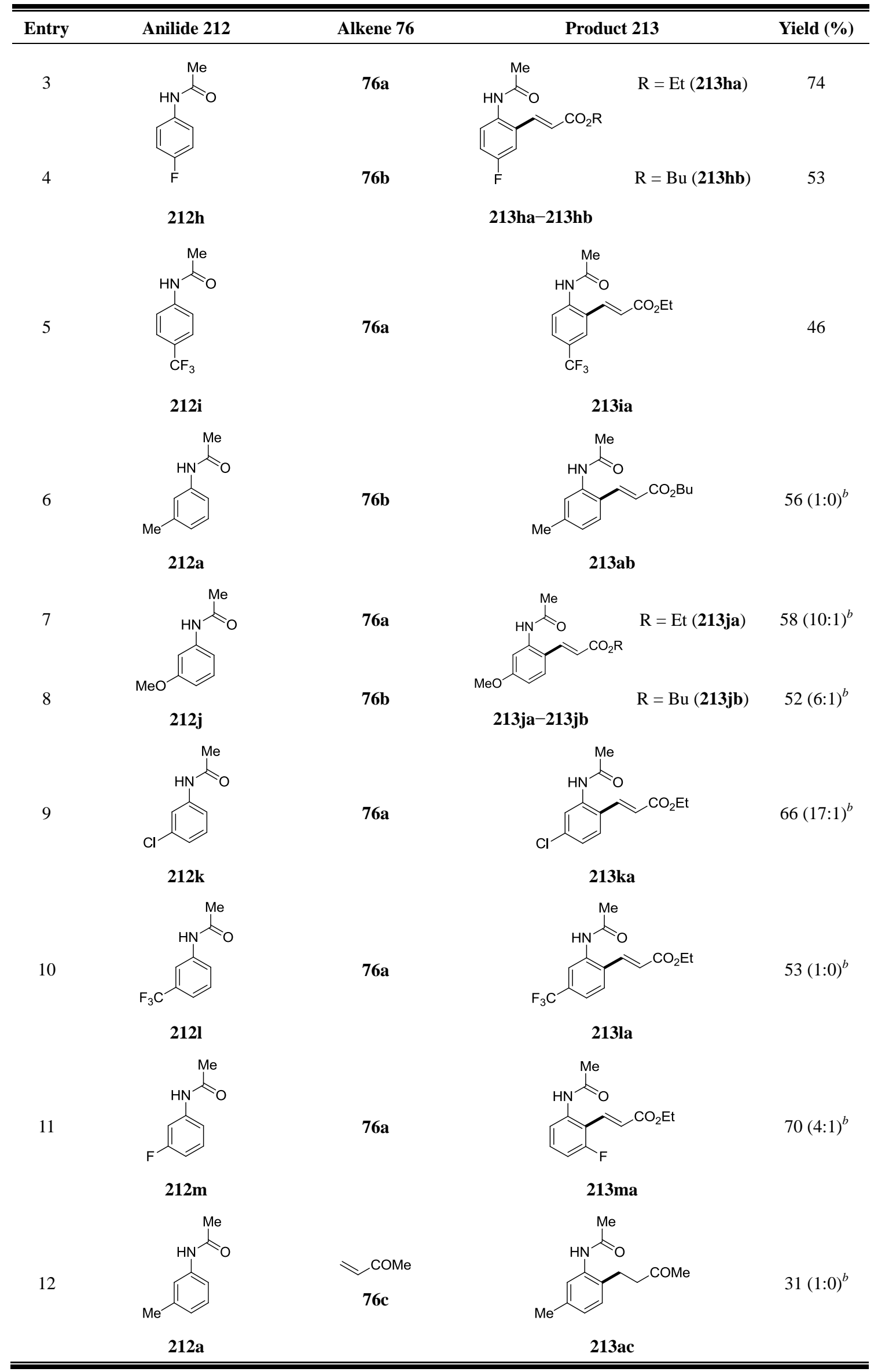


Table 12 (continued)

Entry
${ }^{a}$ Reaction conditions: $212(0.50 \mathrm{mmol}), \mathbf{7 6}(0.75 \mathrm{mmol}),\left[\mathrm{RuCl}_{2}(\text { p-cymene })\right]_{2}\left(5.0\right.$ mol \%), $\mathrm{KPF}_{6}(10$ mol \%),
$\mathrm{Cu}(\mathrm{OAc})_{2} \cdot \mathrm{H}_{2} \mathrm{O}(0.5 \mathrm{mmol}), \mathrm{H}_{2} \mathrm{O}(2.0 \mathrm{~mL}), 120{ }^{\circ} \mathrm{C}, 20 \mathrm{~h}$, under $\mathrm{N}_{2} ;$ isolated yields (of the major isomers). ${ }^{b}$ Ratio
of the regioisomers determined by GC. ${ }^{c} \mathrm{GC}$ conversion.

Furthermore, we were pleased to observe that this ruthenium-catalyzed oxidative $\mathrm{C}-\mathrm{H}$ alkenylation proceeded smoothly even on a large scale $(0.5 \mathrm{~g}-5.0 \mathrm{~g}) .{ }^{131}$ Herein, $5 \mathrm{mmol}$ scale anilide loadings delivered the target product 213aa in 73\% yield (Scheme 75).

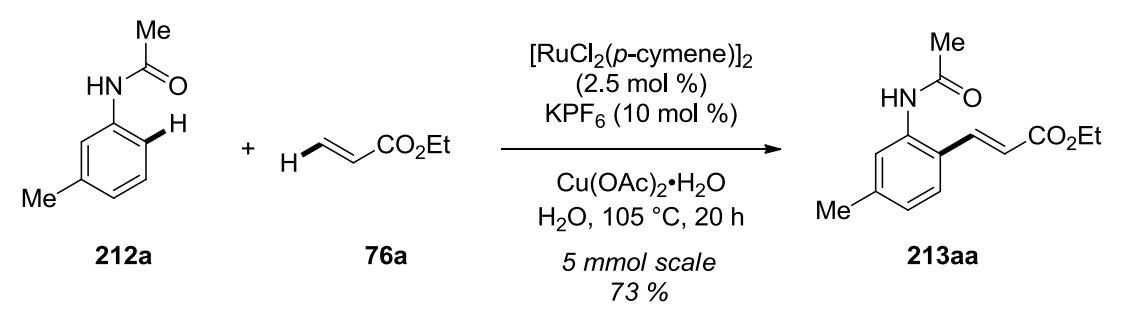

Scheme 75 Ruthenium(II)-catalyzed oxidative alkenylations of anilide 212a in $5 \mathrm{mmol}$ scale

The cationic ruthenium(II) system unfortunately led to low conversions with acrylonitrile (76d), styrene (76e), tert-butyl acrylate (76f), acrolein (76g) and $\alpha$ - or $\beta$-substituted alkenes (76h-k) (Table 13), even when switching $\mathrm{H}_{2} \mathrm{O}$ to the organic solvent $t$-AmOH (entry 3 ).

Table 13 Oxidative alkenylations with alkene derivatives $\mathbf{7 6}^{a}$
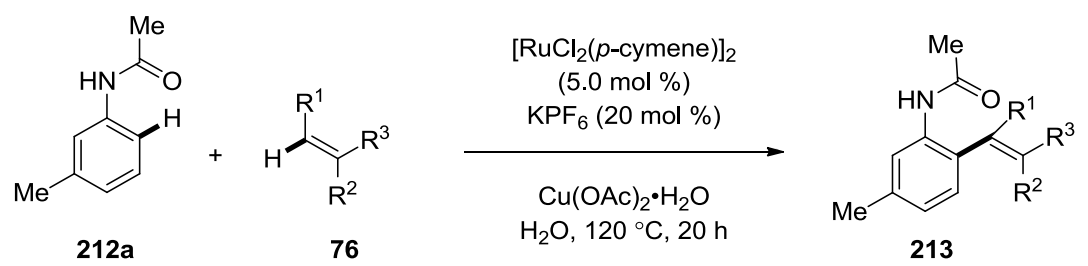

\begin{tabular}{|c|c|c|}
\hline Entry & Alkene 76 & $213(\%)$ \\
\hline 1 & $\widehat{C N}_{(76 d)}$ & 13 \\
\hline 2 & & 13 \\
\hline 3 & $\operatorname{Ph}(76 \mathbf{6})$ & $36^{b}$ \\
\hline 4 & $\mathrm{CO}_{2} \mathrm{tBu} \quad(\mathbf{7 6 f})$ & 0 \\
\hline 5 & $\mathrm{CHO}(\mathbf{7 6 g})$ & 0 \\
\hline 6 & $\mathrm{CN}_{\mathrm{CN}}(76 \mathrm{~h})$ & 0 \\
\hline 7 & $\mathrm{CO}_{2} \mathrm{Et} \quad(\mathbf{7 6 i})$ & 0 \\
\hline
\end{tabular}

(continued)

${ }^{131}$ L. Wang, K. Rauch, A. V. Lygin, S. I. Kozhushkov, L. Ackermann, Org. Synth. submitted. 
Table 13 (continued)

\begin{tabular}{|c|c|c|}
\hline Entry & Alkene 76 & $213(\%)$ \\
\hline \multicolumn{3}{|c|}{$\mathrm{EtO}_{2} \mathrm{C} \leadsto \mathrm{CO}_{2} \mathrm{Et} \quad(\mathbf{7 6 j})$} \\
\hline \multicolumn{3}{|c|}{$(76 k)$} \\
\hline${ }^{a}$ Reaction conditions: & $5 \mathrm{mmol}),\left[\mathrm{RuCl}_{2}(p\right.$ & $\%), \mathrm{KPF}_{6}(20 \mathrm{~mol} \%)$, \\
\hline $\mathrm{Cu}(\mathrm{OAc})_{2} \cdot \mathrm{H}_{2} \mathrm{O}(0.5 \mathrm{~m}$ & $20 \mathrm{~h}$, under $\mathrm{N}_{2} ; \mathrm{GC}$ & $\mathrm{OH}$ as solvent. \\
\hline
\end{tabular}

\subsubsection{Mechanistic Studies}

\subsubsection{Intermolercular Competition Experiments}

Considering the unique features of our ruthenium catalyst, we became interested in understanding its mode of action. Thus, intermolecular competition experiments revealed electron-rich anilides 212 to be preferentially functionalized (Scheme 76), which is in good agreement with an electrophilic activation manifold.

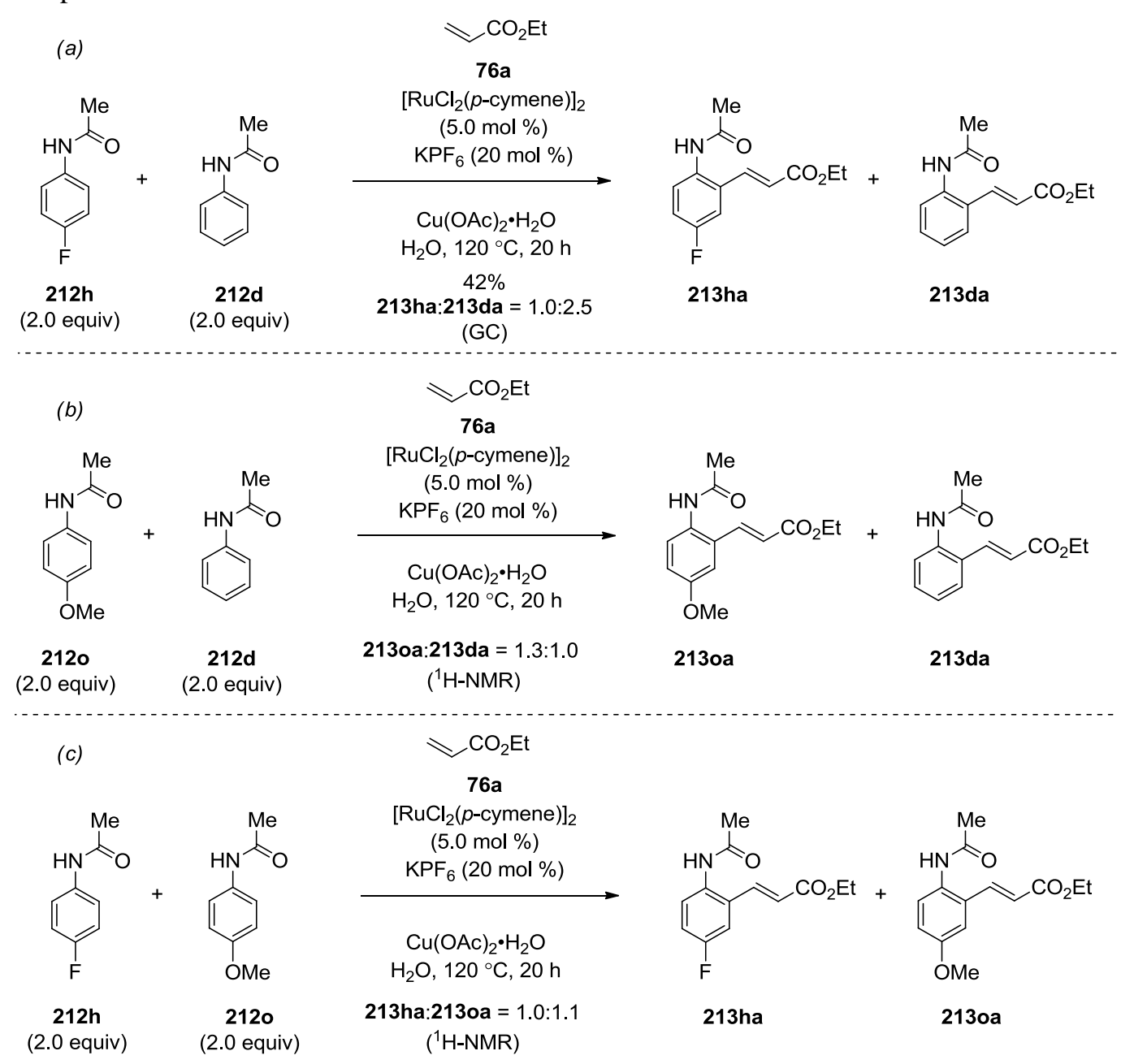

Scheme 76 Intermolecular Competition Experiments

\subsubsection{Reactions in Isotopically Labelled Solvents}


Oxidative alkenylation in $\mathrm{D}_{2} \mathrm{O}$ unraveled the $\mathrm{C}-\mathrm{H}$ bond activation in anilide $\mathbf{2 1 2 d}$ to be reversible in nature (Scheme 77a). ${ }^{128}$ Consistence with this result, an obvious H/D scrambling on both the recycled starting material $[D]_{n}-212 a$ and target product $[D]_{n}-213 a a$ were observed in the presence of alkene 76a under identical reaction conditions in $\mathrm{D}_{2} \mathrm{O}$ (Scheme 77b). These findings can be rationalized in that the ruthenium-catalyzed alkenylation proceeds by a reversible $\mathrm{C}-\mathrm{H}$ bond metalation step.

(a)

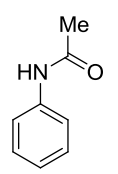

212d

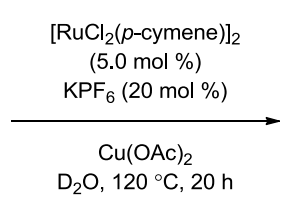

$\mathrm{D}_{2} \mathrm{O}, 120^{\circ} \mathrm{C}, 20 \mathrm{~h}$

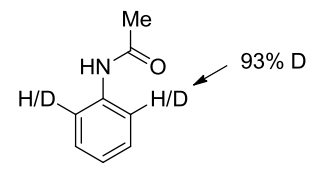

$[D]_{2}-212 d: 81 \%$

(b)<smiles>CC(=O)Nc1cccc(C)c1</smiles>

212a

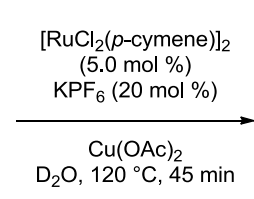

$76 a$

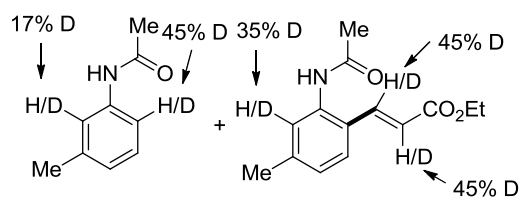

$[D]_{n}-212 a: 67 \%$
[D] $]_{n}-213$ aa: $27 \%$

Scheme 77 Ruthenium-Catalyzed H/D Exchange in $\mathrm{D}_{2} \mathrm{O}$

\subsubsection{Proposed Catalytic Cycle}

Based on our mechanistic studies, we propose the catalytic cycle to involve an initial reversible acetate-assisted $^{8}$ cycloruthenation of the cationic species 233 with anilide 212 to form complex 235 through a transition state 234 (Scheme 78), which subsequently undergoes a migratory insertion with alkene $\mathbf{7 6}$ to furnish the six-membered intermediate 236. Finally, $\beta$-hydride elimination yields the desired product 213, and oxidation of $[\mathrm{RuH}]$ species with $\mathrm{Cu}(\mathrm{OAc})_{2}$ regenerates the catalytically active cationic catalyst 233 .

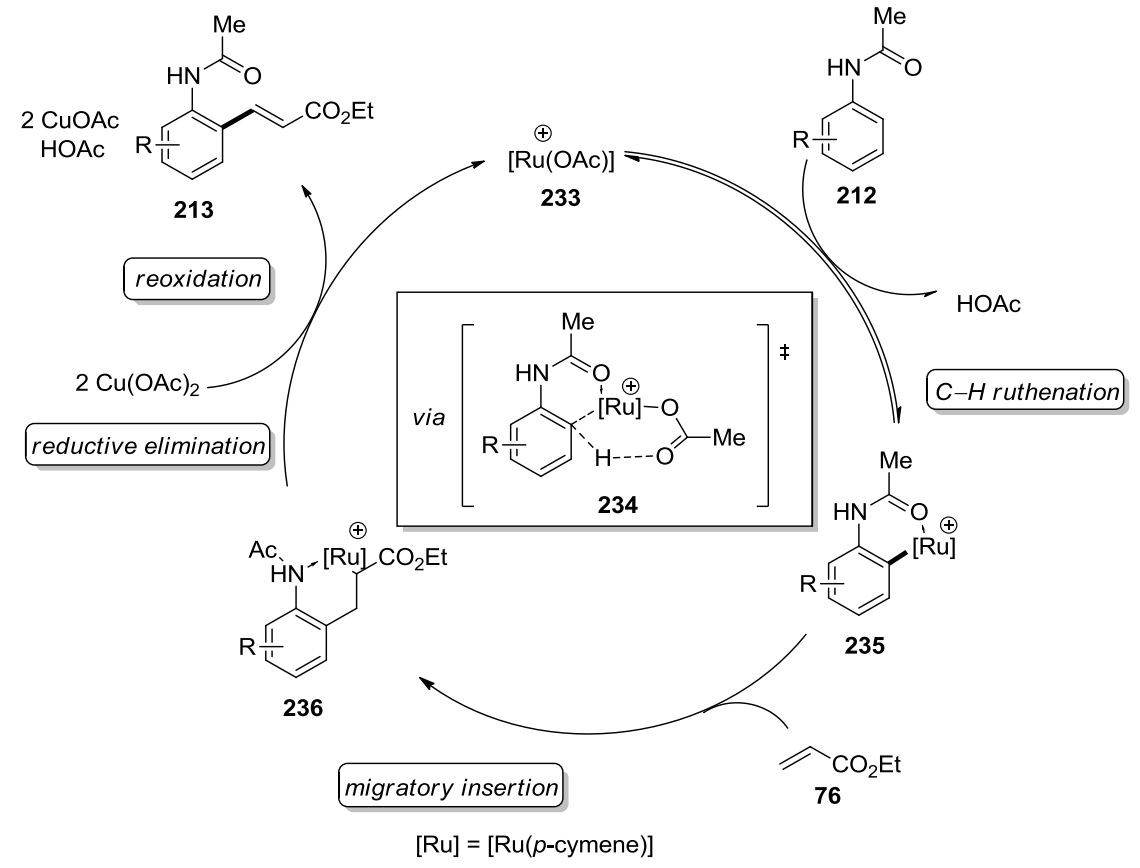

Scheme 78 Proposed mechanism for the ruthenium-catalyzed oxidative alkenylation 


\subsection{Ruthenium-Catalyzed Oxidative C-H Alkenylations of Benzamides}

Notably, the efficient catalysis achieved with the cationic ruthenium(II) complex in water allowed for efficient oxidative alkenylations of benzamides. ${ }^{128}$ Thus, direct $\mathrm{C}-\mathrm{H}$ bond functionalization of heteroaromatic amides 214 occurred with high catalytic efficacy and excellent site selectivity (Table 14). However, the alkenylation of $\mathrm{NH}$-free indole $\mathbf{2 1 4} \mathbf{c}$ did not proceed under the identical reaction conditions (entry 3 ).

Table 14 Oxidative alkenylation of heteroaromatic amides $\mathbf{2 1 4}{ }^{a}$

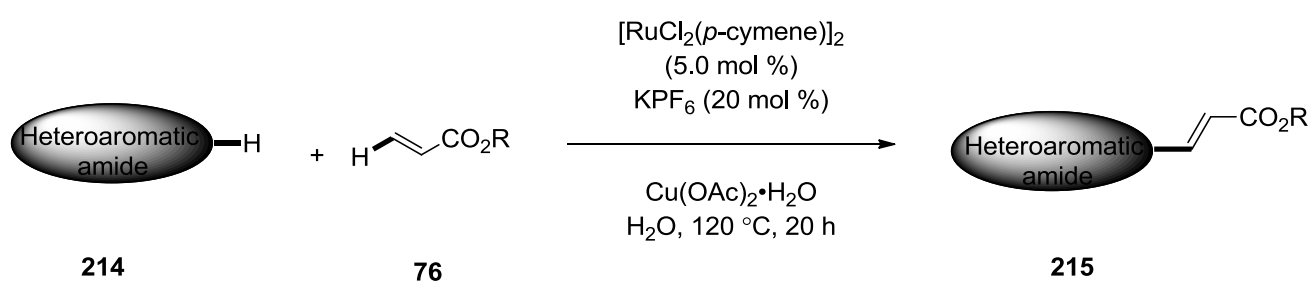

214

76

Alkene 76

Product 215

Yield (\%)

1

Entry Amide 214

214a

2<smiles>CNC(=O)c1cc2ccccc2n1C</smiles>

214b

3<smiles>CNC(=O)c1cc2ccccc2[nH]1</smiles>

214c

4<smiles>CNC(=O)c1cc2ccccc2o1</smiles>

214d

5



214e
$76 a$<smiles>[CH]NC(=O)c1c(C=CC(=O)OCC)n(C)c2ccccc12</smiles>

215aa<smiles>CCOC(=O)C=Cc1c(C(=O)NC)n(C)c2ccccc12</smiles>

215ba

$76 a$<smiles>CCOC(=O)C=Cc1c(C(=O)NC)[nH]c2ccccc12</smiles>

215ca

$76 a$<smiles>CCOC(=O)C=Cc1c(C(=O)NC)oc2ccccc12</smiles>

$36,64^{b}$

215da

$76 a$

76b

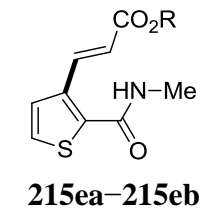

$\mathrm{R}=\mathrm{Et}$ (215ea)

76

$\mathrm{R}=\mathrm{Bu}(\mathbf{2 1 5} \mathbf{e b})$

72
52 $64^{b}$

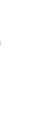

\footnotetext{
${ }^{a}$ Reaction conditions: $214(0.50 \mathrm{mmol}), \mathbf{7 6}(0.75 \mathrm{mmol}),\left[\mathrm{RuCl}_{2}(p \text {-cymene })\right]_{2}(5.0 \mathrm{~mol} \%), \mathrm{KPF}_{6}(20 \mathrm{~mol} \%)$, $\mathrm{Cu}(\mathrm{OAc})_{2} \cdot \mathrm{H}_{2} \mathrm{O}(0.5 \mathrm{mmol}), \mathrm{H}_{2} \mathrm{O}(2.0 \mathrm{~mL}), 120{ }^{\circ} \mathrm{C}, 20 \mathrm{~h}$, under $\mathrm{N}_{2}$; isolated yield. ${ }^{b} t$-AmOH as solvent.
}

Furthermore, the site selectivity within intramolecular competition experiments with heteroaromatic amides was largely governed by electrophilic effects. Hence, substrate $\mathbf{2 1 4 f}$ was 
preferentially functionalized at its C-2 position (Scheme 79).<smiles>C[N+]=O</smiles>

$214 f$

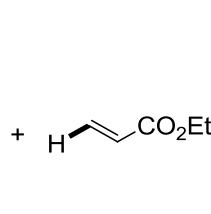

$76 a$

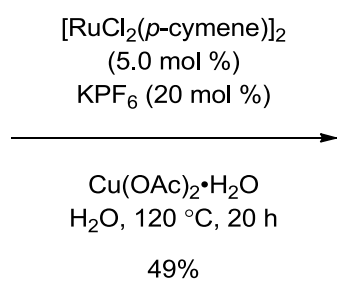

215fa: 215 'fa $=12: 1$

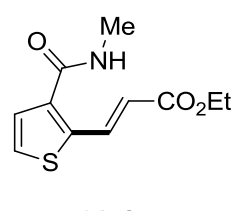

$215 f a$

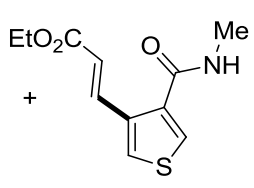

215'fa

Scheme 79 Intramolecular competition experiments with amide $214 \mathrm{f}$ 


\section{$5 \quad$ Ruthenium(II)-Catalyzed $\quad \mathrm{C}\left(\mathrm{sp}^{3}\right)-\mathrm{H} \quad \alpha$-Alkylation of Pyrrolidines with Alkenes}

In spite of the progress on ruthenium-catalyzed $\mathrm{C}\left(\mathrm{sp}^{3}\right)-\mathrm{H}$ alkylations with alkenes in the past years, these protocols were largely restricted to $\mathrm{Ru}_{3}(\mathrm{CO})_{12}$ catalysis under harsh conditions, i.e. relatively high pressure and reaction temperature. ${ }^{95,97,99}$ Taking into consideration our group's recent report on ruthenium-catalyzed hydroarylations with unactivated alkenes through carboxylate-assistance, ${ }^{87}$ we hence set out to develop a novel directed $\mathrm{C}\left(\mathrm{sp}^{3}\right)-\mathrm{H}$ alkylations of alkenes on pyrrolidines by ruthenium(II) catalyst.

\subsection{Optimization Studies}

Based on recently obtained results from our group, ${ }^{132}$ we were interested in exploring representative cocatalytic additives for the envisioned hydroalkylation of unactivated alkenes 111a (Table 15). Not surprisingly, test reactions clearly illustrated the importance of $\left[\mathrm{RuCl}_{2}\left(\mathrm{PPh}_{3}\right)_{3}\right]$ as well as of rac-BINAP. Indeed, simple $\left[\mathrm{RuCl}_{2}\left(\mathrm{PPh}_{3}\right)_{3}\right]$ did not affect the desired $\mathrm{C}-\mathrm{H}$ bond functionalization in the absence of ligands and additives (entry 1). Likewise, in the absence of rac-BINAP satisfactory results were not obtained (entries 2-4). Notably, more promising results were achieved utilizing metal triflate as additives, and AgOTf was identified as being optimal (entries 5-7).

Table 15 Further screenings of the ruthenium(II)-catalyzed C(sp $\left.{ }^{3}\right)-\mathrm{H}$ alkylation of pyrrolidine $\mathbf{2 1 6} \mathbf{a}^{a}$

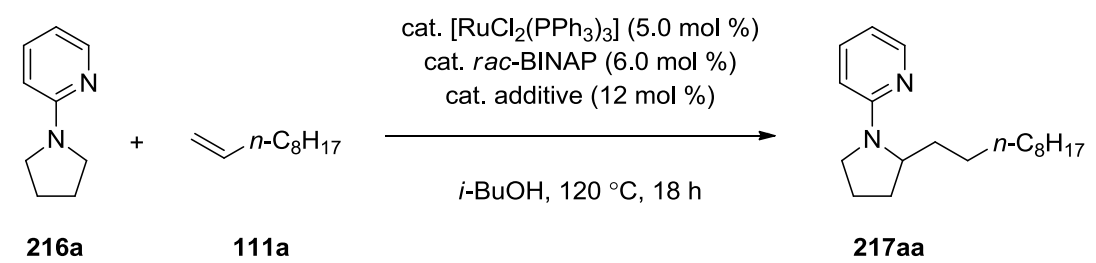

\begin{tabular}{|c|c|c|}
\hline \multicolumn{2}{|c|}{$111 a$} & 217aa \\
\hline Entry & Additive & 217aa $(\%)$ \\
\hline 1 & - & $4^{b}$ \\
\hline 2 & - & 8 \\
\hline 3 & AgOTf & $0^{c}$ \\
\hline 4 & AgOTf & $<1^{b}$ \\
\hline 5 & AgOTf & $73^{d}$ \\
\hline 6 & $\mathrm{AgOAc}$ & 7 \\
\hline 7 & NaOTf & $70^{d}$ \\
\hline \multicolumn{3}{|c|}{$\begin{array}{l}{ }^{a} \text { Reaction conditions: } 216 \mathbf{a}(1.5 \mathrm{mmol}), \mathbf{1 1 1 a}(0.5 \mathrm{mmol}),\left[\mathrm{RuCl}_{2}\left(\mathrm{PPh}_{3}\right)_{3}\right](5.0 \mathrm{~mol} \%), \mathrm{rac} \text {-BINAP }(6.0 \mathrm{~mol} \%) \text {, } \\
\text { additive }(12 \mathrm{~mol} \%), 120{ }^{\circ} \mathrm{C}, 18 \mathrm{~h} \text {; GC analysis with } n \text {-tridecane as an internal standard. }{ }^{b} \text { Without } r a c \text {-BINAP. }{ }^{c} \\
\text { Without }\left[\mathrm{RuCl}_{2}\left(\mathrm{PPh}_{3}\right)_{3}\right]{ }^{d} \text { Isolated yield. }\end{array}$} \\
\hline
\end{tabular}

\subsection{Scope and Limitations}

With a highly selective catalytic system in hand (Table 15, entry 5), we next examined the influence exerted by substituents at the heteroaromatic moiety (Table 16). Thus, the optimized

${ }^{132}$ Ph.D Dissertation, M. Schinkel, University of Göttingen, Göttingen, Germany, 2013. 
ruthenium catalyst proved applicable to high-yielding transformations of pyrrolidines with 3-, 4or 5-substituents on the pyridyl group, thereby selectively delivering the monoalkylated products 217ba-217ea (entries 1-4). Notably, the optimized catalyst system was not restricted to pyridine moieties, but also enabled the $\mathrm{C}-\mathrm{H}$ activation using an isoquinoline (entry 6). Contrarily, methyl groups either on the pyridine (216f) or on the pyrrolidine (216h) had a detrimental effect (entries 5 and 7).

Table 16 Ruthenium(II)-catalyzed C( $\left.\mathrm{sp}^{3}\right)-\mathrm{H}$ alkylation with pyrrolidine $\mathbf{2 1 6}^{a}$
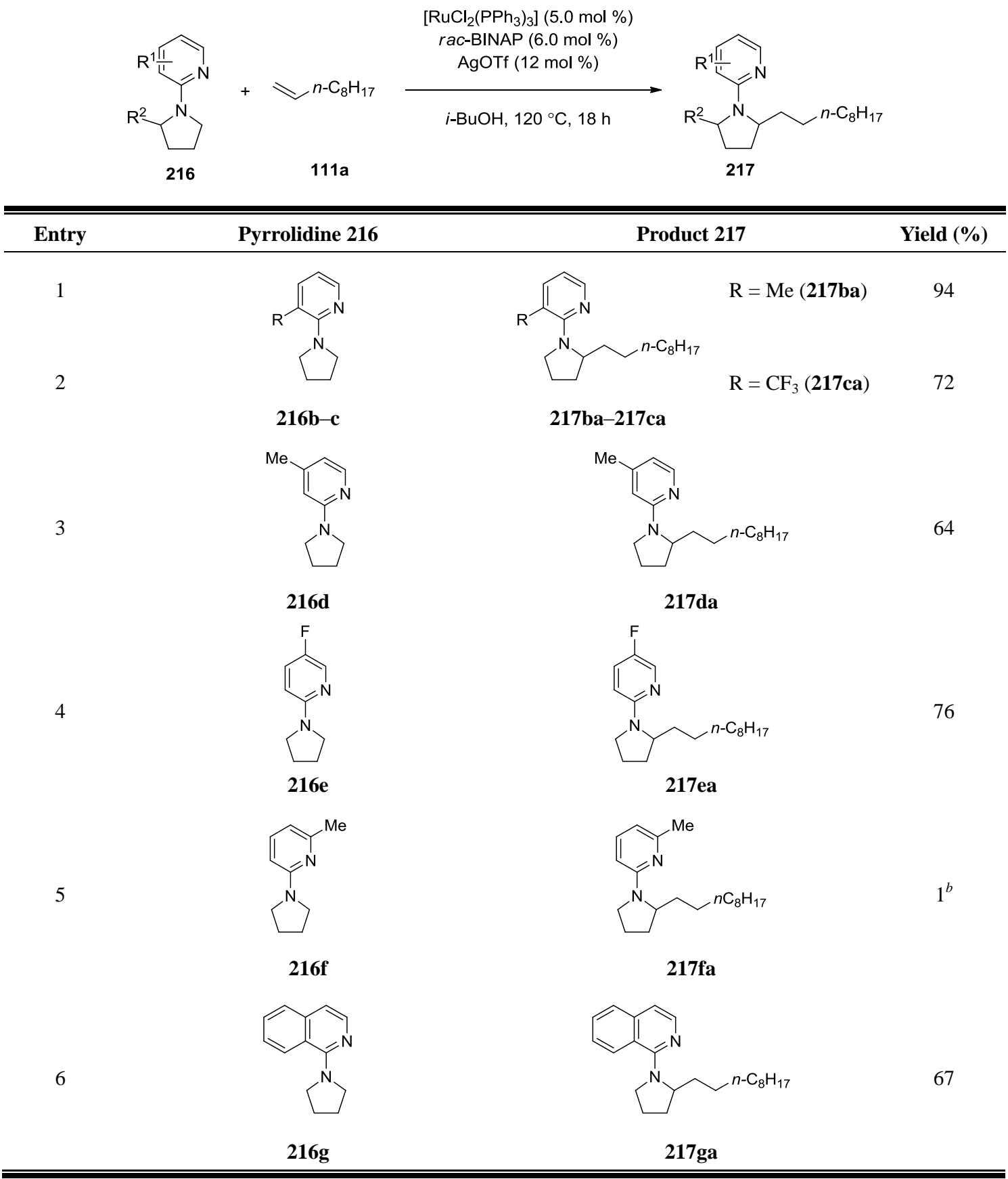

(continued) 
Table 16 (continued)

\begin{tabular}{l}
\hline Entry \\
${ }^{a} \operatorname{Reaction}$ conditions: $\mathbf{2 1 6}(1.5 \mathrm{mmol}), \mathbf{1 1 1 a}(0.5 \mathrm{mmol}),\left[\mathrm{RuCl}_{2}\left(\mathrm{PPh}_{3}\right)_{3}\right](5.0$ mol \%), rac-BINAP $(6.0 \mathrm{~mol} \%)$, \\
$\operatorname{AgOTf}(12 \mathrm{~mol} \%), 120{ }^{\circ} \mathrm{C}, 18 \mathrm{~h}$; isolated yield. ${ }^{b} \mathrm{GC}$ analysis with $n$-tridecane as the internal standard.
\end{tabular}

Thereafter, we explored the versatility of this method by testing a representative set of unactivated alkenes 111 (Table 17). Different alkenes $\mathbf{1 1 1 b}-\mathbf{h}$ furnished the corresponding products $\mathbf{2 1 7} \mathbf{b b}-$ bh in high yields even at a significantly reduced temperature of $80{ }^{\circ} \mathrm{C}$ (entries $\left.1-7\right)$. Notably, the catalytic system tolerated functional groups, such as silanes (111i and 111j) or ethers (111k) (entries 8-10). Intriguingly, competition experiments with haloalkenes $111 \mathrm{l}$ and $\mathbf{1 1 1} \mathrm{m}$ highlighted the excellent chemoselectivity of the $\mathrm{C}\left(\mathrm{sp}^{3}\right)-\mathrm{H}$ alkylations with substrates 1111-n (entries 11-12), in that products stemming from direct $\mathrm{C}-\mathrm{H}$ bond alkylations with the alkyl halide moieties were not observed. ${ }^{26,133}$ Likewise, styrene derivatives 111o-s proved to be suitable substrates, delivering the corresponding alkylated products $\mathbf{2 1 7} \mathbf{b o}-\mathbf{2 1 7 b s}$ in good yields (entries 13-18).

Table 17 Ruthenium(II)-catalyzed C( $\left.\mathrm{sp}^{3}\right)-\mathrm{H}$ alkylation with alkene $\mathbf{1 1 1}^{a}$

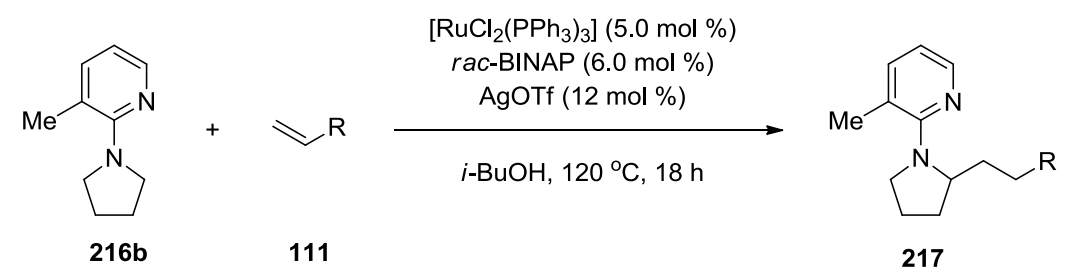

\begin{tabular}{|c|c|c|c|}
\hline Entry & Alkene 111 & Product 217 & Yield $(\%)$ \\
\hline 1 & $\gtrless_{111 b}^{n-C_{4} H_{9}}$ & 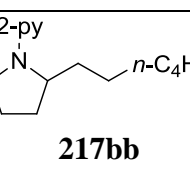 & $73^{b}$ \\
\hline 2 & $\gtrless_{111 \mathrm{c}}^{n-\mathrm{C}_{5} \mathrm{H}_{11}}$ & $\underbrace{n-\mathrm{C}_{5}}_{\mathbf{2 1 7 b c}}$ & $78^{b}$ \\
\hline 3 & $\gtrless_{\text {111d }}^{n-\mathrm{C}_{6} \mathrm{H}_{13}}$ & 217bd & 90 \\
\hline
\end{tabular}

(continued)

133 Selected examples on ruthenium-catalyzed direct alkylations with alkyl halides: ortho-Alkylations: (a) L. Ackermann, P. Novák, R. Vicente, N. Hofmann, Angew. Chem. Int. Ed. 2009, 48, 6045-6048; (b) L. Ackermann, N. Hofmann, R. Vicente, Org. Lett. 2011, 13, 1875-1877; meta-Alkylations: (c) N. Hofmann, L. Ackermann, J. Am. Chem. Soc. 2013, 135, 5877-5884; Highlight article: (d) F. Juliá-Hernández, M. Simonetti, I. Larrosa, Angew. Chem. Int. Ed. 2013, 52, 11458-11460. 
Table 17 (continued)

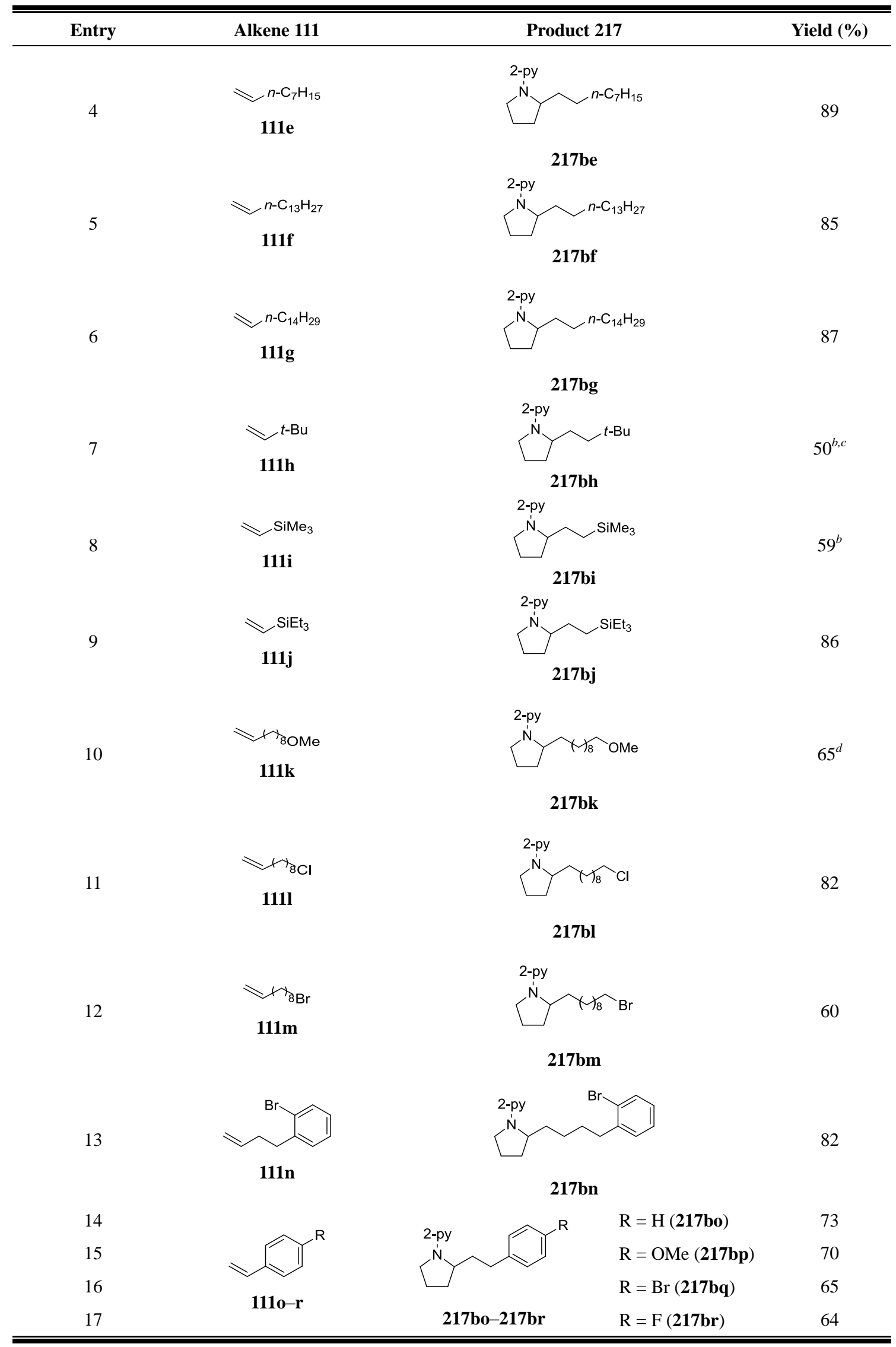


Table 17 (continued)

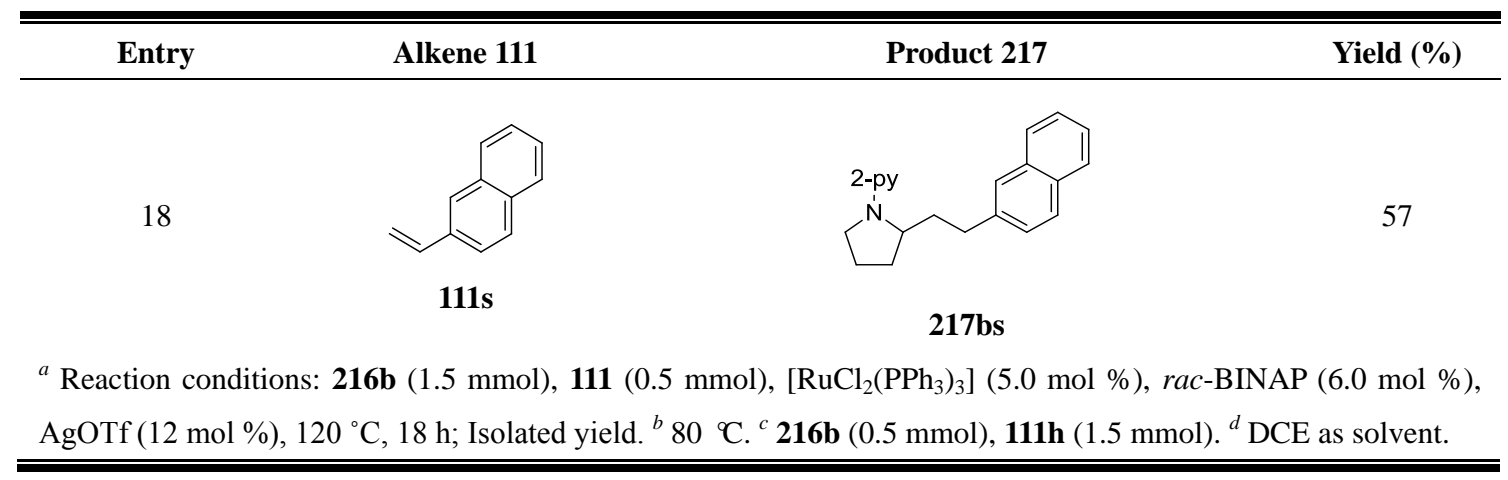

However, nucleophilic substitution occurred upon alkylation of the substrate 111t in the protic solvent $i$-BuOH, affording product 219'bt (Scheme 80a). Fortunately, simply switching the solvent to aprotic DCE delivered the target product 219bt in good yield applying the optimized ruthenium catalyst. Besides, alkene 111u with a ketone moiety was well tolerated, while alkylation along with unexpected hydrogen transfer generated the reduced product $\mathbf{2 1 7 b v}$ in a moderate yield (Scheme 80b).

(a)

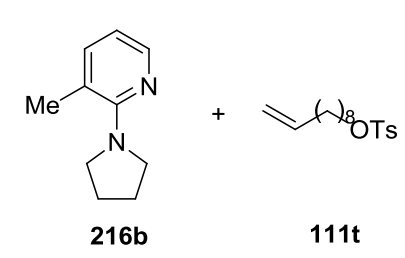

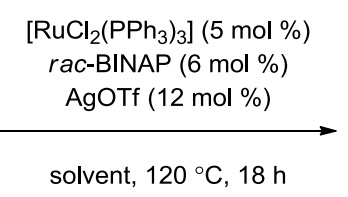

In $i$-BuOH, $\mathrm{R}=\mathrm{OiBu}(\mathbf{2 1 7} \mathbf{b t}): 77 \%$ In DCE, R = OTs $\quad$ (217bt): $63 \%$

(b)

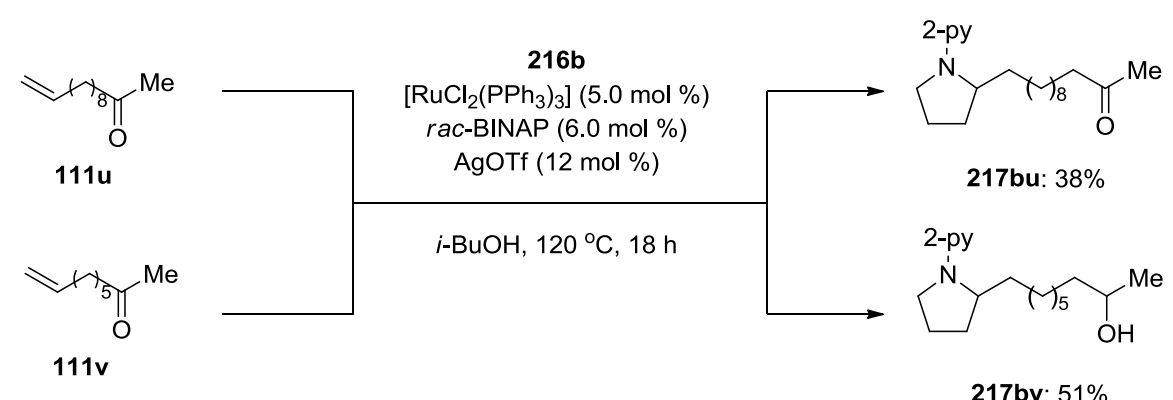

Scheme 80 Ruthenium(II)-catalyzed C( $\left.\mathrm{sp}^{3}\right)-\mathrm{H}$ alkylation with alkenes 111t-v

Unfortunately, substrates with six- or seven-membered rings fused to a pyrrolidine moiety, and among others compounds $\mathbf{2 3 7} \mathbf{a}-\mathbf{b}$ gave unsatisfactory results under the identical conditions (Scheme 81). ${ }^{134}$ Furthermore, substrates $\mathbf{2 3 7} \mathbf{c}-\mathbf{g}$ bearing oxazole, pyrrole, imine, acetyl or cyano directing groups proved inefficient. On the other hand, products of reduction were obtained in low yield from activated alkenes $\mathbf{7 6 a}, \mathbf{7 6 c}$ and $\mathbf{2 3 8 a}-\mathbf{c}$. Terminal, internal and cyclic alkenes $\mathbf{2 3 8 d}-\mathbf{g}$ and diene $\mathbf{2 3 8} \mathbf{h}$ as well as alkynes $\mathbf{2 3 8} \mathbf{i}-\mathbf{j}$ and $\mathbf{3 8 a}$ were inactive under the standard reaction conditions.

${ }^{134}$ For details, see also: B.Sc. Thesis, K. Bielefeld, University of Göttingen, Göttingen, Germany, 2012. 


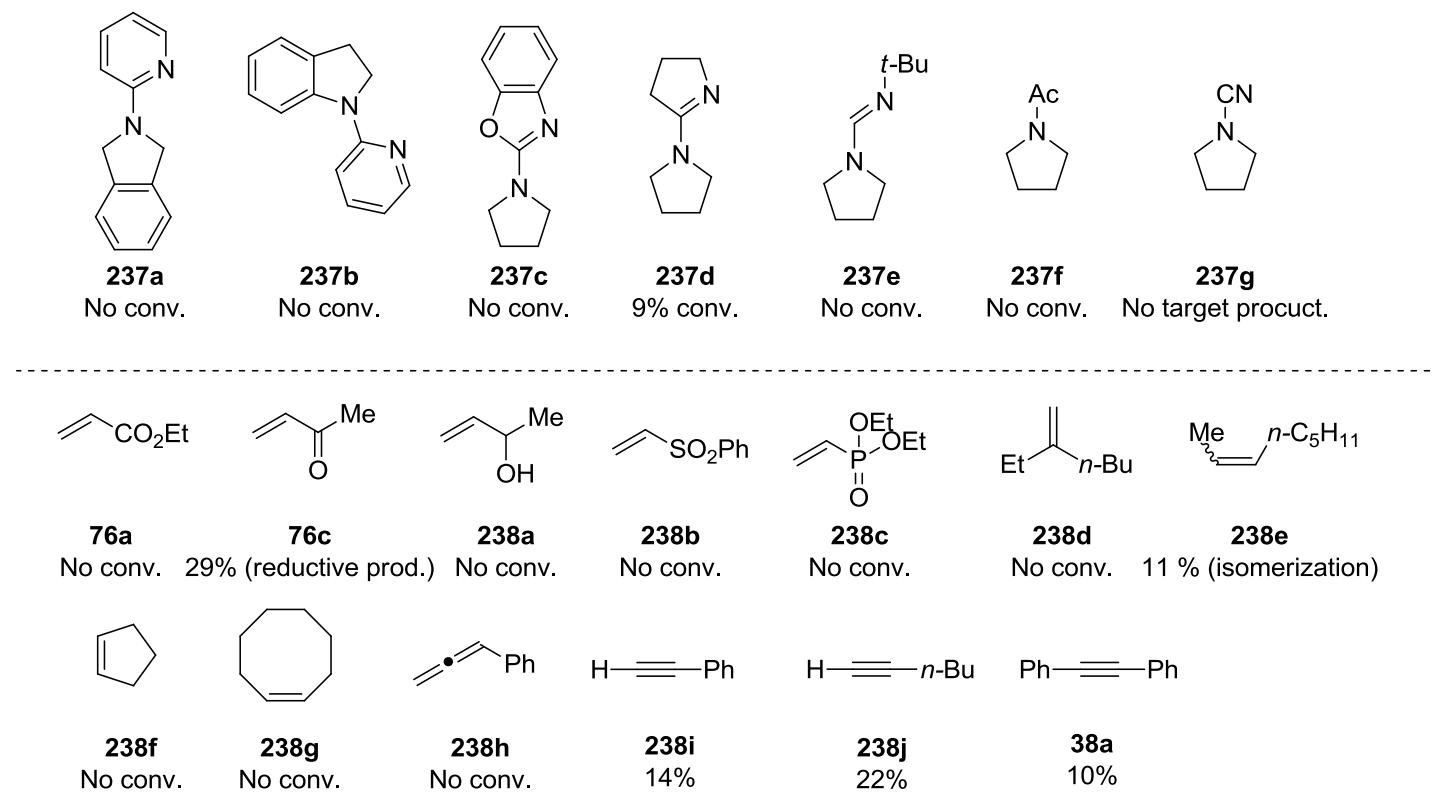

Scheme 81 Limitations of substrate scope under the identical conditions

\subsection{Mechanistic Studies}

\subsubsection{Reactions in the Presence of Radical Scavengers}

Given the unique reactivity profile of the novel ruthenium(II) catalyst, we subsequently performed mechanistic studies to rationalize its mode of action. Thus, SET-type processes could be ruled out by successfully performing the $\mathrm{C}\left(\mathrm{sp}^{3}\right)-\mathrm{H}$ alkylation in the presence of stoichiometric amounts of the radical scavenger TEMPO (Scheme 82).
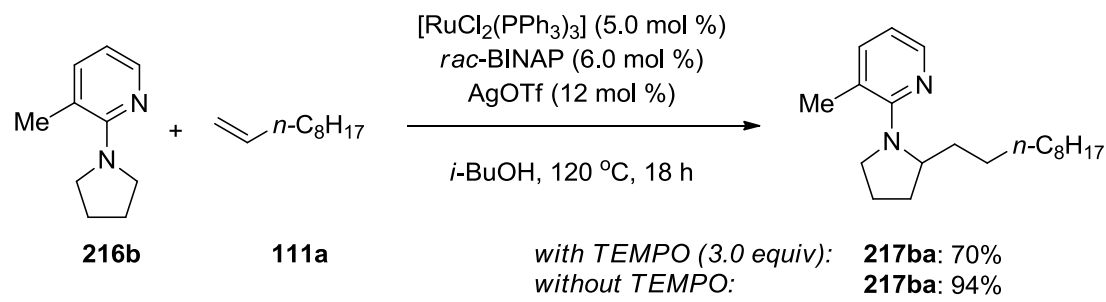

Scheme 82 Mechanistic studies with TEMPO

\subsubsection{Reactions in Isotopically Labelled Reagents}

Next, the H/D exchange reaction was undertaken to obtain information concerning the reaction mechanism. In the present case, ruthenium(II)-catalyzed $\mathrm{C}\left(\mathrm{sp}^{3}\right)-\mathrm{H}$ alkylation in $[\mathrm{D}]_{4}-\mathrm{MeOH}$ (Schemes 83a-b) or with isotopically enriched substrate $[D]_{n}-216 b$ (Scheme 84 ) indicated the C$\mathrm{H}$ bond metalation step to be reversible. Surprisingly, the treatment of 216b under catalytic reaction conditions (either in the absence or presence of 111a) in $[\mathrm{D}]_{4}-\mathrm{MeOH}$ showed significant deuterium incorporation at the $\beta$-positions of the pyrrolidine (Scheme 83a-b). However, this result is in line with the observation reported by Murai and coworkers for ruthenium(0) catalyst (Scheme $83 \mathrm{c}) .^{96}$ 
(a)

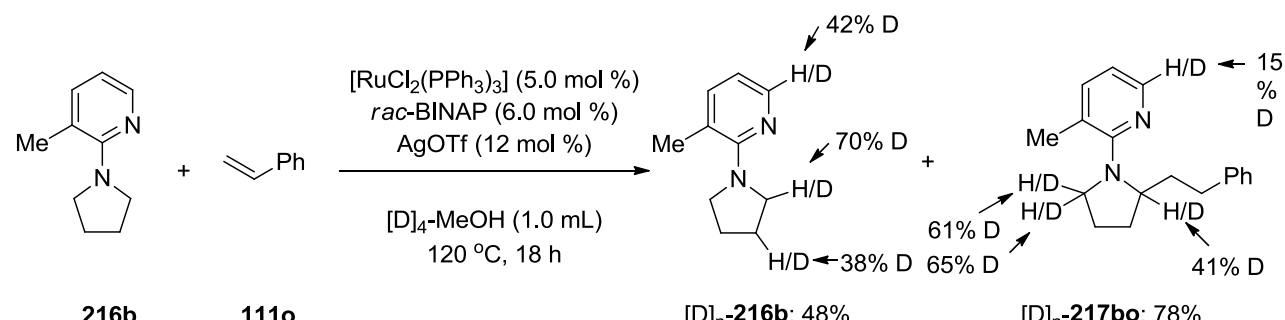

216b

1110

$[D]_{n}-216 b: 48 \%$

$[D]_{n}-217$ bo: $78 \%$

(b)

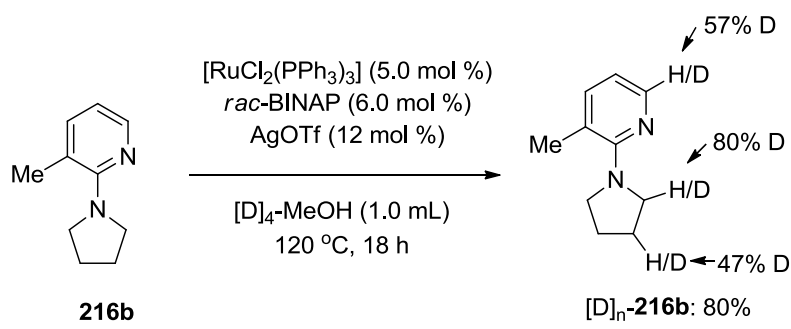

(c) H/D exchange experiment performed by Murai:

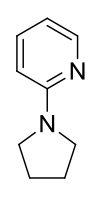

$216 a$

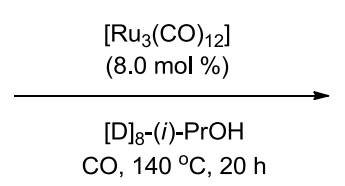

$\mathrm{CO}, 140^{\circ} \mathrm{C}, 20 \mathrm{~h}$

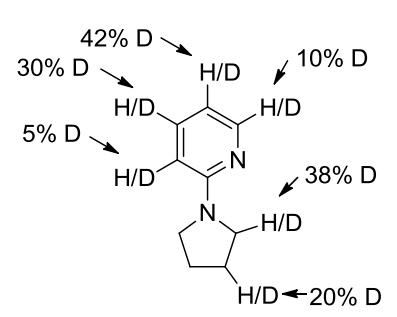

$[D]_{n}-216 a ; 79 \%$

Scheme 83 Studies in isotopically labelled solvents

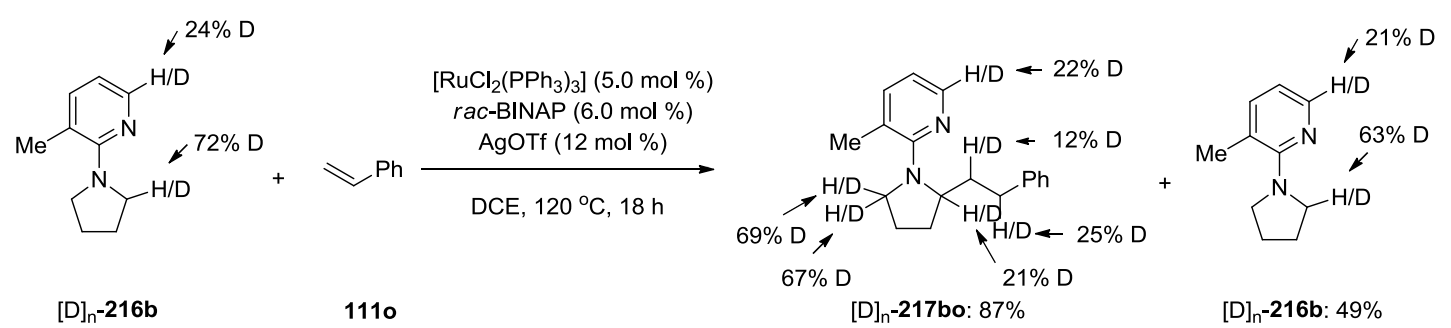

Scheme 84 Studies in isotopically labelled compounds

\subsection{Proposed Catalytic Cycle}

Based on our experimental mechanistic studies, the following catalytic cycle for the ruthenium(II)-catalyzed $\mathrm{C}\left(\mathrm{sp}^{3}\right)-\mathrm{H}$ alkylation of pyrrolidines 216 is postulated (Scheme 85). Initially, the active species $\mathbf{2 3 9}$ is in situ formed from ruthenium precursor. Subsequently, reversible $\mathrm{C}-\mathrm{H}$ bond metalation via transition state $\mathbf{2 4 0}$ forms ruthenacycle $\mathbf{2 4 1}$, which is similar to those observed in the carboxylate-assisted ruthenium-catalyzed oxidative direct $\mathrm{C}-\mathrm{H}$ activations. ${ }^{8}$ Coordination of alkene $\mathbf{1 1 1}$ followed by its regioselective migratory insertion deliver a key intermediate 243. Finally, reductive elimination of $\mathbf{2 4 3}$ affords complex 244, which subsequently releases the desired product $\mathbf{2 1 7}$ and regenerates the active species 239. However, it should be noted that a precise investigation of the exact intermediate structures in terms of the 
ligand sphere is required. Due to the important role of rac-BINAP in the process (Table15, entry 1), it remains questionable as to whether exchange of $r a c$-BINAP with $\mathrm{PPh}_{3}$ as a ligand occurs. ${ }^{84}$

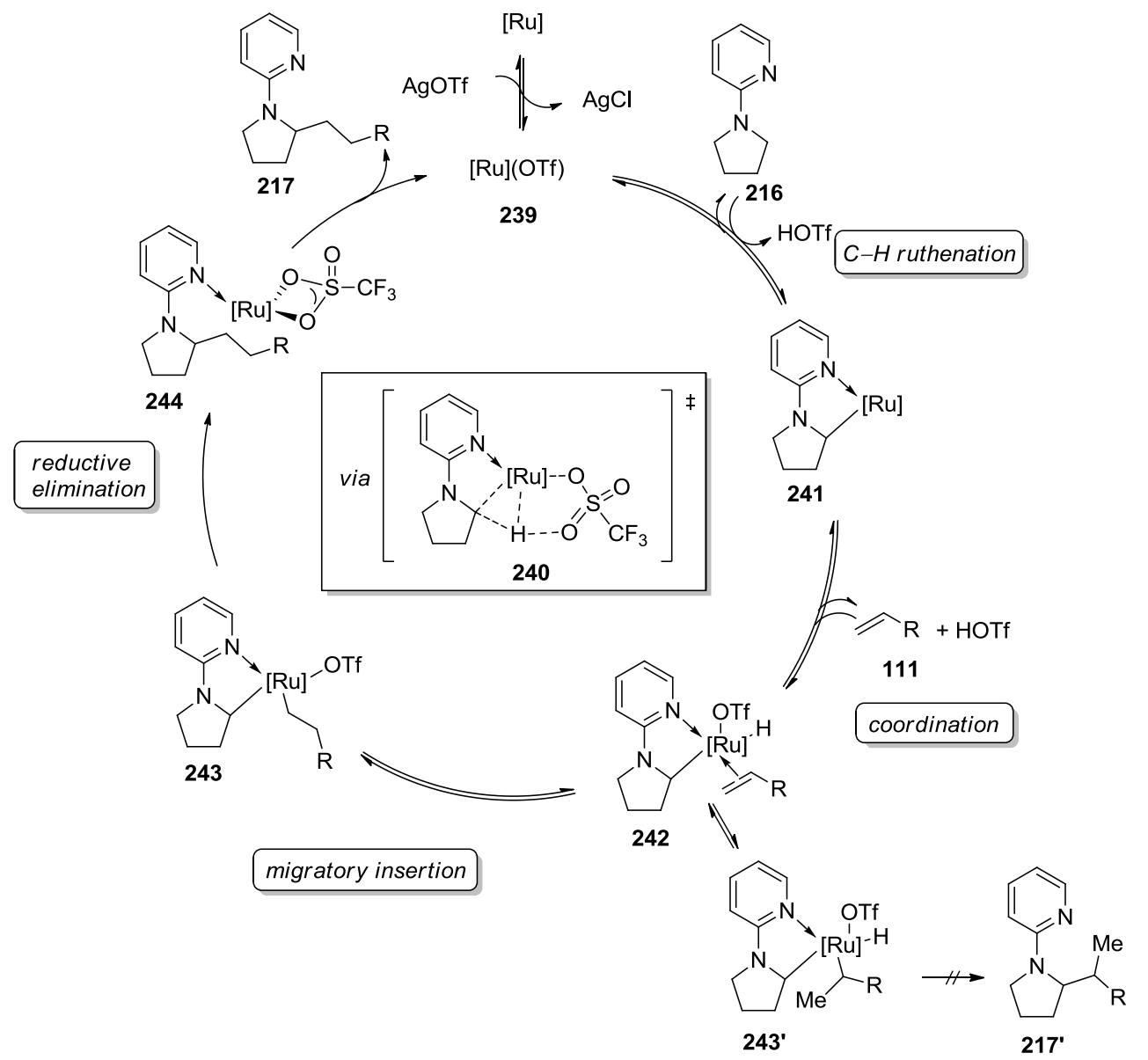

Scheme 85 Proposed reaction mechanism

\subsection{Removal of the Directing Groups}

The pyridyl directing group was efficiently removed according to Maes' recent "one-pot" protocols, namely, hydrogenation/hydride reduction and quaternization/hydride reduction strategies (Scheme 86). ${ }^{135}$ Thus, the hydrogenation/hydride reduction protocol was successfully applied to substrate 217ba and 217bj, delivering the desired $(\mathrm{NH})$-free pyrrolidines under comparably mild conditions (Scheme 86a). Although the pyridine directing group in substrate 217bo was removed under the hydrogenation/hydride reduction strategy as well, the arene ring of the phenethyl moiety was simultaneously reduced. Further switching to the quaternization/hydride reduction strategy led to unsatisfactory result (Scheme 86b).

${ }^{135}$ V. Smout, A. Peschiulli, S. Verbeeck, E. A. Mitchell, W. Herrebout, P. Bultinck, C. M. L. Vande Velde, D. Berthelot, L. Meerpoel, B. U. W. Maes, J. Org. Chem. 2013, 78, 9803-9814. 
(a) "Hydrogenation Hydride Reduction" Strategy<smiles>[R]CCC1CCCN1c1ncccc1C</smiles>

217

1) $\mathrm{Pt} / \mathrm{C}(10 \mathrm{~mol} \%), \mathrm{H}_{2}(1 \mathrm{~atm})$ $\mathrm{HCl}$ (1.2 equiv), $\mathrm{EtOH}$ $23^{\circ} \mathrm{C}, 24 \mathrm{~h}$

2) $\mathrm{NaBH}_{4}$ (4.0 equiv) $\mathrm{MeOH}, 0^{\circ} \mathrm{C}, 15 \mathrm{~min}$

$\mathrm{R}=n-\mathrm{C}_{8} \mathrm{H}_{17}$ (218ba): $70 \%$

$\mathrm{R}=\mathrm{SiEt}_{3} \quad$ (218bj): $61 \%$

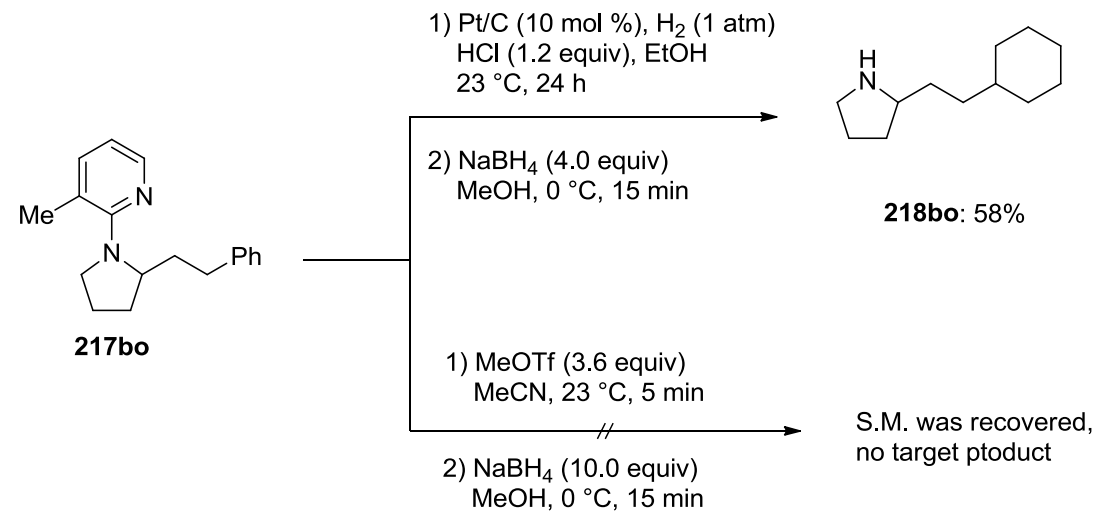

(b) "Quaternization Hydride Reduction" Strategy

Scheme 86 Removal of the directing groups 


\section{Ruthenium-Catalyzed ortho-C-H Halogenations}

In addition to the $\mathrm{C}-\mathrm{C}$ bond formations, ruthenium complexes have been identified as powerful catalysts for the oxidative transformation of otherwise unreactive $\mathrm{C}-\mathrm{H}$ bonds into $\mathrm{C}-\mathrm{O}$ and $\mathrm{C}-\mathrm{N}$ bonds. ${ }^{30}$ In strict contrast, ruthenium-catalyzed intermolecular ${ }^{114} \mathrm{C}-\mathrm{Hal}$ bond forming processes are unfortunately not available. Herein, we established a ruthenium catalytic system which enabled the first ruthenium-catalyzed intermolecular brominations and iodinations of benzamides using $N$-halosuccinimides as halogen sources. ${ }^{136}$

\subsection{Preliminary Studies with Ruthenium(II)-Catalysis}

\subsection{1 ortho-Halogenations of Electron-Rich Arenes}

At the outset of our studies, we explored the widely used $\left[\mathrm{RuCl}_{2}(p \text {-cymene })\right]_{2}$ complex for the halogenation of electron-rich anilide 184a with $\mathrm{CuBr}_{2}$ or NBS as a halogen source (Table 18). To our disappointment, only classical electrophilic aromatic substitution $\left(\mathrm{S}_{\mathrm{E}}{ }^{\mathrm{Ar}}\right)$ occurred delivering the corresponding para-brominated product 245a both in the absence and presence of the catalyst. Further efforts to probe parameters, including oxidant, additive and solvent, unfortunately did not offer the target ortho-brominated product even at the lower reaction temperature (entries 2, 10 and 11). In addition, no conversion was observed with $\mathrm{CuCl}_{2}$ as a halogenating reagent (entries 7 and $8)$.

Table 18 Screenings of the ruthenium(II)-catalyzed C-H halogenations of acetanilide $184 a^{a}$
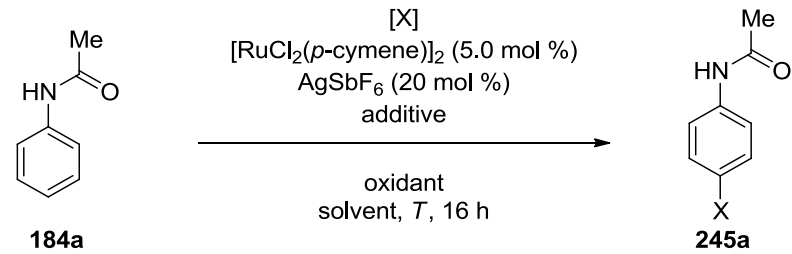

\begin{tabular}{|c|c|c|c|c|c|c|}
\hline Entry & [X] (equiv) & Oxidant (equiv) & Additive (equiv) & Solvent & $\boldsymbol{T}\left({ }^{\circ} \mathbf{C}\right)$ & 245a (\%) \\
\hline 1 & $\mathrm{CuBr}_{2}(2.0)$ & - & PivOH (1.1) & $\mathrm{MeCN}$ & 100 & $76^{b}$ \\
\hline 2 & $\mathrm{CuBr}_{2}(2.0)$ & - & - & DCE & 60 & 10 \\
\hline 3 & $\mathrm{CuBr}_{2}(2.0)$ & $\mathrm{Cu}(\mathrm{OAc})_{2}(2.0)$ & - & DCE & 100 & 49 \\
\hline 4 & $\mathrm{CuBr}_{2}(2.0)$ & - & $\mathrm{PTSA} \cdot \mathrm{H}_{2} \mathrm{O}(1.1)$ & DCE & 100 & 7 \\
\hline 5 & $\mathrm{CuBr}_{2}(2.0)$ & $\mathrm{Cu}(\mathrm{OAc})_{2}(2.0)$ & PivOH (1.1) & $\mathrm{AcOH}$ & 100 & 11 \\
\hline 6 & $\mathrm{CuBr}_{2}(2.0)$ & $\mathrm{Cu}(\mathrm{OAc})_{2}(2.0)$ & PivOH (1.1) & $\mathrm{MeCN}$ & 100 & 63 \\
\hline 7 & $\mathrm{CuCl}_{2}(2.0)$ & - & - & DCE & 60 & 0 \\
\hline 8 & $\mathrm{CuCl}_{2}(2.0)$ & $\mathrm{Cu}(\mathrm{OAc})_{2}(2.0)$ & - & DCE & 90 & 0 \\
\hline 9 & NBS (1.1) & $\mathrm{Cu}(\mathrm{OAc})_{2}(2.0)$ & - & DCE & 120 & $100^{b}$ \\
\hline 10 & NBS (1.1) & - & - & DCE & 60 & 71 \\
\hline 11 & NBS (1.1) & - & $\mathrm{PTSA} \cdot \mathrm{H}_{2} \mathrm{O}(0.5)$ & DCE & 60 & 100 \\
\hline
\end{tabular}

${ }^{136}$ L. Wang, L. Ackermann, Chem. Commun. 2014, 50, 1083-1085. 
Further screenings of directing groups (DG) with $\left[\mathrm{RuCl}_{2}(p \text {-cymene) }]_{2}\right.$ as the catalyst gave unsatisfactory results as well (Scheme 87). For instance, the use of 184b and $\mathbf{1 8 4 c}$ delivered para-brominated products in low yields, whereas no conversion was observed for electron-rich substrates $184 \mathbf{d}-\mathbf{g}$.

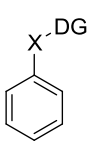

184

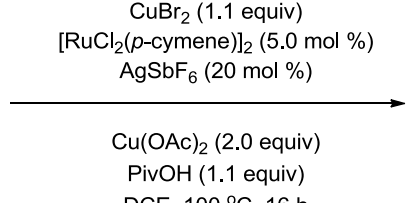

DCE, $100^{\circ} \mathrm{C}, 16 \mathrm{~h}$

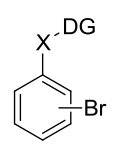

245

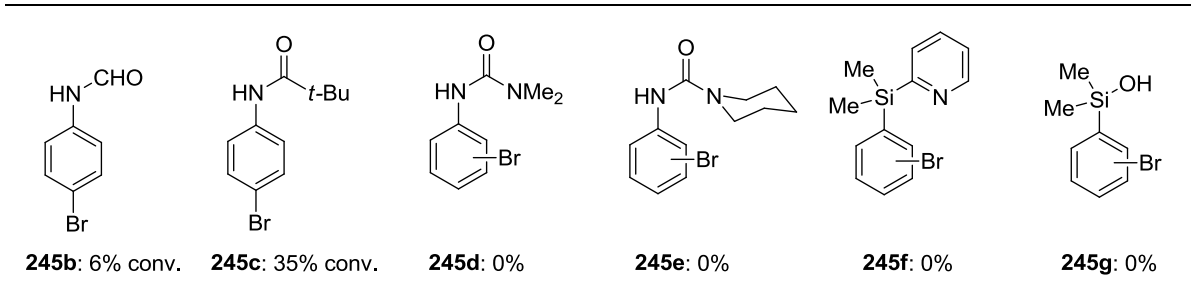

Scheme 87 Ruthenium(II)-catalyzed C-H halogenations of electron-rich arenes $\mathbf{1 8 4}$

\subsection{2 ortho-Halogenations of Electron-Deficient Arenes}

As the bromination of electron-rich substrates always led to significant formation of para electrophilic substitution products, we subsequently turned to more challenging electron-deficient arenes (Table 19). Herein, ortho-bromination on benzamide 219a was observed employing $\mathrm{CuBr}_{2}$ as the halogen source, yet with low conversion (6\%). However, further screenings proved $\mathrm{N}$-bromosuccinimide (NBS) to be more efficient for ruthenium(II)-catalyzed ortho-C-H halogenations under otherwise identical reaction conditions (entry 2). In spite of acids are known to serve as critical additives in the palladium- ${ }^{107,108}$ and rhodium-catalyzed ${ }^{113}$ ortho-C-H halogenations, to our disappointment, no better results were obtained with acidic additives in our ruthenium(II) system. The reason for this is obviously a competitive ortho-C-O bond formation (246a) (entries 3-14), and addition of an external oxidant did not improve the situation (entries 8 and 12). However, we were pleased to observe that switching to a catalytic amount of the corresponding silver(I) carboxylate salt significantly improved the efficacy (entries 15-20), and the target product $220 \mathrm{a}$ was obtained in $43 \%$ isolated yield with $\mathrm{AgO}_{2} \mathrm{CCF}_{3}$ (entry 16). In addition, base additives did shut down the reaction almost completely (entries 21-22).

Table 19 Screenings of the ruthenium(II)-catalyzed C-H brominations of benzamide $219 \mathbf{a}^{a}$

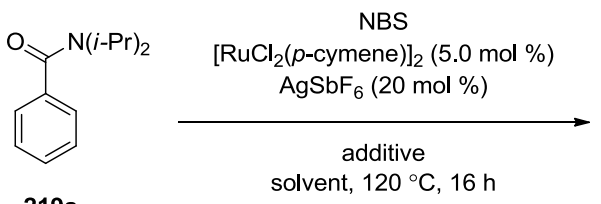

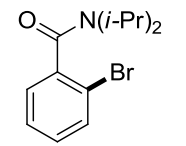

220a

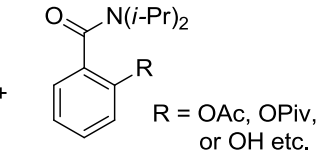

246a

\begin{tabular}{lllll}
\hline \hline Entry & Additive (equiv) & Solvent & Yield of 220a (\%) & 246a (\%) \\
\hline $1^{b}$ & - & DCE & 0 & 0 \\
2 & - & DCE & 27 & 0 \\
3 & PTSA $\cdot \mathrm{H}_{2} \mathrm{O}(1.1)$ & DCE & 0 & 0 \\
4 & TfOH $(1.1)$ & DCE & 11 & 0 \\
\hline \hline
\end{tabular}


Table 19 (continued)

\begin{tabular}{|c|c|c|c|c|}
\hline Entry & Additive (equiv) & Solvent & Yield of $220 \mathrm{a}(\%)$ & $246 a(\%)$ \\
\hline 5 & $\mathrm{MesCO}_{2} \mathrm{H}(1.1)$ & DCE & 9 & 9 \\
\hline 6 & $(1-\mathrm{Ad}) \mathrm{CO}_{2} \mathrm{H}(1.1)$ & DCE & 0 & 0 \\
\hline 7 & PivOH (1.1) & DCE & 20 & 39 \\
\hline $8^{c}$ & PivOH (1.1) & DCE & 12 & 33 \\
\hline 9 & TFA (1.1) & DCE & 21 & 32 \\
\hline 10 & TFA (1.1) & $\mathrm{MeCN}$ & 1 & 4 \\
\hline 11 & TFA (1.1) & $\mathrm{AcOH}$ & 7 & 3 \\
\hline $12^{d}$ & TFA (1.1) & DCE & 2 & 0 \\
\hline 13 & TFAA (1.1) & DCE & 31 & 22 \\
\hline $14^{e}$ & TFA (1.1) & DCE & 0 & 0 \\
\hline $15^{b}$ & $\mathrm{AgO}_{2} \mathrm{CCF}_{3}(0.2)$ & DCE & 0 & 0 \\
\hline 16 & $\mathrm{AgO}_{2} \mathrm{CCF}_{3}(0.2)$ & DCE & $51\left(43^{f}\right)$ & 18 \\
\hline 17 & $\mathrm{AgO}_{2} \mathrm{CCF}_{3}(0.5)$ & DCE & 13 & 32 \\
\hline $18^{g}$ & $\mathrm{AgO}_{2} \mathrm{CCF}_{3}(0.2)$ & DCE & 32 & 16 \\
\hline 19 & $\mathrm{Ag}_{2} \mathrm{O}(0.2)$ & DCE & 5 & 0 \\
\hline 20 & $\operatorname{AgOTf}(0.2)$ & DCE & 11 & 2 \\
\hline 21 & $\mathrm{KO}_{2} \mathrm{CCF}_{3}(0.2)$ & DCE & 5 & 2 \\
\hline 22 & CsOPiv (1.1) & DCE & 0 & 7 \\
\hline
\end{tabular}

Functional directing groups, such as amide, ester, ketone and pyridine (Scheme 88), were also examined under the optimal reaction conditions (Table 19, entry 16). Unfortunately, only low conversions to the ortho-brominated products were observed. Moreover, significant side reactions such as bromination of the methyl group and ortho-oxygenation occurred in acetophenone (247e) and 2-phenylpyridine (247f), respectively.

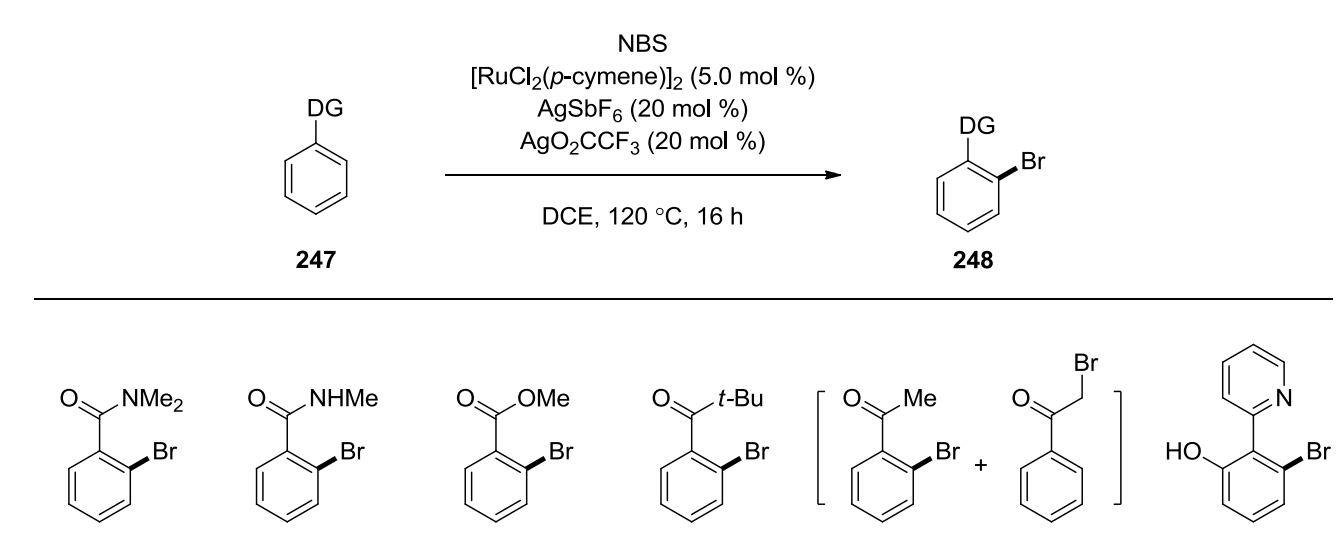

Scheme 88 Ruthenium(II)-catalyzed ortho-C-H halogenations of electron-deficient arenes $\mathbf{2 4 7}$

\subsection{Ruthenium(0)-Catalyzed ortho-C-H Halogenations of Benzamides}




\subsubsection{Optimization Studies}

To our delight, simply switching the catalyst to $\mathrm{Ru}_{3}(\mathrm{CO})_{12}$ for the ortho- $\mathrm{C}-\mathrm{H}$ halogenations of benzamide 219a successfully delivered the desired product 220a in 27\% yield (Table 20, entry 1). Notably, control experiment showed that no conversion of the starting material 219a was detected in the absence of $\mathrm{Ru}_{3}(\mathrm{CO})_{12}$, highlighting the efficiency of the ruthenium(0)-catalyzed pathway (entries 2 and 14). Further investigations indicated that stoichiometric quantities of carboxylate acid not only promoted the ortho-halogenation, but also provoked ortho-oxygenation affording small amounts of the by-product 246a (entries 3-13). Maes has recently reported that alcohol additives were efficient in ruthenium( $(0)$-catalyzed $\mathrm{C}\left(\mathrm{sp}^{3}\right)-\mathrm{H} \alpha$-alkylation reactions. ${ }^{99}$ However, alcohol additives herein completely inhibited the halogenation process (entry 16). It is noteworthy that the use of additional oxidants, such as copper(II) salts, did not improve the yield (entries 5 and 15). Furthermore, switching the solvent to $\mathrm{AcOH}, \mathrm{MeCN}$, or even neat reaction did not improve the reaction efficacy (entries 17-19).

Table 20 Screenings of the ruthenium(0)-catalyzed ortho-C-H halogenations with acids as additives ${ }^{a}$

\begin{tabular}{|c|c|c|c|c|c|}
\hline & $Y^{\mathrm{N}(i-\mathrm{Pr})_{2}}$ & $\begin{array}{c}\text { NBS } \\
{\left[\mathrm{Ru}_{3}(\mathrm{CO})_{12}\right]} \\
(3.3 \mathrm{~mol} \%) \\
\\
\text { additives } \\
\mathrm{DCE}, 120^{\circ} \mathrm{C}, 16 \mathrm{~h}\end{array}$ & $\underbrace{N(i-P r)_{2}}_{B r}$ & 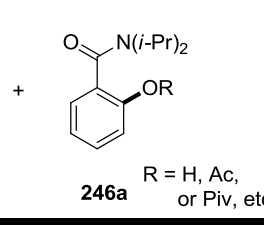 & \\
\hline Entry & Additive A (equiv) & Additive B (equiv) & Solvent & Yield of 220a (\%) & $246 a(\%)$ \\
\hline 1 & - & - & DCE & 27 & 0 \\
\hline $2^{b}$ & - & - & DCE & $<2$ & 0 \\
\hline 3 & $\mathrm{PTSA} \cdot \mathrm{H}_{2} \mathrm{O}(2.0)$ & - & DCE & 5 & 0 \\
\hline 4 & TFA (2.0) & - & DCE & 39 & 0 \\
\hline 5 & TFA (2.0) & $\mathrm{Cu}(\mathrm{OAc})_{2}(2.0)$ & DCE & 43 & 7 \\
\hline 6 & $\mathrm{AcOH}(1.0)$ & - & DCE & 56 & 7 \\
\hline 7 & $\mathrm{Ac}_{2} \mathrm{O}(1.0)$ & - & DCE & 55 & 5 \\
\hline 8 & $\mathrm{AcOH}(1.0)+\mathrm{Ac}_{2} \mathrm{O}(1.0)$ & - & DCE & 54 & 5 \\
\hline 9 & $\mathrm{MesCO}_{2} \mathrm{H}(2.0)$ & - & DCE & 9 & 0 \\
\hline 10 & $\mathrm{PhCO}_{2} \mathrm{H}(2.0)$ & - & DCE & 24 & 0 \\
\hline 11 & $(1-\mathrm{Ad}) \mathrm{CO}_{2} \mathrm{H}(2.0)$ & - & DCE & 57 & $<3$ \\
\hline 12 & PivOH (2.0) & - & DCE & 57 & 11 \\
\hline 13 & $\mathrm{PivOH}(0.2)$ & - & DCE & 19 & 0 \\
\hline $14^{b}$ & $\mathrm{PivOH}(0.2)$ & - & DCE & $<2$ & 0 \\
\hline 15 & $\mathrm{PivOH}(2.0)$ & $\mathrm{CuBr}_{2}(2.0)$ & DCE & 16 & 0 \\
\hline 16 & $\mathrm{PivOH}(2.0)$ & $i$-PrCHOH (5.0) & DCE & 0 & 0 \\
\hline 17 & $\mathrm{PivOH}(0.2)$ & - & $\mathrm{AcOH}$ & 41 & 4 \\
\hline 18 & $\mathrm{PivOH}(0.2)$ & - & $\mathrm{MeCN}$ & 14 & 0 \\
\hline 19 & $\mathrm{PivOH}(0.2)$ & - & neat & 43 & 10 \\
\hline $20^{c}$ & - & - & DCE & 0 & 0 \\
\hline
\end{tabular}

${ }^{a}$ Reaction conditions: 219a $(0.5 \mathrm{mmol})$, NBS $(1.0 \mathrm{mmol}),\left[\mathrm{Ru}_{3}(\mathrm{CO})_{12}\right](3.3 \mathrm{~mol} \%)$, additives, solvent $(2.0 \mathrm{~mL})$, $120{ }^{\circ} \mathrm{C}, 16 \mathrm{~h} ;{ }^{1} \mathrm{H}-\mathrm{NMR}$ yield with 1,3,5-trimethoxybenzene $(0.1 \mathrm{mmol})$ as an internal standard. ${ }^{b}$ without $\left[\mathrm{Ru}_{3}(\mathrm{CO})_{12}\right] .{ }^{c} \mathrm{RuCl}_{3}(10 \mathrm{~mol} \%)$ was used instead of $\left[\mathrm{Ru}_{3}(\mathrm{CO})_{12}\right]$. 
Further investigations revealed that, as in the case of the above-discussed catalytic system from $\left[\mathrm{RuCl}_{2} \text { (p-cymene) }\right]_{2}$ (Table 19 ), base additives did not accelerate the halogenation process catalyzed with $\mathrm{Ru}_{3}(\mathrm{CO})_{12}$ (Table 21, entry 1 ). On the other hand, replacing carboxylic acid with a catalytic amount of silver(I) carboxylate salt significantly improved the desired formation of target product 220a (entries 3-20). To our delight, $\mathrm{AgO}_{2} \mathrm{C}(1-\mathrm{Ad})$ delivered the best isolated yield, and meanwhile no $\mathrm{C}-\mathrm{O}$ bond formation was detected due to the steric effect of the adamantyl moiety (entry 19). It is noteworthy to mention that 0.05 equivalent amount of phosphine ligand slightly accelerated the transformation, while increasing the loadings to 0.2 equivalent completely inhibited the process (entry $11 v s$ entry 12). Further screenings proved 1,2-dichloroethane (DCE) to be superior to other solvents with this ruthenium(0) catalyst (entries 14-17).

Table 21 Screenings of the ruthenium(0)-catalyzed ortho-C-H halogenations with metal salts as additives ${ }^{a}$

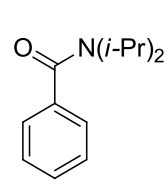

$219 a$

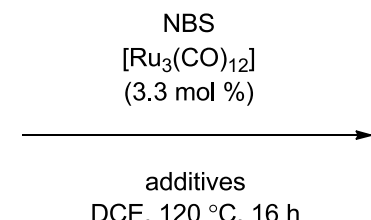

DCE, $120^{\circ} \mathrm{C}, 16 \mathrm{~h}$

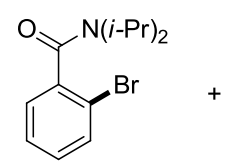

$220 a$

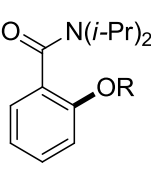

$\mathrm{R}=\mathrm{H}, \mathrm{Ac}$

\begin{tabular}{|c|c|c|c|c|c|}
\hline Entry & Additive A (equiv) & Additive B (equiv) & Solvent & Yield of $220 \mathrm{a}(\%)$ & $246 a(\%)$ \\
\hline 1 & $\mathrm{CsOAc}(0.2)$ & - & DCE & 24 & 0 \\
\hline 2 & $\mathrm{KPF}_{6}(0.2)$ & - & DCE & 0 & 0 \\
\hline 3 & $\operatorname{AgSbF}_{6}(0.2)$ & - & DCE & 18 & 0 \\
\hline 4 & $\mathrm{AgCl}(0.2)$ & - & DCE & 20 & 0 \\
\hline 5 & $\mathrm{Ag}_{2} \mathrm{CO}_{3}(0.2)$ & - & DCE & 34 & 0 \\
\hline 6 & $\mathrm{AgO}_{2} \mathrm{CCF}_{3}(0.2)$ & - & DCE & 41 & 4 \\
\hline 7 & $\mathrm{AgOAc}(0.2)$ & - & DCE & 58 & 7 \\
\hline 8 & $\mathrm{AgOAc}(0.05)$ & - & DCE & 21 & 0 \\
\hline 9 & $\mathrm{AgOAc}(0.5)$ & - & DCE & 48 & 5 \\
\hline 10 & - & $\mathrm{PPh}_{3}(0.05)$ & DCE & 9 & 0 \\
\hline 11 & $\mathrm{AgOAc}(0.2)$ & $\mathrm{PPh}_{3}(0.05)$ & DCE & 53 & 0 \\
\hline 12 & $\mathrm{AgOAc}(0.2)$ & $\mathrm{PPh}_{3}(0.2)$ & DCE & 2 & 0 \\
\hline 13 & $\operatorname{AgOAc}(0.2)$ & $\mathrm{PivOH}(1.1)$ & DCE & 51 & 10 \\
\hline 14 & $\mathrm{AgOAc}(0.2)$ & - & $t-\mathrm{BuOH}$ & 10 & 0 \\
\hline 15 & $\operatorname{AgOAc}(0.2)$ & - & $\mathrm{PhMe}$ & 2 & 0 \\
\hline 16 & $\operatorname{AgOAc}(0.2)$ & - & Pinacolone & 35 & 0 \\
\hline 17 & $\operatorname{AgOAc}(0.2)$ & - & NMP & $<1$ & 0 \\
\hline 18 & $\mathrm{AgOPiv}(0.2)$ & - & DCE & 60 & 6 \\
\hline 19 & $\mathrm{AgO}_{2} \mathrm{C}(1-\mathrm{Ad})(0.2)$ & - & DCE & $64\left(60^{b}\right)$ & 0 \\
\hline $20^{c}$ & $\mathrm{AgO}_{2} \mathrm{C}(1-\mathrm{Ad})(0.2)$ & - & DCE & $<2$ & 0 \\
\hline \multicolumn{6}{|c|}{$\begin{array}{l}{ }^{a} \text { Reaction conditions: } \mathbf{2 1 9 a}(0.5 \mathrm{mmol}) \text {, NBS }(1.0 \mathrm{mmol}),\left[\mathrm{Ru}_{3}(\mathrm{CO})_{12}\right](3.3 \mathrm{~mol} \%) \text {, additives, solvent }(2.0 \mathrm{~mL}) \text {, } \\
120{ }^{\circ} \mathrm{C}, 16 \mathrm{~h} ;{ }^{1} \mathrm{H}-\mathrm{NMR} \text { yield with } 1,3,5 \text {-trimethoxybenzene }(0.1 \mathrm{mmol}) \text { as an internal standard. }{ }^{b} \text { Isolated yield. }{ }^{c} \\
\text { without }\left[\mathrm{Ru}_{3}(\mathrm{CO})_{12}\right] .\end{array}$} \\
\hline
\end{tabular}




\subsubsection{Scope of the Ruthenium(0)-Catalyzed ortho-C-H halogenations}

With the optimized conditions in hand (Table 21, entry 19), we initially examined the influence of different amide $N$-substituents on the efficacy of the corresponding brominations as well as iodinations (Table 22). ${ }^{137}$ Thus, a variety of benzamides 219 provided the desired halogenated products $\mathbf{2 2 0}$ and $\mathbf{2 2 1}$ in good yields. Herein, electron-donating amide group gave a slightly better performance and bulky substituent such as $N, N$-diisopropylamide efficiently directed the bromination as well. In contrast to brominations, successive addition of $\mathrm{N}$-iodosuccinimide (NIS) in two equal portions was required to deliver the iodinated products 221 in best yield. Besides, control experiments demonstrated that omission of the ruthenium(0) catalyst proved to be detrimental.

Table 22 Effect of $N$-substituents on $\mathrm{C}-\mathrm{H}$ halogenations ${ }^{a}$

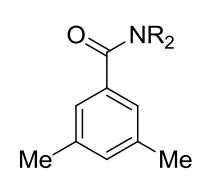

219

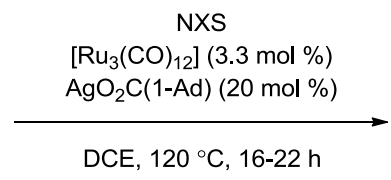

DCE, $120^{\circ} \mathrm{C}, 16-22 \mathrm{~h}$

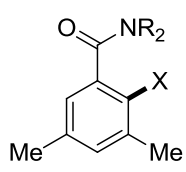

220 / 221

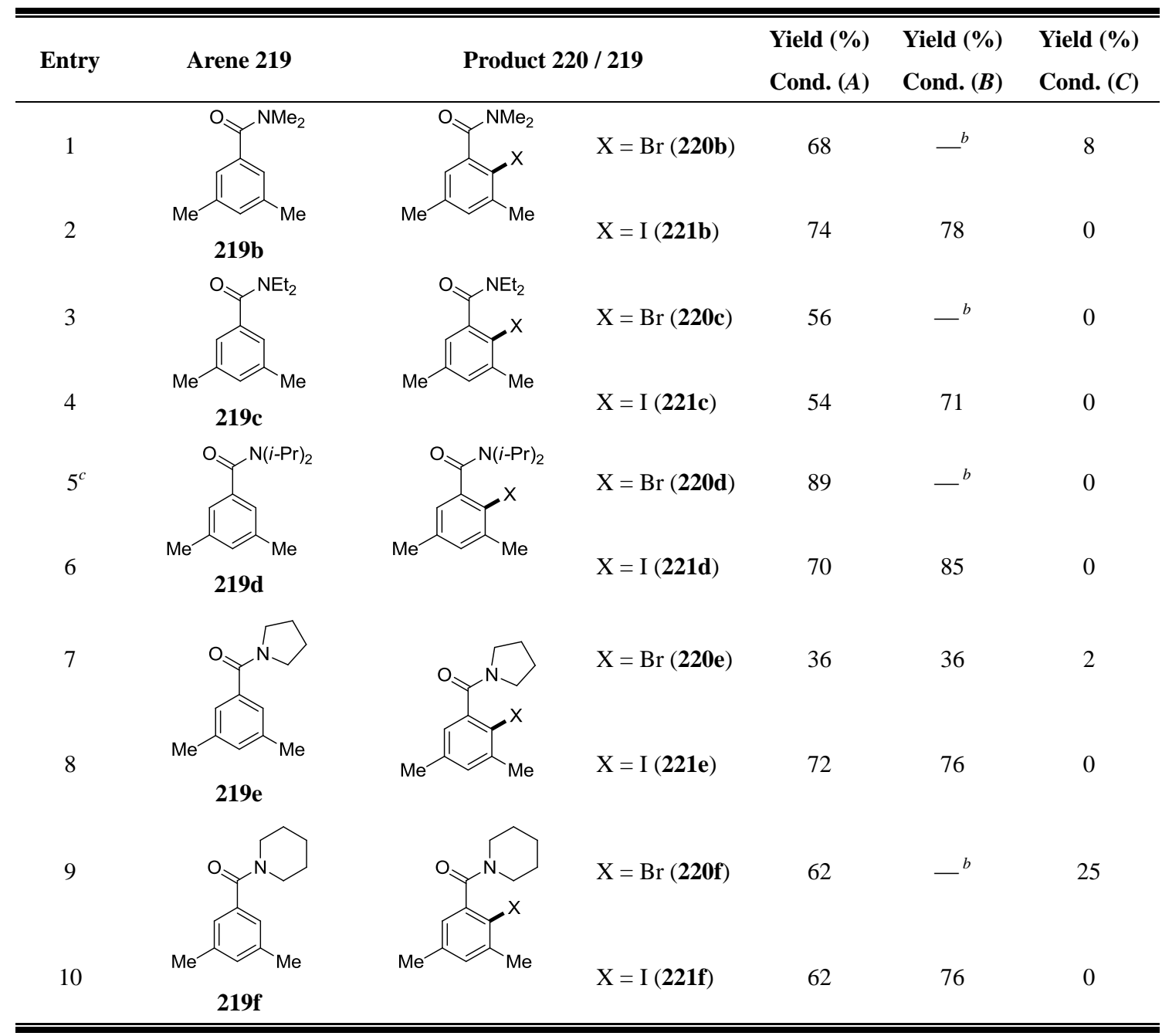

${ }^{137}$ Primary and secondary benzamides provided thus far only unsatisfactory results ( $<15 \%$ conversion). 
Table 22 (continued)

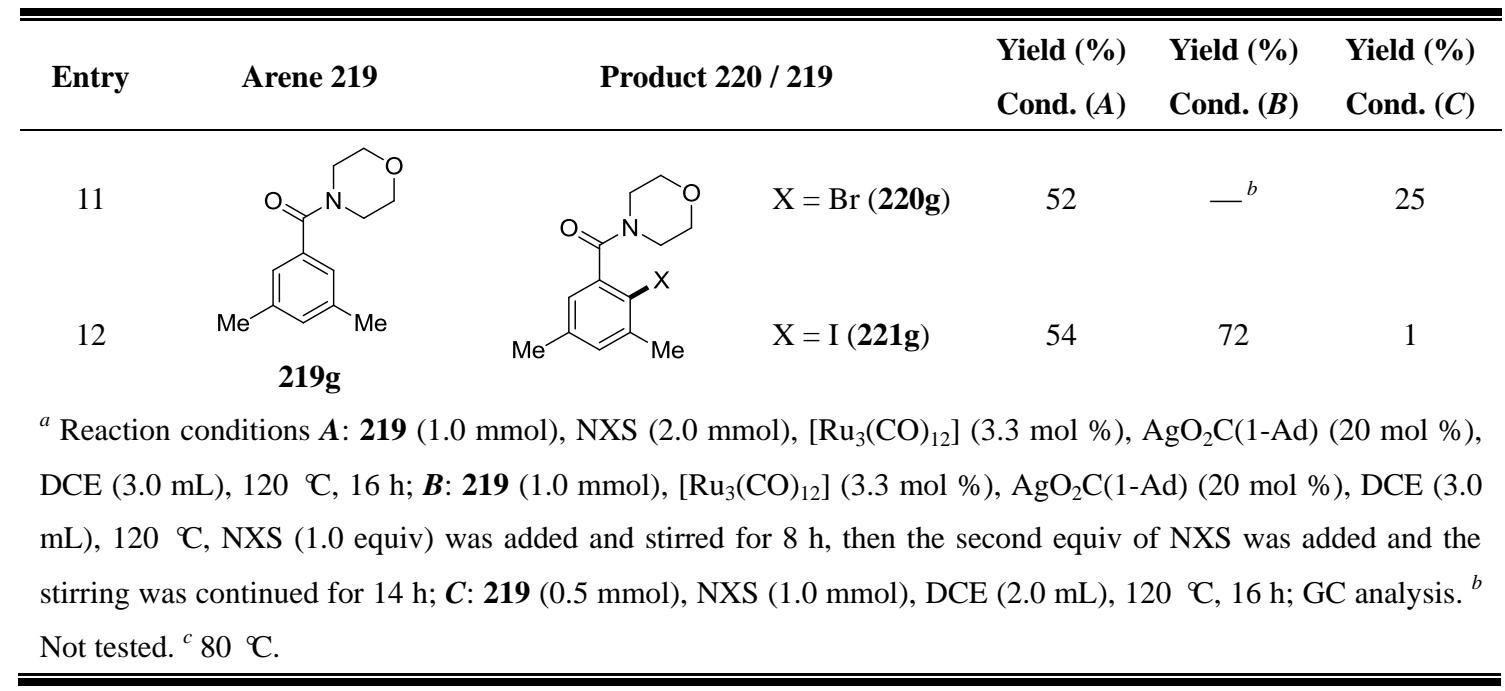

Thereafter, we probed the scope of the $\mathrm{C}-\mathrm{H}$ bromination with differently decorated benzamides 219 (Table 23). Intramolecular competition experiments with meta-methyl arene $219 \mathrm{~h}$ bearing two chemically inequivalent ortho $\mathrm{C}-\mathrm{H}$ bonds showed the less hindered $\mathrm{C}-\mathrm{H}$ bond to be predominantly brominated (entry 1). In contrast, the electron-deficient benzamide 219i afforded mainly isomer 220i, most probably because of the secondary directing group effect (entry 2 ). ${ }^{\text {a }}$ The $\mathrm{C}-\mathrm{H}$ functionalizations of substrates bearing additional (hetero)aromatic moieties proceeded with excellent site-selectivities in the ortho-position to the amide (entries 3-10). Thereby, synthetically useful heterocycles (220q) and functional groups, such as acetyl (220n and 2200) or ester (220p), were well tolerated by the catalyst. ${ }^{138}$

Table 23 Ruthenium(0)-catalyzed ortho-C-H bromination on benzamides $\mathbf{2 1 9}^{a}$

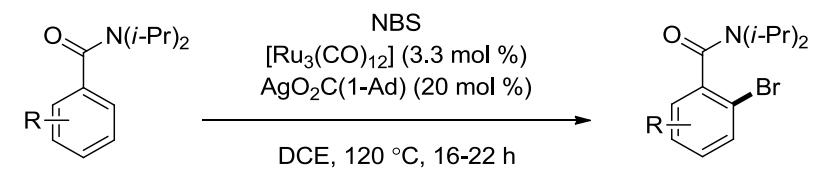

219

\begin{tabular}{lllll}
\hline \hline Entry & Benzamide 219 & Product 220 & Y/B & Yield (\%) \\
\hline & & $\boldsymbol{A}$ & \\
\end{tabular}

(continued)

${ }^{138}$ Under the optimized reaction conditions, the mass balance accounted for the unreacted starting materials as well as the second regioisomers in case of meta-substituted substrates 219. 
Table 23 (continued)

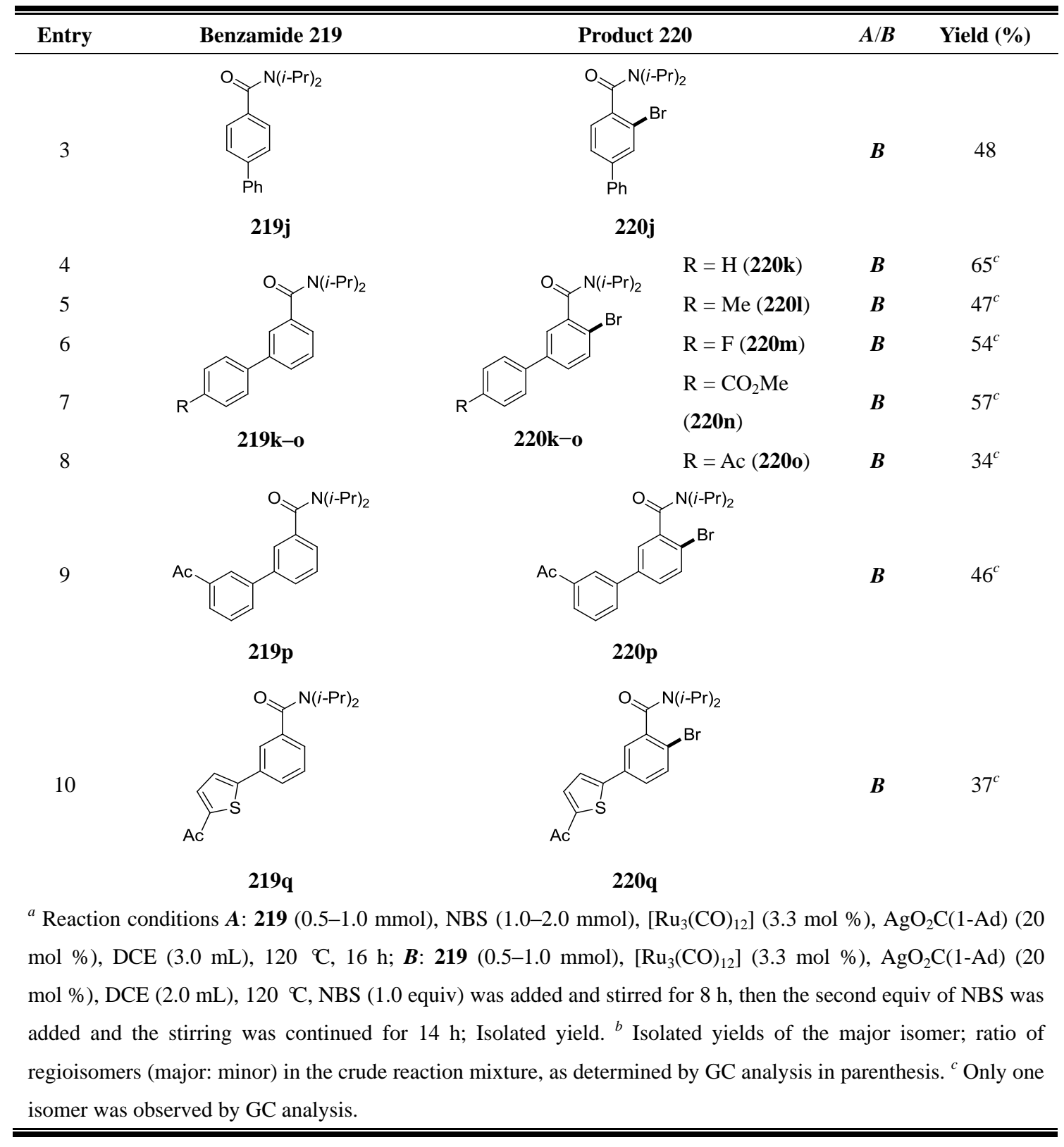

However, ortho-substitution turned out to be detrimental for this transformation, due to the sterically demanding tertiary benzamide directing group: The brominated product 220r was detected in $13 \%$ conversion by GC analysis of the crude reaction mixture (Scheme 89 ). ${ }^{139}$ Besides, electron-withdrawing groups at the para-position, such as $\mathrm{F}(\mathbf{2 1 9})$ and $\mathrm{CF}_{3}(\mathbf{2 1 9 t})$, only led to low conversions. para-Methoxyl benzamide 219u proceeded in high reactivity, however, poor regioselectivities were obtained.

139 Similar result was obtained applying rhodium(I) catalyst, see ref. 113. 


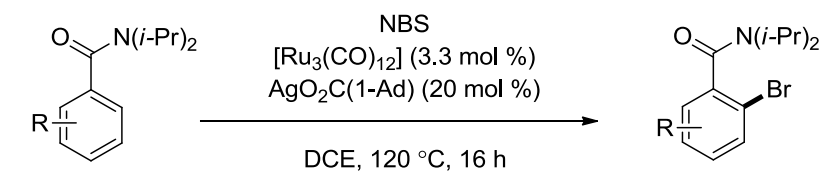

219

220

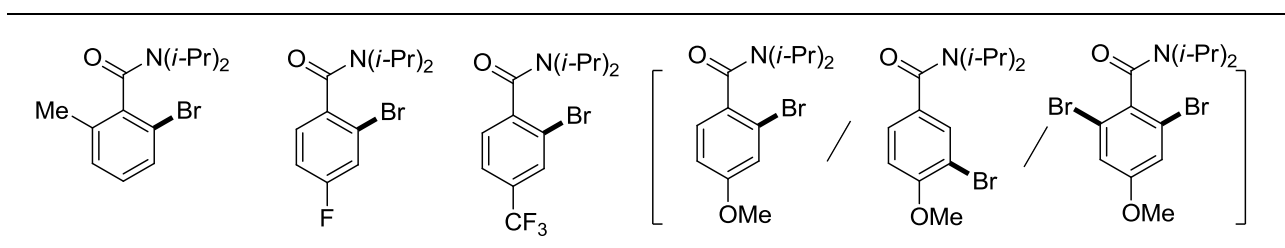

220r: $13 \%$ conv. 220 s: $27 \%$ conv. 220 t: $24 \%$ conv.

220u: $64 \%$ conv. $(3: 1: 3)$

Scheme 89 Limitations of benzamide scope

Furthermore, the versatile ruthenium(0) catalyst displayed a broad substrate scope and allowed for $\mathrm{C}-\mathrm{H}$ iodinations of differently substituted arenes $\mathbf{2 1 9}$ (Table 24). Thus, benzamide 219a provided the mono-halogenated products 221a in moderate yield (entry 1). Importantly, meta-substituted arenes 219 gave the desired products 221 with useful site-selectivities (entries 2-8). As was observed for the bromination (vide supra), the $\mathrm{C}-\mathrm{H}$ iodination herein was neither viable in the absence of the ruthenium( $(0)$ catalyst nor of the additive $\mathrm{AgO}_{2} \mathrm{C}(1-\mathrm{Ad})$ for all benzamides 219.

Table 24 Ruthenium(0)-catalyzed ortho-C-H iodination on benzamides $\mathbf{2 1 9}^{a}$

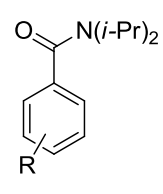

219

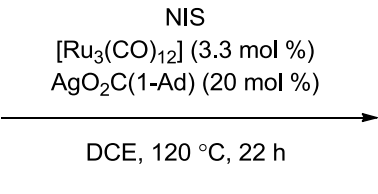

DCE, $120^{\circ} \mathrm{C}, 22 \mathrm{~h}$

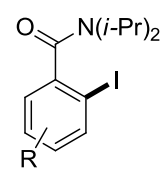

221

Entry

(continued) 
Table 24 (continued)

Entry
Yield (\%)
analysis.
continued for $14 \mathrm{~h}$; Isolated yield. ${ }^{b}$ Isolated yields of the major isomer; ratio of regioisomers (major: minor) in the

\subsubsection{Mechanistic Studies}

\subsubsection{Reactions in the Presence of Radical Scavengers}

In consideration of the unique reactivity profile of the novel ruthenium(0) catalyst, we performed mechanistic studies to delineate its mode of action. To this end, (co)catalysis with a Brønsted acid could be ruled out by successfully performing the $\mathrm{C}-\mathrm{H}$ bromination in the presence of stoichiometric amounts of 2,6-di-tert-butylpyridine (249a) ${ }^{140}$ (Table 25, entry 1). Furthermore, a radical inhibition test was next carried out in order to get insight into whether the reaction proceeds via radical intermediates. When such known effective radical scavengers as 2,2,6,6-tetramethylpiperidin-1-yloxy (TEMPO, 249b), 2,2-diphenyl-1-picrylhydrazyl (DPPH, 249c), 2,6-di-tert-butyl-4-methylphenol (BHT, 249d), trans-stilbene (249e) or 1,1-diphenylethylene (249f) were added to the reaction mixture under otherwise identical conditions, the reaction process was significantly suppressed (Table 25, entries 2-7). The latter could be rationalized in terms of SET-type processes ${ }^{141}$ being operative.

140 T. C. Wabnitz, J.-Q. Yu, J. B. Spencer, Chem.-Eur. J. 2004, 10, 484-493.

141 (a) E. C. Ashby, Acc. Chem. Res. 1988, 21, 414-421; (b) A. Pross, Acc. Chem. Res. 1985, 18, 212-219. 
Table 25 Effect of additives on the ortho-C-H bromination of benzamide 219a ${ }^{a}$

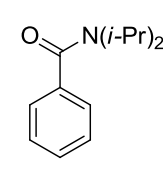

219a

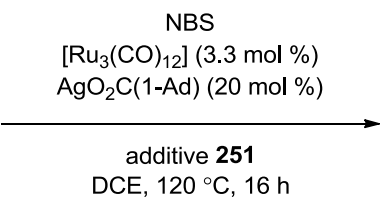

DCE, $120^{\circ} \mathrm{C}, 16 \mathrm{~h}$

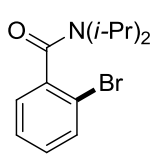

$220 a$

\begin{tabular}{|c|c|c|}
\hline Entry & Additive 249 (equiv) & $220 \mathrm{a}(\%)$ \\
\hline 1 & 2,6-di-tert-Butylpyridine (249a) (1.0) & 61 \\
\hline 2 & TEMPO (249b) (0.2) & 9 \\
\hline 3 & TEMPO (249b) (2.0) & 0 \\
\hline 4 & DPPH (249c) (2.0) & 0 \\
\hline 5 & BHT (249d) (2.0) & 0 \\
\hline 6 & trans-Stilbene (249e) (2.0) & 16 \\
\hline 7 & 1,1-Diphenylethene (249f) (2.0) & 0 \\
\hline \multicolumn{3}{|c|}{$\begin{array}{l}{ }^{a} \text { Reaction conditions: 219a }(0.5 \mathrm{mmol}) \text {, NBS }(1.0 \mathrm{mmol}),\left[\mathrm{Ru}_{3}(\mathrm{CO})_{12}\right](3.3 \mathrm{~mol} \%), \mathrm{AgO}_{2} \mathrm{C}(1-\mathrm{Ad})(20 \mathrm{~mol} \%) \text {, } \\
\text { additive } 249(0.5-1.0 \mathrm{mmol}) \text {, DCE }(2.0 \mathrm{~mL}), 120{ }^{\circ} \mathrm{C}, 16 \mathrm{~h} ;{ }^{1} \mathrm{H}-\mathrm{NMR} \text { yield with } 1,3,5 \text {-trimethoxybenzene }(0.1 \\
\text { mmol }) \text { as an internal standard. }\end{array}$} \\
\hline
\end{tabular}

\subsubsection{Reactions in Isotopically Labelled Reagents}

Furthermore, the catalytic $\mathrm{C}-\mathrm{H}$ functionalization in the presence of isotopically labelled additive $[\mathrm{D}]_{1}-\mathbf{2 5 0}$ highlighted a reversible $\mathrm{C}-\mathrm{H}$ ruthenation event (Scheme 90).

(a)

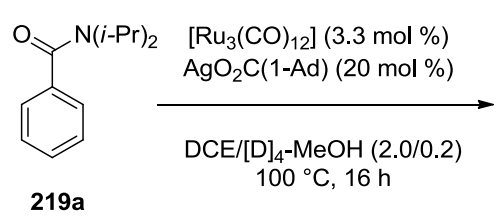

$219 a$

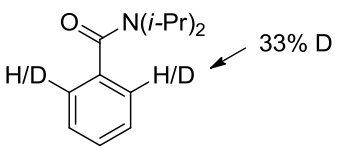

$[D]_{n}-219 a: 90 \%$

(b)

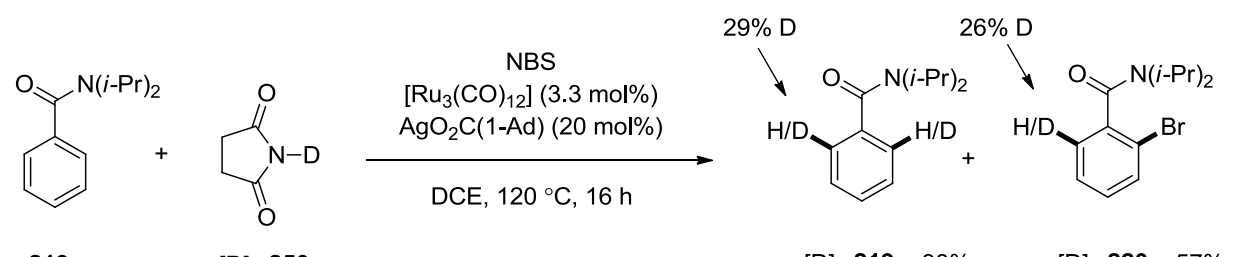

Scheme 90 C-H Functionalization with isotopically labelled reagents

In good agreement with these observations were the results of kinetic isotope effect (KIE) ${ }^{142}$ measurements. The independent experiments with substrates 219a and $[\mathrm{D}]_{5}-\mathbf{2 1 9 a}$ disclosed a KIE of $k_{H} / k_{D} \approx 1.0$, hence indicating the $\mathrm{C}-\mathrm{H}$ cleavage step not to be kinetically relevant (Scheme 91).

142 E. M. Simmons, J. F. Hartwig, Angew. Chem. Int. Ed. 2012, 51, 3066-3072. 


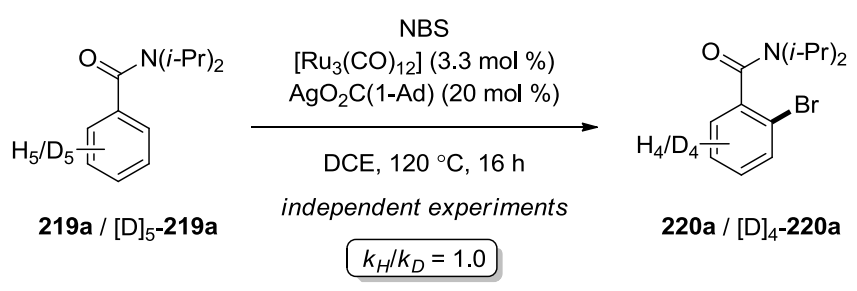

Scheme 91 Kinetic isotope effect studies

\subsubsection{Proposed Catalytic Cycle}

Based on our experimental mechanistic studies and independent kinetic isotope effect measurements, the following catalytic cycle for the ruthenium(0)-catalyzed $\mathrm{C}-\mathrm{H}$ halogenation is proposed (Scheme 92). Analogously to the general mechanism of the carboxylate-assisted ruthenium-catalyzed oxidative direct $\mathrm{C}-\mathrm{H}$ activations, ${ }^{8}$ after chelation with amide substituent, the ruthenium species is expected to form initially a ruthenacycle $\mathbf{2 5 4}$ through reversible $\mathrm{C}-\mathrm{H}$ bond metalation via transition state 253. Subsequently, migratory insertion of $N$-halosuccinimide (NXS) through a SET sequence delivers intermediate 255. Finally, reductive elimination of intermediate $\mathbf{2 5 5}$ releases the desired product $\mathbf{2 2 0}$ or $\mathbf{2 2 1}$ and regenerates ruthenium (0) species $\mathbf{2 5 1}$.

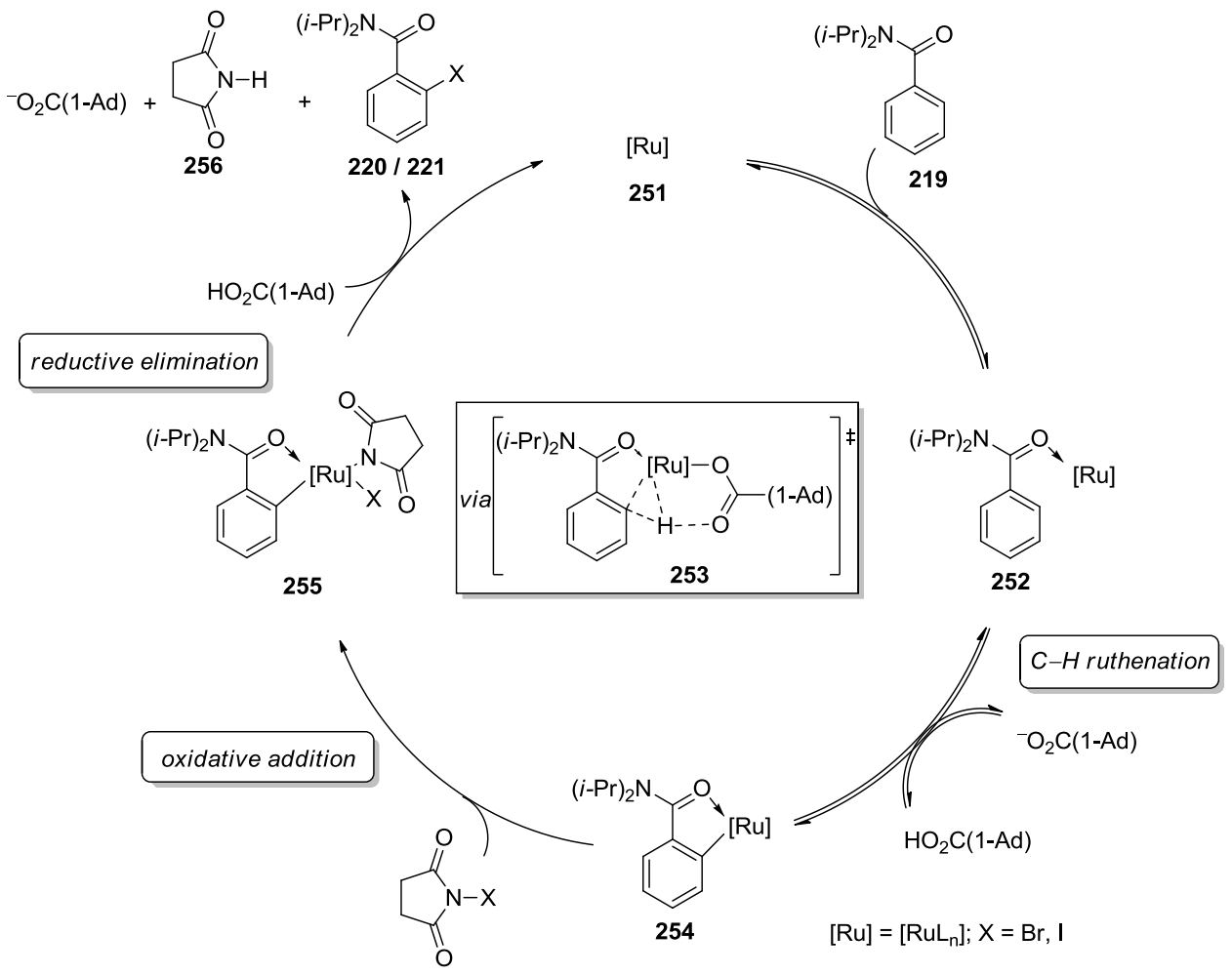

Scheme 92 Proposed catalytic cycle for the ruthenium(0)-catalyzed ortho-C-H halogenations 


\section{Summary and Outlook}

Ruthenium-catalyzed direct $\mathrm{C}-\mathrm{H}$ bond functionalizations was shown to be an attractive approach for the development of sustainable chemical processes. The significant rate acceleration of cycloruthenations by carboxylates has provided the bases for various catalyzed $\mathrm{C}-\mathrm{H}$ bond functionalizations.

In a first project, ruthenium(II)-catalyzed oxidative annulations were realized in an aerobic fashion with cocatalytic amounts of $\mathrm{Cu}(\mathrm{OAc})_{2} \cdot \mathrm{H}_{2} \mathrm{O}$ under an atmosphere of ambient air. Pleasingly, the $\mathrm{C}-\mathrm{H} / \mathrm{N}-\mathrm{H}$ bond functionalization occurred with unparalleled selectivities and ample scope to deliver indole 207 and pyrrole derivatives 209 (Scheme 93). While reactions with $\mathrm{CuBr}_{2}$ as the co-oxidant did not furnish the desired products, cocatalytic amounts of metal acetates restored the catalytic efficacy, thus providing strong evidence for carboxylate-assisted aerobic oxidations. Furthermore, the highly selective conversion of unsymmetrical alkynes $\mathbf{3 8}$ constituted a strong testament to the unique features of chemoselective ruthenium catalysts.
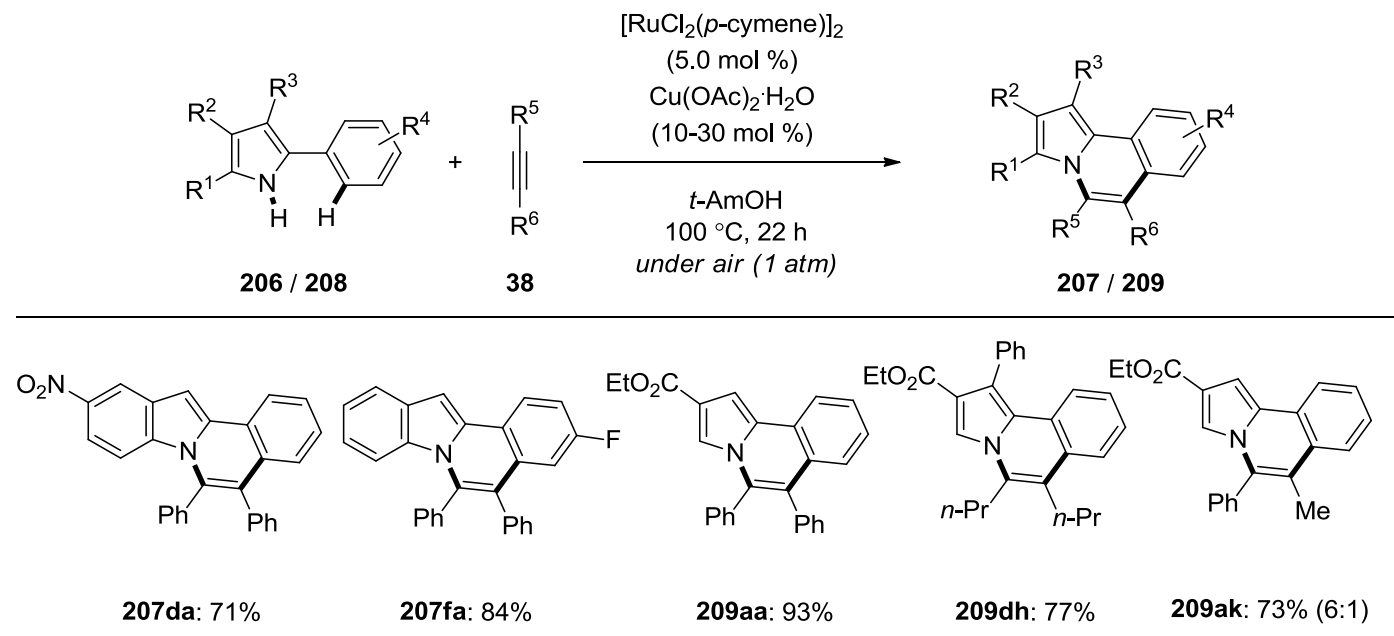

Scheme 93 Ruthenium(II)-catalyzed aerobic oxidative annulation

This efficient ruthenium(II) catalyst also enabled broadly applicable oxidative alkyne annulations with electron-rich enamines $\mathbf{2 1 0}$ to provide diversely decorated pyrroles 211, even with air as the ideal oxidant (Scheme 94). We were delighted to observe that numerous useful electrophilic functional groups were well tolerated, including ester, vinyl, bromo, cyano, and nitro substituents. Notably, oxidative annulations of unsymmetrical alkynes $\mathbf{3 8}$ occurred with synthetically useful levels of regiocontrol. 

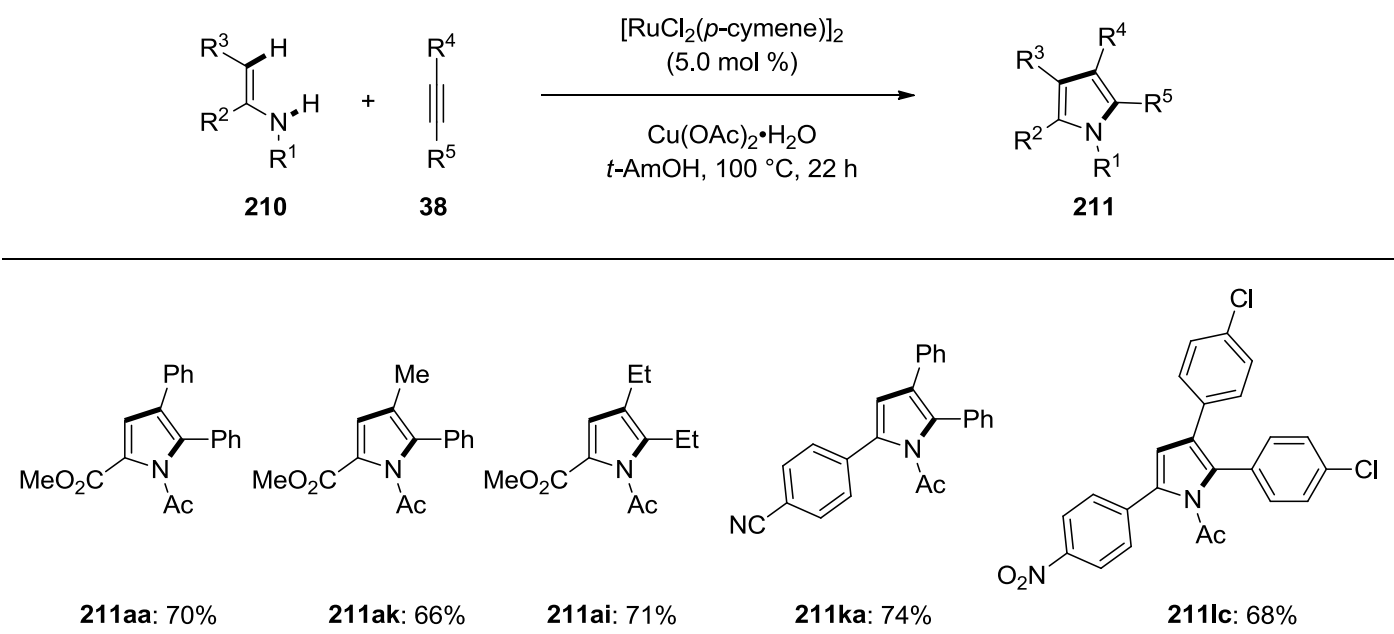

Scheme 94 Ruthenium(II)-catalyzed oxidative pyrrole synthesis by $\mathrm{C}-\mathrm{H}$ activation

Along with the rapid development of the oxidative annulations, challenging oxidative olefinations with electron-rich anilides $\mathbf{2 1 2}$ as well as electron-deficient benzamides $\mathbf{2 1 4}$ were elaborated with $\left[\mathrm{RuCl}_{2}(p \text {-cymene) }]_{2}, \mathrm{KPF}_{6}\right.$ and $\mathrm{Cu}(\mathrm{OAc})_{2} \cdot \mathrm{H}_{2} \mathrm{O}$ as the catalytic system (Scheme 95$)$. Remarkably, this protocol proved to be most effective with water as the reaction medium and provided an expedient access to differently decorated arenes 213 and 215. Furthermore, we were pleased to observe that this ruthenium-catalyzed oxidative $\mathrm{C}-\mathrm{H}$ alkenylations proceeded smoothly even on a large scale.

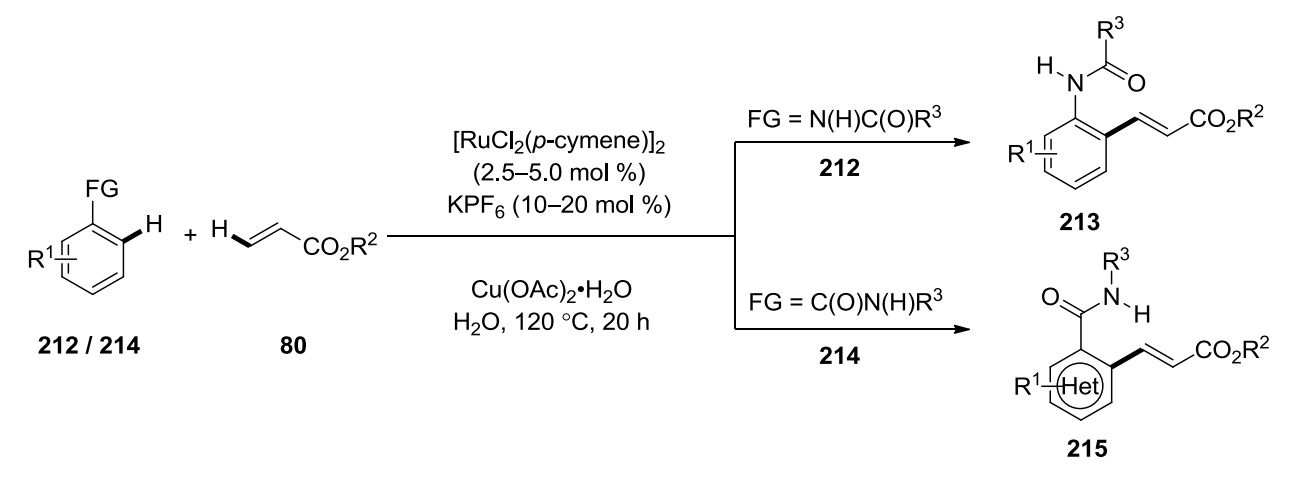<smiles>COC(=O)/C=C/c1cc(F)ccc1NC(C)=O</smiles>

213ha: $74 \%$<smiles>CCOC(=O)C=Cc1ccc(C)cc1NC(C)=O</smiles>

213aa: $87 \%$ $73 \%$ (5 mmol scale)<smiles>CCOC(=O)/C=C/c1c(F)cccc1NC(C)=O</smiles>

213ma: $70 \%$<smiles>CCO/C=C/c1c(C(=O)NC)n(C)c2ccccc12</smiles>

215ba: $71 \%$<smiles>CCOC(=O)C=Cc1ccsc1C(=O)NC</smiles>

215ea: $76 \%$

Scheme 95 Ruthenium-catalyzed oxidative alkenylation

A catalytic system comprising of $\left[\mathrm{RuCl}_{2}\left(\mathrm{PPh}_{3}\right)_{3}\right]$, AgOTf and rac-BINAP enabled step-economical additions of $\mathrm{C}\left(\mathrm{sp}^{3}\right)-\mathrm{H}$ bonds (216) onto unactivated alkenes 111 with ample scope under comparably mild reaction conditions (Scheme 96). Furthermore, the pyridyl directing group was efficiently removed to furnish $(\mathrm{NH})$-free pyrrolidines $\mathbf{2 1 8}$. 


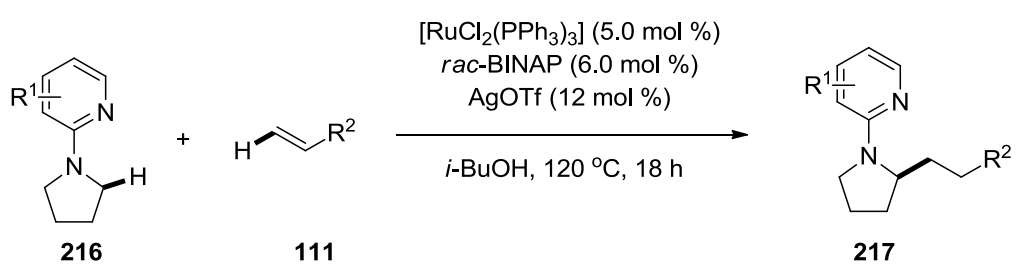

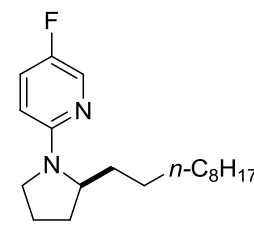

217fa: $76 \%$

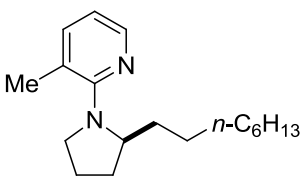

217bd: $90 \%$

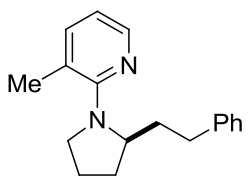

217bo: $73 \%$

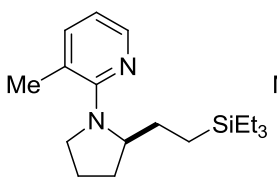

217bj: $86 \%$<smiles>Cc1cccnc1N1CCCC1CCCl</smiles>

217bl: $82 \%$

Scheme 96 Ruthenium(II)-catalyzed direct $\mathrm{C}\left(\mathrm{sp}^{3}\right)-\mathrm{H}$ alkylations with alkenes

Finally, $\left[\mathrm{Ru}_{3}(\mathrm{CO})_{12}\right]$ and $\mathrm{AgO}_{2} \mathrm{C}(1-\mathrm{Ad})$ enabled the first ruthenium-catalyzed intermolecular ortho-selective halogenations of benzamides 219 via $\mathrm{C}-\mathrm{H}$ activation (Scheme 97). Thereby, brominations and iodinations of electron-rich and electron-deficient benzamides were achieved in a highly selective fashion as well as with excellent functional group tolerance. Preliminary mechanistic studies provided evidence for a reversible $\mathrm{C}-\mathrm{H}$ metalation event in this process.

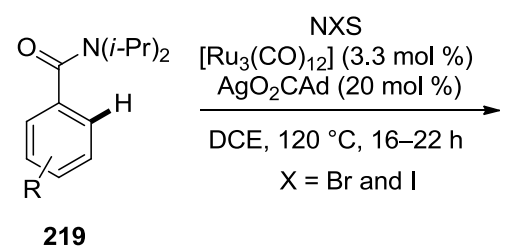

219

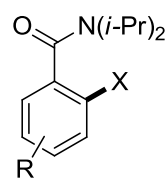

$220 / 221$

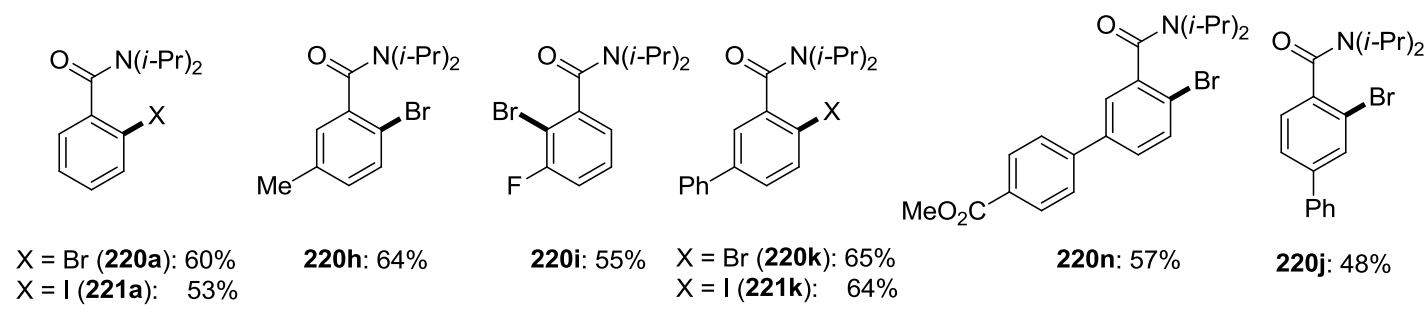

Scheme 97 Ruthenium-catalyzed direct ortho-halogenations

In summary, recent years have witnessed significant progress in transition-metal-catalyzed $\mathrm{C}-\mathrm{H}$ bond functionalizations. Importantly, direct $\mathrm{C}-\mathrm{H}$ arylations, alkylations and hydroarylations with alkenes, as well as challenging oxidative $\mathrm{C}-\mathrm{C}, \mathrm{C}-\mathrm{O}, \mathrm{C}-\mathrm{N}$ and $\mathrm{C}-\mathrm{Hal}$ bond formations have proven viable with ruthenium complexes with considerable progress being accomplished in the past several years. Notable features of the most user-friendly ruthenium catalysts include the remarkably broad substrate scope and the extraordinarily high chemo- and site-selectivity. Particularly, the significant rate acceleration of stoichiometric cyclometalations by carboxylates along with recent detailed experimental and computational studies has provided strong evidence for various $\mathrm{C}-\mathrm{H}$ bond ruthenations to proceed by base-assisted deprotonations. Considering the highly sustainable nature of ruthenium-catalyzed direct $\mathrm{C}-\mathrm{H}$ bond functionalizations, along with 
the improved mechanistic understanding of base-assisted metalations, further exciting developments are expected in this rapidly evolving research area. 


\section{Experimental Section}

\subsection{General Remarks}

Unless otherwise noticed, all reactions were performed under a $\mathrm{N}_{2}$ atmosphere using pre-dried glassware and standard Schlenk techniques.

\section{Solvents}

All solvents for reactions involving moisture-sensitive reagents were dried, distilled and stored under inert atmosphere (argon or nitrogen) according to the following standard procedures. tert-Amylalcohol $(t-\mathrm{AmOH})$ was used as supplied by Merck or stirred over sodium chips for $5 \mathrm{~h}$ at $120{ }^{\circ} \mathrm{C}$ and distilled under ambient pressure; water $\left(\mathrm{H}_{2} \mathrm{O}\right)$ was degassed before its use applying repeated Freeze-Pump-Thaw degassing procedure; 1,2-dichloroethane (DCE), $i$-BuOH, $N, N$-dimethylformamide (DMF), acetonitrile $(\mathrm{MeCN})$ and dimethylacetamide (DMA) were dried over $\mathrm{CaH}_{2}$ for $8 \mathrm{~h}$, degassed and distilled under reduced pressure; dichloromethane (DCM) and tetrahydrofuran (THF) were purified using a solvent purification system (SPS) from MBRAUN; $\mathrm{N}$-methyl-2-pyrrolidone (NMP) was stirred over $\mathrm{CaH}_{2}$ for $4 \mathrm{~h}$ at $150{ }^{\circ} \mathrm{C}$ and subsequently distilled under reduced pressure; methanol $(\mathrm{MeOH})$ was distilled from magnesium methanolate; toluene (PhMe) was either pre-dried over $\mathrm{KH}$ followed by distillation from sodium benzophenone ketyl; 1,4-dioxane was dried by distillation from sodium benzophenone ketyl.

\section{Vacuum}

The following pressures were measured on the used vacuum pump and were not corrected: membrane pump vacuum (MPV): 0.5 mbar, oil pump vacuum (OPV): 0.1 mbar.

Melting Points (M. p.)

Melting points were measured using a Stuart ${ }^{\circledR}$ Melting Point Apparatus SMP3 from BARLOWORLD SCIENTIFIC. Reported values are uncorrected.

\section{Chromatography}

Analytical thin layer chromatography (TLC) was performed on $0.25 \mathrm{~mm}$ silica gel 60F-plates (MACHEREY-NAGEL) with $254 \mathrm{~nm}$ fluorescent indicator from MERCK. Plates were visualized under UV-light or developed by treatment with a $\mathrm{KMnO}_{4}$ solution followed by careful applying a heat gun. Chromatographic purification of products was accomplished by flash column chromatography on MERCK silica gel, grade $60(0.040-0.063 \mathrm{~mm}$ and $0.063-0.200 \mathrm{~mm})$.

\section{Gas Chromatograpgy (GC)}

The conversion of the reactions was monitored applying coupled gas chromatography/mass spectrometry using G1760C GCDplus with mass detector HP 5971, 5890 Series II with mass detector HP 5972 from HEWLETT-PACKARD and 7890A GC-System with mass detector 5975C (Triplex-Axis-Detector) from AGILENT TECHNOLOGIES equipped with HP-5MS columns $(30 \mathrm{~m} \times 0.25 \mathrm{~mm} \times 0.25 \mathrm{~m})$ were used.

\section{High Performance Liquid Chromatography (HPLC)}

Preparative and analytical separations were performed on an HPLC-System from KNAUER (Smartline Pump 100, Dynamic Mixing Chamber, Injection- and Control-Valve, Smartline UV 
Detector 2500). Separation normal phase column $(250 \times 10 \mathrm{~mm})$ from MACHEREY-NAGEL (MN) was used. Organic solvents of HPLC grade were employed. All samples were filtered through Polytetrafluorethylen Filter from ROTH (Ø $25 \mathrm{~mm}, 0.2 \mu \mathrm{m})$ or VWR (Ø $13 \mathrm{~mm}, 0.2 \mu \mathrm{m}$ ) prior to separation.

\section{Nuclear Magnetic Resonance Spectroscopy (NMR)}

Nuclear magnetic resonance (NMR) spectroscopy was performed at 300 or $600 \mathrm{MHz}\left({ }^{1} \mathrm{H}-\mathrm{NMR}\right)$, 75 or $125 \mathrm{MHz}\left({ }^{13} \mathrm{C}-\mathrm{NMR}\right.$, APT) and $283 \mathrm{MHz}\left({ }^{19} \mathrm{~F}-\mathrm{NMR}\right)$ on BRUKER $A M$ 250, VARIAN Unity-300 and Inova 500 instruments. Chemical shifts are reported as $\delta$-values in ppm relative to the residual proton peak of the deuterated solvent or its carbon atom, respectively, or the standard trimethylsilyl (TMS) peak. For characterization of the observed resonance multiplicities the following abbrevations were applied: $s$ (singlet), $d$ (doublet), $t$ (triplet), $q$ (quartet), $m$ (multiplet), $d d$ (doublet of doublet), $d t$ (doublet of triplet), or analogue representations. The coupling constants $J$ are reported in Hertz (Hz).

\section{Infrared Spectroscopy (IR)}

Infrared spectra were recorded on a BRUKER Alpha-P ATR-spectrometer. Liquid probes have been measured as film and solid probes neat. Analysis of the spectral data has been done by using the OPUS 3.1 software from BRUKER, respectively OPUS 6. Absorption ( $\tilde{V})$ is given in wave numbers $\left(\mathrm{cm}^{-1}\right)$. Spectra were recorded in the range of 4000 to $400 \mathrm{~cm}^{-1}$.

\section{Mass Spectrometry (MS)}

MS (EI) and HR-MS (EI) were measured on a Time-of-Flight mass spectrometer AccuTOF from JOEL. ESI-mass spectra were recorded on an Ion-Trap mass spectrometer $L C Q$ from FINNIGAN or on a Time-of-Flight mass spectrometer microTOF from BRUKER. ESI-HR-MS spectra were recorded on a BRUKER APEX IV or a BRUKER DALTONIC \{7T, Fourier Transform Ion Cyclotron Resonance (FTICR)\} mass spectrometer. The ratios of mass to charge $(\mathrm{m} / \mathrm{z})$ are indicated, intensities relative to the base peak $(I=100)$ are written in parentheses.

\section{Reagents}

Chemicals obtained from commercial sources with purity above $95 \%$ were used without further purification.

\subsection{Synthesis of Starting Materials}

The following starting materials were synthesized according to previously described methods: Alkynes 38b-f, ${ }^{143} \mathbf{3 8 j},{ }^{144} \mathbf{3 8 1}-\mathbf{o},{ }^{143} \mathbf{3 8 q} ;{ }^{144} 1,1$-dimethyl-3-phenylurea (184d),${ }^{145}$ $N$-phenylpiperidine-1-carboxamide (184e) ${ }^{146} 2$-\{dimethyl(phenyl)silyl $\}$ pyridine $(\mathbf{1 8 4 f}),{ }^{147}$

\footnotetext{
${ }^{143}$ M. J. Mio, L. C. Kopel, J. B. Braun, T. L. Gadzikwa, K. L. Hull, R. G. Brisbois, C. J. Markworth, P. A. Grieco, Org. Lett. 2002, 4, 3199-3202.

144 J. Zhao, Y. Yu, S. Ma, Chem. -Eur. J. 2010, 16, 74-80.

145 C. E. Houlden, C. D. Bailey, J. G. Ford, M. R. Gagné, G. C. Lloyd-Jones, K. I. Booker-Milburn, J. Am. Chem. Soc. 2008, 130, 10066-10067.

146 L. Jamir, N. Khatun, B. K. Patel, RSC Adv. 2011,1, 447-451.

${ }^{147}$ C. Huang, N. Chernyak, A. S. Dudnik, V. Gevorgyan, Adv. Synth. Catal. 2011, 353, 1285-1305.
} 
dimethyl(phenyl)silanol (184g); ${ }^{148}$ 2-aryl-substituted indoles $\mathbf{2 0 6 b}-\mathbf{c},{ }^{149} \mathbf{2 0 6 d},{ }^{150} \mathbf{2 0 6 e}-\mathbf{h},{ }^{149}$ 206i, ${ }^{151,152} \mathbf{2 0 6 j}-\mathbf{n} ;{ }^{149}$ 2-aryl-substituted pyrroles $\mathbf{2 0 8 a - d ,}{ }^{153} \mathbf{2 0 8 e},{ }^{154} \mathbf{2 0 8 f} ;{ }^{155}$ enamines 210a-b, ${ }^{156}$ 210c, ${ }^{157}$ 210d, ${ }^{158}$ 210f, ${ }^{121} \mathbf{2 1 0 g}-\mathbf{t},{ }^{159}$ anilides 212a,${ }^{160}$ 212b, ${ }^{161}$ 212c, ${ }^{162}$ 212d-e, ${ }^{161}$ 212f, ${ }^{163} \mathbf{2 1 2 g - \mathbf { o }}$; $^{161}$ (hetero)amides 214a, ${ }^{164,165} \mathbf{2 1 4 b},{ }^{166,167} \mathbf{2 1 4 c},{ }^{164,168} \mathbf{2 1 4 d},{ }^{166,168} \mathbf{2 1 4 e},{ }^{164,167}$

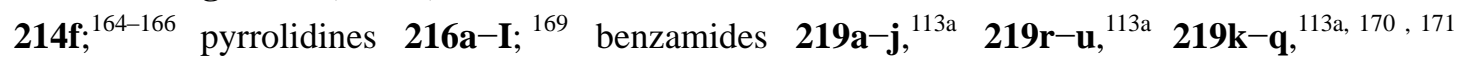
2-(pyridin-2-yl)isoindoline (237a) ${ }^{172}$ 1-(pyridin-2-yl)indoline $\quad(\mathbf{2 3 7 b}){ }^{169}$ 2-(pyrrolidin-1-yl)benzo[d]oxazole (237c), ${ }^{173}$ 5-(pyrrolidin-1-yl)-3,4-dihydro-2H-pyrrole (237d), ${ }^{174}$ (E)-2-methyl$N$-(pyrrolidin-1-ylmethylene)propan-2-amine $\quad(\mathbf{2 3 7 e}),{ }^{175} 1$-(pyrrolidin-1-yl)ethanone $\quad$ (237f), ${ }^{160}$ propa-1,2-dien-1-ylbenzene (238h) ${ }^{176}[\mathrm{D}]_{1}$-succinimide $\left([\mathrm{D}]_{1}-\mathbf{2 5 0}\right) .{ }^{177}$

The following compounds were obtained by the generous courtesy of the persons named below:

Dr. Marvin Schinkel: alkenes $111 k-\mathbf{n},{ }^{132}$ 111t-v. ${ }^{132}$

Karsten Rauch: $\left[\mathrm{RuCl}_{2}(p \text {-cymene })\right]_{2}$.

\subsection{General Procedures}

General procedure A for ruthenium-catalyzed aerobic coupling of substituted indoles 206 and pyrroles 208 with alkynes 38:

148 N. T. Tran, T. Min, A. K. Franz, Chem. -Eur. J. 2011, 17, 9897-9900.

149 D. Kim, M. S. Kang, K. Song, S. O. Kang, J. Ko, Tetrahedron 2008, 64, 10417-10424.

${ }^{150}$ M. S. Newman, C. C. Davis, J. Org. Chem. 1967, 32, 66-68.

151 E. Vazquez, L. W. Davies, J. F. Payack, J. Org. Chem. 2002, 67, 7551-7552.

152 S. Beaumont, P. Retaillleau, P. Dauban, R. H. Dodd, Eur. J. Org. Chem. 2008, 5162-5175.

153 J. Sisko, M. Mellinger, P. W. Shelldrack, N. H. Baine, Org. Synth. 2004, 10, 692-696.

154 R. D. Santo, R. Costi, S. Massa, M. Artico, Synth. Commun. 1995, 25, 795-802.

155 H. O. Bayer, H. Gotthardt, R. Huisgen, Chem. Ber. 1970, 103, 2356-2367.

${ }^{156}$ L. A. Adams, V. K. Aggarwal, R. V. Bonnert, B. Bressel, R. J. Cox, J. Shepherd, J. de Vicente, M. Walter, W. G. Whittingham, C. L. Winn, J. Org. Chem., 2003, 68, 9433-9440.

${ }^{157}$ L. Navarre, R. Martinez, J.-P. Genet, S. Darses, J. Am. Chem. Soc. 2008, 130, 6159-6169.

158 P. Peach, D. J. Cross, J. A. Kenny, I. Mann, I. Houson, L. Campbell, T. Walsgrove, M. Wills, Tetrahedron 2006, $62,1864-1876$.

159 J. T. Reeves, Z. Tan, Z. S. Han, G. Li, Y. Zhang, Y. Xu, D. C. Reeves, N. C. Gonnella, S. Ma, H. Lee, B. Z. Lu, C. H. Senanayake, Angew. Chem. Int. Ed. 2012, 51, 1400-1404.

160 S. Ueda, H. Nagasawa, J. Org. Chem. 2009, 74, 4272-4277.

161 K. K. Park, J. J. Lee, J. Ryu, Tetrahedron 2003, 59, 7651-7659.

162 J.-G. Kim, D. O. Jang, Synlett 2010, 2093-2096.

${ }^{163}$ E. Moulin, F. Niess, M. Maaloum, E. Buhler, I. Nyrkova, N. Giuseppone, Angew. Chem. Int. Ed. 2010, 49, 6974-6978.

164 S. Hanada, T. Ishida, Y. Motoyama, H. Nagashima, J. Org. Chem. 2007, 72, 7551-7559.

165 T. K. Hyster, T. Rovis, J. Am. Chem. Soc. 2010, 132, 10565-10569.

166 L. J. Martin, A. L. Marzinzik, S. V. Ley, I. R. Baxendale, Org. Lett. 2011, 13, 320-323.

167 J. A. Letizia, M. R. Salata, C. M. Tribout, A. Facchetti, M. A. Ratner, T. J. Marks, J. Am. Chem. Soc. 2008, 130, 9679-9694.

168 A. R. Katritzky, K. Akutagawa, Tetrahedron Lett. 1985, 26, 5935-5938.

169 M. Pichowicz, S. Crumpler, E. McDonald, J. Blagg, Tetrahedron 2010, 66, 2398-2403.

170 T. Ishiyama, K. Ishida, N. Miyaura, Tetrahedron 2001, 57, 9813-9816.

${ }^{171}$ L. Wang, X. Cui, J. Li, Y. Wu, Z. Zhu, Y. Wu, Eur. J. Org. Chem. 2012, 595-603.

172 A. Martínez-Asencio, D. J. Ramón, M. Yus, Tetrahedron 2011, 67, 3140-3149.

173 R. P. Lester, J. E. Camp, ACS Sustainable Chem. Eng. 2013, 1, 545-548.

174 S. J. Pastine, D. V. Gribkov, D. Sames, J. Am. Chem. Soc. 2006, 128, 14220-14219.

175 A. I. Meyers, P. D. Edwards, W. F. Rieker, T. R. Bailey, J. Am. Chem. Soc. 1984, 106, 3270-3276.

${ }^{176}$ H. Clavier, K. L. Jeune, I. de Riggi, A. Tenaglia, G. Buono, Org. Lett. 2011, 13, 308-311.

177 G. Adembri, F. De Sio, Ric. Sci. 1963, 3, 907-910. 
A mixture of 2-aryl indole 206 or pyrrole 208 (0.50 mmol), alkyne 38 (1.00 mmol), $\left[\mathrm{RuCl}_{2}(p \text {-cymene })\right]_{2}(15.3 \mathrm{mg}, 5.0 \mathrm{~mol} \%)$ and $\mathrm{Cu}(\mathrm{OAc})_{2} \cdot \mathrm{H}_{2} \mathrm{O}(10 \mathrm{mg}, 10.0 \mathrm{~mol} \%$ or $30 \mathrm{mg}$, $30.0 \mathrm{~mol} \%)$ in $t-\mathrm{AmOH}(2.0 \mathrm{~mL})$ was stirred at $100{ }^{\circ} \mathrm{C}$ under air $(1 \mathrm{~atm})$ for $22 \mathrm{~h}$. At ambient temperature, the reaction mixture was diluted with $\mathrm{H}_{2} \mathrm{O}(75 \mathrm{~mL})$ and extracted with EtOAc $(3 \times$ $75 \mathrm{~mL})$. The combined organic phase was washed with brine $(50 \mathrm{~mL})$ and dried over anhydrous $\mathrm{Na}_{2} \mathrm{SO}_{4}$. After filtration and evaporation of the solvents under reduced pressure, the crude product was purified by column chromatography on silica gel ( $n$-hexane/EtOAc or $n$-hexane/ $\mathrm{CH}_{2} \mathrm{Cl}_{2}$ ) to yield compound 207 and 209.

General procedure B for ruthenium-catalyzed oxidative coupling of substituted indoles 206 and pyrroles 208 with alkynes 38 :

A mixture of 2-aryl indole 206 or pyrrole 208 (0.50 mmol), alkyne 38 (1.00 mmol), $\left[\mathrm{RuCl}_{2}(p \text {-cymene })\right]_{2}(15.3 \mathrm{mg}, 5.0 \mathrm{~mol} \%)$ and $\mathrm{Cu}(\mathrm{OAc})_{2} \cdot \mathrm{H}_{2} \mathrm{O}(200 \mathrm{mg}, 1.00 \mathrm{mmol})$ in $t$-AmOH $(2.0 \mathrm{~mL})$ was stirred at $100{ }^{\circ} \mathrm{C}$ under $\mathrm{N}_{2}$ for $22 \mathrm{~h}$. At ambient temperature, the reaction mixture was diluted with $\mathrm{H}_{2} \mathrm{O}(75 \mathrm{~mL})$ and extracted with EtOAc $(3 \times 75 \mathrm{~mL})$. The combined organic phase was washed with brine $(50 \mathrm{~mL})$ and dried over anhydrous $\mathrm{Na}_{2} \mathrm{SO}_{4}$. After filtration and evaporation of the solvents under reduced pressure, the crude product was purified by column chromatography on silica gel ( $n$-hexane/EtOAc or $n$-hexane $/ \mathrm{CH}_{2} \mathrm{Cl}_{2}$ ) to yield compound 207 and 209.

General procedure C for ruthenium-catalyzed oxidative annulation of alkynes 38 with enamines 210:

A mixture of enamine $210(0.50 \mathrm{mmol})$, alkyne $38(1.00 \mathrm{mmol}),\left[\mathrm{RuCl}_{2}(p \text {-cymene })\right]_{2}(15.3 \mathrm{mg}$, $5.0 \mathrm{~mol} \%)$ and $\mathrm{Cu}(\mathrm{OAc})_{2} \cdot \mathrm{H}_{2} \mathrm{O}(200 \mathrm{mg}, 1.00 \mathrm{mmol})$ in $t-\mathrm{AmOH}(2.0 \mathrm{~mL})$ was stirred at $120{ }^{\circ} \mathrm{C}$ under $\mathrm{N}_{2}$ for $22 \mathrm{~h}$. At ambient temperature, the reaction mixture was diluted with sat. aq. $\mathrm{NH}_{4} \mathrm{Cl} / \mathrm{NH}_{3}(1: 1,75 \mathrm{~mL})$ and extracted with EtOAc $(3 \times 75 \mathrm{~mL})$. The combined organic phase was washed with sat. aq. $\mathrm{NH}_{4} \mathrm{Cl} / \mathrm{NH}_{3}(1: 1,50 \mathrm{~mL})$ and dried over anhydrous $\mathrm{Na}_{2} \mathrm{SO}_{4}$. After filtration and evaporation of the solvents under reduced pressure, the crude product was purified by column chromatography on silica gel ( $n$-hexane/EtOAc) to yield compound 211.

General procedure D for ruthenium-catalyzed oxidative alkenylation of anilides 212 and heteroamides 214:

A mixture of anilide 212 or heteroarylamide $214(0.50 \mathrm{mmol})$, acrylate $\mathbf{7 6}(0.75 \mathrm{mmol})$, $\left[\mathrm{RuCl}_{2}(p \text {-cymene })\right]_{2}(15.3 \mathrm{mg}, 5.0 \mathrm{~mol} \mathrm{\%}), \mathrm{KPF}_{6}(18.4 \mathrm{mg}, 20 \mathrm{~mol} \%)$ and $\mathrm{Cu}(\mathrm{OAc})_{2} \cdot \mathrm{H}_{2} \mathrm{O}$ (99.5 mg, $1.00 \mathrm{mmol}$ ) in $\mathrm{H}_{2} \mathrm{O}\left(2.0 \mathrm{~mL}\right.$ ) (sealed tube) was stirred at $120{ }^{\circ} \mathrm{C}$ under $\mathrm{N}_{2}$ for $20 \mathrm{~h}$. At ambient temperature, the mixture was diluted with $\mathrm{H}_{2} \mathrm{O}(75 \mathrm{~mL})$ and extracted with EtOAc $(3 \times 75 \mathrm{~mL})$. The combined organic phase was washed with brine $(50 \mathrm{~mL})$ and dried over anhydrous $\mathrm{Na}_{2} \mathrm{SO}_{4}$. After filtration and evaporation of the solvents under reduced pressure, the crude product was purified by column chromatography on silica gel ( $n$-hexane/EtOAc) to yield compound 213 and 215.

General procedure $\mathrm{E}$ for ruthenium-catalyzed $\mathrm{C}\left(\mathrm{sp}^{3}\right)-\mathrm{H} \alpha$-alkylation of pyrrolidine 216 with alkene 111:

A suspension of $\left[\mathrm{RuCl}_{2}\left(\mathrm{PPh}_{3}\right)_{3}\right](24.0 \mathrm{mg}, 5.0 \mathrm{~mol} \%)$, rac-BINAP (18.7 mg, $\left.6.0 \mathrm{~mol} \%\right)$, AgOTf (15.4 mg, $12 \mathrm{~mol} \%)$, pyrrolidine $216(1.5 \mathrm{mmol})$ and alkene $111(0.5 \mathrm{mmol})$ in $i$-BuOH $(1.0 \mathrm{~mL})$ 
was stirred at $120{ }^{\circ} \mathrm{C}$ under $\mathrm{N}_{2}$ for $18 \mathrm{~h}$. At ambient temperature, $\mathrm{CuCl}(50 \mathrm{mg})$, tridecane $(25 \mu \mathrm{L})$ and EtOAc $(5 \mathrm{~mL})$ were added to the reaction mixture. After GC analysis, the solvents were evaporated in reduced pressure. Purification by column chromatography on silica gel (n-hexane/EtOAc) yielded compound 217.

General procedure $F$ for the removal of 2-pyrridyl directing groups (217): ${ }^{135}$

Step 1: A $25 \mathrm{~mL}$ Schlenk flask was charged with compound 217 (0.5 mmol) and Pt/C (5\% Pt, $195 \mathrm{mg}, 10 \mathrm{~mol} \%)$. Under $\mathrm{N}_{2}$, EtOH (4.5 mL) was added. To the resulting black suspension was added $1.25 \mathrm{M} \mathrm{HCl}$ in EtOH $(0.5 \mathrm{~mL}, 0.6 \mathrm{mmol})$, and the reaction mixture was subsequently flushed twice with $\mathrm{H}_{2}$. The reaction mixture was then stirred under $\mathrm{H}_{2}(1 \mathrm{~atm})$ at $23{ }^{\circ} \mathrm{C}$ for $24 \mathrm{~h}$. The solids were removed by filtration through a short pad of celite, the pad was washed with $\mathrm{CH}_{2} \mathrm{Cl}_{2}(3 \times 10 \mathrm{~mL})$, and the combined filtrate was evaporated to dryness.

Step 2: The residue was dissolved in $\mathrm{MeOH}(5 \mathrm{~mL})$, and the resulting solution was cooled to $0{ }^{\circ} \mathrm{C}$ using an ice/water bath. $\mathrm{NaBH}_{4}(76 \mathrm{mg}, 2.0 \mathrm{mmol})$ was added portionwise to the cooled solution under magnetic stirring at $0{ }^{\circ} \mathrm{C}$. After complete addition of $\mathrm{NaBH}_{4}$, the reaction mixture was stirred further at $0{ }^{\circ} \mathrm{C}$ for $15 \mathrm{~min}$. The volatiles were removed in reduced pressure. Purification by column chromatography on silica gel $\left(\mathrm{CH}_{2} \mathrm{Cl}_{2} / \mathrm{MeOH}\right)$ yielded compound 218 .

General procedure $G$ for ruthenium-catalyzed ortho-C-H halogenation of benzamide 219:

To a seal tube equipped with a magnetic stir bar were added $\mathrm{Ru}_{3}(\mathrm{CO})_{12}(10.5 \mathrm{mg}, 3.3 \mathrm{~mol} \%)$, $\mathrm{AgO}_{2} \mathrm{C}(1-\mathrm{Ad})(28.7 \mathrm{mg}, 20 \mathrm{~mol} \%)$ and DCE $(2.0 \mathrm{~mL})$ under $\mathrm{N}_{2}$. Benzamide substrate 219 $(0.5 \mathrm{mmol})$ and $N$-halosuccinimide $(1.0 \mathrm{mmol})$ were added. After being stirred at ambient temperature for $10 \mathrm{~min}$, the tube was placed in a pre-heated oil-bath and stirred at $120{ }^{\circ} \mathrm{C}$ for $16 \mathrm{~h}$. The reaction mixture was then allowed to cool to ambient temperature, diluted with EtOAc $(5 \mathrm{~mL})$ and filtered through a short pad of silica gel and eluted with EtOAc $(50 \mathrm{~mL})$. After removing the solvent under reduced pressure, purification by column chromatography on silica gel (n-hexane/EtOAc) yielded the corresponding compound 220.

\section{General procedure $\mathbf{H}$ for ruthenium-catalyzed ortho-C-H halogenation of benzamides 219:}

To a seal tube equipped with a magnetic stir bar were added $\mathrm{Ru}_{3}(\mathrm{CO})_{12}(10.5 \mathrm{mg}, 3.3 \mathrm{~mol} \%)$, $\mathrm{AgO}_{2} \mathrm{C}(1-\mathrm{Ad})(28.7 \mathrm{mg}, 20 \mathrm{~mol} \%)$ and DCE $(2.0 \mathrm{~mL})$ under $\mathrm{N}_{2}$. Benzamide substrate 219 $(0.5 \mathrm{mmol})$ and the first portion of $N$-halosuccinimide $(0.5 \mathrm{mmol})$ were added. After being stirred at ambient temperature for $10 \mathrm{~min}$, the tube was placed in a pre-heated oil-bath and stirred at $120{ }^{\circ} \mathrm{C}$ for $8 \mathrm{~h}$. The mixture was then allowed to cool to ambient temperature, the second portion of $N$-halosuccinimide $(0.5 \mathrm{mmol})$ was added under $\mathrm{N}_{2}$ and the stirring was continued for further $14 \mathrm{~h}$ at $120^{\circ} \mathrm{C}$. The mixture was then allowed to cool to ambient temperature, diluted with EtOAc $(5 \mathrm{~mL})$ and filtered through a short pad of silica gel and eluted with EtOAc $(50 \mathrm{~mL})$. After removing the solvent under reduced pressure, purification by column chromatography on silica gel ( $n$-hexane/EtOAc) yielded the corresponding compound 220 and 221.

\subsection{Analytical Data}

\subsubsection{Analytical Data for the Products of Ruthenium-Catalyzed Aerobic Coupling of Substituted Indoles 206 or Pyrroles 208 with Alkynes 38}




\section{Synthesis of 5,6-diphenylindolo[2,1-a]isoquinoline (207aa)}

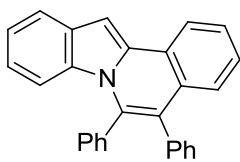

The general procedure A was followed using 2-phenylindole (206a) $(96.5 \mathrm{mg}$, $0.50 \mathrm{mmol})$, diphenylacetylene (38a) $(178 \mathrm{mg}, 1.00 \mathrm{mmol})$ and $\mathrm{Cu}(\mathrm{OAc})_{2} \cdot \mathrm{H}_{2} \mathrm{O}$ (10 mg, $10.0 \mathrm{~mol} \%)$. After $22 \mathrm{~h}$, purification by column chromatography on silica gel ( $n$-hexane/EtOAc: $20 / 1)$ yielded 207aa $(151 \mathrm{mg}, 82 \%)$ as a white

solid.

M. p. $=205-206^{\circ} \mathrm{C}$.

${ }^{1} \mathrm{H}-\mathrm{NMR}\left(300 \mathrm{MHz}, \mathrm{CDCl}_{3}\right): \delta=8.31(\mathrm{~d}, J=6.7 \mathrm{~Hz}, 1 \mathrm{H}), 7.76(\mathrm{~d}, J=8.0 \mathrm{~Hz}, 1 \mathrm{H}), 7.51(\mathrm{ddd}, J=$ 7.7, 7.2, 1.3 Hz, 1H), 7.38 (s, 1H), 7.38-7.14 (m, 13H), 6.82 (ddd, $J=7.8,7.0,1.3 \mathrm{~Hz}, 1 \mathrm{H}), 6.01$ $(\mathrm{d}, J=8.7 \mathrm{~Hz}, 1 \mathrm{H})$

${ }^{13} \mathrm{C}-\mathrm{NMR}\left(75 \mathrm{MHz}, \mathrm{CDCl}_{3}\right): \delta=136.7\left(\mathrm{C}_{\mathrm{q}}\right), 136.0\left(\mathrm{C}_{\mathrm{q}}\right), 135.9\left(\mathrm{C}_{\mathrm{q}}\right), 135.3\left(\mathrm{C}_{\mathrm{q}}\right), 132.7\left(\mathrm{C}_{\mathrm{q}}\right), 131.8$ $(\mathrm{CH}), 130.8(\mathrm{CH}), 130.2\left(\mathrm{C}_{\mathrm{q}}\right), 129.7\left(\mathrm{C}_{\mathrm{q}}\right), 128.7(\mathrm{CH}), 128.6(\mathrm{CH}), 127.8(\mathrm{CH}), 127.3(\mathrm{CH}), 127.0$ $(\mathrm{CH}), 126.7(\mathrm{CH}), 126.2(\mathrm{CH}), 125.4\left(\mathrm{C}_{\mathrm{q}}\right), 123.3(\mathrm{CH}), 121.6(\mathrm{CH}), 121.4\left(\mathrm{C}_{\mathrm{q}}\right), 120.2(\mathrm{CH}), 120.1$ $(\mathrm{CH}), 114.6(\mathrm{CH}), 94.2(\mathrm{CH})$.

IR (ATR): $\tilde{V}=1543,1484,1443,1377,1338,1245,1030,756,736,696 \mathrm{~cm}^{-1}$.

MS (EI) $m / z$ (relative intensity): 369 (100) $\left[\mathrm{M}^{+}\right], 291$ (13).

HR-MS (EI) $m / z$ calcd for $\mathrm{C}_{28} \mathrm{H}_{19} \mathrm{NO}^{+} 369.1517$, found 369.1518 .

The spectral data were in accordance with those reported in the literature. ${ }^{117}$

\section{Synthesis of 10-fluoro-5,6-diphenylindolo[2,1-a]isoquinoline (207ba)}

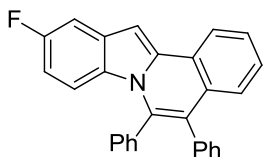

The general procedure $\mathbf{A}$ was followed using 5-fluoro-2-phenyl-1 $H$-indole (206b) (106 mg, $0.50 \mathrm{mmol})$, diphenylacetylene (38a) (178 mg, $1.00 \mathrm{mmol})$ and $\mathrm{Cu}(\mathrm{OAc})_{2} \cdot \mathrm{H}_{2} \mathrm{O}(10 \mathrm{mg}, 10.0 \mathrm{~mol} \%)$. After $22 \mathrm{~h}$, purification by column chromatography on silica gel ( $n$-hexane/EtOAc: $50 / 1)$ yielded 207ba (102 mg,

$54 \%)$ as a yellow solid.

M. p. $=227-228^{\circ} \mathrm{C}$.

${ }^{1} \mathrm{H}-\mathrm{NMR}\left(300 \mathrm{MHz}, \mathrm{CDCl}_{3}\right): \delta=8.26(\mathrm{~d}, J=7.8 \mathrm{~Hz}, 1 \mathrm{H}), 7.49(\mathrm{ddd}, J=7.8,7.8,1.2 \mathrm{~Hz}, 1 \mathrm{H})$, 7.39-7.11 (m, 14H), 6.52 (ddd, $J=9.2,9.1,2.6 \mathrm{~Hz} .1 \mathrm{H}), 5.86(\mathrm{dd}, J=9.4,4.6 \mathrm{~Hz}, 1 \mathrm{H})$.

${ }^{13} \mathrm{C}-\mathrm{NMR}\left(75 \mathrm{MHz}, \mathrm{CDCl}_{3}\right): \delta=158.6\left(\mathrm{~d},{ }^{1} J_{\mathrm{C}-\mathrm{F}}=238 \mathrm{~Hz}, \mathrm{C}_{\mathrm{q}}\right), 137.4\left(\mathrm{C}_{\mathrm{q}}\right), 136.5\left(\mathrm{C}_{\mathrm{q}}\right), 135.7\left(\mathrm{C}_{\mathrm{q}}\right)$, $135.0\left(\mathrm{C}_{\mathrm{q}}\right), 131.7(\mathrm{CH}), 130.8(\mathrm{CH}), 130.3\left(\mathrm{~d},{ }^{3} J_{\mathrm{C}-\mathrm{F}}=10 \mathrm{~Hz}, \mathrm{C}_{\mathrm{q}}\right), 130.2\left(\mathrm{C}_{\mathrm{q}}\right), 129.4\left(\mathrm{C}_{\mathrm{q}}\right), 128.8$ $(\mathrm{CH}), 128.7(\mathrm{CH}), 127.8(\mathrm{CH}), 127.6(\mathrm{CH}), 127.1(\mathrm{CH}), 126.8(\mathrm{CH}), 126.2(\mathrm{CH}), 124.9\left(\mathrm{C}_{\mathrm{q}}\right)$, $123.4(\mathrm{CH}), 121.6\left(\mathrm{C}_{\mathrm{q}}\right), 111.6\left(\mathrm{~d},{ }^{3} J_{\mathrm{C}-\mathrm{F}}=9 \mathrm{~Hz}, \mathrm{CH}\right), 108.5\left(\mathrm{~d},{ }^{2} J_{\mathrm{C}-\mathrm{F}}=26 \mathrm{~Hz}, \mathrm{CH}\right), 104.3\left(\mathrm{~d},{ }^{2} J_{\mathrm{C}-\mathrm{F}}\right.$ $=23 \mathrm{~Hz}, \mathrm{CH}), 94.0\left(\mathrm{~d},{ }^{4} J_{\mathrm{C}-\mathrm{F}}=4 \mathrm{~Hz}, \mathrm{CH}\right)$.

${ }^{19} \mathrm{~F}-\mathrm{NMR}\left(283 \mathrm{MHz}, \mathrm{CDCl}_{3}\right): \delta=-(121.7-121.8)(\mathrm{m})$.

IR (ATR): $\tilde{V}=3054,1610,1539,1485,1441,1117,855,787,753,696 \mathrm{~cm}^{-1}$.

MS (EI) $\mathrm{m} / z$ (relative intensity): $387(100)\left[\mathbf{M}^{+}\right], 309$ (30).

HR-MS (EI) $m / z$ calcd for $\mathrm{C}_{28} \mathrm{H}_{18} \mathrm{FN}^{+} 387.1383$, found 387.1382 .

\section{Synthesis of 10-bromo-5,6-diphenylindolo[2,1-a] isoquinoline $(207 \mathrm{ca})$}

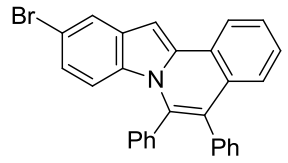

The general procedure $\mathbf{A}$ was followed using 5-bromo-2-phenyl-1 $H$-indole (206c) $(136 \mathrm{mg}, 0.50 \mathrm{mmol})$, diphenylacetylene (38a) (178 mg, $1.00 \mathrm{mmol})$ and $\mathrm{Cu}(\mathrm{OAc})_{2} \cdot \mathrm{H}_{2} \mathrm{O}(10 \mathrm{mg}, 10.0 \mathrm{~mol} \%)$. After $22 \mathrm{~h}$, purification by column chromatography on silica gel ( $n$-hexane $/ \mathrm{CH}_{2} \mathrm{Cl}_{2}: 5 / 1$ ) yielded 207ca (72 mg, $32 \%)$ as a yellow solid.

M. p. $=213-214{ }^{\circ} \mathrm{C}$. 
${ }^{1} \mathrm{H}-\mathrm{NMR}\left(300 \mathrm{MHz}, \mathrm{CDCl}_{3}\right): \delta=8.29(\mathrm{~d}, J=8.0 \mathrm{~Hz}, 1 \mathrm{H}), 7.90(\mathrm{~d}, J=2.0 \mathrm{~Hz}, 1 \mathrm{H}), 7.53(\mathrm{dd}, J=$ 7.6, 7.2 Hz, 1H), 7.38-7.12 (m, 13H), $6.87(\mathrm{dd}, J=9.0,2.0 \mathrm{~Hz}, 1 \mathrm{H}), 5.81(\mathrm{~d}, J=9.0 \mathrm{~Hz}, 1 \mathrm{H})$. ${ }^{13} \mathrm{C}-\mathrm{NMR}\left(75 \mathrm{MHz}, \mathrm{CDCl}_{3}\right): \delta=136.9\left(\mathrm{C}_{\mathrm{q}}\right), 136.4\left(\mathrm{C}_{\mathrm{q}}\right), 135.6\left(\mathrm{C}_{\mathrm{q}}\right), 134.9\left(\mathrm{C}_{\mathrm{q}}\right), 131.7(\mathrm{CH}), 131.3$ $\left(\mathrm{C}_{\mathrm{q}}\right), 131.2\left(\mathrm{C}_{\mathrm{q}}\right), 130.7(\mathrm{CH}), 130.3\left(\mathrm{C}_{\mathrm{q}}\right), 128.9(\mathrm{CH}), 128.8(\mathrm{CH}), 127.9(\mathrm{CH}), 127.7(\mathrm{CH}), 127.2$ $(\mathrm{CH}), 126.9(\mathrm{CH}), 126.3(\mathrm{CH}), 125.0\left(\mathrm{C}_{\mathrm{q}}\right), 123.4(\mathrm{CH}), 122.8(\mathrm{CH}), 122.4(\mathrm{CH}), 122.0\left(\mathrm{C}_{\mathrm{q}}\right), 111.9$ $(\mathrm{CH}), 111.2\left(\mathrm{C}_{\mathrm{q}}\right), 93.5(\mathrm{CH})$.

IR (ATR): $\tilde{V}=3056,1620,1487,1377,1030,725,696 \mathrm{~cm}^{-1}$.

MS (EI) m/z (relative intensity): 449 (100) $\left[\mathrm{M}^{+}\right]\left({ }^{81} \mathrm{Br}\right), 447$ (97) $\left[\mathrm{M}^{+}\right]\left({ }^{79} \mathrm{Br}\right), 367$ (44), 291 (37).

HR-MS (ESI) $\mathrm{m} / \mathrm{z}$ calcd for $\mathrm{C}_{28} \mathrm{H}_{18} \mathrm{BrN}^{+}$447.0623, found 447.0634.

\section{Synthesis of 10-nitro-5,6-diphenylindolo[2,1-a]isoquinoline (207da)}

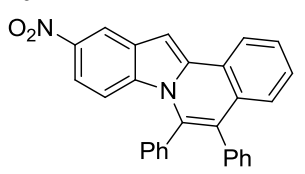

The general procedure $\mathbf{A}$ was followed using 5-nitro-2-phenyl-1H-indole (206d) (119 mg, $0.50 \mathrm{mmol})$, diphenylacetylene (38a) (178 mg, $1.00 \mathrm{mmol})$ and $\mathrm{Cu}(\mathrm{OAc})_{2} \cdot \mathrm{H}_{2} \mathrm{O}(10 \mathrm{mg}, 10.0 \mathrm{~mol} \%)$. After $22 \mathrm{~h}$, purification by column chromatography on silica gel ( $n$-hexane/EtOAc: 25/1) yielded 207da (141

$\mathrm{mg}, 71 \%)$ as a yellow solid.

M. p. $=281-282{ }^{\circ} \mathrm{C}$.

${ }^{1} \mathrm{H}-\mathrm{NMR}\left(300 \mathrm{MHz}, \mathrm{CDCl}_{3}\right): \delta=8.66(\mathrm{~s}, 1 \mathrm{H}), 8.28(\mathrm{~d}, J=7.8 \mathrm{~Hz}, 1 \mathrm{H}), 7.63(\mathrm{dd}, J=9.4,2.3 \mathrm{~Hz}$, 1H), 7.58-7.45 (m, 2H), 7.44-7.30 (m, 4H), 7.30-7.08 (m, 8H), $5.96(\mathrm{~d}, J=9.4 \mathrm{~Hz}, 1 \mathrm{H})$. ${ }^{13} \mathrm{C}-\mathrm{NMR}\left(75 \mathrm{MHz}, \mathrm{CDCl}_{3}\right): \delta=138.5\left(\mathrm{C}_{\mathrm{q}}\right), 138.8(\mathrm{CH}), 135.9\left(\mathrm{C}_{\mathrm{q}}\right), 135.3\left(\mathrm{C}_{\mathrm{q}}\right), 134.9\left(\mathrm{C}_{\mathrm{q}}\right), 134.5$ $(\mathrm{CH}), 131.4(\mathrm{CH}), 130.7\left(\mathrm{C}_{\mathrm{q}}\right), 130.2(\mathrm{CH}), 129.2(\mathrm{CH}), 128.9(\mathrm{CH}), 128.8(\mathrm{CH}), 128.4(\mathrm{CH})$, 128.0 (CH), $127.7(\mathrm{CH}), 127.1(\mathrm{CH}), 126.6\left(\mathrm{C}_{\mathrm{q}}\right), 124.7\left(\mathrm{C}_{\mathrm{q}}\right), 123.6(\mathrm{CH}), 123.6\left(\mathrm{C}_{\mathrm{q}}\right), 116.7\left(\mathrm{C}_{\mathrm{q}}\right)$, $114.8\left(\mathrm{C}_{\mathrm{q}}\right), 114.6(\mathrm{CH}), 95.9(\mathrm{CH})$.

IR (ATR): $\tilde{V}=3060,1600,1545,1505,1487,1336,1073,759,731,696 \mathrm{~cm}^{-1}$.

MS (EI) $m / z$ (relative intensity): 414 (100) $\left[\mathrm{M}^{+}\right], 384$ (27), 368 (30), 291 (13).

HR-MS (EI) $m / z$ calcd for $\mathrm{C}_{28} \mathrm{H}_{18} \mathrm{~N}_{2} \mathrm{O}_{2}{ }^{+} 414.1368$, found 414.1384 .

\section{Synthesis of 10-methyl-5,6-diphenylindolo[2,1-a]isoquinoline (207ea)}

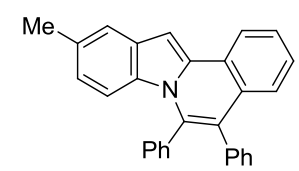

The general procedure $\mathbf{A}$ was followed using 5-methyl-2-phenyl- $1 H$-indole (206e) (103 mg, $0.50 \mathrm{mmol})$, diphenylacetylene (38a) $(178 \mathrm{mg}, 1.00 \mathrm{mmol})$ and $\mathrm{Cu}(\mathrm{OAc})_{2} \cdot \mathrm{H}_{2} \mathrm{O}(10 \mathrm{mg}, 10.0 \mathrm{~mol} \%)$. After $22 \mathrm{~h}$, purification by column chromatography on silica gel ( $n$-hexane/ $\mathrm{CH}_{2} \mathrm{Cl}_{2}$ : 4/1) yielded 207ea (14 mg,

$7 \%)$ as a yellow solid.

The general procedure $\mathbf{B}$ was followed using 5-methyl-2-phenyl-1H-indole (206e) (103 mg, $0.50 \mathrm{mmol})$ and diphenylacetylene (38a) $(178 \mathrm{mg}, 1.00 \mathrm{mmol})$. After $22 \mathrm{~h}$, purification by column chromatography on silica gel ( $n$-hexane/ $\mathrm{CH}_{2} \mathrm{Cl}_{2}$ : 4/1) yielded 207ea $(126 \mathrm{mg}, 65 \%)$ as a yellow solid.

M. p. $=236-237^{\circ} \mathrm{C}$.

${ }^{1} \mathrm{H}-\mathrm{NMR}\left(300 \mathrm{MHz}, \mathrm{CDCl}_{3}\right): \delta=8.29(\mathrm{~d}, J=8.0 \mathrm{~Hz}, 1 \mathrm{H}), 7.57(\mathrm{~s}, 1 \mathrm{H}), 7.51(\mathrm{dd}, J=8.0,7.2 \mathrm{~Hz}$, $1 \mathrm{H}), 7.40-7.29(\mathrm{~m}, 7 \mathrm{H}), 7.27-7.12(\mathrm{~m}, 6 \mathrm{H}), 6.66(\mathrm{dd}, J=8.8,2.7 \mathrm{~Hz}, 1 \mathrm{H}), 5.87(\mathrm{~d}, J=8.8 \mathrm{~Hz}$, $1 \mathrm{H}), 2.44(\mathrm{~s}, 3 \mathrm{H})$.

${ }^{13} \mathrm{C}-\mathrm{NMR}\left(75 \mathrm{MHz}, \mathrm{CDCl}_{3}\right): \delta=136.8\left(\mathrm{C}_{\mathrm{q}}\right), 136.0\left(\mathrm{C}_{\mathrm{q}}\right), 135.4\left(\mathrm{C}_{\mathrm{q}}\right), 135.2\left(\mathrm{C}_{\mathrm{q}}\right), 131.8(\mathrm{CH}), 131.1$ $\left(\mathrm{C}_{\mathrm{q}}\right), 130.9(\mathrm{CH}), 130.8(\mathrm{CH}), 130.2\left(\mathrm{C}_{\mathrm{q}}\right), 130.0\left(\mathrm{C}_{\mathrm{q}}\right), 128.6(\mathrm{CH}), 128.5(\mathrm{CH}), 127.8(\mathrm{CH}), 127.1$ $(\mathrm{CH}), 126.9(\mathrm{CH}), 126.7(\mathrm{CH}), 126.1(\mathrm{CH}), 125.5\left(\mathrm{C}_{\mathrm{q}}\right), 123.2\left(\mathrm{C}_{\mathrm{q}}\right), 121.9(\mathrm{CH}), 121.0\left(\mathrm{C}_{\mathrm{q}}\right), 119.7$ $(\mathrm{CH}), 114.2(\mathrm{CH}), 93.7(\mathrm{CH}), 21.3\left(\mathrm{CH}_{3}\right)$. 
IR (ATR): $\tilde{V}=3047,1614,1574,1443,1376,745,697,650 \mathrm{~cm}^{-1}$.

MS (EI) $m / z$ (relative intensity): $383(100)\left[\mathrm{M}^{+}\right], 367$ (25), 306 (10).

HR-MS (EI) $m / z$ calcd for $\mathrm{C}_{29} \mathrm{H}_{21} \mathrm{~N}^{+} 383.1674$, found 399.1676 .

\section{Synthesis of 3-fluoro-5,6-diphenylindolo[2,1-a]isoquinoline (207fa)}

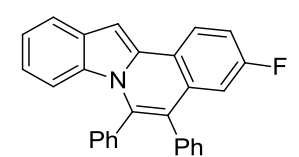

The general procedure A was followed using 2-(4-fluorophenyl)- $1 H$-indole (206f) (106 mg, $0.50 \mathrm{mmol})$, diphenylacetylene (38a) $(178 \mathrm{mg}, 1.00 \mathrm{mmol})$ and $\mathrm{Cu}(\mathrm{OAc})_{2} \cdot \mathrm{H}_{2} \mathrm{O}(10 \mathrm{mg}, 10.0 \mathrm{~mol} \%)$. After $22 \mathrm{~h}$, purification by column chromatography on silica gel ( $n$-hexane/EtOAc: 10/1) yielded 207fa $(164 \mathrm{mg}, 84 \%)$ as a yellow solid.

M. p. $=178-179^{\circ} \mathrm{C}$.

${ }^{1} \mathrm{H}-\mathrm{NMR}\left(300 \mathrm{MHz}, \mathrm{CDCl}_{3}\right): \delta=8.26(\mathrm{dd}, J=8.7,5.5 \mathrm{~Hz}, 1 \mathrm{H}), 7.79(\mathrm{~d}, J=8.0 \mathrm{~Hz}, 1 \mathrm{H})$, $7.40-7.28(\mathrm{~m}, 6 \mathrm{H}), 7.28-7.11(\mathrm{~m}, 7 \mathrm{H}), 6.87-6.76(\mathrm{~m}, 2 \mathrm{H}), 6.00(\mathrm{~d}, J=8.7 \mathrm{~Hz}, 1 \mathrm{H})$.

${ }^{13} \mathrm{C}-\mathrm{NMR}\left(75 \mathrm{MHz}, \mathrm{CDCl}_{3}\right): \delta=162.0\left(\mathrm{~d},{ }^{1} J_{\mathrm{C}-\mathrm{F}}=246 \mathrm{~Hz}, \mathrm{C}_{\mathrm{q}}\right), 137.1\left(\mathrm{C}_{\mathrm{q}}\right), 136.1\left(\mathrm{C}_{\mathrm{q}}\right), 135.4\left(\mathrm{C}_{\mathrm{q}}\right)$, $135.0\left(\mathrm{C}_{\mathrm{q}}\right), 132.6\left(\mathrm{C}_{\mathrm{q}}\right), 132.3\left(\mathrm{~d},{ }^{3} \mathrm{~J}_{\mathrm{C}-\mathrm{F}}=9 \mathrm{~Hz}, \mathrm{C}_{\mathrm{q}}\right), 131.6(\mathrm{CH}), 130.6(\mathrm{CH}), 129.7\left(\mathrm{C}_{\mathrm{q}}\right), 128.8$ $(\mathrm{CH}), 128.6(\mathrm{CH}), 128.0(\mathrm{CH}), 127.0(\mathrm{CH}), 125.4\left(\mathrm{~d},{ }^{3} \mathrm{~J}_{\mathrm{C}-\mathrm{F}}=9 \mathrm{~Hz}, \mathrm{CH}\right), 121.9\left(\mathrm{C}_{\mathrm{q}}\right), 121.9(\mathrm{CH})$, $121.8(\mathrm{CH}), 120.8\left(\mathrm{~d},{ }^{4} J_{\mathrm{C}-\mathrm{F}}=3 \mathrm{~Hz}, \mathrm{C}_{\mathrm{q}}\right), 120.1(\mathrm{CH}), 111.2\left(\mathrm{~d},{ }^{2} J_{\mathrm{C}-\mathrm{F}}=23 \mathrm{~Hz}, \mathrm{CH}\right), 114.6(\mathrm{CH})$, $111.6\left(\mathrm{~d},{ }^{2} J_{\mathrm{C}-\mathrm{F}}=23 \mathrm{~Hz}, \mathrm{CH}\right), 93.9(\mathrm{CH})$.

${ }^{19} \mathrm{~F}-\mathrm{NMR}\left(283 \mathrm{MHz}, \mathrm{CDCl}_{3}\right): \delta=-(112.6-112.7)(\mathrm{m})$.

IR (ATR): $\tilde{V}=3055,1609,1546,1481,1438,1273,775,738,724,693 \mathrm{~cm}^{-1}$.

MS (EI) $m / z$ (relative intensity): 387 (100) $\left[\mathrm{M}^{+}\right], 309$ (37).

HR-MS (EI) $m / z$ calcd for $\mathrm{C}_{28} \mathrm{H}_{18} \mathrm{FN}^{+} 387.1383$, found 387.1412.

\section{Synthesis of 5,6-diphenyl-3-(trifluoromethyl)indolo[2,1-a]isoquinoline (207ga)}

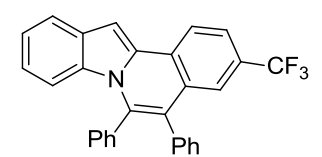

The general procedure $\mathbf{A}$ was followed using 2-\{4-(trifluoromethyl)phenyl $\}-1 H$-indole $(\mathbf{2 0 7 g})$ (131 $\mathrm{mg}, 0.50 \mathrm{mmol})$, diphenylacetylene (38a) $(178 \mathrm{mg}, 1.00 \mathrm{mmol})$ and $\mathrm{Cu}(\mathrm{OAc})_{2} \cdot \mathrm{H}_{2} \mathrm{O}(10 \mathrm{mg}$, $10.0 \mathrm{~mol} \%)$. After $22 \mathrm{~h}$, purification by column chromatography on silica gel ( $n$-hexane/ $\mathrm{CH}_{2} \mathrm{Cl}_{2}$ : 5/1) yielded 207ga (158 $\mathrm{mg}, 72 \%)$ as a yellow solid.

M. p. $=225-226^{\circ} \mathrm{C}$.

${ }^{1} \mathrm{H}-\mathrm{NMR}\left(300 \mathrm{MHz}, \mathrm{CDCl}_{3}\right): \delta=8.38(\mathrm{~d}, J=8.4 \mathrm{~Hz}, 1 \mathrm{H}), 7.82(\mathrm{~d}, J=8.0 \mathrm{~Hz}, 1 \mathrm{H}), 7.71(\mathrm{~d}, J=$ $8.4 \mathrm{~Hz}, 1 \mathrm{H}), 7.51(\mathrm{~s}, 1 \mathrm{H}), 7.41-7.28(\mathrm{~m}, 6 \mathrm{H}), 7.28-7.20(\mathrm{~m}, 4 \mathrm{H}), 7.20-7.12(\mathrm{~m}, 2 \mathrm{H}), 6.86$ (ddd, $J=7.8,7.8,1.3 \mathrm{~Hz}, 1 \mathrm{H}), 6.00(\mathrm{~d}, J=8.8 \mathrm{~Hz}, 1 \mathrm{H})$.

${ }^{13} \mathrm{C}-\mathrm{NMR}\left(75 \mathrm{MHz}, \mathrm{CDCl}_{3}\right): \delta=137.3\left(\mathrm{C}_{\mathrm{q}}\right), 135.7\left(\mathrm{C}_{\mathrm{q}}\right), 134.8\left(\mathrm{C}_{\mathrm{q}}\right), 134.6\left(\mathrm{C}_{\mathrm{q}}\right), 132.9\left(\mathrm{C}_{\mathrm{q}}\right), 131.7$ $(\mathrm{CH}), 130.6(\mathrm{CH}), 130.1\left(\mathrm{C}_{\mathrm{q}}\right), 129.5\left(\mathrm{C}_{\mathrm{q}}\right), 129.3\left(\mathrm{q},{ }^{2} J_{\mathrm{C}-\mathrm{F}}=22 \mathrm{~Hz}, \mathrm{C}_{\mathrm{q}}\right), 128.9(\mathrm{CH}), 128.1(\mathrm{CH})$, $127.9\left(\mathrm{C}_{\mathrm{q}}\right), 127.2(\mathrm{CH}), 124.1\left(\mathrm{q},{ }^{1} J_{\mathrm{C}-\mathrm{F}}=273 \mathrm{~Hz}, \mathrm{C}_{\mathrm{q}}\right), 123.8(\mathrm{CH}), 123.2\left(\mathrm{q},{ }^{2} J_{\mathrm{C}-\mathrm{F}}=19 \mathrm{~Hz}, \mathrm{CH}\right)$, $123.2\left(\mathrm{q},{ }^{3} J_{\mathrm{C}-\mathrm{F}}=11 \mathrm{~Hz}, \mathrm{CH}\right), 123.2\left(\mathrm{q},{ }^{4} J_{\mathrm{C}-\mathrm{F}}=4 \mathrm{~Hz}, \mathrm{CH}\right), 122.0(\mathrm{CH}), 121.0(\mathrm{CH}), 120.9\left(\mathrm{C}_{\mathrm{q}}\right)$, $120.6(\mathrm{CH}), 114.7(\mathrm{CH}), 96.0(\mathrm{CH})$.

${ }^{19} \mathrm{~F}-\mathrm{NMR}\left(283 \mathrm{MHz}, \mathrm{CDCl}_{3}\right): \delta=-62.3$ (s).

IR (ATR): $\tilde{V}=3062,1618,1544,1485,1345,1272,1017,977,744,695 \mathrm{~cm}^{-1}$.

MS (EI) $m / z$ (relative intensity): 437 (100) $\left[\mathrm{M}^{+}\right], 359$ (11).

HR-MS (EI) $m / z$ calcd for $\mathrm{C}_{29} \mathrm{H}_{18} \mathrm{~F}_{3} \mathrm{~N}^{+} 437.1391$, found 437.1376. 


\section{Synthesis of 3-nitro-5,6-diphenylindolo[2,1-a]isoquinoline (207ha)}

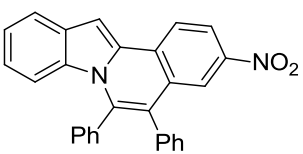

The general procedure A was followed using 2-(4-nitrophenyl)-1H-indole (206h) (119 mg, $0.50 \mathrm{mmol})$, diphenylacetylene (38a) (178 mg, $1.00 \mathrm{mmol})$ and $\mathrm{Cu}(\mathrm{OAc})_{2} \cdot \mathrm{H}_{2} \mathrm{O}(10 \mathrm{mg}, 10.0 \mathrm{~mol} \%)$. After $22 \mathrm{~h}$, purification by column chromatography on silica gel ( $n$-hexane/ $\left.\mathrm{CH}_{2} \mathrm{Cl}_{2}: 7 / 1\right)$ yielded 207 ha $(92 \mathrm{mg}, 44 \%)$ as a yellow solid.

M. p. $=224-225^{\circ} \mathrm{C}$.

${ }^{1} \mathrm{H}-\mathrm{NMR}\left(300 \mathrm{MHz}, \mathrm{CDCl}_{3}\right): \delta=8.38(\mathrm{~d}, J=8.2 \mathrm{~Hz}, 1 \mathrm{H}), 7.83(\mathrm{~d}, J=7.8 \mathrm{~Hz}, 1 \mathrm{H}), 7.71(\mathrm{~d}$, $J=8.2 \mathrm{~Hz}, 1 \mathrm{H}), 7.51(\mathrm{~s}, 1 \mathrm{H}), 7.45-7.08(\mathrm{~m}, 12 \mathrm{H}), 6.87(\mathrm{dd}, J=8.2,7.4 \mathrm{~Hz}, 1 \mathrm{H}), 6.01(\mathrm{~d}, J=8.8$ $\mathrm{Hz}, 1 \mathrm{H})$.

${ }^{13} \mathrm{C}-\mathrm{NMR}\left(75 \mathrm{MHz}, \mathrm{CDCl}_{3}\right): \delta=137.3\left(\mathrm{C}_{\mathrm{q}}\right), 135.7\left(\mathrm{C}_{\mathrm{q}}\right), 134.9\left(\mathrm{C}_{\mathrm{q}}\right), 134.7\left(\mathrm{C}_{\mathrm{q}}\right), 132.9\left(\mathrm{C}_{\mathrm{q}}\right), 131.7$ $(\mathrm{CH}), 130.6(\mathrm{CH}), 130.2\left(\mathrm{C}_{\mathrm{q}}\right), 129.5\left(\mathrm{C}_{\mathrm{q}}\right), 128.9(\mathrm{CH}), 128.7(\mathrm{CH}), 128.1(\mathrm{CH}), 127.9\left(\mathrm{C}_{\mathrm{q}}\right), 127.2$ $(\mathrm{CH}), 125.9\left(\mathrm{C}_{\mathrm{q}}\right), 123.8(\mathrm{CH}), 123.2(\mathrm{CH}), 123.1(\mathrm{CH}), 122.0(\mathrm{CH}), 121.0(\mathrm{CH}), 120.9\left(\mathrm{C}_{\mathrm{q}}\right), 120.6$ $(\mathrm{CH}), 114.7(\mathrm{CH}), 96.0(\mathrm{CH})$.

IR (ATR): $\tilde{V}=3061,3032,1618,1597,1544,1485,1444,1169,825,658 \mathrm{~cm}^{-1}$.

MS (EI) $m / z$ (relative intensity): 414 (100) $\left[\mathrm{M}^{+}\right], 384$ (27), 368 (30).

HR-MS (EI) $m / z$ calcd for $\mathrm{C}_{28} \mathrm{H}_{18} \mathrm{~N}_{2} \mathrm{O}_{2}{ }^{+} 414.1368$, found 414.1368.

\section{Synthesis of methyl 5,6-diphenylindolo[2,1-a]isoquinoline-3-carboxylate (207ia)}

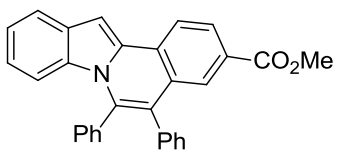

The general procedure A was followed using methyl 4-(1H-indol-2-yl)benzoate (206i) (126 $\mathrm{mg}, \quad 0.50 \quad \mathrm{mmol})$, diphenylacetylene (38a) (178 $\mathrm{mg}, 1.00 \mathrm{mmol})$ and $\mathrm{Cu}(\mathrm{OAc})_{2} \cdot \mathrm{H}_{2} \mathrm{O}$ (10 mg, $10.0 \mathrm{~mol} \%)$. After $22 \mathrm{~h}$, purification by column chromatography on silica gel ( $n$-hexane/ $\mathrm{CH}_{2} \mathrm{Cl}_{2}$ : 2/1) yielded 207ia $(122 \mathrm{mg}, 57 \%$ ) as a yellow solid.

M. p. $=256-257^{\circ} \mathrm{C}$.

${ }^{1} \mathrm{H}-\mathrm{NMR}\left(300 \mathrm{MHz}, \mathrm{CDCl}_{3}\right): \delta=8.33(\mathrm{~d}, J=8.3 \mathrm{~Hz}, 1 \mathrm{H}), 8.13(\mathrm{dd}, J=8.3,1.6 \mathrm{~Hz}, 1 \mathrm{H}), 7.86(\mathrm{~s}$, $1 \mathrm{H}), 7.82(\mathrm{~d}, J=8.0 \mathrm{~Hz}, 1 \mathrm{H}), 7.51(\mathrm{~s}, 1 \mathrm{H}), 7.39-7.28(\mathrm{~m}, 5 \mathrm{H}), 7.27-7.15(\mathrm{~m}, 6 \mathrm{H}), 6.86(\mathrm{dd}, J=$ 7.8, 7.7 Hz, 1H), 6.00 (d, $J=8.7 \mathrm{~Hz}, 1 \mathrm{H}), 3.86$ (s, 3H).

${ }^{13} \mathrm{C}-\mathrm{NMR}\left(75 \mathrm{MHz}, \mathrm{CDCl}_{3}\right): \delta=166.8\left(\mathrm{C}_{\mathrm{q}}\right), 136.7\left(\mathrm{C}_{\mathrm{q}}\right), 135.9\left(\mathrm{C}_{\mathrm{q}}\right), 135.0\left(\mathrm{C}_{\mathrm{q}}\right), 134.9\left(\mathrm{C}_{\mathrm{q}}\right), 133.0$ $\left(\mathrm{C}_{\mathrm{q}}\right), 131.7(\mathrm{CH}), 130.7(\mathrm{CH}), 129.9\left(\mathrm{C}_{\mathrm{q}}\right), 129.5\left(\mathrm{C}_{\mathrm{q}}\right), 128.9\left(\mathrm{C}_{\mathrm{q}}\right), 128.8(\mathrm{CH}), 128.6(\mathrm{CH}), 128.5$ $\left(\mathrm{C}_{\mathrm{q}}\right), 128.0(\mathrm{CH}), 127.8(\mathrm{CH}), 127.5(\mathrm{CH}), 127.0(\mathrm{CH}), 123.2(\mathrm{CH}), 121.9(\mathrm{CH}), 121.3\left(\mathrm{C}_{\mathrm{q}}\right), 120.9$ (CH), $120.6(\mathrm{CH}), 114.7(\mathrm{CH}), 96.3(\mathrm{CH}), 52.1\left(\mathrm{CH}_{3}\right)$.

IR (ATR): $\tilde{V}=3025,1708,1604,1544,1484,1441,1382,762,738,701 \mathrm{~cm}^{-1}$.

MS (EI) $m / z$ (relative intensity): 387 (100) $\left[\mathrm{M}^{+}\right], 367$ (9), 291 (10).

HR-MS (EI) $m / z$ calcd for $\mathrm{C}_{30} \mathrm{H}_{21} \mathrm{NO}_{2}{ }^{+} 387.1572$, found 387.1578 .

The spectral data were in accordance with those reported in the literature. ${ }^{117}$

\section{Synthesis of 3-chloro-5,6-diphenylindolo[2,1-a]isoquinoline (207ja)}

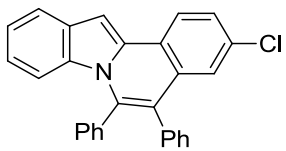

The general procedure A was 2-2-(4-chlorophenyl)-1H-indole (206j) (113 $\mathrm{mg}, \quad 0.50 \quad \mathrm{mmol})$, diphenylacetylene (38a) (178 mg, $1.00 \mathrm{mmol})$ and $\mathrm{Cu}(\mathrm{OAc})_{2} \cdot \mathrm{H}_{2} \mathrm{O}(10 \mathrm{mg}$, $10.0 \mathrm{~mol} \%$ ). After $22 \mathrm{~h}$, purification by column chromatography on silica gel ( $n$-hexane/ $\mathrm{CH}_{2} \mathrm{Cl}_{2}$ : 10/1) yielded 207ja (26mg, 13\%) as a yellow solid.

The general procedure $\mathbf{B}$ was followed using 2-2-(4-chlorophenyl)-1H-indole (206j) (113 $\mathrm{mg}$, $0.50 \mathrm{mmol}$ ) and diphenylacetylene (38a) $(178 \mathrm{mg}, 1.00 \mathrm{mmol})$. After $22 \mathrm{~h}$, purification by column 
chromatography on silica gel ( $n$-hexane/ $\left.\mathrm{CH}_{2} \mathrm{Cl}_{2}: 10 / 1\right)$ yielded $207 \mathbf{j a}(104 \mathrm{mg}, 51 \%)$ as a yellow solid.

M. p. $=241-238^{\circ} \mathrm{C}$.

${ }^{1} \mathrm{H}-\mathrm{NMR}\left(300 \mathrm{MHz}, \mathrm{CDCl}_{3}\right): \delta=8.17(\mathrm{~d}, J=8.7 \mathrm{~Hz}, 1 \mathrm{H}), 7.81(\mathrm{~d}, J=8.0 \mathrm{~Hz}, 1 \mathrm{H}), 7.48-7.10(\mathrm{~m}$, $14 \mathrm{H}), 6.92(\mathrm{dd}, J=8.2,7.1 \mathrm{~Hz}, 1 \mathrm{H}), 6.03(\mathrm{~d}, J=8.2 \mathrm{~Hz}, 1 \mathrm{H})$.

${ }^{13} \mathrm{C}-\mathrm{NMR}\left(75 \mathrm{MHz}, \mathrm{CDCl}_{3}\right): \delta=137.1\left(\mathrm{C}_{\mathrm{q}}\right), 135.9\left(\mathrm{C}_{\mathrm{q}}\right), 135.0\left(\mathrm{C}_{\mathrm{q}}\right), 134.9\left(\mathrm{C}_{\mathrm{q}}\right), 133.1\left(\mathrm{C}_{\mathrm{q}}\right), 132.7$

$\left(\mathrm{C}_{\mathrm{q}}\right), 131.6(\mathrm{CH}), 131.6\left(\mathrm{C}_{\mathrm{q}}\right), 130.6(\mathrm{CH}), 129.6\left(\mathrm{C}_{\mathrm{q}}\right), 128.8(\mathrm{CH}), 128.6(\mathrm{CH}), 128.0(\mathrm{CH}), 127.2$ $(\mathrm{CH}), 127.0(\mathrm{CH}), 125.4(\mathrm{CH}), 124.7(\mathrm{CH}), 123.7\left(\mathrm{C}_{\mathrm{q}}\right), 121.8(\mathrm{CH}), 120.4(\mathrm{CH}), 120.4\left(\mathrm{C}_{\mathrm{q}}\right), 120.3$ $(\mathrm{CH}), 114.6(\mathrm{CH}), 94.6(\mathrm{CH})$.

IR (ATR): $\tilde{V}=3048,1594,1546,1479,1441,1417,1071,759,700 \mathrm{~cm}^{-1}$.

MS (EI) $m / z$ (relative intensity): 403 (100) $\left[\mathrm{M}^{+}\right], 367$ (10), 291 (10).

HR-MS (ESI) $\mathrm{m} / z$ calcd for $\mathrm{C}_{28} \mathrm{H}_{18} \mathrm{ClN}^{+} 403.1128$, found 403.1118 .

The spectral data were in accordance with those reported in the literature. ${ }^{117}$

\section{Synthesis of 3-methyl-5,6-diphenylindolo[2,1-a]isoquinoline (207ka)}

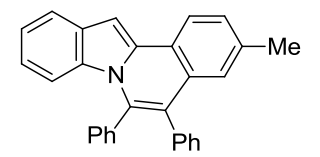

The general procedure A was followed using 2-2-( $p$-tolyl)- $1 H$-indole (206k) (104 mg, $0.50 \mathrm{mmol})$, diphenylacetylene (38a) $(178 \mathrm{mg}, 1.00 \mathrm{mmol})$ and $\mathrm{Cu}(\mathrm{OAc})_{2} \cdot \mathrm{H}_{2} \mathrm{O}(10 \mathrm{mg}, 10.0 \mathrm{~mol} \%)$. After $22 \mathrm{~h}$, purification by column chromatography on silica gel ( $n$-hexane/ $\left.\mathrm{CH}_{2} \mathrm{Cl}_{2}: 10 / 1\right)$ yielded $207 \mathrm{ka}(11 \mathrm{mg}, 6 \%)$ as a yellow solid.

The general procedure $\mathbf{B}$ was followed using 2-2-( $p$-tolyl)- $1 H$-indole (206k) $(104 \mathrm{mg}, 0.50 \mathrm{mmol})$ and diphenylacetylene (38a) (178 $\mathrm{mg}, 1.00 \mathrm{mmol}$ ). After $22 \mathrm{~h}$, purification by column chromatography on silica gel ( $n$-hexane/ $\left.\mathrm{CH}_{2} \mathrm{Cl}_{2}: 10 / 1\right)$ yielded 207ka (106 mg, 55\%) as a yellow solid.

M. p. $=249-250^{\circ} \mathrm{C}$.

${ }^{1} \mathrm{H}-\mathrm{NMR}\left(300 \mathrm{MHz}, \mathrm{CDCl}_{3}\right): \delta=8.21(\mathrm{~d}, J=8.2 \mathrm{~Hz}, 1 \mathrm{H}), 7.78(\mathrm{~d}, J=7.9 \mathrm{~Hz}, 1 \mathrm{H}), 7.43-7.14(\mathrm{~m}$, $12 \mathrm{H}), 6.95(\mathrm{~s}, 1 \mathrm{H}), 6.81(\mathrm{dd}, J=7.8,7.8 \mathrm{~Hz}, 1 \mathrm{H}), 5.99(\mathrm{~d}, J=8.7 \mathrm{~Hz}, 1 \mathrm{H}), 2.36(\mathrm{~s}, 3 \mathrm{H})$.

${ }^{13} \mathrm{C}-\mathrm{NMR}\left(75 \mathrm{MHz}, \mathrm{CDCl}_{3}\right): \delta=137.3\left(\mathrm{C}_{\mathrm{q}}\right), 136.8\left(\mathrm{C}_{\mathrm{q}}\right), 136.1\left(\mathrm{C}_{\mathrm{q}}\right), 136.0\left(\mathrm{C}_{\mathrm{q}}\right), 135.4\left(\mathrm{C}_{\mathrm{q}}\right), 132.6$ $\left(\mathrm{C}_{\mathrm{q}}\right), 131.8(\mathrm{CH}), 130.8(\mathrm{CH}), 130.2\left(\mathrm{C}_{\mathrm{q}}\right), 129.8\left(\mathrm{C}_{\mathrm{q}}\right), 128.6(\mathrm{CH}), 128.5(\mathrm{CH}), 128.4(\mathrm{CH}), 127.8$ $(\mathrm{CH}), 126.7(\mathrm{CH}), 126.0(\mathrm{CH}), 123.3(\mathrm{CH}), 123.0\left(\mathrm{C}_{\mathrm{q}}\right), 121.5(\mathrm{CH}), 121.3\left(\mathrm{C}_{\mathrm{q}}\right), 120.0(\mathrm{CH}), 119.8$ $(\mathrm{CH}), 114.5(\mathrm{CH}), 93.4(\mathrm{CH}), 21.7\left(\mathrm{CH}_{3}\right)$.

IR (ATR): $\tilde{V}=3024,1595,1541,1483,1341,1021,759,692 \mathrm{~cm}^{-1}$.

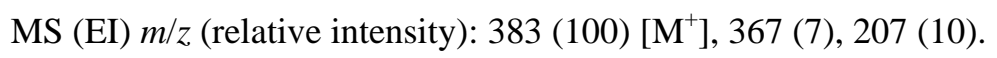

HR-MS (EI) $m / z$ calcd for $\mathrm{C}_{29} \mathrm{H}_{21} \mathrm{~N}^{+} 383.1674$, found 383.1664 .

The spectral data were in accordance with those reported in the literature. ${ }^{117}$

\section{Synthesis of 7, 8-diphenylbenzo[ $h]$ indolo[2,1-a]isoquinoline (207la)}

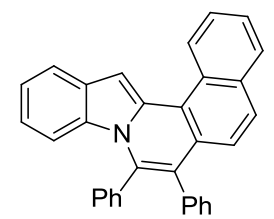

The general procedure $\mathbf{A}$ was followed using 2-(naphthalen-1-yl)-1H-indole (206) $(122 \mathrm{mg}, 0.50 \mathrm{mmol})$, diphenylacetylene (38a) (178 mg, $1.00 \mathrm{mmol})$ and $\mathrm{Cu}(\mathrm{OAc})_{2} \cdot \mathrm{H}_{2} \mathrm{O}(10 \mathrm{mg}, 10.0 \mathrm{~mol} \%)$. After $22 \mathrm{~h}$, purification by column chromatography on silica gel ( $n$-hexane/ $\left.\mathrm{CH}_{2} \mathrm{Cl}_{2}: 5 / 1\right)$ yielded 207la $(97 \mathrm{mg}$, $46 \%$ ) as a yellow solid.

M. p. $=213-215^{\circ} \mathrm{C}$.

${ }^{1} \mathrm{H}-\mathrm{NMR}\left(300 \mathrm{MHz}, \mathrm{CDCl}_{3}\right): \delta=9.40(\mathrm{~d}, J=8.6 \mathrm{~Hz}, 1 \mathrm{H}), 8.06(\mathrm{~s}, 1 \mathrm{H}), 7.96(\mathrm{dd}, J=9.0,8.6 \mathrm{~Hz}$, 2H), $7.84(\mathrm{ddd}, J=7.6,7.6,1.2 \mathrm{~Hz}, 1 \mathrm{H}), 7.76(\mathrm{~d}, J=8.6 \mathrm{~Hz}, 1 \mathrm{H}), 7.66(\mathrm{dd}, J=7.3,7.3 \mathrm{~Hz}, 1 \mathrm{H})$, 
7.46-7.18 (m, 12H), 6.92 (ddd, 8.0, 7.8, 1.2 Hz, 1H), $6.17(\mathrm{~d}, J=8.7 \mathrm{~Hz}, 1 \mathrm{H})$.

${ }^{13} \mathrm{C}-\mathrm{NMR}\left(75 \mathrm{MHz}, \mathrm{CDCl}_{3}\right): \delta=137.2\left(\mathrm{C}_{\mathrm{q}}\right), 136.6\left(\mathrm{C}_{\mathrm{q}}\right), 135.6\left(\mathrm{C}_{\mathrm{q}}\right), 134.9\left(\mathrm{C}_{\mathrm{q}}\right), 132.8\left(\mathrm{C}_{\mathrm{q}}\right), 132.0$ $(\mathrm{CH}), 131.7\left(\mathrm{C}_{\mathrm{q}}\right), 130.7(\mathrm{CH}), 130.2\left(\mathrm{C}_{\mathrm{q}}\right), 129.5\left(\mathrm{C}_{\mathrm{q}}\right), 129.5\left(\mathrm{C}_{\mathrm{q}}\right), 128.9(\mathrm{CH}), 128.6(\mathrm{CH}), 128.6$ $(\mathrm{CH}), 127.9(\mathrm{CH}), 127.9(\mathrm{CH}), 127.2(\mathrm{CH}), 126.8(\mathrm{CH}), 125.9(\mathrm{CH}), 125.7(\mathrm{CH}), 124.2(\mathrm{CH})$, $122.1\left(\mathrm{C}_{\mathrm{q}}\right), 122.0(\mathrm{CH}), 121.2\left(\mathrm{C}_{\mathrm{q}}\right), 120.3(\mathrm{CH}), 120.2(\mathrm{CH}), 114.9(\mathrm{CH}), 99.3(\mathrm{CH})$.

IR (ATR): $\tilde{V}=3057,1588,1543,1467,1360,1208,1017,818,730,695 \mathrm{~cm}^{-1}$.

MS (EI) $m / z$ (relative intensity): 419 (100) $\left[\mathrm{M}^{+}\right], 341$ (20).

HR-MS (EI) $m / z$ calcd for $\mathrm{C}_{32} \mathrm{H}_{21} \mathrm{~N}^{+} 419.1674$, found 419.1678 .

The spectral data were in accordance with those reported in the literature. ${ }^{117}$

\section{Synthesis of 6,7-Diphenylbenzo[g]indolo[2,1-a]isoquinoline (207ma)}

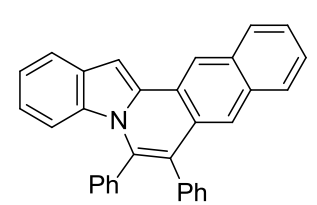

The general procedure A was followed using 2-(naphthalen-2-yl)-1 $H$-indole (206m) (121 mg, $0.50 \mathrm{mmol})$, diphenylacetylene (38a) (178 mg, $1.00 \mathrm{mmol})$ and $\mathrm{Cu}(\mathrm{OAc})_{2} \cdot \mathrm{H}_{2} \mathrm{O}(10 \mathrm{mg}, 10.0 \mathrm{~mol} \%)$. After $22 \mathrm{~h}$, purification by column chromatography on silica gel ( $n$-hexane/ $\left.\mathrm{CH}_{2} \mathrm{Cl}_{2}: 5 / 1\right)$ yielded 207ma (13 $\mathrm{mg}, 6 \%)$ as a yellow solid.

The general procedure $\mathbf{B}$ was followed using 2-(naphthalen-2-yl)-1H-indole (206m) (121 mg, 0.50 $\mathrm{mmol}$ ) and diphenylacetylene (38a) (178 $\mathrm{mg}, 1.00 \mathrm{mmol})$. After $22 \mathrm{~h}$, purification by column chromatography on silica gel ( $n$-hexane/ $\left.\mathrm{CH}_{2} \mathrm{Cl}_{2}: 5 / 1\right)$ yielded $207 \mathrm{ma}(97 \mathrm{mg}, 46 \%)$ as a yellow solid.

M. p. $=262-263^{\circ} \mathrm{C}$.

${ }^{1} \mathrm{H}-\mathrm{NMR}\left(300 \mathrm{MHz}, \mathrm{CDCl}_{3}\right): \delta=8.73(\mathrm{~s}, 1 \mathrm{H}), 8.00(\mathrm{~d}, J=8.1 \mathrm{~Hz}, 1 \mathrm{H}), 7.83(\mathrm{~d}, J=7.7 \mathrm{~Hz}, 1 \mathrm{H})$, $7.74(\mathrm{~d}, J=7.8 \mathrm{~Hz}, 1 \mathrm{H}), 7.59(\mathrm{~d}, J=2.8 \mathrm{~Hz}, 2 \mathrm{H}), 7.54-7.16(\mathrm{~m}, 13 \mathrm{H}), 6.89(\mathrm{dd}, J=7.8,7.8 \mathrm{~Hz}$, $1 \mathrm{H}), 5.99(\mathrm{~d}, J=8.2 \mathrm{~Hz}, 1 \mathrm{H})$.

${ }^{13} \mathrm{C}-\mathrm{NMR}\left(75 \mathrm{MHz}, \mathrm{CDCl}_{3}\right): \delta=136.8\left(\mathrm{C}_{\mathrm{q}}\right), 135.8\left(\mathrm{C}_{\mathrm{q}}\right), 135.6\left(\mathrm{C}_{\mathrm{q}}\right), 135.3\left(\mathrm{C}_{\mathrm{q}}\right), 133.6\left(\mathrm{C}_{\mathrm{q}}\right), 132.6$ $\left(\mathrm{C}_{\mathrm{q}}\right), 132.2\left(\mathrm{C}_{\mathrm{q}}\right), 131.9(\mathrm{CH}), 130.9(\mathrm{CH}), 129.5\left(\mathrm{C}_{\mathrm{q}}\right), 129.2\left(\mathrm{C}_{\mathrm{q}}\right), 128.6(\mathrm{CH}), 128.4(\mathrm{CH}), 128.1$ $(\mathrm{CH}), 127.9(\mathrm{CH}), 127.6(\mathrm{CH}), 126.8(\mathrm{CH}), 126.0(\mathrm{CH}), 125.8(\mathrm{CH}), 124.8(\mathrm{CH}), 124.2\left(\mathrm{C}_{\mathrm{q}}\right)$, $121.9(\mathrm{CH}), 121.7(\mathrm{CH}), 121.4\left(\mathrm{C}_{\mathrm{q}}\right), 120.8(\mathrm{CH}), 120.3(\mathrm{CH}), 114.4(\mathrm{CH}), 96.7(\mathrm{CH})$.

IR (ATR): $\tilde{V}=3051,3021,1625,1487,1375,1022,736,722,694 \mathrm{~cm}^{-1}$.

MS (EI) $m / z$ (relative intensity): $419(100)\left[\mathrm{M}^{+}\right], 341$ (18).

HR-MS (EI) $\mathrm{m} / z$ calcd for $\mathrm{C}_{32} \mathrm{H}_{21} \mathrm{~N}^{+} 419.1674$, found 419.1678 .

\section{Synthesis of 5,6-bis $\{4$-(trifluoromethyl)phenyl\}indolo[2,1-a]isoquinoline (207ab)}

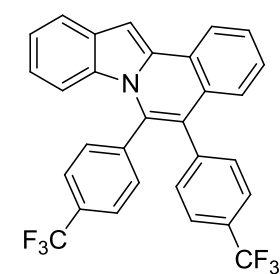

The general procedure $\mathbf{A}$ was followed using 2-phenyl-1H-indole (206a) (97.0 $\mathrm{mg}, \quad 0.50 \mathrm{mmol}$ ), 1,2-bis $\{4$-(trifluoromethyl)phenyl $\}$ ethyne $(\mathbf{3 8 b})$ (314 mg, $1.00 \mathrm{mmol})$ and $\mathrm{Cu}(\mathrm{OAc})_{2} \cdot \mathrm{H}_{2} \mathrm{O}(10 \mathrm{mg}, 10.0 \mathrm{~mol} \%)$. After $22 \mathrm{~h}$, purification by column chromatography on silica gel ( $n$-hexane/ $\left.\mathrm{CH}_{2} \mathrm{Cl}_{2}: 10 / 1\right)$ yielded 207ab (137 $\mathrm{mg}, 54 \%)$ as a yellow solid.

M. p. $=287-288^{\circ} \mathrm{C}$.

${ }^{1} \mathrm{H}-\mathrm{NMR}\left(300 \mathrm{MHz}, \mathrm{CDCl}_{3}\right): \delta=8.32(\mathrm{~d}, J=7.8 \mathrm{~Hz}, 1 \mathrm{H}), 7.82(\mathrm{~d}, J=7.8 \mathrm{~Hz}, 1 \mathrm{H}), 7.64(\mathrm{~d}, J=$ $7.8 \mathrm{~Hz}, 2 \mathrm{H}), 7.59-7.48(\mathrm{~m}, 3 \mathrm{H}), 7.48-7.33(\mathrm{~m}, 4 \mathrm{H}), 7.33-7.18(\mathrm{~m}, 3 \mathrm{H}), 7.05(\mathrm{~d}, J=7.8 \mathrm{~Hz}, 1 \mathrm{H})$, $6.88(\mathrm{dd}, J=7.8,7.8 \mathrm{~Hz}, 1 \mathrm{H}), 5.95(\mathrm{~d}, J=8.6 \mathrm{~Hz}, 1 \mathrm{H})$.

${ }^{13} \mathrm{C}-\mathrm{NMR}\left(75 \mathrm{MHz}, \mathrm{CDCl}_{3}\right): \delta=140.2\left(\mathrm{C}_{\mathrm{q}}\right), 138.5\left(\mathrm{C}_{\mathrm{q}}\right), 135.7\left(\mathrm{C}_{\mathrm{q}}\right), 134.5\left(\mathrm{C}_{\mathrm{q}}\right), 132.5\left(\mathrm{C}_{\mathrm{q}}\right), 132.1$ $(\mathrm{CH}), 131.2\left(\mathrm{q},{ }^{2} J_{\mathrm{C}-\mathrm{F}}=33 \mathrm{~Hz}, \mathrm{C}_{\mathrm{q}}\right), 131.2(\mathrm{CH}), 129.8\left(\mathrm{C}_{\mathrm{q}}\right), 129.7\left(\mathrm{q},{ }^{2} J_{\mathrm{C}-\mathrm{F}}=33 \mathrm{~Hz}, \mathrm{C}_{\mathrm{q}}\right), 129.2$ $\left(\mathrm{C}_{\mathrm{q}}\right), 127.8\left(\mathrm{q},{ }^{3} J_{\mathrm{C}-\mathrm{F}}=11 \mathrm{~Hz}, \mathrm{CH}\right), 125.9(\mathrm{CH}), 125.8\left(\mathrm{q},{ }^{4} J_{\mathrm{C}-\mathrm{F}}=4 \mathrm{~Hz}, \mathrm{CH}\right), 125.6\left(\mathrm{C}_{\mathrm{q}}\right), 125.1(\mathrm{q}$, 
$\left.{ }^{3} J_{\mathrm{C}-\mathrm{F}}=11 \mathrm{~Hz}, \mathrm{CH}\right), 125.1\left(\mathrm{q},{ }^{4} J_{\mathrm{C}-\mathrm{F}}=4 \mathrm{~Hz}, \mathrm{CH}\right), 124.0\left(\mathrm{q},{ }^{1} J_{\mathrm{C}-\mathrm{F}}=272 \mathrm{~Hz}, \mathrm{C}_{\mathrm{q}}\right) \cdot 123.7\left(\mathrm{q},{ }^{1} J_{\mathrm{C}-\mathrm{F}}=\right.$ $\left.272 \mathrm{~Hz}, \mathrm{C}_{\mathrm{q}}\right), 123.5(\mathrm{CH}), 122.1(\mathrm{CH}), 120.7(\mathrm{CH}), 120.7\left(\mathrm{C}_{\mathrm{q}}\right), 120.6(\mathrm{CH}), 114.0(\mathrm{CH}), 94.9(\mathrm{CH})$. ${ }^{19} \mathrm{~F}-\mathrm{NMR}\left(283 \mathrm{MHz}, \mathrm{CDCl}_{3}\right): \delta=-62.6(\mathrm{~s}),-62.7(\mathrm{~s})$.

IR (ATR): $\tilde{V}=3065,1612,1576,1545,1446,1322,1171,1105,1066,759 \mathrm{~cm}^{-1}$.

MS (EI) $m / z$ (relative intensity): 505 (100) $\left[\mathrm{M}^{+}\right], 435$ (10), 359 (15), 291 (10).

HR-MS (EI) $m / z$ calcd for $\mathrm{C}_{30} \mathrm{H}_{17} \mathrm{~F}_{6} \mathrm{~N}^{+} 505.1265$, found 505.1269.

The spectral data were in accordance with those reported in the literature. ${ }^{117}$

\section{Synthesis of 5,6-di-( $p$-tolyl)indolo[2,1-a]isoquinoline (207ac)}

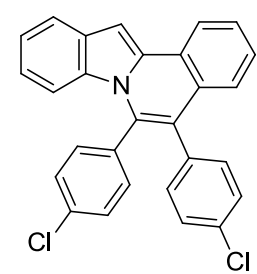

The general procedure A was followed using 2-phenyl-1 $H$-indole (206a) (97 mg, $0.50 \mathrm{mmol})$, 1,2-bis(4-chlorophenyl)ethyne (38c) $(247 \mathrm{mg}, 1.00 \mathrm{mmol})$ and $\mathrm{Cu}(\mathrm{OAc})_{2} \cdot \mathrm{H}_{2} \mathrm{O}(10 \mathrm{mg}, 10.0 \mathrm{~mol} \%)$. After $22 \mathrm{~h}$, purification by column chromatography on silica gel ( $n$-hexane/ $\left.\mathrm{CH}_{2} \mathrm{Cl}_{2}: 10 / 1\right)$ yielded $207 \mathrm{ac}(14 \mathrm{mg}$, $6 \%)$ as a yellow solid.

The general procedure B was followed using 2-phenyl-1 $H$-indole (206a) (97 mg, $0.50 \mathrm{mmol}$ ) and 1,2-bis(4-chlorophenyl)ethyne (38c) (247 mg, $1.00 \mathrm{mmol})$. After $22 \mathrm{~h}$, purification by column chromatography on silica gel ( $n$-hexane $\left./ \mathrm{CH}_{2} \mathrm{Cl}_{2}: 10 / 1\right)$ yielded $207 \mathbf{a c}$ (176 $\mathrm{mg}, 82 \%)$ as a yellow solid.

M. p. $=251-252^{\circ} \mathrm{C}$.

${ }^{1} \mathrm{H}-\mathrm{NMR}\left(300 \mathrm{MHz}, \mathrm{CDCl}_{3}\right): \delta=8.29(\mathrm{~d}, J=8.2 \mathrm{~Hz}, 1 \mathrm{H}), 7.81(\mathrm{~d}, J=7.8 \mathrm{~Hz}, 1 \mathrm{H}), 7.50(\mathrm{ddd}, J=$ 7.8, 7.5, 1.2 Hz, 1H), $7.38(\mathrm{~s}, 1 \mathrm{H}), 7.39-7.35(\mathrm{~m}, 3 \mathrm{H}), 7.29-7.21(\mathrm{~m}, 5 \mathrm{H}), 7.13-7.06(\mathrm{~m}, 3 \mathrm{H})$, 6.90 (ddd, $J=7.8,7.8,1.2 \mathrm{~Hz}, 1 \mathrm{H}), 6.09(\mathrm{~d}, J=8.6 \mathrm{~Hz}, 1 \mathrm{H})$.

${ }^{13} \mathrm{C}-\mathrm{NMR}\left(75 \mathrm{MHz}, \mathrm{CDCl}_{3}\right): \delta=135.7\left(\mathrm{C}_{\mathrm{q}}\right), 135.0\left(\mathrm{C}_{\mathrm{q}}\right), 134.9\left(\mathrm{C}_{\mathrm{q}}\right), 134.9\left(\mathrm{C}_{\mathrm{q}}\right), 133.5\left(\mathrm{C}_{\mathrm{q}}\right), 133.0$ $\left(\mathrm{C}_{\mathrm{q}}\right), 133.0(\mathrm{CH}), 132.5\left(\mathrm{C}_{\mathrm{q}}\right), 132.1(\mathrm{CH}), 129.7\left(\mathrm{C}_{\mathrm{q}}\right), 129.6\left(\mathrm{C}_{\mathrm{q}}\right), 129.2(\mathrm{CH}), 128.3(\mathrm{CH}), 127.5$ $(\mathrm{CH}), 127.4(\mathrm{CH}), 125.9(\mathrm{CH}), 125.4\left(\mathrm{C}_{\mathrm{q}}\right), 123.4(\mathrm{CH}), 121.9(\mathrm{CH}), 120.6\left(\mathrm{C}_{\mathrm{q}}\right), 120.5(\mathrm{CH}), 120.4$ $(\mathrm{CH}), 114.2(\mathrm{CH}), 94.6(\mathrm{CH})$.

IR (ATR): $\tilde{V}=3064,1619,1591,1538,1484,1443,1393,1087,1014,737 \mathrm{~cm}^{-1}$.

MS (EI) $m / z$ (relative intensity): 437 (100) $\left[\mathrm{M}^{+}\right], 401$ (9), 365 (11), 291 (10), 182 (18).

HR-MS (EI) $m / z$ calcd for $\mathrm{C}_{28} \mathrm{H}_{17} \mathrm{Cl}_{2} \mathrm{~N}^{+} 437.0738$, found 437.0728 .

The spectral data were in accordance with those reported in the literature. ${ }^{117}$

\section{Synthesis of ethyl 5,6-diphenylpyrrolo[2,1-a]isoquinoline-2-carboxylate (209aa)}

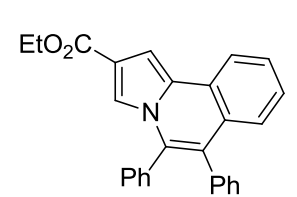

The general procedure $\mathbf{A}$ was followed using ethyl 5-phenyl-1H-pyrrole-3-carboxylate (208a) (108 mg, $0.50 \mathrm{mmol})$, diphenylacetylene (38a) (178 mg, $1.00 \mathrm{mmol})$ and $\mathrm{Cu}(\mathrm{OAc})_{2} \cdot \mathrm{H}_{2} \mathrm{O}(10 \mathrm{mg}$, $10.0 \mathrm{~mol} \%$ ). After $22 \mathrm{~h}$, purification by column chromatography on silica gel ( $n$-hexane/ $\left.\mathrm{CH}_{2} \mathrm{Cl}_{2}: 5 / 1\right)$ yielded 209aa $(182 \mathrm{mg}, 93 \%)$ as a yellow solid.

M. p. $=200-201^{\circ} \mathrm{C}$.

${ }^{1} \mathrm{H}-\mathrm{NMR}\left(300 \mathrm{MHz}, \mathrm{CDCl}_{3}\right): \delta=8.15(\mathrm{~d}, J=8.0 \mathrm{~Hz}, 1 \mathrm{H}), 7.54-7.37(\mathrm{~m}, 2 \mathrm{H}), 7.38(\mathrm{~d}, J=1.6 \mathrm{~Hz}$, 1H), 7.36-7.19 (m, 10H), 7.19-7.11 (m, 2H), 4.33 (q, $J=7.1 \mathrm{~Hz}, 2 \mathrm{H}), 1.37$ (t, $J=7.1 \mathrm{~Hz}, 3 \mathrm{H})$. ${ }^{13} \mathrm{C}-\mathrm{NMR}\left(75 \mathrm{MHz}, \mathrm{CDCl}_{3}\right): \delta=165.1\left(\mathrm{C}_{\mathrm{q}}\right), 136.2\left(\mathrm{C}_{\mathrm{q}}\right), 133.8\left(\mathrm{C}_{\mathrm{q}}\right), 133.3\left(\mathrm{C}_{\mathrm{q}}\right), 131.3(\mathrm{CH}), 130.8$ $\left(\mathrm{C}_{\mathrm{q}}\right), 130.5(\mathrm{CH}), 128.7(\mathrm{CH}), 128.7(\mathrm{CH}), 128.4\left(\mathrm{C}_{\mathrm{q}}\right), 127.9(\mathrm{CH}), 127.7(\mathrm{CH}), 127.1(\mathrm{CH}), 126.6$ $(\mathrm{CH}), 126.2(\mathrm{CH}), 125.7\left(\mathrm{C}_{\mathrm{q}}\right), 124.6\left(\mathrm{C}_{\mathrm{q}}\right), 122.1(\mathrm{CH}), 118.7(\mathrm{CH}), 118.3\left(\mathrm{C}_{\mathrm{q}}\right), 101.3(\mathrm{CH}), 60.1$ $\left(\mathrm{CH}_{2}\right), 14.5\left(\mathrm{CH}_{3}\right)$.

IR (ATR): $\tilde{V}=2979,1702,1513,1454,1418,1235,1207,1144,749,700 \mathrm{~cm}^{-1}$. 
MS (EI) $\mathrm{m} / z$ (relative intensity): $391(100)\left[\mathrm{M}^{+}\right], 318(90)$.

HR-MS (EI) $m / z$ calcd for $\mathrm{C}_{27} \mathrm{H}_{21} \mathrm{NO}_{2}{ }^{+} 391.1572$, found 391.1576 .

\section{Synthesis of 5,6-diphenylpyrrolo[2,1-a]isoquinoline-2-carbonitrile (209ba)}

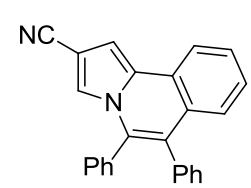

The general procedure $\mathbf{A}$ was followed using 5-phenyl-1H-pyrrole-3-carbonitrile $\quad(\mathbf{2 0 8 b}) \quad(84.0 \quad \mathrm{mg}, \quad 0.50 \quad \mathrm{mmol})$, diphenylacetylene (38a) $(178 \mathrm{mg}, 1.00 \mathrm{mmol})$ and $\mathrm{Cu}(\mathrm{OAc})_{2} \cdot \mathrm{H}_{2} \mathrm{O}(10 \mathrm{mg}, 10.0$ mol \%). After $22 \mathrm{~h}$, purification by column chromatography on silica gel ( $n$-hexane/ $\left.\mathrm{CH}_{2} \mathrm{Cl}_{2}: 10 / 1\right)$ yielded $209 \mathrm{ba}(70 \mathrm{mg}, 40 \%$ ) as a white solid.

M. p. $=228-229^{\circ} \mathrm{C}$.

${ }^{1} \mathrm{H}-\mathrm{NMR}\left(300 \mathrm{MHz}, \mathrm{CDCl}_{3}\right): \delta=8.11(\mathrm{~d}, J=8.0 \mathrm{~Hz}, 1 \mathrm{H}), 7.55(\mathrm{ddd}, J=7.6,7.4,1.3 \mathrm{~Hz}, 1 \mathrm{H})$, 7.40-7.30 (m, 4H), 7.30-7.21 (m, 8H), 7.21-7.10 (m, 2H).

${ }^{13} \mathrm{C}-\mathrm{NMR}\left(75 \mathrm{MHz}, \mathrm{CDCl}_{3}\right): \delta=135.7\left(\mathrm{C}_{\mathrm{q}}\right), 133.2\left(\mathrm{C}_{\mathrm{q}}\right), 132.7\left(\mathrm{C}_{\mathrm{q}}\right), 131.1(\mathrm{CH}), 130.9\left(\mathrm{C}_{\mathrm{q}}\right), 130.3$ $(\mathrm{CH}), 129.1(\mathrm{CH}), 128.9(\mathrm{CH}), 128.5\left(\mathrm{C}_{\mathrm{q}}\right), 128.0(\mathrm{CH}), 128.0(\mathrm{CH}), 127.3(\mathrm{CH}), 127.0(\mathrm{CH})$, $126.8(\mathrm{CH}), 125.3\left(\mathrm{C}_{\mathrm{q}}\right), 124.7\left(\mathrm{C}_{\mathrm{q}}\right), 122.2(\mathrm{CH}), 120.7(\mathrm{CH}), 116.5\left(\mathrm{C}_{\mathrm{q}}\right), 103.0(\mathrm{CH}), 95.5\left(\mathrm{C}_{\mathrm{q}}\right)$.

IR (ATR): $\tilde{V}=3132,2107,1598,1513,1487,1389,1131,760,754,697 \mathrm{~cm}^{-1}$.

MS (EI) $m / z$ (relative intensity): $344(100)\left[\mathrm{M}^{+}\right], 266(10)$.

HR-MS (EI) $m / z$ calcd for $\mathrm{C}_{25} \mathrm{H}_{16} \mathrm{~N}_{2}{ }^{+} 344.1313$, found 344.1324 .

Synthesis of 1-(5,6-diphenylpyrrolo[2,1-a]isoquinolin-2-yl)ethanone (209ca)

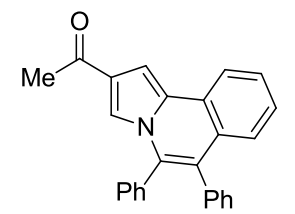

The general procedure $\mathbf{A}$ was followed using 1-(5-phenyl-1H-pyrrol-3-yl)ethanone $\quad(\mathbf{2 0 8 c}) \quad(93.0 \quad \mathrm{mg}, \quad 0.50 \quad \mathrm{mmol})$, diphenylacetylene (38a) $(178 \mathrm{mg}, 1.00 \mathrm{mmol})$ and $\mathrm{Cu}(\mathrm{OAc})_{2} \cdot \mathrm{H}_{2} \mathrm{O}(10 \mathrm{mg}$, $10.0 \mathrm{~mol} \%)$. After $22 \mathrm{~h}$, purification by column chromatography on silica gel (n-hexane/ $\mathrm{CH}_{2} \mathrm{Cl}_{2}$ : 10/1) yielded 209ca (137 $\mathrm{mg}, 76 \%$ ) as a white solid.

M. p. $=206^{\circ} \mathrm{C}$ (dec.).

${ }^{1} \mathrm{H}-\mathrm{NMR}\left(300 \mathrm{MHz}, \mathrm{CDCl}_{3}\right): \delta=8.15($ d. $J=8.2 \mathrm{~Hz}, 1 \mathrm{H}), 7.56-7.38(\mathrm{~m}, 2 \mathrm{H}), 7.39-7.10(\mathrm{~m}$, $13 \mathrm{H}), 2.49$ (s, 3H).

${ }^{13} \mathrm{C}-\mathrm{NMR}\left(75 \mathrm{MHz}, \mathrm{CDCl}_{3}\right): \delta=194.6\left(\mathrm{C}_{\mathrm{q}}\right), 136.1\left(\mathrm{C}_{\mathrm{q}}\right), 133.8\left(\mathrm{C}_{\mathrm{q}}\right), 133.2\left(\mathrm{C}_{\mathrm{q}}\right), 131.3\left(\mathrm{C}_{\mathrm{q}}\right), 131.2$ $(\mathrm{CH}), 130.4(\mathrm{CH}), 128.8(\mathrm{CH}), 128.8(\mathrm{CH}), 128.5\left(\mathrm{C}_{\mathrm{q}}\right), 128.0(\mathrm{CH}), 127.8(\mathrm{CH}), 127.1(\mathrm{CH})$, $127.0\left(\mathrm{C}_{\mathrm{q}}\right), 126.7(\mathrm{CH}), 126.4(\mathrm{CH}), 125.8\left(\mathrm{C}_{\mathrm{q}}\right), 125.0\left(\mathrm{C}_{\mathrm{q}}\right), 122.1(\mathrm{CH}), 118.2(\mathrm{CH}), 100.3(\mathrm{CH})$, $27.5\left(\mathrm{CH}_{3}\right)$.

IR (ATR): $\tilde{V}=3023,1651,1511,1458,1241,1143,799,773,700,644 \mathrm{~cm}^{-1}$.

MS (EI) $m / z$ (relative intensity): 361 (100) $\left[\mathrm{M}^{+}\right], 346$ (27), 318 (30).

HR-MS (EI) $m / z$ calcd for $\mathrm{C}_{26} \mathrm{H}_{19} \mathrm{NO}^{+} 361.1467$, found 361.1456 .

\section{Synthesis of ethyl 1,5,6-triphenylpyrrolo[2,1-a]isoquinoline-2-carboxylate (209da)}

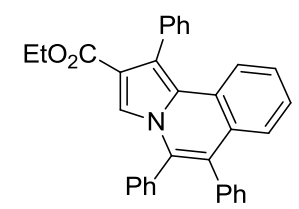

The general procedure $\mathbf{A}$ was followed using ethyl 4,5-diphenyl-1H-pyrrole-3-carboxylate (208d) (146 mg, $0.50 \quad \mathrm{mmol})$, diphenylacetylene (38a) $(178 \mathrm{mg}, 1.00 \mathrm{mmol})$ and $\mathrm{Cu}(\mathrm{OAc})_{2} \cdot \mathrm{H}_{2} \mathrm{O}(10 \mathrm{mg}$, $10.0 \mathrm{~mol} \%)$. After $22 \mathrm{~h}$, purification by column chromatography on silica gel ( $n$-hexane/ $\left.\mathrm{CH}_{2} \mathrm{Cl}_{2}: 10 / 1\right)$ yielded 209da (176 $\left.\mathrm{mg}, 75 \%\right)$ as a white solid.

M. p. $=243-244{ }^{\circ} \mathrm{C}$.

${ }^{1} \mathrm{H}-\mathrm{NMR}\left(300 \mathrm{MHz}, \mathrm{CDCl}_{3}\right): \delta=7.57-7.38(\mathrm{~m}, 7 \mathrm{H}), 7.41-7.29(\mathrm{~m}, 5 \mathrm{H}), 7.29-7.06(\mathrm{~m}, 8 \mathrm{H}), 4.08$ $(\mathrm{q}, J=7.0 \mathrm{~Hz}, 2 \mathrm{H}), 1.04(\mathrm{t}, J=7.0 \mathrm{~Hz}, 3 \mathrm{H})$. 
${ }^{13} \mathrm{C}-\mathrm{NMR}\left(75 \mathrm{MHz}, \mathrm{CDCl}_{3}\right): \delta=164.8\left(\mathrm{C}_{\mathrm{q}}\right), 136.8\left(\mathrm{C}_{\mathrm{q}}\right), 136.4\left(\mathrm{C}_{\mathrm{q}}\right), 133.6\left(\mathrm{C}_{\mathrm{q}}\right), 133.3\left(\mathrm{C}_{\mathrm{q}}\right), 131.3$ $(\mathrm{CH}), 130.6(\mathrm{CH}), 130.5(\mathrm{CH}), 129.1\left(\mathrm{C}_{\mathrm{q}}\right), 128.8(\mathrm{CH}), 128.8(\mathrm{CH}), 128.4(\mathrm{CH}), 127.9(\mathrm{CH})$, 127.2 (CH), $127.1(\mathrm{CH}), 127.0(\mathrm{CH}), 126.7\left(\mathrm{C}_{\mathrm{q}}\right), 126.6(\mathrm{CH}), 126.4\left(\mathrm{C}_{\mathrm{q}}\right), 125.7(\mathrm{CH}), 124.7\left(\mathrm{C}_{\mathrm{q}}\right)$, $122.7(\mathrm{CH}), 119.9\left(\mathrm{C}_{\mathrm{q}}\right), 118.9(\mathrm{CH}), 117.6\left(\mathrm{C}_{\mathrm{q}}\right), 59.6\left(\mathrm{CH}_{2}\right), 13.9\left(\mathrm{CH}_{3}\right)$.

IR (ATR): $\tilde{V}=3049,1713,1601,1514,1456,1206,1137,776,761,699 \mathrm{~cm}^{-1}$.

MS (EI) $m / z$ (relative intensity): 467 (100) $\left[\mathrm{M}^{+}\right], 394$ (30).

HR-MS (EI) $m / z$ calcd for $\mathrm{C}_{33} \mathrm{H}_{25} \mathrm{NO}_{2}{ }^{+} 467.1885$, found 467.1872 .

Synthesis of ethyl 5,6-di(4-fluorophenyl)pyrrolo[2,1-a]isoquinoline-2-carboxylate (209ad)

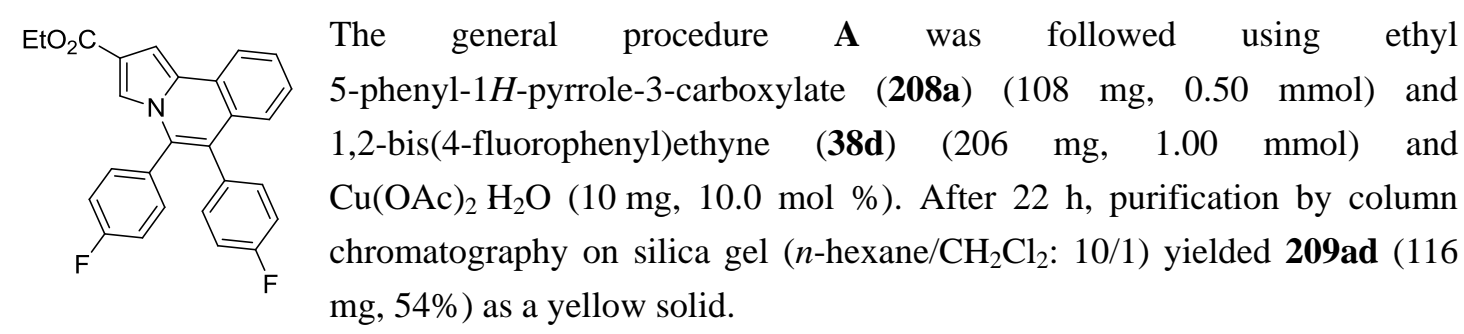

M. p. $=240-241^{\circ} \mathrm{C}$.

${ }^{1} \mathrm{H}-\mathrm{NMR}\left(300 \mathrm{MHz}, \mathrm{CDCl}_{3}\right): \delta=8.14(\mathrm{~d}, J=8.0 \mathrm{~Hz}, 1 \mathrm{H}), 7.56-7.41(\mathrm{~m}, 2 \mathrm{H}), 7.41-6.84(\mathrm{~m}$, $11 \mathrm{H}) ; 4.34(\mathrm{q}, J=7.1 \mathrm{~Hz}, 2 \mathrm{H}), 1.37(\mathrm{t}, J=7.1 \mathrm{~Hz}, 3 \mathrm{H})$.

${ }^{13} \mathrm{C}-\mathrm{NMR}\left(75 \mathrm{MHz}, \mathrm{CDCl}_{3}\right): \delta=164.9\left(\mathrm{C}_{\mathrm{q}}\right), 162.6\left(\mathrm{~d},{ }^{1} J_{\mathrm{C}-\mathrm{F}}=250 \mathrm{~Hz}, \mathrm{C}_{\mathrm{q}}\right), 161.9\left(\mathrm{~d},{ }^{1} J_{\mathrm{C}-\mathrm{F}}=\right.$ $\left.247 \mathrm{~Hz}, \mathrm{C}_{\mathrm{q}}\right), 133.0\left(\mathrm{C}_{\mathrm{q}}\right), 132.9\left(\mathrm{~d},{ }^{3} J_{\mathrm{C}-\mathrm{F}}=8 \mathrm{~Hz}, \mathrm{CH}\right), 132.4\left(\mathrm{~d},{ }^{3} J_{\mathrm{C}-\mathrm{F}}=8 \mathrm{~Hz}, \mathrm{CH}\right), 132.0\left(\mathrm{~d},{ }^{4} J_{\mathrm{C}-\mathrm{F}}=\right.$ $\left.4 \mathrm{~Hz}, \mathrm{C}_{\mathrm{q}}\right), 130.8\left(\mathrm{C}_{\mathrm{q}}\right), 129.2\left(\mathrm{~d},{ }^{4} J_{\mathrm{C}-\mathrm{F}}=4 \mathrm{~Hz}, \mathrm{C}_{\mathrm{q}}\right), 128.1\left(\mathrm{C}_{\mathrm{q}}\right), 128.0(\mathrm{CH}), 126.4(\mathrm{CH}), 126.4(\mathrm{CH})$, $125.8\left(\mathrm{C}_{\mathrm{q}}\right), 124.0\left(\mathrm{C}_{\mathrm{q}}\right), 122.2(\mathrm{CH}), 118.6\left(\mathrm{C}_{\mathrm{q}}\right), 118.4(\mathrm{CH}), 116.2\left(\mathrm{~d},{ }^{2} J_{\mathrm{C}-\mathrm{F}}=22 \mathrm{~Hz}, \mathrm{CH}\right), 111.2(\mathrm{~d}$, $\left.{ }^{2} J_{\mathrm{C}-\mathrm{F}}=22 \mathrm{~Hz}, \mathrm{CH}\right), 101.6(\mathrm{CH}), 60.2\left(\mathrm{CH}_{2}\right), 14.4\left(\mathrm{CH}_{3}\right)$.

${ }^{19} \mathrm{~F}-\mathrm{NMR}\left(283 \mathrm{MHz}, \mathrm{CDCl}_{3}\right): \delta=-(111.2-111.4)(\mathrm{m}),-(114.3-114.5)(\mathrm{m})$.

IR (ATR): $\tilde{V}=3144,2989,1697,1598,1545,1501,1216,816,789,756 \mathrm{~cm}^{-1}$.

MS (EI) $\mathrm{m} / z$ (relative intensity): $387(100)\left[\mathrm{M}^{+}\right], 354$ (60).

HR-MS (EI) $m / z$ calcd for $\mathrm{C}_{27} \mathrm{H}_{19} \mathrm{~F}_{2} \mathrm{NO}_{2}{ }^{+} 387.1384$, found 387.1379 .

Synthesis of dimethyl 3-methyl-5,6-di(n-propyl)pyrrolo[2,1-a]isoquinoline-1,2-dicarboxylate (209fe)

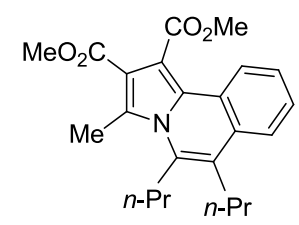

The general procedure A was followed using dimethyl 2-methyl-5-phenyl-1 $H$-pyrrole- 3,4-dicarboxylate (208f) $(137 \mathrm{mg}$, $0.50 \mathrm{mmol})$, 4-octyne (38e) $(110 \mathrm{mg}, 1.00 \mathrm{mmol})$ and $\mathrm{Cu}(\mathrm{OAc})_{2} \cdot \mathrm{H}_{2} \mathrm{O}$ $(10.0 \mathrm{mg}, 10.0 \mathrm{~mol} \%)$. After $22 \mathrm{~h}$, purification by column chromatography on silica gel ( $n$-hexane/ EtOAc: 10/1) yielded 209fe (99 mg, 48\%) as a

yellow oil.

The general procedure $\mathbf{A}$ was followed using dimethyl 2-methyl-5-phenyl-1H-pyrrole3,4-dicarboxylate (208f) $(137 \mathrm{mg}, 0.50 \mathrm{mmol})$, 4-octyne (38e) $(110 \mathrm{mg}, 1.00 \mathrm{mmol})$ and $\mathrm{Cu}(\mathrm{OAc})_{2} \cdot \mathrm{H}_{2} \mathrm{O}(30.0 \mathrm{mg}, 30.0 \mathrm{~mol} \%)$. After $22 \mathrm{~h}$, purification by column chromatography on silica gel ( $n$-hexane/ EtOAc: $10 / 1)$ yielded 209fe $(141 \mathrm{mg}, 74 \%)$ as a yellow oil.

${ }^{1} \mathrm{H}-\mathrm{NMR}\left(300 \mathrm{MHz}, \mathrm{CDCl}_{3}\right): \delta=8.17(\mathrm{~d}, J=7.2 \mathrm{~Hz}, 1 \mathrm{H}), 7.67$ (d, $\left.J=7.0 \mathrm{~Hz}, 1 \mathrm{H}\right), 7.46-7.36(\mathrm{~m}$, 2H), 3.99 (s, 3H), 3.87 (s, 3H), $3.12(\mathrm{t}, J=8.2 \mathrm{~Hz}, 2 \mathrm{H}), 2.97$ (s, 3H), 2.79 (t, $J=8.2 \mathrm{~Hz}, 2 \mathrm{H}$ ), 1.70-1.52 (m, 4H), 1.09 (t, $J=7.3 \mathrm{~Hz}, 3 \mathrm{H}), 1.02$ (t, $J=7.3 \mathrm{~Hz}, 3 \mathrm{H})$.

${ }^{13} \mathrm{C}-\mathrm{NMR}\left(75 \mathrm{MHz}, \mathrm{CDCl}_{3}\right): \delta=169.0\left(\mathrm{C}_{\mathrm{q}}\right), 165.7\left(\mathrm{C}_{\mathrm{q}}\right), 154.7\left(\mathrm{C}_{\mathrm{q}}\right), 128.8\left(\mathrm{C}_{\mathrm{q}}\right), 128.4\left(\mathrm{C}_{\mathrm{q}}\right), 127.9$ $\left(\mathrm{C}_{\mathrm{q}}\right), 126.9(\mathrm{CH}), 126.8(\mathrm{CH}), 124.7\left(\mathrm{C}_{\mathrm{q}}\right), 123.6(\mathrm{CH}), 123.1(\mathrm{CH}), 122.2\left(\mathrm{C}_{\mathrm{q}}\right), 116.4\left(\mathrm{C}_{\mathrm{q}}\right), 109.2$ 
$\left(\mathrm{C}_{\mathrm{q}}\right), 52.5\left(\mathrm{CH}_{3}\right), 51.7\left(\mathrm{CH}_{3}\right), 50.5\left(\mathrm{CH}_{2}\right), 50.2\left(\mathrm{CH}_{2}\right), 25.4\left(\mathrm{CH}_{2}\right), 25.0\left(\mathrm{CH}_{2}\right), 14.8\left(\mathrm{CH}_{3}\right), 14.4$ $\left(\mathrm{CH}_{3}\right), 13.4\left(\mathrm{CH}_{3}\right)$.

IR (ATR): $\tilde{V}=2954,1708,1526,1455,1438,1199,1118,1091,755,730 \mathrm{~cm}^{-1}$.

MS (EI) $m / z$ (relative intensity): 381 (100) $\left[\mathrm{M}^{+}\right], 350$ (30), 334 (38), 263 (28).

HR-MS (EI) $\mathrm{m} / z$ calcd for $\mathrm{C}_{23} \mathrm{H}_{27} \mathrm{NO}_{4}{ }^{+} 381.1940$, found 381.1933 .

\section{Synthesis of ethyl 5,6-dimethyl-1-phenylpyrrolo[2,1-a]isoquinoline-2-carboxylate (209de)}

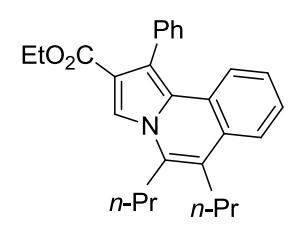

The general procedure $\mathbf{A}$ was followed using ethyl 4,5-diphenyl-1H-pyrrole-3-carboxylate (208d) $(72.8 \mathrm{mg}, 0.25 \mathrm{mmol})$, 4-octyne (38e) $(55.0 \mathrm{mg}, 0.50 \mathrm{mmol})$ and $\mathrm{Cu}(\mathrm{OAc})_{2} \cdot \mathrm{H}_{2} \mathrm{O}(15.0 \mathrm{mg}$, $30.0 \mathrm{~mol} \%)$. After $22 \mathrm{~h}$, purification by column chromatography on silica gel ( $n$-hexane/EtOAc: $20 / 1)$ yielded 209de $(77 \mathrm{mg}, 77 \%$ ) as a yellow oil.

${ }^{1} \mathrm{H}-\mathrm{NMR}\left(300 \mathrm{MHz}, \mathrm{CDCl}_{3}\right): \delta=7.97(\mathrm{~s}, 1 \mathrm{H}), 7.69(\mathrm{~d}, J=8.2 \mathrm{~Hz}, 1 \mathrm{H}), 7.65-7.57(\mathrm{~m}, 6 \mathrm{H}), 7.32$ (ddd, $J=7.7,7.7,1.2 \mathrm{~Hz}, 1 \mathrm{H}), 7.09$ (ddd, $J=7.7,7.7,1.2 \mathrm{~Hz}, 1 \mathrm{H}$ ), 4.15 (q, $J=7.1 \mathrm{~Hz}, 2 \mathrm{H}), 3.02$ (t, $J=8.0 \mathrm{~Hz}, 2 \mathrm{H}), 2.87(\mathrm{t}, J=8.0 \mathrm{~Hz}, 2 \mathrm{H}), 1.92-1.77(\mathrm{~m}, 2 \mathrm{H}), 1.75-1.61(\mathrm{~m}, 2 \mathrm{H}), 1.22-1.01(\mathrm{~m}$, 9H).

${ }^{13} \mathrm{C}-\mathrm{NMR}\left(75 \mathrm{MHz}, \mathrm{CDCl}_{3}\right): \delta=166.0\left(\mathrm{C}_{\mathrm{q}}\right), 157.2\left(\mathrm{C}_{\mathrm{q}}\right), 152.5\left(\mathrm{C}_{\mathrm{q}}\right), 150.6(\mathrm{CH}), 128.5(\mathrm{CH})$, $127.7\left(\mathrm{C}_{\mathrm{q}}\right), 127.0(\mathrm{CH}), 126.5\left(\mathrm{C}_{\mathrm{q}}\right), 126.5\left(\mathrm{C}_{\mathrm{q}}\right), 126.1(\mathrm{CH}), 125.7(\mathrm{CH}), 123.6(\mathrm{CH}), 123.1(\mathrm{CH})$, $119.8\left(\mathrm{C}_{\mathrm{q}}\right), 119.4\left(\mathrm{C}_{\mathrm{q}}\right), 117.4\left(\mathrm{C}_{\mathrm{q}}\right), 116.5(\mathrm{CH}), 59.6\left(\mathrm{CH}_{2}\right), 30.7\left(\mathrm{CH}_{2}\right), 30.0\left(\mathrm{CH}_{2}\right), 23.4\left(\mathrm{CH}_{2}\right)$, $20.3\left(\mathrm{CH}_{2}\right), 14.5\left(\mathrm{CH}_{3}\right), 14.3\left(\mathrm{CH}_{3}\right), 13.9\left(\mathrm{CH}_{3}\right)$.

IR (ATR): $\tilde{V}=2958,1698,1604,1519,1457,1202,1111,758,731,698 \mathrm{~cm}^{-1}$.

MS (EI) $\mathrm{m} / z$ (relative intensity): 399 (100) $\left[\mathrm{M}^{+}\right], 370$ (45), 282 (35).

HR-MS (EI) $m / z$ calcd for $\mathrm{C}_{27} \mathrm{H}_{29} \mathrm{NO}_{2}{ }^{+} 399.2178$, found 399.2178 .

\section{Synthesis of dimethyl 5,6-diethyl-3-methylpyrrolo[2,1-a]isoquinoline-1,2-dicarboxylate} (209f)<smiles>CCc1c(C(C)=O)n2c(C)c(C(C)=O)c(C(C)=O)c2c2ccccc12</smiles>

The general procedure $\mathbf{A}$ was followed using dimethyl 2-methyl-5-phenyl-1H-pyrrole- 3,4-dicarboxylate (208f) $\quad(137 \quad \mathrm{mg}$, $0.50 \mathrm{mmol})$, 3-hexyne (38f) $(82.0 \mathrm{mg}, 1.00 \mathrm{mmol})$ and $\mathrm{Cu}(\mathrm{OAc})_{2} \cdot \mathrm{H}_{2} \mathrm{O}$ (30.0 mg, $30.0 \mathrm{~mol} \%$ ). After $22 \mathrm{~h}$, purification by column chromatography on silica gel ( $n$-hexane/ EtOAc: 10/1) yielded $209 f f(152 \mathrm{mg}, 86 \%)$ as a yellow oil.

${ }^{1} \mathrm{H}-\mathrm{NMR}\left(300 \mathrm{MHz}, \mathrm{CDCl}_{3}\right): \delta=8.17(\mathrm{~d}, J=6.8 \mathrm{~Hz}, 1 \mathrm{H}), 7.71(\mathrm{~d}, J=6.7 \mathrm{~Hz}, 1 \mathrm{H}), 7.46-7.34(\mathrm{~m}$, 2H), 3.99 (s, 3H), 3.88 (s, 3H), 3.21 (q, $J=7.4 \mathrm{~Hz}, 2 \mathrm{H}), 3.01$ (s, 3H), 2.89 (q, $J=7.5 \mathrm{~Hz}, 2 \mathrm{H}$ ), $1.25(\mathrm{t}, J=7.5 \mathrm{~Hz}, 3 \mathrm{H}), 1.24(\mathrm{t}, J=7.4 \mathrm{~Hz}, 3 \mathrm{H})$.

${ }^{13} \mathrm{C}-\mathrm{NMR}\left(75 \mathrm{MHz}, \mathrm{CDCl}_{3}\right): \delta=168.8\left(\mathrm{C}_{\mathrm{q}}\right), 165.7\left(\mathrm{C}_{\mathrm{q}}\right), 155.7\left(\mathrm{C}_{\mathrm{q}}\right), 128.6\left(\mathrm{C}_{\mathrm{q}}\right), 128.5\left(\mathrm{C}_{\mathrm{q}}\right), 127.6$ $\left(\mathrm{C}_{\mathrm{q}}\right), 126.9(\mathrm{CH}), 126.8(\mathrm{CH}), 125.0\left(\mathrm{C}_{\mathrm{q}}\right), 125.4(\mathrm{CH}), 125.4(\mathrm{CH}), 125.2\left(\mathrm{C}_{\mathrm{q}}\right), 116.6\left(\mathrm{C}_{\mathrm{q}}\right), 109.6$ $\left(\mathrm{C}_{\mathrm{q}}\right), 52.4\left(\mathrm{CH}_{3}\right), 51.6\left(\mathrm{CH}_{3}\right), 21.6\left(\mathrm{CH}_{2}\right), 20.9\left(\mathrm{CH}_{2}\right), 14.9\left(\mathrm{CH}_{3}\right), 14.4\left(\mathrm{CH}_{3}\right), 14.4\left(\mathrm{CH}_{3}\right)$. IR (ATR): $\tilde{V}=2948,1706,1525,1482,1439,1200,1131,1083,784,755 \mathrm{~cm}^{-1}$.

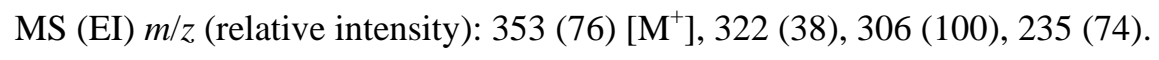

HR-MS (EI) $\mathrm{m} / z$ calcd for $\mathrm{C}_{21} \mathrm{H}_{23} \mathrm{NO}_{4}{ }^{+} 353.1627$, found 353.1636 .

\section{Synthesis of ethyl 5,6-diethyl-1-phenylpyrrolo[2,1-a]isoquinoline-2-carboxylate (209df)}

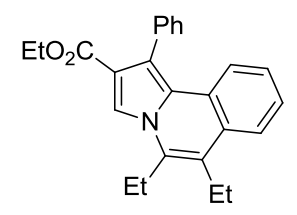

The general procedure $\mathbf{A}$ was followed using ethyl 2-methyl-4,5-diphenyl1H-pyrrole-3-carboxylate (208d) $(72.8 \mathrm{mg}, 0.25 \mathrm{mmol}), 3$-hexyne (38f) $(55.0 \mathrm{mg}, 0.50 \mathrm{mmol})$ and $\mathrm{Cu}(\mathrm{OAc})_{2} \cdot \mathrm{H}_{2} \mathrm{O}(15.0 \mathrm{mg}, 30.0 \mathrm{~mol} \%)$. After $22 \mathrm{~h}$, 
purification by column chromatography on silica gel ( $n$-hexane/EtOAc: 20/1) yielded 209df (74 mg, 76\%) as a white solid. M. p. $=141-138^{\circ} \mathrm{C}$.

${ }^{1} \mathrm{H}-\mathrm{NMR}\left(300 \mathrm{MHz}, \mathrm{CDCl}_{3}\right): \delta=8.01(\mathrm{~s}, 1 \mathrm{H}), 7.73(\mathrm{~d}, J=8.4 \mathrm{~Hz}, 1 \mathrm{H}), 7.64-7.38(\mathrm{~m}, 6 \mathrm{H}), 7.32$ (ddd, $J=7.7,7.6,1.3 \mathrm{~Hz}, 1 \mathrm{H}), 7.09(\mathrm{ddd}, J=7.7,7.6,1.2 \mathrm{~Hz}, 1 \mathrm{H}), 4.16(\mathrm{q}, J=7.4 \mathrm{~Hz}, 2 \mathrm{H}), 3.09$ (q, $J=7.6 \mathrm{~Hz}, 2 \mathrm{H}), 2.96(\mathrm{q}, J=7.6 \mathrm{~Hz}, 2 \mathrm{H}), 1.45(\mathrm{t}, J=7.6 \mathrm{~Hz}, 3 \mathrm{H}), 1.31$ (t, $J=7.6 \mathrm{~Hz}, 3 \mathrm{H}), 1.11$ (t, $J=7.4 \mathrm{~Hz}, 3 \mathrm{H})$.

${ }^{13} \mathrm{C}-\mathrm{NMR}\left(75 \mathrm{MHz}, \mathrm{CDCl}_{3}\right): \delta=166.0\left(\mathrm{C}_{\mathrm{q}}\right), 157.3\left(\mathrm{C}_{\mathrm{q}}\right), 155.4\left(\mathrm{C}_{\mathrm{q}}\right), 150.7(\mathrm{CH}), 128.5(\mathrm{CH})$, $127.6\left(\mathrm{C}_{\mathrm{q}}\right), 127.0(\mathrm{CH}), 126.5\left(\mathrm{C}_{\mathrm{q}}\right), 126.5\left(\mathrm{C}_{\mathrm{q}}\right), 126.2(\mathrm{CH}), 125.8(\mathrm{CH}), 123.6(\mathrm{CH}), 123.3(\mathrm{CH})$, $120.8\left(\mathrm{C}_{\mathrm{q}}\right), 119.6\left(\mathrm{C}_{\mathrm{q}}\right), 117.7\left(\mathrm{C}_{\mathrm{q}}\right), 116.4(\mathrm{CH}), 59.6\left(\mathrm{CH}_{2}\right), 21.8\left(\mathrm{CH}_{2}\right), 20.8\left(\mathrm{CH}_{2}\right), 14.7\left(\mathrm{CH}_{3}\right)$, $14.0\left(\mathrm{CH}_{3}\right), 11.7\left(\mathrm{CH}_{3}\right)$.

IR (ATR): $\tilde{V}=2966,1695,1602,1521,1444,1268,1219,1034,757,703 \mathrm{~cm}^{-1}$.

MS (EI) $m / z$ (relative intensity): 371 (100) $\left[\mathrm{M}^{+}\right], 298$ (23), 282 (20).

HR-MS (EI) $m / z$ calcd for $\mathrm{C}_{25} \mathrm{H}_{25} \mathrm{NO}_{2}{ }^{+} 371.1885$, found 371.1887 .

Synthesis of dimethyl 6-(n-butyl)-5-(4-methoxyphenyl)-3-methylpyrrolo[2,1-a]isoquinoline1,2-di-caboxylate (209fg)

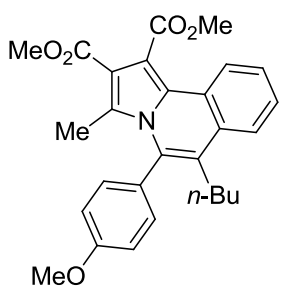

The general procedure $\mathbf{A}$ was followed using dimethyl 2-methyl-5-phenyl-1H-pyrrole- 3,4-dicarboxylate (208f) (137 $\mathrm{mg}$, $0.50 \mathrm{mmol}), \quad 1$-(hex-1-yn-1-yl)-4-methoxybenzene (38g) (188 mg, 1.00 $\mathrm{mmol})$ and $\mathrm{Cu}(\mathrm{OAc})_{2} \cdot \mathrm{H}_{2} \mathrm{O}(30 \mathrm{mg}, 30.0 \mathrm{~mol} \%)$. After $22 \mathrm{~h}$, purification by column chromatography on silica gel ( $n$-hexane/EtOAc: 10/1) yielded $209 f$ g (169 mg, 74\%, 6:1 mixture of regioisomers according to ${ }^{1} \mathrm{H}-\mathrm{NMR}$ as a yellow oil. Purification by a second column chromatography on silica gel ( $n$-hexane/EtOAc: 20/1) yielded the major regioisomer (146 $\mathrm{mg}, 64 \%$ ) as a yellow solid.

M. p. $=138-143{ }^{\circ} \mathrm{C}$.

${ }^{1} \mathrm{H}-\mathrm{NMR}\left(300 \mathrm{MHz}, \mathrm{CDCl}_{3}\right): \delta=8.31-8.24(\mathrm{~d}, J=7.1 \mathrm{~Hz}, 1 \mathrm{H}), 7.76-7.71(\mathrm{~d}, J=7.0 \mathrm{~Hz}, 1 \mathrm{H})$, $7.50-7.45(\mathrm{~m}, 2 \mathrm{H}), 7.27(\mathrm{~d}, J=10.8 \mathrm{~Hz}, 2 \mathrm{H}), 6.99(\mathrm{~d}, J=10.8 \mathrm{~Hz}, 2 \mathrm{H}), 4.00(\mathrm{~s}, 3 \mathrm{H}), 3.90(\mathrm{~s}, 3 \mathrm{H})$, $3.82(\mathrm{~s}, 3 \mathrm{H}), 2.49$ (t, $J=8.2 \mathrm{~Hz}, 2 \mathrm{H}), 1.92(\mathrm{~s}, 3 \mathrm{H}), 1.52-1.39(\mathrm{~m}, 2 \mathrm{H}), 1.31-1.18(\mathrm{~m}, 2 \mathrm{H}), 0.76$ (t, $J=7.3 \mathrm{~Hz}, 3 \mathrm{H})$.

${ }^{13} \mathrm{C}-\mathrm{NMR}\left(75 \mathrm{MHz}, \mathrm{CDCl}_{3}\right): \delta=168.9\left(\mathrm{C}_{\mathrm{q}}\right), 165.6\left(\mathrm{C}_{\mathrm{q}}\right), 160.0\left(\mathrm{C}_{\mathrm{q}}\right), 133.2\left(\mathrm{C}_{\mathrm{q}}\right), 132.0(\mathrm{CH}), 130.1$ $\left(\mathrm{C}_{\mathrm{q}}\right), 127.6\left(\mathrm{C}_{\mathrm{q}}\right), 127.5\left(\mathrm{C}_{\mathrm{q}}\right), 127.4(\mathrm{CH}), 126.9(\mathrm{CH}), 125.3\left(\mathrm{C}_{\mathrm{q}}\right), 124.1(\mathrm{CH}), 124.0\left(\mathrm{C}_{\mathrm{q}}\right), 123.4$ $(\mathrm{CH}), 111.9\left(\mathrm{C}_{\mathrm{q}}\right), 113.6(\mathrm{CH}), 112.2\left(\mathrm{C}_{\mathrm{q}}\right), 109.0\left(\mathrm{C}_{\mathrm{q}}\right), 55.3\left(\mathrm{CH}_{3}\right), 52.5\left(\mathrm{CH}_{3}\right), 51.6\left(\mathrm{CH}_{3}\right), 32.3$ $\left(\mathrm{CH}_{2}\right), 28.2\left(\mathrm{CH}_{2}\right), 22.9\left(\mathrm{CH}_{2}\right), 14.1\left(\mathrm{CH}_{3}\right), 13.6\left(\mathrm{CH}_{3}\right)$.

IR (ATR): $\tilde{v}=2954,1705,1604,1525,1509,1438,1240,1171,1021,798 \mathrm{~cm}^{-1}$.

MS (EI) $m / z$ (relative intensity): 459 (100) $\left[\mathrm{M}^{+}\right], 386$ (70), 341 (60).

HR-MS (EI) $\mathrm{m} / z$ calcd for $\mathrm{C}_{28} \mathrm{H}_{29} \mathrm{NO}_{5}{ }^{+} 459.2046$, found 459.2041 .

\section{Synthesis of ethyl 6-butyl-5-(4-methoxyphenyl)pyrrolo[2,1-a]isoquinoline-2-carboxylate} (209ag)

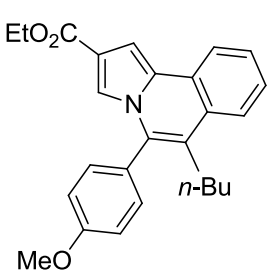

The general procedure A was followed using ethyl 5-phenyl-1H-pyrrole-3-carboxylate (208a) (108 $\mathrm{mg}, 0.50 \mathrm{mmol})$, 1-(hex-1-yn-1-yl)-4-methoxybenzene (38g) (188 mg, $1.00 \mathrm{mmol})$ and $\mathrm{Cu}(\mathrm{OAc})_{2} \cdot \mathrm{H}_{2} \mathrm{O}(30.0 \mathrm{mg}, 30.0 \mathrm{~mol} \%)$. After $22 \mathrm{~h}$, purification by column chromatography on silica gel ( $n$-hexane/ EtOAc: 30/1) yielded 209ag (160 mg, 76\%, 8:1 mixture of regioisomers according to $\left.{ }^{1} \mathrm{H}-\mathrm{NMR}\right)$ as a 
yellow oil. Purification by a second column chromatography on silica gel ( $n$-hexane/EtOAc: $30 / 1)$ yielded the major regioisomer ( $95 \mathrm{mg}, 47 \%$ ) as a yellow oil.

${ }^{1} \mathrm{H}-\mathrm{NMR}\left(300 \mathrm{MHz}, \mathrm{CDCl}_{3}\right): \delta=8.10(\mathrm{~d}, J=7.6 \mathrm{~Hz}, 1 \mathrm{H}), 7.76(\mathrm{~d}, J=7.8 \mathrm{~Hz}, 1 \mathrm{H}), 7.55-7.45(\mathrm{~m}$, 2H), $7.40(\mathrm{~s}, 1 \mathrm{H}), 7.51(\mathrm{~d}, J=8.4 \mathrm{~Hz}, 2 \mathrm{H}), 7.20(\mathrm{~s}, 1 \mathrm{H}), 7.10(\mathrm{~d}, J=8.4 \mathrm{~Hz}, 2 \mathrm{H}), 4.52(\mathrm{q}, J=$ $7.4 \mathrm{~Hz}, 2 \mathrm{H}), 3.92(\mathrm{~s}, 3 \mathrm{H}), 2.60(\mathrm{t}, J=8.0 \mathrm{~Hz}, 2 \mathrm{H}), 1.61-1.49(\mathrm{~m}, 2 \mathrm{H}), 1.36(\mathrm{t}, J=7.0 \mathrm{~Hz}, 3 \mathrm{H})$, $1.29(\mathrm{~m}, 2 \mathrm{H}), 0.85(\mathrm{t}, J=7.4 \mathrm{~Hz}, 3 \mathrm{H})$.

${ }^{13} \mathrm{C}-\mathrm{NMR}\left(75 \mathrm{MHz}, \mathrm{CDCl}_{3}\right): \delta=165.1\left(\mathrm{C}_{\mathrm{q}}\right), 160.0\left(\mathrm{C}_{\mathrm{q}}\right), 152.8\left(\mathrm{C}_{\mathrm{q}}\right), 131.2(\mathrm{CH}), 130.4\left(\mathrm{C}_{\mathrm{q}}\right), 127.2$ $(\mathrm{CH}), 127.1\left(\mathrm{C}_{\mathrm{q}}\right), 126.2\left(\mathrm{C}_{\mathrm{q}}\right), 126.2(\mathrm{CH}), 125.9\left(\mathrm{C}_{\mathrm{q}}\right), 124.5(\mathrm{CH}), 122.6(\mathrm{CH}), 121.7\left(\mathrm{C}_{\mathrm{q}}\right), 118.4$ $(\mathrm{CH}), 117.6\left(\mathrm{C}_{\mathrm{q}}\right), 114.8(\mathrm{CH}), 100.9(\mathrm{CH}), 60.0\left(\mathrm{CH}_{2}\right), 55.3\left(\mathrm{CH}_{3}\right), 32.5\left(\mathrm{CH}_{2}\right), 28.2\left(\mathrm{CH}_{2}\right), 22.9$ $\left(\mathrm{CH}_{2}\right), 14.4\left(\mathrm{CH}_{3}\right), 13.7\left(\mathrm{CH}_{3}\right)$.

IR (ATR): $\tilde{V}=2955,1705,1607,1508,1454,1289,1241,1173,1025,751 \mathrm{~cm}^{-1}$.

MS (EI) $\mathrm{m} / z$ (relative intensity): $401(100)\left[\mathrm{M}^{+}\right], 358$ (20), 285 (35).

HR-MS (EI) $m / z$ calcd for $\mathrm{C}_{26} \mathrm{H}_{27} \mathrm{NO}_{3}{ }^{+} 401.1991$, found 401.1989 .

\section{Synthesis of ethyl 6-methyl-5-phenylpyrrolo[2,1-a]isoquinoline-2-carboxylate (209ah)}

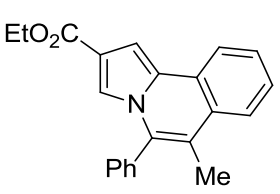

The general procedure A was followed using ethyl 5-phenyl-1 $H$-pyrrole-3-carboxylate $\quad(108 \quad \mathrm{mg}, \quad 0.50 \quad \mathrm{mmol}) \quad$ (208a), 1-phenyl-1-propyne (38h) $(116 \mathrm{mg}, 1.00 \mathrm{mmol})$ and $\mathrm{Cu}(\mathrm{OAc})_{2} \cdot \mathrm{H}_{2} \mathrm{O}$ (30.0 mg, $30.0 \mathrm{~mol} \%$ ). After $22 \mathrm{~h}$, purification by column chromatography on silica gel ( $n$-hexane/EtOAc: 20/1) yielded 209ah $(120 \mathrm{mg}, 73 \%, 5: 1$ mixture of regioisomers according to ${ }^{1} \mathrm{H}-\mathrm{NMR}$ ) as a yellow solid. Purification by a second column chromatography on silica gel ( $n$-hexane/EtOAc: 30/1) yielded the major regioisomer $(41 \mathrm{mg}, 25 \%)$ as a yellow solid. M. p. $=114-111{ }^{\circ} \mathrm{C}$.

${ }^{1} \mathrm{H}-\mathrm{NMR}\left(300 \mathrm{MHz}, \mathrm{CDCl}_{3}\right): \delta=8.10(\mathrm{~d}, J=7.8 \mathrm{~Hz}, 1 \mathrm{H}), 7.76(\mathrm{~d}, J=7.8 \mathrm{~Hz}, 1 \mathrm{H}), 7.60-7.38(\mathrm{~m}$, $8 \mathrm{H}), 7.25(\mathrm{~d}, J=1.6 \mathrm{~Hz}, 1 \mathrm{H}), 4.51(\mathrm{q}, J=7.1 \mathrm{~Hz}, 2 \mathrm{H}), 2.21(\mathrm{~s}, 3 \mathrm{H}), 1.55(\mathrm{t}, J=7.1 \mathrm{~Hz}, 3 \mathrm{H})$. ${ }^{13} \mathrm{C}-\mathrm{NMR}\left(75 \mathrm{MHz}, \mathrm{CDCl}_{3}\right): \delta=165.2\left(\mathrm{C}_{\mathrm{q}}\right), 153.9\left(\mathrm{C}_{\mathrm{q}}\right), 153.0\left(\mathrm{C}_{\mathrm{q}}\right), 150.6\left(\mathrm{C}_{\mathrm{q}}\right), 150.1(\mathrm{CH}), 129.6$ $(\mathrm{CH}), 129.5(\mathrm{CH}), 128.1\left(\mathrm{C}_{\mathrm{q}}\right), 127.6(\mathrm{CH}), 126.5(\mathrm{CH}), 125.9\left(\mathrm{C}_{\mathrm{q}}\right), 124.2(\mathrm{CH}), 122.5(\mathrm{CH}), 118.5$ $(\mathrm{CH}), 117.7\left(\mathrm{C}_{\mathrm{q}}\right), 116.6\left(\mathrm{C}_{\mathrm{q}}\right), 101.1(\mathrm{CH}), 60.0\left(\mathrm{CH}_{2}\right), 15.0\left(\mathrm{CH}_{3}\right), 14.4\left(\mathrm{CH}_{3}\right)$. IR (ATR): $\tilde{V}=2974,1695,1544,1516,1454,1240,1178,1019,747,703 \mathrm{~cm}^{-1}$. MS (EI) $m / z$ (relative intensity): $329(100)\left[\mathrm{M}^{+}\right], 256(55)$.

HR-MS (EI) $m / z$ calcd for $\mathrm{C}_{22} \mathrm{H}_{19} \mathrm{NO}_{2}{ }^{+} 329.1416$, found 329.1417 .

\section{Intermolecular competition experiment with indoles 206b and 2060 (Scheme 64a)}
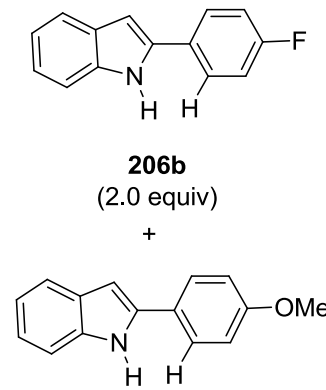

2060 (2.0 equiv)

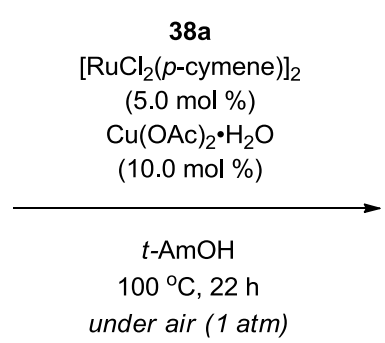

A mixture of 2-(4-fluorophenyl)-1H-indole (206b) (219 $\mathrm{mg}, \quad 1.00 \quad \mathrm{mmol})$,

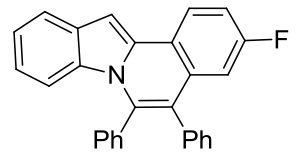

207ba: $34 \%$

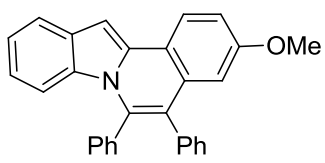

207oa: --2-(4-methoxyphenyl)-1H-indole (206o) (209 mg, $1.00 \mathrm{mmol}$ ), diphenylacetylene (38a) $(89.0 \mathrm{mg}$, $0.50 \mathrm{mmol}),\left[\mathrm{RuCl}_{2}(p \text {-cymene })\right]_{2}(15.3 \mathrm{mg}, 5.0 \mathrm{~mol} \%)$ and $\mathrm{Cu}(\mathrm{OAc})_{2} \cdot \mathrm{H}_{2} \mathrm{O}(10.0 \mathrm{mg}, 10.0 \mathrm{~mol} \%)$ 
in $t$ - $\mathrm{AmOH}(2.0 \mathrm{~mL})$ was stirred at $100{ }^{\circ} \mathrm{C}$ under air for $22 \mathrm{~h}$. At ambient temperature, the mixture was diluted with $\mathrm{H}_{2} \mathrm{O}(75 \mathrm{~mL})$ and extracted with EtOAc $(3 \times 75 \mathrm{~mL})$. The combined organic phase was washed with brine $(50 \mathrm{~mL})$ and dried over anhydrous $\mathrm{Na}_{2} \mathrm{SO}_{4}$. After filtration and evaporation of the solvents under reduced pressure, the crude product was purified by column chromatography on silica gel ( $n$-hexane/EtOAc: $50 / 1)$ to yield 207ba as a yellow solid (66 mg, $34 \%)$.

\section{Intermolecular competition experiment with alkynes 38b and 38i (Scheme 64b)}
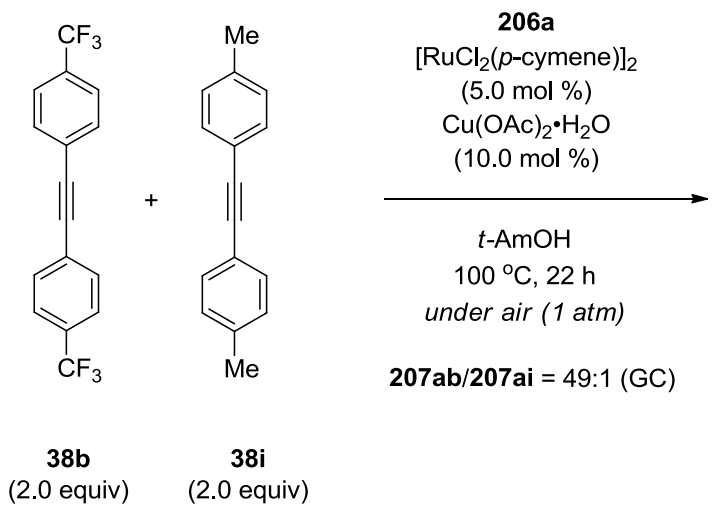

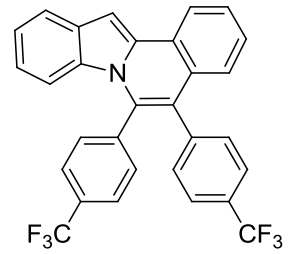

207ab: $34 \%$

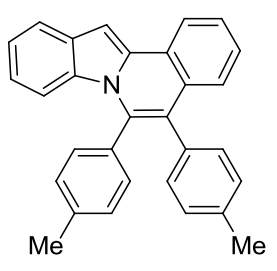

207ai: ---

A mixture of 2-phenylindole (206a) $(48.0 \mathrm{mg}, 0.25 \mathrm{mmol}), 1,2$-di-(p-tolyl)ethyne (38i) (103 mg, $0.50 \mathrm{mmol}), \quad$ 1,2-bis $\{$ 4-(trifluoromethyl)phenyl\}ethyne $\quad(\mathbf{3 8 b}) \quad(157 \quad \mathrm{mg}, \quad 0.50 \mathrm{mmol})$, $\left[\mathrm{RuCl}_{2}(p \text {-cymene })\right]_{2}(7.7 \mathrm{mg}, 5.0 \mathrm{~mol} \%)$ and $\mathrm{Cu}(\mathrm{OAc})_{2} \cdot \mathrm{H}_{2} \mathrm{O}(5.0 \mathrm{mg}, 10.0 \mathrm{~mol} \%)$ in $t$-AmOH $(2.0 \mathrm{~mL})$ was stirred at $100{ }^{\circ} \mathrm{C}$ under air for $22 \mathrm{~h}$. At ambient temperature, the mixture was diluted with $\mathrm{H}_{2} \mathrm{O}(75 \mathrm{~mL})$ and extracted with EtOAc $(3 \times 75 \mathrm{~mL})$. The combined organic phase was washed with brine $(50 \mathrm{~mL})$ and dried over anhydrous $\mathrm{Na}_{2} \mathrm{SO}_{4}$. After filtration and evaporation of the solvents under reduced pressure, the crude product was purified by column chromatography on silica gel ( $n$-hexane/EtOAc: 50/1) to yield 207ab as a yellow solid (43 $\mathrm{mg}, 34 \%$ ).

\section{Annulation with meta-fluorophenyl-substituted indole 206p (Scheme 65)}

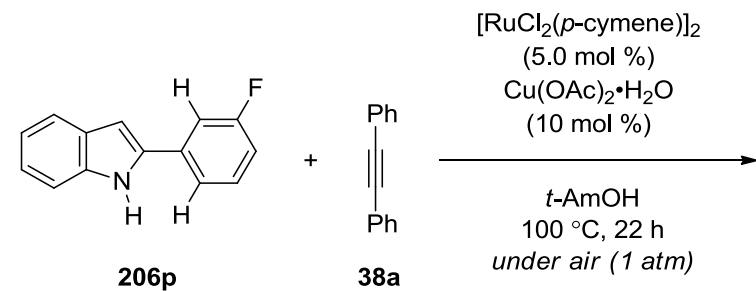

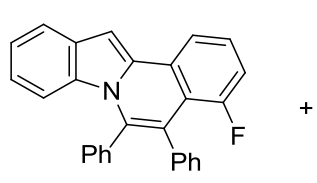

207'pa: $40 \%$<smiles>Fc1ccc2c(-c3ccccc3)c(-c3ccccc3)n3c4ccccc4cc3c2c1</smiles>

207"pa: $9 \%$

A mixture of 2-(3-fluorophenyl)-1H-indole (206p) (106 mg, $0.50 \mathrm{mmol})$, diphenylacetylene (38a) (178 mg, $1.00 \mathrm{mmol}),\left[\mathrm{RuCl}_{2}(p \text {-cymene })\right]_{2}(15.3 \mathrm{mg}, 5.0 \mathrm{~mol} \%)$ and $\mathrm{Cu}(\mathrm{OAc})_{2} \cdot \mathrm{H}_{2} \mathrm{O}(10.0 \mathrm{mg}$, $10.0 \mathrm{~mol} \%)$ in $t-\mathrm{AmOH}(2.0 \mathrm{~mL})$ was stirred at $100{ }^{\circ} \mathrm{C}$ under air for $22 \mathrm{~h}$. At ambient temperature, the mixture was diluted with $\mathrm{H}_{2} \mathrm{O}(75 \mathrm{~mL})$ and extracted with EtOAc $(3 \times 75 \mathrm{~mL})$. The combined organic phase was washed with brine $(50 \mathrm{~mL})$ and dried over anhydrous $\mathrm{Na}_{2} \mathrm{SO}_{4}$. After filtration and evaporation of the solvents under reduced pressure, the crude product was purified by column chromatography on silica gel ( $n$-hexane/ $\mathrm{CH}_{2} \mathrm{Cl}_{2}$ : 10/1) to yield 207'pa (78 $\mathrm{mg}, 40 \%$ ) as yellow solid and 207"pa (17 mg, 9\%) as yellow solid. 


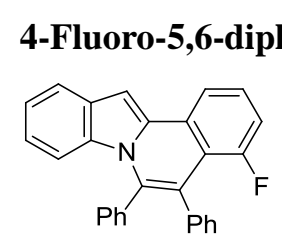

henylindolo[2,1-a]isoquinoline (207'pa)

M. p. $=209-210{ }^{\circ} \mathrm{C}$.

${ }^{1} \mathrm{H}-\mathrm{NMR}\left(300 \mathrm{MHz}, \mathrm{CDCl}_{3}\right): \delta=8.12(\mathrm{~d}, J=7.8 \mathrm{~Hz}, 1 \mathrm{H}), 7.83(\mathrm{~d}, J=7.8 \mathrm{~Hz}$, $1 \mathrm{H}), 7.52-7.10(\mathrm{~m}, 13 \mathrm{H}), 7.05(\mathrm{dd}, J=12.4,7.8 \mathrm{~Hz}, 1 \mathrm{H}), 6.88(\mathrm{dd}, J=7.8$, $7.8 \mathrm{~Hz}, 1 \mathrm{H}), 5.96(\mathrm{~d}, J=8.8 \mathrm{~Hz}, 1 \mathrm{H})$.

${ }^{13} \mathrm{C}-\mathrm{NMR}\left(75 \mathrm{MHz}, \mathrm{CDCl}_{3}\right): \delta=159.1\left(\mathrm{~d},{ }^{1} J_{\mathrm{C}-\mathrm{F}}=254 \mathrm{~Hz}, \mathrm{C}_{\mathrm{q}}\right), 138.7\left(\mathrm{~d},{ }^{4} J_{\mathrm{C}-\mathrm{F}}=3 \mathrm{~Hz}, \mathrm{C}_{\mathrm{q}}\right), 137.5$ $\left(\mathrm{C}_{\mathrm{q}}\right), 134.9\left(\mathrm{~d},{ }^{4} J_{\mathrm{C}-\mathrm{F}}=3 \mathrm{~Hz}, \mathrm{C}_{\mathrm{q}}\right), 134.8\left(\mathrm{C}_{\mathrm{q}}\right), 132.8\left(\mathrm{C}_{\mathrm{q}}\right), 131.0(\mathrm{CH}), 130.9(\mathrm{CH}), 129.6\left(\mathrm{C}_{\mathrm{q}}\right)$, $128.7(\mathrm{CH}), 128.5(\mathrm{CH}), 128.0\left(\mathrm{~d},{ }^{3} J_{\mathrm{C}-\mathrm{F}}=9 \mathrm{~Hz}, \mathrm{CH}\right), 127.7\left(\mathrm{~d},{ }^{3} J_{\mathrm{C}-\mathrm{F}}=4 \mathrm{~Hz}, \mathrm{C}_{\mathrm{q}}\right), 127.1(\mathrm{CH})$, $126.3(\mathrm{CH}), 121.9(\mathrm{CH}), 120.6(\mathrm{CH}), 120.4(\mathrm{CH}), 119.4\left(\mathrm{~d},{ }^{4} J_{\mathrm{C}-\mathrm{F}}=4 \mathrm{~Hz}, \mathrm{CH}\right), 118.6\left(\mathrm{~d},{ }^{2} J_{\mathrm{C}-}\right.$ $\left.\mathrm{F}=9 \mathrm{~Hz}, \mathrm{C}_{\mathrm{q}}\right), 117.0\left(\mathrm{~d},{ }^{4} J_{\mathrm{C}-\mathrm{F}}=3 \mathrm{~Hz}, \mathrm{C}_{\mathrm{q}}\right), 114.7(\mathrm{CH}), 114.4\left(\mathrm{~d},{ }^{2} J_{\mathrm{C}-\mathrm{F}}=22 \mathrm{~Hz}, \mathrm{CH}\right), 96.1(\mathrm{CH})$.

${ }^{19} \mathrm{~F}-\mathrm{NMR}\left(283 \mathrm{MHz}, \mathrm{CDCl}_{3}\right): \delta=-(107.8-108.9)(\mathrm{m})$.

IR (ATR): $\tilde{V}=3056,1608,1539,1487,1461,1440,1230,773,739,693 \mathrm{~cm}^{-1}$.

MS (EI) $\mathrm{m} / z$ (relative intensity): 387 (100) $\left[\mathrm{M}^{+}\right], 309$ (13).

HR-MS (EI) $m / z$ calcd for $\mathrm{C}_{28} \mathrm{H}_{18} \mathrm{FN}^{+} 387.1383$, found 387.1411 .

2-Fluoro-5,6-diphenylindolo[2,1-a]isoquinoline (207"pa)

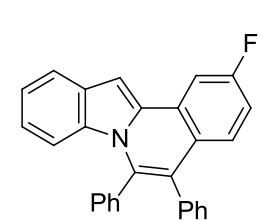

M. p. $=226-227^{\circ} \mathrm{C}$.

${ }^{1} \mathrm{H}-\mathrm{NMR}\left(300 \mathrm{MHz}, \mathrm{CDCl}_{3}\right): \delta=7.93(\mathrm{dd}, J=9.7,2.6 \mathrm{~Hz}, 1 \mathrm{H}), 7.81(\mathrm{~d}, J=$ $8.0 \mathrm{~Hz}, 1 \mathrm{H}), 7.43-7.27(\mathrm{~m}, 6 \mathrm{H}), 7.27-7.09(\mathrm{~m}, 7 \mathrm{H}), 7.05$ (ddd, $J=8.8,8.6,2.6$ $\mathrm{Hz}, 1 \mathrm{H}), 6.84(\mathrm{ddd}, J=8.0,7.7,1.3 \mathrm{~Hz}, 1 \mathrm{H}), 6.01(\mathrm{~d}, J=8.8 \mathrm{~Hz}, 1 \mathrm{H})$.

${ }^{13} \mathrm{C}-\mathrm{NMR}\left(75 \mathrm{MHz}, \mathrm{CDCl}_{3}\right): \delta=161.8\left(\mathrm{~d},{ }^{1} J_{\mathrm{C}-\mathrm{F}}=247 \mathrm{~Hz}, \mathrm{C}_{\mathrm{q}}\right), 136.7\left(\mathrm{C}_{\mathrm{q}}\right)$, $136.7\left(\mathrm{C}_{\mathrm{q}}\right), 135.3\left(\mathrm{C}_{\mathrm{q}}\right), 135.3\left(\mathrm{C}_{\mathrm{q}}\right), 133.0\left(\mathrm{C}_{\mathrm{q}}\right), 131.8(\mathrm{CH}), 131.0(\mathrm{CH}), 129.6\left(\mathrm{C}_{\mathrm{q}}\right), 129(\mathrm{CH})$, $128.6(\mathrm{CH}), 128.5\left(\mathrm{~d},{ }^{3} J_{\mathrm{C}-\mathrm{F}}=9 \mathrm{~Hz}, \mathrm{CH}\right), 127.9(\mathrm{CH}), 127.2\left(\mathrm{~d},{ }^{3} J_{\mathrm{C}-\mathrm{F}}=9 \mathrm{~Hz}, \mathrm{C}_{\mathrm{q}}\right), 126.9(\mathrm{CH})$, $126.8\left(\mathrm{~d},{ }^{4} J_{\mathrm{C}-\mathrm{F}}=2 \mathrm{~Hz}, \mathrm{C}_{\mathrm{q}}\right), 121.9(\mathrm{CH}), 121.0\left(\mathrm{C}_{\mathrm{q}}\right), 120.6(\mathrm{CH}), 120.5(\mathrm{CH}), 111.3\left(\mathrm{CH},{ }^{2} J_{\mathrm{C}-\mathrm{F}}=23\right.$ $\mathrm{Hz}), 114.7(\mathrm{CH}), 108.7\left(\mathrm{~d},{ }^{2} \mathrm{~J}_{\mathrm{C}-\mathrm{F}}=23 \mathrm{~Hz}, \mathrm{CH}\right), 96.1(\mathrm{CH})$.

${ }^{19} \mathrm{~F}-\mathrm{NMR}\left(283 \mathrm{MHz}, \mathrm{CDCl}_{3}\right): \delta=-(113.7-113.8)(\mathrm{m})$.

IR (ATR): $\tilde{V}=3061,1608,1538,1487,1340,1167,956,732,694,651 \mathrm{~cm}^{-1}$.

MS (EI) $m / z$ (relative intensity): 387 (100) $\left[\mathrm{M}^{+}\right], 309$ (9).

HR-MS (EI) $m / z$ calcd for $\mathrm{C}_{28} \mathrm{H}_{18} \mathrm{FN}^{+} 387.1383$, found 387.1419.

\section{Aerobic oxidative annulation in $[\mathrm{D}]_{4}-\mathrm{MeOH}$ (Scheme 66a)}
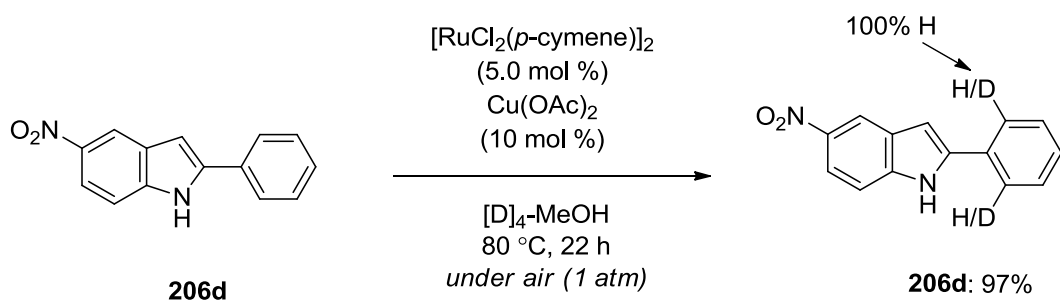

A mixture of 5-nitro-2-phenyl-1H-indole (206d) $(119 \mathrm{mg}, 0.50 \mathrm{mmol}),\left[\mathrm{RuCl}_{2}(p \text {-cymene })\right]_{2}$ $(15.3 \mathrm{mg}, 5.0 \mathrm{~mol} \%)$ and $\mathrm{Cu}(\mathrm{OAc})_{2}(9.1 \mathrm{mg}, 10.0 \mathrm{~mol} \%)$ in $[\mathrm{D}]_{4}-\mathrm{MeOH}(2.0 \mathrm{~mL})$ was stirred at $76{ }^{\circ} \mathrm{C}$ under air for $22 \mathrm{~h}$. At ambient temperature, the crude mixture was evaporated under reduced pressure and purified by column chromatography on silica gel ( $n$-hexane/EtOAc: $10 / 1)$ to yield 206d (116 mg, 97\%) as a yellow solid. No deuterium incorporation was detected by ${ }^{1} \mathrm{H}-\mathrm{NMR}$ spectroscopy. 
Aerobic oxidative annulation in $[\mathrm{D}]_{4}-\mathrm{MeOH}$ (Scheme 66b)

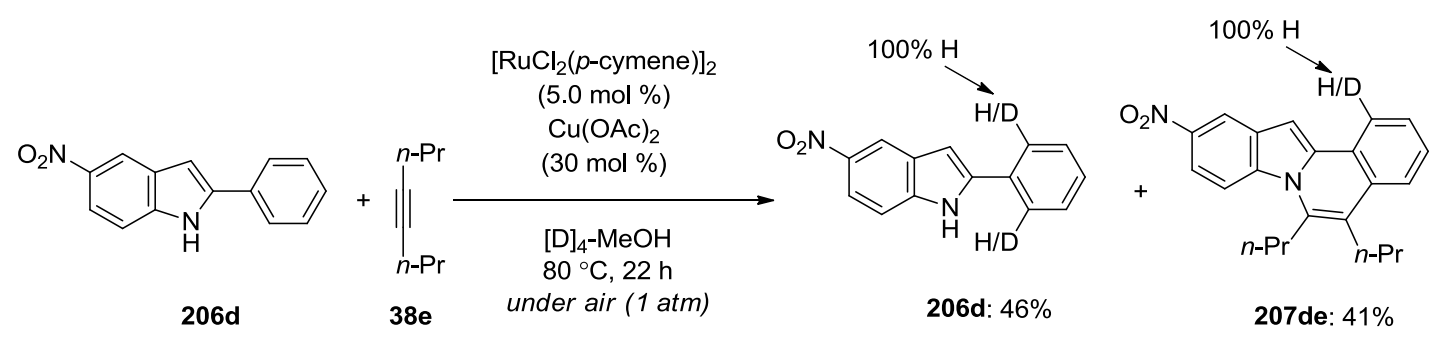

A mixture of 5-nitro-2-phenyl-1H-indole (206d) $(119 \mathrm{mg}, 0.50 \mathrm{mmol}), 4$-octyne (38e) $(110 \mathrm{mg}$, $1.00 \mathrm{mmol}),\left[\mathrm{RuCl}_{2}(p \text {-cymene })\right]_{2}(15.3 \mathrm{mg}, 5.0 \mathrm{~mol} \%)$ and $\mathrm{Cu}(\mathrm{OAc})_{2}(27.1 \mathrm{mg}, 30.0 \mathrm{~mol} \%)$ in $[\mathrm{D}]_{4}-\mathrm{MeOH}(2.0 \mathrm{~mL})$ was stirred at $76{ }^{\circ} \mathrm{C}$ under air for $22 \mathrm{~h}$. At ambient temperature, the mixture was diluted with $\mathrm{H}_{2} \mathrm{O}(75 \mathrm{~mL})$ and extracted with EtOAc $(3 \times 75 \mathrm{~mL})$. The combined organic phase was washed with brine $(50 \mathrm{~mL})$ and dried over anhydrous $\mathrm{Na}_{2} \mathrm{SO}_{4}$. After filtration and evaporation of the solvents under reduced pressure, the crude product was purified by column chromatography on silica gel ( $n$-hexane/EtOAc: $40 / 1 \rightarrow 10 / 1)$ to yield 207de $(76 \mathrm{mg}, 46 \%)$ as a yellow solid and 206d (49 mg, 41\%) as a yellow solid. No deuterium incorporation was detected by ${ }^{1}$ H-NMR spectroscopy.

\subsubsection{Analytical Data for the Products of Ruthenium-Catalyzed Oxidative Annulation of Alkynes 38 with Enamines 210}

Synthesis of methyl 1-acetyl-4,5-diphenyl-1H-pyrrole-2-carboxylate (211aa)<smiles>COc1cc(-c2ccccc2)c(-c2ccccc2)n1C</smiles>

The general procedure $\mathbf{C}$ was followed using 2-acetamidoacrylate (210a) (71.5 mg, $0.50 \mathrm{mmol}$ ) and diphenylacetylene (38a) (178 $\mathrm{mg}, 1.00 \mathrm{mmol})$. After $22 \mathrm{~h}$, purification by column chromatography on silica gel ( $n$-hexane/EtOAc: 10/1) yielded 211aa (111 $\mathrm{mg}, 70 \%)$ as a yellow oil.

${ }^{1} \mathrm{H}-\mathrm{NMR}\left(300 \mathrm{MHz}, \mathrm{CDCl}_{3}\right): \delta=7.48-7.28(\mathrm{~m}, 5 \mathrm{H}), 7.28-7.07$ (m, 6H), $3.89(\mathrm{~s}, 3 \mathrm{H}), 2.33(\mathrm{~s}$, $3 \mathrm{H})$.

${ }^{13} \mathrm{C}-\mathrm{NMR}\left(75 \mathrm{MHz}, \mathrm{CDCl}_{3}\right): \delta=173.8\left(\mathrm{C}_{\mathrm{q}}\right), 161.0\left(\mathrm{C}_{\mathrm{q}}\right), 134.5\left(\mathrm{C}_{\mathrm{q}}\right), 133.9\left(\mathrm{C}_{\mathrm{q}}\right), 130.6\left(\mathrm{C}_{\mathrm{q}}\right)$, $130.6(\mathrm{CH}), 128.8(\mathrm{CH}), 128.5(\mathrm{CH}), 128.2(\mathrm{CH}), 128.0(\mathrm{CH}), 126.4(\mathrm{CH}), 124.8\left(\mathrm{C}_{\mathrm{q}}\right), 122.9\left(\mathrm{C}_{\mathrm{q}}\right)$, $118.3(\mathrm{CH}), 51.8\left(\mathrm{CH}_{3}\right), 28.8\left(\mathrm{CH}_{3}\right)$.

IR (ATR): $\tilde{V}=3060,2953,1759,1702,1440,1381,1253,1207,756,694 \mathrm{~cm}^{-1}$.

MS (EI) $m / z$ (relative intensity): 319 (18) $\left[\mathrm{M}^{+}\right], 277$ (100), 245 (33), 215 (34), 43 (27).

HR-MS (EI) $\mathrm{m} / z$ calcd for $\mathrm{C}_{20} \mathrm{H}_{17} \mathrm{NO}_{3}{ }^{+} 319.1206$, found 319.1197 .

The spectral data were in accordance with those reported in the literature. ${ }^{123 a}$

\section{Synthesis of methyl 4,5-diphenyl-1H-pyrrole-2-carboxylate (212aa)}

Ph The general procedure $\mathbf{C}$ was followed using

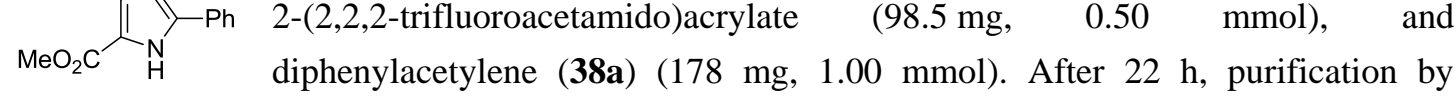
column chromatography on silica gel (n-hexane/EtOAc: 10/1) yielded 212aa as a white solid (21 mg, 15\%).

M.p. $=174-175^{\circ} \mathrm{C}$.

${ }^{1} \mathrm{H}-\mathrm{NMR}\left(300 \mathrm{MHz}, \mathrm{CDCl}_{3}\right): \delta=9.56(\mathrm{~s}, 1 \mathrm{H}), 7.55-7.18(\mathrm{~m}, 10 \mathrm{H}), 7.07(\mathrm{~d}, J=2.8 \mathrm{~Hz}, 1 \mathrm{H})$, 
$3.85(\mathrm{~s}, 3 \mathrm{H})$.

${ }^{13} \mathrm{C}-\mathrm{NMR}\left(75 \mathrm{MHz}, \mathrm{CDCl}_{3}\right): \delta=161.7\left(\mathrm{C}_{\mathrm{q}}\right), 136.3\left(\mathrm{C}_{\mathrm{q}}\right), 133.4\left(\mathrm{C}_{\mathrm{q}}\right), 131.8\left(\mathrm{C}_{\mathrm{q}}\right), 128.6(\mathrm{CH}), 128.4$ $(\mathrm{CH}), 128.3(\mathrm{CH}), 128.0(\mathrm{CH}), 127.9(\mathrm{CH}), 126.3(\mathrm{CH}), 124.1\left(\mathrm{C}_{\mathrm{q}}\right), 122.0\left(\mathrm{C}_{\mathrm{q}}\right), 116.8(\mathrm{CH}), 51.6$ $\left(\mathrm{CH}_{3}\right)$.

IR (ATR): $\tilde{V}=3257,1668,1602,1454,1440,1225,1203,1009,762,692 \mathrm{~cm}^{-1}$.

MS (EI) $\mathrm{m} / z$ (relative intensity): 277 (100) $\left[\mathrm{M}^{+}\right], 245$ (72), 215 (70), 189 (28), 43 (20).

HR-MS (EI) $m / z$ calcd for $\mathrm{C}_{18} \mathrm{H}_{15} \mathrm{NO}_{2}^{+} 277.1103$, found 277.1094 .

\section{Synthesis of ethyl 1-acetyl-4,5-diphenyl-1H-pyrrole-2-carboxylate (211ba)}

The general procedure $\mathbf{C}$ was followed using ethyl 2-acetamidoacrylate (210b)
$(78.5 \mathrm{mg}, 0.50 \mathrm{mmol})$ and diphenylacetylene (38a) (178 mg, 1.00 mmol). After
$22 \mathrm{~h}$, purification by column chromatography on silica gel ( $n$-hexane/EtOAc:
$20 / 1)$ yielded $211 \mathrm{ba}(113 \mathrm{mg}, 68 \%)$ as a white solid. M.p. $=94-95^{\circ} \mathrm{C}$.

${ }^{1} \mathrm{H}-\mathrm{NMR}\left(300 \mathrm{MHz}, \mathrm{CDCl}_{3}\right): \delta=7.49-7.26(\mathrm{~m}, 5 \mathrm{H}), 7.25-7.03(\mathrm{~m}, 6 \mathrm{H}), 4.36(\mathrm{q}, J=7.2 \mathrm{~Hz}, 2 \mathrm{H})$, $3.00(\mathrm{~s}, 3 \mathrm{H}), 1.39$ (t, $J=7.2 \mathrm{~Hz}, 3 \mathrm{H})$.

${ }^{13} \mathrm{C}-\mathrm{NMR}\left(75 \mathrm{MHz}, \mathrm{CDCl}_{3}\right): \delta=173.9\left(\mathrm{C}_{\mathrm{q}}\right), 160.6\left(\mathrm{C}_{\mathrm{q}}\right), 134.4\left(\mathrm{C}_{\mathrm{q}}\right), 134.0\left(\mathrm{C}_{\mathrm{q}}\right), 130.7\left(\mathrm{C}_{\mathrm{q}}\right), 130.7$ $(\mathrm{CH}), 128.8(\mathrm{CH}), 128.5(\mathrm{CH}), 128.2(\mathrm{CH}), 128.0(\mathrm{CH}), 126.4(\mathrm{CH}), 124.7\left(\mathrm{C}_{\mathrm{q}}\right), 123.3\left(\mathrm{C}_{\mathrm{q}}\right)$, $118.2(\mathrm{CH}), 60.8\left(\mathrm{CH}_{2}\right), 28.9\left(\mathrm{CH}_{3}\right), 14.3\left(\mathrm{CH}_{3}\right)$.

IR (ATR): $\tilde{V}=2998,1753,1697,1499,1460,1258,1219,1190,770,701 \mathrm{~cm}^{-1}$. MS (EI) $m / z$ (relative intensity): 333 (5) $\left[\mathrm{M}^{+}\right], 291$ (100), 245 (62), 215 (38), 189 (20).

HR-MS (EI) $m / z$ calcd for $\mathrm{C}_{21} \mathrm{H}_{19} \mathrm{NO}_{3}{ }^{+} 333.1365$, found 333.1356 .

\section{Synthesis of isopropyl 1-acetyl-4,5-diphenyl-1H-pyrrole-2-carboxylate (211ca)}

$\mathrm{Ph} \quad$ The general procedure $\mathbf{C}$ was followed using isopropyl 2-acetamidoacrylate (210c) $(85.5 \mathrm{mg}, 0.50 \mathrm{mmol})$ and diphenylacetylene (38a) $(178 \mathrm{mg}, 1.00 \mathrm{mmol})$. After $22 \mathrm{~h}$, purification by column chromatography on silica gel ( $n$-hexane/EtOAc: $30 / 1)$ yielded 210ca $(111 \mathrm{mg}, 66 \%)$ as a colorless oil.

${ }^{1} \mathrm{H}-\mathrm{NMR}\left(300 \mathrm{MHz}, \mathrm{CDCl}_{3}\right): \delta=7.38-7.27(\mathrm{~m}, 5 \mathrm{H}), 7.21-7.11(\mathrm{~m}, 6 \mathrm{H}), 5.21$ (sept., $J=6.2 \mathrm{~Hz}$, $1 \mathrm{H}), 2.30(\mathrm{~s}, 3 \mathrm{H}), 1.36(\mathrm{~d}, J=6.2 \mathrm{~Hz}, 6 \mathrm{H})$.

${ }^{13} \mathrm{C}-\mathrm{NMR}\left(75 \mathrm{MHz}, \mathrm{CDCl}_{3}\right): \delta=173.9\left(\mathrm{C}_{\mathrm{q}}\right), 160.2\left(\mathrm{C}_{\mathrm{q}}\right), 134.2\left(\mathrm{C}_{\mathrm{q}}\right), 134.0\left(\mathrm{C}_{\mathrm{q}}\right), 130.7\left(\mathrm{C}_{\mathrm{q}}\right), 130.7$ $(\mathrm{CH}), 128.8(\mathrm{CH}), 128.5(\mathrm{CH}), 128.2(\mathrm{CH}), 128.0(\mathrm{CH}), 126.3(\mathrm{CH}), 124.7\left(\mathrm{C}_{\mathrm{q}}\right), 123.7\left(\mathrm{C}_{\mathrm{q}}\right)$, $118.0(\mathrm{CH}), 68.5(\mathrm{CH}), 28.9\left(\mathrm{CH}_{3}\right), 21.9\left(\mathrm{CH}_{3}\right)$.

IR (ATR): $\tilde{V}=3030,1760,1695,1460,1385,1254,1206,1104,757,695 \mathrm{~cm}^{-1}$.

MS (EI) $\mathrm{m} / z$ (relative intensity): 347 (9) [ $\left[\mathrm{M}^{+}\right], 305$ (100), 263 (70), 245 (77), 214 (47), 191 (22).

HR-MS (EI) $m / z$ calcd for $\mathrm{C}_{22} \mathrm{H}_{21} \mathrm{NO}_{3}{ }^{+} 347.1521$, found 347.1516 .

\section{Synthesis of 1-acetyl-2-methyl-4,5-diphenyl-1H-pyrrole-3-carbonitrile (211fa)}

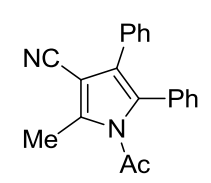

The general procedure $\mathbf{C}$ was followed using $N$-(1-cyanoprop-1-en-2-yl)acetamide (210f) $(62.0 \mathrm{mg}, 0.50 \mathrm{mmol})$ and diphenylacetylene (38a) $(178 \mathrm{mg}, 1.00 \mathrm{mmol})$. After $22 \mathrm{~h}$, purification by column chromatography on silica gel ( $n$-hexane/EtOAc: 10/1) yielded $211 \mathrm{fa}$ (65 $\mathrm{mg}, 43 \%$ ) as a white solid.

M.p. $=243-244^{\circ} \mathrm{C}$.

${ }^{1} \mathrm{H}-\mathrm{NMR}\left(300 \mathrm{MHz}, \mathrm{CDCl}_{3}\right): \delta=7.39-7.31(\mathrm{~m}, 3 \mathrm{H}), 7.28-7.14(\mathrm{~m}, 7 \mathrm{H}), 2.64(\mathrm{~s}, 3 \mathrm{H}), 1.95$ (s, $3 \mathrm{H})$. 
${ }^{13} \mathrm{C}-\mathrm{NMR}\left(75 \mathrm{MHz}, \mathrm{CDCl}_{3}\right): \delta=172.2\left(\mathrm{C}_{\mathrm{q}}\right), 140.8\left(\mathrm{C}_{\mathrm{q}}\right), 131.4\left(\mathrm{C}_{\mathrm{q}}\right), 131.4\left(\mathrm{C}_{\mathrm{q}}\right), 130.2(\mathrm{CH}), 129.6$ $\left(\mathrm{C}_{\mathrm{q}}\right), 129.1(\mathrm{CH}), 129.0(\mathrm{CH}), 128.8(\mathrm{CH}), 128.3(\mathrm{CH}), 127.4(\mathrm{CH}), 125.4\left(\mathrm{C}_{\mathrm{q}}\right), 111.6\left(\mathrm{C}_{\mathrm{q}}\right), 97.2$ $\left(\mathrm{C}_{\mathrm{q}}\right), 27.9\left(\mathrm{CH}_{3}\right), 14.2\left(\mathrm{CH}_{3}\right)$.

IR (ATR): $\tilde{V}=2977,2198,1521,1441,1362,1072,1003,717,703,574 \mathrm{~cm}^{-1}$.

MS (EI) $m / z$ (relative intensity): $300(20)\left[\mathrm{M}^{+}\right], 258$ (100), 238 (20), 43 (32).

HR-MS (EI) $m / z$ calcd for $\mathrm{C}_{20} \mathrm{H}_{16} \mathrm{~N}_{2} \mathrm{O}^{+} 300.1263$, found 300.1259 .

The spectral data were in accordance with those reported in the literature. ${ }^{122}$

\section{Synthesis of 1-(2,3,5-triphenyl-1H-pyrrol-1-yl)ethanone (211ga)}

$\mathrm{Ph} \quad$ The general procedure $\mathbf{C}$ was followed using $N$-(1-phenylvinyl)acetamide (210g) (76.5 mg, $0.50 \mathrm{mmol})$ and diphenylacetylene (38a) $(178 \mathrm{mg}, 1.00 \mathrm{mmol})$. After Ph $22 \mathrm{~h}$, purification by column chromatography on silica gel ( $n$-hexane/EtOAc: $30 / 1)$ yielded 211ga ( $88 \mathrm{mg}, 52 \%$ ) as a yellow solid.

M.p. $=131-132{ }^{\circ} \mathrm{C}$.

${ }^{1} \mathrm{H}-\mathrm{NMR}\left(300 \mathrm{MHz}, \mathrm{CDCl}_{3}\right): \delta=7.46-7.40(\mathrm{~m}, 4 \mathrm{H}), 7.38-7.33$ (m, 6H), 7.21-7.14 (m, 5H), 6.54 (s, 1H), $2.02(\mathrm{~s}, 3 \mathrm{H})$.

${ }^{13} \mathrm{C}-\mathrm{NMR}\left(75 \mathrm{MHz}, \mathrm{CDCl}_{3}\right): \delta=172.8\left(\mathrm{C}_{\mathrm{q}}\right), 134.8\left(\mathrm{C}_{\mathrm{q}}\right), 134.7\left(\mathrm{C}_{\mathrm{q}}\right), 133.4\left(\mathrm{C}_{\mathrm{q}}\right), 132.8\left(\mathrm{C}_{\mathrm{q}}\right), 131.0$ $(\mathrm{CH}), 130.9\left(\mathrm{C}_{\mathrm{q}}\right), 128.5(\mathrm{CH}), 128.4(\mathrm{CH}), 128.4(\mathrm{CH}), 128.1(\mathrm{CH}), 128.1(\mathrm{CH}), 128.1(\mathrm{CH})$, $127.6(\mathrm{CH}), 126.2(\mathrm{CH}), 125.5\left(\mathrm{C}_{\mathrm{q}}\right), 113.6(\mathrm{CH}), 28.6\left(\mathrm{CH}_{3}\right)$.

IR (ATR): $\tilde{V}=3061,3029,1721,1620,1485,1288,1268,1026,789,762 \mathrm{~cm}^{-1}$.

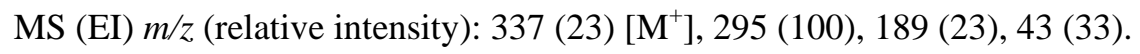

HR-MS (EI) $m / z$ calcd for $\mathrm{C}_{24} \mathrm{H}_{19} \mathrm{NO}^{+} 337.1467$, found 337.1461 .

\section{Synthesis of 1-\{5-[4-(trifluoromethyl)phenyl]-2,3-diphenyl-1H-pyrrol-1-yl\}ethanone (211ha)}

$\mathrm{Ph}$ The general procedure $\mathbf{C}$ was followed using $N$-\{1-[4-(trifluoromethyl)phenyl]vinyl\}-acetamide $\quad(\mathbf{2 1 0 h}) \quad(111 \quad \mathrm{mg}$, $0.50 \mathrm{mmol}$ ) and diphenylacetylene (38a) $(178 \mathrm{mg}, 1.00 \mathrm{mmol})$. After $22 \mathrm{~h}$, purification by column chromatography on silica gel ( $n$-hexane/EtOAc: $40 / 1)$ yielded 211ha (138 $\mathrm{mg}, 68 \%$ ) as a white solid.

M.p. $=133-134{ }^{\circ} \mathrm{C}$.

${ }^{1} \mathrm{H}-\mathrm{NMR}\left(300 \mathrm{MHz}, \mathrm{CDCl}_{3}\right): \delta=7.67(\mathrm{~d}, J=8.2 \mathrm{~Hz}, 2 \mathrm{H}), 7.53(\mathrm{~d}, J=8.2 \mathrm{~Hz}, 2 \mathrm{H}), 7.43-7.33(\mathrm{~m}$, $5 \mathrm{H}), 7.24-7.13(\mathrm{~m}, 5 \mathrm{H}), 6.59(\mathrm{~s}, 1 \mathrm{H}), 2.03(\mathrm{~s}, 3 \mathrm{H})$.

${ }^{13} \mathrm{C}-\mathrm{NMR}\left(75 \mathrm{MHz}, \mathrm{CDCl}_{3}\right): \delta=172.5\left(\mathrm{C}_{\mathrm{q}}\right), 137.0\left(\mathrm{C}_{\mathrm{q}}\right), 134.4\left(\mathrm{C}_{\mathrm{q}}\right), 133.6\left(\mathrm{C}_{\mathrm{q}}\right), 132.5\left(\mathrm{C}_{\mathrm{q}}\right), 131.5$ $\left(\mathrm{C}_{\mathrm{q}}\right), 130.9(\mathrm{CH}), 129.7\left(\mathrm{q},{ }^{2} J_{\mathrm{C}-\mathrm{F}}=32 \mathrm{~Hz}, \mathrm{C}_{\mathrm{q}}\right), 128.6(\mathrm{CH}), 128.5(\mathrm{CH}), 128.5(\mathrm{CH}), 128.2(\mathrm{CH})$, $128.1(\mathrm{CH}), 127.7\left(\mathrm{q},{ }^{1} J_{\mathrm{C}-\mathrm{F}}=273 \mathrm{~Hz}, \mathrm{C}_{\mathrm{q}}\right), 126.4(\mathrm{CH}), 125.9\left(\mathrm{C}_{\mathrm{q}}\right), 125.3\left(\mathrm{q},{ }^{3} J_{\mathrm{C}-\mathrm{F}}=4 \mathrm{~Hz}, \mathrm{CH}\right)$, $114.8(\mathrm{CH}), 28.5\left(\mathrm{CH}_{3}\right)$.

${ }^{19} \mathrm{~F}-\mathrm{NMR}\left(283 \mathrm{MHz}, \mathrm{CDCl}_{3}\right): \delta=-62.5(\mathrm{~s})$.

IR (ATR): $\tilde{V}=3063,3032,1723,1615,1268,1111,1064,847,766,694 \mathrm{~cm}^{-1}$.

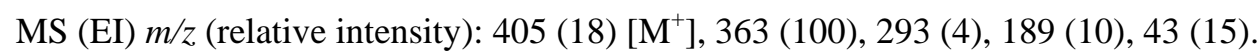

HR-MS (EI) $\mathrm{m} / z$ calcd for $\mathrm{C}_{25} \mathrm{H}_{18} \mathrm{~F}_{3} \mathrm{NO}^{+} 405.1340$, found 405.1346 .

\section{Synthesis of 1-\{5-(4-fluorophenyl)-2,3-diphenyl-1H-pyrrol-1-yl\}ethanone (211ia)}

$\mathrm{Ph}$ The general procedure $\mathbf{C}$ was followed using $N$-\{1-(4-fluorophenyl)vinyl $\}$ acetamide $\quad(\mathbf{2 1 0 i}) \quad(89.5 \mathrm{mg}, \quad 0.50 \mathrm{mmol})$ and diphenylacetylene (38a) $(178 \mathrm{mg}, 1.00 \mathrm{mmol})$. After $22 \mathrm{~h}$, purification by 
column chromatography on silica gel ( $n$-hexane/EtOAc: $30 / 1)$ yielded 211ia (94 mg, 53\%) as a white solid.

M.p. $=144-145^{\circ} \mathrm{C}$.

${ }^{1} \mathrm{H}-\mathrm{NMR}\left(300 \mathrm{MHz}, \mathrm{CDCl}_{3}\right): \delta=7.46-7.30(\mathrm{~m}, 7 \mathrm{H}), 7.24-7.07(\mathrm{~m}, 7 \mathrm{H}), 6.51(\mathrm{~s}, 1 \mathrm{H}), 2.01(\mathrm{~s}$, $3 \mathrm{H})$.

${ }^{13} \mathrm{C}-\mathrm{NMR}\left(75 \mathrm{MHz}, \mathrm{CDCl}_{3}\right): \delta=172.7\left(\mathrm{C}_{\mathrm{q}}\right), 162.3\left(\mathrm{~d},{ }^{1} J_{\mathrm{C}-\mathrm{F}}=248 \mathrm{~Hz}, \mathrm{C}_{\mathrm{q}}\right), 134.7\left(\mathrm{C}_{\mathrm{q}}\right), 133.9\left(\mathrm{C}_{\mathrm{q}}\right)$, $132.8\left(\mathrm{C}_{\mathrm{q}}\right), 130.8(\mathrm{CH}), 130.7\left(\mathrm{C}_{\mathrm{q}}\right), 130.4\left(\mathrm{~d},{ }^{3} J_{\mathrm{C}-\mathrm{F}}=8 \mathrm{~Hz}, \mathrm{CH}\right), 129.5\left(\mathrm{~d},{ }^{4} J_{\mathrm{C}-\mathrm{F}}=3 \mathrm{~Hz}, \mathrm{C}_{\mathrm{q}}\right), 128.5$ $(\mathrm{CH}), 128.2(\mathrm{CH}), 128.2(\mathrm{CH}), 128.1(\mathrm{CH}), 126.3(\mathrm{CH}), 125.5\left(\mathrm{C}_{\mathrm{q}}\right), 111.4\left(\mathrm{~d},{ }^{2} J_{\mathrm{C}-\mathrm{F}}=21 \mathrm{~Hz}, \mathrm{CH}\right)$, $113.7(\mathrm{CH}), 28.6\left(\mathrm{CH}_{3}\right)$.

${ }^{19} \mathrm{~F}-\mathrm{NMR}\left(283 \mathrm{MHz}, \mathrm{CDCl}_{3}\right): \delta=-(114.1-114.2)(\mathrm{m})$.

IR (ATR): $\tilde{V}=3024,1722,1585,1493,1365,1279,958,840,767,694 \mathrm{~cm}^{-1}$.

MS (EI) $m / z$ (relative intensity): 355 (15) $\left[\mathrm{M}^{+}\right], 313$ (100), 207 (7), 189 (7), 43 (13).

HR-MS (EI) $m / z$ calcd for $\mathrm{C}_{24} \mathrm{H}_{18} \mathrm{FNO}^{+} 355.1372$, found 355.1384 .

\section{Synthesis of 1-\{5-(4-bromophenyl)-2,3-diphenyl-1H-pyrrol-1-yl\}ethanone (211ja)}

$\mathrm{Ph}$ The general procedure $\mathbf{C}$ was followed using $N$-\{1-(4-bromophenyl)vinyl $\}$ acetamide $(\mathbf{2 1 0 j}) \quad(119 \mathrm{mg}, 0.50 \mathrm{mmol})$ and diphenylacetylene (38a) (178 mg, $1.00 \mathrm{mmol})$. After $22 \mathrm{~h}$, purification by column chromatography on silica gel ( $n$-hexane/EtOAc: $30 / 1$ ) yielded 211 ja (120 mg, 58\%) as a white solid.

M.p. $=120-121^{\circ} \mathrm{C}$.

${ }^{1} \mathrm{H}-\mathrm{NMR}\left(300 \mathrm{MHz}, \mathrm{CDCl}_{3}\right): \delta=7.54(\mathrm{~d}, J=8.6 \mathrm{~Hz}, 2 \mathrm{H}), 7.40-7.34(\mathrm{~m}, 5 \mathrm{H}), 7.31(\mathrm{~d}, J=8.6 \mathrm{~Hz}$, $2 \mathrm{H}), 7.23-7.14(\mathrm{~m}, 5 \mathrm{H}), 6.53(\mathrm{~s}, 1 \mathrm{H}), 2.02(\mathrm{~s}, 3 \mathrm{H})$.

${ }^{13} \mathrm{C}-\mathrm{NMR}\left(75 \mathrm{MHz}, \mathrm{CDCl}_{3}\right): \delta=172.5\left(\mathrm{C}_{\mathrm{q}}\right), 134.5\left(\mathrm{C}_{\mathrm{q}}\right), 133.7\left(\mathrm{C}_{\mathrm{q}}\right), 132.6\left(\mathrm{C}_{\mathrm{q}}\right), 132.3\left(\mathrm{C}_{\mathrm{q}}\right), 131.5$ $(\mathrm{CH}), 131.0\left(\mathrm{C}_{\mathrm{q}}\right), 130.8(\mathrm{CH}), 130.0(\mathrm{CH}), 128.5(\mathrm{CH}), 128.2(\mathrm{CH}), 128.1(\mathrm{CH}), 128.1(\mathrm{CH})$, $126.3(\mathrm{CH}), 125.7\left(\mathrm{C}_{\mathrm{q}}\right), 121.6\left(\mathrm{C}_{\mathrm{q}}\right), 114.0(\mathrm{CH}), 28.5\left(\mathrm{CH}_{3}\right)$.

IR (ATR): $\tilde{V}=3060,3026,1722,1585,1482,1365,1278,1069,1011,743 \mathrm{~cm}^{-1}$.

MS (EI) $m / z$ (relative intensity): $417(17)\left[\mathrm{M}^{+}\right]\left({ }^{81} \mathrm{Br}\right), 415(17)\left[\mathrm{M}^{+}\right]\left({ }^{79} \mathrm{Br}\right), 373(100), 293(20)$, 189 (27), 43 (52).

HR-MS (EI) $m / z$ calcd for $\mathrm{C}_{24} \mathrm{H}_{18} \mathrm{BrNO}^{+} 415.0572$, found 415.0589 .

\section{Synthesis of 4-(1-acetyl-4,5-diphenyl-1H-pyrrol-2-yl)benzonitrile (211ka)}

$\mathrm{Ph}$ The general procedure $\mathbf{C}$ was followed using $N$-\{1-(4-cyanophenyl)vinyl $\}$ acetamide (210k) $(93.0 \mathrm{mg}, 0.50 \mathrm{mmol})$ and diphenylacetylene (38a) (178 $\mathrm{mg}, 1.00 \mathrm{mmol})$. After $22 \mathrm{~h}$, purification by column chromatography on silica gel ( $n$-hexane/EtOAc: $20 / 1)$ yielded $211 \mathbf{k a}$

(134 $\mathrm{mg}, 74 \%)$ as a yellow solid.

M.p. $=145-146^{\circ} \mathrm{C}$.

${ }^{1} \mathrm{H}-\mathrm{NMR}\left(300 \mathrm{MHz}, \mathrm{CDCl}_{3}\right): \delta=7.66(\mathrm{~d}, J=8.5 \mathrm{~Hz}, 2 \mathrm{H}), 7.48(\mathrm{~d}, J=8.5 \mathrm{~Hz}, 2 \mathrm{H}), 7.41-7.31(\mathrm{~m}$, 5H), 7.21-7.10 (m, 5H), $6.59(\mathrm{~s}, 1 \mathrm{H}), 2.00(\mathrm{~s}, 3 \mathrm{H})$.

${ }^{13} \mathrm{C}-\mathrm{NMR}\left(75 \mathrm{MHz}, \mathrm{CDCl}_{3}\right): \delta=172.4\left(\mathrm{C}_{\mathrm{q}}\right), 138.0\left(\mathrm{C}_{\mathrm{q}}\right), 134.2\left(\mathrm{C}_{\mathrm{q}}\right), 133.3\left(\mathrm{C}_{\mathrm{q}}\right), 132.3\left(\mathrm{C}_{\mathrm{q}}\right), 132.0$ $(\mathrm{CH}), 132.0\left(\mathrm{C}_{\mathrm{q}}\right), 130.9(\mathrm{CH}), 128.7(\mathrm{CH}), 128.7(\mathrm{CH}), 128.7(\mathrm{CH}), 128.2(\mathrm{CH}), 128.1(\mathrm{CH})$, $126.6(\mathrm{CH}), 126.2\left(\mathrm{C}_{\mathrm{q}}\right), 118.8\left(\mathrm{C}_{\mathrm{q}}\right), 111.4(\mathrm{CH}), 110.7\left(\mathrm{C}_{\mathrm{q}}\right), 28.4\left(\mathrm{CH}_{3}\right)$. IR (ATR): $\tilde{V}=3061,2103,1731,1603,1490,1267,1208,824,696,552 \mathrm{~cm}^{-1}$. MS (EI) $m / z$ (relative intensity): $362(10)\left[\mathrm{M}^{+}\right], 320$ (100), $214(6), 189$ (8), 43 (15). 
HR-MS (EI) $m / z$ calcd for $\mathrm{C}_{25} \mathrm{H}_{18} \mathrm{~N}_{2} \mathrm{O}^{+} 362.1419$, found 362.1416 .

\section{Synthesis of 1-\{5-(4-nitrophenyl)-2,3-diphenyl-1H-pyrrol-1-yl\}ethanone (211la)}<smiles>Cn1c(-c2ccc([N+](=O)[O-])cc2)cc(-c2ccccc2)c1-c1ccccc1</smiles>

The general procedure $\mathbf{C}$ was followed using $N$-\{1-(4-nitrophenyl)vinyl $\}$ acetamide (2111) $(103 \mathrm{mg}, 0.50 \mathrm{mmol})$ and diphenylacetylene (38a) (178 mg, $1.00 \mathrm{mmol})$. After $22 \mathrm{~h}$, purification by column chromatography on silica gel ( $n$-hexane/EtOAc: 20/1) yielded 211la (136 $\mathrm{mg}, 71 \%)$ as a yellow solid.

M.p. $=184-185^{\circ} \mathrm{C}$.

${ }^{1} \mathrm{H}-\mathrm{NMR}\left(300 \mathrm{MHz}, \mathrm{CDCl}_{3}\right): \delta=8.27(\mathrm{~d}, J=8.6 \mathrm{~Hz}, 2 \mathrm{H}), 7.55(\mathrm{~d}, J=8.6 \mathrm{~Hz}, 2 \mathrm{H}), 7.44-7.32(\mathrm{~m}$, $5 \mathrm{H}), 7.24-7.11(\mathrm{~m}, 5 \mathrm{H}), 6.66(\mathrm{~s}, 1 \mathrm{H}), 2.03(\mathrm{~s}, 3 \mathrm{H})$.

${ }^{13} \mathrm{C}-\mathrm{NMR}\left(75 \mathrm{MHz}, \mathrm{CDCl}_{3}\right): \delta=172.3\left(\mathrm{C}_{\mathrm{q}}\right), 146.6\left(\mathrm{C}_{\mathrm{q}}\right), 139.9\left(\mathrm{C}_{\mathrm{q}}\right), 134.1\left(\mathrm{C}_{\mathrm{q}}\right), 133.0\left(\mathrm{C}_{\mathrm{q}}\right), 132.3$ $\left(\mathrm{C}_{\mathrm{q}}\right), 132.2\left(\mathrm{C}_{\mathrm{q}}\right), 130.9(\mathrm{CH}), 128.8(\mathrm{CH}), 128.8(\mathrm{CH}), 128.7(\mathrm{CH}), 128.3(\mathrm{CH}), 128.1(\mathrm{CH}), 126.6$ $(\mathrm{CH}), 126.4\left(\mathrm{C}_{\mathrm{q}}\right), 123.6(\mathrm{CH}), 111.9(\mathrm{CH}), 28.4\left(\mathrm{CH}_{3}\right)$.

IR (ATR): $\tilde{V}=3104,1733,1595,1508,1338,1264,1206,784,692,491 \mathrm{~cm}^{-1}$.

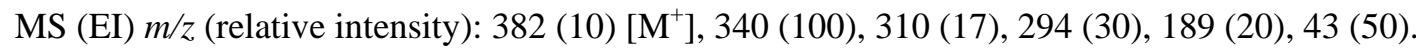

HR-MS (EI) $m / z$ calcd for $\mathrm{C}_{24} \mathrm{H}_{18} \mathrm{~N}_{2} \mathrm{O}_{3}{ }^{+} 382.1317$, found 382.1330 .

\section{Synthesis of 1-\{2,3-diphenyl-5-(p-tolyl)-1H-pyrrol-1-yl\}ethanone (211ma)}

$\mathrm{Ph} \quad$ The general procedure $\mathbf{C}$ was followed using $N$-\{1-(p-tolyl)vinyl $\}$ acetamide (210m) $(87.5 \mathrm{mg}, 0.50 \mathrm{mmol})$ and diphenylacetylene (38a) $(178 \mathrm{mg}$, $1.00 \mathrm{mmol}$ ). After $22 \mathrm{~h}$, purification by column chromatography on silica gel (n-hexane/EtOAc: 10/1) yielded 211ma (32 mg, 18\%) as a white solid.

M.p. $=104-105^{\circ} \mathrm{C}$.

${ }^{1} \mathrm{H}-\mathrm{NMR}\left(300 \mathrm{MHz}, \mathrm{CDCl}_{3}\right): \delta=7.44-7.30(\mathrm{~m}, 7 \mathrm{H}), 7.26-7.13(\mathrm{~m}, 7 \mathrm{H}), 6.53(\mathrm{~s}, 1 \mathrm{H}), 2.38(\mathrm{~s}$, $3 \mathrm{H}), 2.05(\mathrm{~s}, 3 \mathrm{H})$.

${ }^{13} \mathrm{C}-\mathrm{NMR}\left(75 \mathrm{MHz}, \mathrm{CDCl}_{3}\right): \delta=172.9\left(\mathrm{C}_{\mathrm{q}}\right), 137.5\left(\mathrm{C}_{\mathrm{q}}\right), 134.9\left(\mathrm{C}_{\mathrm{q}}\right), 134.8\left(\mathrm{C}_{\mathrm{q}}\right), 132.9\left(\mathrm{C}_{\mathrm{q}}\right), 130.9$ $(\mathrm{CH}), 130.6\left(\mathrm{C}_{\mathrm{q}}\right), 130.5\left(\mathrm{C}_{\mathrm{q}}\right), 129.2(\mathrm{CH}), 128.3(\mathrm{CH}), 128.3(\mathrm{CH}), 128.1(\mathrm{CH}), 128.1(\mathrm{CH}), 128.0$ $(\mathrm{CH}), 126.1(\mathrm{CH}), 125.4\left(\mathrm{C}_{\mathrm{q}}\right), 113.2(\mathrm{CH}), 28.6\left(\mathrm{CH}_{3}\right), 21.2\left(\mathrm{CH}_{3}\right)$.

IR (ATR): $\tilde{V}=3050,1723,1601,1495,1276,1206,957,764,694,546 \mathrm{~cm}^{-1}$.

MS (EI) $m / z$ (relative intensity): 351 (13) $\left[\mathrm{M}^{+}\right], 309$ (100), 189 (7), 43 (10).

HR-MS (EI) $m / z$ calcd for $\mathrm{C}_{25} \mathrm{H}_{21} \mathrm{NO}^{+} 351.1623$, found 351.1627 .

\section{Synthesis of 1-\{5-(4-methoxyphenyl)-2,3-diphenyl-1H-pyrrol-1-yl\}ethanone (211na)}

$\mathrm{Ph}$ The general procedure $\mathbf{C}$ was followed using -Ph $N$-\{1-(4-methoxyphenyl)vinyl $\}$ acetamide (210n) $(95.5 \mathrm{mg}, 0.50 \mathrm{mmol})$ and diphenylacetylene (38a) $(178 \mathrm{mg}, 1.00 \mathrm{mmol})$. After $22 \mathrm{~h}$, purification by
column chromatography on silica gel ( $n$-hexane/EtOAc: 20/1) yielded 211na (52 $\mathrm{mg}, 28 \%$ ) as a white solid.

M.p. $=105-106^{\circ} \mathrm{C}$.

${ }^{1} \mathrm{H}-\mathrm{NMR}\left(300 \mathrm{MHz}, \mathrm{CDCl}_{3}\right): \delta=7.38-7.32(\mathrm{~m}, 7 \mathrm{H}), 7.23-7.11(\mathrm{~m}, 5 \mathrm{H}), 6.97(\mathrm{~d}, J=8.4 \mathrm{~Hz}, 2 \mathrm{H})$, $6.48(\mathrm{~s}, 1 \mathrm{H}), 3.86(\mathrm{~s}, 3 \mathrm{H}), 2.03(\mathrm{~s}, 3 \mathrm{H})$.

${ }^{13} \mathrm{C}-\mathrm{NMR}\left(75 \mathrm{MHz}, \mathrm{CDCl}_{3}\right): \delta=172.9\left(\mathrm{C}_{\mathrm{q}}\right), 159.2\left(\mathrm{C}_{\mathrm{q}}\right), 134.9\left(\mathrm{C}_{\mathrm{q}}\right), 134.6\left(\mathrm{C}_{\mathrm{q}}\right), 132.9\left(\mathrm{C}_{\mathrm{q}}\right), 130.9$ $(\mathrm{CH}), 130.4\left(\mathrm{C}_{\mathrm{q}}\right), 129.8(\mathrm{CH}), 128.3(\mathrm{CH}), 128.1(\mathrm{CH}), 128.1(\mathrm{CH}), 127.9(\mathrm{CH}), 126.1(\mathrm{CH})$, $125.8\left(\mathrm{C}_{\mathrm{q}}\right), 125.4\left(\mathrm{C}_{\mathrm{q}}\right), 113.9(\mathrm{CH}), 113.0(\mathrm{CH}), 55.3\left(\mathrm{CH}_{3}\right), 28.6\left(\mathrm{CH}_{3}\right)$. 
IR (ATR): $\tilde{V}=3058,3028,1730,1599,1281,1246,1174,1023,764,694 \mathrm{~cm}^{-1}$.

MS (EI) $m / z$ (relative intensity): 367 (30) $\left[\mathrm{M}^{+}\right], 325$ (100), 310 (27), 276 (13), 178 (14), 43 (52).

HR-MS (EI) $\mathrm{m} / z$ calcd for $\mathrm{C}_{25} \mathrm{H}_{21} \mathrm{NO}_{2}{ }^{+} 367.1572$, found 367.1562 .

\section{Synthesis of 1-\{5-[3-(trifluoromethyl)phenyl]-2,3-diphenyl-1H-pyrrol-1-yl\}ethanone (2110a)}

The general procedure C was followed using
$N$ - $\{1$-[3-(trifluoromethyl)phenyl]vinyl $\}$-acetamide $(\mathbf{2 1 0 0}) \quad(111 \mathrm{mg}$,
$0.50 \mathrm{mmol})$ and diphenylacetylene $(\mathbf{3 8 a})(178 \mathrm{mg}, 1.00 \mathrm{mmol})$. After $22 \mathrm{~h}$,
purification by column chromatography on silica gel $(n$-hexane/EtOAc: 30/1) yielded 2110a (146 $\mathrm{mg}, 72 \%$ ) as a white solid.

M.p. $=111-112^{\circ} \mathrm{C}$.

${ }^{1} \mathrm{H}-\mathrm{NMR}\left(300 \mathrm{MHz}, \mathrm{CDCl}_{3}\right): \delta=7.70(\mathrm{~s}, 1 \mathrm{H}), 7.59(\mathrm{~d}, J=7.3 \mathrm{~Hz}, 1 \mathrm{H}), 7.59(\mathrm{~d}, J=7.8 \mathrm{~Hz}, 1 \mathrm{H})$, $7.50(\mathrm{dd}, J=7.8,7.3 \mathrm{~Hz}, 1 \mathrm{H}), 7.38-7.31(\mathrm{~m}, 5 \mathrm{H}), 7.22-7.12(\mathrm{~m}, 5 \mathrm{H}), 6.56(\mathrm{~s}, 1 \mathrm{H}), 1.99(\mathrm{~s}, 3 \mathrm{H})$.

${ }^{13} \mathrm{C}-\mathrm{NMR}\left(75 \mathrm{MHz}, \mathrm{CDCl}_{3}\right): \delta=172.4\left(\mathrm{C}_{\mathrm{q}}\right), 134.4\left(\mathrm{C}_{\mathrm{q}}\right), 134.3\left(\mathrm{C}_{\mathrm{q}}\right), 133.6\left(\mathrm{C}_{\mathrm{q}}\right), 132.6\left(\mathrm{C}_{\mathrm{q}}\right), 131.8$ $\left(\mathrm{q},{ }^{4} J_{\mathrm{C}-\mathrm{F}}=1 \mathrm{~Hz}, \mathrm{CH}\right), 131.2\left(\mathrm{C}_{\mathrm{q}}\right), 130.9(\mathrm{CH}), 130.7\left(\mathrm{q},{ }^{2} J_{\mathrm{C}-\mathrm{F}}=32 \mathrm{~Hz}, \mathrm{C}_{\mathrm{q}}\right), 128.7(\mathrm{CH}), 128.6$ $(\mathrm{CH}), 128.4(\mathrm{CH}), 128.2(\mathrm{CH}), 128.2(\mathrm{CH}), 127.7\left(\mathrm{q},{ }^{1} J_{\mathrm{C}-\mathrm{F}}=272 \mathrm{~Hz}, \mathrm{C}_{\mathrm{q}}\right), 126.4(\mathrm{CH}), 125.9\left(\mathrm{C}_{\mathrm{q}}\right)$, $125.3\left(\mathrm{q},{ }^{3} J_{\mathrm{C}-\mathrm{F}}=4 \mathrm{~Hz}, \mathrm{CH}\right), 124.1\left(\mathrm{q},{ }^{3} J_{\mathrm{C}-\mathrm{F}}=4 \mathrm{~Hz}, \mathrm{CH}\right), 114.7(\mathrm{CH}), 28.5\left(\mathrm{CH}_{3}\right)$.

${ }^{19} \mathrm{~F}-\mathrm{NMR}\left(283 \mathrm{MHz}, \mathrm{CDCl}_{3}\right): \delta=-62.7$ (s).

IR (ATR): $\tilde{V}=3072,1733,1585,1446,1365,1119,1111,1072,763,693 \mathrm{~cm}^{-1}$.

MS (EI) $\mathrm{m} / z$ (relative intensity): 405 (10) [ $\left.\mathrm{M}^{+}\right], 363$ (100), 189 (9), 43 (12).

HR-MS (EI) $\mathrm{m} / z$ calcd for $\mathrm{C}_{25} \mathrm{H}_{18} \mathrm{~F}_{3} \mathrm{NO}^{+} 405.1340$, found 405.1327 .

\section{Synthesis of 1-\{2,3-diphenyl-5-(o-tolyl)-1H-pyrrol-1-yl\}ethanone (211pa)}

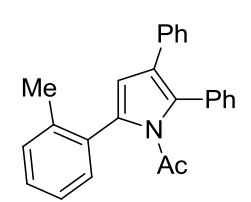

The general procedure $\mathbf{C}$ was followed using $N$-\{1-(o-tolyl)vinyl $\}$ acetamide (210p) $(87.5 \mathrm{mg}, 0.50 \mathrm{mmol})$ and diphenylacetylene (38) $(178 \mathrm{mg}, 1.00 \mathrm{mmol})$. After $22 \mathrm{~h}$, purification by column chromatography on silica gel ( $n$-hexane/EtOAc: $30 / 1)$ yielded 211pa (120 mg, 68\%) as a yellow solid.

M.p. $=145-146^{\circ} \mathrm{C}$.

${ }^{1} \mathrm{H}-\mathrm{NMR}\left(300 \mathrm{MHz}, \mathrm{CDCl}_{3}\right): \delta=7.46-7.15(\mathrm{~m}, 14 \mathrm{H}), 6.45(\mathrm{~s}, 1 \mathrm{H}), 2.37(\mathrm{~s}, 3 \mathrm{H}), 1.94(\mathrm{~s}, 3 \mathrm{H})$.

${ }^{13} \mathrm{C}-\mathrm{NMR}\left(75 \mathrm{MHz}, \mathrm{CDCl}_{3}\right): \delta=171.6\left(\mathrm{C}_{\mathrm{q}}\right), 137.6\left(\mathrm{C}_{\mathrm{q}}\right), 137.6\left(\mathrm{C}_{\mathrm{q}}\right), 134.8\left(\mathrm{C}_{\mathrm{q}}\right), 133.8\left(\mathrm{C}_{\mathrm{q}}\right), 133.7$ $\left(\mathrm{C}_{\mathrm{q}}\right), 133.3\left(\mathrm{C}_{\mathrm{q}}\right), 130.7(\mathrm{CH}), 130.3(\mathrm{CH}), 129.9(\mathrm{CH}), 128.4(\mathrm{CH}), 128.3(\mathrm{CH}), 128.1(\mathrm{CH}), 128.1$ $(\mathrm{CH}), 127.8(\mathrm{CH}), 126.1(\mathrm{CH}), 125.6(\mathrm{CH}), 125.5\left(\mathrm{C}_{\mathrm{q}}\right), 113.7(\mathrm{CH}), 27.6\left(\mathrm{CH}_{3}\right), 20.2\left(\mathrm{CH}_{3}\right)$. IR (ATR): $\tilde{V}=3053,1733,1615,1445,1318,1267,1111,1071,762,692 \mathrm{~cm}^{-1}$.

MS (EI) $m / z$ (relative intensity): 351 (25) [ $\left.\mathrm{M}^{+}\right], 309$ (100), 230 (11), 202 (12), 191 (10), 43 (65).

HR-MS (EI) $m / z$ calcd for $\mathrm{C}_{25} \mathrm{H}_{21} \mathrm{NO}^{+} 351.1623$, found 351.1634 .

\section{Synthesis of 1-\{2,3-diphenyl-5-(pyridin-3-yl)-1H-pyrrol-1-yl\}ethanone (211qa)}

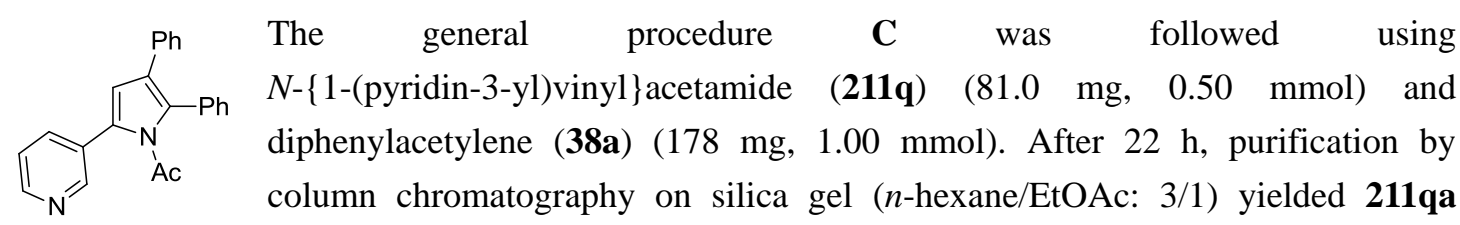
(54 $\mathrm{mg}, 32 \%)$ as a yellow solid.

M.p. $=100-101^{\circ} \mathrm{C}$.

${ }^{1} \mathrm{H}-\mathrm{NMR}\left(300 \mathrm{MHz}, \mathrm{CDCl}_{3}\right): \delta=8.71(\mathrm{~s}, 1 \mathrm{H}), 7.57(\mathrm{~d} . J=5.2 \mathrm{~Hz}, 1 \mathrm{H}), 7.75(\mathrm{dt}, J=7.8,1.6 \mathrm{~Hz}$, 1H), 7.48-7.30 (m, 6H), 7.26-7.13 (m, 5H), $6.56(\mathrm{~s}, 1 \mathrm{H}), 1.99(\mathrm{~s}, 3 \mathrm{H})$. 
${ }^{13} \mathrm{C}-\mathrm{NMR}\left(75 \mathrm{MHz}, \mathrm{CDCl}_{3}\right): \delta=172.2\left(\mathrm{C}_{\mathrm{q}}\right), 149.2(\mathrm{CH}), 148.4(\mathrm{CH}), 136.1(\mathrm{CH}), 134.3\left(\mathrm{C}_{\mathrm{q}}\right)$, $132.6\left(\mathrm{C}_{\mathrm{q}}\right), 131.7\left(\mathrm{C}_{\mathrm{q}}\right), 131.2\left(\mathrm{C}_{\mathrm{q}}\right), 130.7(\mathrm{CH}), 129.5\left(\mathrm{C}_{\mathrm{q}}\right), 128.7(\mathrm{CH}), 128.4(\mathrm{CH}), 128.2(\mathrm{CH})$, $128.1(\mathrm{CH}), 126.4(\mathrm{CH}), 126.0\left(\mathrm{C}_{\mathrm{q}}\right), 122.8(\mathrm{CH}), 114.8(\mathrm{CH}), 28.3\left(\mathrm{CH}_{3}\right)$.

IR (ATR): $\tilde{V}=3060,3030,1720,1672,1599,1571,1267,1208,764,693 \mathrm{~cm}^{-1}$.

MS (EI) $\mathrm{m} / z$ (relative intensity): 338 (20) $\left[\mathrm{M}^{+}\right], 296$ (100), 191 (11), 43 (12).

HR-MS (EI) $m / z$ calcd for $\mathrm{C}_{23} \mathrm{H}_{18} \mathrm{~N}_{2} \mathrm{O}^{+} 338.1419$, found 338.1410.

Synthesis of 1-\{2,3-diphenyl-5-(thiophen-2-yl)-1H-pyrrol-1-yl\}ethanone (211ra) and 2,3-diphenyl-5-(thiophen-2-yl)-1H-pyrrole (212ra)

The general procedure $\mathbf{C}$ was followed using $N$-\{1-(thiophen-2-yl)vinyl $\}$ acetamide (210r) $(83.5 \mathrm{mg}, 0.50 \mathrm{mmol})$ and diphenylacetylene (38a) $(178 \mathrm{mg}, 1.00 \mathrm{mmol})$. After $22 \mathrm{~h}$, purification by column chromatography on silica gel ( $n$-hexane/EtOAc: $30 / 1)$ yielded $211 \mathrm{ra}(57 \mathrm{mg}, 33 \%)$ as a yellow solid and 212ra (46 $\mathrm{mg}, 30 \%)$ as a yellow solid.

1-\{2,3-diphenyl-5-(thiophen-2-yl)-1H-pyrrol-1-yl\}ethanone (211ra):

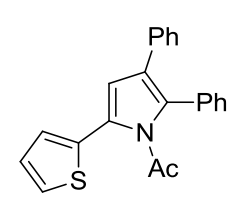

M.p. $=171-172{ }^{\circ} \mathrm{C}$.

${ }^{1} \mathrm{H}-\mathrm{NMR}\left(300 \mathrm{MHz}, \mathrm{CDCl}_{3}\right): \delta=7.38-7.29(\mathrm{~m}, 6 \mathrm{H}), 7.21-7.12(\mathrm{~m}, 6 \mathrm{H}), 7.06$ (dd, $J=5.1,5.1 \mathrm{~Hz}, 1 \mathrm{H}), 6.59(\mathrm{~s}, 1 \mathrm{H}), 2.02(\mathrm{~s}, 3 \mathrm{H})$.

${ }^{13} \mathrm{C}-\mathrm{NMR}\left(75 \mathrm{MHz}, \mathrm{CDCl}_{3}\right): \delta=172.8\left(\mathrm{C}_{\mathrm{q}}\right), 134.6\left(\mathrm{C}_{\mathrm{q}}\right), 134.0\left(\mathrm{C}_{\mathrm{q}}\right), 132.6\left(\mathrm{C}_{\mathrm{q}}\right)$,

$131.0\left(\mathrm{C}_{\mathrm{q}}\right), 130.6(\mathrm{CH}), 128.5(\mathrm{CH}), 128.2(\mathrm{CH}), 128.2(\mathrm{CH}), 128.1(\mathrm{CH}), 127.6(\mathrm{CH}), 127.2$ $(\mathrm{CH}), 127.1\left(\mathrm{C}_{\mathrm{q}}\right), 126.3(\mathrm{CH}), 126.1(\mathrm{CH}), 125.6\left(\mathrm{C}_{\mathrm{q}}\right), 114.8(\mathrm{CH}), 28.3\left(\mathrm{CH}_{3}\right)$.

IR (ATR): $\tilde{V}=3097,1722,1600,1496,1363,1277,1197,1028,767,695 \mathrm{~cm}^{-1}$.

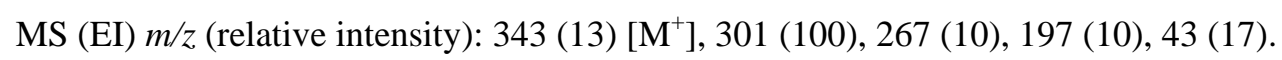

HR-MS (EI) $m / z$ calcd for $\mathrm{C}_{22} \mathrm{H}_{17} \mathrm{NOS}^{+} 343.1031$, found 343.1043 .

2,3-Diphenyl-5-(thiophen-2-yl)-1H-pyrrole (212ra):

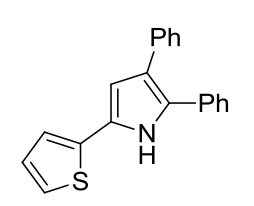

M.p. $=92-94{ }^{\circ} \mathrm{C}$.

${ }^{1} \mathrm{H}-\mathrm{NMR}\left(300 \mathrm{MHz}, \mathrm{CDCl}_{3}\right): \delta=8.27\left(\mathrm{~s}_{\mathrm{br}}, 1 \mathrm{H}\right), 7.44-7.16(\mathrm{~m}, 11 \mathrm{H}), 7.11(\mathrm{~d}, J=$ $3.5 \mathrm{~Hz}, 1 \mathrm{H}), 7.05(\mathrm{dd}, J=5.1,5.1 \mathrm{~Hz}, 1 \mathrm{H}), 6.61(\mathrm{~d}, J=2.7 \mathrm{~Hz}, 1 \mathrm{H})$.

${ }^{13} \mathrm{C}-\mathrm{NMR}\left(75 \mathrm{MHz}, \mathrm{CDCl}_{3}\right): \delta=136.0\left(\mathrm{C}_{\mathrm{q}}\right), 135.6\left(\mathrm{C}_{\mathrm{q}}\right), 132.8\left(\mathrm{C}_{\mathrm{q}}\right), 128.9\left(\mathrm{C}_{\mathrm{q}}\right)$,

$128.7(\mathrm{CH}), 128.4(\mathrm{CH}), 128.3(\mathrm{CH}), 127.7(\mathrm{CH}), 127.4(\mathrm{CH}), 127.0(\mathrm{CH}), 126.9\left(\mathrm{C}_{\mathrm{q}}\right), 126.0$ $(\mathrm{CH}), 123.6\left(\mathrm{C}_{\mathrm{q}}\right), 123.0(\mathrm{CH}), 121.1(\mathrm{CH}), 109.2(\mathrm{CH})$.

IR (ATR): $\tilde{V}=3411,3055,3024,1600,1492,1439,1199,1070,759,689 \mathrm{~cm}^{-1}$.

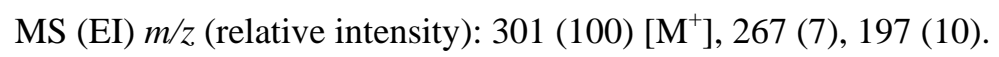

HR-MS (EI) $m / z$ calcd for $\mathrm{C}_{20} \mathrm{H}_{15} \mathrm{NS}^{+} 301.0925$, found 301.0939 .

\section{Synthesis of $(E)$-2,3-diphenyl-5-styryl-1H-pyrrole (212sa)}

$\mathrm{Ph}$ The general procedure $\mathbf{C}$ was followed using (E)- $N$-(4-phenylbuta-1,3-dien-2-yl)acetamide (210s) $(87.5 \mathrm{mg}, 0.50 \mathrm{mmol})$ and $\mathrm{Ph}$ diphenylacetylene $(\mathbf{3 8 a})(178 \mathrm{mg}, 1.00 \mathrm{mmol})$. After $22 \mathrm{~h}$, purification by
column chromatography on silica gel ( $n$-hexane/EtOAc: $10 / 1)$ yielded 211sa $(78 \mathrm{mg}, 48 \%)$ as a yellow solid.

M.p. $=87-88^{\circ} \mathrm{C}$.

${ }^{1} \mathrm{H}-\mathrm{NMR}\left(300 \mathrm{MHz}, \mathrm{CDCl}_{3}\right): \delta=8.35\left(\mathrm{~s}_{\mathrm{br}}, 1 \mathrm{H}\right), 7.54-7.44(\mathrm{~m}, 2 \mathrm{H}), 7.38-7.23(\mathrm{~m}, 13 \mathrm{H}), 7.01(\mathrm{~d}$, $J=16.6 \mathrm{~Hz}, 1 \mathrm{H}), 6.77(\mathrm{~d}, J=16.6 \mathrm{~Hz}, 1 \mathrm{H}), 6.55(\mathrm{~d}, J=2.7 \mathrm{~Hz}, 1 \mathrm{H})$.

${ }^{13} \mathrm{C}-\mathrm{NMR}\left(75 \mathrm{MHz}, \mathrm{CDCl}_{3}\right): \delta=137.3\left(\mathrm{C}_{\mathrm{q}}\right), 136.2\left(\mathrm{C}_{\mathrm{q}}\right), 132.8\left(\mathrm{C}_{\mathrm{q}}\right), 130.9\left(\mathrm{C}_{\mathrm{q}}\right), 129.5\left(\mathrm{C}_{\mathrm{q}}\right), 128.7$ $(\mathrm{CH}), 128.7(\mathrm{CH}), 128.4(\mathrm{CH}), 128.3(\mathrm{CH}), 127.4(\mathrm{CH}), 127.1(\mathrm{CH}), 127.0(\mathrm{CH}), 125.9(\mathrm{CH})$, 
$125.9(\mathrm{CH}), 123.9(\mathrm{CH}), 123.8\left(\mathrm{C}_{\mathrm{q}}\right), 118.3(\mathrm{CH}), 111.7(\mathrm{CH})$.

IR (ATR): $\tilde{V}=3058,3026,2951,2925,1684,1598,1504,1447,1261,760,693 \mathrm{~cm}^{-1}$.

MS (EI) $m / z$ (relative intensity): 321 (100) $\left[\mathrm{M}^{+}\right], 243$ (9), 213 (8).

HR-MS (EI) $m / z$ calcd for $\mathrm{C}_{24} \mathrm{H}_{19} \mathrm{~N}^{+} 321.1517$, found 321.1519 .

\section{Synthesis of 1-\{5-(4-nitrophenyl)-2,3-di-p-tolyl-1H-pyrrol-1-yl\}ethanone (211li)}

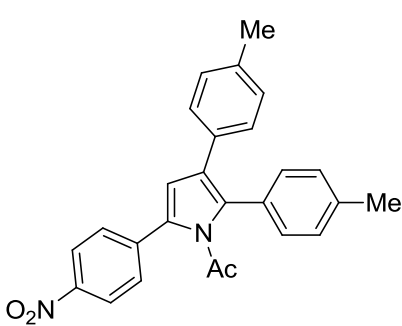

The general procedure $\mathbf{C}$ was followed using $N$-\{1-(4-nitrophenyl)vinyl $\}$ acetamide (210I) $(103 \mathrm{mg}, 0.50 \mathrm{mmol})$ and 1,2-di-p-tolylacetylene (38i) $(206 \mathrm{mg}, 1.00 \mathrm{mmol})$. After $22 \mathrm{~h}$, purification by column chromatography on silica gel ( $n$-hexane/EtOAc: $30 / 1)$ yielded 2111 i $(130 \mathrm{mg}, 63 \%)$ as a yellow solid.

M.p. $=143-144^{\circ} \mathrm{C}$.

${ }^{1} \mathrm{H}-\mathrm{NMR}\left(300 \mathrm{MHz}, \mathrm{CDCl}_{3}\right): \delta=8.23(\mathrm{~d}, J=8.6 \mathrm{~Hz}, 2 \mathrm{H}), 7.52(\mathrm{~d}, J=8.6 \mathrm{~Hz}, 2 \mathrm{H}), 7.24(\mathrm{~d}, J=$ $8.2 \mathrm{~Hz}, 2 \mathrm{H}), 7.19(\mathrm{~d}, J=8.0 \mathrm{~Hz}, 2 \mathrm{H}), 7.06(\mathrm{~d}, J=8.2 \mathrm{~Hz}, 2 \mathrm{H}), 7.01(\mathrm{~d}, J=8.0 \mathrm{~Hz}, 2 \mathrm{H}), 6.61(\mathrm{~s}$, $1 \mathrm{H}), 2.39\left(\mathrm{CH}_{3}\right), 2.28\left(\mathrm{CH}_{3}\right), 2.01\left(\mathrm{CH}_{3}\right)$.

${ }^{13} \mathrm{C}-\mathrm{NMR}\left(75 \mathrm{MHz}, \mathrm{CDCl}_{3}\right): \delta=172.5\left(\mathrm{C}_{\mathrm{q}}\right), 146.4\left(\mathrm{C}_{\mathrm{q}}\right), 140.1\left(\mathrm{C}_{\mathrm{q}}\right), 138.7\left(\mathrm{C}_{\mathrm{q}}\right), 136.2\left(\mathrm{C}_{\mathrm{q}}\right), 132.8$ $\left(\mathrm{C}_{\mathrm{q}}\right), 132.2\left(\mathrm{C}_{\mathrm{q}}\right), 131.2\left(\mathrm{C}_{\mathrm{q}}\right), 130.7(\mathrm{CH}), 129.5(\mathrm{CH}), 129.3\left(\mathrm{C}_{\mathrm{q}}\right), 129.0(\mathrm{CH}), 128.6(\mathrm{CH})$, $127.9(\mathrm{CH}), 126.1\left(\mathrm{C}_{\mathrm{q}}\right), 123.6(\mathrm{CH}), 116.0(\mathrm{CH}), 28.4\left(\mathrm{CH}_{3}\right), 21.4\left(\mathrm{CH}_{3}\right), 21.1\left(\mathrm{CH}_{3}\right)$.

IR (ATR): $\tilde{V}=3025,2905,1723,1593,1502,1334,1262,1108,817,752 \mathrm{~cm}^{-1}$.

MS (EI) $\mathrm{m} / z$ (relative intensity): $410(20)\left[\mathrm{M}^{+}\right], 368$ (100), 322 (23), 43 (17).

HR-MS (EI) $m / z$ calcd for $\mathrm{C}_{26} \mathrm{H}_{22} \mathrm{~N}_{2} \mathrm{O}_{3}{ }^{+} 410.1630$, found 410.1633 .

Synthesis of 1-\{2,3-bis(4-methoxyphenyl)-5-(4-nitrophenyl)-1H-pyrrol-1-yl\}ethanone (211lj)

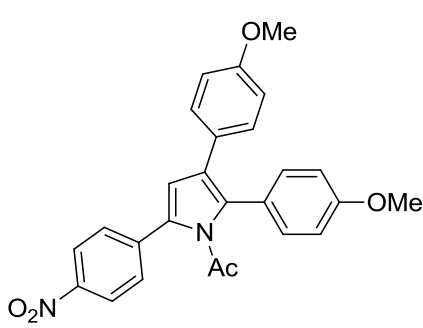

The general procedure $\mathbf{C}$ was followed using $N$-\{1-(4-nitrophenyl)vinyl $\}$ acetamide (210l) $(103 \mathrm{mg}, 0.50 \mathrm{mmol})$ and 1,2-bis(4-methoxyphenyl)ethyne (38j) (238 $\mathrm{mg}, 1.00 \mathrm{mmol})$. After $22 \mathrm{~h}$, purification by column chromatography on silica gel ( $n$-hexane/EtOAc: 10/1) yielded $\mathbf{2 1 0 l j}(111 \mathrm{mg}, 52 \%$ ) as a yellow solid.

M.p. $=117-118^{\circ} \mathrm{C}$.

${ }^{1} \mathrm{H}-\mathrm{NMR}\left(300 \mathrm{MHz}, \mathrm{CDCl}_{3}\right): \delta=8.22(\mathrm{~d}, J=8.8 \mathrm{~Hz}, 2 \mathrm{H}), 7.51(\mathrm{~d}, J=8.8 \mathrm{~Hz}, 2 \mathrm{H}), 7.26(\mathrm{~d}, J=$ $8.8 \mathrm{~Hz}, 2 \mathrm{H}), 7.08(\mathrm{~d}, J=8.7 \mathrm{~Hz}, 2 \mathrm{H}), 6.92(\mathrm{~d}, J=8.7 \mathrm{~Hz}, 2 \mathrm{H}), 6.75(\mathrm{~d}, J=8.8 \mathrm{~Hz}, 2 \mathrm{H}), 6.59(\mathrm{~s}$, $1 \mathrm{H}), 3.84(\mathrm{~s}, 3 \mathrm{H}), 3.75(\mathrm{~s}, 3 \mathrm{H}), 2.01(\mathrm{~s}, 3 \mathrm{H})$.

${ }^{13} \mathrm{C}-\mathrm{NMR}\left(75 \mathrm{MHz}, \mathrm{CDCl}_{3}\right): \delta=172.4\left(\mathrm{C}_{\mathrm{q}}\right), 159.8\left(\mathrm{C}_{\mathrm{q}}\right), 158.3\left(\mathrm{C}_{\mathrm{q}}\right), 146.4\left(\mathrm{C}_{\mathrm{q}}\right), 140.1\left(\mathrm{C}_{\mathrm{q}}\right), 132.7$ $\left(\mathrm{C}_{\mathrm{q}}\right), 132.2(\mathrm{CH}), 131.8\left(\mathrm{C}_{\mathrm{q}}\right), 129.1(\mathrm{CH}), 128.5(\mathrm{CH}), 126.6\left(\mathrm{C}_{\mathrm{q}}\right), 125.9\left(\mathrm{C}_{\mathrm{q}}\right), 124.4\left(\mathrm{C}_{\mathrm{q}}\right), 123.6$ $(\mathrm{CH}), 111.9(\mathrm{CH}), 114.2(\mathrm{CH}), 113.7(\mathrm{CH}), 55.2\left(\mathrm{CH}_{3}\right), 55.1\left(\mathrm{CH}_{3}\right), 28.4\left(\mathrm{CH}_{3}\right)$. IR (ATR): $\tilde{V}=2952,2836,1726,1595,1515,1493,1339,1245,1029,752 \mathrm{~cm}^{-1}$. MS (EI) $\mathrm{m} / z$ (relative intensity): 438 (26) $\left[\mathrm{M}^{+}\right], 400$ (100), 385 (23), 354 (17), 339 (15), 43 (26). HR-MS (EI) $m / z$ calcd for $\mathrm{C}_{26} \mathrm{H}_{22} \mathrm{~N}_{2} \mathrm{O}_{5}{ }^{+} 438.1529$, found 438.1511 . 
Synthesis of 1-\{2,3-bis[4-(trifluoromethyl)phenyl]-5-(4-nitrophenyl)-1H-pyrrol-1-yl\}ethanone (211lb)

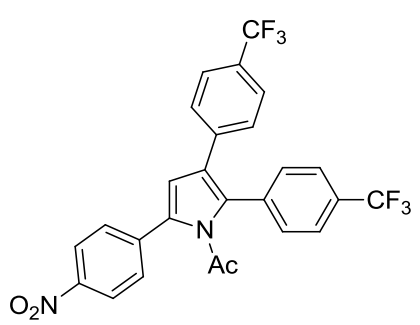

The general procedure $\mathbf{C}$ was followed using $N$-\{1-(4-nitrophenyl)vinyl $\}$ acetamide (210l) $(103 \mathrm{mg}, 0.50 \mathrm{mmol})$ and 1,2-bis $\{4$-(trifluoromethyl)phenyl $\}$ acetylene (38b) (314 mg, $1.00 \mathrm{mmol})$. After $22 \mathrm{~h}$, purification by column chromatography on silica gel ( $n$-hexane/EtOAc: $20 / 1)$ yielded 211lb (174 mg, 67\%) as a yellow solid.

M.p. $=161-162^{\circ} \mathrm{C}$.

${ }^{1} \mathrm{H}-\mathrm{NMR}\left(300 \mathrm{MHz}, \mathrm{CDCl}_{3}\right): \delta=8.30(\mathrm{~d}, J=8.9 \mathrm{~Hz}, 2 \mathrm{H}), 7.68(\mathrm{~d}, J=7.2 \mathrm{~Hz}, 2 \mathrm{H}), 7.60(\mathrm{~d}, J=$ $8.4 \mathrm{~Hz}, 2 \mathrm{H}), 7.54-7.43(\mathrm{~m}, 4 \mathrm{H}), 7.22$ (d, $J=8.4 \mathrm{~Hz}, 2 \mathrm{H}), 6.68(\mathrm{~s}, 1 \mathrm{H}), 2.07$ (s, 3H).

${ }^{13} \mathrm{C}-\mathrm{NMR}\left(75 \mathrm{MHz}, \mathrm{CDCl}_{3}\right): \delta=171.7\left(\mathrm{C}_{\mathrm{q}}\right), 147.0\left(\mathrm{C}_{\mathrm{q}}\right), 139.0\left(\mathrm{C}_{\mathrm{q}}\right), 137.3\left(\mathrm{q},{ }^{4} J_{\mathrm{C}-\mathrm{F}}=1 \mathrm{~Hz}, \mathrm{C}_{\mathrm{q}}\right)$, $135.2\left(\mathrm{q},{ }^{4} J_{\mathrm{C}-\mathrm{F}}=1 \mathrm{~Hz}, \mathrm{C}_{\mathrm{q}}\right), 133.5\left(\mathrm{C}_{\mathrm{q}}\right), 131.3\left(\mathrm{C}_{\mathrm{q}}\right), 131.2(\mathrm{CH}), 130.8\left({ }^{2} J_{\mathrm{C}-\mathrm{F}}=32 \mathrm{~Hz}, \mathrm{C}_{\mathrm{q}}\right), 128.9(\mathrm{q}$, $\left.{ }^{2} J_{\mathrm{C}-\mathrm{F}}=32 \mathrm{~Hz}, \mathrm{C}_{\mathrm{q}}\right), 128.7(\mathrm{CH}), 128.3(\mathrm{CH}), 125.8\left(\mathrm{C}_{\mathrm{q}}\right), 125.7\left(\mathrm{q},{ }^{3} J_{\mathrm{C}-\mathrm{F}}=4 \mathrm{~Hz}, \mathrm{CH}\right), 125.4\left(\mathrm{q},{ }^{3} J_{\mathrm{C}-}\right.$ $\mathrm{F}=4 \mathrm{~Hz}, \mathrm{CH}), 124.1\left(\mathrm{~d},{ }^{1} J_{\mathrm{C}-\mathrm{F}}=272 \mathrm{~Hz}, \mathrm{C}_{\mathrm{q}}\right), 123.9(\mathrm{CH}), 123.7\left(\mathrm{q},{ }^{1} J_{\mathrm{C}-\mathrm{F}}=272 \mathrm{~Hz}, \mathrm{C}_{\mathrm{q}}\right), 111.5$ $(\mathrm{CH}), 28.8\left(\mathrm{CH}_{3}\right)$.

${ }^{19} \mathrm{~F}-\mathrm{NMR}\left(283 \mathrm{MHz}, \mathrm{CDCl}_{3}\right): \delta=-62.6(\mathrm{~s}),-62.7(\mathrm{~s})$.

IR (ATR): $\tilde{V}=1727,1613,1593,1514,1338,1321,1265,1117,854,832 \mathrm{~cm}^{-1}$.

MS (EI) $m / z$ (relative intensity): 518 (4) $\left[\mathrm{M}^{+}\right], 476$ (100), 446 (28), 430 (30), 43 (52).

HR-MS (EI) $m / z$ calcd for $\mathrm{C}_{26} \mathrm{H}_{16} \mathrm{~F}_{6} \mathrm{~N}_{2} \mathrm{O}_{3}{ }^{+} 518.1065$, found 518.1081.

\section{Synthesis of 1-\{2,3-bis(4-fluorophenyl)-5-(4-nitrophenyl)-1H-pyrrol-1-yl\}ethanone (211lk)}

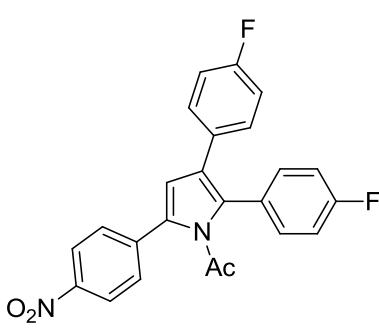

The general procedure $\mathbf{C}$ was followed using $N$-\{1-(4-nitrophenyl)vinyl $\}$ acetamide (210l) $(103 \mathrm{mg}, 0.50 \mathrm{mmol})$ and 1,2-bis(4-fluorophenyl)acetylene (38k) (212 mg, $1.00 \mathrm{mmol})$. After $22 \mathrm{~h}$, purification by column chromatography on silica gel (n-hexane/EtOAc: 20/1) yielded 211lk (140 mg, 67\%) as a yellow solid.

M.p. $=172-173^{\circ} \mathrm{C}$.

${ }^{1} \mathrm{H}-\mathrm{NMR}\left(300 \mathrm{MHz}, \mathrm{CDCl}_{3}\right): \delta=8.25(\mathrm{~d}, J=9.0 \mathrm{~Hz}, 2 \mathrm{H}), 7.53(\mathrm{~d}, J=9.0 \mathrm{~Hz}, 2 \mathrm{H}), 7.31(\mathrm{dd}, J=$ 8.8, 8.4 Hz, 2H), 7.14-7.03 (m, 4H), $6.90(\mathrm{dd}, J=8.8,8.7 \mathrm{~Hz}, 2 \mathrm{H}), 6.59$ (s, 1H), 2.04 (s, 3H).

${ }^{13} \mathrm{C}-\mathrm{NMR}\left(75 \mathrm{MHz}, \mathrm{CDCl}_{3}\right): \delta=172.0\left(\mathrm{C}_{\mathrm{q}}\right), 162.7\left(\mathrm{~d},{ }^{1} J_{\mathrm{C}-\mathrm{F}}=251 \mathrm{~Hz}, \mathrm{C}_{\mathrm{q}}\right), 161.9\left(\mathrm{~d},{ }^{1} J_{\mathrm{C}-\mathrm{F}}=\right.$ $\left.245 \mathrm{~Hz}, \mathrm{C}_{\mathrm{q}}\right), 146.7\left(\mathrm{C}_{\mathrm{q}}\right), 139.6\left(\mathrm{C}_{\mathrm{q}}\right), 132.9\left(\mathrm{C}_{\mathrm{q}}\right), 132.9\left(\mathrm{~d},{ }^{3} J_{\mathrm{C}-\mathrm{F}}=8 \mathrm{~Hz}, \mathrm{CH}\right), 131.2\left(\mathrm{C}_{\mathrm{q}}\right), 130.0(\mathrm{~d}$, $\left.{ }^{4} J_{\mathrm{C}-\mathrm{F}}=3 \mathrm{~Hz}, \mathrm{C}_{\mathrm{q}}\right), 129.7\left(\mathrm{~d},{ }^{3} J_{\mathrm{C}-\mathrm{F}}=8 \mathrm{~Hz}, \mathrm{CH}\right), 128.5(\mathrm{CH}), 127.9\left(\mathrm{~d},{ }^{4} J_{\mathrm{C}-\mathrm{F}}=3 \mathrm{~Hz}, \mathrm{C}_{\mathrm{q}}\right), 125.8\left(\mathrm{C}_{\mathrm{q}}\right)$, $123.8(\mathrm{CH}), 116.0\left(\mathrm{~d},{ }^{2} J_{\mathrm{C}-\mathrm{F}}=22 \mathrm{~Hz}, \mathrm{CH}\right), 111.7(\mathrm{CH}), 111.3\left(\mathrm{~d},{ }^{2} J_{\mathrm{C}-\mathrm{F}}=22 \mathrm{~Hz}, \mathrm{CH}\right), 28.5\left(\mathrm{CH}_{3}\right)$.

${ }^{19} \mathrm{~F}-\mathrm{NMR}\left(283 \mathrm{MHz}, \mathrm{CDCl}_{3}\right): \delta=-(114.4-114.7)(\mathrm{m}),-(111.2-111.5)(\mathrm{m})$.

IR (ATR): $\tilde{V}=1721,1595,1492,1333,1217,1118,1104,847,816,523 \mathrm{~cm}^{-1}$.

MS (EI) $m / z$ (relative intensity): 418 (10) $\left[\mathrm{M}^{+}\right], 376$ (100), 346 (20), 330 (30), 207 (12), 43 (20).

HR-MS (EI) $m / z$ calcd for $\mathrm{C}_{24} \mathrm{H}_{16} \mathrm{~F}_{2} \mathrm{~N}_{2} \mathrm{O}_{3}{ }^{+} 418.1129$, found 418.1125 . 
Synthesis of 1-\{2,3-bis(4-chlorophenyl)-5-(4-nitrophenyl)-1H-pyrrol-1-yl\}ethanone (211lc)

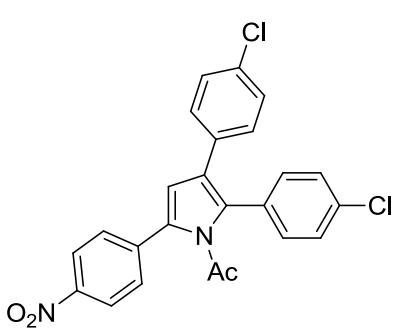

The general procedure $\mathbf{C}$ was followed using $N$-\{1-(4-nitrophenyl)vinyl $\}$ acetamide (210l) $(103 \mathrm{mg}, 0.50 \mathrm{mmol})$ and 1,2-bis(4-chlorophenyl)acetylene (38c) (247 mg, $1.00 \mathrm{mmol})$. After $22 \mathrm{~h}$, purification by column chromatography on silica gel ( $n$-hexane/EtOAc: $30 / 1)$ yielded 211lc (154 $\mathrm{mg}, 68 \%)$ as a yellow solid.

M.p. $=117-118^{\circ} \mathrm{C}$

${ }^{1} \mathrm{H}-\mathrm{NMR}\left(300 \mathrm{MHz}, \mathrm{CDCl}_{3}\right): \delta=8.25(\mathrm{~d}, J=8.6 \mathrm{~Hz}, 2 \mathrm{H}), 7.54(\mathrm{~d}, J=8.6 \mathrm{~Hz}, 2 \mathrm{H}), 7.37(\mathrm{~d}, J=$ $8.6 \mathrm{~Hz}, 2 \mathrm{H}), 7.26(\mathrm{~d}, J=8.6 \mathrm{~Hz}, 2 \mathrm{H}), 7.19(\mathrm{~d}, J=8.6 \mathrm{~Hz}, 2 \mathrm{H}), 7.04(\mathrm{~d}, J=8.6 \mathrm{~Hz}, 2 \mathrm{H}), 6.59(\mathrm{~s}$, $1 \mathrm{H}), 2.04(\mathrm{~s}, 3 \mathrm{H})$.

${ }^{13} \mathrm{C}-\mathrm{NMR}\left(75 \mathrm{MHz}, \mathrm{CDCl}_{3}\right): \delta=171.8\left(\mathrm{C}_{\mathrm{q}}\right), 146.7\left(\mathrm{C}_{\mathrm{q}}\right), 139.3\left(\mathrm{C}_{\mathrm{q}}\right), 135.0\left(\mathrm{C}_{\mathrm{q}}\right), 133.1\left(\mathrm{C}_{\mathrm{q}}\right), 132.6$ $\left(\mathrm{C}_{\mathrm{q}}\right), 132.3\left(\mathrm{C}_{\mathrm{q}}\right), 132.1(\mathrm{CH}), 131.2\left(\mathrm{C}_{\mathrm{q}}\right), 130.2\left(\mathrm{C}_{\mathrm{q}}\right), 129.3(\mathrm{CH}), 129.0(\mathrm{CH}), 128.6(\mathrm{CH})$, $128.5(\mathrm{CH}), 125.6\left(\mathrm{C}_{\mathrm{q}}\right), 123.7(\mathrm{CH}), 111.5(\mathrm{CH}), 28.7\left(\mathrm{CH}_{3}\right)$.

IR (ATR): $\tilde{V}=3104,1729,1514,1486,1341,1257,1091,1012,832 \mathrm{~cm}^{-1}$.

MS (EI) m/z (relative intensity): 450 (9) [M+ $], 408$ (100), 378 (20), 362 (28), 327 (13), 291 (15), 189 (12), 43 (43).

HR-MS (EI) $m / z$ calcd for $\mathrm{C}_{24} \mathrm{H}_{16} \mathrm{Cl}_{2} \mathrm{~N}_{2} \mathrm{O}_{3}{ }^{+} 450.0538$, found 450.0539 .

\section{Synthesis of diethyl 4,4'-\{1-acetyl-5-(4-nitrophenyl)-1H-pyrrole-2,3-diyl $\}$ dibenzoate (2111l)}

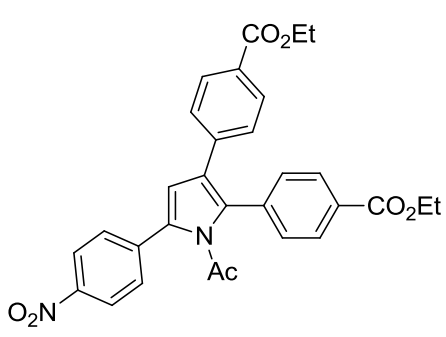

The general procedure $\mathbf{C}$ was followed using $N$-\{1-(4-nitrophenyl)vinyl $\}$ acetamide (210l) $(103 \mathrm{mg}, 0.50 \mathrm{mmol})$ and diethyl 4,4'-(ethyne-1,2-diyl)dibenzoate (381) (322 mg, $1.00 \mathrm{mmol})$. After $22 \mathrm{~h}$, purification by column chromatography on silica gel ( $n$-hexane/EtOAc: 5/1) yielded $2111 \mathrm{l}(168 \mathrm{mg}, 64 \%)$ as a yellow solid.

M.p. $=188-189^{\circ} \mathrm{C}$.

${ }^{1} \mathrm{H}-\mathrm{NMR}\left(300 \mathrm{MHz}, \mathrm{CDCl}_{3}\right): \delta=8.26(\mathrm{~d} . J=9.0 \mathrm{~Hz}, 2 \mathrm{H}), 8.06(\mathrm{~d}, J=8.2 \mathrm{~Hz}, 2 \mathrm{H}), 7.87(\mathrm{~d}, J=$ $8.2 \mathrm{~Hz} .2 \mathrm{H}), 7.56(\mathrm{~d}, J=9.0 \mathrm{~Hz}, 2 \mathrm{H}), 7.40(\mathrm{~d}, J=8.7 \mathrm{~Hz}, 2 \mathrm{H}), 7.16(\mathrm{~d}, J=8.7 \mathrm{~Hz}, 2 \mathrm{H}), 6.66(\mathrm{~s}$, $1 \mathrm{H}), 4.39$ (q, $J=7.2 \mathrm{~Hz}, 2 \mathrm{H}), 4.32(\mathrm{q}, J=7.2 \mathrm{~Hz}, 2 \mathrm{H}), 2.04(\mathrm{~s}, 3 \mathrm{H}), 1.40(\mathrm{t}, J=7.2 \mathrm{~Hz}, 3 \mathrm{H}), 1.37$ (t, $J=7.2 \mathrm{~Hz}, 3 \mathrm{H})$.

${ }^{13} \mathrm{C}-\mathrm{NMR}\left(75 \mathrm{MHz}, \mathrm{CDCl}_{3}\right): \delta=171.8\left(\mathrm{C}_{\mathrm{q}}\right), 166.1\left(\mathrm{C}_{\mathrm{q}}\right), 165.8\left(\mathrm{C}_{\mathrm{q}}\right), 146.9\left(\mathrm{C}_{\mathrm{q}}\right), 139.2\left(\mathrm{C}_{\mathrm{q}}\right), 138.4$ $\left(\mathrm{C}_{\mathrm{q}}\right), 136.2\left(\mathrm{C}_{\mathrm{q}}\right), 133.5\left(\mathrm{C}_{\mathrm{q}}\right), 131.8\left(\mathrm{C}_{\mathrm{q}}\right), 130.7(\mathrm{CH}), 129.8(\mathrm{CH}), 129.6(\mathrm{CH}), 128.8(\mathrm{CH}), 128.7$ $\left(\mathrm{C}_{\mathrm{q}}\right), 128.7\left(\mathrm{C}_{\mathrm{q}}\right), 127.9(\mathrm{CH}), 126.1\left(\mathrm{C}_{\mathrm{q}}\right), 123.7(\mathrm{CH}), 111.5(\mathrm{CH}), 61.3\left(\mathrm{CH}_{2}\right), 61.0\left(\mathrm{CH}_{2}\right), 28.7$ $\left(\mathrm{CH}_{3}\right), 14.4\left(\mathrm{CH}_{3}\right), 14.4\left(\mathrm{CH}_{3}\right)$.

IR (ATR): $\tilde{V}=2995,1723,1707,1594,1514,1341,1269,1104,1024,752 \mathrm{~cm}^{-1}$.

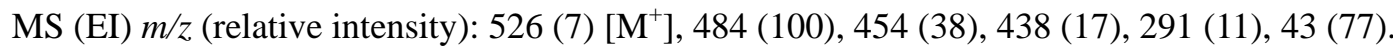

HR-MS (EI) $m / z$ calcd for $\mathrm{C}_{30} \mathrm{H}_{26} \mathrm{~N}_{2} \mathrm{O}_{7}{ }^{+} 526.1740$, found 526.1735 .

\section{Synthesis of 1-\{2,3-bis(3-chlorophenyl)-5-(4-nitrophenyl)-1H-pyrrol-1-yl\}ethanone (211lm)}

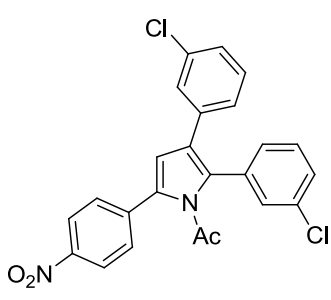

The general procedure $\mathbf{C}$ was followed using $N$-\{1-(4-nitrophenyl)vinyl $\}$ acetamide (210l) $(103 \mathrm{mg}, 0.50 \mathrm{mmol})$ and 1,2-bis(3-chlorophenyl)acetylene (38m) (247 mg, $1.00 \mathrm{mmol})$. After $22 \mathrm{~h}$, purification by column chromatography on silica gel ( $n$-hexane/EtOAc: 20/1) yielded $211 \mathrm{~lm}$ (152 $\mathrm{mg}, 67 \%$ ) as a yellow solid. 
M.p. $=120-121^{\circ} \mathrm{C}$.

${ }^{1} \mathrm{H}-\mathrm{NMR}\left(300 \mathrm{MHz}, \mathrm{CDCl}_{3}\right): \delta=8.25(\mathrm{~d}, J=9.0 \mathrm{~Hz}, 2 \mathrm{H}), 7.54(\mathrm{~d}, J=9.0 \mathrm{~Hz}, 2 \mathrm{H}), 7.38-7.30(\mathrm{~m}$, $3 \mathrm{H}), 7.24(\mathrm{dt}, J=7.2,1.4 \mathrm{~Hz}, 1 \mathrm{H}), 7.18(\mathrm{~s}, 1 \mathrm{H}), 7.16-7.08(\mathrm{~m}, 2 \mathrm{H}), 6.94(\mathrm{dt}, J=7.2,1.7 \mathrm{~Hz}, 1 \mathrm{H})$, $6.61(\mathrm{~s}, 1 \mathrm{H}), 2.06(\mathrm{~s}, 3 \mathrm{H})$.

${ }^{13} \mathrm{C}-\mathrm{NMR}\left(75 \mathrm{MHz}, \mathrm{CDCl}_{3}\right): \delta=171.8\left(\mathrm{C}_{\mathrm{q}}\right), 146.9\left(\mathrm{C}_{\mathrm{q}}\right), 139.4\left(\mathrm{C}_{\mathrm{q}}\right), 135.6\left(\mathrm{C}_{\mathrm{q}}\right), 134.7\left(\mathrm{C}_{\mathrm{q}}\right), 134.3$ $\left(\mathrm{C}_{\mathrm{q}}\right), 133.5\left(\mathrm{C}_{\mathrm{q}}\right), 133.3\left(\mathrm{C}_{\mathrm{q}}\right), 131.0\left(\mathrm{C}_{\mathrm{q}}\right), 130.8(\mathrm{CH}), 130.0(\mathrm{CH}), 129.6(\mathrm{CH}), 129.2(\mathrm{CH}), 129.1$ $(\mathrm{CH}), 128.7(\mathrm{CH}), 128.2(\mathrm{CH}), 126.9(\mathrm{CH}), 126.2(\mathrm{CH}), 125.6\left(\mathrm{C}_{\mathrm{q}}\right), 123.8(\mathrm{CH}), 111.5(\mathrm{CH}), 28.6$ $\left(\mathrm{CH}_{3}\right)$.

IR (ATR): $\tilde{V}=3062,1749,1593,1565,1508,1340,1200,1096,853,789 \mathrm{~cm}^{-1}$.

MS (EI) $m / z$ (relative intensity): 450 (10) [ $\left.\mathrm{M}^{+}\right], 408$ (100), 362 (22), 327 (15), 291 (15), 43 (39).

HR-MS (EI) $m / z$ calcd for $\mathrm{C}_{24} \mathrm{H}_{16} \mathrm{Cl}_{2} \mathrm{~N}_{2} \mathrm{O}_{3}{ }^{+} 450.0538$, found 450.0534 .

\section{Synthesis of methyl 1-acetyl-4,5-di(naphthalen-1-yl)-1 H-pyrrole-2-carboxylate (211an)}

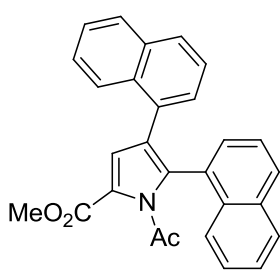

The general procedure $\mathbf{C}$ was followed using methyl 2-acetamidoacrylate (210a) $(71.5 \mathrm{mg}, 0.50 \mathrm{mmol})$, and 1,2-di(naphthalen-1-yl)acetylene (38n) (278 mg, $1.00 \mathrm{mmol}$ ). After $22 \mathrm{~h}$, purification by column chromatography on silica gel ( $n$-hexane/EtOAc: 10/1) yielded 211an (120 mg, 57\%) as a white solid.

M.p. $=176-181^{\circ} \mathrm{C}$

${ }^{1} \mathrm{H}-\mathrm{NMR}\left(300 \mathrm{MHz}, \mathrm{CDCl}_{3}\right): \delta=8.11(\mathrm{~d}, J=7.2 \mathrm{~Hz}, 1 \mathrm{H}), 7.84-7.71(\mathrm{~m}, 3 \mathrm{H}), 7.70-7.55(\mathrm{~m}, 2 \mathrm{H})$, 7.52-7.27 (m 7H), 7.16-7.03 (m, 2H), 3.93 (s, 3H), 2.16 (s, 3H).

${ }^{13} \mathrm{C}-\mathrm{NMR}\left(75 \mathrm{MHz}, \mathrm{CDCl}_{3}\right): \delta=172.7\left(\mathrm{C}_{\mathrm{q}}\right), 161.4\left(\mathrm{C}_{\mathrm{q}}\right), 134.6\left(\mathrm{C}_{\mathrm{q}}\right), 133.5\left(\mathrm{C}_{\mathrm{q}}\right), 133.2\left(\mathrm{C}_{\mathrm{q}}\right), 133.1$ $\left(\mathrm{C}_{\mathrm{q}}\right), 132.3\left(\mathrm{C}_{\mathrm{q}}\right), 131.5\left(\mathrm{C}_{\mathrm{q}}\right), 129.8(\mathrm{CH}), 129.5(\mathrm{CH}), 128.3(\mathrm{CH}), 128.2\left(\mathrm{C}_{\mathrm{q}}\right), 128.2(\mathrm{CH}), 127.6$ $(\mathrm{CH}), 127.5(\mathrm{CH}), 126.7(\mathrm{CH}), 126.1(\mathrm{CH}), 125.9(\mathrm{CH}), 125.7(\mathrm{CH}), 125.6(\mathrm{CH}), 125.3(\mathrm{CH})$, $125.1\left(\mathrm{C}_{\mathrm{q}}\right), 125.0(\mathrm{CH}), 124.9(\mathrm{CH}), 123.8\left(\mathrm{C}_{\mathrm{q}}\right), 121.4(\mathrm{CH}), 52.0\left(\mathrm{CH}_{3}\right), 27.7\left(\mathrm{CH}_{3}\right)$.

IR (ATR): $\tilde{V}=3056,1744,1708,1486,1382,1249,1230,760,775 \mathrm{~cm}^{-1}$.

MS (EI) $m / z$ (relative intensity): 419 (16) [ $\left.\mathrm{M}^{+}\right], 377$ (100), 317 (70), 289 (25), 163 (7).

HR-MS (EI) $m / z$ calcd for $\mathrm{C}_{29} \mathrm{H}_{21} \mathrm{NO}_{3}{ }^{+} 419.1521$, found 419.1519 .

\section{Synthesis of methyl 1-acetyl-4,5-dipropyl-1H-pyrrole-2-carboxylate (211ae)}

$n$-Pr The general procedure $\mathbf{C}$ was followed using methyl 2-acetamidoacrylate (210a) $(71.5 \mathrm{mg}, 0.50 \mathrm{mmol})$, and 4-octyne (38e) $(110 \mathrm{mg}, 1.00 \mathrm{mmol})$. After $22 \mathrm{~h}$, purification by column chromatography on silica gel ( $n$-hexane/EtOAc: 20/1) yielded 211ae (72 $\mathrm{mg}, 57 \%$ ) as a colorless oil.

${ }^{1} \mathrm{H}-\mathrm{NMR}\left(300 \mathrm{MHz}, \mathrm{CDCl}_{3}\right): \delta=6.82(\mathrm{~s}, 1 \mathrm{H}), 3.76(\mathrm{~s}, 3 \mathrm{H}), 2.57(\mathrm{t}, J=7.6 \mathrm{~Hz}, 2 \mathrm{H}), 2.50(\mathrm{~s}, 3 \mathrm{H})$, $2.32(\mathrm{t}, J=7.4 \mathrm{~Hz}, 2 \mathrm{H}), 1.63-1.43(\mathrm{~m}, 4 \mathrm{H}), 0.93(\mathrm{t}, J=7.2 \mathrm{~Hz}, 3 \mathrm{H}), 0.91(\mathrm{t}, J=7.2 \mathrm{~Hz}, 3 \mathrm{H})$.

${ }^{13} \mathrm{C}-\mathrm{NMR}\left(75 \mathrm{MHz}, \mathrm{CDCl}_{3}\right): \delta=174.0\left(\mathrm{C}_{\mathrm{q}}\right), 161.1\left(\mathrm{C}_{\mathrm{q}}\right), 138.4\left(\mathrm{C}_{\mathrm{q}}\right), 123.3\left(\mathrm{C}_{\mathrm{q}}\right), 121.5\left(\mathrm{C}_{\mathrm{q}}\right)$, 121.4 (CH), $51.5\left(\mathrm{CH}_{3}\right), 28.5\left(\mathrm{CH}_{3}\right), 27.4\left(\mathrm{CH}_{2}\right), 27.0\left(\mathrm{CH}_{2}\right), 23.6\left(\mathrm{CH}_{2}\right), 23.6\left(\mathrm{CH}_{2}\right), 13.9\left(\mathrm{CH}_{3}\right)$, $13.9\left(\mathrm{CH}_{3}\right)$.

IR (ATR): $\tilde{V}=2960,1738,1702,1478,1437,1374,1227,1186,1054,762 \mathrm{~cm}^{-1}$.

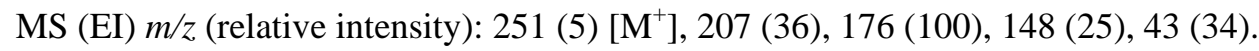

HR-MS (EI) $\mathrm{m} / z$ calcd for $\mathrm{C}_{14} \mathrm{H}_{21} \mathrm{NO}_{3}{ }^{+} 251.1521$, found 251.1525 .

The spectral data were in accordance with those reported in the literature. ${ }^{123 a}$ 


\section{Synthesis of methyl 1-acetyl-4,5-diethyl-1 $\mathrm{H}$-pyrrole-2-carboxylate (211af)}<smiles>CCc1cc(OC)n(C)c1OC</smiles>

The general procedure $\mathbf{C}$ was followed using methyl 2-acetamidoacrylate (210a) $(71.5 \mathrm{mg}, 0.50 \mathrm{mmol})$, and 3-hexyne (38f) $(82 \mathrm{mg}, 1.00 \mathrm{mmol})$. After $22 \mathrm{~h}$, purification by column chromatography on silica gel ( $n$-hexane/EtOAc: 20/1) yielded 211af (76 $\mathrm{mg}, 71 \%$ ) as a colorless oil.

${ }^{1} \mathrm{H}-\mathrm{NMR}\left(300 \mathrm{MHz}, \mathrm{CDCl}_{3}\right): \delta=6.84(\mathrm{~s}, 1 \mathrm{H}), 3.79(\mathrm{~s}, 3 \mathrm{H}), 2.62(\mathrm{q}, J=7.2 \mathrm{~Hz}, 2 \mathrm{H}), 2.50(\mathrm{~s}, 3 \mathrm{H})$, $2.37(\mathrm{q}, J=7.2 \mathrm{~Hz}, 2 \mathrm{H}), 1.14(\mathrm{t}, J=7.2 \mathrm{~Hz}, 3 \mathrm{H}), 1.11(\mathrm{t}, J=7.2 \mathrm{~Hz}, 3 \mathrm{H})$.

${ }^{13} \mathrm{C}-\mathrm{NMR}\left(75 \mathrm{MHz}, \mathrm{CDCl}_{3}\right): \delta=173.9\left(\mathrm{C}_{\mathrm{q}}\right), 161.0\left(\mathrm{C}_{\mathrm{q}}\right), 139.4\left(\mathrm{C}_{\mathrm{q}}\right), 124.3\left(\mathrm{C}_{\mathrm{q}}\right), 121.4\left(\mathrm{C}_{\mathrm{q}}\right), 120.9$ $(\mathrm{CH}), 51.5\left(\mathrm{CH}_{3}\right), 28.4\left(\mathrm{CH}_{3}\right), 18.4\left(\mathrm{CH}_{2}\right), 18.4\left(\mathrm{CH}_{2}\right), 14.9\left(\mathrm{CH}_{3}\right), 14.7\left(\mathrm{CH}_{3}\right)$. IR (ATR): $\tilde{V}=2966,1738,1698,1481,1437,1378,1239,1186,940,762 \mathrm{~cm}^{-1}$.

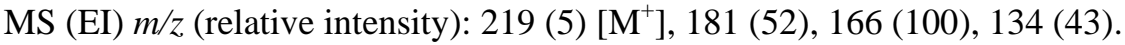

HR-MS (EI) $\mathrm{m} / z$ calcd for $\mathrm{C}_{12} \mathrm{H}_{17} \mathrm{NO}_{3}{ }^{+} 219.1206$, found 219.1208 .

\section{Synthesis of 1-\{3-methyl-5-(4-nitrophenyl)-2-phenyl-1H-pyrrol-1-yl\}ethanone (211lh)}

$\mathrm{Me}$ The general procedure $\mathbf{C}$ was followed using $N$-\{1-(4-nitrophenyl)vinyl $\}$ acetamide (210l) $\quad(103 \mathrm{mg}, 0.50 \mathrm{mmol})$ and propyn-1-benzene (38h) (116 mg, $1.00 \mathrm{mmol})$. After $22 \mathrm{~h}$, purification by column chromatography on silica gel ( $n$-hexane/EtOAc: $30 / 1)$ yielded 211lh (72 $\mathrm{mg}, 45 \%)$ as a yellow solid.

M.p. $=149-150{ }^{\circ} \mathrm{C}$.

${ }^{1} \mathrm{H}-\mathrm{NMR}\left(300 \mathrm{MHz}, \mathrm{CDCl}_{3}\right): \delta=8.19(\mathrm{~d}, J=8.9 \mathrm{~Hz}, 2 \mathrm{H}), 7.50-7.38(\mathrm{~m}, 5 \mathrm{H}), 7.36-7.28(\mathrm{~m}, 2 \mathrm{H})$, $6.32(\mathrm{~s}, 1 \mathrm{H}), 1.99(\mathrm{~s}, 3 \mathrm{H}), 1.99$ (s, 3H).

${ }^{13} \mathrm{C}-\mathrm{NMR}\left(75 \mathrm{MHz}, \mathrm{CDCl}_{3}\right): \delta=171.8\left(\mathrm{C}_{\mathrm{q}}\right), 146.3\left(\mathrm{C}_{\mathrm{q}}\right), 140.4\left(\mathrm{C}_{\mathrm{q}}\right), 133.1\left(\mathrm{C}_{\mathrm{q}}\right), 132.7\left(\mathrm{C}_{\mathrm{q}}\right), 132.7$ $\left(\mathrm{C}_{\mathrm{q}}\right), 130.0(\mathrm{CH}), 128.7(\mathrm{CH}), 128.6(\mathrm{CH}), 128.2(\mathrm{CH}), 123.4(\mathrm{CH}), 121.9\left(\mathrm{C}_{\mathrm{q}}\right), 117.7(\mathrm{CH})$, $28.1\left(\mathrm{CH}_{3}\right), 11.3\left(\mathrm{CH}_{3}\right)$.

IR (ATR): $\tilde{V}=2924,1720,1592,1506,1344,1264,1107,853,752,701 \mathrm{~cm}^{-1}$.

MS (EI) $\mathrm{m} / z$ (relative intensity): 320 (15) $\left[\mathrm{M}^{+}\right], 278$ (100), 248 (12), 232 (30), 43 (27).

HR-MS (EI) $m / z$ calcd for $\mathrm{C}_{19} \mathrm{H}_{16} \mathrm{~N}_{2} \mathrm{O}_{3}{ }^{+} 320.1161$, found 320.1114 .

\section{Synthesis of methyl 1-acetyl-4-methyl-5-phenyl-1H-pyrrole-2-carboxylate (211ah)}

Me The general procedure $\mathbf{C}$ was followed using methyl 2-acetamidoacrylate (210a) (71.5 mg, $0.50 \mathrm{mmol})$, and prop-1-yn-1-ylbenzene (38h) $(116 \mathrm{mg}, 1.00 \mathrm{mmol})$. After $22 \mathrm{~h}$, purification by column chromatography on silica gel (n-hexane/EtOAc: $30 / 1)$ yielded 211ah $(85 \mathrm{mg}, 66 \%)$ as a white solid.

M.p. $=109-110{ }^{\circ} \mathrm{C}$.

${ }^{1} \mathrm{H}-\mathrm{NMR}\left(300 \mathrm{MHz}, \mathrm{CDCl}_{3}\right): \delta=7.46-7.37(\mathrm{~m}, 3 \mathrm{H}), 7.32-7.26(\mathrm{~m}, 2 \mathrm{H}), 6.85(\mathrm{~s}, 1 \mathrm{H}), 3.84(\mathrm{~s}$, $3 \mathrm{H}), 2.27$ (s, 3H), 1.99 (s, 3H).

${ }^{13} \mathrm{C}-\mathrm{NMR}\left(75 \mathrm{MHz}, \mathrm{CDCl}_{3}\right): \delta=173.5\left(\mathrm{C}_{\mathrm{q}}\right), 161.2\left(\mathrm{C}_{\mathrm{q}}\right), 135.6\left(\mathrm{C}_{\mathrm{q}}\right), 131.0\left(\mathrm{C}_{\mathrm{q}}\right), 129.8(\mathrm{CH}), 128.4$ $(\mathrm{CH}), 128.4(\mathrm{CH}), 122.6\left(\mathrm{C}_{\mathrm{q}}\right), 120.5(\mathrm{CH}), 119.6\left(\mathrm{C}_{\mathrm{q}}\right), 51.7\left(\mathrm{CH}_{3}\right), 28.5\left(\mathrm{CH}_{3}\right), 11.1\left(\mathrm{CH}_{3}\right)$. IR (ATR): $\tilde{V}=2952,1747,1696,1556,1464,1443,1375,1230,772,584 \mathrm{~cm}^{-1}$. MS (EI) $\mathrm{m} / \mathrm{z}$ (relative intensity): 257 (7) $\left[\mathrm{M}^{+}\right], 213$ (100), 183 (63), 155 (39), 43 (25).

HR-MS (EI) $\mathrm{m} / z$ calcd for $\mathrm{C}_{15} \mathrm{H}_{15} \mathrm{NO}_{3}{ }^{+} 257.1052$, found 257.1056 .

The spectral data were in accordance with those reported in the literature. ${ }^{123 a}$ 
Synthesis of methyl 1-acetyl-4-ethyl-5-phenyl-1H-pyrrole-2-carboxylate (211ao)

Et The general procedure $\mathbf{C}$ was followed using methyl 2-acetamidoacrylate (210a) (71.5 mg, $0.50 \mathrm{mmol}$ ), and but-1-yn-1-ylbenzene (38o) (130 mg, $1.00 \mathrm{mmol}$ ). After $22 \mathrm{~h}$, purification by column chromatography on silica gel ( $n$-hexane/EtOAc: 30/1) yielded 211 ao (74 mg, 54\%) as a yellow oil.

${ }^{1} \mathrm{H}-\mathrm{NMR}\left(300 \mathrm{MHz}, \mathrm{CDCl}_{3}\right): \delta=7.45-7.37(\mathrm{~m} \mathrm{3H}), 7.32-7.26(\mathrm{~m}, 2 \mathrm{H}), 6.92(\mathrm{~s}, 1 \mathrm{H}), 3.85(\mathrm{~s}, 3 \mathrm{H})$, $2.34(\mathrm{q}, J=7.2 \mathrm{~Hz}, 2 \mathrm{H}), 2.26(\mathrm{~s}, 3 \mathrm{H}), 1.11(\mathrm{t}, J=7.2 \mathrm{~Hz}, 3 \mathrm{H})$.

${ }^{13} \mathrm{C}-\mathrm{NMR}\left(75 \mathrm{MHz}, \mathrm{CDCl}_{3}\right): \delta=173.3\left(\mathrm{C}_{\mathrm{q}}\right), 161.0\left(\mathrm{C}_{\mathrm{q}}\right), 135.0\left(\mathrm{C}_{\mathrm{q}}\right), 131.0\left(\mathrm{C}_{\mathrm{q}}\right), 129.9(\mathrm{CH})$, 128.4 (CH), $128.3(\mathrm{CH}), 126.3\left(\mathrm{C}_{\mathrm{q}}\right), 122.7\left(\mathrm{C}_{\mathrm{q}}\right), 118.8(\mathrm{CH}), 51.8\left(\mathrm{CH}_{3}\right), 28.5\left(\mathrm{CH}_{3}\right), 18.8\left(\mathrm{CH}_{2}\right)$, $15.2\left(\mathrm{CH}_{3}\right)$.

IR (ATR): $\tilde{V}=2961,2927,1726,1599,1448,1261,1070,759,699 \mathrm{~cm}^{-1}$.

MS (EI) $m / z$ (relative intensity): 271 (4) $\left[\mathrm{M}^{+}\right], 229$ (100), 212 (73), 197 (20), 182 (40), 169 (15), 154 (32), 43 (57).

HR-MS (EI) $m / z$ calcd for $\mathrm{C}_{16} \mathrm{H}_{17} \mathrm{NO}_{3}{ }^{+} 271.1206$, found 271.1211 .

Ruthenium-catalyzed aerobic oxidative coupling with enamine 210a (Scheme 69)
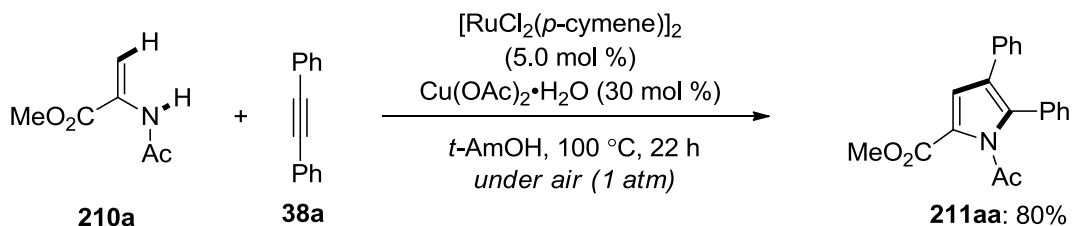

A mixture of methyl 2-acetamidoacrylate (210a) $(71.5 \mathrm{mg}, 0.50 \mathrm{mmol})$, diphenylacetylene (38a) (178 mg, $1.00 \mathrm{mmol}),\left[\mathrm{RuCl}_{2}(p \text {-cymene) }]_{2}(15.3 \mathrm{mg}, 5.0 \mathrm{~mol} \%)\right.$ and $\mathrm{Cu}(\mathrm{OAc})_{2} \cdot \mathrm{H}_{2} \mathrm{O}(30.0 \mathrm{mg}$, $30 \mathrm{~mol} \%)$ in $t$-AmOH $(2.0 \mathrm{~mL})$ was stirred at $100{ }^{\circ} \mathrm{C}$ under ambient air for $22 \mathrm{~h}$. At ambient temperature, the reaction mixture was diluted with sat. aq. $\mathrm{NH}_{4} \mathrm{Cl} / \mathrm{NH}_{3}(1: 1,75 \mathrm{~mL})$ and extracted with EtOAc $(3 \times 75 \mathrm{~mL})$. The combined organic phase was washed with sat. aq. $\mathrm{NH}_{4} \mathrm{Cl} / \mathrm{NH}_{3}(1: 1$, $50 \mathrm{~mL}$ ) and dried over anhydrous $\mathrm{Na}_{2} \mathrm{SO}_{4}$. After filtration and evaporation of the solvents under reduced pressure, the crude product was purified by column chromatography on silica gel (n-hexane/EtOAc: $10 / 1)$ to yield 211aa (128 mg, 76\%) as a yellow oil.

Intermolecular competition experiment with alkynes $38 \mathrm{~m}$ and $38 \mathrm{~b}$ (Scheme 70)

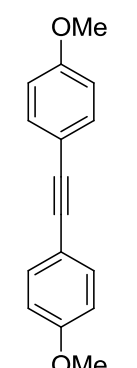

$38 \mathbf{j}$
$(2.0$ equiv $)$

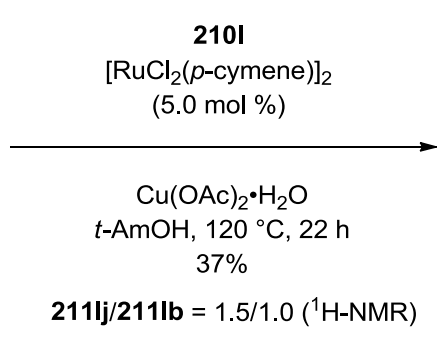

(1) $=1.5 / 1.0(1 \mathrm{H} N \mathrm{NMR})$

$$
\text { (2.0 equiv) (2.0 equiv) }
$$

A mixture of $N$-\{1-(4-nitrophenyl)vinyl $\}$ acetamide

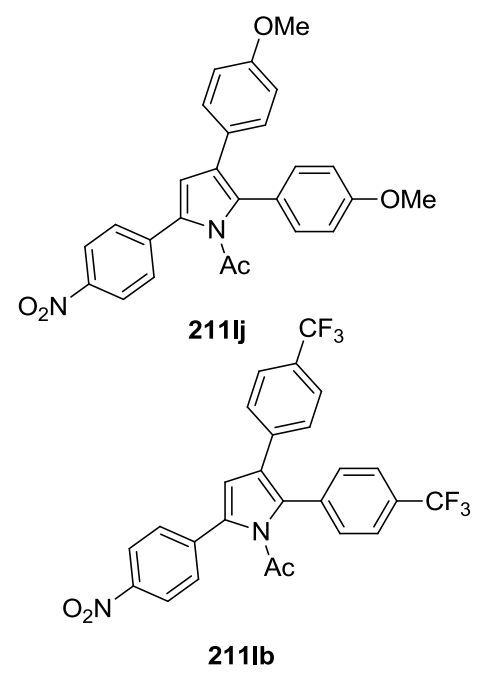

(210l) (103 mg, $0.50 \quad \mathrm{mmol})$, 
1,2-bis(4-methoxyphenyl)acetylene

$(\mathbf{3 8 j})$

$(238$

$\mathrm{mg}$,

$1.00 \mathrm{mmol})$,

1,2-bis $\{4$-(trifluoromethyl)phenyl $\}$ acetylene (38b) (314 mg, $1.00 \mathrm{mmol}),\left[\mathrm{RuCl}_{2}(p \text {-cymene) }]_{2}\right.$ $(15.3 \mathrm{mg}, 5.0 \mathrm{~mol} \%)$ and $\mathrm{Cu}(\mathrm{OAc})_{2} \cdot \mathrm{H}_{2} \mathrm{O}(200 \mathrm{mg}, 1.00 \mathrm{mmol})$ in $t$-AmOH $(2.0 \mathrm{~mL})$ was stirred at $120{ }^{\circ} \mathrm{C}$ under $\mathrm{N}_{2}$ for $22 \mathrm{~h}$. At ambient temperature, the reaction mixture was diluted with sat. aq. $\mathrm{NH}_{4} \mathrm{Cl} / \mathrm{NH}_{3}(1: 1,75 \mathrm{~mL})$ and extracted with EtOAc $(3 \times 75 \mathrm{~mL})$. The combined organic phase was washed with sat. aq. $\mathrm{NH}_{4} \mathrm{Cl} / \mathrm{NH}_{3}(1: 1,50 \mathrm{~mL})$ and dried over anhydrous $\mathrm{Na}_{2} \mathrm{SO}_{4}$. After filtration and evaporation of the solvents under reduced pressure, the crude product was purified by column chromatography on silica gel ( $n$-hexane/EtOAc: $20 / 1$ ) to yield a mixture of $\mathbf{2 1 1} \mathbf{j}$ and $\mathbf{2 1 1 l b}$ as a yellow solid. The ratio of products $\mathbf{2 1 1} \mathbf{j} / \mathbf{2 1 1 l b}$ was found to be $1.5 / 1.0$ by ${ }^{1} \mathrm{H}-\mathrm{NMR}$ spectroscopy.

Intermolecular competition experiment with enamines 210n and 2101 (Scheme 71a)
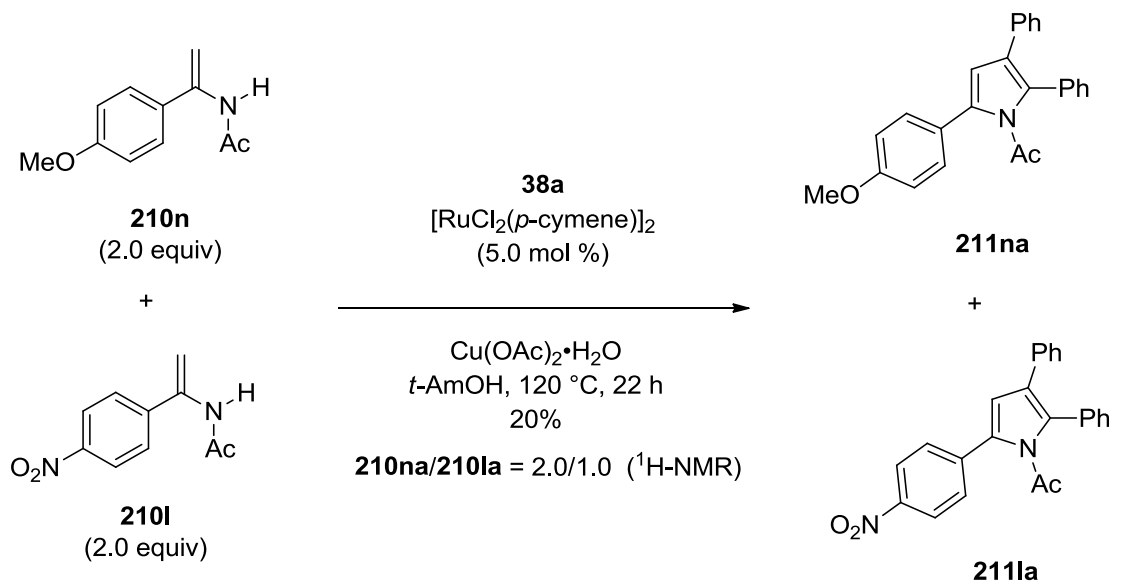

A mixture of $N$-\{1-(4-methoxyphenyl)vinyl $\}$ acetamide $\quad(210 n) \quad(191 \mathrm{mg}, 1.00 \mathrm{mmol})$, $N$-\{1-(4-nitrophenyl)vinyl $\}$ acetamide (210l) (206 $\mathrm{mg}, 1.00 \mathrm{mmol}$ ), diphenylacetylene (38a) (89.0 mg, $0.50 \mathrm{mmol}),\left[\mathrm{RuCl}_{2}(p \text {-cymene })\right]_{2}(15.3 \mathrm{mg}, 5.0 \mathrm{~mol} \%)$ and $\mathrm{Cu}(\mathrm{OAc})_{2} \cdot \mathrm{H}_{2} \mathrm{O}(200 \mathrm{mg}$, $1.00 \mathrm{mmol})$ in $t$-AmOH $(2.0 \mathrm{~mL})$ was stirred at $120^{\circ} \mathrm{C}$ under $\mathrm{N}_{2}$ for $22 \mathrm{~h}$. At ambient temperature, the reaction mixture was diluted with sat. aq. $\mathrm{NH}_{4} \mathrm{Cl} / \mathrm{NH}_{3}(1: 1,75 \mathrm{~mL})$ and extracted with EtOAc $(3 \times 75 \mathrm{~mL})$. The combined organic phase was washed with sat. aq. $\mathrm{NH}_{4} \mathrm{Cl} / \mathrm{NH}_{3}(1: 1,50 \mathrm{~mL})$ and dried over anhydrous $\mathrm{Na}_{2} \mathrm{SO}_{4}$. After filtration and evaporation of the solvents under reduced pressure, the crude product was purified by column chromatography on silica gel (n-hexane/EtOAc: 20/1) to yield a mixture of 211na and 211la as a yellow oil. The ratio of products 211 na/211la was found to be $2.0 / 1.0$ by ${ }^{1} \mathrm{H}-\mathrm{NMR}$ spectroscopy.

Intermolecular competition experiment with enamines 210n and 210g (Scheme 71b)
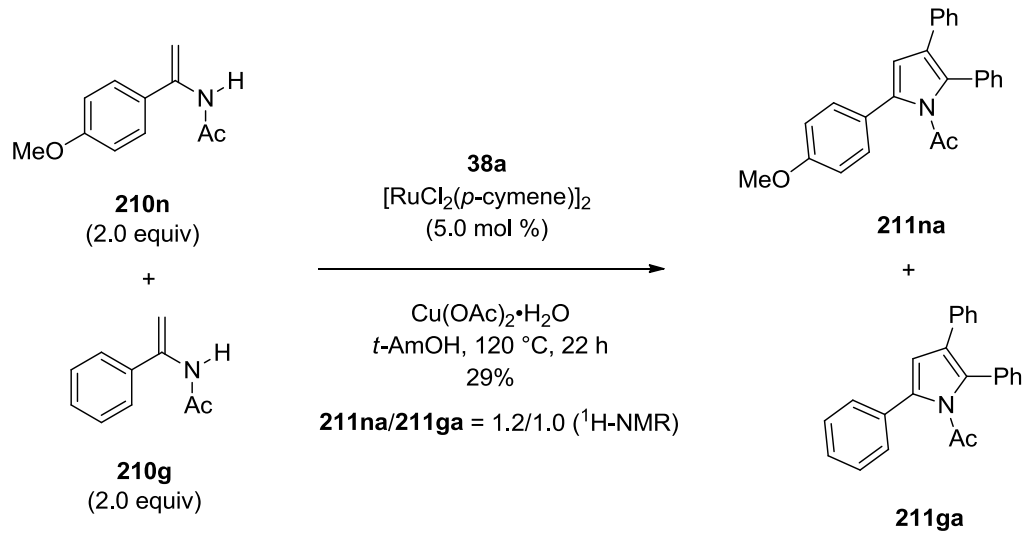
A mixture of $\mathrm{N}$-\{1-(4-methoxyphenyl)vinyl $\}$ acetamide (210n) (191 $\mathrm{mg}, 1.00 \mathrm{mmol})$, $N$-(1-phenylvinyl)acetamide (210g) (161 mg, $1.00 \mathrm{mmol})$, diphenylacetylene (38a) (89.0 $\mathrm{mg}$, $0.50 \mathrm{mmol}),\left[\mathrm{RuCl}_{2}(p \text {-cymene })\right]_{2}(15.3 \mathrm{mg}, 5.0 \mathrm{~mol} \%)$ and $\mathrm{Cu}(\mathrm{OAc})_{2} \cdot \mathrm{H}_{2} \mathrm{O}(200 \mathrm{mg}, 1.00 \mathrm{mmol})$ in $t$ - $\mathrm{AmOH}(2.0 \mathrm{~mL})$ was stirred at $120{ }^{\circ} \mathrm{C}$ under $\mathrm{N}_{2}$ for $22 \mathrm{~h}$. At ambient temperature, the reaction mixture was diluted with sat. aq. $\mathrm{NH}_{4} \mathrm{Cl} / \mathrm{NH}_{3}(1: 1,75 \mathrm{~mL})$ and extracted with EtOAc $(3 \times 75 \mathrm{~mL})$. The combined organic phase was washed with sat. aq. $\mathrm{NH}_{4} \mathrm{Cl} / \mathrm{NH}_{3}(1: 1,50 \mathrm{~mL})$ and dried over anhydrous $\mathrm{Na}_{2} \mathrm{SO}_{4}$. After filtration and evaporation of the solvents under reduced pressure, the crude product was purified by column chromatography on silica gel ( $n$-hexane/EtOAc: 20/1) to yield a mixture of 211na and 211ga as a yellow oil. The ratio of products 211na/211ga was found to be $1.2 / 1.0$ by ${ }^{1} \mathrm{H}-\mathrm{NMR}$ spectroscopy.

Intermolecular competition experiment with enamines $210 \mathrm{~g}$ and 2101 (Scheme 71c)
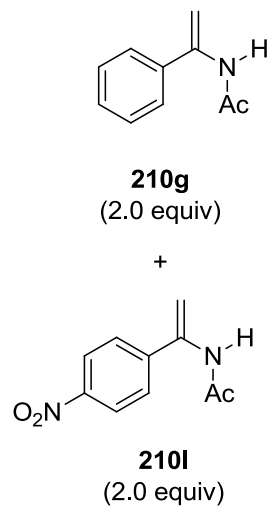

A mixture of $N$-(1-phenylvinyl)acetamide $\quad(\mathbf{2 1 0 g})$<smiles></smiles>

211ga

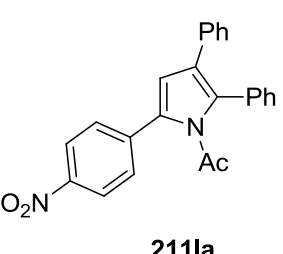
$N$-\{1-(4-nitrophenyl)vinyl $\}$ acetamide (2101) (206 $\mathrm{mg}, 1.00 \mathrm{mmol})$, diphenylacetylene (38a) (89.0 mg, $0.50 \mathrm{mmol}),\left[\mathrm{RuCl}_{2}(p \text {-cymene })\right]_{2}(15.3 \mathrm{mg}, 5.0 \mathrm{~mol} \%)$ and $\mathrm{Cu}(\mathrm{OAc})_{2} \cdot \mathrm{H}_{2} \mathrm{O}(200 \mathrm{mg}$, $1.00 \mathrm{mmol})$ in $t$-AmOH $(2.0 \mathrm{~mL})$ was stirred at $120^{\circ} \mathrm{C}$ under $\mathrm{N}_{2}$ for $22 \mathrm{~h}$. At ambient temperature, the reaction mixture was diluted with sat. aq. $\mathrm{NH}_{4} \mathrm{Cl} / \mathrm{NH}_{3}(1: 1,75 \mathrm{~mL})$ and extracted with EtOAc $(3 \times 75 \mathrm{~mL})$. The combined organic phase was washed with sat. aq. $\mathrm{NH}_{4} \mathrm{Cl} / \mathrm{NH}_{3}(1: 1,50 \mathrm{~mL})$ and dried over anhydrous $\mathrm{Na}_{2} \mathrm{SO}_{4}$. After filtration and evaporation of the solvents under reduced pressure, the crude product was purified by column chromatography on silica gel (n-hexane/EtOAc: 20/1) to yield a mixture of 211ga and 211la as a yellow oil. The ratio of products 211 ga/211la was found to be $3.0 / 1.0$ by ${ }^{1} \mathrm{H}-\mathrm{NMR}$ spectroscopy.

\section{Ruthenium-catalyzed H/D exchange with 2101 (Scheme 72a)}

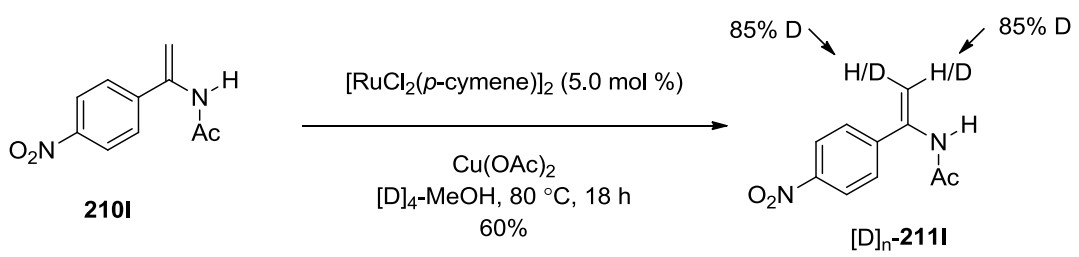

A mixture of $N$-\{1-(4-nitrophenyl)vinyl $\}$ acetamide $\quad(\mathbf{2 1 0}) \quad(103 \quad \mathrm{mg}, \quad 0.50 \quad \mathrm{mmol})$, $\left[\mathrm{RuCl}_{2}(p \text {-cymene })\right]_{2}(15.3 \mathrm{mg}, 5.0 \mathrm{~mol} \%)$, and $\mathrm{Cu}(\mathrm{OAc})_{2}(182 \mathrm{mg}, 1.00 \mathrm{mmol})$ in $[\mathrm{D}]_{4}-\mathrm{MeOH}$ $(2.0 \mathrm{~mL})$ was stirred at $80{ }^{\circ} \mathrm{C}$ under $\mathrm{N}_{2}$ for $18 \mathrm{~h}$. After cooling to ambient temperature, the reaction mixture was diluted with sat. aq. $\mathrm{NH}_{4} \mathrm{Cl} / \mathrm{NH}_{3}(50 \mathrm{~mL})$ and extracted with EtOAc $(3 \times 40 \mathrm{~mL})$. The combined organic phase was washed with brine $(30 \mathrm{~mL})$ and dried over $\mathrm{Na}_{2} \mathrm{SO}_{4}$. After filtration 
and evaporation of the solvents under reduced pressure, the crude product was purified by column chromatography on silica gel ( $n$-hexane/EtOAc: $1 / 1$ ) to give the mixture of $[\mathrm{D}]_{\mathrm{n}}-\mathbf{2 1 0 1}$ and $\mathbf{2 1 0 1}$ as a white solid (63 mg, 60\%). The deuterium incorporation was estimated to be $85 \%$ by ${ }^{1} \mathrm{H}-\mathrm{NMR}$ spectroscopy.

Ruthenium-catalyzed oxidative annulation of alkyne with enamine 2101 in $[\mathrm{D}]_{4}-\mathrm{MeOH}$ (Scheme 72b)

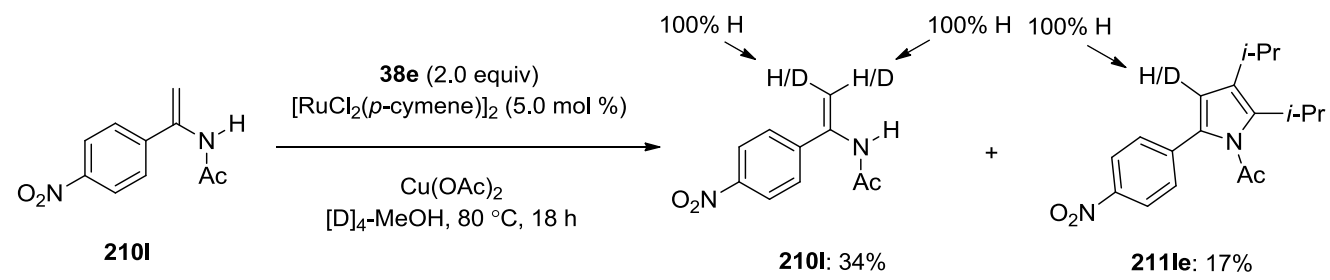

A mixture of $N$-\{1-(4-nitrophenyl)vinyl $\}$ acetamide $\quad(\mathbf{2 1 0 l}) \quad(103 \quad \mathrm{mg}, \quad 0.50 \quad \mathrm{mmol})$, diphenylacetylene (38e) (178 mg, $1.00 \mathrm{mmol})$, [ $\mathrm{RuCl}_{2}(p$-cymene $\left.)\right]_{2}(15.3 \mathrm{mg}, 5.0 \mathrm{~mol} \%)$, and $\mathrm{Cu}(\mathrm{OAc})_{2}(182 \mathrm{mg}, 1.00 \mathrm{mmol})$ in $[\mathrm{D}]_{4}-\mathrm{MeOH}(2.0 \mathrm{~mL})$ was stirred at $80{ }^{\circ} \mathrm{C}$ under $\mathrm{N}_{2}$ for $18 \mathrm{~h}$. After cooling to ambient temperature, the reaction mixture was diluted with sat. aq. $\mathrm{NH}_{4} \mathrm{Cl} / \mathrm{NH}_{3}$ $(50 \mathrm{~mL})$ and extracted with EtOAc $(3 \times 40 \mathrm{~mL})$. The combined organic phase was washed with brine $(30 \mathrm{~mL})$ and dried over $\mathrm{Na}_{2} \mathrm{SO}_{4}$. After filtration and evaporation of the solvents under reduced pressure, the mixture was separated by column chromatography on silica gel (n-hexane/EtOAc: 10/1 to 1/1) to give 211le as a red solid (33 mg, 17\%) and $\mathbf{2 1 0 1}$ as a white solid (35 mg, 34\%). No deuterium incorporation was detected by ${ }^{1} \mathrm{H}-\mathrm{NMR}$ spectroscopy.

\subsubsection{Analytical Data for the Products of Ruthenium-Catalyzed Oxidative} Alkenylation of Anilides 212 and Heteroamides 214

\section{Synthesis of $(E)$-ethyl 3-(2-acetamido-4-methylphenyl)acrylate (213aa)}<smiles>CCOC(=O)Cc1ccc(C)cc1NC(C)=O</smiles>

The general procedure D was followed using acetanilide 212a $(74.5 \mathrm{mg}$, $0.50 \mathrm{mmol})$, ethyl acrylate $(\mathbf{7 6 a})(75.0 \mathrm{mg}, 0.75 \mathrm{mmol}),\left[\mathrm{RuCl}_{2}(p \text {-cymene })\right]_{2}$ $(7.7 \mathrm{mg}, 5.0 \mathrm{~mol} \%)$ and $\mathrm{KPF}_{6}(9.2 \mathrm{mg}, 10 \mathrm{~mol} \%)$. After $20 \mathrm{~h}$, purification by column chromatography on silica gel ( $n$-hexane/EtOAc: $3 / 1$ ) yielded 213aa

(108 $\mathrm{mg}, 87 \%)$ as a white solid.

M.p. $=155-156^{\circ} \mathrm{C}$.

${ }^{1} \mathrm{H}-\mathrm{NMR}\left(300 \mathrm{MHz}, \mathrm{CDCl}_{3}\right): \delta=7.76(\mathrm{~d}, J=15.6 \mathrm{~Hz}, 1 \mathrm{H}), 7.54\left(\mathrm{~s}_{\mathrm{br}}, 1 \mathrm{H}\right), 7.50(\mathrm{~s}, 1 \mathrm{H}), 7.43(\mathrm{~d}$, $J=8.2 \mathrm{~Hz}, 1 \mathrm{H}), 6.99$ (d, $J=8.2 \mathrm{~Hz}, 1 \mathrm{H}), 6.33(\mathrm{~d}, J=15.6 \mathrm{~Hz}, 1 \mathrm{H}), 4.22(\mathrm{q}, J=7.1 \mathrm{~Hz}, 2 \mathrm{H}), 2.38$ (s, 3H), $2.20(\mathrm{~s}, 3 \mathrm{H}), 1.30(\mathrm{t}, J=7.1 \mathrm{~Hz}, 3 \mathrm{H})$.

${ }^{13} \mathrm{C}-\mathrm{NMR}\left(75 \mathrm{MHz}, \mathrm{CDCl}_{3}\right): \delta=168.9\left(\mathrm{C}_{\mathrm{q}}\right), 166.9\left(\mathrm{C}_{\mathrm{q}}\right), 141.4\left(\mathrm{C}_{\mathrm{q}}\right), 139.2(\mathrm{CH}), 135.7\left(\mathrm{C}_{\mathrm{q}}\right), 126.9$ $(\mathrm{CH}), 126.9(\mathrm{CH}), 125.9(\mathrm{CH}), 124.9\left(\mathrm{C}_{\mathrm{q}}\right), 119.3(\mathrm{CH}), 60.6\left(\mathrm{CH}_{2}\right), 24.1\left(\mathrm{CH}_{3}\right), 21.4\left(\mathrm{CH}_{3}\right), 14.2$ $\left(\mathrm{CH}_{3}\right)$.

IR (ATR): $\tilde{V}=3226,1711,1660,1635,1609,1537,1493,1163,984,814 \mathrm{~cm}^{-1}$.

MS (EI) m/z (relative intensity): 247 (28) $\left[\mathrm{M}^{+}\right], 204$ (25), 160 (97), 138 (20) 132 (92), 117 (22).

HR-MS (EI) $m / z$ calcd for $\mathrm{C}_{14} \mathrm{H}_{17} \mathrm{NO}_{3}{ }^{+} 247.1206$, found 247.1209. 


\section{Synthesis of $(E)$-ethyl 3-(2-pivalamidophenyl)acrylate (213ea)}

$\overbrace{\mathrm{CO}_{2} \mathrm{Et}}^{\mathrm{N}} \prod_{\mathrm{O}}^{t-\mathrm{Bu}}$

The representative procedure $\mathbf{D}$ was followed using acetanilide $213 \mathrm{e}(88.5 \mathrm{mg}$, $0.50 \mathrm{mmol})$, ethyl acrylate (76a) $(75.0 \mathrm{mg}, 0.75 \mathrm{mmol}),\left[\mathrm{RuCl}_{2}(p \text {-cymene })\right]_{2}$ $(15.3 \mathrm{mg}, 5.0 \mathrm{~mol} \%)$ and $\mathrm{KPF}_{6}(18.4 \mathrm{mg}, 20 \mathrm{~mol} \%)$. After $20 \mathrm{~h}$, purification by column chromatography on silica gel ( $n$-hexane/EtOAc: $5 / 1)$ yielded 213ea (86 $\mathrm{mg}, 62 \%)$ as a white solid.

M.p. $=81-82^{\circ} \mathrm{C}$.

${ }^{1} \mathrm{H}-\mathrm{NMR}\left(300 \mathrm{MHz}, \mathrm{CDCl}_{3}\right): \delta=7.75(\mathrm{~d}, J=16.4 \mathrm{~Hz}, 1 \mathrm{H}), 7.70(\mathrm{~d}, J=8.4 \mathrm{~Hz}, 1 \mathrm{H}), 7.54(\mathrm{~d}, J=$ $8.0 \mathrm{~Hz}, 1 \mathrm{H}), 7.40\left(\mathrm{~s}_{\mathrm{br}}, 1 \mathrm{H}\right), 7.37(\mathrm{dd}, J=8.4,7.8 \mathrm{~Hz}, 1 \mathrm{H}), 7.20(\mathrm{dd}, J=8.0,7.8 \mathrm{~Hz}, 1 \mathrm{H}), 6.38(\mathrm{~d}$, $J=16.4 \mathrm{~Hz}, 1 \mathrm{H}), 4.34(\mathrm{q}, J=7.1 \mathrm{~Hz}, 2 \mathrm{H}), 1.36(\mathrm{~s}, 9 \mathrm{H}), 1.32(\mathrm{t}, J=7.1 \mathrm{~Hz}, 3 \mathrm{H})$.

${ }^{13} \mathrm{C}-\mathrm{NMR}\left(75 \mathrm{MHz}, \mathrm{CDCl}_{3}\right): \delta=176.9\left(\mathrm{C}_{\mathrm{q}}\right), 166.5\left(\mathrm{C}_{\mathrm{q}}\right), 139.2(\mathrm{CH}), 136.1\left(\mathrm{C}_{\mathrm{q}}\right), 130.6(\mathrm{CH})$, $128.1\left(\mathrm{C}_{\mathrm{q}}\right), 127.1(\mathrm{CH}), 125.8(\mathrm{CH}), 125.1(\mathrm{CH}), 120.8(\mathrm{CH}), 60.3\left(\mathrm{CH}_{2}\right), 39.6\left(\mathrm{C}_{\mathrm{q}}\right), 27.6\left(\mathrm{CH}_{3}\right)$, $14.2\left(\mathrm{CH}_{3}\right)$.

IR (ATR): $\tilde{V}=3266,2979,1711,1638,1477,1365,1173,1036,984,760 \mathrm{~cm}^{-1}$.

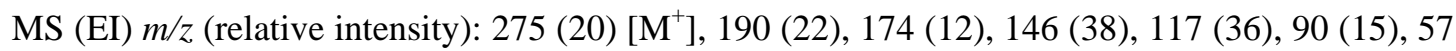
(100).

HR-MS (EI) $m / z$ calcd for $\mathrm{C}_{16} \mathrm{H}_{21} \mathrm{NO}_{3}{ }^{+} 275.1521$, found 275.1522 .

\section{Synthesis of $(E)$-ethyl 3-(2-acetamido-5-methylphenyl)acrylate (213ga)}<smiles>CCOC(=O)Cc1cc(C)ccc1NC(C)=O</smiles>

The general procedure D was followed using acetanilide $212 \mathrm{~g}(74.5 \mathrm{mg}$, $0.50 \mathrm{mmol})$, ethyl acrylate (76a) $(75.0 \mathrm{mg}, 0.75 \mathrm{mmol}),\left[\mathrm{RuCl}_{2}(p \text {-cymene })\right]_{2}$ (15.3 mg, $5.0 \mathrm{~mol} \%)$ and $\mathrm{KPF}_{6}(18.4 \mathrm{mg}, 20 \mathrm{~mol} \%)$. After $20 \mathrm{~h}$, purification by column chromatography on silica gel ( $n$-hexane/EtOAc: $2 / 1$ ) yielded

213ga ( $83 \mathrm{mg}, 67 \%)$ as a white solid.

M.p. $=134-135^{\circ} \mathrm{C}$.

${ }^{1} \mathrm{H}-\mathrm{NMR}\left(300 \mathrm{MHz}, \mathrm{CDCl}_{3}\right): \delta=7.76(\mathrm{~d}, J=15.8 \mathrm{~Hz}, 1 \mathrm{H}), 7.53(\mathrm{~d}, J=8.2 \mathrm{~Hz}, 1 \mathrm{H}), 7.38(\mathrm{~s}, 1 \mathrm{H})$, $7.35\left(\mathrm{~s}_{\mathrm{br}}, 1 \mathrm{H}\right), 7.17(\mathrm{~d}, J=8.2 \mathrm{~Hz}, 1 \mathrm{H}), 6.37(\mathrm{~d}, J=15.8 \mathrm{~Hz}, 1 \mathrm{H}), 4.24(\mathrm{q}, J=7.1 \mathrm{~Hz}, 2 \mathrm{H}), 2.32(\mathrm{~s}$, $3 \mathrm{H}), 2.20(\mathrm{~s}, 3 \mathrm{H}), 1.32(\mathrm{t}, J=7.1 \mathrm{~Hz}, 3 \mathrm{H})$.

${ }^{13} \mathrm{C}-\mathrm{NMR}\left(75 \mathrm{MHz}, \mathrm{CDCl}_{3}\right): \delta=169.0\left(\mathrm{C}_{\mathrm{q}}\right), 166.8\left(\mathrm{C}_{\mathrm{q}}\right), 139.4(\mathrm{CH}), 135.7\left(\mathrm{C}_{\mathrm{q}}\right), 133.4\left(\mathrm{C}_{\mathrm{q}}\right), 131.5$ $(\mathrm{CH}), 127.8\left(\mathrm{C}_{\mathrm{q}}\right), 127.3(\mathrm{CH}), 125.5(\mathrm{CH}), 120.2(\mathrm{CH}), 60.6\left(\mathrm{CH}_{2}\right), 24.0\left(\mathrm{CH}_{3}\right), 20.9\left(\mathrm{CH}_{3}\right), 14.2$ $\left(\mathrm{CH}_{3}\right)$.

IR (ATR): $\tilde{V}=3269,1712,1658,1636,1525,1363,1299,1174,970,815 \mathrm{~cm}^{-1}$.

MS (EI) $m / z$ (relative intensity): 247 (40) $\left[\mathrm{M}^{+}\right], 205$ (37), 160 (100), 132 (76), 117 (12).

HR-MS (EI) $m / z$ calcd for $\mathrm{C}_{14} \mathrm{H}_{17} \mathrm{NO}_{3}{ }^{+} 247.1206$, found 247.1204 .

Synthesis of $(E)$-(n)-butyl 3-(2-acetamido-5-methylphenyl)acrylate (213gb)<smiles>CCCCOC(=O)Cc1cc(C)ccc1NC(C)=O</smiles>

The general procedure $\mathbf{D}$ was followed using acetanilide $\mathbf{2 1 2 \mathrm { g }}(74.5 \mathrm{mg}$, $0.50 \mathrm{mmol}), \quad n$-butyl acrylate $\quad(\mathbf{7 6 b}) \quad(96.0 \mathrm{mg}, \quad 0.75 \mathrm{mmol})$, $\left[\operatorname{RuCl}_{2}(p \text {-cymene) }]_{2}(15.3 \mathrm{mg}, 5.0 \mathrm{~mol} \%)\right.$ and $\mathrm{KPF}_{6}(18.4 \mathrm{mg}, 20 \mathrm{~mol} \%)$. After $20 \mathrm{~h}$, purification by column chromatography on silica gel ( $n$-hexane/EtOAc: $1 / 1)$ yielded 213gb $(75 \mathrm{mg}, 55 \%)$ as a white solid.

M.p. $=112-113^{\circ} \mathrm{C}$.

${ }^{1} \mathrm{H}-\mathrm{NMR}\left(300 \mathrm{MHz}, \mathrm{CDCl}_{3}\right): \delta=7.76(\mathrm{~d}, J=16.0 \mathrm{~Hz}, 1 \mathrm{H}), 7.51(\mathrm{~d}, J=8.4 \mathrm{~Hz}, 1 \mathrm{H}), 7.37(\mathrm{~s}, 1 \mathrm{H})$, $7.34(\mathrm{sbr}, 1 \mathrm{H}), 7.16(\mathrm{~d}, J=8.4 \mathrm{~Hz}, 1 \mathrm{H}), 6.35(\mathrm{~d}, J=16.0 \mathrm{~Hz}, 1 \mathrm{H}), 4.16(\mathrm{t}, J=6.7 \mathrm{~Hz}, 2 \mathrm{H}), 2.30(\mathrm{~s}$, $3 \mathrm{H}), 2.18$ (s, 3H), 1.70-1.59 (m, 2H), 1.47-1.32 (m, 2H), $0.93(\mathrm{t}, J=7.3 \mathrm{~Hz}, 3 \mathrm{H})$. 
${ }^{13} \mathrm{C}-\mathrm{NMR}\left(75 \mathrm{MHz}, \mathrm{CDCl}_{3}\right): \delta=168.9\left(\mathrm{C}_{\mathrm{q}}\right), 166.9\left(\mathrm{C}_{\mathrm{q}}\right), 139.4(\mathrm{CH}), 135.7\left(\mathrm{C}_{\mathrm{q}}\right), 133.3\left(\mathrm{C}_{\mathrm{q}}\right), 131.5$ $(\mathrm{CH}), 127.8\left(\mathrm{C}_{\mathrm{q}}\right), 127.3(\mathrm{CH}), 125.6(\mathrm{CH}), 120.2(\mathrm{CH}), 64.5\left(\mathrm{CH}_{2}\right), 30.7\left(\mathrm{CH}_{2}\right), 24.0\left(\mathrm{CH}_{3}\right), 20.9$ $\left(\mathrm{CH}_{3}\right), 19.1\left(\mathrm{CH}_{2}\right), 13.7\left(\mathrm{CH}_{3}\right)$.

IR (ATR): $\tilde{V}=3269,1711,1656,1584,1527,1277,1241,1161,979,812 \mathrm{~cm}^{-1}$.

MS (EI) $m / z$ (relative intensity): 275 (25) [ $\left.\mathrm{M}^{+}\right], 233$ (20), 160 (100), 132 (64), 117 (9).

HR-MS (EI) $\mathrm{m} / z$ calcd for $\mathrm{C}_{16} \mathrm{H}_{21} \mathrm{NO}_{3}{ }^{+} 275.1521$, found 275.1529 .

The spectral data were in accordance with those reported in the literature. ${ }^{178}$

\section{Synthesis of (E)-ethyl 3-(2-acetamido-5-fluorophenyl)acrylate (213ha)}

The general procedure $\mathbf{D}$ was followed using acetanilide $\mathbf{2 1 2 h}(76.5 \mathrm{mg}$, $0.50 \mathrm{mmol})$, ethyl acrylate (76a) $(75.0 \mathrm{mg}, 0.75 \mathrm{mmol}),\left[\mathrm{RuCl}_{2}(p \text {-cymene })\right]_{2}$ (15.3 mg, $5.0 \mathrm{~mol} \%)$ and $\mathrm{KPF}_{6}(18.4 \mathrm{mg}, 20 \mathrm{~mol} \%)$. After $20 \mathrm{~h}$, purification by column chromatography on silica gel ( $n$-hexane/EtOAc: $2 / 1)$ yielded 213ha

(93 $\mathrm{mg}, 74 \%)$ as a white solid.

M.p. $=143-144^{\circ} \mathrm{C}$.

${ }^{1} \mathrm{H}-\mathrm{NMR}\left(300 \mathrm{MHz}, \mathrm{CDCl}_{3}\right): \delta=7.72(\mathrm{~d}, J=15.6 \mathrm{~Hz}, 1 \mathrm{H}), 7.59(\mathrm{~s}, 1 \mathrm{H}), 7.55(\mathrm{~d}, J=7.6 \mathrm{~Hz}, 1 \mathrm{H})$, $7.21(\mathrm{~d}, J=8.2 \mathrm{~Hz}, 1 \mathrm{H}), 7.05(\mathrm{dd}, J=8.2,8.0 \mathrm{~Hz}, 1 \mathrm{H}), 6.34(\mathrm{~d}, J=15.6 \mathrm{~Hz}, 1 \mathrm{H}), 4.24(\mathrm{q}, J=7.1$ $\mathrm{Hz}, 2 \mathrm{H}), 2.19(\mathrm{~s}, 3 \mathrm{H}), 1.32(\mathrm{t}, J=7.1 \mathrm{~Hz}, 3 \mathrm{H})$.

${ }^{13} \mathrm{C}-\mathrm{NMR}\left(75 \mathrm{MHz}, \mathrm{CDCl}_{3}\right): \delta=169.3\left(\mathrm{C}_{\mathrm{q}}\right), 166.4\left(\mathrm{C}_{\mathrm{q}}\right), 160.2\left(\mathrm{~d},{ }^{1} J_{\mathrm{C}-\mathrm{F}}=247 \mathrm{~Hz}, \mathrm{C}_{\mathrm{q}}\right), 138.3(\mathrm{~d}$, $\left.{ }^{4} J_{\mathrm{C}-\mathrm{F}}=2 \mathrm{~Hz}, \mathrm{CH}\right), 131.9\left(\mathrm{~d},{ }^{4} J_{\mathrm{C}-\mathrm{F}}=3 \mathrm{~Hz}, \mathrm{C}_{\mathrm{q}}\right), 130.2\left(\mathrm{~d},{ }^{3} J_{\mathrm{C}-\mathrm{F}}=8 \mathrm{~Hz}, \mathrm{C}_{\mathrm{q}}\right), 127.9\left(\mathrm{~d},{ }^{3} J_{\mathrm{C}-\mathrm{F}}=8 \mathrm{~Hz}\right.$, $\mathrm{CH}), 121.4(\mathrm{CH}), 117.7\left(\mathrm{~d},{ }^{2} J_{\mathrm{C}-\mathrm{F}}=23 \mathrm{~Hz}, \mathrm{CH}\right), 113.1\left(\mathrm{~d},{ }^{2} J_{\mathrm{C}-\mathrm{F}}=23 \mathrm{~Hz}, \mathrm{CH}\right), 60.8\left(\mathrm{CH}_{2}\right), 23.8$ $\left(\mathrm{CH}_{3}\right), 14.2\left(\mathrm{CH}_{3}\right)$.

${ }^{19} \mathrm{~F}-\mathrm{NMR}\left(\mathrm{CDCl}_{3}, 283 \mathrm{MHz}\right): \delta=-(111.3-111.5)(\mathrm{m})$.

IR (ATR): $\tilde{V}=3249,1717,1656,1636,1527,1486,1419,1264,1177,971,852 \mathrm{~cm}^{-1}$.

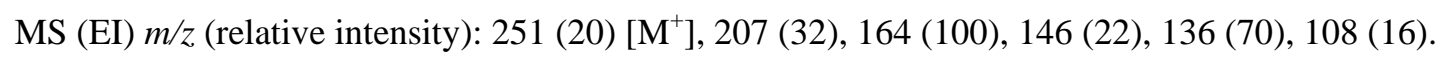
HR-MS (EI) $m / z$ calcd for $\mathrm{C}_{13} \mathrm{H}_{14} \mathrm{FNO}_{3}{ }^{+} 251.0958$, found 251.0956 .

\section{Synthesis of (E)-(n)-butyl 3-(2-acetamido-5-fluorophenyl)acrylate (213hb)}

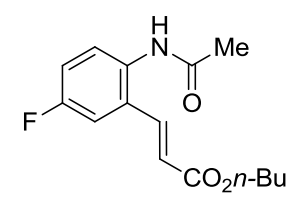

The general procedure D was followed using acetanilide $212 \mathrm{~h}(76.5 \mathrm{mg}$, $0.50 \mathrm{mmol}), \quad n$-butyl acrylate $\quad(\mathbf{7 6 b}) \quad(96.0 \mathrm{mg}, \quad 0.75 \mathrm{mmol})$, $\left[\operatorname{RuCl}_{2}(p \text {-cymene })\right]_{2}(15.3 \mathrm{mg}, 5.0 \mathrm{~mol} \%)$ and $\mathrm{KPF}_{6}(18.4 \mathrm{mg}, 20 \mathrm{~mol} \%)$. After $20 \mathrm{~h}$, purification by column chromatography on silica gel ( $n$-hexane/EtOAc: $1 / 1)$ yielded $\mathbf{2 1 3 h b}(74 \mathrm{mg}, 53 \%$ ) as a white solid.

M.p. $=138-139^{\circ} \mathrm{C}$.

${ }^{1} \mathrm{H}-\mathrm{NMR}\left(300 \mathrm{MHz}, \mathrm{CDCl}_{3}\right): \delta=7.71(\mathrm{~s}, 1 \mathrm{H}), 7.68(\mathrm{~d}, J=15.8 \mathrm{~Hz}, 1 \mathrm{H}), 7.51(\mathrm{dd}, J=8.8,5.4 \mathrm{~Hz}$, $1 \mathrm{H}), 7.18(\mathrm{~d}, J=8.8 \mathrm{~Hz}, 1 \mathrm{H}), 7.01(\mathrm{dd}, J=8.2,2.9 \mathrm{~Hz}, 1 \mathrm{H}), 6.30(\mathrm{~d}, J=15.8 \mathrm{~Hz}, 1 \mathrm{H}), 4.14(\mathrm{t}, J=$ $6.5 \mathrm{~Hz}, 2 \mathrm{H}), 2.15(\mathrm{~s}, 3 \mathrm{H}), 1.70-1.56(\mathrm{~m}, 2 \mathrm{H}), 1.46-1.31(\mathrm{~m}, 2 \mathrm{H}), 0.92(\mathrm{t}, J=7.3 \mathrm{~Hz}, 3 \mathrm{H})$.

${ }^{13} \mathrm{C}-\mathrm{NMR}\left(75 \mathrm{MHz}, \mathrm{CDCl}_{3}\right): \delta=169.3\left(\mathrm{C}_{\mathrm{q}}\right), 166.5\left(\mathrm{C}_{\mathrm{q}}\right), 160.3\left(\mathrm{~d},{ }^{1} J_{\mathrm{C}-\mathrm{F}}=246 \mathrm{~Hz}, \mathrm{C}_{\mathrm{q}}\right), 138.3(\mathrm{CH})$, $131.8\left(\mathrm{~d},{ }^{4} J_{\mathrm{C}-\mathrm{F}}=2 \mathrm{~Hz}, \mathrm{C}_{\mathrm{q}}\right), 130.3\left(\mathrm{~d},{ }^{3} J_{\mathrm{C}-\mathrm{F}}=8 \mathrm{~Hz}, \mathrm{C}_{\mathrm{q}}\right), 128.0\left(\mathrm{~d},{ }^{3} J_{\mathrm{C}-\mathrm{F}}=8 \mathrm{~Hz}, \mathrm{CH}\right), 121.2(\mathrm{CH})$, $117.6\left(\mathrm{~d},{ }^{2} J_{\mathrm{C}-\mathrm{F}}=22 \mathrm{~Hz}, \mathrm{CH}\right), 113.0\left(\mathrm{~d},{ }^{2} J_{\mathrm{C}-\mathrm{F}}=22 \mathrm{~Hz}, \mathrm{CH}\right), 64.7\left(\mathrm{CH}_{2}\right), 30.6\left(\mathrm{CH}_{2}\right), 23.7\left(\mathrm{CH}_{3}\right)$, $19.1\left(\mathrm{CH}_{2}\right), 13.6\left(\mathrm{CH}_{3}\right)$.

${ }^{19} \mathrm{~F}-\mathrm{NMR}\left(\mathrm{CDCl}_{3}, 283 \mathrm{MHz}\right): \delta=-111.4(\mathrm{~m})$. IR (ATR): $\tilde{V}=3255,2955,1717,1656,1636,1527,1486,1174,1015,852 \mathrm{~cm}^{-1}$.

${ }^{178}$ L. L. Chng, J. Zhang, J. Yang, M. Amoura, J. Y. Ying, Adv. Synth. Catal. 2011, 353, 2988-2998. 
MS (EI) $m / z$ (relative intensity): 279 (11) $\left[\mathrm{M}^{+}\right], 237$ (16), 164 (100), 136 (55), 108 (10). HR-MS (EI) $m / z$ calcd for $\mathrm{C}_{15} \mathrm{H}_{18} \mathrm{FNO}_{3}{ }^{+} 279.1271$, found 279.1268 .

The spectral data were in accordance with those reported in the literature. ${ }^{178}$

\section{Synthesis of $(E)$-ethyl 3-\{2-acetamido-5-(trifluoromethyl)phenyl\}acrylate (213ia)}<smiles>CCOC=Cc1cc(C(F)(F)F)ccc1NC(C)=O</smiles>

The general procedure $\mathbf{D}$ was followed using acetanilide $\mathbf{2 1 2 i}(101.5 \mathrm{mg}$, $0.50 \mathrm{mmol})$, ethyl acrylate (76a) $(75.0 \mathrm{mg}, 0.75 \mathrm{mmol}),\left[\mathrm{RuCl}_{2}(p \text {-cymene })\right]_{2}$ $(15.3 \mathrm{mg}, 5.0 \mathrm{~mol} \%)$ and $\mathrm{KPF}_{6}(18.4 \mathrm{mg}, 20 \mathrm{~mol} \%)$. After $20 \mathrm{~h}$, purification $\mathrm{CO}_{2} \mathrm{Et}$ by column chromatography on silica gel ( $n$-hexane/EtOAc: $\left.3 / 1\right)$ yielded 213ia (69 $\mathrm{mg}, 46 \%)$ as a white solid.

M.p. $=168-169^{\circ} \mathrm{C}$.

${ }^{1} \mathrm{H}-\mathrm{NMR}\left(300 \mathrm{MHz}, \mathrm{CDCl}_{3}\right): \delta=8.01\left(\mathrm{~s}_{\mathrm{br}}, 1 \mathrm{H}\right), 7.78(\mathrm{~d}, J=16.3 \mathrm{~Hz}, 1 \mathrm{H}), 7.77(\mathrm{~d}, J=8.4 \mathrm{~Hz}$, $1 \mathrm{H}), 7.73(\mathrm{~s}, 1 \mathrm{H}), 7.57(\mathrm{~d}, J=8.4 \mathrm{~Hz}, 1 \mathrm{H}), 6.43(\mathrm{~d}, J=16.3 \mathrm{~Hz}, 1 \mathrm{H}), 4.25(\mathrm{q}, J=7.1 \mathrm{~Hz}, 2 \mathrm{H})$, $2.23(\mathrm{~s}, 3 \mathrm{H}), 1.32(\mathrm{t}, J=7.1 \mathrm{~Hz}, 3 \mathrm{H})$.

${ }^{13} \mathrm{C}-\mathrm{NMR}\left(75 \mathrm{MHz}, \mathrm{CDCl}_{3}\right): \delta=169.0\left(\mathrm{C}_{\mathrm{q}}\right), 166.3\left(\mathrm{C}_{\mathrm{q}}\right), 138.8\left(\mathrm{C}_{\mathrm{q}}\right), 137.8(\mathrm{CH}), 127.2\left(\mathrm{q},{ }^{3} J_{\mathrm{C}-\mathrm{F}}=\right.$ $10 \mathrm{~Hz}, \mathrm{CH}), 127.0\left(\mathrm{q},{ }^{2} J_{\mathrm{C}-\mathrm{F}}=33 \mathrm{~Hz}, \mathrm{C}_{\mathrm{q}}\right), 124.4\left(\mathrm{q},{ }^{4} J_{\mathrm{C}-\mathrm{F}}=4 \mathrm{~Hz}, \mathrm{CH}\right), 124.2\left(\mathrm{q},{ }^{3} J_{\mathrm{C}-\mathrm{F}}=11 \mathrm{~Hz}\right.$, $\mathrm{CH}), 123.6\left(\mathrm{q},{ }^{1} J_{\mathrm{C}-\mathrm{F}}=273 \mathrm{~Hz}, \mathrm{C}_{\mathrm{q}}\right), 122.4(\mathrm{CH}), 121.8\left(\mathrm{C}_{\mathrm{q}}\right), 61.0\left(\mathrm{CH}_{2}\right), 24.2\left(\mathrm{CH}_{3}\right), 14.2\left(\mathrm{CH}_{3}\right)$.

${ }^{19} \mathrm{~F}-\mathrm{NMR}\left(\mathrm{CDCl}_{3}, 283 \mathrm{MHz}\right): \delta=-62.6(\mathrm{~s})$.

IR (ATR): $\tilde{V}=3269,1719,1661,1585,1527,1369,1278,1108,1039,834 \mathrm{~cm}^{-1}$.

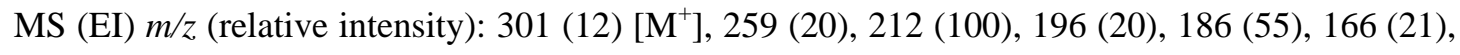
43 (38).

HR-MS (EI) $m / z$ calcd for $\mathrm{C}_{14} \mathrm{H}_{14} \mathrm{~F}_{3} \mathrm{NO}_{3}{ }^{+} 301.0926$, found 301.0920 .

\section{Synthesis of $(E)$-(n)-butyl 3-(2-acetamido-4-methylphenyl)acrylate (213ab)}<smiles>CCCCOCc1ccc(C)cc1NC(C)=O</smiles>

The general procedure $\mathbf{D}$ was followed using acetanilide 212a $(74.5 \mathrm{mg}$, $0.50 \mathrm{mmol}), \quad n$-butyl acrylate $\quad(\mathbf{7 6 b}) \quad(96.0 \mathrm{mg}, \quad 0.75 \mathrm{mmol})$, $\left[\mathrm{RuCl}_{2}(p \text {-cymene })\right]_{2}(15.3 \mathrm{mg}, 5.0 \mathrm{~mol} \%)$ and $\mathrm{KPF}_{6}(18.4 \mathrm{mg}, 20 \mathrm{~mol} \%)$. After $20 \mathrm{~h}$, purification by column chromatography on silica gel ( $n$-hexane/EtOAc: $3 / 1$ ) yielded 213ab $(77 \mathrm{mg}, 56 \%)$ as a white solid.

M.p. $=138-139^{\circ} \mathrm{C}$.

${ }^{1} \mathrm{H}-\mathrm{NMR}\left(300 \mathrm{MHz}, \mathrm{CDCl}_{3}\right): \delta=7.77(\mathrm{~d}, J=16.0 \mathrm{~Hz}, 1 \mathrm{H}), 7.51\left(\mathrm{~s}_{\mathrm{br}}, 1 \mathrm{H}\right), 7.51(\mathrm{~s}, 1 \mathrm{H}), 7.44(\mathrm{~d}$, $J=8.0 \mathrm{~Hz}, 1 \mathrm{H}), 6.99(\mathrm{~d}, J=8.0 \mathrm{~Hz}, 1 \mathrm{H}), 6.33(\mathrm{~d}, J=16.0 \mathrm{~Hz}, 1 \mathrm{H}), 4.17(\mathrm{t}, J=6.7 \mathrm{~Hz}, 2 \mathrm{H}), 2.38$ (s, 3H), $2.20(\mathrm{~s}, 3 \mathrm{H}), 1.72-1.59(\mathrm{~m}, 2 \mathrm{H}), 1.48-1.33(\mathrm{~m}, 2 \mathrm{H}), 0.94(\mathrm{t}, J=7.4 \mathrm{~Hz}, 3 \mathrm{H})$.

${ }^{13} \mathrm{C}-\mathrm{NMR}\left(75 \mathrm{MHz}, \mathrm{CDCl}_{3}\right): \delta=168.9\left(\mathrm{C}_{\mathrm{q}}\right), 167.0\left(\mathrm{C}_{\mathrm{q}}\right), 141.4\left(\mathrm{C}_{\mathrm{q}}\right), 139.2(\mathrm{CH}), 135.7\left(\mathrm{C}_{\mathrm{q}}\right), 126.9$ $(\mathrm{CH}), 126.8(\mathrm{CH}), 125.9\left(\mathrm{C}_{\mathrm{q}}\right), 124.9(\mathrm{CH}), 119.3(\mathrm{CH}), 64.5\left(\mathrm{CH}_{2}\right), 30.7\left(\mathrm{CH}_{2}\right), 24.1\left(\mathrm{CH}_{3}\right)$, $21.4\left(\mathrm{CH}_{3}\right), 19.1\left(\mathrm{CH}_{2}\right), 13.7\left(\mathrm{CH}_{3}\right)$.

IR (ATR): $\tilde{V}=3267,2958,1708,1656,1569,1532,1251,1067,973,813 \mathrm{~cm}^{-1}$.

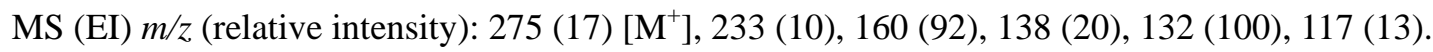

HR-MS (EI) $\mathrm{m} / z$ calcd for $\mathrm{C}_{14} \mathrm{H}_{17} \mathrm{NO}_{3}{ }^{+} 275.1521$, found 275.1525 .

The spectral data were in accordance with those reported in the literature. ${ }^{178}$

\section{Synthesis of $(E)$-ethyl 3-(2-acetamido-4-methoxyphenyl)acrylate (213ja)}<smiles>CCOC(=O)C=Cc1ccc(OC)cc1NC(C)=O</smiles>

The general procedure D was followed using acetanilide $\mathbf{2 1 2 j}$ (82.5 mg, $0.50 \mathrm{mmol})$, ethyl acrylate (76a) $(75.0 \mathrm{mg}, 0.75 \mathrm{mmol}),\left[\mathrm{RuCl}_{2}(p \text {-cymene })\right]_{2}$ $(15.3 \mathrm{mg}, 5.0 \mathrm{~mol} \%)$ and $\mathrm{KPF}_{6}(18.4 \mathrm{mg}, 20 \mathrm{~mol} \%)$. After $20 \mathrm{~h}$, 
purification by column chromatography on silica gel ( $n$-hexane/EtOAc: $2 / 1)$ yielded 213ja (77 mg, $58 \%)$ as a white solid.

M.p. $=132-133^{\circ} \mathrm{C}$.

${ }^{1} \mathrm{H}-\mathrm{NMR}\left(300 \mathrm{MHz}, \mathrm{CDCl}_{3}\right): \delta=7.75($ d. $J=15.7 \mathrm{~Hz}, 1 \mathrm{H}), 7.58\left(\mathrm{~s}_{\mathrm{br}}, 1 \mathrm{H}\right), 7.47(\mathrm{~d}, J=8.4 \mathrm{~Hz}$, $1 \mathrm{H}), 7.40(\mathrm{~s}, 1 \mathrm{H}), 7.72(\mathrm{~d}, J=8.4 \mathrm{~Hz}, 1 \mathrm{H}), 6.26(\mathrm{~d}, J=15.7 \mathrm{~Hz}, 1 \mathrm{H}), 4.23(\mathrm{q}, J=7.1 \mathrm{~Hz}, 2 \mathrm{H})$, $3.76(\mathrm{~s}, 3 \mathrm{H}), 2.22(\mathrm{~s}, 3 \mathrm{H}), 1.31(\mathrm{t}, J=7.1 \mathrm{~Hz}, 3 \mathrm{H})$.

${ }^{13} \mathrm{C}-\mathrm{NMR}\left(75 \mathrm{MHz}, \mathrm{CDCl}_{3}\right): \delta=168.8\left(\mathrm{C}_{\mathrm{q}}\right), 167.1\left(\mathrm{C}_{\mathrm{q}}\right), 161.6\left(\mathrm{C}_{\mathrm{q}}\right), 138.7(\mathrm{CH}), 137.4\left(\mathrm{C}_{\mathrm{q}}\right), 128.2$ $(\mathrm{CH}), 119.3\left(\mathrm{C}_{\mathrm{q}}\right), 117.8(\mathrm{CH}), 112.5(\mathrm{CH}), 109.2(\mathrm{CH}), 60.5\left(\mathrm{CH}_{2}\right), 55.4\left(\mathrm{CH}_{3}\right), 14.3\left(\mathrm{CH}_{3}\right), 14.3$ $\left(\mathrm{CH}_{3}\right)$.

IR (ATR): $\tilde{v}=3258,2976,1697,1660,1610,1573,1435,1259,1110,768 \mathrm{~cm}^{-1}$.

MS (EI) m/z (relative intensity): 263 (30) [ $\left.\mathrm{M}^{+}\right], 218$ (20), 176 (65), 148 (70), 132 (38), 104 (22).

HR-MS (EI) $\mathrm{m} / z$ calcd for $\mathrm{C}_{14} \mathrm{H}_{17} \mathrm{NO}_{4}{ }^{+} 263.1118$, found 263.1114 .

\section{Synthesis of $(E)$-(n)-butyl 3-(2-acetamido-4-methoxyphenyl)acrylate (213jb)}<smiles>COC(=O)C=Cc1ccc(OC)cc1NC(C)=O</smiles>

The general procedure $\mathbf{D}$ was followed using acetanilide $\mathbf{2 1 2} \mathbf{j}(82.5 \mathrm{mg}$, $0.50 \mathrm{mmol}), \quad n$-butyl acrylate $\quad(\mathbf{7 6 b}) \quad(96.0 \mathrm{mg}, \quad 0.75 \mathrm{mmol})$, $\left[\mathrm{RuCl}_{2}(p \text {-cymene })\right]_{2}(15.3 \mathrm{mg}, 5.0 \mathrm{~mol} \%)$ and $\mathrm{KPF}_{6}(18.4 \mathrm{mg}, 20 \mathrm{~mol} \%)$. After $20 \mathrm{~h}$, purification by column chromatography on silica gel ( $n$-hexane/EtOAc: $3 / 1$ ) yielded 213jb (76 $\mathrm{mg}, 52 \%$ ) as a white solid.

M.p. $=138-139^{\circ} \mathrm{C}$.

${ }^{1} \mathrm{H}-\mathrm{NMR}\left(300 \mathrm{MHz}, \mathrm{CDCl}_{3}\right): \delta=7.75(\mathrm{~d}, J=16.4 \mathrm{~Hz}, 1 \mathrm{H}), 7.61\left(\mathrm{~s}_{\mathrm{br}}, 1 \mathrm{H}\right), 7.47(\mathrm{~d}, J=8.8 \mathrm{~Hz}$, 1H), $7.40(\mathrm{~s}, 1 \mathrm{H}), 6.72(\mathrm{~d}, J=8.8 \mathrm{~Hz}, 1 \mathrm{H}), 6.27(\mathrm{~d}, J=16.4 \mathrm{~Hz}, 1 \mathrm{H}), 4.16(\mathrm{t}, J=6.4 \mathrm{~Hz}, 2 \mathrm{H}), 3.76$ (s, 3H), 2.22 (s, 3H) 1.78-1.59 (m, 2H), 1.51-1.33 (m, 2H), 0.94 (t, J=7.1 Hz, 3H).

${ }^{13} \mathrm{C}-\mathrm{NMR}\left(75 \mathrm{MHz}, \mathrm{CDCl}_{3}\right): \delta=167.1\left(\mathrm{C}_{\mathrm{q}}\right), 161.8\left(\mathrm{C}_{\mathrm{q}}\right), 138.7(\mathrm{CH}), 137.6\left(\mathrm{C}_{\mathrm{q}}\right), 137.6\left(\mathrm{C}_{\mathrm{q}}\right), 128.4$ $(\mathrm{CH}), 118.2(\mathrm{CH}), 112.6(\mathrm{CH}), 112.6\left(\mathrm{C}_{\mathrm{q}}\right), 109.3(\mathrm{CH}), 64.4\left(\mathrm{CH}_{2}\right), 55.5\left(\mathrm{CH}_{3}\right), 30.8\left(\mathrm{CH}_{2}\right), 24.2$ $\left(\mathrm{CH}_{3}\right), 19.2\left(\mathrm{CH}_{2}\right), 13.6\left(\mathrm{CH}_{3}\right)$.

IR (ATR): $\tilde{V}=3266,2952,1697,1660,1609,1573,1244,1110,972,767 \mathrm{~cm}^{-1}$.

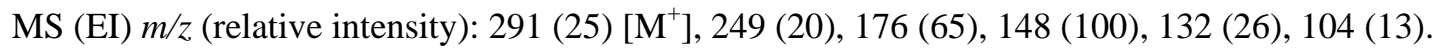
HR-MS (EI) $m / z$ calcd for $\mathrm{C}_{14} \mathrm{H}_{17} \mathrm{NO}_{3}{ }^{+} 291.1471$, found 291.1472 .

The spectral data were in accordance with those reported in the literature. ${ }^{178}$

\section{Synthesis of $(E)$-ethyl 3-(2-acetamido-4-chlorophenyl)acrylate (213ka)}

Cl ${ }_{\mathrm{N}}^{\mathrm{H}} \mathrm{Me}$ The general procedure $\mathbf{D}$ was followed using acetanilide $212 \mathrm{k}(84.5 \mathrm{mg}$, $0.50 \mathrm{mmol})$, ethyl acrylate (76a) $(150 \mathrm{mg}, 1.50 \mathrm{mmol}),\left[\mathrm{RuCl}_{2}(p \text {-cymene })\right]_{2}$ (15.3 mg, $5.0 \mathrm{~mol} \%)$ and $\mathrm{KPF}_{6}(18.4 \mathrm{mg}, 20 \mathrm{~mol} \%)$. After $20 \mathrm{~h}$, purification by column chromatography on silica gel ( $n$-hexane/EtOAc: 1/1) yielded

213ka (88 $\mathrm{mg}, 66 \%)$ as a white solid.

M.p. $=167-168^{\circ} \mathrm{C}$.

${ }^{1} \mathrm{H}-\mathrm{NMR}\left(300 \mathrm{MHz}, \mathrm{CDCl}_{3}\right): \delta=7.87(\mathrm{~s}, 1 \mathrm{H}), 7.75\left(\mathrm{~s}_{\mathrm{br}}, 1 \mathrm{H}\right), 7.69(\mathrm{~d}, J=15.8 \mathrm{~Hz}, 1 \mathrm{H}), 7.39(\mathrm{~d}$, $J=8.6 \mathrm{~Hz}, 1 \mathrm{H}), 7.09(\mathrm{~d}, J=8.6 \mathrm{~Hz}, 1 \mathrm{H}), 6.30(\mathrm{~d}, J=15.8 \mathrm{~Hz}, 1 \mathrm{H}), 4.22(\mathrm{q}, J=7.3 \mathrm{~Hz}, 2 \mathrm{H}), 2.19$ (s, 3H), $1.30(\mathrm{t}, J=7.3 \mathrm{~Hz}, 3 \mathrm{H})$.

${ }^{13} \mathrm{C}-\mathrm{NMR}\left(75 \mathrm{MHz}, \mathrm{CDCl}_{3}\right): \delta=169.1\left(\mathrm{C}_{\mathrm{q}}\right), 166.6\left(\mathrm{C}_{\mathrm{q}}\right), 138.2(\mathrm{CH}), 136.8\left(\mathrm{C}_{\mathrm{q}}\right), 136.3\left(\mathrm{C}_{\mathrm{q}}\right), 127.8$ $(\mathrm{CH}), 125.8(\mathrm{CH}), 125.6\left(\mathrm{C}_{\mathrm{q}}\right), 124.9(\mathrm{CH}), 120.6(\mathrm{CH}), 60.8\left(\mathrm{CH}_{2}\right), 24.0\left(\mathrm{CH}_{3}\right), 14.2\left(\mathrm{CH}_{3}\right)$. IR (ATR): $\tilde{V}=3249,1712,1665,1568,1521,1474,1266,1244,975,810 \mathrm{~cm}^{-1}$. MS (EI) $m / z$ (relative intensity): 267 (18) $\left[\mathrm{M}^{+}\right], 225$ (25), 176 (100), 152 (90), 117 (30), 89 (32). 
HR-MS (EI) $\mathrm{m} / z$ calcd for $\mathrm{C}_{13} \mathrm{H}_{14} \mathrm{ClNO}_{3}{ }^{+} 267.0662$, found 267.0622 .

\section{Synthesis of $(E)$-ethyl 3-\{2-acetamido-4-(trifluoromethyl)phenyl\}acrylate (213la)}<smiles>CCOC(=O)Cc1ccc(C(F)(F)F)cc1NC(C)=O</smiles>

The general procedure D was followed using acetanilide 2131 $(102 \mathrm{mg}$, $0.50 \mathrm{mmol})$, ethyl acrylate (76a) $(75.0 \mathrm{mg}, 0.75 \mathrm{mmol}),\left[\mathrm{RuCl}_{2}(p \text {-cymene })\right]_{2}$ (15.3 mg, $5.0 \mathrm{~mol} \%)$ and $\mathrm{KPF}_{6}(18.4 \mathrm{mg}, 20 \mathrm{~mol} \%)$. After $20 \mathrm{~h}$, purification by column chromatography on silica gel ( $n$-hexane/EtOAc: $4 / 1)$ yielded

213la (76 $\mathrm{mg}, 53 \%$ ) as a white solid.

M.p. $=138-139$ C.

${ }^{1} \mathrm{H}-\mathrm{NMR}\left(300 \mathrm{MHz}, \mathrm{CDCl}_{3}\right): \delta=7.98(\mathrm{~s}, 1 \mathrm{H}), 7.96\left(\mathrm{~s}_{\mathrm{br}}, 1 \mathrm{H}\right), 7.73(\mathrm{~d}, J=15.8 \mathrm{~Hz}, 1 \mathrm{H}), 7.55(\mathrm{~d}$, $J=8.2 \mathrm{~Hz}, 1 \mathrm{H}), 7.36(\mathrm{~d}, J=8.2 \mathrm{~Hz}, 1 \mathrm{H}), 6.48(\mathrm{~d}, J=15.8 \mathrm{~Hz}, 1 \mathrm{H}), 4.23(\mathrm{q}, J=7.1 \mathrm{~Hz}, 2 \mathrm{H}), 2.20$ $(\mathrm{s}, 3 \mathrm{H}), 1.31(\mathrm{t}, J=7.1 \mathrm{~Hz}, 3 \mathrm{H})$.

${ }^{13} \mathrm{C}-\mathrm{NMR}\left(75 \mathrm{MHz}, \mathrm{CDCl}_{3}\right): \delta=169.3\left(\mathrm{C}_{\mathrm{q}}\right), 166.2\left(\mathrm{C}_{\mathrm{q}}\right), 138.0(\mathrm{CH}), 136.2\left(\mathrm{C}_{\mathrm{q}}\right), 132.1\left(\mathrm{q},{ }^{2} J_{\mathrm{C}-\mathrm{F}}=\right.$ $\left.33 \mathrm{~Hz}, \mathrm{C}_{\mathrm{q}}\right), 130.6\left(\mathrm{C}_{\mathrm{q}}\right), 127.4(\mathrm{CH}), 123.4\left(\mathrm{q},{ }^{1} J_{\mathrm{C}-\mathrm{F}}=273 \mathrm{~Hz}, \mathrm{C}_{\mathrm{q}}\right), 122.5(\mathrm{CH}), 122.1\left(\mathrm{q},{ }^{3} J_{\mathrm{C}-\mathrm{F}}=14\right.$ $\mathrm{Hz}, \mathrm{CH}), 121.7\left(\mathrm{q},{ }^{3} \mathrm{~J}_{\mathrm{C}-\mathrm{F}}=12 \mathrm{~Hz}, \mathrm{CH}\right), 60.9\left(\mathrm{CH}_{2}\right), 23.9\left(\mathrm{CH}_{3}\right), 14.1\left(\mathrm{CH}_{3}\right)$.

${ }^{19} \mathrm{~F}-\mathrm{NMR}\left(\mathrm{CDCl}_{3}, 283 \mathrm{MHz}\right): \delta=-63.0(\mathrm{~s})$. IR (ATR): $\tilde{V}=3255,2984,1712,1661,1531,1387,1328,1110,822,553 \mathrm{~cm}^{-1}$.

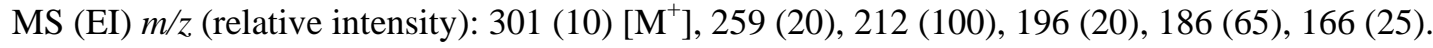
HR-MS (EI) $m / z$ calcd for $\mathrm{C}_{14} \mathrm{H}_{14} \mathrm{~F}_{3} \mathrm{NO}_{3}{ }^{+} 301.0926$, found 301.0918 .

\section{Synthesis of $(E)$-ethyl 3-(2-acetamido-6-fluorophenyl)acrylate (213ma)}<smiles>CCOC=Cc1c(F)cccc1NC(C)=O</smiles>

The general procedure D was followed using acetanilide $212 \mathrm{~m}(76.5 \mathrm{mg}$, $0.50 \mathrm{mmol})$, ethyl acrylate (76a) $(75.0 \mathrm{mg}, 0.75 \mathrm{mmol}),\left[\mathrm{RuCl}_{2}(p \text {-cymene })\right]_{2}$ (15.3 mg, $5.0 \mathrm{~mol} \%)$ and $\mathrm{KPF}_{6}(18.4 \mathrm{mg}, 20 \mathrm{~mol} \%)$. After $20 \mathrm{~h}$, purification by column chromatography on silica gel ( $n$-hexane/EtOAc: $2 / 1)$ yielded 213ma (88 $\mathrm{mg}, 70 \%)$ as a white solid.

M.p. $=138-143^{\circ} \mathrm{C}$.

${ }^{1} \mathrm{H}-\mathrm{NMR}\left(300 \mathrm{MHz}, \mathrm{CDCl}_{3}\right): \delta=7.65-7.52(\mathrm{~m}, 2 \mathrm{H}), 7.60(\mathrm{~d}, J=16.9 \mathrm{~Hz}, 1 \mathrm{H}), 7.30(\mathrm{dd}, J=9.6$, $9.6 \mathrm{~Hz}, 1 \mathrm{H}), 6.93(\mathrm{dd}, J=9.6,8.7 \mathrm{~Hz}, 1 \mathrm{H}), 6.57(\mathrm{~d}, J=16.9 \mathrm{~Hz}, 1 \mathrm{H}), 4.25(\mathrm{q}, J=7.1 \mathrm{~Hz}, 2 \mathrm{H})$, $2.21(\mathrm{~s}, 3 \mathrm{H}), 1.32(\mathrm{t}, J=7.1 \mathrm{~Hz}, 3 \mathrm{H})$.

${ }^{13} \mathrm{C}-\mathrm{NMR}\left(75 \mathrm{MHz}, \mathrm{CDCl}_{3}\right): \delta=168.8\left(\mathrm{C}_{\mathrm{q}}\right), 166.9\left(\mathrm{C}_{\mathrm{q}}\right), 161.3\left(\mathrm{~d},{ }^{1} J_{\mathrm{C}-\mathrm{F}}=252 \mathrm{~Hz}, \mathrm{C}_{\mathrm{q}}\right), 137.3(\mathrm{~d}$, $\left.{ }^{4} J_{\mathrm{C}-\mathrm{F}}=4 \mathrm{~Hz}, \mathrm{C}_{\mathrm{q}}\right), 133.3(\mathrm{CH}), 130.8\left(\mathrm{~d},{ }^{3} J_{\mathrm{C}-\mathrm{F}}=10 \mathrm{~Hz}, \mathrm{CH}\right), 124.8\left(\mathrm{~d},{ }^{3} J_{\mathrm{C}-\mathrm{F}}=11 \mathrm{~Hz}, \mathrm{CH}\right), 120.5$ $(\mathrm{CH}), 116.1\left(\mathrm{~d},{ }^{2} J_{\mathrm{C}-\mathrm{F}}=10 \mathrm{~Hz}, \mathrm{C}_{\mathrm{q}}\right), 112.8\left(\mathrm{~d},{ }^{2} J_{\mathrm{C}-\mathrm{F}}=24 \mathrm{~Hz}, \mathrm{CH}\right), 60.8\left(\mathrm{CH}_{2}\right), 24.2\left(\mathrm{CH}_{3}\right), 14.2$ $\left(\mathrm{CH}_{3}\right)$.

${ }^{19} \mathrm{~F}-\mathrm{NMR}\left(\mathrm{CDCl}_{3}, 283 \mathrm{MHz}\right): \delta=-110.4$ (s). IR (ATR): $\tilde{V}=3264,1719,1664,1636,1572,1364,1184,1029,751,530 \mathrm{~cm}^{-1}$.

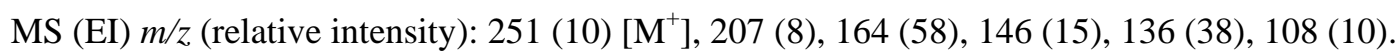
HR-MS (EI) $\mathrm{m} / z$ calcd for $\mathrm{C}_{13} \mathrm{H}_{14} \mathrm{FNO}_{3}{ }^{+} 251.0958$, found 251.0959 .

\section{Synthesis of $N$-\{5-methyl-2-(3-oxobutyl)phenyl\}acetamide (213ac)}

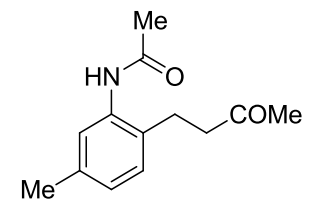

The general procedure $\mathbf{D}$ was followed using $N$-( $m$-tolyl $)$ acetamide 212a (74.5 $\mathrm{mg}, \quad 0.50 \mathrm{mmol}), 3$-buten-2-one (76c) $(52.5 \mathrm{mg}, 0.75 \mathrm{mmol})$, $\left[\mathrm{RuCl}_{2}(p \text {-cymene })\right]_{2}(15.3 \mathrm{mg}, 5.0 \mathrm{~mol} \%)$ and $\mathrm{KPF}_{6}(18.4 \mathrm{mg}, 20 \mathrm{~mol} \%)$. After $20 \mathrm{~h}$, purification by column chromatography on silica gel ( $n$-hexane/EtOAc: $3 / 1 \rightarrow 2 / 1$ ) yielded 213ac (34 mg, 31\%) as a white solid. 
M.p. $=132-133^{\circ} \mathrm{C}$.

${ }^{1} \mathrm{H}-\mathrm{NMR}\left(300 \mathrm{MHz}, \mathrm{CDCl}_{3}\right): \delta=9.00\left(\mathrm{~s}_{\mathrm{br}}, 1 \mathrm{H}\right), 7.62(\mathrm{~s}, 1 \mathrm{H}), 6.99(\mathrm{~d}, J=8.0 \mathrm{~Hz}, 1 \mathrm{H}), 6.88(\mathrm{~d}, J=$ $8.0 \mathrm{~Hz}, 1 \mathrm{H}), 2.88(\mathrm{t}, J=6.7 \mathrm{~Hz}, 2 \mathrm{H}), 2.76(\mathrm{t}, J=6.7 \mathrm{~Hz}, 2 \mathrm{H}), 2.30(\mathrm{~s}, 3 \mathrm{H}), 2.27(\mathrm{~s}, 3 \mathrm{H}), 2.13(\mathrm{~s}$, $3 \mathrm{H})$.

${ }^{13} \mathrm{C}-\mathrm{NMR}\left(75 \mathrm{MHz}, \mathrm{CDCl}_{3}\right): \delta=208.7\left(\mathrm{C}_{\mathrm{q}}\right), 169.1\left(\mathrm{C}_{\mathrm{q}}\right), 137.0\left(\mathrm{C}_{\mathrm{q}}\right), 135.6\left(\mathrm{C}_{\mathrm{q}}\right), 129.8(\mathrm{CH}), 129.7$ $\left(\mathrm{C}_{\mathrm{q}}\right), 126.2(\mathrm{CH}), 125.0(\mathrm{CH}), 45.7\left(\mathrm{CH}_{2}\right), 30.2\left(\mathrm{CH}_{3}\right), 24.5\left(\mathrm{CH}_{3}\right), 23.7\left(\mathrm{CH}_{2}\right), 21.3\left(\mathrm{CH}_{3}\right)$.

IR (ATR): $\tilde{V}=3276,2949,1708,1650,1576,1531,1370,1284,1161,814,553 \mathrm{~cm}^{-1}$.

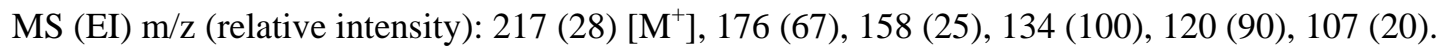

HR-MS (EI) $\mathrm{m} / \mathrm{z}$ calcd for $\mathrm{C}_{13} \mathrm{H}_{17} \mathrm{NO}_{2}{ }^{+} 217.1259$, found 217.1257 .

\section{Ruthenium-catalyzed oxidative alkenylations of anilide 212a in 5 mmol scale (Scheme 75)}
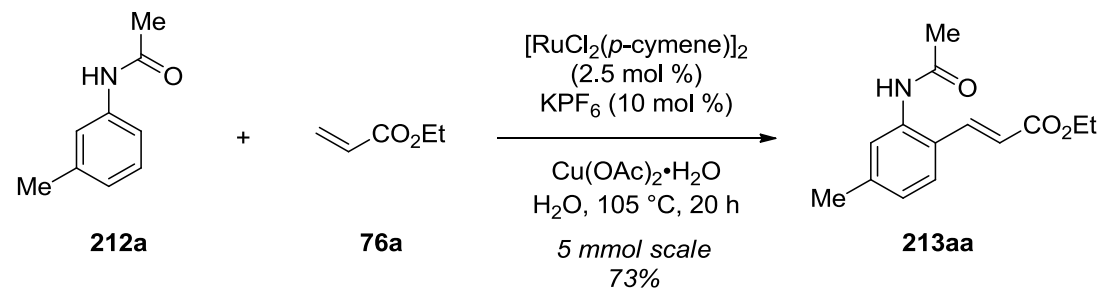

A mixture of acetanilide 212a $(715 \mathrm{mg}, 5.0 \mathrm{mmol}$ ), ethyl acrylate (76a) $(750 \mathrm{mg}, 7.5 \mathrm{mmol})$, $\left[\mathrm{RuCl}_{2}(p \text {-cymene })\right]_{2}(76.5 \mathrm{mg}, 2.5 \mathrm{~mol} \%), \mathrm{KPF}_{6}(92.0 \mathrm{mg}, 10 \mathrm{~mol} \%)$ and $\mathrm{Cu}(\mathrm{OAc})_{2} \cdot \mathrm{H}_{2} \mathrm{O}(1.0 \mathrm{~g}$, $5.0 \mathrm{mmol})$ in $\mathrm{H}_{2} \mathrm{O}(2.0 \mathrm{~mL})$ was stirred at $105{ }^{\circ} \mathrm{C}$ under $\mathrm{N}_{2}$ for $20 \mathrm{~h}$. At ambient temperature, the mixture was diluted with sat. aq. $\mathrm{NH}_{4} \mathrm{Cl} / \mathrm{NH}_{3}(1: 1,100 \mathrm{~mL})$ and extracted with EtOAc $(2 \times 100$ $\mathrm{mL})$. The combined organic phase was dried over anhydrous $\mathrm{Na}_{2} \mathrm{SO}_{4}(50 \mathrm{~g})$. After filtration and evaporation of the solvents under reduced pressure, the crude product was purified by column chromatography on silica gel ( $n$-hexane/EtOAc/ $\left./ \mathrm{CH}_{2} \mathrm{Cl}_{2}: 9 / 5 / 1 \rightarrow 6 / 4 / 1\right)$ to yield 213aa $(901 \mathrm{mg}$, $73 \%)$ as a white solid.

\section{Intermolecular competition experiment with anilides 212h and 212d (Scheme 76a)}
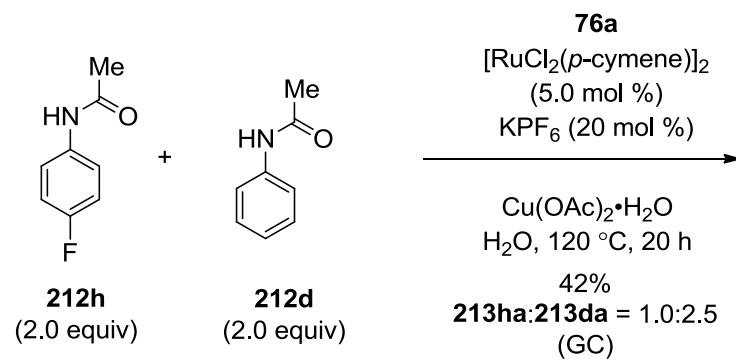

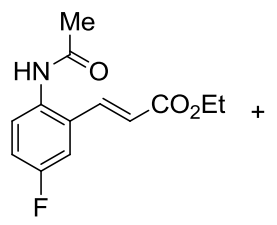

213ha<smiles>CCOC(=O)Nc1ccccc1C(=O)OCC</smiles>

213da

A mixture of $N$-(4-fluorophenyl)acetamide $(\mathbf{2 1 2 h})(153 \mathrm{mg}, 1.00 \mathrm{mmol}), \mathrm{N}$-phenylacetamide (212d) $(135 \mathrm{mg}, 1.00 \mathrm{mmol})$, ethyl acrylate (76a) $(50.0 \mathrm{mg}, 0.50 \mathrm{mmol}),\left[\mathrm{RuCl}_{2}(p \text {-cymene })\right]_{2}$ $(15.3 \mathrm{mg}, 5.0 \mathrm{~mol} \%), \mathrm{KPF}_{6}(18.4 \mathrm{mg}, 20 \mathrm{~mol} \%)$ and $\mathrm{Cu}(\mathrm{OAc})_{2} \cdot \mathrm{H}_{2} \mathrm{O}(99.5 \mathrm{mg}, 1.00 \mathrm{mmol})$ in $\mathrm{H}_{2} \mathrm{O}(2.0 \mathrm{~mL})$ was stirred at $120{ }^{\circ} \mathrm{C}$ under $\mathrm{N}_{2}$ for $20 \mathrm{~h}$. At ambient temperature, the mixture was diluted with $\mathrm{H}_{2} \mathrm{O}(75 \mathrm{~mL})$ and extracted with EtOAc $(3 \times 75 \mathrm{~mL})$. The combined organic phase was washed with brine $(50 \mathrm{~mL})$ and dried over anhydrous $\mathrm{Na}_{2} \mathrm{SO}_{4}$. After filtration and evaporation of the solvents under reduced pressure, the conversion of the crude mixture was determined by GC $(38 \%$, 213ha:213da $=1.0: 2.5)$. 
Intermolecular competition experiment with anilides 2120 and $212 d$ (Scheme 76b)

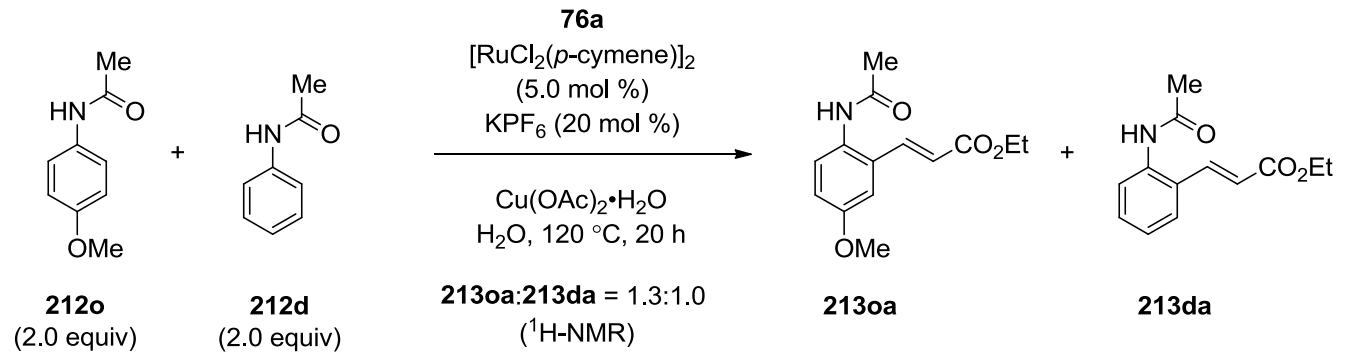

A mixture of $N$-(4-methoxyphenyl)acetamide (2120) $(165 \mathrm{mg}, 1.00 \mathrm{mmol}), N$-phenylacetamide (212d) $(135 \mathrm{mg}, 1.00 \mathrm{mmol})$, ethyl acrylate (76a) $(50.0 \mathrm{mg}, 0.50 \mathrm{mmol}),\left[\mathrm{RuCl}_{2}(p \text {-cymene })\right]_{2}$ $(15.3 \mathrm{mg}, 5.0 \mathrm{~mol} \%), \mathrm{KPF}_{6}(18.4 \mathrm{mg}, 20 \mathrm{~mol} \%)$ and $\mathrm{Cu}(\mathrm{OAc})_{2} \cdot \mathrm{H}_{2} \mathrm{O}(99.5 \mathrm{mg}, 1.00 \mathrm{mmol})$ in $\mathrm{H}_{2} \mathrm{O}(2.0 \mathrm{~mL})$ was stirred at $120{ }^{\circ} \mathrm{C}$ under $\mathrm{N}_{2}$ for $20 \mathrm{~h}$. At ambient temperature, the mixture was diluted with $\mathrm{H}_{2} \mathrm{O}(75 \mathrm{~mL})$ and extracted with EtOAc $(3 \times 75 \mathrm{~mL})$. The combined organic phase was washed with brine $(50 \mathrm{~mL})$ and dried over anhydrous $\mathrm{Na}_{2} \mathrm{SO}_{4}$. After filtration and evaporation of the solvents under reduced pressure, the crude product was purified by column chromatography on silica gel ( $n$-hexane/EtOAc: 2/1) to yield a mixture of 213oa and 213da as a white solid. The ratio of products 213oa:213da was found to be 1.3:1.0 by ${ }^{1} \mathrm{H}$-NMR spectroscopy.

\section{Intermolecular competition experiment with anilides $212 \mathrm{~h}$ and 2120 (Scheme 76c)}
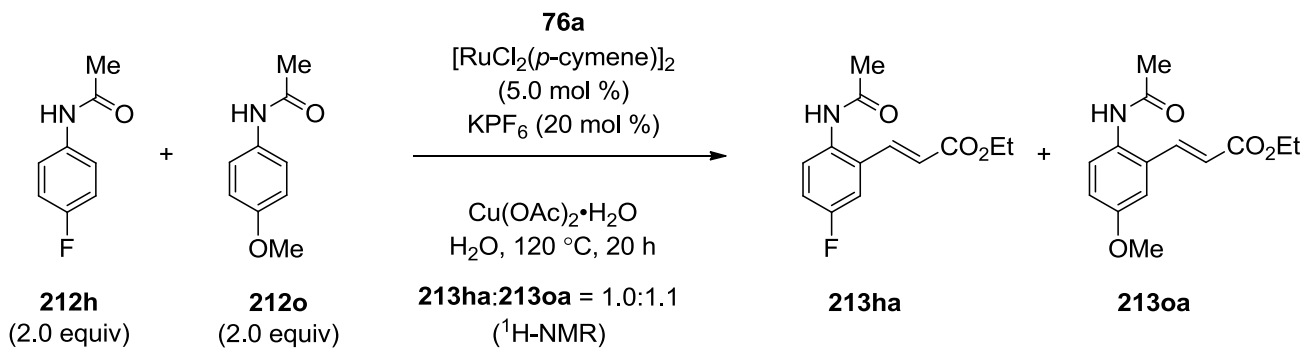

A mixture of $N$-(4-fluorophenyl)acetamide $\quad(\mathbf{2 1 2 h}) \quad(153 \quad \mathrm{mg}, \quad 1.00 \quad \mathrm{mmol})$, $\mathrm{N}$-(4-methoxyphenyl)acetamide (2120) (165 mg, $1.00 \mathrm{mmol})$, ethyl acrylate (76a) (50.0 $\mathrm{mg}$, $0.50 \mathrm{mmol}), \quad\left[\mathrm{RuCl}_{2}(p \text {-cymene })\right]_{2} \quad(15.3 \mathrm{mg}, 5.0 \mathrm{~mol} \%), \mathrm{KPF}_{6}(18.4 \mathrm{mg}, 20 \mathrm{~mol} \%)$ and $\mathrm{Cu}(\mathrm{OAc})_{2} \cdot \mathrm{H}_{2} \mathrm{O}(99.5 \mathrm{mg}, 1.00 \mathrm{mmol})$ in $\mathrm{H}_{2} \mathrm{O}(2.0 \mathrm{~mL})$ was stirred at $120{ }^{\circ} \mathrm{C}$ under $\mathrm{N}_{2}$ for $20 \mathrm{~h}$. At ambient temperature, the mixture was diluted with $\mathrm{H}_{2} \mathrm{O}(75 \mathrm{~mL})$ and extracted with EtOAc $(3 \times 75 \mathrm{~mL})$. The combined organic phase was washed with brine $(50 \mathrm{~mL})$ and dried over anhydrous $\mathrm{Na}_{2} \mathrm{SO}_{4}$. After filtration and evaporation of the solvents under reduced pressure, the crude product was purified by column chromatography on silica gel ( $n$-hexane/EtOAc: $2 / 1)$ to yield a mixture of 213ha and 213oa as a white solid. The ratio of products 213ha:213oa was found to be 1.0:1.1 by ${ }^{1} \mathrm{H}-\mathrm{NMR}$ spectroscopy.

\section{Ruthenium-catalyzed H/D exchange in $\mathrm{D}_{\mathbf{2}} \mathrm{O}$ (Scheme 77b)}
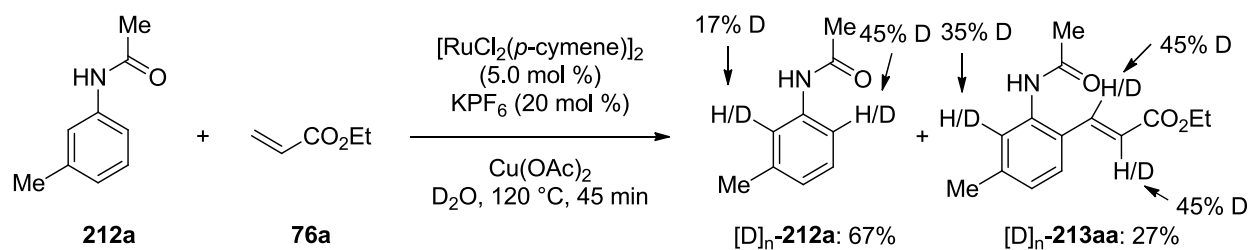

A mixture of acetanilide (212a) (149 mg, $1.00 \mathrm{mmol})$, ethyl acylate (76a) $(150 \mathrm{mg}, 1.50 \mathrm{mmol}$ ), $\left[\mathrm{RuCl}_{2}(p \text {-cymene })\right]_{2}(30.6 \mathrm{mg}, 5.0 \mathrm{~mol} \%), \mathrm{KPF}_{6}(36.8 \mathrm{mg}, 20 \mathrm{~mol} \%)$ and $\mathrm{Cu}(\mathrm{OAc})_{2}(181 \mathrm{mg}$, 
$1.00 \mathrm{mmol})$ in $\mathrm{D}_{2} \mathrm{O}(3.0 \mathrm{~mL})$ was stirred at $120{ }^{\circ} \mathrm{C}$ under $\mathrm{N}_{2}$ for $45 \mathrm{~min}$. At ambient temperature, the mixture was diluted with sat. aq. $\mathrm{NH}_{4} \mathrm{Cl} / \mathrm{NH}_{3}(1: 1,50 \mathrm{~mL})$ and extracted with EtOAc $(3 \times 50 \mathrm{~mL})$. The combined organic phase was washed with brine $(50 \mathrm{~mL})$ and dried over anhydrous $\mathrm{Na}_{2} \mathrm{SO}_{4}$. After filtration and evaporation of the solvents under reduced pressure, the crude product was purified by column chromatography on silica gel ( $n$-hexane/EtOAc: $2 / 1 \rightarrow 1 / 1$ ) to yield $[\mathrm{D}]_{\mathrm{n}}$-212a $(100 \mathrm{mg}, 67 \%)$ as a white solid and $[\mathrm{D}]_{\mathrm{n}}$-213aa $(67 \mathrm{mg}, 27 \%)$ as a white solid. The deuterium incorporation was estimated by ${ }^{1} \mathrm{H}-\mathrm{NMR}$ spectroscopy.

\section{Synthesis of $(E)$-ethyl 3-\{1-methyl-3-(methylcarbamoyl)-1H-indol-2-yl\}acrylate (215aa)}

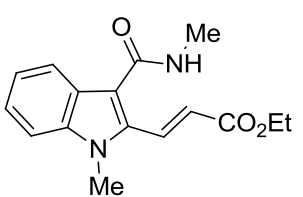

The general procedure D was followed using indole 214a (94 mg, $0.50 \mathrm{mmol})$, ethyl acrylate (76a) $(75 \mathrm{mg}, 0.75 \mathrm{mmol}),\left[\mathrm{RuCl}_{2}(p \text {-cymene })\right]_{2}$ $(15.3 \mathrm{mg}, 5.0 \mathrm{~mol} \%)$ and $\mathrm{KPF}_{6}(18.4 \mathrm{mg}, 20 \mathrm{~mol} \%)$. After $20 \mathrm{~h}$, purification by column chromatography on silica gel ( $n$-hexane/EtOAc: $1 / 1)$

yielded 215aa (75mg, 52\%) as a white solid.

M.p. $=193-194^{\circ} \mathrm{C}$.

${ }^{1} \mathrm{H}-\mathrm{NMR}\left(300 \mathrm{MHz}, \mathrm{CDCl}_{3}\right): \delta=8.08(\mathrm{~d}, J=16.3 \mathrm{~Hz}, 1 \mathrm{H}), 7.79(\mathrm{~d}, J=8.0 \mathrm{~Hz}, 1 \mathrm{H}), 7.36-7.30(\mathrm{~m}$, $2 \mathrm{H}), 7.21(\mathrm{dd}, J=8.0,5.1 \mathrm{~Hz}, 1 \mathrm{H}), 6.53(\mathrm{~d}, J=16.3 \mathrm{~Hz}, 1 \mathrm{H}), 6.00\left(\mathrm{~s}_{\mathrm{br}}, 1 \mathrm{H}\right), 4.28(\mathrm{q}, J=7.1 \mathrm{~Hz}$, $2 \mathrm{H}), 3.78\left(\mathrm{CH}_{3}\right), 3.05(\mathrm{~d}, J=5.0 \mathrm{~Hz}, 3 \mathrm{H}), 1.35(\mathrm{t}, J=7.1 \mathrm{~Hz}, 3 \mathrm{H})$.

${ }^{13} \mathrm{C}-\mathrm{NMR}\left(75 \mathrm{MHz}, \mathrm{CDCl}_{3}\right): \delta=166.4\left(\mathrm{C}_{\mathrm{q}}\right), 165.7\left(\mathrm{C}_{\mathrm{q}}\right), 138.1\left(\mathrm{C}_{\mathrm{q}}\right), 135.1\left(\mathrm{C}_{\mathrm{q}}\right), 132.1(\mathrm{CH}), 125.2$ $\left(\mathrm{C}_{\mathrm{q}}\right), 124.2(\mathrm{CH}), 123.4(\mathrm{CH}), 121.7(\mathrm{CH}), 120.2(\mathrm{CH}), 113.8\left(\mathrm{C}_{\mathrm{q}}\right), 110.1(\mathrm{CH}), 60.8\left(\mathrm{CH}_{2}\right), 31.4$ $\left(\mathrm{CH}_{3}\right), 26.6\left(\mathrm{CH}_{3}\right), 14.3\left(\mathrm{CH}_{3}\right)$.

IR (ATR): $\tilde{V}=3264,1698,1628,1543,1467,1400,1237,1173,1027,731 \mathrm{~cm}^{-1}$.

MS (EI) $m / z$ (relative intensity): 286 (30) $\left[\mathrm{M}^{+}\right], 219$ (100), 199 (40), 184 (25), 128 (10).

HR-MS (EI) $m / z$ calcd for $\mathrm{C}_{16} \mathrm{H}_{18} \mathrm{~N}_{2} \mathrm{O}_{3}{ }^{+} 286.1317$, found 286.1321 .

\section{Synthesis of $(E)$-ethyl 3-\{1-methyl-2-(methylcarbamoyl)-1H-indol-3-yl\}acrylate (215ba)}

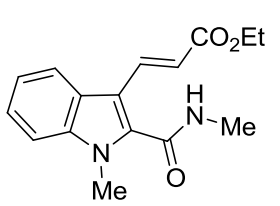

The general procedure D was followed using indole 214b $(94 \mathrm{mg}$, $0.50 \mathrm{mmol})$, ethyl acrylate (76a) $(75 \mathrm{mg}, 0.75 \mathrm{mmol}),\left[\mathrm{RuCl}_{2}(p \text {-cymene })\right]_{2}$ (15.3 mg, $5.0 \mathrm{~mol} \%$ ) and $\mathrm{KPF}_{6}(18.4 \mathrm{mg}, 20 \mathrm{~mol} \%)$. After $20 \mathrm{~h}$, purification by column chromatography on silica gel ( $n$-hexane/EtOAc: 1/1) yielded

215ba (102 $\mathrm{mg}, 71 \%)$ as a white solid.

M.p. $=173-174{ }^{\circ} \mathrm{C}$.

${ }^{1} \mathrm{H}-\mathrm{NMR}\left(300 \mathrm{MHz}, \mathrm{CDCl}_{3}\right): \delta=7.97(\mathrm{~d}, J=16.0 \mathrm{~Hz}, 1 \mathrm{H}), 7.91(\mathrm{~d}, J=8.2 \mathrm{~Hz}, 1 \mathrm{H}), 7.46-7.32$ $(\mathrm{m}, 2 \mathrm{H}), 7.26(\mathrm{dd}, J=8.8,4.0 \mathrm{~Hz}, 1 \mathrm{H}), 6.48(\mathrm{~d}, J=16.0 \mathrm{~Hz}, 1 \mathrm{H}), 6.30\left(\mathrm{~s}_{\mathrm{br}}, 1 \mathrm{H}\right), 4.19(\mathrm{q}, J=$ $7.1 \mathrm{~Hz}, 2 \mathrm{H}), 3.85$ (s, 3H), $3.10(\mathrm{~d}, J=5.1 \mathrm{~Hz}, 3 \mathrm{H}), 1.29$ (t, $J=7.1 \mathrm{~Hz}, 3 \mathrm{H})$.

${ }^{13} \mathrm{C}-\mathrm{NMR}\left(75 \mathrm{MHz}, \mathrm{CDCl}_{3}\right): \delta=167.9\left(\mathrm{C}_{\mathrm{q}}\right), 162.2\left(\mathrm{C}_{\mathrm{q}}\right), 138.1\left(\mathrm{C}_{\mathrm{q}}\right), 136.4\left(\mathrm{C}_{\mathrm{q}}\right), 136.3(\mathrm{CH}), 124.6$

$\left(\mathrm{C}_{\mathrm{q}}\right), 124.5(\mathrm{CH}), 122.0(\mathrm{CH}), 121.4(\mathrm{CH}), 116.1(\mathrm{CH}), 111.3(\mathrm{CH}), 110.4\left(\mathrm{C}_{\mathrm{q}}\right), 60.3\left(\mathrm{CH}_{2}\right), 31.3$ $\left(\mathrm{CH}_{3}\right), 26.9\left(\mathrm{CH}_{3}\right), 14.3\left(\mathrm{CH}_{3}\right)$.

IR (ATR): $\tilde{V}=3271,2981,1709,1623,1547,1469,1368,1131,977,730 \mathrm{~cm}^{-1}$.

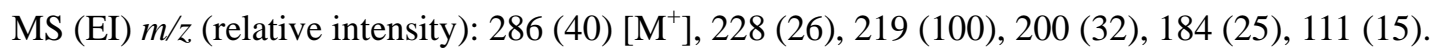

HR-MS (EI) $m / z$ calcd for $\mathrm{C}_{16} \mathrm{H}_{18} \mathrm{~N}_{2} \mathrm{O}_{3}{ }^{+} 286.1317$, found 286.1321 . 
Synthesis of $(E)$-ethyl 3-\{2-(methylcarbamoyl)benzofuran-3-yl\}acrylate (215da)

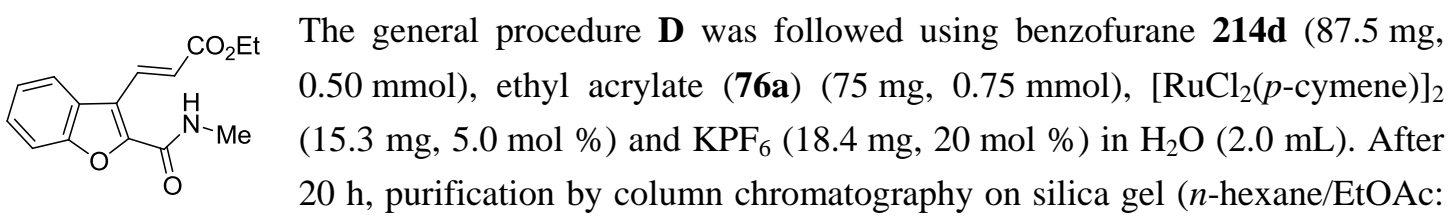

2/1) yielded 215da as a white solid (49 $\mathrm{mg}, 36 \%$ ).

The general procedure D was followed using benzofurane $\mathbf{2 1 4 d}(87.5 \mathrm{mg}, 0.50 \mathrm{mmol}$ ), ethyl acrylate (76a) $(75 \mathrm{mg}, 0.75 \mathrm{mmol}),\left[\mathrm{RuCl}_{2} \text { (p-cymene) }\right]_{2}(15.3 \mathrm{mg}, 5.0 \mathrm{~mol} \%)$ and $\mathrm{KPF}_{6}(18.4 \mathrm{mg}$, $20 \mathrm{~mol} \%)$ in $t$-AmOH $(2.0 \mathrm{~mL})$. After $20 \mathrm{~h}$, purification by column chromatography on silica gel ( $n$-hexane/EtOAc: $2 / 1$ ) yielded 215 da as a white solid (87 $\mathrm{mg}, 64 \%$ ).

M.p. $=141-138^{\circ} \mathrm{C}$.

${ }^{1} \mathrm{H}-\mathrm{NMR}\left(300 \mathrm{MHz}, \mathrm{CDCl}_{3}\right): \delta=8.66(\mathrm{~d}, J=16.0 \mathrm{~Hz}, 1 \mathrm{H}), 7.88(\mathrm{~d}, J=7.9 \mathrm{~Hz}, 1 \mathrm{H}), 7.52-7.30$ $(\mathrm{m}, 3 \mathrm{H}), 6.86\left(\mathrm{~s}_{\mathrm{br}}, 1 \mathrm{H}\right), 6.69(\mathrm{~d}, J=16.0 \mathrm{~Hz}, 1 \mathrm{H}), 4.28(\mathrm{q}, J=7.1 \mathrm{~Hz}, 2 \mathrm{H}), 3.04(\mathrm{~d}, J=5.1 \mathrm{~Hz}$, $3 \mathrm{H}), 1.34(\mathrm{t}, J=7.1 \mathrm{~Hz}, 3 \mathrm{H})$.

${ }^{13} \mathrm{C}-\mathrm{NMR}\left(75 \mathrm{MHz}, \mathrm{CDCl}_{3}\right): \delta=166.5\left(\mathrm{C}_{\mathrm{q}}\right), 159.6\left(\mathrm{C}_{\mathrm{q}}\right), 153.5\left(\mathrm{C}_{\mathrm{q}}\right), 145.5\left(\mathrm{C}_{\mathrm{q}}\right), 124.8(\mathrm{CH}), 127.4$ $(\mathrm{CH}), 125.7\left(\mathrm{C}_{\mathrm{q}}\right), 124.4(\mathrm{CH}), 122.7(\mathrm{CH}), 122.3(\mathrm{CH}), 120.1\left(\mathrm{C}_{\mathrm{q}}\right), 111.9(\mathrm{CH}), 60.6\left(\mathrm{CH}_{2}\right), 26.0$ $\left(\mathrm{CH}_{3}\right), 14.3\left(\mathrm{CH}_{3}\right)$.

IR (ATR): $\tilde{V}=3308,1714,1649,1569,1523,1269,1170,1146,743,692 \mathrm{~cm}^{-1}$.

MS (EI) $m / z$ (relative intensity): 273 (5) $\left[\mathrm{M}^{+}\right], 200$ (100), 187 (9), 111 (10).

HR-MS (EI) $m / z$ calcd for $\mathrm{C}_{15} \mathrm{H}_{15} \mathrm{NO}_{4}{ }^{+} 273.1001$, found 273.0997 .

\section{Synthesis of $(E)$-ethyl 3-\{2-(methylcarbamoyl)thiophen-3-yl\}acrylate (215ea)}

$\mathrm{CO}_{2} \mathrm{Et}$ The general procedure D was followed using thiophene $\mathbf{2 1 4 e}(70.5 \mathrm{mg}$, $0.50 \mathrm{mmol})$, ethyl acrylate (76a) $(75 \mathrm{mg}, 0.75 \mathrm{mmol}), \quad\left[\mathrm{RuCl}_{2}(p \text {-cymene })\right]_{2}$ (15.3 mg, $5.0 \mathrm{~mol} \%$ ) and $\mathrm{KPF}_{6}(18.4 \mathrm{mg}, 20 \mathrm{~mol} \%)$. After $20 \mathrm{~h}$, purification by column chromatography on silica gel ( $n$-hexane/EtOAc: 1/1) yielded 215ea

(92 $\mathrm{mg}, 76 \%)$ as a white solid.

M.p. $=92-93{ }^{\circ} \mathrm{C}$.

${ }^{1} \mathrm{H}-\mathrm{NMR}\left(300 \mathrm{MHz}, \mathrm{CDCl}_{3}\right): \delta=8.25(\mathrm{~d}, J=16.0 \mathrm{~Hz}, 1 \mathrm{H}), 7.31(\mathrm{dd}, J=6.1,5.4 \mathrm{~Hz}, 1 \mathrm{H}), 7.29$ $(\mathrm{dd}, J=6.1,5.4 \mathrm{~Hz}, 1 \mathrm{H}), 6.32(\mathrm{~d}, J=16.0 \mathrm{~Hz}, 1 \mathrm{H}), 5.94(\mathrm{~s}, 1 \mathrm{H}), 4.25(\mathrm{q}, J=7.1 \mathrm{~Hz}, 2 \mathrm{H}), 3.00$ $(\mathrm{d}, J=4.9 \mathrm{~Hz}, 3 \mathrm{H}), 1.32(\mathrm{t}, J=7.1 \mathrm{~Hz}, 3 \mathrm{H})$.

${ }^{13} \mathrm{C}-\mathrm{NMR}\left(75 \mathrm{MHz}, \mathrm{CDCl}_{3}\right): \delta=166.7\left(\mathrm{C}_{\mathrm{q}}\right), 162.2\left(\mathrm{C}_{\mathrm{q}}\right), 138.4\left(\mathrm{C}_{\mathrm{q}}\right), 136.4(\mathrm{CH}), 136.0\left(\mathrm{C}_{\mathrm{q}}\right), 127.0$ $(\mathrm{CH}), 126.7(\mathrm{CH}), 121.4(\mathrm{CH}), 60.6\left(\mathrm{CH}_{2}\right), 27.0\left(\mathrm{CH}_{3}\right), 14.3\left(\mathrm{CH}_{3}\right)$.

IR (ATR): $\tilde{V}=3266,2976,1707,1624,1539,1247,1119,1036,981,613 \mathrm{~cm}^{-1}$.

MS (EI) $m / z$ (relative intensity): 239 (25) $\left[\mathrm{M}^{+}\right], 166$ (76), 152 (100), 137 (23), 125 (22), 97 (25).

HR-MS (EI) $m / z$ calcd for $\mathrm{C}_{11} \mathrm{H}_{13} \mathrm{NO}_{3} \mathrm{~S}^{+} 239.0616$, found 239.0615 .

\section{Synthesis of $(E)$-(n)-butyl 3-\{2-(methylcarbamoyl)thiophen-3-yl $\}$ acrylate (215eb)}

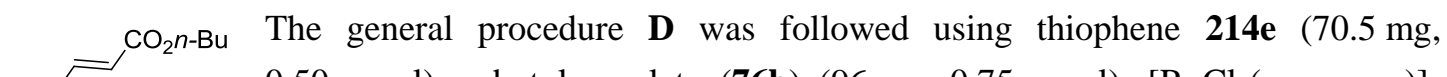
$0.50 \mathrm{mmol}), n$-butyl acrylate (76b) (96 mg, $0.75 \mathrm{mmol}),\left[\mathrm{RuCl}_{2}(p \text {-cymene) }]_{2}\right.$ (15.3 mg, $5.0 \mathrm{~mol} \%$ ) and $\mathrm{KPF}_{6}(18.4 \mathrm{mg}, 20 \mathrm{~mol} \%$ ). After $20 \mathrm{~h}$, purification by column chromatography on silica gel ( $n$-hexane/EtOAc: $2 / 1)$ yielded 215eb

(96 mg, 72\%) as a white solid.

M.p. $=93-94{ }^{\circ} \mathrm{C}$.

${ }^{1} \mathrm{H}-\mathrm{NMR}\left(300 \mathrm{MHz}, \mathrm{CDCl}_{3}\right): \delta=8.18(\mathrm{~d}, J=16.1 \mathrm{~Hz}, 1 \mathrm{H}), 7.26(\mathrm{~d}, J=5.2 \mathrm{~Hz}, 1 \mathrm{H}), 7.22(\mathrm{~d}, J=$ 
$5.2 \mathrm{~Hz}, 1 \mathrm{H}), 6.25(\mathrm{~d}, J=16.1 \mathrm{~Hz}, 1 \mathrm{H}), 6.20\left(\mathrm{~s}_{\mathrm{br}}, 1 \mathrm{H}\right), 4.14(\mathrm{q}, J=6.4 \mathrm{~Hz}, 2 \mathrm{H}), 2.93(\mathrm{~d}, J=5.0 \mathrm{~Hz}$, $1 \mathrm{H}), 1.69-1.57$ (m, 2H), 1.44-1.29 (m, 2H), 0.90 (t, $J=7.3 \mathrm{~Hz}, 3 \mathrm{H})$.

${ }^{13} \mathrm{C}-\mathrm{NMR}\left(75 \mathrm{MHz}, \mathrm{CDCl}_{3}\right): \delta=166.8\left(\mathrm{C}_{\mathrm{q}}\right), 162.6\left(\mathrm{C}_{\mathrm{q}}\right), 138.2\left(\mathrm{C}_{\mathrm{q}}\right), 136.4(\mathrm{CH}), 126.9(\mathrm{CH})$, $126.5(\mathrm{CH}), 121.0(\mathrm{CH}), 109.1\left(\mathrm{C}_{\mathrm{q}}\right), 64.3\left(\mathrm{CH}_{2}\right), 30.7\left(\mathrm{CH}_{2}\right), 26.9\left(\mathrm{CH}_{3}\right), 18.8\left(\mathrm{CH}_{2}\right), 13.7\left(\mathrm{CH}_{3}\right)$. IR (ATR): $\tilde{V}=3272,2952,1706,1625,1541,1270,1227,1066,987,737 \mathrm{~cm}^{-1}$.

MS (EI) $\mathrm{m} / z$ (relative intensity): 267 (25) [ $\left.\mathrm{M}^{+}\right], 208$ (10), 166 (100), 152 (16).

HR-MS (EI) $\mathrm{m} / z$ calcd for $\mathrm{C}_{13} \mathrm{H}_{17} \mathrm{NO}_{3} \mathrm{~S}^{+} 267.0929$, found 267.0922 .

\section{Intramolecular competition experiments with amide 214f (Scheme 81)}

A mixture of thiophene $214 \mathrm{f}(70.5 \mathrm{mg}, 0.50 \mathrm{mmol})$, ethyl acrylate (76a) $(75 \mathrm{mg}, 0.75 \mathrm{mmol}$ ), $\left[\mathrm{RuCl}_{2}(p \text {-cymene })\right]_{2}(15.3 \mathrm{mg}, 5.0 \mathrm{~mol} \%), \mathrm{KPF}_{6}(18.4 \mathrm{mg}, 20 \mathrm{~mol} \%)$ and $\mathrm{Cu}(\mathrm{OAc})_{2} \cdot \mathrm{H}_{2} \mathrm{O}$ (99.5 mg, $1.00 \mathrm{mmol})$ in $\mathrm{H}_{2} \mathrm{O}(2.0 \mathrm{~mL})$ was stirred under $\mathrm{N}_{2}$ for $20 \mathrm{~h}$ at $120{ }^{\circ} \mathrm{C}$. At ambient temperature, the mixture was diluted with $\mathrm{H}_{2} \mathrm{O}(75 \mathrm{~mL})$ and extracted with EtOAc $(3 \times 75 \mathrm{~mL})$. The combined organic phase was washed with brine $(50 \mathrm{~mL})$ and dried over anhydrous $\mathrm{Na}_{2} \mathrm{SO}_{4}$. After filtration and evaporation of the solvents under reduced pressure, the crude product was purified by column chromatography on silica gel ( $n$-hexane/EtOAc: $1 / 1)$ to yield a mixture of 215fa and 215' fa (59 mg, 49\%, 12:1 mixture of regioisomers according to ${ }^{1} \mathrm{H}-\mathrm{NMR}$ ) as a white solid. Recrystallization ( $n$-hexane/ $\mathrm{CH}_{2} \mathrm{Cl}_{2}: 2 / 1$ ) gave the major regioisomer $\mathbf{2 1 5 f a ~ ( 4 4 ~} \mathrm{mg}, 37 \%$ ) as a white solid.

\section{(E)-Ethyl 3-\{3-(methylcarbamoyl)thiophen-2-yl\}acrylate (215fa)}

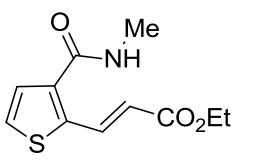

M.p. $=128-129^{\circ} \mathrm{C}$.

${ }^{1} \mathrm{H}-\mathrm{NMR}\left(300 \mathrm{MHz}, \mathrm{CDCl}_{3}\right): \delta=8.32(\mathrm{~d}, J=15.9 \mathrm{~Hz}, 1 \mathrm{H}), 7.25(\mathrm{~d}, J=5.1 \mathrm{~Hz}$, $1 \mathrm{H}), 7.14(\mathrm{~d}, J=5.1 \mathrm{~Hz}, 1 \mathrm{H}), 6.26(\mathrm{~d}, J=15.9 \mathrm{~Hz}, 1 \mathrm{H}), 6.03(\mathrm{sbr}, 1 \mathrm{H}), 4.21(\mathrm{q}$, $J=7.1 \mathrm{~Hz}, 2 \mathrm{H}), 2.96(\mathrm{~d}, J=4.5 \mathrm{~Hz}, 3 \mathrm{H}), 1.29(\mathrm{t}, J=7.1 \mathrm{~Hz}, 3 \mathrm{H})$.

${ }^{13} \mathrm{C}-\mathrm{NMR}\left(75 \mathrm{MHz}, \mathrm{CDCl}_{3}\right): \delta=166.2\left(\mathrm{C}_{\mathrm{q}}\right), 164.3\left(\mathrm{C}_{\mathrm{q}}\right), 141.0\left(\mathrm{C}_{\mathrm{q}}\right), 137.3\left(\mathrm{C}_{\mathrm{q}}\right), 135.4(\mathrm{CH}), 127.6$ $(\mathrm{CH}), 126.9(\mathrm{CH}), 120.0(\mathrm{CH}), 60.6\left(\mathrm{CH}_{2}\right), 26.7\left(\mathrm{CH}_{3}\right), 14.3\left(\mathrm{CH}_{3}\right)$.

IR (ATR): $\tilde{V}=3381,3103,1712,1626,1549,1436,1296,1252,982,719 \mathrm{~cm}^{-1}$.

MS (EI) $m / z$ (relative intensity): 239 (13) $\left[\mathrm{M}^{+}\right], 166$ (100), 152 (20), 137 (20) 109 (10).

HR-MS (EI) $\mathrm{m} / z$ calcd for $\mathrm{C}_{11} \mathrm{H}_{13} \mathrm{NO}_{3} \mathrm{~S}^{+} 239.0616$, found 239.0611 .

\subsubsection{Analytical Data for the Products of Ruthenium-Catalyzed C(sp $\left.{ }^{3}\right)-H$ $\alpha$-Alkylation of Pyrrolidine 209 with Alkene 111}

\section{Synthesis of 2-(2-n-decylpyrrolidin-1-yl)-3-methylpyridine (217ba)}

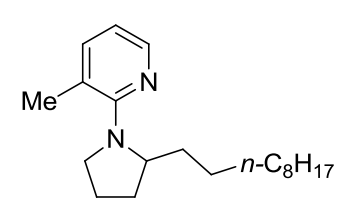

The general procedure $\mathbf{E}$ was followed using 3-methyl-2-(pyrrolidin-1-yl)pyridine (216b) (243 $\mathrm{mg}, 1.5 \mathrm{mmol}$ ) and 1-decene (111a) (70.1 mg, $0.5 \mathrm{mmol})$. After $18 \mathrm{~h}$, purification by column chromatography on silica gel ( $n$-hexane/EtOAc: $40 / 1 \rightarrow 30 / 1)$ yielded 217ba (138 $\mathrm{mg}, 94 \%$ ) as a colorless oil.

${ }^{1} \mathrm{H}-\mathrm{NMR}\left(300 \mathrm{MHz}, \mathrm{CDCl}_{3}\right): \delta=8.06(\mathrm{dd}, J=5.0,2.0 \mathrm{~Hz}, 1 \mathrm{H}), 7.30-7.27(\mathrm{~m}, 1 \mathrm{H}), 6.65(\mathrm{dd}, J=$ 7.1, 5.0 Hz, 1H), 4.28-4.20 (m, 1H), 3.70-3.62 (m, 1H), 3.23-3.11 (m, 1H), $2.23(\mathrm{~s}, 3 \mathrm{H}), 2.19-$ $2.09(\mathrm{~m}, 1 \mathrm{H}), 1.95-1.54(\mathrm{~m}, 4 \mathrm{H}), 1.29-1.17(\mathrm{~m}, 17 \mathrm{H}), 0.89-0.85(\mathrm{~m}, 3 \mathrm{H})$.

${ }^{13} \mathrm{C}-\mathrm{NMR}\left(75 \mathrm{MHz}, \mathrm{CDCl}_{3}\right): \delta=159.6\left(\mathrm{C}_{\mathrm{q}}\right), 144.6(\mathrm{CH}), 139.1(\mathrm{CH}), 121.9\left(\mathrm{C}_{\mathrm{q}}\right), 114.6(\mathrm{CH})$, 58.2 $(\mathrm{CH}), 51.7\left(\mathrm{CH}_{2}\right), 34.2\left(\mathrm{CH}_{2}\right), 31.9\left(\mathrm{CH}_{2}\right), 31.2\left(\mathrm{CH}_{2}\right), 29.9\left(\mathrm{CH}_{2}\right), 29.6\left(\mathrm{CH}_{2}\right), 29.6\left(\mathrm{CH}_{2}\right)$, 
$29.6\left(\mathrm{CH}_{2}\right), 29.3\left(\mathrm{CH}_{2}\right), 25.9\left(\mathrm{CH}_{2}\right), 24.9\left(\mathrm{CH}_{2}\right), 22.7\left(\mathrm{CH}_{2}\right), 20.1\left(\mathrm{CH}_{3}\right), 14.1\left(\mathrm{CH}_{3}\right)$.

IR (ATR): $\tilde{V}=2922,2853,1588,1564,1384,1346,1186,993,775 \mathrm{~cm}^{-1}$.

MS (EI) m/z (relative intensity): 302 (5) $\left[\mathrm{M}^{+}\right], 287$ (3), 208 (5), 161 (100), 133 (10), 107 (9), 92 (14), 43 (10).

HR-MS (EI) $m / z$ calcd for $\mathrm{C}_{20} \mathrm{H}_{34} \mathrm{~N}_{2}{ }^{+} 302.2722$, found 302.2724.

\section{Synthesis of 2-(2-n-decylpyrrolidin-1-yl)-3-(trifluoromethyl)pyridine (217ca)}

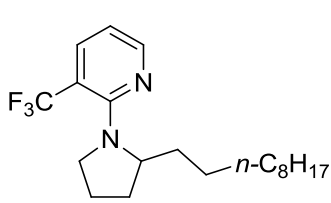

The general procedure $\mathbf{E}$ was followed using 2-(pyrrolidin-1-yl)-3-(trifluoromethyl)pyridine (216c) (324 mg, $1.5 \mathrm{mmol}$ ) and 1-decene (2a) (70.1 $\mathrm{mg}, 0.5 \mathrm{mmol})$. After $18 \mathrm{~h}$, purification by column chromatography on silica gel ( $n$-hexane/EtOAc: 100/1) yielded

217ca (128 mg, 72\%) as a colorless oil.

${ }^{1} \mathrm{H}-\mathrm{NMR}\left(300 \mathrm{MHz}, \mathrm{CDCl}_{3}\right): \delta=8.25(\mathrm{dd}, J=4.9,1.8 \mathrm{~Hz}, 1 \mathrm{H}), 7.75(\mathrm{~d}, J=7.4 \mathrm{~Hz}, 1 \mathrm{H}), 6.61(\mathrm{dd}$, $J=7.4,4.9 \mathrm{~Hz}, 1 \mathrm{H}), 4.47-4.36(\mathrm{~m}, 1 \mathrm{H}), 3.65-3.53(\mathrm{~m}, 1 \mathrm{H}), 3.41-3.31(\mathrm{~m}, 1 \mathrm{H}), 2.14-2.04(\mathrm{~m}$, $1 \mathrm{H}), 1.97-1.87(\mathrm{~m}, 1 \mathrm{H}), 1.82-1.56(\mathrm{~m}, 3 \mathrm{H}), 1.35-1.16(\mathrm{~m}, 17 \mathrm{H}), 0.85(\mathrm{t}, J=6.6 \mathrm{~Hz}, 3 \mathrm{H})$.

${ }^{13} \mathrm{C}-\mathrm{NMR}\left(75 \mathrm{MHz}, \mathrm{CDCl}_{3}\right): \delta=155.7\left(\mathrm{C}_{\mathrm{q}}\right), 150.4(\mathrm{CH}), 137.0\left(\mathrm{q},{ }^{3} J_{\mathrm{C}-\mathrm{F}}=6 \mathrm{~Hz}, \mathrm{CH}\right), 124.6(\mathrm{q}$, $\left.{ }^{1} J_{\mathrm{C}-\mathrm{F}}=272 \mathrm{~Hz}, \mathrm{C}_{\mathrm{q}}\right), 111.8(\mathrm{CH}), 110.7\left(\mathrm{q},{ }^{2} J_{\mathrm{C}-\mathrm{F}}=32 \mathrm{~Hz}, \mathrm{C}_{\mathrm{q}}\right), 58.9(\mathrm{CH}), 51.6\left(\mathrm{q}, J_{\mathrm{C}-\mathrm{F}}=5 \mathrm{~Hz}\right.$, $\left.\mathrm{CH}_{2}\right), 33.6\left(\mathrm{CH}_{2}\right), 31.9\left(\mathrm{CH}_{2}\right), 30.5\left(\mathrm{CH}_{2}\right), 29.8\left(\mathrm{CH}_{2}\right), 29.6\left(\mathrm{CH}_{2}\right), 29.6\left(\mathrm{CH}_{2}\right), 29.6\left(\mathrm{CH}_{2}\right), 29.3$ $\left(\mathrm{CH}_{2}\right), 25.6\left(\mathrm{CH}_{2}\right), 25.5\left(\mathrm{CH}_{2}\right), 22.7\left(\mathrm{CH}_{2}\right), 14.1\left(\mathrm{CH}_{3}\right)$.

${ }^{19} \mathrm{~F}-\mathrm{NMR}\left(283 \mathrm{MHz}, \mathrm{CDCl}_{3}\right): \delta=-56.6(\mathrm{~s})$. IR (ATR): $\tilde{V}=2923,2854,1596,1556,1449,1369,1302,1097,1019,767 \mathrm{~cm}^{-1}$. MS (EI) $m / z$ (relative intensity): $356(4)\left[\mathrm{M}^{+}\right], 213$ (100), 175 (4), $146(5)$.

HR-MS (EI) $m / z$ calcd for $\mathrm{C}_{20} \mathrm{H}_{31} \mathrm{~F}_{3} \mathrm{~N}_{2}{ }^{+} 356.2439$, found 356.2432.

\section{Synthesis of 3-methyl-2-(2-n-nonylpyrrolidin-1-yl)pyridine (217da)}

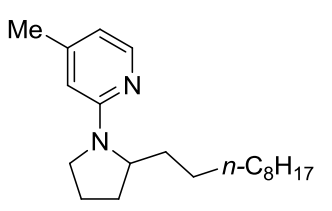

The general procedure $\mathbf{E}$ was followed using 4-methyl-2-(pyrrolidin-1-yl)pyridine (216d) (243 $\mathrm{mg}, 1.5 \mathrm{mmol})$ and 1-decene (111a) $(70.1 \mathrm{mg}, 0.5 \mathrm{mmol})$. After $18 \mathrm{~h}$, purification by column chromatography on silica gel ( $n$-hexane/EtOAc: $20 / 1 \rightarrow 10 / 1)$ yielded 217da (97 $\mathrm{mg}, 64 \%)$ as a colorless oil.

${ }^{1} \mathrm{H}-\mathrm{NMR}\left(300 \mathrm{MHz}, \mathrm{CDCl}_{3}\right): \delta=7.99(\mathrm{~d}, J=5.2 \mathrm{~Hz}, 1 \mathrm{H}), 6.32(\mathrm{dd}, J=5.2,1.2 \mathrm{~Hz}, 1 \mathrm{H}), 6.12(\mathrm{~s}$, $1 \mathrm{H}), 3.93-3.82(\mathrm{~m}, 1 \mathrm{H}), 3.56-3.46(\mathrm{~m}, 1 \mathrm{H}), 3.41-3.29(\mathrm{~m}, 1 \mathrm{H}), 2.22(\mathrm{~s}, 3 \mathrm{H}), 2.04-1.65(\mathrm{~m}, 5 \mathrm{H})$, $1.38-1.12(\mathrm{~m}, 17 \mathrm{H}), 0.86(\mathrm{t}, J=6.6 \mathrm{~Hz}, 3 \mathrm{H})$.

${ }^{13} \mathrm{C}-\mathrm{NMR}\left(75 \mathrm{MHz}, \mathrm{CDCl}_{3}\right): \delta=157.4\left(\mathrm{C}_{\mathrm{q}}\right), 147.9(\mathrm{CH}), 147.4\left(\mathrm{C}_{\mathrm{q}}\right), 112.5(\mathrm{CH}), 106.8(\mathrm{CH})$, 57.6 (CH), $47.4\left(\mathrm{CH}_{2}\right), 33.0\left(\mathrm{CH}_{2}\right), 31.9\left(\mathrm{CH}_{2}\right), 30.1\left(\mathrm{CH}_{2}\right), 29.8\left(\mathrm{CH}_{2}\right), 29.7\left(\mathrm{CH}_{2}\right), 29.6\left(\mathrm{CH}_{2}\right)$, $29.6\left(\mathrm{CH}_{2}\right), 29.3\left(\mathrm{CH}_{2}\right), 26.4\left(\mathrm{CH}_{2}\right), 23.4\left(\mathrm{CH}_{2}\right), 22.7\left(\mathrm{CH}_{2}\right), 21.3\left(\mathrm{CH}_{3}\right), 14.1\left(\mathrm{CH}_{3}\right)$.

IR (ATR): $\tilde{V}=2921,2852,1708,1604,1553,1453,1297,1176,792,447 \mathrm{~cm}^{-1}$. MS (EI) $m / z$ (relative intensity): $302(5)\left[\mathrm{M}^{+}\right], 161$ (100), 133 (7), 92 (9), 41 (7).

HR-MS (EI) $\mathrm{m} / z$ calcd for $\mathrm{C}_{20} \mathrm{H}_{34} \mathrm{~N}_{2}{ }^{+} 302.2722$, found 302.2722 .

\section{Synthesis of 2-(2-n-decylpyrrolidin-1-yl)-5-fluoropyridine (217ea)}

The general procedure $\mathbf{E}$ was followed using 5-fluoro-2-(pyrrolidin-1-yl)pyridine (216e) (249 mg, $1.5 \mathrm{mmol}$ ) and 1-decene (111a) (70.1 mg, $0.5 \mathrm{mmol})$. After $18 \mathrm{~h}$, purification by column chromatography on silica gel ( $n$-hexane/EtOAc: 40/1) yielded 217ea (116 mg, 
$76 \%)$ as a colorless oil.

${ }^{1} \mathrm{H}-\mathrm{NMR}\left(300 \mathrm{MHz}, \mathrm{CDCl}_{3}\right): \delta=7.99(\mathrm{~d}, J=3.0 \mathrm{~Hz}, 1 \mathrm{H}), 7.17$ (ddd, $\left.J=8.8,3.0,1.1 \mathrm{~Hz}, 1 \mathrm{H}\right)$, $6.24(\mathrm{dd}, J=8.8,3.0 \mathrm{~Hz}, 1 \mathrm{H}), 3.87-3.78(\mathrm{~m}, 1 \mathrm{H}), 3.52-3.43(\mathrm{~m}, 1 \mathrm{H}), 3.35-3.25(\mathrm{~m}, 1 \mathrm{H})$, $2.04-1.65(\mathrm{~m}, 5 \mathrm{H}), 1.34-1.16(\mathrm{~m}, 17 \mathrm{H}), 0.86(\mathrm{t}, J=6.6 \mathrm{~Hz}, 3 \mathrm{H})$.

${ }^{13} \mathrm{C}-\mathrm{NMR}\left(75 \mathrm{MHz}, \mathrm{CDCl}_{3}\right): \delta=154.1\left(\mathrm{C}_{\mathrm{q}}\right), 152.4\left(\mathrm{~d},{ }^{1} J_{\mathrm{C}-\mathrm{F}}=240 \mathrm{~Hz}, \mathrm{C}_{\mathrm{q}}\right), 134.6\left(\mathrm{~d},{ }^{2} J_{\mathrm{C}-\mathrm{F}}=24 \mathrm{~Hz}\right.$, $\mathrm{CH}), 124.6\left(\mathrm{~d},{ }^{2} J_{\mathrm{C}-\mathrm{F}}=20 \mathrm{~Hz}, \mathrm{CH}\right), 106.4\left(\mathrm{~d},{ }^{3} J_{\mathrm{C}-\mathrm{F}}=4 \mathrm{~Hz}, \mathrm{CH}\right), 58.2(\mathrm{CH}), 47.4\left(\mathrm{CH}_{2}\right), 33.1\left(\mathrm{CH}_{2}\right)$, $31.9\left(\mathrm{CH}_{2}\right), 30.2\left(\mathrm{CH}_{2}\right), 29.8\left(\mathrm{CH}_{2}\right), 29.7\left(\mathrm{CH}_{2}\right), 29.6\left(\mathrm{CH}_{2}\right), 29.6\left(\mathrm{CH}_{2}\right), 29.3\left(\mathrm{CH}_{2}\right), 26.5\left(\mathrm{CH}_{2}\right)$, $23.5\left(\mathrm{CH}_{2}\right), 22.7\left(\mathrm{CH}_{2}\right), 14.1\left(\mathrm{CH}_{3}\right)$.

${ }^{19} \mathrm{~F}-\mathrm{NMR}\left(283 \mathrm{MHz}, \mathrm{CDCl}_{3}\right): \delta=-(146.91-146.95)(\mathrm{m})$.

IR (ATR): $\tilde{V}=2922,2852,1613,1492,1407,1224,762 \mathrm{~cm}^{-1}$.

MS (EI) $\mathrm{m} / z$ (relative intensity): $306(22)\left[\mathrm{M}^{+}\right], 305(100)\left[(\mathrm{M}-\mathrm{H})^{+}\right], 165$ (18).

HR-MS (EI) $m / z$ calcd for $\mathrm{C}_{19} \mathrm{H}_{31} \mathrm{FN}_{2}{ }^{+} 306.2471$, found 306.2387.

\section{Synthesis of 1-(2-n-decylpyrrolidin-1-yl)isoquinoline (217ga)}

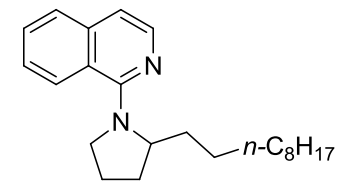

The general procedure $\mathbf{E}$ was followed using 1-(pyrrolidin-1-yl)isoquinoline (216g) $(297 \mathrm{mg}, 1.5 \mathrm{mmol})$ and 1-decene (111a) $(70.1 \mathrm{mg}, 0.5 \mathrm{mmol})$. After $18 \mathrm{~h}$, purification by column chromatography on silica gel ( $n$-hexane/EtOAc: 40/1) yielded 217ga (113

$\mathrm{mg}, 67 \%)$ as a colorless oil.

${ }^{1} \mathrm{H}-\mathrm{NMR}\left(300 \mathrm{MHz}, \mathrm{CDCl}_{3}\right): \delta=8.10(\mathrm{~d}, J=8.6 \mathrm{~Hz}, 1 \mathrm{H}), 8.03(\mathrm{~d}, J=5.7 \mathrm{~Hz}, 1 \mathrm{H}), 7.65(\mathrm{~d}, J=$ $8.2 \mathrm{~Hz}, 1 \mathrm{H}), 7.52(\mathrm{ddd}, J=8.2,8.2,1.2 \mathrm{~Hz}, 1 \mathrm{H}), 7.38$ (ddd, $J=8.6,8.2,1.2 \mathrm{~Hz}, 1 \mathrm{H}), 7.01(\mathrm{~d}, J=$ $5.7 \mathrm{~Hz}, 1 \mathrm{H}), 4.61-4.50(\mathrm{~m}, 1 \mathrm{H}), 4.02-3.92(\mathrm{~m}, 1 \mathrm{H}), 3.65-3.56(\mathrm{~m}, 1 \mathrm{H}), 2.26-2.13(\mathrm{~m}, 1 \mathrm{H})$, 1.99-1.81 (m, 2H), 1.81-1.61 (m, 2H), 1.43-1.16 (m, 17H), $0.87(\mathrm{t}, J=6.7 \mathrm{~Hz}, 3 \mathrm{H})$.

${ }^{13} \mathrm{C}-\mathrm{NMR}\left(75 \mathrm{MHz}, \mathrm{CDCl}_{3}\right): \delta=158.8\left(\mathrm{C}_{\mathrm{q}}\right), 140.9(\mathrm{CH}), 138.6\left(\mathrm{C}_{\mathrm{q}}\right), 129.0(\mathrm{CH}), 126.5(\mathrm{CH})$, $126.3(\mathrm{CH}), 124.4(\mathrm{CH}), 121.4\left(\mathrm{C}_{\mathrm{q}}\right), 112.4(\mathrm{CH}), 58.9(\mathrm{CH}), 54.8\left(\mathrm{CH}_{2}\right), 34.0\left(\mathrm{CH}_{2}\right), 31.9\left(\mathrm{CH}_{2}\right)$, $31.2\left(\mathrm{CH}_{2}\right), 29.9\left(\mathrm{CH}_{2}\right), 29.6\left(\mathrm{CH}_{2}\right), 29.6\left(\mathrm{CH}_{2}\right), 29.6\left(\mathrm{CH}_{2}\right), 29.3\left(\mathrm{CH}_{2}\right), 25.9\left(\mathrm{CH}_{2}\right), 25.9\left(\mathrm{CH}_{2}\right)$, $22.7\left(\mathrm{CH}_{2}\right), 14.1\left(\mathrm{CH}_{3}\right)$.

IR (ATR): $\tilde{V}=2921,2852,1585,1551,1503,1408,1346,761,743,681 \mathrm{~cm}^{-1}$.

MS (EI) m/z (relative intensity): 338 (14) [M+], 255 (7), 225 (6), 197 (100), 183 (15), 169 (22), 143 (33), 128 (27).

HR-MS (EI) $\mathrm{m} / z$ calcd for $\mathrm{C}_{23} \mathrm{H}_{34} \mathrm{~N}_{2}{ }^{+} 338.2722$, found 338.2730 .

\section{Synthesis of 2-(2-n-hexylpyrrolidin-1-yl)-3-methylpyridine (217bb)}

The general procedure $\mathbf{E}$ was followed using 3-methyl-2-(pyrrolidin-1-yl)pyridine (216b) (243 $\mathrm{mg}, 1.5 \mathrm{mmol}$ ) and 1-hexene (111b) $(38.0 \mathrm{mg}, 0.5 \mathrm{mmol})$ at $80{ }^{\circ} \mathrm{C}$. After $18 \mathrm{~h}$, purification by column chromatography on silica gel ( $n$-hexane/EtOAc: $40 / 1)$ yielded 217bb (90 $\mathrm{mg}, 73 \%$ ) as a colorless oil.

${ }^{1} \mathrm{H}-\mathrm{NMR}\left(300 \mathrm{MHz}, \mathrm{CDCl}_{3}\right): \delta=8.04(\mathrm{dd}, J=5.0,1.8 \mathrm{~Hz}, 1 \mathrm{H}), 7.26(\mathrm{dd}, J=7.4,1.8 \mathrm{~Hz}, 1 \mathrm{H})$, $6.62(\mathrm{dd}, J=7.4,5.0 \mathrm{~Hz}, 1 \mathrm{H}), 4.29-4.16(\mathrm{~m}, 1 \mathrm{H}), 3.70-3.58(\mathrm{~m}, 1 \mathrm{H}), 3.21-3.09(\mathrm{~m}, 1 \mathrm{H}), 2.20(\mathrm{~s}$, $3 \mathrm{H}), 2.17-2.05(\mathrm{~m}, 1 \mathrm{H}), 1.93-1.52(\mathrm{~m}, 4 \mathrm{H}), 1.29-1.14(\mathrm{~m}, 9 \mathrm{H}), 0.83(\mathrm{t}, J=6.3 \mathrm{~Hz}, 3 \mathrm{H})$.

${ }^{13} \mathrm{C}-\mathrm{NMR}\left(75 \mathrm{MHz}, \mathrm{CDCl}_{3}\right): \delta=159.7\left(\mathrm{C}_{\mathrm{q}}\right), 144.7(\mathrm{CH}), 138.9(\mathrm{CH}), 121.9\left(\mathrm{C}_{\mathrm{q}}\right), 114.7(\mathrm{CH})$, $58.1(\mathrm{CH}), 51.7\left(\mathrm{CH}_{2}\right), 34.3\left(\mathrm{CH}_{2}\right), 31.9\left(\mathrm{CH}_{2}\right), 31.2\left(\mathrm{CH}_{2}\right), 29.6\left(\mathrm{CH}_{2}\right), 25.9\left(\mathrm{CH}_{2}\right), 24.9\left(\mathrm{CH}_{2}\right)$, $22.6\left(\mathrm{CH}_{2}\right), 20.0\left(\mathrm{CH}_{3}\right), 14.1\left(\mathrm{CH}_{3}\right)$.

IR (ATR): $\tilde{V}=2922,2856,1588,1563,1383,1345,975,774 \mathrm{~cm}^{-1}$. MS (EI) $\mathrm{m} / z$ (relative 
intensity): 246 (7) [ $\left.\mathrm{M}^{+}\right], 161$ (100), 154 (8), 133 (12), 92 (17).

HR-MS (EI) $m / z$ calcd for $\mathrm{C}_{16} \mathrm{H}_{26} \mathrm{~N}_{2}{ }^{+} 246.2076$, found 226.2068 .

\section{Synthesis of 2-(2-n-heptylpyrrolidin-1-yl)-3-methylpyridine (217bc)}

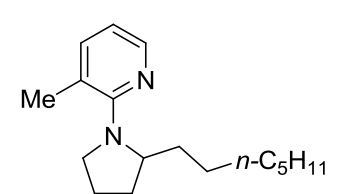

The general procedure $\mathbf{E}$ was followed using 3-methyl-2-(pyrrolidin-1-yl)pyridine (216b) (243 $\mathrm{mg}, 1.5 \mathrm{mmol}$ ) and 1-heptene (111c) $(49.0 \mathrm{mg}, 0.5 \mathrm{mmol})$ at $80{ }^{\circ} \mathrm{C}$. After $18 \mathrm{~h}$, purification by column chromatography on silica gel ( $n$-hexane/EtOAc: $40 / 1)$ yielded

217bc (103 mg, 78\%) as a colorless oil.

${ }^{1} \mathrm{H}-\mathrm{NMR}\left(300 \mathrm{MHz}, \mathrm{CDCl}_{3}\right): \delta=8.04(\mathrm{dd}, J=4.9,1.8 \mathrm{~Hz}, 1 \mathrm{H}), 7.26(\mathrm{dd}, J=7.4,1.8 \mathrm{~Hz}, 1 \mathrm{H})$, $6.62(\mathrm{dd}, J=7.4,4.9 \mathrm{~Hz}, 1 \mathrm{H}), 4.28-4.15(\mathrm{~m}, 1 \mathrm{H}), 3.70-3.57(\mathrm{~m}, 1 \mathrm{H}), 3.21-3.09$ (m, 1H), $2.21(\mathrm{~s}$, $3 \mathrm{H}), 2.17-2.05(\mathrm{~m}, 1 \mathrm{H}), 1.95-1.52(\mathrm{~m}, 5 \mathrm{H}), 1.35-1.11(\mathrm{~m}, 10 \mathrm{H}), 0.84(\mathrm{t}, J=6.1 \mathrm{~Hz}, 3 \mathrm{H})$.

${ }^{13} \mathrm{C}-\mathrm{NMR}\left(75 \mathrm{MHz}, \mathrm{CDCl}_{3}\right): \delta=159.7\left(\mathrm{C}_{\mathrm{q}}\right), 144.7(\mathrm{CH}), 138.9(\mathrm{CH}), 121.8\left(\mathrm{C}_{\mathrm{q}}\right), 114.7(\mathrm{CH})$, $58.1(\mathrm{CH}), 51.7\left(\mathrm{CH}_{2}\right), 34.2\left(\mathrm{CH}_{2}\right), 31.8\left(\mathrm{CH}_{2}\right), 31.2\left(\mathrm{CH}_{2}\right), 29.8\left(\mathrm{CH}_{2}\right), 29.3\left(\mathrm{CH}_{2}\right), 25.9\left(\mathrm{CH}_{2}\right)$, $24.9\left(\mathrm{CH}_{2}\right), 22.6\left(\mathrm{CH}_{2}\right), 20.0\left(\mathrm{CH}_{3}\right), 14.1\left(\mathrm{CH}_{3}\right)$.

IR (ATR): $\tilde{V}=2922,2854,1588,1564,1383,1346,774 \mathrm{~cm}^{-1}$.

MS (EI) $m / z$ (relative intensity): $260(5)\left[\mathrm{M}^{+}\right], 168$ (5), 161 (100), 133 (10), 92 (16).

HR-MS (EI) $m / z$ calcd for $\mathrm{C}_{17} \mathrm{H}_{28} \mathrm{~N}_{2}{ }^{+} 260.2252$, found 260.2244 .

\section{Synthesis of 3-methyl-2-(2-n-octylpyrrolidin-1-yl)pyridine (217bd)}

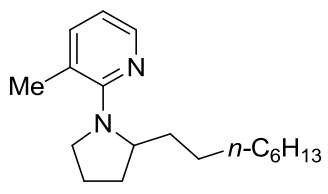

The general procedure $\mathbf{E}$ was followed using 3-methyl-2-(pyrrolidin-1-yl)pyridine (216b) (243 $\mathrm{mg}, 1.5 \mathrm{mmol}$ ) and 1-octene (111d) $(56.1 \mathrm{mg}, 0.5 \mathrm{mmol})$. After $18 \mathrm{~h}$, purification by column chromatography on silica gel $(n$-hexane/EtOAc: $40 / 1 \rightarrow 30 / 1)$ yielded

217bd (123 $\mathrm{mg}, 90 \%$ ) as a colorless oil.

${ }^{1} \mathrm{H}-\mathrm{NMR}\left(300 \mathrm{MHz}, \mathrm{CDCl}_{3}\right): \delta=8.04(\mathrm{dd}, J=4.9,1.8 \mathrm{~Hz}, 1 \mathrm{H}), 7.26(\mathrm{dd}, J=7.4,1.8 \mathrm{~Hz}, 1 \mathrm{H})$, $6.62(\mathrm{dd}, J=7.4,4.9 \mathrm{~Hz}, 1 \mathrm{H}), 4.28-4.16(\mathrm{~m}, 1 \mathrm{H}), 3.69-3.58(\mathrm{~m}, 1 \mathrm{H}), 3.20-3.10(\mathrm{~m}, 1 \mathrm{H}), 2.20(\mathrm{~s}$, $3 \mathrm{H}), 2.17-2.06(\mathrm{~m}, 1 \mathrm{H}), 1.95-1.50(\mathrm{~m}, 5 \mathrm{H}), 1.34-1.11(\mathrm{~m}, 12 \mathrm{H}), 0.84(\mathrm{t}, J=6.1 \mathrm{~Hz}, 3 \mathrm{H})$.

${ }^{13} \mathrm{C}-\mathrm{NMR}\left(75 \mathrm{MHz}, \mathrm{CDCl}_{3}\right): \delta=159.7\left(\mathrm{C}_{\mathrm{q}}\right), 144.7(\mathrm{CH}), 138.9(\mathrm{CH}), 121.8\left(\mathrm{C}_{\mathrm{q}}\right), 114.7(\mathrm{CH})$, $58.1(\mathrm{CH}), 51.7\left(\mathrm{CH}_{2}\right), 34.2\left(\mathrm{CH}_{2}\right), 31.9\left(\mathrm{CH}_{2}\right), 31.2\left(\mathrm{CH}_{2}\right), 29.9\left(\mathrm{CH}_{2}\right), 29.6\left(\mathrm{CH}_{2}\right), 29.2\left(\mathrm{CH}_{2}\right)$, $25.9\left(\mathrm{CH}_{2}\right), 24.9\left(\mathrm{CH}_{2}\right), 22.6\left(\mathrm{CH}_{2}\right), 20.0\left(\mathrm{CH}_{3}\right), 14.1\left(\mathrm{CH}_{3}\right)$.

IR (ATR): $\tilde{V}=2921,2853,1588,1383,1346,775 \mathrm{~cm}^{-1}$.

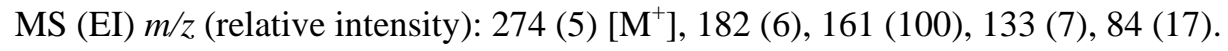

HR-MS (EI) $m / z$ calcd for $\mathrm{C}_{18} \mathrm{H}_{30} \mathrm{~N}_{2}{ }^{+} 274.2409$, found 274.2405 .

\section{Synthesis of 3-methyl-2-(2-n-nonylpyrrolidin-1-yl)pyridine (217be)}

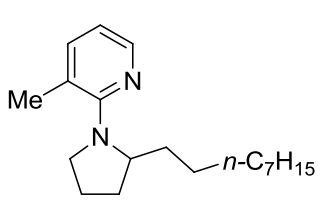

The general procedure $\mathbf{E}$ was followed using 3-methyl-2-(pyrrolidin-1-yl)pyridine (216b) (243 mg, $1.5 \mathrm{mmol}$ ) and 1-nonene (111e) $(63.0 \mathrm{mg}, 0.5 \mathrm{mmol})$. After $18 \mathrm{~h}$, purification by column chromatography on silica gel ( $n$-hexane/EtOAc: $40 / 1 \rightarrow 30 / 1)$ yielded 217be (129 mg, 89\%) as a colorless oil.

${ }^{1} \mathrm{H}-\mathrm{NMR}\left(300 \mathrm{MHz}, \mathrm{CDCl}_{3}\right): \delta=8.04(\mathrm{dd}, J=4.9,1.8 \mathrm{~Hz}, 1 \mathrm{H}), 7.26(\mathrm{dd}, J=7.4,1.8 \mathrm{~Hz}, 1 \mathrm{H})$, $6.62(\mathrm{dd}, J=7.4,4.9 \mathrm{~Hz}, 1 \mathrm{H}), 4.28-4.15(\mathrm{~m}, 1 \mathrm{H}), 3.69-3.58(\mathrm{~m}, 1 \mathrm{H}), 3.20-3.10(\mathrm{~m}, 1 \mathrm{H}), 2.21(\mathrm{~s}$, $3 \mathrm{H}), 2.17-2.06(\mathrm{~m}, 1 \mathrm{H}), 1.95-1.51(\mathrm{~m}, 5 \mathrm{H}), 1.32-1.12(\mathrm{~m}, 14 \mathrm{H}), 0.85(\mathrm{t}, J=6.1 \mathrm{~Hz}, 3 \mathrm{H})$.

${ }^{13} \mathrm{C}-\mathrm{NMR}\left(75 \mathrm{MHz}, \mathrm{CDCl}_{3}\right): \delta=159.7\left(\mathrm{C}_{\mathrm{q}}\right), 144.7(\mathrm{CH}), 139.0(\mathrm{CH}), 121.9\left(\mathrm{C}_{\mathrm{q}}\right), 114.7(\mathrm{CH})$, 
$58.2(\mathrm{CH}), 51.7\left(\mathrm{CH}_{2}\right), 34.2\left(\mathrm{CH}_{2}\right), 31.9\left(\mathrm{CH}_{2}\right), 31.2\left(\mathrm{CH}_{2}\right), 29.9\left(\mathrm{CH}_{2}\right), 29.6\left(\mathrm{CH}_{2}\right), 29.6\left(\mathrm{CH}_{2}\right)$, $29.3\left(\mathrm{CH}_{2}\right), 25.9\left(\mathrm{CH}_{2}\right), 24.9\left(\mathrm{CH}_{2}\right), 22.7\left(\mathrm{CH}_{2}\right), 20.0\left(\mathrm{CH}_{3}\right), 14.1\left(\mathrm{CH}_{3}\right)$.

IR (ATR): $\tilde{V}=2921,2853,1588,1564,1383,1345,775 \mathrm{~cm}^{-1}$.

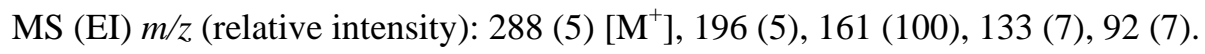

HR-MS (EI) $m / z$ calcd for $\mathrm{C}_{19} \mathrm{H}_{32} \mathrm{~N}_{2}{ }^{+} 288.2565$, found 288.2562 .

\section{Synthesis of 3-methyl-2-(2-n-pentadecylpyrrolidin-1-yl)pyridine (217bf)}

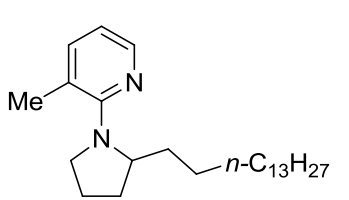

The general procedure $\mathbf{E}$ was followed using 3-methyl-2-(pyrrolidin-1-yl)pyridine (216b) $(243 \mathrm{mg}, 1.5 \mathrm{mmol}$ ) and 1-pentadecene (111f) (105 mg, $0.5 \mathrm{mmol})$. After $18 \mathrm{~h}$, purification by column chromatography on silica gel ( $n$-hexane/EtOAc: $30 / 1)$ yielded 217bf (159 $\mathrm{mg}, 85 \%)$ as a colorless oil.

${ }^{1} \mathrm{H}-\mathrm{NMR}\left(300 \mathrm{MHz}, \mathrm{CDCl}_{3}\right): \delta=8.04(\mathrm{dd}, J=4.9,2.0 \mathrm{~Hz}, 1 \mathrm{H}), 7.26(\mathrm{dd}, J=7.4,2.0 \mathrm{~Hz}, 1 \mathrm{H})$, $6.62(\mathrm{dd}, J=7.4,4.9 \mathrm{~Hz}, 1 \mathrm{H}), 4.27-4.16(\mathrm{~m}, 1 \mathrm{H}), 3.69-3.59(\mathrm{~m}, 1 \mathrm{H}), 3.20-3.11(\mathrm{~m}, 1 \mathrm{H}), 2.21(\mathrm{~s}$, $3 \mathrm{H}), 2.17-2.06(\mathrm{~m}, 1 \mathrm{H}), 1.95-1.51(\mathrm{~m}, 5 \mathrm{H}), 1.35-1.10(\mathrm{~m}, 26 \mathrm{H}), 0.86(\mathrm{t}, J=6.6 \mathrm{~Hz}, 3 \mathrm{H})$.

${ }^{13} \mathrm{C}-\mathrm{NMR}\left(75 \mathrm{MHz}, \mathrm{CDCl}_{3}\right): \delta=159.6\left(\mathrm{C}_{\mathrm{q}}\right), 144.6(\mathrm{CH}), 138.9(\mathrm{CH}), 121.8\left(\mathrm{C}_{\mathrm{q}}\right), 114.6(\mathrm{CH})$, $58.2(\mathrm{CH}), 51.7\left(\mathrm{CH}_{2}\right), 34.3\left(\mathrm{CH}_{2}\right), 32.0\left(\mathrm{CH}_{2}\right), 31.3\left(\mathrm{CH}_{2}\right), 30.0\left(\mathrm{CH}_{2}\right), 29.8\left(\mathrm{CH}_{2}\right), 29.8\left(\mathrm{CH}_{2}\right)$, $29.8\left(\mathrm{CH}_{2}\right), 29.8\left(\mathrm{CH}_{2}\right), 29.7\left(\mathrm{CH}_{2}\right), 29.7\left(\mathrm{CH}_{2}\right), 29.7\left(\mathrm{CH}_{2}\right), 29.7\left(\mathrm{CH}_{2}\right), 29.4\left(\mathrm{CH}_{2}\right), 26.0\left(\mathrm{CH}_{2}\right)$, $25.0\left(\mathrm{CH}_{2}\right), 22.8\left(\mathrm{CH}_{2}\right), 20.1\left(\mathrm{CH}_{3}\right), 14.2\left(\mathrm{CH}_{3}\right)$.

IR (ATR): $\tilde{V}=2920,2851,1588,1384,1346,1186,992,775 \mathrm{~cm}^{-1}$.

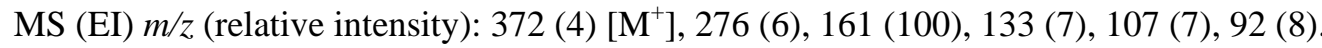

HR-MS (EI) $m / z$ calcd for $\mathrm{C}_{25} \mathrm{H}_{44} \mathrm{~N}_{2}{ }^{+} 372.3504 .0572$, found 372.3510 .

\section{Synthesis of 2-(2-n-hexadecylpyrrolidin-1-yl)-3-methylpyridine (217bg)}

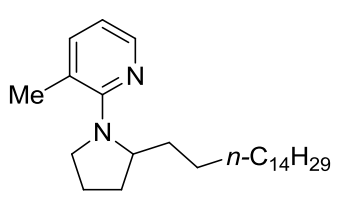

The general procedure $\mathbf{E}$ was followed using 3-methyl-2-(pyrrolidin-1-yl)pyridine (216b) $(243 \mathrm{mg}, 1.5 \mathrm{mmol}$ ) and 1-hexadecene (111g) (112 $\mathrm{mg}, 0.5 \mathrm{mmol})$. After $18 \mathrm{~h}$, purification by column chromatography on silica gel ( $n$-hexane/EtOAc: $40 / 1)$ yielded 217bg (168 mg, 87\%) as a colorless oil.

${ }^{1} \mathrm{H}-\mathrm{NMR}\left(300 \mathrm{MHz}, \mathrm{CDCl}_{3}\right): \delta=8.04(\mathrm{dd}, J=4.9,1.9 \mathrm{~Hz}, 1 \mathrm{H}), 7.26(\mathrm{dd}, J=7.4,1.9 \mathrm{~Hz}, 1 \mathrm{H})$, $6.62(\mathrm{dd}, J=7.4,4.9 \mathrm{~Hz}, 1 \mathrm{H}), 4.27-4.16(\mathrm{~m}, 1 \mathrm{H}), 3.68-3.58(\mathrm{~m}, 1 \mathrm{H}), 3.20-3.11(\mathrm{~m}, 1 \mathrm{H}), 2.21(\mathrm{~s}$, $3 \mathrm{H}), 2.17-2.06(\mathrm{~m}, 1 \mathrm{H}), 1.98-1.50(\mathrm{~m}, 5 \mathrm{H}), 1.30-1.15(\mathrm{~m}, 28 \mathrm{H}), 0.86(\mathrm{t}, J=6.6 \mathrm{~Hz}, 3 \mathrm{H})$.

${ }^{13} \mathrm{C}-\mathrm{NMR}\left(75 \mathrm{MHz}, \mathrm{CDCl}_{3}\right): \delta=159.7\left(\mathrm{C}_{\mathrm{q}}\right), 144.7(\mathrm{CH}), 139.0(\mathrm{CH}), 121.9\left(\mathrm{C}_{\mathrm{q}}\right), 114.7(\mathrm{CH})$, $58.2(\mathrm{CH}), 51.7\left(\mathrm{CH}_{2}\right), 34.3\left(\mathrm{CH}_{2}\right), 31.9\left(\mathrm{CH}_{2}\right), 31.2\left(\mathrm{CH}_{2}\right), 29.9\left(\mathrm{CH}_{2}\right), 29.7\left(\mathrm{CH}_{2}\right), 29.7\left(\mathrm{CH}_{2}\right)$, $29.7\left(\mathrm{CH}_{2}\right), 29.7\left(\mathrm{CH}_{2}\right), 29.7\left(\mathrm{CH}_{2}\right), 29.7\left(\mathrm{CH}_{2}\right), 29.7\left(\mathrm{CH}_{2}\right), 29.7\left(\mathrm{CH}_{2}\right), 29.6\left(\mathrm{CH}_{2}\right), 29.4\left(\mathrm{CH}_{2}\right)$, $25.9\left(\mathrm{CH}_{2}\right), 24.9\left(\mathrm{CH}_{2}\right), 22.7\left(\mathrm{CH}_{2}\right), 20.0\left(\mathrm{CH}_{3}\right), 14.1\left(\mathrm{CH}_{3}\right)$.

IR (ATR): $\tilde{v}=2920,2851,1588,1384,1346,992,775 \mathrm{~cm}^{-1}$.

MS (EI) $m / z$ (relative intensity): 386 (5) [ $\left.\mathrm{M}^{+}\right], 371$ (4), 294 (7), 161 (100), 133 (7), 107 (8), 92 (7). HR-MS (EI) $m / z$ calcd for $\mathrm{C}_{26} \mathrm{H}_{46} \mathrm{~N}_{2}{ }^{+} 386.3661$, found 386.3662 .

\section{Synthesis of 2-\{2-(3,3-dimethylbutyl)pyrrolidin-1-yl\}-3-methylpyridine (217bh)}

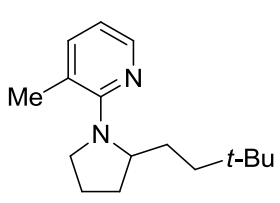

The general procedure $\mathbf{E}$ was followed using 3-methyl-2-(pyrrolidin-1-yl)pyridine (216b) $\quad(81.0 \mathrm{mg}, \quad 0.5 \mathrm{mmol})$ and 3,3-dimethyl-1-butene (111h) $(63.1 \mathrm{mg}, 1.5 \mathrm{mmol})$ at $80{ }^{\circ} \mathrm{C}$. After $18 \mathrm{~h}$, purification by column chromatography on silica gel ( $n$-hexane/EtOAc: $30 / 1)$ 
yielded 217bh (62 $\mathrm{mg}, 50 \%)$ as a colorless oil.

${ }^{1} \mathrm{H}-\mathrm{NMR}\left(300 \mathrm{MHz}, \mathrm{CDCl}_{3}\right): \delta=8.04(\mathrm{dd}, J=5.0,1.9 \mathrm{~Hz}, 1 \mathrm{H}), 7.26(\mathrm{dd}, J=7.2,1.9 \mathrm{~Hz}, 1 \mathrm{H})$, $6.62(\mathrm{dd}, J=7.2,5.0 \mathrm{~Hz}, 1 \mathrm{H}), 4.22-4.12(\mathrm{~m}, 1 \mathrm{H}), 3.69-3.59(\mathrm{~m}, 1 \mathrm{H}), 3.22-3.13(\mathrm{~m}, 1 \mathrm{H}), 2.21(\mathrm{~s}$, $3 \mathrm{H}), 2.16-2.06(\mathrm{~m}, 1 \mathrm{H}), 1.91-1.53(\mathrm{~m}, 4 \mathrm{H}), 1.20-1.07(\mathrm{~m}, 3 \mathrm{H}), 0.78(\mathrm{~s}, 9 \mathrm{H})$.

${ }^{13} \mathrm{C}-\mathrm{NMR}\left(75 \mathrm{MHz}, \mathrm{CDCl}_{3}\right): \delta=159.5\left(\mathrm{C}_{\mathrm{q}}\right), 144.7(\mathrm{CH}), 139.0(\mathrm{CH}), 121.7\left(\mathrm{C}_{\mathrm{q}}\right), 114.6(\mathrm{CH})$, $58.6(\mathrm{CH}), 51.7\left(\mathrm{CH}_{2}\right), 39.8\left(\mathrm{CH}_{2}\right), 31.2\left(\mathrm{CH}_{2}\right), 30.1\left(\mathrm{C}_{\mathrm{q}}\right), 29.3\left(\mathrm{CH}_{3}\right), 29.0\left(\mathrm{CH}_{2}\right), 24.9\left(\mathrm{CH}_{2}\right)$, $20.0\left(\mathrm{CH}_{3}\right)$.

IR (ATR): $\tilde{V}=2951,2864,1588,1383,1343,992,775 \mathrm{~cm}^{-1}$.

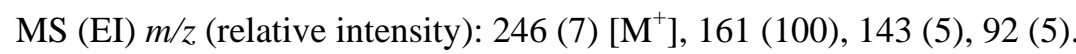

HR-MS (EI) $m / z$ calcd for $\mathrm{C}_{16} \mathrm{H}_{26} \mathrm{~N}_{2}{ }^{+} 246.2076$, found 246.2078 .

\section{Synthesis of 3-methyl-2-\{2-[2-(trimethylsilyl)ethyl]pyrrolidin-1-yl\}pyridine (217bi)}

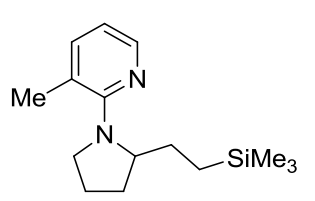

The general procedure $\mathbf{E}$ was followed using 3-methyl-2-(pyrrolidin-1-yl)pyridine (216b) (243 $\mathrm{mg}, 1.5 \mathrm{mmol})$ and trimethyl(vinyl)silane (111i) $(50.1 \mathrm{mg}, 0.5 \mathrm{mmol})$ at $80{ }^{\circ} \mathrm{C}$. After $18 \mathrm{~h}$, purification by column chromatography on silica gel ( $n$-hexane/EtOAc: 40/1) yielded 217bi (78 $\mathrm{mg}, 59 \%)$ as a colorless oil.

${ }^{1} \mathrm{H}-\mathrm{NMR}\left(300 \mathrm{MHz}, \mathrm{CDCl}_{3}\right): \delta=8.03(\mathrm{dd}, J=5.0,1.9 \mathrm{~Hz}, 1 \mathrm{H}), 7.25(\mathrm{dd}, J=7.2,1.9 \mathrm{~Hz}, 1 \mathrm{H})$, $6.62(\mathrm{dd}, J=7.2,5.0 \mathrm{~Hz}, 1 \mathrm{H}), 4.25-4.13(\mathrm{~m}, 1 \mathrm{H}), 3.71-3.60(\mathrm{~m}, 1 \mathrm{H}), 3.24-3.15(\mathrm{~m}, 1 \mathrm{H}), 2.21(\mathrm{~s}$, $3 \mathrm{H}), 2.17-2.07(\mathrm{~m}, 1 \mathrm{H}), 1.94-1.55(\mathrm{~m}, 4 \mathrm{H}), 1.25-1.11(\mathrm{~m}, 1 \mathrm{H}), 0.54-0.31(\mathrm{~m}, 2 \mathrm{H}),-0.11(\mathrm{~s}, 9 \mathrm{H})$. ${ }^{13} \mathrm{C}-\mathrm{NMR}\left(75 \mathrm{MHz}, \mathrm{CDCl}_{3}\right): \delta=159.5\left(\mathrm{C}_{\mathrm{q}}\right), 144.7(\mathrm{CH}), 139.0(\mathrm{CH}), 121.5\left(\mathrm{C}_{\mathrm{q}}\right), 114.5(\mathrm{CH})$, $60.4(\mathrm{CH}), 52.0\left(\mathrm{CH}_{2}\right), 30.7\left(\mathrm{CH}_{2}\right), 27.9\left(\mathrm{CH}_{2}\right), 24.8\left(\mathrm{CH}_{2}\right), 20.1\left(\mathrm{CH}_{3}\right), 12.1\left(\mathrm{CH}_{2}\right),-1.8\left(\mathrm{CH}_{3}\right)$. IR (ATR): $\tilde{V}=2952,2870,1588,1384,1348,1245,1186,832,774,691 \mathrm{~cm}^{-1}$.

MS (EI) $m / z$ (relative intensity): $262(6)\left[\mathrm{M}^{+}\right], 261(10)\left[(\mathrm{M}-\mathrm{H})^{+}\right], 161$ (100), 92 (18), 73 (20). HR-MS (ESI) $m / z$ calcd for $\left[\left(\mathrm{C}_{15} \mathrm{H}_{26} \mathrm{~N}_{2} \mathrm{Si}\right) \mathrm{H}\right]^{+} 263.1938$, found 263.1940 .

\section{Synthesis of 3-methyl-2-\{2-[2-(triethylsilyl)ethyl]pyrrolidin-1-yl\}pyridine (217bj)}

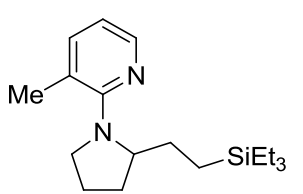

The general procedure $\mathbf{E}$ was followed using 3-methyl-2-(pyrrolidin-1-yl)pyridine (216b) (243 $\mathrm{mg}, 1.5 \mathrm{mmol})$ and triethyl(vinyl)silane (111j) $(71.2 \mathrm{mg}, 0.5 \mathrm{mmol})$. After $18 \mathrm{~h}$, purification by column chromatography on silica gel ( $n$-hexane/EtOAc: $40 / 1)$ yielded $\mathbf{2 1 7 b j}$ (131 mg, 86\%) as a colorless oil.

${ }^{1} \mathrm{H}-\mathrm{NMR}\left(300 \mathrm{MHz}, \mathrm{CDCl}_{3}\right): \delta=8.03(\mathrm{dd}, J=4.9,1.9 \mathrm{~Hz}, 1 \mathrm{H}), 7.24(\mathrm{dd}, J=7.2,1.9 \mathrm{~Hz}, 1 \mathrm{H})$, $6.60(\mathrm{dd}, J=7.2,4.9 \mathrm{~Hz}, 1 \mathrm{H}), 4.25-4.13(\mathrm{~m}, 1 \mathrm{H}), 3.71-3.60(\mathrm{~m}, 1 \mathrm{H}), 3.25-3.15(\mathrm{~m}, 1 \mathrm{H}), 2.20(\mathrm{~s}$, $3 \mathrm{H}), 2.18-2.08(\mathrm{~m}, 1 \mathrm{H}), 1.94-1.53(\mathrm{~m}, 4 \mathrm{H}), 1.27-1.14(\mathrm{~m}, 1 \mathrm{H}), 0.84(\mathrm{t}, J=7.4 \mathrm{~Hz}, 9 \mathrm{H})$, $0.49-0.35(\mathrm{~m}, 8 \mathrm{H})$.

${ }^{13} \mathrm{C}-\mathrm{NMR}\left(75 \mathrm{MHz}, \mathrm{CDCl}_{3}\right): \delta=159.4\left(\mathrm{C}_{\mathrm{q}}\right), 144.7(\mathrm{CH}), 138.9(\mathrm{CH}), 121.5\left(\mathrm{C}_{\mathrm{q}}\right), 114.5(\mathrm{CH})$, 60.6 (CH), $51.9\left(\mathrm{CH}_{2}\right), 30.6\left(\mathrm{CH}_{2}\right), 27.6\left(\mathrm{CH}_{2}\right), 24.8\left(\mathrm{CH}_{2}\right), 20.1\left(\mathrm{CH}_{3}\right), 7.3\left(\mathrm{CH}_{3}\right), 6.4\left(\mathrm{CH}_{2}\right), 3.2$ $\left(\mathrm{CH}_{2}\right)$. IR (ATR): $\tilde{V}=2950,2872,1588,1385,1347,1186,1014,772,725 \mathrm{~cm}^{-1}$.

MS (EI) $m / z$ (relative intensity): 304 (3) [ $\left[\mathrm{M}^{+}\right], 275$ (4), 161 (100), 92 (5).

HR-MS (EI) $m / z$ calcd for $\mathrm{C}_{18} \mathrm{H}_{32} \mathrm{~N}_{2} \mathrm{Si}^{+} 304.2335$, found 304.2299 . 


\section{Synthesis of 2-\{2-(10-methoxy- $n$-decyl)pyrrolidin-1-yl\}-3-methylpyridine (217bk)}

The general procedure $\mathbf{E}$ was followed using 3-methyl-2-(pyrrolidin-1-yl)pyridine (216b) $(243 \mathrm{mg}, 1.5 \mathrm{mmol})$ and
10-methoxy-1-decene (111k) (79.1 mg, $0.5 \mathrm{mmol})$ in DCE. After $18 \mathrm{~h}$, $30 / 1 \rightarrow 20 / 1)$ yielded $217 \mathbf{b k}(104 \mathrm{mg}, 65 \%)$ as a colorless oil.

${ }^{1} \mathrm{H}-\mathrm{NMR}\left(300 \mathrm{MHz}, \mathrm{CDCl}_{3}\right): \delta=8.03(\mathrm{dd}, J=4.9,2.0 \mathrm{~Hz}, 1 \mathrm{H}), 7.25(\mathrm{dd}, J=7.4,2.0 \mathrm{~Hz}, 1 \mathrm{H})$, $6.62(\mathrm{dd}, J=7.4,4.9 \mathrm{~Hz}, 1 \mathrm{H}), 4.27-4.16(\mathrm{~m}, 1 \mathrm{H}), 3.68-3.58(\mathrm{~m}, 1 \mathrm{H}), 3.33(\mathrm{t}, J=6.76 \mathrm{~Hz}, 2 \mathrm{H})$, $3.30(\mathrm{~s}, 3 \mathrm{H}), 3.19-3.10(\mathrm{~m}, 1 \mathrm{H}), 2.20(\mathrm{~s}, 3 \mathrm{H}), 2.17-2.06(\mathrm{~m}, 1 \mathrm{H}), 1.94-1.46(\mathrm{~m}, 6 \mathrm{H}), 1.32-1.15$ (m, 15H).

${ }^{13} \mathrm{C}-\mathrm{NMR}\left(75 \mathrm{MHz}, \mathrm{CDCl}_{3}\right): \delta=159.7\left(\mathrm{C}_{\mathrm{q}}\right), 144.6(\mathrm{CH}), 138.9(\mathrm{CH}), 121.8\left(\mathrm{C}_{\mathrm{q}}\right), 114.7(\mathrm{CH})$, $72.9\left(\mathrm{CH}_{2}\right), 58.5(\mathrm{CH}), 58.1\left(\mathrm{CH}_{3}\right), 51.7\left(\mathrm{CH}_{2}\right), 34.2\left(\mathrm{CH}_{2}\right), 31.2\left(\mathrm{CH}_{2}\right), 29.9\left(\mathrm{CH}_{2}\right), 29.6\left(\mathrm{CH}_{2}\right)$, $29.6\left(\mathrm{CH}_{2}\right), 29.5\left(\mathrm{CH}_{2}\right), 29.5\left(\mathrm{CH}_{2}\right), 29.4\left(\mathrm{CH}_{2}\right), 26.1\left(\mathrm{CH}_{2}\right), 25.9\left(\mathrm{CH}_{2}\right), 24.9\left(\mathrm{CH}_{2}\right), 20.0\left(\mathrm{CH}_{3}\right)$. IR (ATR): $\tilde{V}=2922,2853,1588,1384,1346,1116,992,775 \mathrm{~cm}^{-1}$.

MS (ESI) $m / z$ (relative intensity): $332(5)\left[\mathrm{M}^{+}\right], 240$ (7), 161 (100), 133 (12), 92 (13).

HR-MS (ESI) $m / z$ calcd for $\mathrm{C}_{21} \mathrm{H}_{26} \mathrm{~N}_{2} \mathrm{O}^{+} 332.2828$, found 332.2826 .

\section{Synthesis of 2-\{2-(10-chloro- $n$-decyl)pyrrolidin-1-yl\}-3-methylpyridine (217bl)}

The general procedure $\mathbf{E}$ was followed using 3-methyl-2-(pyrrolidin-1-yl)pyridine (216b) (243 $\mathrm{mg}, 1.5 \mathrm{mmol})$ and 10-chloro-1-decene (111) $(87.3 \mathrm{mg}, 0.5 \mathrm{mmol})$. After $18 \mathrm{~h}$, purification by column chromatography on silica gel ( $n$-hexane/EtOAc: $30 / 1)$ yielded $217 \mathbf{b l}$ (138 mg, 82\%) as a colorless oil.

${ }^{1} \mathrm{H}-\mathrm{NMR}\left(300 \mathrm{MHz}, \mathrm{CDCl}_{3}\right): \delta=8.04(\mathrm{dd}, J=4.9,1.9 \mathrm{~Hz}, 1 \mathrm{H}), 7.26(\mathrm{dd}, J=7.4,1.9 \mathrm{~Hz}, 1 \mathrm{H})$, $6.62(\mathrm{dd}, J=7.4,4.9 \mathrm{~Hz}, 1 \mathrm{H}), 4.27-4.16(\mathrm{~m}, 1 \mathrm{H}), 3.68-3.59(\mathrm{~m}, 1 \mathrm{H}), 3.50(\mathrm{t}, J=7.4 \mathrm{~Hz}, 2 \mathrm{H})$, 3.19-3.10 (m, 1H), $2.21(\mathrm{~s}, 3 \mathrm{H}), 2.17-2.06(\mathrm{~m}, 1 \mathrm{H}), 1.93-1.54(\mathrm{~m}, 6 \mathrm{H}), 1.44-1.14(\mathrm{~m}, 15 \mathrm{H})$.

${ }^{13} \mathrm{C}-\mathrm{NMR}\left(75 \mathrm{MHz}, \mathrm{CDCl}_{3}\right): \delta=159.7\left(\mathrm{C}_{\mathrm{q}}\right), 144.7(\mathrm{CH}), 138.9(\mathrm{CH}), 121.8\left(\mathrm{C}_{\mathrm{q}}\right), 114.7(\mathrm{CH})$, $58.1(\mathrm{CH}), 51.7\left(\mathrm{CH}_{2}\right), 45.2\left(\mathrm{CH}_{2}\right), 34.2\left(\mathrm{CH}_{2}\right), 32.6\left(\mathrm{CH}_{2}\right), 31.2\left(\mathrm{CH}_{2}\right), 29.8\left(\mathrm{CH}_{2}\right), 29.5\left(\mathrm{CH}_{2}\right)$, $29.4\left(\mathrm{CH}_{2}\right), 29.4\left(\mathrm{CH}_{2}\right), 28.8\left(\mathrm{CH}_{2}\right), 26.8\left(\mathrm{CH}_{2}\right), 25.9\left(\mathrm{CH}_{2}\right), 24.9\left(\mathrm{CH}_{2}\right), 20.0\left(\mathrm{CH}_{3}\right)$.

IR (ATR): $\tilde{V}=2923,2853,1588,1383,1346,992,776,650 \mathrm{~cm}^{-1}$.

MS (EI) $m / z$ (relative intensity): 336 (4) [ $\left[\mathrm{M}^{+}\right], 244$ (4), 161 (100), 133 (8), 92 (11).

HR-MS (EI) $\mathrm{m} / z$ calcd for $\mathrm{C}_{20} \mathrm{H}_{33} \mathrm{ClN}_{2}{ }^{+} 336.2332$, found 336.2336 .

\section{Synthesis of 2-\{2-(10-bromo-n-decyl)pyrrolidin-1-yl\}-3-methylpyridine (217bm)}

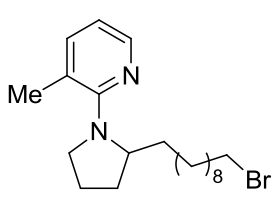

The general procedure $\mathbf{E}$ was followed using 3-methyl-2-(pyrrolidin-1-yl)pyridine (216b) (243 $\mathrm{mg}, 1.5 \mathrm{mmol})$ and 10-bromo-1-decene (111m) (110 mg, $0.5 \mathrm{mmol})$ in DCE. After $18 \mathrm{~h}$, purification by column chromatography on silica gel ( $n$-hexane/EtOAc: $30 / 1)$ yielded 217bm (114 $\mathrm{mg}, 60 \%)$ as a colorless oil.

${ }^{1} \mathrm{H}-\mathrm{NMR}\left(300 \mathrm{MHz}, \mathrm{CDCl}_{3}\right): \delta=8.04(\mathrm{dd}, J=4.9,1.9 \mathrm{~Hz}, 1 \mathrm{H}), 7.25(\mathrm{dd}, J=7.2,1.9 \mathrm{~Hz}, 1 \mathrm{H})$, $6.62(\mathrm{dd}, J=7.2,4.9 \mathrm{~Hz}, 1 \mathrm{H}), 4.28-4.17(\mathrm{~m}, 1 \mathrm{H}), 3.69-3.58(\mathrm{~m}, 1 \mathrm{H}), 3.50(\mathrm{t}, J=7.2 \mathrm{~Hz}, 2 \mathrm{H})$, 3.19-3.10 (m, 1H), $2.20(\mathrm{~s}, 3 \mathrm{H}), 2.16-2.05(\mathrm{~m}, 1 \mathrm{H}), 1.94-1.52(\mathrm{~m}, 6 \mathrm{H}), 1.43-1.12(\mathrm{~m}, 15 \mathrm{H})$.

${ }^{13} \mathrm{C}-\mathrm{NMR}\left(75 \mathrm{MHz}, \mathrm{CDCl}_{3}\right): \delta=159.7\left(\mathrm{C}_{\mathrm{q}}\right), 144.7(\mathrm{CH}), 138.9(\mathrm{CH}), 121.8\left(\mathrm{C}_{\mathrm{q}}\right), 114.7(\mathrm{CH})$, $58.1(\mathrm{CH}), 51.7\left(\mathrm{CH}_{2}\right), 45.1\left(\mathrm{CH}_{2}\right), 34.2\left(\mathrm{CH}_{2}\right), 32.6\left(\mathrm{CH}_{2}\right), 31.2\left(\mathrm{CH}_{2}\right), 29.8\left(\mathrm{CH}_{2}\right), 29.5\left(\mathrm{CH}_{2}\right)$, $29.4\left(\mathrm{CH}_{2}\right), 29.4\left(\mathrm{CH}_{2}\right), 28.8\left(\mathrm{CH}_{2}\right), 26.8\left(\mathrm{CH}_{2}\right), 25.9\left(\mathrm{CH}_{2}\right), 24.9\left(\mathrm{CH}_{2}\right), 20.0\left(\mathrm{CH}_{3}\right)$. 
IR (ATR): $\tilde{V}=2923,2853,1707,1588,1384,1346,992,775,650 \mathrm{~cm}^{-1}$.

MS (ESI) $\mathrm{m} / z$ (relative intensity): $383(100)\left[(\mathrm{M}+\mathrm{H})^{+}\right]\left({ }^{81} \mathrm{Br}\right), 381(100)\left[(\mathrm{M}+\mathrm{H})^{+}\right]\left({ }^{79} \mathrm{Br}\right)$.

HR-MS (ESI) $m / z$ calcd for $\left[\left(\mathrm{C}_{20} \mathrm{H}_{33} \mathrm{BrN}_{2}\right) \mathrm{H}\right]^{+} 381.1900$, found 381.1897 .

\section{Synthesis of 2-\{2-[4-(2-bromophenyl)butyl]pyrrolidin-1-yl\}-3-methylpyridine (217bn)}

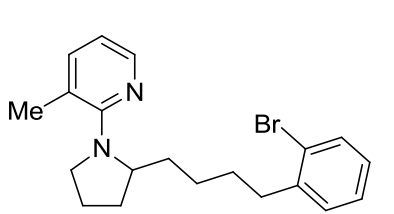

The general procedure $\mathbf{E}$ was followed using 3-methyl-2-(pyrrolidin-1-yl)pyridine (216b) (243 $\mathrm{mg}, 1.5 \mathrm{mmol}$ ) and 1-bromo-2-(but-3-en-1-yl)benzene (111n) (105 mg, 0.5 mmol). After $18 \mathrm{~h}$, purification by column chromatography on silica gel (n-hexane/EtOAc: $30 / 1)$ yielded 217bn (152 $\mathrm{mg}, 82 \%)$ as a colorless oil.

${ }^{1} \mathrm{H}-\mathrm{NMR}\left(300 \mathrm{MHz}, \mathrm{CDCl}_{3}\right): \delta=8.05(\mathrm{dd}, J=4.9,1.9 \mathrm{~Hz}, 1 \mathrm{H}), 7.48(\mathrm{dd}, J=8.1,1.1 \mathrm{~Hz}, 1 \mathrm{H})$, $7.26(\mathrm{dd}, J=7.4,1.9 \mathrm{~Hz}, 1 \mathrm{H}), 7.21-7.11(\mathrm{~m}, 2 \mathrm{H}), 7.00(\mathrm{ddd}, J=7.4,7.4,2.6 \mathrm{~Hz}, 1 \mathrm{H}), 6.62(\mathrm{dd}$, $J=7.4,4.9 \mathrm{~Hz}, 1 \mathrm{H}), 4.34-4.23(\mathrm{~m}, 1 \mathrm{H}), 3.70-3.60(\mathrm{~m}, 1 \mathrm{H}), 3.19-3.10(\mathrm{~m}, 1 \mathrm{H}), 3.50(\mathrm{td}, J=7.4$, $2.1 \mathrm{~Hz}, 2 \mathrm{H}), 2.21(\mathrm{~s}, 3 \mathrm{H}), 2.18-2.07(\mathrm{~m}, 1 \mathrm{H}), 1.96-1.83(\mathrm{~m}, 1 \mathrm{H}), 1.82-1.67(\mathrm{~m}, 2 \mathrm{H}), 1.65-1.49$ $(\mathrm{m}, 3 \mathrm{H}), 1.46-1.21(\mathrm{~m}, 3 \mathrm{H})$.

${ }^{13} \mathrm{C}-\mathrm{NMR}\left(75 \mathrm{MHz}, \mathrm{CDCl}_{3}\right): \delta=159.7\left(\mathrm{C}_{\mathrm{q}}\right), 144.6(\mathrm{CH}), 138.0\left(\mathrm{C}_{\mathrm{q}}\right), 139.0(\mathrm{CH}), 132.6(\mathrm{CH})$, 130.2 $(\mathrm{CH}), 127.2(\mathrm{CH}), 127.2(\mathrm{CH}), 124.4\left(\mathrm{C}_{\mathrm{q}}\right), 121.9\left(\mathrm{C}_{\mathrm{q}}\right), 114.8(\mathrm{CH}), 58.0(\mathrm{CH}), 51.9\left(\mathrm{CH}_{2}\right)$, 36.0 $\left(\mathrm{CH}_{2}\right), 33.9\left(\mathrm{CH}_{2}\right), 31.1\left(\mathrm{CH}_{2}\right), 30.0\left(\mathrm{CH}_{2}\right), 25.6\left(\mathrm{CH}_{2}\right), 25.0\left(\mathrm{CH}_{2}\right), 20.0\left(\mathrm{CH}_{3}\right)$.

IR (ATR): $\tilde{V}=2930,2858,1587,1382,1346,1020,776,746 \mathrm{~cm}^{-1}$.

MS (EI) $m / z$ (relative intensity): $373(100)\left[\mathrm{M}^{+}\right]\left({ }^{81} \mathrm{Br}\right), 371(100)\left[\mathrm{M}^{+}\right]\left({ }^{79} \mathrm{Br}\right), 317$ (6), 265 (13), 171 (35), 161 (40), 33 (22), 92 (17).

HR-MS (ESI) $m / z$ calcd for $\left[\left(\mathrm{C}_{20} \mathrm{H}_{25} \mathrm{BrN}_{2}\right) \mathrm{H}\right]^{+} 373.1274$, found 373.1274 .

\section{Synthesis of 3-methyl-2-(2-phenethylpyrrolidin-1-yl)pyridine (217bo)}

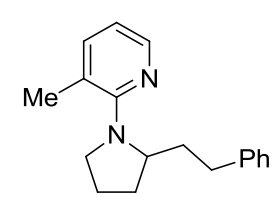

The general procedure $\mathbf{E}$ was followed using 3-methyl-2-(pyrrolidin-1-yl)pyridine (216b) (243 mg, $1.5 \mathrm{mmol}$ ) and styrene (1110) $(52.1 \mathrm{mg}, 0.5 \mathrm{mmol})$. After $18 \mathrm{~h}$, purification by column chromatography on silica gel ( $n$-hexane/EtOAc: $25 / 1)$ yielded 217 bo $(98 \mathrm{mg}$,

73\%) as a colorless oil.

${ }^{1} \mathrm{H}-\mathrm{NMR}\left(300 \mathrm{MHz}, \mathrm{CDCl}_{3}\right): \delta=8.06(\mathrm{dd}, J=4.9,1.9 \mathrm{~Hz}, 1 \mathrm{H}), 7.30-7.18(\mathrm{~m}, 3 \mathrm{H}), 7.17-7.09(\mathrm{~m}$, $3 \mathrm{H}), 6.65(\mathrm{dd}, J=7.2,4.9 \mathrm{~Hz}, 1 \mathrm{H}), 4.41-4.31(\mathrm{~m}, 1 \mathrm{H}), 3.73-3.64(\mathrm{~m}, 1 \mathrm{H}), 3.22-3.14(\mathrm{~m}, 1 \mathrm{H})$, $2.68-2.56(\mathrm{~m}, 2 \mathrm{H}), 2.25-2.14(\mathrm{~m}, 1 \mathrm{H}), 2.19(\mathrm{~s}, 3 \mathrm{H}), 2.06-1.90(\mathrm{~m}, 2 \mathrm{H}), 1.84-1.54(\mathrm{~m}, 3 \mathrm{H})$.

${ }^{13} \mathrm{C}-\mathrm{NMR}\left(75 \mathrm{MHz}, \mathrm{CDCl}_{3}\right): \delta=159.7\left(\mathrm{C}_{\mathrm{q}}\right), 144.8(\mathrm{CH}), 138.8\left(\mathrm{C}_{\mathrm{q}}\right), 139.1(\mathrm{CH}), 128.3(\mathrm{CH})$, $128.2(\mathrm{CH}), 125.5(\mathrm{CH}), 122.1\left(\mathrm{C}_{\mathrm{q}}\right), 111.0(\mathrm{CH}), 57.8(\mathrm{CH}), 51.7\left(\mathrm{CH}_{2}\right), 35.9\left(\mathrm{CH}_{2}\right), 32.2\left(\mathrm{CH}_{2}\right)$, $31.1\left(\mathrm{CH}_{2}\right), 24.9\left(\mathrm{CH}_{2}\right), 19.8\left(\mathrm{CH}_{3}\right)$.

IR (ATR): $\tilde{V}=2956,2862,1587,1382,1346,1186,1099,776,696 \mathrm{~cm}^{-1}$.

MS (EI) $m / z$ (relative intensity): 266 (5) [ $\left.\mathrm{M}^{+}\right], 175$ (26), 161 (100), 133 (7), 92 (17).

HR-MS (EI) $m / z$ calcd for $\mathrm{C}_{18} \mathrm{H}_{22} \mathrm{~N}_{2}{ }^{+} 266.1783$, found 266.1792 .

\section{Synthesis of 2-\{2-(4-methoxyphenethyl)pyrrolidin-1-yl\}-3-methylpyridine (217bp)}

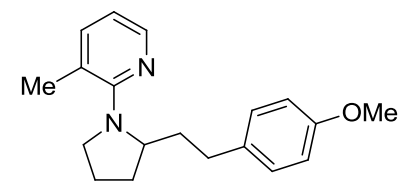

The general procedure $\mathbf{E}$ was followed using 3-methyl-2-(pyrrolidin-1-yl)pyridine (216b) $(243 \mathrm{mg}, 1.5 \mathrm{mmol})$ and 4-methoxystyrene (111p) (67.1 mg, $0.5 \mathrm{mmol})$. After $18 \mathrm{~h}$, purification by column chromatography on silica gel ( $n$-hexane/EtOAc: $30 / 1 \rightarrow 20 / 1)$ yielded 217bp $(104 \mathrm{mg}, 70 \%)$ as a colorless oil. 
${ }^{1} \mathrm{H}-\mathrm{NMR}\left(300 \mathrm{MHz}, \mathrm{CDCl}_{3}\right): \delta=8.04(\mathrm{dd}, J=5.0,1.9 \mathrm{~Hz}, 1 \mathrm{H}), 7.26(\mathrm{dd}, J=7.3,1.9 \mathrm{~Hz}, 1 \mathrm{H})$, $7.04(\mathrm{~d}, J=8.6 \mathrm{~Hz}, 2 \mathrm{H}), 6.76(\mathrm{~d}, J=8.6 \mathrm{~Hz}, 2 \mathrm{H}), 6.65(\mathrm{dd}, J=7.3,5.0 \mathrm{~Hz}, 1 \mathrm{H}), 4.38-4.26(\mathrm{~m}$, $1 \mathrm{H}), 3.75(\mathrm{~s}, 3 \mathrm{H}), 3.70-3.61(\mathrm{~m}, 1 \mathrm{H}), 3.20-3.12(\mathrm{~m}, 1 \mathrm{H}), 2.61-2.47(\mathrm{~m}, 2 \mathrm{H}), 2.24-2.11(\mathrm{~m}, 1 \mathrm{H})$, $2.18(\mathrm{~s}, 3 \mathrm{H}), 2.01-1.49(\mathrm{~m}, 5 \mathrm{H})$.

${ }^{13} \mathrm{C}-\mathrm{NMR}\left(75 \mathrm{MHz}, \mathrm{CDCl}_{3}\right): \delta=159.6\left(\mathrm{C}_{\mathrm{q}}\right), 157.5\left(\mathrm{C}_{\mathrm{q}}\right), 144.7(\mathrm{CH}), 139.0(\mathrm{CH}), 134.8\left(\mathrm{C}_{\mathrm{q}}\right)$, $129.1(\mathrm{CH}), 122.1\left(\mathrm{C}_{\mathrm{q}}\right), 114.9(\mathrm{CH}), 113.6(\mathrm{CH}), 57.8(\mathrm{CH}), 55.2\left(\mathrm{CH}_{3}\right), 51.8\left(\mathrm{CH}_{2}\right), 36.2\left(\mathrm{CH}_{2}\right)$, $31.3\left(\mathrm{CH}_{2}\right), 31.2\left(\mathrm{CH}_{2}\right), 25.0\left(\mathrm{CH}_{2}\right), 19.9\left(\mathrm{CH}_{3}\right)$.

IR (ATR): $\tilde{V}=2952,2862,1587,1510,1382,1347,1241,1176,1035,820,776 \mathrm{~cm}^{-1}$.

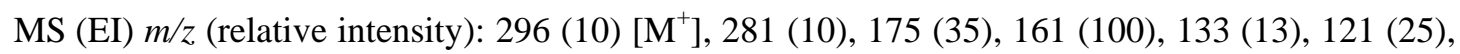
92 (27).

HR-MS (EI) $m / z$ calcd for $\mathrm{C}_{19} \mathrm{H}_{24} \mathrm{~N}_{2} \mathrm{O}^{+} 296.1889$, found 296.1887 .

\section{Synthesis of 2-\{2-(4-bromophenethyl)pyrrolidin-1-yl\}-3-methylpyridine (217bq)}

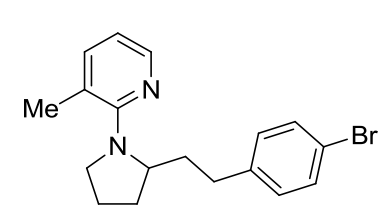

The general procedure $\mathbf{E}$ was followed using 3-methyl-2-(pyrrolidin-1-yl)pyridine (216b) (243 mg, $1.5 \mathrm{mmol}$ ) and 4-bromostyrene (111q) $(91.5 \mathrm{mg}, 0.5 \mathrm{mmol})$. After $18 \mathrm{~h}$, purification by column chromatography on silica gel ( $n$-hexane/EtOAc: $30 / 1)$ yielded 217bq (112 $\mathrm{mg}, 65 \%)$ as a colorless oil.

${ }^{1} \mathrm{H}-\mathrm{NMR}\left(300 \mathrm{MHz}, \mathrm{CDCl}_{3}\right): \delta=8.05(\mathrm{dd}, J=4.9,1.9 \mathrm{~Hz}, 1 \mathrm{H}), 7.32(\mathrm{~d}, J=8.6 \mathrm{~Hz}, 2 \mathrm{H}), 7.26(\mathrm{dd}$, $J=7.4,1.9 \mathrm{~Hz}, 1 \mathrm{H}), 6.99(\mathrm{~d}, J=8.6 \mathrm{~Hz}, 2 \mathrm{H}), 6.65(\mathrm{dd}, J=7.4,4.9 \mathrm{~Hz}, 1 \mathrm{H}), 4.40-4.29(\mathrm{~m}, 1 \mathrm{H})$, 3.72-3.61 (m, 1H), 3.20-3.09 (m, 1H), 2.65-2.48 (m, 2H), $2.19(\mathrm{~s}, 3 \mathrm{H}), 2.17-2.10(\mathrm{~m}, 1 \mathrm{H})$, $2.04-1.51(\mathrm{~m}, 5 \mathrm{H})$.

${ }^{13} \mathrm{C}-\mathrm{NMR}\left(75 \mathrm{MHz}, \mathrm{CDCl}_{3}\right): \delta=159.6\left(\mathrm{C}_{\mathrm{q}}\right), 144.6(\mathrm{CH}), 141.6\left(\mathrm{C}_{\mathrm{q}}\right), 139.0(\mathrm{CH}), 131.1(\mathrm{CH})$, $130.0(\mathrm{CH}), 122.0\left(\mathrm{C}_{\mathrm{q}}\right), 119.1\left(\mathrm{C}_{\mathrm{q}}\right), 111.0(\mathrm{CH}), 57.7(\mathrm{CH}), 52.0\left(\mathrm{CH}_{2}\right), 35.7\left(\mathrm{CH}_{2}\right), 31.7\left(\mathrm{CH}_{2}\right)$, $31.1\left(\mathrm{CH}_{2}\right), 25.0\left(\mathrm{CH}_{2}\right), 19.8\left(\mathrm{CH}_{3}\right)$.

IR (ATR): $\tilde{V}=2958,2862,1587,1487,1382,1347,1010,776 \mathrm{~cm}^{-1}$.

MS (EI) $m / z$ (relative intensity): $346(4)\left[\mathrm{M}^{+}\right]\left({ }^{81} \mathrm{Br}\right), 344(4)\left[\mathrm{M}^{+}\right]\left({ }^{79} \mathrm{Br}\right), 175$ (38), 161 (100), 147 (10), 133 (18), 92 (23).

HR-MS (EI) $m / z$ calcd for $\mathrm{C}_{18} \mathrm{H}_{21} \mathrm{BrN}_{2}{ }^{+} 344.0888$, found 344.0879.

\section{Synthesis of 2-\{2-(4-fluorophenethyl)pyrrolidin-1-yl\}-3-methylpyridine (217br)}

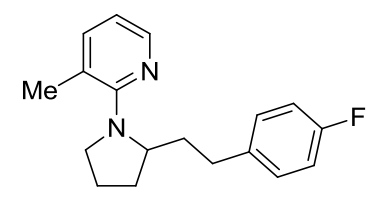

The general procedure $\mathbf{E}$ was followed using 3-methyl-2-(pyrrolidin-1-yl)pyridine (216b) $(243 \mathrm{mg}, 1.5 \mathrm{mmol})$ and 4-fluorostyrene (111r) $(61.1 \mathrm{mg}, 0.5 \mathrm{mmol})$. After $18 \mathrm{~h}$, purification by column chromatography on silica gel ( $n$-hexane/EtOAc: $30 / 1 \rightarrow 20 / 1)$ yielded 217br (91 mg, 64\%) as a colorless oil.

${ }^{1} \mathrm{H}-\mathrm{NMR}\left(300 \mathrm{MHz}, \mathrm{CDCl}_{3}\right): \delta=8.05(\mathrm{dd}, J=4.9,1.9 \mathrm{~Hz}, 1 \mathrm{H}), 7.27(\mathrm{dd}, J=7.3,1.9 \mathrm{~Hz}, 1 \mathrm{H})$, 7.07 (ddd, $J=8.7,8.7,2.3 \mathrm{~Hz}, 2 \mathrm{H}), 6.76(\mathrm{dd}, J=8.7,8.7 \mathrm{~Hz}, 2 \mathrm{H}), 6.65(\mathrm{dd}, J=7.3,4.9 \mathrm{~Hz}, 1 \mathrm{H})$, 4.41-4.29 (m, 1H), 3.73-3.62 (m, 1H), 3.21-3.11 (m, 1H), 2.66-2.51 (m, 2H), 2.23-2.12 (m, 1H), $2.19(\mathrm{~s}, 3 \mathrm{H}), 2.03-1.51(\mathrm{~m}, 5 \mathrm{H})$.

${ }^{13} \mathrm{C}-\mathrm{NMR}\left(75 \mathrm{MHz}, \mathrm{CDCl}_{3}\right): \delta=161.1\left(\mathrm{~d},{ }^{1} J_{\mathrm{C}-\mathrm{F}}=243 \mathrm{~Hz}, \mathrm{C}_{\mathrm{q}}\right), 159.7\left(\mathrm{C}_{\mathrm{q}}\right), 144.6(\mathrm{CH}), 139.0$ $(\mathrm{CH}), 138.2\left(\mathrm{~d},{ }^{4} J_{\mathrm{C}-\mathrm{F}}=3 \mathrm{~Hz}, \mathrm{C}_{\mathrm{q}}\right), 129.5\left(\mathrm{~d},{ }^{3} J_{\mathrm{C}-\mathrm{F}}=8 \mathrm{~Hz}, \mathrm{CH}\right), 122.0\left(\mathrm{C}_{\mathrm{q}}\right), 111.0(\mathrm{CH}), 114.7(\mathrm{~d}$, $\left.{ }^{2} J_{\mathrm{C}-\mathrm{F}}=21 \mathrm{~Hz}, \mathrm{CH}\right), 57.7(\mathrm{CH}), 51.9\left(\mathrm{CH}_{2}\right), 36.0\left(\mathrm{CH}_{2}\right), 31.4\left(\mathrm{CH}_{2}\right), 31.1\left(\mathrm{CH}_{2}\right), 25.0\left(\mathrm{CH}_{2}\right), 19.8$ $\left(\mathrm{CH}_{3}\right)$.

${ }^{19} \mathrm{~F}-\mathrm{NMR}\left(283 \mathrm{MHz}, \mathrm{CDCl}_{3}\right): \delta=-(118.2-118.3)(\mathrm{m})$. 
IR (ATR): $\tilde{V}=2955,2864,1587,1508,1382,1348,1216,822,776 \mathrm{~cm}^{-1}$. MS (EI) $m / z$ (relative intensity): 284 (5) [ $\left.\mathrm{M}^{+}\right], 175$ (32), 161 (100), 133 (12), 109 (17), 92 (27). HR-MS (EI) $m / z$ calcd for $\mathrm{C}_{18} \mathrm{H}_{21} \mathrm{FN}_{2}{ }^{+} 284.1689$, found 284.1692 .

\section{Synthesis of 3-methyl-2-\{2-[2-(naphthalen-2-yl)ethyl]pyrrolidin-1-yl\}pyridine (217bs)}

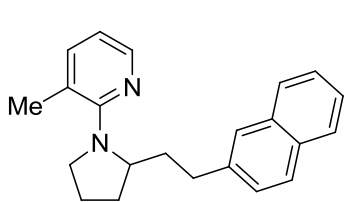

The general procedure $\mathbf{E}$ was followed using 3-methyl-2-(pyrrolidin-1-yl)pyridine (216b) (243 mg, $1.5 \mathrm{mmol})$ and 2-vinylnaphthalene (111s) $(77.1 \mathrm{mg}, 0.5 \mathrm{mmol})$. After $18 \mathrm{~h}$, purification by column chromatography on silica gel ( $n$-hexane/EtOAc: 25/1) yielded 217bs (91 $\mathrm{mg}, 57 \%$ ) as a white solid.

M.p. $=93-94{ }^{\circ} \mathrm{C}$.

${ }^{1} \mathrm{H}-\mathrm{NMR}\left(300 \mathrm{MHz}, \mathrm{CDCl}_{3}\right): \delta=8.09(\mathrm{dd}, J=4.9,2.0 \mathrm{~Hz}, 1 \mathrm{H}), 7.79-7.69(\mathrm{~m}, 3 \mathrm{H}), 7.58(\mathrm{~s}, 1 \mathrm{H})$, 7.45-7.35 (m, 2H), 7.31-7.25 (m, 2H), $6.67(\mathrm{dd}, J=7.4,4.9 \mathrm{~Hz}, 1 \mathrm{H}), 4.48-4.36(\mathrm{~m}, 1 \mathrm{H})$, 3.75-3.65 (m, 1H), 3.23-3.14 (m, 1H), 2.87-2.72 (m, 2H), 2.27-2.07 (m, 2H), $2.20(\mathrm{~s}, 3 \mathrm{H})$, $2.00-1.64(\mathrm{~m}, 4 \mathrm{H})$.

${ }^{13} \mathrm{C}-\mathrm{NMR}\left(75 \mathrm{MHz}, \mathrm{CDCl}_{3}\right): \delta=159.7\left(\mathrm{C}_{\mathrm{q}}\right), 144.7(\mathrm{CH}), 140.2\left(\mathrm{C}_{\mathrm{q}}\right), 139.0(\mathrm{CH}), 133.6\left(\mathrm{C}_{\mathrm{q}}\right)$, $131.8\left(\mathrm{C}_{\mathrm{q}}\right), 127.6(\mathrm{CH}), 127.5(\mathrm{CH}), 127.4(\mathrm{CH}), 127.3(\mathrm{CH}), 126.0(\mathrm{CH}), 125.7(\mathrm{CH}), 124.9$ $(\mathrm{CH}), 122.0\left(\mathrm{C}_{\mathrm{q}}\right), 111.0(\mathrm{CH}), 57.9(\mathrm{CH}), 51.9\left(\mathrm{CH}_{2}\right), 35.7\left(\mathrm{CH}_{2}\right), 32.4\left(\mathrm{CH}_{2}\right), 31.2\left(\mathrm{CH}_{2}\right), 25.0$ $\left(\mathrm{CH}_{2}\right), 19.9\left(\mathrm{CH}_{3}\right)$.

IR (ATR): $\tilde{V}=2963,2919,2858,1588,1563,1382,1320,862,815,786,475 \mathrm{~cm}^{-1}$. MS (EI) $m / z$ (relative intensity): 316 (10) [ $\left.\mathrm{M}^{+}\right], 175$ (50), 161 (100), 141 (20), 111 (15), 92 (30). HR-MS (EI) $m / z$ calcd for $\mathrm{C}_{22} \mathrm{H}_{24} \mathrm{~N}_{2}{ }^{+} 316.1939$, found 316.1927.

\section{Synthesis of 2-\{2-(10-isobutoxy- $n$-decyl)pyrrolidin-1-yl\}-3-methylpyridine (217'bt)}

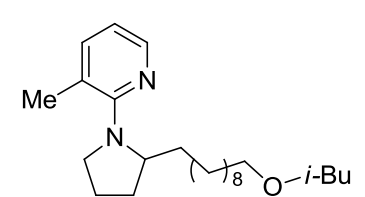

The general procedure $\mathbf{E}$ was followed using 3-methyl-2-(pyrrolidin-1-yl)pyridine (216b) $(243 \mathrm{mg}, 1.5 \mathrm{mmol})$ and 9-decen-1-yl 4-methylbenzenesulfonate (111t) (155 mg, $0.5 \mathrm{mmol}$ ). After $18 \mathrm{~h}$, purification by column chromatography on silica gel ( $n$-hexane/EtOAc: $40 / 1 \rightarrow 30 / 1)$ yielded 217'bt (144 mg, 77\%) as a colorless oil.

${ }^{1} \mathrm{H}-\mathrm{NMR}\left(300 \mathrm{MHz}, \mathrm{CDCl}_{3}\right): \delta=8.04(\mathrm{dd}, J=4.9,2.0 \mathrm{~Hz}, 1 \mathrm{H}), 7.25(\mathrm{dd}, J=7.4,2.0 \mathrm{~Hz}, 1 \mathrm{H})$, $6.61(\mathrm{dd}, J=7.4,4.9 \mathrm{~Hz}, 1 \mathrm{H}), 4.27-4.16(\mathrm{~m}, 1 \mathrm{H}), 3.68-3.58(\mathrm{~m}, 1 \mathrm{H}), 3.35(\mathrm{t}, J=6.7 \mathrm{~Hz}, 2 \mathrm{H})$, $3.31(\mathrm{~d}, J=6.7 \mathrm{~Hz}, 2 \mathrm{H}), 2.20(\mathrm{~s}, 3 \mathrm{H}), 2.17-2.06(\mathrm{~m}, 1 \mathrm{H}), 1.95-1.47(\mathrm{~m}, 8 \mathrm{H}), 1.33-1.13(\mathrm{~m}, 15 \mathrm{H})$, $0.87(\mathrm{~d}, J=7.0 \mathrm{~Hz}, 6 \mathrm{H})$.

${ }^{13} \mathrm{C}-\mathrm{NMR}\left(75 \mathrm{MHz}, \mathrm{CDCl}_{3}\right): \delta=159.7\left(\mathrm{C}_{\mathrm{q}}\right), 144.7(\mathrm{CH}), 138.9(\mathrm{CH}), 121.8\left(\mathrm{C}_{\mathrm{q}}\right), 114.7(\mathrm{CH})$, $77.8\left(\mathrm{CH}_{2}\right), 71.0\left(\mathrm{CH}_{2}\right), 58.1(\mathrm{CH}), 51.7\left(\mathrm{CH}_{2}\right), 34.2\left(\mathrm{CH}_{2}\right), 31.2\left(\mathrm{CH}_{2}\right), 29.9\left(\mathrm{CH}_{2}\right), 29.7\left(\mathrm{CH}_{2}\right)$, $29.6\left(\mathrm{CH}_{2}\right), 29.6\left(\mathrm{CH}_{2}\right), 29.5\left(\mathrm{CH}_{2}\right), 29.5\left(\mathrm{CH}_{2}\right), 28.4(\mathrm{CH}), 26.2\left(\mathrm{CH}_{2}\right), 25.9\left(\mathrm{CH}_{2}\right), 24.9\left(\mathrm{CH}_{2}\right)$, $20.0\left(\mathrm{CH}_{3}\right), 19.4\left(\mathrm{CH}_{3}\right)$.

IR (ATR): $\tilde{V}=2923,2852,1588,1565,1384,1346,1110,992,775 \mathrm{~cm}^{-1}$. MS (EI) m/z (relative intensity): 374 (5) [M+ $], 331$ (6), 282 (5), 161 (100), 133 (7), 107 (96), 92 (6).

HR-MS (EI) $m / z$ calcd for $\mathrm{C}_{24} \mathrm{H}_{38} \mathrm{~N}_{2} \mathrm{O} 374.3297$, found 374.3285 . 
Synthesis of 10-\{1-(3-methylpyridin-2-yl)pyrrolidin-2-yl\}- $n$-decyl 4-methylbenzenesulfonate (217bt)

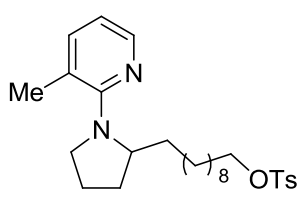

The general procedure $\mathbf{E}$ was followed using 3-methyl-2-(pyrrolidin-1-yl)pyridine (216b) (243 $\mathrm{mg}, 1.5 \mathrm{mmol})$ and 9-decen-1-yl 4-methylbenzenesulfonate (111t) $(155 \mathrm{mg}, 0.5 \mathrm{mmol})$ in DCE. After $18 \mathrm{~h}$, purification by column chromatography on silica gel ( $n$-hexane/EtOAc: $15 / 1 \rightarrow 5 / 1)$ yielded $217 b t(148 \mathrm{mg}, 63 \%)$ as a colorless oil.

${ }^{1} \mathrm{H}-\mathrm{NMR}\left(300 \mathrm{MHz}, \mathrm{CDCl}_{3}\right): \delta=8.03(\mathrm{dd}, J=4.9,1.9 \mathrm{~Hz}, 1 \mathrm{H}), 7.75(\mathrm{~d}, J=8.3 \mathrm{~Hz}, 2 \mathrm{H}), 7.31(\mathrm{~d}$, $J=8.3 \mathrm{~Hz}, 2 \mathrm{H}), 7.25(\mathrm{dd}, J=7.2,1.9 \mathrm{~Hz}, 1 \mathrm{H}), 6.61(\mathrm{dd}, J=7.2,4.9 \mathrm{~Hz}, 1 \mathrm{H}), 4.28-4.15(\mathrm{~m}, 1 \mathrm{H})$, $3.98(\mathrm{t}, J=6.6 \mathrm{~Hz}, 2 \mathrm{H}), 3.69-3.58(\mathrm{~m}, 1 \mathrm{H}), 3.21-3.08(\mathrm{~m}, 1 \mathrm{H}), 2.41(\mathrm{~s}, 3 \mathrm{H}), 2.20(\mathrm{~s}, 3 \mathrm{H})$, 2.16-2.05 (m, 1H), 1.94-1.52 (m, 6H), 1.30-1.09 (m, 15H).

${ }^{13} \mathrm{C}-\mathrm{NMR}\left(75 \mathrm{MHz}, \mathrm{CDCl}_{3}\right): \delta=159.6\left(\mathrm{C}_{\mathrm{q}}\right), 144.5(\mathrm{CH}), 144.5\left(\mathrm{C}_{\mathrm{q}}\right), 139.0(\mathrm{CH}), 133.2\left(\mathrm{C}_{\mathrm{q}}\right)$, $129.7(\mathrm{CH}), 127.8(\mathrm{CH}), 121.9\left(\mathrm{C}_{\mathrm{q}}\right), 114.6(\mathrm{CH}), 70.6\left(\mathrm{CH}_{2}\right), 58.1(\mathrm{CH}), 51.7\left(\mathrm{CH}_{2}\right), 34.2\left(\mathrm{CH}_{2}\right)$, $31.2\left(\mathrm{CH}_{2}\right), 29.8\left(\mathrm{CH}_{2}\right), 29.5\left(\mathrm{CH}_{2}\right), 29.3\left(\mathrm{CH}_{2}\right), 29.3\left(\mathrm{CH}_{2}\right), 28.8\left(\mathrm{CH}_{2}\right), 28.7\left(\mathrm{CH}_{2}\right), 25.8\left(\mathrm{CH}_{2}\right)$, $25.2\left(\mathrm{CH}_{2}\right), 24.9\left(\mathrm{CH}_{2}\right), 21.6\left(\mathrm{CH}_{3}\right), 20.0\left(\mathrm{CH}_{3}\right)$.

IR (ATR): $\tilde{V}=2923,2851,1588,1385,1356,1174,1097,956,775,553 \mathrm{~cm}^{-1}$.

MS (EI) $m / z$ (relative intensity): 472 (3) [ $\left.\mathrm{M}^{+}\right], 376$ (3), 161 (100), 133 (10), 107 (14), 92 (13).

HR-MS (EI) $m / z$ calcd for $\mathrm{C}_{27} \mathrm{H}_{40} \mathrm{~N}_{2} \mathrm{O}_{3} \mathrm{~S}^{+} 472.2760$, found 472.2767 .

\section{Synthesis of 12-\{1-(3-methylpyridin-2-yl)pyrrolidin-2-yl\}dodecan-2-one (217bu)}

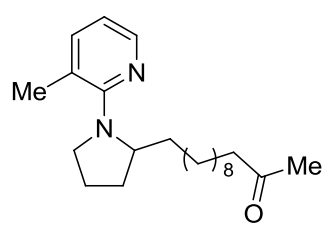

The general procedure $\mathbf{E}$ was followed using 3-methyl-2-(pyrrolidin-1-yl)pyridine (216b) (243 $\mathrm{mg}, 1.5 \mathrm{mmol})$ and 11-dodecen-2-one (111u) (99.1 mg, $0.5 \mathrm{mmol}$ ) in DCE. After $18 \mathrm{~h}$, purification by column chromatography on silica gel ( $n$-hexane/EtOAc: 10/1) yielded 217bu (69 mg, 38\%) as a white solid.

M.p. $=62-63{ }^{\circ} \mathrm{C}$.

${ }^{1} \mathrm{H}-\mathrm{NMR}\left(300 \mathrm{MHz}, \mathrm{CDCl}_{3}\right): \delta=8.01(\mathrm{dd}, J=4.9,1.9 \mathrm{~Hz}, 1 \mathrm{H}), 7.23(\mathrm{dd}, J=7.2,1.9 \mathrm{~Hz}, 1 \mathrm{H})$, $6.60(\mathrm{dd}, J=7.2,4.9 \mathrm{~Hz}, 1 \mathrm{H}), 4.27-4.15(\mathrm{~m}, 1 \mathrm{H}), 3.68-3.56(\mathrm{~m}, 1 \mathrm{H}), 3.17-3.06(\mathrm{~m}, 1 \mathrm{H}), 2.36(\mathrm{t}$, $J=6.9 \mathrm{~Hz}, 2 \mathrm{H}), 2.18(\mathrm{~s}, 3 \mathrm{H}), 2.15-2.01(\mathrm{~m}, 1 \mathrm{H}), 2.08(\mathrm{~s}, 3 \mathrm{H}), 1.92-1.45(\mathrm{~m}, 6 \mathrm{H}), 1.28-1.12(\mathrm{~m}$, $15 \mathrm{H})$.

${ }^{13} \mathrm{C}-\mathrm{NMR}\left(75 \mathrm{MHz}, \mathrm{CDCl}_{3}\right): \delta=207.1\left(\mathrm{C}_{\mathrm{q}}\right), 159.7\left(\mathrm{C}_{\mathrm{q}}\right), 144.6(\mathrm{CH}), 138.9(\mathrm{CH}), 121.8\left(\mathrm{C}_{\mathrm{q}}\right)$, 114.6 (CH), $58.1(\mathrm{CH}), 51.6\left(\mathrm{CH}_{2}\right), 43.7\left(\mathrm{CH}_{2}\right), 34.2\left(\mathrm{CH}_{2}\right), 31.1\left(\mathrm{CH}_{2}\right), 29.8\left(\mathrm{CH}_{2}\right), 29.7\left(\mathrm{CH}_{3}\right)$, $29.5\left(\mathrm{CH}_{2}\right), 29.4\left(\mathrm{CH}_{2}\right), 29.4\left(\mathrm{CH}_{2}\right), 29.3\left(\mathrm{CH}_{2}\right), 29.1\left(\mathrm{CH}_{2}\right), 25.8\left(\mathrm{CH}_{2}\right), 24.8\left(\mathrm{CH}_{2}\right), 23.8\left(\mathrm{CH}_{2}\right)$, $19.9\left(\mathrm{CH}_{3}\right)$.

IR (ATR): $\tilde{V}=2922,2853,1714,1588,1384,1347,1164,776,731 \mathrm{~cm}^{-1}$.

MS (EI) $m / z$ (relative intensity): $344(4)\left[\mathrm{M}^{+}\right], 252$ (6), 161 (100), 133 (12), 92 (16).

HR-MS (ESI) $m / z$ calcd for $\left[\left(\mathrm{C}_{22} \mathrm{H}_{36} \mathrm{~N}_{2} \mathrm{O}\right) \mathrm{H}\right]^{+} 345.2900$, found 345.2900 .

\section{Synthesis of 9-\{1-(3-methylpyridin-2-yl)pyrrolidin-2-yl\}nonan-2-ol (217bv)}

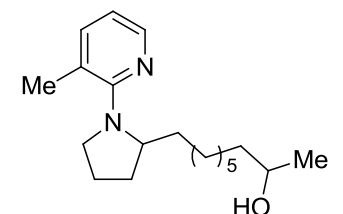

The general procedure $\mathbf{E}$ was followed using 3-methyl-2-(pyrrolidin-1-yl)pyridine (216b) (243 $\mathrm{mg}, 1.5 \mathrm{mmol})$ and 8-nonen-2-one (111v) (70.0 mg, $0.5 \mathrm{mmol})$. After $18 \mathrm{~h}$, purification by column chromatography on silica gel (n-hexane/EtOAc: $10 / 1 \rightarrow 5 / 1)$ yielded 217bv (77 $\mathrm{mg}, 51 \%$ ) as a colorless oil.

${ }^{1} \mathrm{H}-\mathrm{NMR}\left(300 \mathrm{MHz}, \mathrm{CDCl}_{3}\right): \delta=8.02(\mathrm{dd}, J=4.9,1.8 \mathrm{~Hz}, 1 \mathrm{H}), 7.26(\mathrm{dd}, J=7.2,1.8 \mathrm{~Hz}, 1 \mathrm{H})$, 
$6.62(\mathrm{dd}, J=7.2,4.9 \mathrm{~Hz}, 1 \mathrm{H}), 4.27-4.15(\mathrm{~m}, 1 \mathrm{H}), 3.76-3.68(\mathrm{~m}, 1 \mathrm{H}), 3.68-3.58(\mathrm{~m}, 1 \mathrm{H})$, 3.19-3.09 (m, 1H), $2.20(\mathrm{~s}, 3 \mathrm{H}), 2.16-2.05(\mathrm{~m}, 1 \mathrm{H}), 1.94-1.50(\mathrm{~m}, 5 \mathrm{H}), 1.44-1.14(\mathrm{~m}, 13 \mathrm{H}), 1.13$ $(\mathrm{d}, J=6.4 \mathrm{~Hz}, 3 \mathrm{H})$.

${ }^{13} \mathrm{C}-\mathrm{NMR}\left(75 \mathrm{MHz}, \mathrm{CDCl}_{3}\right): \delta=159.6\left(\mathrm{C}_{\mathrm{q}}\right), 144.6(\mathrm{CH}), 139.0(\mathrm{CH}), 121.9\left(\mathrm{C}_{\mathrm{q}}\right), 114.6(\mathrm{CH})$, $68.0(\mathrm{CH}), 58.1(\mathrm{CH}), 51.7\left(\mathrm{CH}_{2}\right), 39.3\left(\mathrm{CH}_{2}\right), 34.2\left(\mathrm{CH}_{2}\right), 31.2\left(\mathrm{CH}_{2}\right), 29.8\left(\mathrm{CH}_{2}\right), 29.5\left(\mathrm{CH}_{2}\right)$, $29.5\left(\mathrm{CH}_{2}\right), 25.8\left(\mathrm{CH}_{2}\right), 25.7\left(\mathrm{CH}_{2}\right), 24.9\left(\mathrm{CH}_{2}\right), 23.4\left(\mathrm{CH}_{3}\right), 20.0\left(\mathrm{CH}_{3}\right)$.

IR (ATR): $\tilde{V}=3364,2924,2854,1588,1384,1346,1102,776,730 \mathrm{~cm}^{-1}$. MS (EI) $m / z$ (relative intensity): 304 (5) $\left[\mathrm{M}^{+}\right], 289$ (5), 161 (100), 133 (12), 92 (18).

HR-MS (EI) $m / z$ calcd for $\mathrm{C}_{19} \mathrm{H}_{32} \mathrm{~N}_{2} \mathrm{O}^{+} 304.2515$, found 304.2519 .

\section{Mechanistic studies with TEMPO (Scheme 82)}
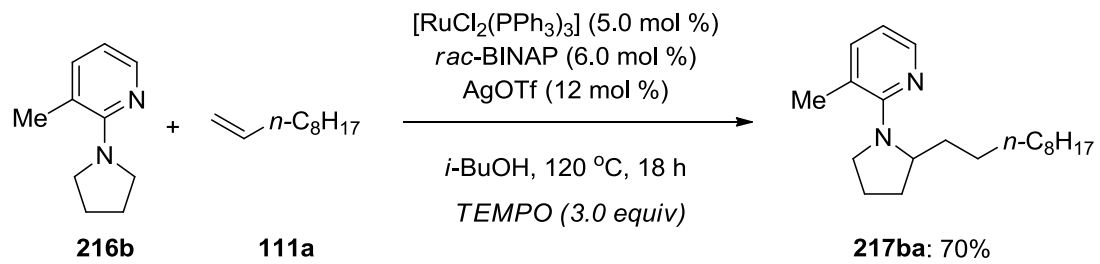

A suspension of $\left[\mathrm{RuCl}_{2}\left(\mathrm{PPh}_{3}\right)_{3}\right](24.0 \mathrm{mg}, 5.0 \mathrm{~mol} \%)$, rac-BINAP (18.7 mg, 6.0 mol \%), AgOTf (15.4 mg, $12 \mathrm{~mol} \%)$, TEMPO (234 mg, $1.5 \mathrm{mmol}), 3$-methyl-2-(pyrrolidin-1-yl)pyridine (216b) (243 mg, $1.5 \mathrm{mmol})$ and 1-decene (111a) $(70.1 \mathrm{mg}, 0.5 \mathrm{mmol})$ in $i$-BuOH $(1.0 \mathrm{~mL})$ was stirred at $120{ }^{\circ} \mathrm{C}$ under $\mathrm{N}_{2}$ for $18 \mathrm{~h}$. At ambient temperature, EtOAc $(5 \mathrm{~mL})$ and silica $(1.5 \mathrm{~g})$ were added to the reaction mixture and the solvents were evaporated in reduced pressure. Purification by column chromatography on silica gel ( $n$-hexane/EtOAc: $40 / 1 \rightarrow 30 / 1)$ yielded $\mathbf{2 1 7 b a}(106 \mathrm{mg}, 70 \%)$ as a colorless oil.

\section{Studies with isotopically labelled $[\mathrm{D}]_{4}-\mathrm{MeOH}$ (Scheme 83a)}
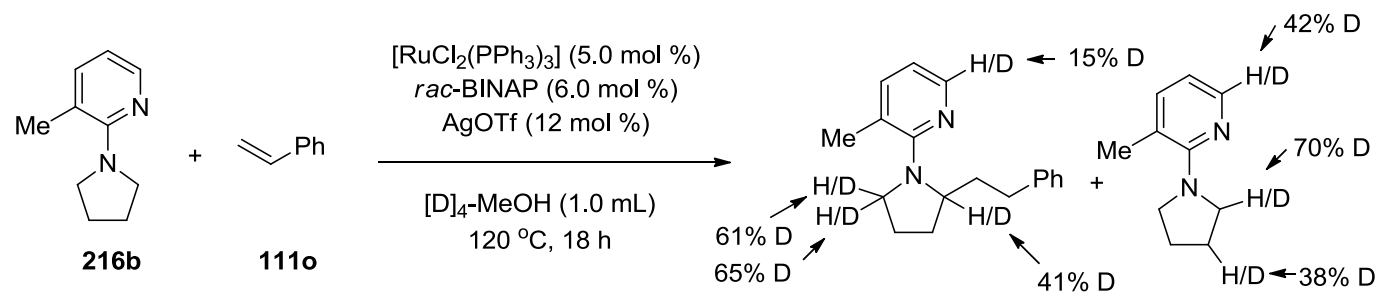

$[D]_{n}-217$ bo: $78 \%$

$[D]_{n}-216 b: 48 \%$

A suspension of $\left[\mathrm{RuCl}_{2}\left(\mathrm{PPh}_{3}\right)_{3}\right](24.0 \mathrm{mg}, 5.0 \mathrm{~mol} \%)$, rac-BINAP (18.7 mg, $\left.6.0 \mathrm{~mol} \%\right)$, AgOTf (15.4 mg, $12 \mathrm{~mol} \%$ ), 3-methyl-2-(pyrrolidin-1-yl)pyridine (216b) (243 mg, $1.5 \mathrm{mmol}$ ) and styrene (1110) $(52.1 \mathrm{mg}, 0.5 \mathrm{mmol})$ in $[\mathrm{D}]_{4}-\mathrm{MeOH}(1.0 \mathrm{~mL})$ was stirred at $120{ }^{\circ} \mathrm{C}$ under $\mathrm{N}_{2}$ for 18 h. $\mathrm{CuCl}(50 \mathrm{mg})$, EtOAc $(5 \mathrm{~mL})$ and silica $(1.5 \mathrm{~g})$ were added to the cold reaction mixture and the solvents were evaporated in vacuo. Purification by column chromatography on silica gel (n-hexane/EtOAc: $20 / 1 \rightarrow 10 / 1)$ to give $[\mathrm{D}]_{\mathrm{n}}$-217bo $(104 \mathrm{mg}, 78 \%)$ as a colorless oil and $[\mathrm{D}]_{\mathrm{n}}-\mathbf{2 1 6 b}$ (118 mg, 48\%) as a colorless oil. The deuterium incorporation was estimated by ${ }^{1} \mathrm{H}-\mathrm{NMR}$ spectroscopy. 


\section{Studies with isotopically labelled $[\mathrm{D}]_{4}-\mathrm{MeOH}$ (Scheme 83b)}

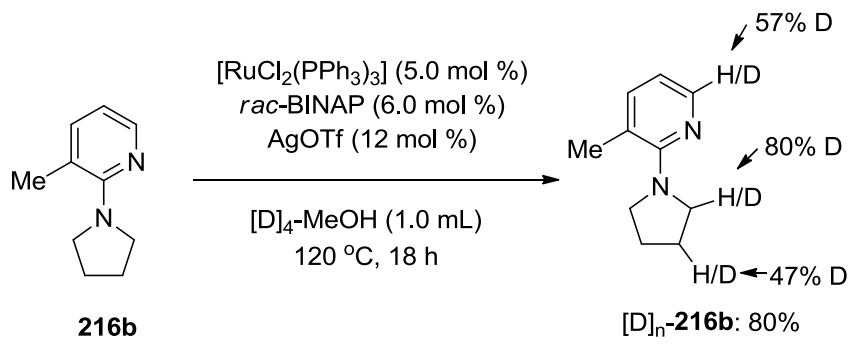

A suspension of $\left[\mathrm{RuCl}_{2}\left(\mathrm{PPh}_{3}\right)_{3}\right]$ (24.0 mg, $\left.5.0 \mathrm{~mol} \%\right)$, rac-BINAP (18.7 mg, $\left.6.0 \mathrm{~mol} \%\right)$, AgOTf (15.4 mg, $12 \mathrm{~mol} \%)$ and 3-methyl-2-(pyrrolidin-1-yl)pyridine (216b) $(81.0 \mathrm{mg}, 0.5 \mathrm{mmol})$ in $[\mathrm{D}]_{4}-\mathrm{MeOH}(1.0 \mathrm{~mL})$ was stirred at $120{ }^{\circ} \mathrm{C}$ under $\mathrm{N}_{2}$ for $18 \mathrm{~h}$. EtOAc $(5 \mathrm{~mL})$ and silica $(1.5 \mathrm{~g})$ were added to the cold reaction mixture and the solvents were evaporated in vacuo. Purification by column chromatography on silica gel ( $n$-hexane/EtOAc: 20/1 $\rightarrow 10 / 1)$ yielded compound $[D]_{\mathrm{n}}-\mathbf{2 1 6 b}(65 \mathrm{mg}, 76 \%)$ as a colorless oil. The deuterium incorporation was estimated by ${ }^{1} \mathrm{H}-\mathrm{NMR}$ spectroscopy.

\section{Studies with isotopically labelled compounds (Scheme 84)}

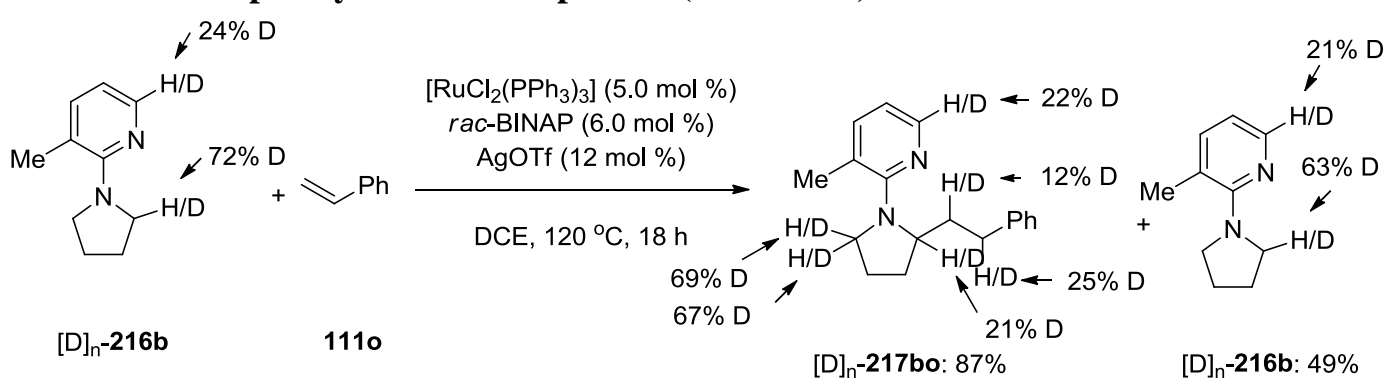

A suspension of $\left[\mathrm{RuCl}_{2}\left(\mathrm{PPh}_{3}\right)_{3}\right](24.0 \mathrm{mg}, 5.0 \mathrm{~mol} \%)$, rac-BINAP (18.7 mg, $\left.6.0 \mathrm{~mol} \%\right)$, AgOTf $(15.4 \mathrm{mg}, 12 \mathrm{~mol} \%),[\mathrm{D}]_{\mathrm{n}}-\mathbf{2 1 6 b}(243 \mathrm{mg}, 1.5 \mathrm{mmol})$ and $111 \mathrm{o}(52.1 \mathrm{mg}, 0.5 \mathrm{mmol})$ in DCE $(1.0 \mathrm{~mL})$ was stirred at $120^{\circ} \mathrm{C}$ under $\mathrm{N}_{2}$ for $18 \mathrm{~h} . \mathrm{CuCl}(50 \mathrm{mg})$, EtOAc $(5 \mathrm{~mL})$ and silica $(1.5 \mathrm{~g})$ were added to the cold reaction mixture and the solvents were evaporated in vacuo. Purification by column chromatography on silica gel ( $n$-hexane/EtOAc: $25 / 1 \rightarrow 10 / 1)$ to give $[\mathrm{D}]_{\mathrm{n}}-\mathbf{2 1 7} \mathbf{b o}(116 \mathrm{mg}$, $87 \%)$ as a colorless oil and $[\mathrm{D}]_{\mathrm{n}}-\mathbf{2 1 6 b}(120 \mathrm{mg}, 49 \%)$ as a colorless oil. The deuterium incorporation was estimated by ${ }^{1} \mathrm{H}-\mathrm{NMR}$ spectroscopy.

\section{Synthesis of 2-decylpyrrolidine (218ba)}

${ }_{n-\mathrm{C}_{8} \mathrm{H}_{17}}$ The general procedure $\mathbf{F}$ was followed using $\square-\mathrm{C}_{8} \mathrm{H}_{17}$ 2-(2-decylpyrrolidin-1-yl)-3-methylpyridine (217ba) (151 mg, $0.5 \mathrm{mmol}$ ). Purification by column chromatography on silica gel $\left(\mathrm{CH}_{2} \mathrm{Cl}_{2} / \mathrm{MeOH}: 20 / 1 \rightarrow 10 / 1\right)$ yielded $\mathbf{2 1 8 b a}$ (74 $\mathrm{mg}, 70 \%)$ as a white solid.

M.p. $=88-89^{\circ} \mathrm{C}$.

${ }^{1} \mathrm{H}-\mathrm{NMR}\left(300 \mathrm{MHz},[\mathrm{d}]_{6}-\mathrm{DMSO}\right): \delta=9.34\left(\mathrm{~s}_{\mathrm{br}}, 1 \mathrm{H}\right), 3.38-3.24(\mathrm{~m}, 1 \mathrm{H}), 3.19-3.00(\mathrm{~m}, 2 \mathrm{H})$, 2.11-1.98 (m, 1H), 1.96-1.38 (m, 6H), 1.39-1.18 (m, 16H), $0.85(\mathrm{t}, J=6.7 \mathrm{~Hz}, 3 \mathrm{H})$.

${ }^{13} \mathrm{C}-\mathrm{NMR}\left(75 \mathrm{MHz},[\mathrm{d}]_{6}\right.$-DMSO): $\delta=59.3(\mathrm{CH}), 43.7\left(\mathrm{CH}_{2}\right), 31.3\left(\mathrm{CH}_{2}\right), 31.2\left(\mathrm{CH}_{2}\right), 29.7\left(\mathrm{CH}_{2}\right)$, $28.9\left(\mathrm{CH}_{2}\right), 28.8\left(\mathrm{CH}_{2}\right), 28.7\left(\mathrm{CH}_{2}\right), 28.6\left(\mathrm{CH}_{2}\right), 28.6\left(\mathrm{CH}_{2}\right), 26.1\left(\mathrm{CH}_{2}\right), 22.9\left(\mathrm{CH}_{2}\right), 22.0\left(\mathrm{CH}_{2}\right)$, $13.8\left(\mathrm{CH}_{3}\right)$.

IR (ATR): $\tilde{V}=2919,2850,2744,1461,1385,1030,730 \mathrm{~cm}^{-1}$.

MS (ESI) $m / z$ (relative intensity): $210(100)\left[(\mathrm{M}+\mathrm{H})^{+}\right]$. 
HR-MS (ESI) $m / z$ calcd for $\left[\left(\mathrm{C}_{14} \mathrm{H}_{29} \mathrm{~N}\right) \mathrm{H}\right]^{+} 210.2373$, found 210.2375 .

\section{Synthesis of 2-\{2-(triethylsilyl)ethyl\}pyrrolidine (218bj)}

$\mathrm{H}$ The general procedure $\mathbf{F}$ was followed using ${ }^{\mathrm{N}} \mathrm{SiEt}_{3}$ 3-methyl-2-\{2-[2-(triethylsilyl)ethyl]pyrrolidin-1-yl $\}$ pyridine (217bj) $(152 \mathrm{mg}$, $0.5 \mathrm{mmol})$. Purification by column chromatography on silica gel $\left(\mathrm{CH}_{2} \mathrm{Cl}_{2} / \mathrm{MeOH}\right.$ :

$20 / 1 \rightarrow 10 / 1 \rightarrow 5 / 1)$ yielded $\mathbf{2 1 8 b j}(65 \mathrm{mg}, 61 \%)$ as a white solid.

M.p. $=52-53{ }^{\circ} \mathrm{C}$.

${ }^{1} \mathrm{H}-\mathrm{NMR}\left(300 \mathrm{MHz}, \mathrm{CDCl}_{3}\right): \delta=7.52\left(\mathrm{~s}_{\mathrm{br}}, 1 \mathrm{H}\right), 3.35-3.09(\mathrm{~m}, 3 \mathrm{H}), 2.16-2.00(\mathrm{~m}, 1 \mathrm{H}), 2.00-1.69$ $(\mathrm{m}, 3 \mathrm{H}), 1.64-1.43(\mathrm{~m}, 2 \mathrm{H}), 0.91(\mathrm{t}, J=7.8 \mathrm{~Hz}, 9 \mathrm{H}), 0.67-0.38(\mathrm{~m}, 8 \mathrm{H})$.

${ }^{13} \mathrm{C}-\mathrm{NMR}\left(75 \mathrm{MHz},[\mathrm{d}]_{6}\right.$-DMSO): $\delta=62.1(\mathrm{CH}), 44.1\left(\mathrm{CH}_{2}\right), 29.4\left(\mathrm{CH}_{2}\right), 26.3\left(\mathrm{CH}_{2}\right), 23.1\left(\mathrm{CH}_{2}\right)$, $8.0\left(\mathrm{CH}_{2}\right), 7.2\left(\mathrm{CH}_{3}\right), 2.7\left(\mathrm{CH}_{2}\right)$.

IR (ATR): $\tilde{V}=2950,2873,2730,1459,1414,1015,758,720 \mathrm{~cm}^{-1}$.

MS (ESI) $m / z$ (relative intensity): $212(100)\left[(\mathrm{M}+\mathrm{H})^{+}\right]$.

HR-MS (ESI) $m / z$ calcd for $\left[\left(\mathrm{C}_{12} \mathrm{H}_{27} \mathrm{NSi}\right) \mathrm{H}\right]^{+} 212.1986$, found 212.1987.

\section{Synthesis of 2-(2-cyclohexylethyl)pyrrolidine (218bo)}

The general procedure $\mathbf{F}$ was followed using 3-methyl-2-(2-phenethylpyrrolidin-1-yl)pyridine (217bo) (195 mg, $0.5 \mathrm{mmol}$ ). Purification by column chromatography on silica gel $\left(\mathrm{CH}_{2} \mathrm{Cl}_{2} / \mathrm{MeOH}\right.$ : $10 / 1 \rightarrow 5 / 1 \rightarrow 3 / 1)$ yielded $\mathbf{2 1 8 b o}(53 \mathrm{mg}, 58 \%)$ as a white solid.

M.p. $=99-100{ }^{\circ} \mathrm{C}$.

${ }^{1} \mathrm{H}-\mathrm{NMR}\left(300 \mathrm{MHz}[\mathrm{D}]_{6}-\mathrm{DMSO}\right): \delta=6.93\left(\mathrm{~s}_{\mathrm{br}}, 1 \mathrm{H}\right), 3.33-3.18(\mathrm{~m}, 1 \mathrm{H}), 3.17-2.95(\mathrm{~m}, 2 \mathrm{H})$, 2.12-1.96 (m, 1H), 1.95-1.37 (m, 10H), 1.33-1.00 (m, 6H), 0.96-0.75 (m, 2H).

${ }^{13} \mathrm{C}-\mathrm{NMR}\left(75 \mathrm{MHz},[\mathrm{d}]_{6}-\mathrm{DMSO}\right): \delta=59.5(\mathrm{CH}), 43.8\left(\mathrm{CH}_{2}\right), 36.7(\mathrm{CH}), 33.7\left(\mathrm{CH}_{2}\right), 32.6\left(\mathrm{CH}_{2}\right)$, $29.8\left(\mathrm{CH}_{2}\right), 28.9\left(\mathrm{CH}_{2}\right), 26.0\left(\mathrm{CH}_{2}\right), 25.6\left(\mathrm{CH}_{2}\right), 23.0\left(\mathrm{CH}_{2}\right)$.

IR (ATR): $\tilde{V}=1917,1851,1575,1588,1448,1412,1027,387 \mathrm{~cm}^{-1}$.

MS (ESI) $m / z$ (relative intensity): $182(100)\left[(\mathrm{M}+\mathrm{H})^{+}\right]$.

HR-MS (ESI) $m / z$ calcd for $\left[\left(\mathrm{C}_{12} \mathrm{H}_{23} \mathrm{~N}\right) \mathrm{H}\right]^{+} 182.1903$, found 182.1905 .

\subsubsection{Analytical Data for the Products of Ruthenium-Catalyzed ortho-C-H Halogenation of Benzamide 219}

\section{Synthesis of 2-bromo- $N, N$-diisopropylbenzamide (220a)}

$\mathrm{O}^{\mathrm{N}(i-\mathrm{Pr})_{2}}$ The general procedure $\mathbf{G}$ was followed using $N, N$-diisopropylbenzamide (219a) (103 mg, $0.5 \mathrm{mmol})$ and NBS (178 mg, $1.0 \mathrm{mmol})$. After $16 \mathrm{~h}$, purification by column chromatography on silica gel ( $n$-hexane/EtOAc: $10 / 1 \rightarrow 5 / 1)$ yielded 220 a (86 $\mathrm{mg}, 60 \%)$ as a white solid.

M.p. $=73-74{ }^{\circ} \mathrm{C}$.

${ }^{1} \mathrm{H}-\mathrm{NMR}\left(300 \mathrm{MHz}, \mathrm{CDCl}_{3}\right): \delta=7.57(\mathrm{~d}, J=7.6 \mathrm{~Hz}, 1 \mathrm{H}), 7.53(\mathrm{dd}, J=7.6,7.6 \mathrm{~Hz}, 1 \mathrm{H})$, $7.22-7.12(\mathrm{~m}, 2 \mathrm{H}), 3.65-3.43(\mathrm{~m}, 2 \mathrm{H}), 1.56(\mathrm{~d}, J=6.7 \mathrm{~Hz}, 3 \mathrm{H}), 1.55(\mathrm{~d}, J=6.7 \mathrm{~Hz}, 3 \mathrm{H}), 1.22(\mathrm{~d}$, $J=6.7 \mathrm{~Hz}, 3 \mathrm{H}), 1.04(\mathrm{~d}, J=6.7 \mathrm{~Hz}, 3 \mathrm{H})$.

${ }^{13} \mathrm{C}-\mathrm{NMR}\left(75 \mathrm{MHz}, \mathrm{CDCl}_{3}\right): \delta=168.0\left(\mathrm{C}_{\mathrm{q}}\right), 140.1\left(\mathrm{C}_{\mathrm{q}}\right), 132.7(\mathrm{CH}), 129.3(\mathrm{CH}), 127.4(\mathrm{CH})$, $126.5(\mathrm{CH}), 118.8\left(\mathrm{C}_{\mathrm{q}}\right), 51.1(\mathrm{CH}), 45.9(\mathrm{CH}), 20.7\left(\mathrm{CH}_{3}\right), 20.6\left(\mathrm{CH}_{3}\right), 20.5\left(\mathrm{CH}_{3}\right), 20.0\left(\mathrm{CH}_{3}\right)$. IR (ATR): $\tilde{V}=2975,2930,1626,1438,1339,1019,770 \mathrm{~cm}^{-1}$. 
MS (EI) $\mathrm{m} / z$ (relative intensity): 285 (7) $\left[\mathrm{M}^{+}\right]\left({ }^{81} \mathrm{Br}\right), 283(7)\left[\mathrm{M}^{+}\right]\left({ }^{79} \mathrm{Br}\right), 238$ (25), 240 (26), 185 (98), 185 (100).

HR-MS (EI) $\mathrm{m} / z$ calcd for $\mathrm{C}_{13} \mathrm{H}_{18} \mathrm{BrNO}^{+} 283.0572$, found 283.0567 .

The spectral data were in accordance with those reported in the literature. ${ }^{113 a}$

\section{Synthesis of 2-bromo- $N, N, 3,5$-tetramethylbenzamide (220b)}

$\mathrm{O}_{-} \mathrm{NMe}_{2}$ The general procedure $\mathbf{G}$ was followed using $N, N, 3,5$-tetramethylbenzamide (219b) $\mathrm{Y}_{\mathrm{Br}}^{\mathrm{NMe}_{2}}(177 \mathrm{mg}, 1.0 \mathrm{mmol})$ and NBS $(356 \mathrm{mg}, 2.0 \mathrm{mmol})$. After $16 \mathrm{~h}$, purification by Me ${ }_{\mathrm{Me}}$ column chromatography on silica gel ( $n$-hexane/EtOAc: $\left.3 / 1 \rightarrow 2 / 1\right)$ yielded $220 \mathrm{~b}$ $(175 \mathrm{mg}, 68 \%)$ as a yellow solid.

M.p. $=103-104{ }^{\circ} \mathrm{C}$.

${ }^{1} \mathrm{H}-\mathrm{NMR}\left(300 \mathrm{MHz}, \mathrm{CDCl}_{3}\right): \delta=7.02(\mathrm{~s}, 1 \mathrm{H}), 6.86(\mathrm{~s}, 1 \mathrm{H}), 3.10(\mathrm{~s}, 3 \mathrm{H}), 2.84(\mathrm{~s}, 3 \mathrm{H}), 2.35(\mathrm{~s}, 3 \mathrm{H})$, $2.25(\mathrm{~s}, 3 \mathrm{H})$.

${ }^{13} \mathrm{C}-\mathrm{NMR}\left(75 \mathrm{MHz}, \mathrm{CDCl}_{3}\right): \delta=169.8\left(\mathrm{C}_{\mathrm{q}}\right), 138.9\left(\mathrm{C}_{\mathrm{q}}\right), 138.5\left(\mathrm{C}_{\mathrm{q}}\right), 137.6\left(\mathrm{C}_{\mathrm{q}}\right), 131.7(\mathrm{CH}), 125.5$ $(\mathrm{CH}), 117.9\left(\mathrm{C}_{\mathrm{q}}\right), 38.2\left(\mathrm{CH}_{3}\right), 34.5\left(\mathrm{CH}_{3}\right), 23.0\left(\mathrm{CH}_{3}\right), 20.7\left(\mathrm{CH}_{3}\right)$.

IR (ATR): $\tilde{V}=2918,2871,1626,1508,1441,1392,1257,1130,1020,865,665 \mathrm{~cm}^{-1}$.

MS (EI) $\mathrm{m} / z$ (relative intensity): $257(17)\left[\mathrm{M}^{+}\right]\left({ }^{81} \mathrm{Br}\right), 255(20)\left[\mathrm{M}^{+}\right]\left({ }^{79} \mathrm{Br}\right), 219$ (97), 209 (100), 104 (35).

HR-MS (EI) $m / z$ calcd for $\mathrm{C}_{11} \mathrm{H}_{14} \mathrm{BrNO}^{+} 255.0259$, found 255.0249.

\section{Synthesis of 2-iodo- $N, N, 3,5$-tetramethylbenzamide (221b)}

The general procedure $\mathbf{G}$ was followed using $N, N, 3,5$-tetramethylbenzamide (219b)
$(177 \mathrm{mg}, 1.0 \mathrm{mmol})$ and NIS (450 mg, $2.0 \mathrm{mmol})$. After $16 \mathrm{~h}$, purification by
column chromatography on silica gel ( $n$-hexane/EtOAc: $3 / 1)$ yielded $\mathbf{2 2 1 b}(224 \mathrm{mg}$,
$\begin{aligned} & 74 \%) \text { as a yellow solid. }\end{aligned}$

The general procedure $\mathbf{H}$ was followed using $N, N, 3,5$-tetramethylbenzamide (219b) (177 mg, $1.0 \mathrm{mmol}$ ) and NIS (450 mg, $2.0 \mathrm{mmol}$ ). After $22 \mathrm{~h}$, purification by column chromatography on silica gel ( $n$-hexane/EtOAc: $3 / 1)$ yielded $\mathbf{2 2 1 b}(237 \mathrm{mg}, 78 \%)$ as a yellow solid.

M.p. $=82-83^{\circ} \mathrm{C}$.

${ }^{1} \mathrm{H}-\mathrm{NMR}\left(300 \mathrm{MHz}, \mathrm{CDCl}_{3}\right): \delta=6.98(\mathrm{~s}, 1 \mathrm{H}), 6.76$ (s, 1H), 3.07 (s, 3H), 2.79 (s, 3H), $2.36(\mathrm{~s}, 3 \mathrm{H})$, $2.21(\mathrm{~s}, 3 \mathrm{H})$.

${ }^{13} \mathrm{C}-\mathrm{NMR}\left(75 \mathrm{MHz}, \mathrm{CDCl}_{3}\right): \delta=171.3\left(\mathrm{C}_{\mathrm{q}}\right), 143.5\left(\mathrm{C}_{\mathrm{q}}\right), 138.0\left(\mathrm{C}_{\mathrm{q}}\right), 138.4\left(\mathrm{C}_{\mathrm{q}}\right), 130.3(\mathrm{CH}), 124.8$ $(\mathrm{CH}), 94.9\left(\mathrm{C}_{\mathrm{q}}\right), 38.3\left(\mathrm{CH}_{3}\right), 34.5\left(\mathrm{CH}_{3}\right), 28.4\left(\mathrm{CH}_{3}\right), 20.6\left(\mathrm{CH}_{3}\right)$.

IR (ATR): $\tilde{V}=2913,2853,1626,1505,1441,1399,1125,1003,863,663 \mathrm{~cm}^{-1}$.

MS (EI) $m / z$ (relative intensity): 303 (38) $\left[\mathrm{M}^{+}\right], 259$ (100), 231 (24), 104 (20).

HR-MS (EI) $m / z$ calcd for $\mathrm{C}_{11} \mathrm{H}_{14} \mathrm{INO}^{+} 303.0120$, found 303.0118.

\section{Synthesis of 2-bromo- $N, N$-diethyl-3,5-dimethylbenzamide (220c)}

$\mathrm{O}_{\mathrm{NEt}_{2}}$ The general procedure $\mathbf{G}$ was followed using $\mathrm{N}, \mathrm{N}$-diethyl-3,5-dimethylbenzamide Br (219c) $(205 \mathrm{mg}, 1.0 \mathrm{mmol})$ and NBS (356 mg, $2.0 \mathrm{mmol})$. After $16 \mathrm{~h}$, purification by column chromatography on silica gel ( $n$-hexane/EtOAc: $5 / 1)$ yielded 220c (159 $\mathrm{mg}, 56 \%)$ as a colorless oil.

${ }^{1} \mathrm{H}-\mathrm{NMR}\left(300 \mathrm{MHz}, \mathrm{CDCl}_{3}\right.$ ): $\delta=7.02(\mathrm{~s}, 1 \mathrm{H}), 6.85(\mathrm{~s}, 1 \mathrm{H}), 3.79$ (hex, $J=6.9 \mathrm{~Hz}, 1 \mathrm{H}$ ), 3.31 (hex, $J=6.9 \mathrm{~Hz}, 1 \mathrm{H}), 3.19-3.05(\mathrm{~m}, 2 \mathrm{H}), 2.35(\mathrm{~s}, 3 \mathrm{H}), 2.25(\mathrm{~s}, 3 \mathrm{H}), 1.25(\mathrm{t}, J=6.9 \mathrm{~Hz}, 3 \mathrm{H}), 1.04(\mathrm{t}, J=$ $6.9 \mathrm{~Hz}, 3 \mathrm{H})$. 
${ }^{13} \mathrm{C}-\mathrm{NMR}\left(75 \mathrm{MHz}, \mathrm{CDCl}_{3}\right): \delta=169.0\left(\mathrm{C}_{\mathrm{q}}\right), 139.0\left(\mathrm{C}_{\mathrm{q}}\right), 138.4\left(\mathrm{C}_{\mathrm{q}}\right), 137.2\left(\mathrm{C}_{\mathrm{q}}\right), 131.4(\mathrm{CH}), 125.3$ $(\mathrm{CH}), 117.9\left(\mathrm{C}_{\mathrm{q}}\right), 38.5\left(\mathrm{CH}_{2}\right), 38.6\left(\mathrm{CH}_{2}\right), 23.0\left(\mathrm{CH}_{3}\right), 20.6\left(\mathrm{CH}_{3}\right), 13.8\left(\mathrm{CH}_{3}\right), 12.4\left(\mathrm{CH}_{3}\right)$.

IR (ATR): $\tilde{V}=2973,2932,1631,1433,1132,1023,767,649 \mathrm{~cm}^{-1}$.

MS (EI) $m / z$ (relative intensity): $285(27)\left[\mathrm{M}^{+}\right]\left({ }^{81} \mathrm{Br}\right), 283(28)\left[\mathrm{M}^{+}\right]\left({ }^{79} \mathrm{Br}\right), 219$ (98), 209 (100), 133 (22), 104 (48).

HR-MS (ESI) $m / z$ calcd for $\left[\left(\mathrm{C}_{13} \mathrm{H}_{18} \mathrm{BrNO}\right) \mathrm{H}\right]^{+} 284.0645$, found 284.0645 .

\section{Synthesis of $N, N$-diethyl-2-iodo-3,5-dimethylbenzamide (221c)}

$\mathrm{O}_{\mathrm{NEt}_{2}}$ The general procedure $\mathbf{G}$ was followed using $\mathrm{N}, \mathrm{N}$-diethyl-3,5-dimethylbenzamide (219c) $(205 \mathrm{mg}, 1.0 \mathrm{mmol})$ and NIS (450 mg, $2.0 \mathrm{mmol})$. After $16 \mathrm{~h}$, purification by column chromatography on silica gel ( $n$-hexane/EtOAc: $10 / 1 \rightarrow 5 / 1)$ and normal phase HPLC ( $n$-hexane/EtOAc: $15 / 1 \rightarrow 7 / 1)$ yielded 221c $(179 \mathrm{mg}, 54 \%)$ as a colorless oil.

The general procedure $\mathbf{H}$ was followed using $N, N$-diethyl-3,5-dimethylbenzamide (219c) (205 mg, $1.0 \mathrm{mmol}$ ) and NIS (450 mg, $2.0 \mathrm{mmol})$. After $22 \mathrm{~h}$, purification by column chromatography on silica gel ( $n$-hexane/EtOAc: $10 / 1 \rightarrow 5 / 1$ ) and normal phase HPLC ( $n$-hexane/EtOAc: $15 / 1 \rightarrow 7 / 1$ ) yielded 221c (235 $\mathrm{mg}, 71 \%)$ as a colorless oil.

${ }^{1} \mathrm{H}-\mathrm{NMR}\left(300 \mathrm{MHz}, \mathrm{CDCl}_{3}\right.$ ): $\delta=7.02(\mathrm{~s}, 1 \mathrm{H}), 6.79$ (s, $\left.1 \mathrm{H}\right), 3.84$ (hex, $J=6.9 \mathrm{~Hz}, 1 \mathrm{H}$ ), 3.28 (hex, $J=6.9 \mathrm{~Hz}, 1 \mathrm{H}), 3.20-3.03(\mathrm{~m}, 2 \mathrm{H}), 2.39(\mathrm{~s}, 3 \mathrm{H}), 2.24(\mathrm{~s}, 3 \mathrm{H}), 1.28(\mathrm{t}, J=6.9 \mathrm{~Hz}, 3 \mathrm{H}), 1.05(\mathrm{t}, J=$ $6.9 \mathrm{~Hz}, 3 \mathrm{H})$.

${ }^{13} \mathrm{C}-\mathrm{NMR}\left(75 \mathrm{MHz}, \mathrm{CDCl}_{3}\right): \delta=170.7\left(\mathrm{C}_{\mathrm{q}}\right), 143.6\left(\mathrm{C}_{\mathrm{q}}\right), 138.1\left(\mathrm{C}_{\mathrm{q}}\right), 138.2\left(\mathrm{C}_{\mathrm{q}}\right), 130.2(\mathrm{CH}), 124.8$ $(\mathrm{CH}), 95.4\left(\mathrm{C}_{\mathrm{q}}\right), 38.6\left(\mathrm{CH}_{2}\right), 38.7\left(\mathrm{CH}_{2}\right), 28.5\left(\mathrm{CH}_{3}\right), 20.7\left(\mathrm{CH}_{3}\right), 13.8\left(\mathrm{CH}_{3}\right), 12.3\left(\mathrm{CH}_{3}\right)$.

IR (ATR): $\tilde{V}=2972,2932,1628,1432,1317,1129,1008,857,766,648 \mathrm{~cm}^{-1}$.

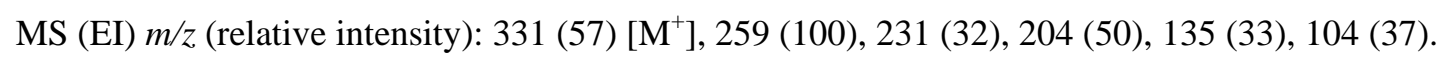
HR-MS (EI) $\mathrm{m} / z$ calcd for $\mathrm{C}_{13} \mathrm{H}_{18} \mathrm{INO}^{+} 331.0433$, found 331.0432 .

\section{Synthesis of 2-bromo- $N, N$-diisopropyl-3,5-dimethylbenzamide (220d)}

$\mathrm{O}^{\mathrm{N}(i-\mathrm{Pr})_{2}}$ The general procedure $\mathbf{G}$ was followed using $\mathrm{C}_{\mathrm{Br}}^{\mathrm{B}(i-\mathrm{Pr})_{2}} \mathrm{~N}, \mathrm{~N}$-diisopropyl-3,5-dimethylbenzamide (219d) $(233 \mathrm{mg}, 1.0 \mathrm{mmol})$ and NBS $\left(356 \mathrm{mg}, 2.0 \mathrm{mmol}\right.$ ) at $80^{\circ} \mathrm{C}$. After $16 \mathrm{~h}$, purification by column chromatography on silica gel ( $n$-hexane/EtOAc: 10/1) yielded 220d (277 $\mathrm{mg}, 89 \%)$ as a white

solid.

M.p. $=200-201{ }^{\circ} \mathrm{C}$.

${ }^{1} \mathrm{H}-\mathrm{NMR}\left(300 \mathrm{MHz}, \mathrm{CDCl}_{3}\right): \delta=7.00(\mathrm{~s}, 1 \mathrm{H}), 6.76(\mathrm{~s}, 1 \mathrm{H}), 3.63$ (sept, $\left.J=6.7 \mathrm{~Hz}, 1 \mathrm{H}\right), 3.50$ (sept, $J=6.7 \mathrm{~Hz}, 1 \mathrm{H}), 2.36(\mathrm{~s}, 3 \mathrm{H}), 2.25(\mathrm{~s}, 3 \mathrm{H}), 1.57(\mathrm{~d}, J=6.7 \mathrm{~Hz}, 3 \mathrm{H}), 1.55(\mathrm{~d}, J=6.7 \mathrm{~Hz}, 3 \mathrm{H}), 1.22$ $(\mathrm{d}, J=6.7 \mathrm{~Hz}, 3 \mathrm{H}), 1.05(\mathrm{~d}, J=6.7 \mathrm{~Hz}, 3 \mathrm{H})$.

${ }^{13} \mathrm{C}-\mathrm{NMR}\left(75 \mathrm{MHz}, \mathrm{CDCl}_{3}\right): \delta=168.7\left(\mathrm{C}_{\mathrm{q}}\right), 140.4\left(\mathrm{C}_{\mathrm{q}}\right), 138.4\left(\mathrm{C}_{\mathrm{q}}\right), 137.2\left(\mathrm{C}_{\mathrm{q}}\right), 130.9(\mathrm{CH}), 124.4$ $(\mathrm{CH}), 117.7\left(\mathrm{C}_{\mathrm{q}}\right), 51.0(\mathrm{CH}), 45.7(\mathrm{CH}), 23.0\left(\mathrm{CH}_{3}\right), 20.7\left(\mathrm{CH}_{3}\right), 20.6\left(\mathrm{CH}_{3}\right), 20.6\left(\mathrm{CH}_{3}\right), 20.5$ $\left(\mathrm{CH}_{3}\right), 19.9\left(\mathrm{CH}_{3}\right)$.

IR (ATR): $\tilde{v}=2960,2928,1626,1438,1368,1346,1207,1026,865,778 \mathrm{~cm}^{-1}$.

MS (EI) $\mathrm{m} / z$ (relative intensity): $313(15)\left[\mathrm{M}^{+}\right]\left({ }^{81} \mathrm{Br}\right), 311(15)\left[\mathrm{M}^{+}\right]\left({ }^{79} \mathrm{Br}\right), 270$ (28), 268 (28), 219 (98), 209 (100), 104 (17).

HR-MS (EI) $\mathrm{m} / z$ calcd for $\mathrm{C}_{15} \mathrm{H}_{22} \mathrm{BrNO}^{+} 311.0885$, found 311.0877 . 


\section{Synthesis of 2-iodo- $N, N$-diisopropyl-3,5-dimethylbenzamide (221d)}

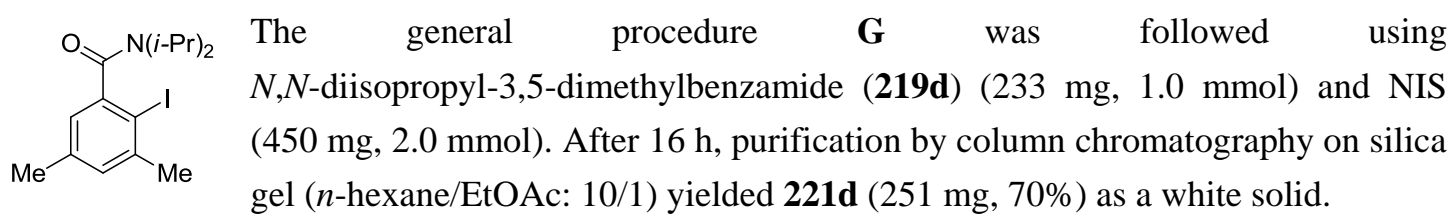

The general procedure $\mathbf{H}$ was followed using $N, N$-diisopropyl-3,5-dimethylbenzamide (219d) $(233 \mathrm{mg}, 1.0 \mathrm{mmol}$ ) and NIS (450 mg, $2.0 \mathrm{mmol})$. After $22 \mathrm{~h}$, purification by column chromatography on silica gel ( $n$-hexane/EtOAc: 10/1) yielded 221d (305 mg, 85\%) as a white solid.

M.p. $=195-196^{\circ} \mathrm{C}$.

${ }^{1} \mathrm{H}-\mathrm{NMR}\left(300 \mathrm{MHz}, \mathrm{CDCl}_{3}\right): \delta=6.98(\mathrm{~s}, 1 \mathrm{H}), 6.71(\mathrm{~s}, 1 \mathrm{H}), 3.59$ (hept, $\left.J=6.8 \mathrm{~Hz}, 1 \mathrm{H}\right), 3.48$ (hept $J=6.8 \mathrm{~Hz}, 1 \mathrm{H}), 2.39$ (s, 3H), $2.23(\mathrm{~s}, 3 \mathrm{H}), 1.60(\mathrm{~d}, J=6.8 \mathrm{~Hz}, 3 \mathrm{H}), 1.54(\mathrm{~d}, J=6.8 \mathrm{~Hz}, 3 \mathrm{H}), 1.24$ (d, $J=6.8 \mathrm{~Hz}, 3 \mathrm{H}), 1.03(\mathrm{~d}, J=6.8 \mathrm{~Hz}, 3 \mathrm{H})$.

${ }^{13} \mathrm{C}-\mathrm{NMR}\left(75 \mathrm{MHz}, \mathrm{CDCl}_{3}\right): \delta=170.5\left(\mathrm{C}_{\mathrm{q}}\right), 145.0\left(\mathrm{C}_{\mathrm{q}}\right), 138.2\left(\mathrm{C}_{\mathrm{q}}\right), 138.2\left(\mathrm{C}_{\mathrm{q}}\right), 129.9(\mathrm{CH}), 123.8$ $(\mathrm{CH}), 95.0\left(\mathrm{C}_{\mathrm{q}}\right), 51.1(\mathrm{CH}), 45.8(\mathrm{CH}), 28.5\left(\mathrm{CH}_{3}\right), 20.7\left(\mathrm{CH}_{3}\right), 20.7\left(\mathrm{CH}_{3}\right), 20.7\left(\mathrm{CH}_{3}\right), 20.6$ $\left(\mathrm{CH}_{3}\right), 19.9\left(\mathrm{CH}_{3}\right)$.

IR (ATR): $\tilde{V}=2958,2926,1625,1438,1368,1344,1206,864,777,630 \mathrm{~cm}^{-1}$.

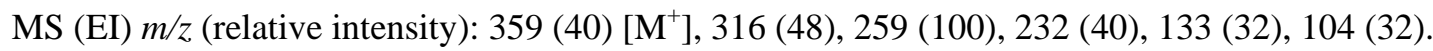

HR-MS (ESI) $m / z$ calcd for $\left[\left(\mathrm{C}_{15} \mathrm{H}_{22} \mathrm{INO}\right) \mathrm{H}\right]^{+} 360.0824$, found 360.0817 .

\section{Synthesis of (2-bromo-3,5-dimethylphenyl)(pyrrolidin-1-yl)methanone (220e)}

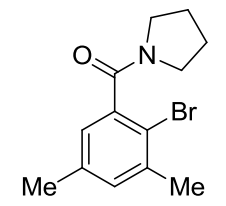

$$
\text { The general procedure } \mathbf{G} \text { was followed using }
$$
(3,5-dimethylphenyl)(pyrrolidin-1-yl)methanone (219e) (203 $\mathrm{mg}, 1.0 \mathrm{mmol})$ and NBS $(356 \mathrm{mg}, 2.0 \mathrm{mmol})$. After $16 \mathrm{~h}$, purification by column chromatography on silica gel ( $n$-hexane/EtOAc: $2 / 1 \rightarrow 1 / 1)$ and normal phase HPLC ( $n$-hexane/EtOAc: $3 / 1 \rightarrow 2 / 1)$ yielded 220e (102 $\mathrm{mg}, 36 \%$ ) as a white solid.

The general procedure $\mathbf{H}$ was followed using (3,5-dimethylphenyl)(pyrrolidin-1-yl)methanone (219e) $(203 \mathrm{mg}, 1.0 \mathrm{mmol})$ and NBS $(356 \mathrm{mg}, 2.0 \mathrm{mmol})$. After $22 \mathrm{~h}$, purification by column chromatography on silica gel ( $n$-hexane/EtOAc: $2 / 1 \rightarrow 1 / 1)$ and normal phase HPLC ( $n$-hexane/EtOAc: $3 / 1 \rightarrow 2 / 1)$ yielded 220e $(102 \mathrm{mg}, 36 \%$ ) as a white solid.

M.p. $=68-69^{\circ} \mathrm{C}$.

${ }^{1} \mathrm{H}-\mathrm{NMR}\left(300 \mathrm{MHz}, \mathrm{CDCl}_{3}\right): \delta=7.03(\mathrm{~s}, 1 \mathrm{H}), 6.90(\mathrm{~s}, 1 \mathrm{H}), 3.64(\mathrm{t}, J=6.7 \mathrm{~Hz}, 2 \mathrm{H}), 3.31-3.08(\mathrm{~m}$, $2 \mathrm{H}), 2.36(\mathrm{~s}, 3 \mathrm{H}), 2.26(\mathrm{~s}, 3 \mathrm{H}), 2.00-1.83(\mathrm{~m}, 4 \mathrm{H})$.

${ }^{13} \mathrm{C}-\mathrm{NMR}\left(75 \mathrm{MHz}, \mathrm{CDCl}_{3}\right): \delta=168.0\left(\mathrm{C}_{\mathrm{q}}\right), 139.9\left(\mathrm{C}_{\mathrm{q}}\right), 138.5\left(\mathrm{C}_{\mathrm{q}}\right), 137.6\left(\mathrm{C}_{\mathrm{q}}\right), 131.6(\mathrm{CH}), 125.3$ $(\mathrm{CH}), 117.5\left(\mathrm{C}_{\mathrm{q}}\right), 43.0\left(\mathrm{CH}_{2}\right), 45.3\left(\mathrm{CH}_{2}\right), 25.8\left(\mathrm{CH}_{3}\right), 24.6\left(\mathrm{CH}_{2}\right), 23.0\left(\mathrm{CH}_{2}\right), 20.7\left(\mathrm{CH}_{3}\right)$.

IR (ATR): $\tilde{V}=2971,2874,1629,1433,1023,859,706,621 \mathrm{~cm}^{-1}$.

MS (EI) $\mathrm{m} / z$ (relative intensity): $283(30)\left[\mathrm{M}^{+}\right]\left({ }^{81} \mathrm{Br}\right), 281(31)\left[\mathrm{M}^{+}\right]\left({ }^{79} \mathrm{Br}\right), 219$ (98), 209 (100), 202 (37), 104 (38).

HR-MS (EI) $m / z$ calcd for $\mathrm{C}_{13} \mathrm{H}_{16} \mathrm{BrNO}^{+} 281.0415$, found 281.0405 .

\section{Synthesis of (2-iodo-3,5-dimethylphenyl)(pyrrolidin-1-yl)methanone (221e)}

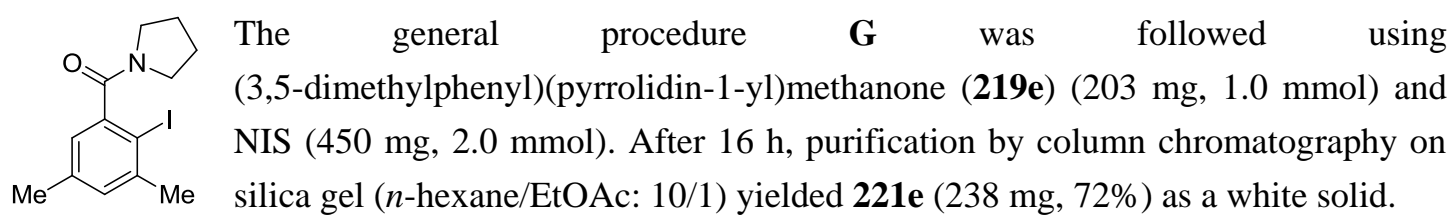


The general procedure $\mathbf{H}$ was followed using (3,5-dimethylphenyl)(pyrrolidin-1-yl)methanone (219e) (203 mg, $1.0 \mathrm{mmol})$ and NIS (450 mg, $2.0 \mathrm{mmol})$. After $22 \mathrm{~h}$, purification by column chromatography on silica gel ( $n$-hexane/EtOAc: $10 / 1)$ yielded 221e $(250 \mathrm{mg}, 76 \%)$ as a white solid.

M.p. $=107-108^{\circ} \mathrm{C}$.

${ }^{1} \mathrm{H}-\mathrm{NMR}\left(300 \mathrm{MHz}, \mathrm{CDCl}_{3}\right): \delta=7.00(\mathrm{~s}, 1 \mathrm{H}), 6.76(\mathrm{~s}, 1 \mathrm{H}), 3.61(\mathrm{t}, J=6.7 \mathrm{~Hz}, 2 \mathrm{H}), 3.25-3.01(\mathrm{~m}$, $2 \mathrm{H}), 2.38(\mathrm{~s}, 3 \mathrm{H}), 2.23(\mathrm{~s}, 3 \mathrm{H}), 1.99-1.76(\mathrm{~m}, 4 \mathrm{H})$.

${ }^{13} \mathrm{C}-\mathrm{NMR}\left(75 \mathrm{MHz}, \mathrm{CDCl}_{3}\right): \delta=169.5\left(\mathrm{C}_{\mathrm{q}}\right), 144.7\left(\mathrm{C}_{\mathrm{q}}\right), 138.1\left(\mathrm{C}_{\mathrm{q}}\right), 138.5\left(\mathrm{C}_{\mathrm{q}}\right), 130.4(\mathrm{CH}), 124.6$ $(\mathrm{CH}), 94.7\left(\mathrm{C}_{\mathrm{q}}\right), 48.3\left(\mathrm{CH}_{2}\right), 45.4\left(\mathrm{CH}_{2}\right), 28.4\left(\mathrm{CH}_{3}\right), 25.9\left(\mathrm{CH}_{2}\right), 24.5\left(\mathrm{CH}_{2}\right), 20.7\left(\mathrm{CH}_{3}\right)$.

IR (ATR): $\tilde{V}=2963,2930,1626,1434,1364,1322,1148,1036,816,608 \mathrm{~cm}^{-1}$.

MS (EI) $m / z$ (relative intensity): 329 (67) [ $\left.\mathrm{M}^{+}\right], 259$ (100), 231 (34), 202 (49), 133 (37), 104 (38).

HR-MS (EI) $m / z$ calcd for $\mathrm{C}_{13} \mathrm{H}_{16} \mathrm{INO} 329.0277$, found 329.0275 .

\section{Synthesis of (2-bromo-3,5-dimethylphenyl)(piperidin-1-yl)methanone (220f)}

The general procedure $\mathbf{D}$ was followed using $\mathrm{O}_{Y} \mathrm{~N}$ (3,5-dimethylphenyl)(piperidin-1-yl)methanone (219f) $(215 \mathrm{mg}, 1.0 \mathrm{mmol})$ and $Y^{\mathrm{Br}}$ NBS (356 mg, $\left.2.0 \mathrm{mmol}\right)$. After $16 \mathrm{~h}$, purification by column chromatography on Me ${ }_{\mathrm{Me}}$ silica gel $(n$-hexane/EtOAc: $5 / 1 \rightarrow 4 / 1)$ and normal phase HPLC $(n$-hexane/EtOAc: $10 / 1 \rightarrow 5 / 1)$ yielded $220 f(198 \mathrm{mg}, 67 \%)$ as a white solid.

M.p. $=107-108^{\circ} \mathrm{C}$.

${ }^{1} \mathrm{H}-\mathrm{NMR}\left(300 \mathrm{MHz}, \mathrm{CDCl}_{3}\right): \delta=6.99(\mathrm{~s}, 1 \mathrm{H}), 6.76(\mathrm{~s}, 1 \mathrm{H}), 3.76-3.58(\mathrm{~m}, 2 \mathrm{H}), 3.22-3.05(\mathrm{~m}$, $2 \mathrm{H}), 2.32(\mathrm{~s}, 3 \mathrm{H}), 2.22(\mathrm{~s}, 3 \mathrm{H}), 1.71-1.50(\mathrm{~m}, 5 \mathrm{H}), 1.48-1.31(\mathrm{~m}, 1 \mathrm{H})$.

${ }^{13} \mathrm{C}-\mathrm{NMR}\left(75 \mathrm{MHz}, \mathrm{CDCl}_{3}\right): \delta=168.0\left(\mathrm{C}_{\mathrm{q}}\right), 138.8\left(\mathrm{C}_{\mathrm{q}}\right), 138.4\left(\mathrm{C}_{\mathrm{q}}\right), 137.3\left(\mathrm{C}_{\mathrm{q}}\right), 131.4(\mathrm{CH}), 125.2$ $(\mathrm{CH}), 117.8\left(\mathrm{C}_{\mathrm{q}}\right), 47.7\left(\mathrm{CH}_{2}\right), 38.2\left(\mathrm{CH}_{2}\right), 26.1\left(\mathrm{CH}_{3}\right), 25.3\left(\mathrm{CH}_{2}\right), 24.4\left(\mathrm{CH}_{2}\right), 23.0\left(\mathrm{CH}_{2}\right), 20.6$ $\left(\mathrm{CH}_{3}\right)$.

IR (ATR): $\tilde{V}=2937,2855,1624,1439,1217,1021,792,659 \mathrm{~cm}^{-1}$.

MS (EI) $m / z$ (relative intensity): $297(32)\left[\mathrm{M}^{+}\right]\left({ }^{81} \mathrm{Br}\right), 295$ (34) $\left[\mathrm{M}^{+}\right]\left({ }^{79} \mathrm{Br}\right), 219$ (98), 209 (100), 135 (27), 104 (38).

HR-MS (EI) $\mathrm{m} / z$ calcd for $\mathrm{C}_{14} \mathrm{H}_{18} \mathrm{BrNO}^{+} 295.0572$, found 295.0576 .

\section{Synthesis of (2-iodo-3,5-dimethylphenyl)(piperidin-1-yl)methanone (221f)}

The general procedure $\mathbf{G}$ was followed using $\mathrm{O}^{\mathrm{N}}$ (3,5-dimethylphenyl)(piperidin-1-yl)methanone (219f) $(215 \mathrm{mg}, 1.0 \mathrm{mmol})$ and NIS $(450 \mathrm{mg}, 2.0 \mathrm{mmol})$. After $16 \mathrm{~h}$, purification by column chromatography on
silica gel $(n$-hexane/EtOAc: $5 / 1 \rightarrow 4 / 1)$ yielded $221 \mathrm{f}(219 \mathrm{mg}, 62 \%)$ as a white solid.

The general procedure $\mathbf{H}$ was followed using (3,5-dimethylphenyl)(piperidin-1-yl)methanone (219f) $(215 \mathrm{mg}, 1.0 \mathrm{mmol})$ and NIS (450 mg, $2.0 \mathrm{mmol})$. After $22 \mathrm{~h}$, purification by column chromatography on silica gel ( $n$-hexane/EtOAc: $5 / 1 \rightarrow 4 / 1)$ yielded $221 \mathrm{f}(275 \mathrm{mg}, 76 \%)$ as a white solid.

M.p. $=77-78^{\circ} \mathrm{C}$.

${ }^{1} \mathrm{H}-\mathrm{NMR}\left(300 \mathrm{MHz}, \mathrm{CDCl}_{3}\right): \delta=7.01(\mathrm{~s}, 1 \mathrm{H}), 6.77(\mathrm{~s}, 1 \mathrm{H}), 3.84-3.74(\mathrm{~m}, 1 \mathrm{H}), 3.70-3.60(\mathrm{~m}$, $1 \mathrm{H}), 3.25-3.07(\mathrm{~m}, 2 \mathrm{H}), 2.41(\mathrm{~s}, 3 \mathrm{H}), 2.25(\mathrm{~s}, 3 \mathrm{H}), 1.76-1.54(\mathrm{~m}, 5 \mathrm{H}), 1.53-1.35(\mathrm{~m}, 1 \mathrm{H})$.

${ }^{13} \mathrm{C}-\mathrm{NMR}\left(75 \mathrm{MHz}, \mathrm{CDCl}_{3}\right): \delta=169.8\left(\mathrm{C}_{\mathrm{q}}\right), 143.6\left(\mathrm{C}_{\mathrm{q}}\right), 138.2\left(\mathrm{C}_{\mathrm{q}}\right), 138.4\left(\mathrm{C}_{\mathrm{q}}\right), 130.3(\mathrm{CH}), 124.7$ $(\mathrm{CH}), 95.1\left(\mathrm{C}_{\mathrm{q}}\right), 47.8\left(\mathrm{CH}_{2}\right), 38.3\left(\mathrm{CH}_{2}\right), 28.5\left(\mathrm{CH}_{3}\right), 26.1\left(\mathrm{CH}_{2}\right), 25.3\left(\mathrm{CH}_{2}\right), 24.5\left(\mathrm{CH}_{2}\right), 20.7$ 
$\left(\mathrm{CH}_{3}\right)$.

IR (ATR): $\tilde{V}=2936,2852,1625,1435,1215,1006,855,658 \mathrm{~cm}^{-1}$.

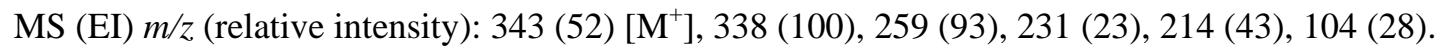

HR-MS (EI) $m / z$ calcd for $\mathrm{C}_{14} \mathrm{H}_{18} \mathrm{INO}^{+} 343.0433$, found 343.0438 .

\section{Synthesis of (2-bromo-3,5-dimethylphenyl)(morpholino)methanone (220g)}

$C_{0}$ The general procedure $\mathbf{G}$ was followed using $\mathrm{O}^{\mathrm{N}}$ (3,5-dimethylphenyl)(morpholino)methanone (219g) $(217 \mathrm{mg}, 1.0 \mathrm{mmol})$ and NBS (356 mg, $2.0 \mathrm{mmol})$. After $16 \mathrm{~h}$, purification by column chromatography on silica gel $(n$-hexane/EtOAc: $3 / 1 \rightarrow 2 / 1)$ and normal phase HPLC $(n$-hexane/EtOAc: $5 / 1 \rightarrow 3 / 1)$ yielded $220 \mathrm{~g}(155 \mathrm{mg}, 52 \%)$ as a white solid.

M.p. $=118-119^{\circ} \mathrm{C}$.

${ }^{1} \mathrm{H}-\mathrm{NMR}\left(300 \mathrm{MHz}, \mathrm{CDCl}_{3}\right): \delta=7.05(\mathrm{~s}, 1 \mathrm{H}), 6.85(\mathrm{~s}, 1 \mathrm{H}), 3.92-3.63(\mathrm{~m}, 5 \mathrm{H}), 3.33-3.13(\mathrm{~m}$, $1 \mathrm{H}), 3.32-3.11(\mathrm{~m}, 2 \mathrm{H}), 2.34$ (s, 3H), 2.25 (s, 3H).

${ }^{13} \mathrm{C}-\mathrm{NMR}\left(75 \mathrm{MHz}, \mathrm{CDCl}_{3}\right): \delta=168.3\left(\mathrm{C}_{\mathrm{q}}\right), 138.7\left(\mathrm{C}_{\mathrm{q}}\right), 137.8\left(\mathrm{C}_{\mathrm{q}}\right), 137.7\left(\mathrm{C}_{\mathrm{q}}\right), 132.0(\mathrm{CH}), 125.5$ $(\mathrm{CH}), 117.9\left(\mathrm{C}_{\mathrm{q}}\right), 66.7\left(\mathrm{CH}_{2}\right), 66.6\left(\mathrm{CH}_{2}\right), 47.1\left(\mathrm{CH}_{2}\right), 41.9\left(\mathrm{CH}_{2}\right), 23.0\left(\mathrm{CH}_{3}\right), 20.7\left(\mathrm{CH}_{3}\right)$.

IR (ATR): $\tilde{V}=2913,2848,1630,1436,1112,1020,860,618 \mathrm{~cm}^{-1}$.

MS (EI) $\mathrm{m} / z$ (relative intensity): 299 (16) $\left[\mathrm{M}^{+}\right]\left({ }^{81} \mathrm{Br}\right), 297$ (18) $\left[\mathrm{M}^{+}\right]\left({ }^{79} \mathrm{Br}\right), 219$ (100), 209 (98), 104 (33).

HR-MS (ESI) $m / z$ calcd for $\left[\left(\mathrm{C}_{13} \mathrm{H}_{16} \mathrm{INO}_{2}\right) \mathrm{H}\right]^{+} 298.0437$, found 298.0445 .

\section{Synthesis of (2-iodo-3,5-dimethylphenyl)(morpholino)methanone (221g)}

NiS (450 mg, $2.0 \mathrm{mmol})$. After $16 \mathrm{~h}$, purification by column chromatography on
silica gel $(n$-hexane/EtOAc: $3 / 1 \rightarrow 2 / 1)$ and normal phase HPLC ( $n$-hexane/EtOAc: $7 / 1 \rightarrow 3 / 1)$ yielded $221 \mathrm{~g}(186 \mathrm{mg}, 54 \%)$ as a white solid.

The general procedure $\mathbf{H}$ was followed using (3,5-dimethylphenyl)(morpholino)methanone (219g) $(217 \mathrm{mg}, 1.0 \mathrm{mmol})$ and NIS $(450 \mathrm{mg}, 2.0 \mathrm{mmol})$. After $22 \mathrm{~h}$, purification by column chromatography on silica gel ( $n$-hexane/EtOAc: $3 / 1 \rightarrow 2 / 1)$ and normal phase HPLC ( $n$-hexane/EtOAc: $7 / 1 \rightarrow 3 / 1)$ yielded $\mathbf{2 2 1 g}(248 \mathrm{mg}, 72 \%)$ as a white solid.

M.p. $=135-136^{\circ} \mathrm{C}$.

${ }^{1} \mathrm{H}-\mathrm{NMR}\left(300 \mathrm{MHz}, \mathrm{CDCl}_{3}\right): \delta=7.03(\mathrm{~s}, 1 \mathrm{H}), 6.77(\mathrm{~s}, 1 \mathrm{H}), 3.86-3.68(\mathrm{~m}, 5 \mathrm{H}), 3.60-3.50(\mathrm{~m}$, $1 \mathrm{H}), 3.32-3.11(\mathrm{~m}, 2 \mathrm{H}), 2.40(\mathrm{~s}, 3 \mathrm{H}), 2.25(\mathrm{~s}, 3 \mathrm{H})$.

${ }^{13} \mathrm{C}-\mathrm{NMR}\left(75 \mathrm{MHz}, \mathrm{CDCl}_{3}\right): \delta=170.0\left(\mathrm{C}_{\mathrm{q}}\right), 138.5\left(\mathrm{C}_{\mathrm{q}}\right), 138.2\left(\mathrm{C}_{\mathrm{q}}\right), 138.6\left(\mathrm{C}_{\mathrm{q}}\right), 130.8(\mathrm{CH}), 124.9$ $(\mathrm{CH}), 95.0\left(\mathrm{C}_{\mathrm{q}}\right), 66.6\left(\mathrm{CH}_{2}\right), 66.5\left(\mathrm{CH}_{2}\right), 47.1\left(\mathrm{CH}_{2}\right), 41.8\left(\mathrm{CH}_{2}\right), 28.5\left(\mathrm{CH}_{3}\right), 20.7\left(\mathrm{CH}_{3}\right)$.

IR (ATR): $\tilde{V}=2901,2856,1627,1460,1434,1106,1007,860,662 \mathrm{~cm}^{-1}$.

MS (EI) $\mathrm{m} / z$ (relative intensity): 345 (30) $\left[\mathrm{M}^{+}\right], 359$ (100), 2313 (17), 104 (20).

HR-MS (EI) $\mathrm{m} / z$ calcd for $\mathrm{C}_{13} \mathrm{H}_{16} \mathrm{INO}_{2}{ }^{+} 345.0226$, found 345.0209 .

\section{Synthesis of 2-bromo- $N, N$-diisopropyl-5-methylbenzamide (220h)}

$\mathrm{O}_{Y}^{\mathrm{N}(i-\mathrm{Pr})_{2}}$ The general procedure $\mathbf{G}$ was followed using $N, N$-diisopropyl-3-methylbenzamide $(\mathbf{2 1 9 h})(110 \mathrm{mg}, 0.5 \mathrm{mmol})$ and NBS (178 mg, $1.0 \mathrm{mmol})$. After $16 \mathrm{~h}$, purification by column chromatography on silica gel ( $n$-hexane/EtOAc: $10 / 1 \rightarrow 5 / 1)$ yielded $220 \mathrm{~h}(95 \mathrm{mg}, 64 \%)$ as a white solid. 
M.p. $=162-163^{\circ} \mathrm{C}$.

${ }^{1} \mathrm{H}-\mathrm{NMR}\left(300 \mathrm{MHz}, \mathrm{CDCl}_{3}\right): \delta=7.40(\mathrm{~d}, J=8.2 \mathrm{~Hz}, 1 \mathrm{H}), 7.03-6.94(\mathrm{~m}, 2 \mathrm{H}), 3.61$ (sept, $J=$ $6.7 \mathrm{~Hz}, 1 \mathrm{H}), 3.51$ (sept, $J=6.7 \mathrm{~Hz}, 1 \mathrm{H}), 2.29(\mathrm{~s}, 3 \mathrm{H}), 1.57(\mathrm{~d}, J=6.7 \mathrm{~Hz}, 3 \mathrm{H}), 1.55(\mathrm{~d}, J=6.7 \mathrm{~Hz}$, $3 \mathrm{H}), 1.23(\mathrm{~d}, J=6.7 \mathrm{~Hz}, 3 \mathrm{H}), 1.06(\mathrm{~d}, J=6.7 \mathrm{~Hz}, 3 \mathrm{H})$.

${ }^{13} \mathrm{C}-\mathrm{NMR}\left(75 \mathrm{MHz}, \mathrm{CDCl}_{3}\right): \delta=168.3\left(\mathrm{C}_{\mathrm{q}}\right), 139.9\left(\mathrm{C}_{\mathrm{q}}\right), 137.6\left(\mathrm{C}_{\mathrm{q}}\right), 132.5(\mathrm{CH}), 130.2(\mathrm{CH})$, 127.1 (CH), $111.4\left(\mathrm{C}_{\mathrm{q}}\right), 51.1(\mathrm{CH}), 45.9(\mathrm{CH}), 20.8\left(\mathrm{CH}_{3}\right), 20.8\left(\mathrm{CH}_{3}\right), 20.6\left(\mathrm{CH}_{3}\right), 20.6\left(\mathrm{CH}_{3}\right)$, $20.1\left(\mathrm{CH}_{3}\right)$.

IR (ATR): $\tilde{V}=2960,2928,1626,1441,1337,1044,831,764,622,459 \mathrm{~cm}^{-1}$.

MS (EI) $m / z$ (relative intensity): $299(5)\left[\mathrm{M}^{+}\right]\left({ }^{81} \mathrm{Br}\right), 297(5)\left[\mathrm{M}^{+}\right]\left({ }^{79} \mathrm{Br}\right), 256$ (25), 254 (25), 199 (97), 197 (100).

HR-MS (EI) $m / z$ calcd for $\mathrm{C}_{14} \mathrm{H}_{20} \mathrm{BrNO}^{+} 297.0728$, found 297.0721.

The spectral data were in accordance with those reported in the literature. ${ }^{113 a}$

\section{Synthesis of 2-bromo-3-fluoro- $N, N$-diisopropylbenzamide (220i)}

$\mathrm{O}_{Y} \mathrm{~N}(-\mathrm{-P})_{2}$ The general procedure $\mathbf{H}$ was followed using 3-fluoro- $N, N$-diisopropylbenzamide<smiles>Cc1cccc(F)c1Br</smiles>
(219i) $(219 \mathrm{mg}, 1.0 \mathrm{mmol})$ and NBS (356 mg, $2.0 \mathrm{mmol})$. After $22 \mathrm{~h}$, purification by column chromatography on silica gel ( $n$-hexane/EtOAc: $5 / 1)$ yielded $220 \mathbf{i}$ $(165 \mathrm{mg}, 55 \%)$ as a white solid.

M.p. $=134-135^{\circ} \mathrm{C}$.

${ }^{1} \mathrm{H}-\mathrm{NMR}\left(300 \mathrm{MHz}, \mathrm{CDCl}_{3}\right): \delta=7.28(\mathrm{dddd}, J=8.2,7.8,4.9,0.8 \mathrm{~Hz}, 1 \mathrm{H}), 7.06(\mathrm{ddd}, J=8.2,8.2$, $1.5 \mathrm{~Hz}, 1 \mathrm{H}), 6.95(\mathrm{dq}, J=7.8,0.8 \mathrm{~Hz}, 1 \mathrm{H}), 3.63-3.43(\mathrm{~m}, 2 \mathrm{H}), 1.56(\mathrm{~d}, J=6.7 \mathrm{~Hz}, 3 \mathrm{H}), 1.54(\mathrm{~d}$, $J=6.7 \mathrm{~Hz}, 3 \mathrm{H}), 1.21(\mathrm{~d}, J=6.7 \mathrm{~Hz}, 3 \mathrm{H}), 1.05(\mathrm{~d}, J=6.7 \mathrm{~Hz}, 3 \mathrm{H})$.

${ }^{13} \mathrm{C}-\mathrm{NMR}\left(75 \mathrm{MHz}, \mathrm{CDCl}_{3}\right): \delta=166.9\left(\mathrm{~d},{ }^{4} J_{\mathrm{C}-\mathrm{F}}=2 \mathrm{~Hz}, \mathrm{C}_{\mathrm{q}}\right), 159.2\left(\mathrm{~d},{ }^{1} J_{\mathrm{C}-\mathrm{F}}=249 \mathrm{~Hz}, \mathrm{C}_{\mathrm{q}}\right), 138.2$ $\left(\mathrm{C}_{\mathrm{q}}\right), 129.2\left(\mathrm{~d},{ }^{3} J_{\mathrm{C}-\mathrm{F}}=8 \mathrm{~Hz}, \mathrm{CH}\right), 121.8\left(\mathrm{~d},{ }^{4} J_{\mathrm{C}-\mathrm{F}}=4 \mathrm{~Hz}, \mathrm{CH}\right), 111.8\left(\mathrm{~d},{ }^{2} J_{\mathrm{C}-\mathrm{F}}=22 \mathrm{~Hz}, \mathrm{CH}\right), 106.4$ $\left(\mathrm{d},{ }^{2} J_{\mathrm{C}-\mathrm{F}}=22 \mathrm{~Hz}, \mathrm{C}_{\mathrm{q}}\right), 51.2(\mathrm{CH}), 46.1(\mathrm{CH}), 20.7\left(\mathrm{CH}_{3}\right), 20.6\left(\mathrm{CH}_{3}\right), 20.6\left(\mathrm{CH}_{3}\right), 20.1\left(\mathrm{CH}_{3}\right)$.

${ }^{19} \mathrm{~F}-\mathrm{NMR}\left(283 \mathrm{MHz}, \mathrm{CDCl}_{3}\right): \delta=-(105.1-105.2)(\mathrm{m})$.

IR (ATR): $\tilde{V}=2970,2932,2874,1625,1437,1339,1205,1041,790,603 \mathrm{~cm}^{-1}$.

MS (EI) $m / z$ (relative intensity): $303(4)\left[\mathrm{M}^{+}\right]\left({ }^{81} \mathrm{Br}\right), 301(4)\left[\mathrm{M}^{+}\right]\left({ }^{79} \mathrm{Br}\right), 202$ (90), 200 (100), 174 (16), 172 (18), 57 (48).

HR-MS (ESI) $m / z$ calcd for $\left[\left(\mathrm{C}_{13} \mathrm{H}_{17} \mathrm{FBrNO}\right) \mathrm{H}\right]^{+} 302.0556$, found 302.0551 .

\section{Synthesis of 3-bromo- $N, N$-diisopropyl-[1,1'-biphenyl]-4-carboxamide (220j)}

$\mathrm{O}^{\mathrm{N}(i-\mathrm{Pr})_{2}}$ The general procedure $\mathbf{H}$ was followed using 3-bromo- $N, N$-diisopropyl-[1,1'-biphenyl]-4-carboxamide $(\mathbf{2 1 9 j})(281 \mathrm{mg}, 1.0 \mathrm{mmol})$
and NBS $(712 \mathrm{mg}, 4.0 \mathrm{mmol})$. After $22 \mathrm{~h}$, purification by column chromatography on
silica gel $(n$-hexane/EtOAc: $5 / 1)$ and normal phase HPLC ( $n$-hexane/EtOAc: $15 / 1 \rightarrow 1 / 9)$ yielded $220 \mathbf{j}(173 \mathrm{mg}, 48 \%)$ as a colorless oil.

${ }^{1} \mathrm{H}-\mathrm{NMR}\left(300 \mathrm{MHz}, \mathrm{CDCl}_{3}\right): \delta=7.76(\mathrm{~d}, J=1.6 \mathrm{~Hz}, 1 \mathrm{H}), 7.57-7.49(\mathrm{~m}, 3 \mathrm{H}), 7.47-7.39(\mathrm{~m} \mathrm{2H})$, 7.39-7.32 (m, 1H), $7.22(\mathrm{~d}, J=7.8 \mathrm{~Hz}, 1 \mathrm{H}), 3.68$ (sept, $J=6.7 \mathrm{~Hz}, 1 \mathrm{H}), 3.53$ (sept, $J=6.7 \mathrm{~Hz}$, $1 \mathrm{H}), 1.59(\mathrm{~d}, J=6.7 \mathrm{~Hz}, 3 \mathrm{H}), 1.57(\mathrm{~d}, J=6.7 \mathrm{~Hz}, 3 \mathrm{H}), 1.25(\mathrm{~d}, J=6.7 \mathrm{~Hz}, 3 \mathrm{H}), 1.08(\mathrm{~d}, J=$ $6.7 \mathrm{~Hz}, 3 \mathrm{H})$.

${ }^{13} \mathrm{C}-\mathrm{NMR}\left(75 \mathrm{MHz}, \mathrm{CDCl}_{3}\right): \delta=168.1\left(\mathrm{C}_{\mathrm{q}}\right), 138.6\left(\mathrm{C}_{\mathrm{q}}\right), 139.0\left(\mathrm{C}_{\mathrm{q}}\right), 138.7\left(\mathrm{C}_{\mathrm{q}}\right), 131.3(\mathrm{CH}), 128.9$ $(\mathrm{CH}), 128.0(\mathrm{CH}), 127.0(\mathrm{CH}), 126.8(\mathrm{CH}), 126.3(\mathrm{CH}), 119.3\left(\mathrm{C}_{\mathrm{q}}\right), 51.2(\mathrm{CH}), 46.0(\mathrm{CH}), 20.8$ $\left(\mathrm{CH}_{3}\right), 20.7\left(\mathrm{CH}_{3}\right), 20.6\left(\mathrm{CH}_{3}\right), 20.1\left(\mathrm{CH}_{3}\right)$.

IR (ATR): $\tilde{V}=2968,2931,1631,1437,1336,1044,754,696 \mathrm{~cm}^{-1}$. 
MS (EI) $m / z$ (relative intensity): $361(10)\left[\mathrm{M}^{+}\right]\left({ }^{81} \mathrm{Br}\right), 359(10)\left[\mathrm{M}^{+}\right]\left({ }^{79} \mathrm{Br}\right), 318(32), 316(33)$, 261 (99), 259 (100), 152 (70).

HR-MS (EI) $\mathrm{m} / z$ calcd for $\mathrm{C}_{19} \mathrm{H}_{22} \mathrm{BrNO}^{+} 359.0885$, found 359.0885 .

\section{Synthesis of 4-bromo- $N, N$-diisopropyl-[1,1'-biphenyl]-3-carboxamide (220k)}

The general procedure H was followed using
$N, N$-diisopropyl-[1,1'-biphenyl]-3-carboxamide $(\mathbf{2 1 9 k})(141 \mathrm{mg}, 0.5 \mathrm{mmol})$ and
$\mathrm{NBS}(267 \mathrm{mg}, 1.5 \mathrm{mmol})$. After $22 \mathrm{~h}$, purification by column chromatography on
silica gel $(n$-hexane/EtOAc: $20 / 1 \rightarrow 10 / 1)$ yielded $220 \mathbf{k}(117 \mathrm{mg}, 65 \%)$ as a white solid.

M.p. $=151-152^{\circ} \mathrm{C}$.

${ }^{1} \mathrm{H}-\mathrm{NMR}\left(300 \mathrm{MHz}, \mathrm{CDCl}_{3}\right): \delta=7.61(\mathrm{~d}, J=8.2 \mathrm{~Hz}, 1 \mathrm{H}), 7.55(\mathrm{~d}, J=7.8 \mathrm{~Hz}, 2 \mathrm{H}), 7.51-7.37(\mathrm{~m}$, 4H), $7.36(\mathrm{~d}, J=2.2 \mathrm{~Hz}, 1 \mathrm{H}), 3.69$ (sept, $J=6.6 \mathrm{~Hz}, 1 \mathrm{H}), 3.55$ (sept, $J=6.6 \mathrm{~Hz}, 1 \mathrm{H}), 1.61$ (d, $J=$ $6.6 \mathrm{~Hz}, 3 \mathrm{H}), 1.59(\mathrm{~d}, J=6.6 \mathrm{~Hz}, 3 \mathrm{H}), 1.26(\mathrm{~d}, J=6.6 \mathrm{~Hz}, 3 \mathrm{H}), 1.08(\mathrm{~d}, J=6.6 \mathrm{~Hz}, 3 \mathrm{H})$.

${ }^{13} \mathrm{C}-\mathrm{NMR}\left(75 \mathrm{MHz}, \mathrm{CDCl}_{3}\right): \delta=168.0\left(\mathrm{C}_{\mathrm{q}}\right), 140.8\left(\mathrm{C}_{\mathrm{q}}\right), 140.5\left(\mathrm{C}_{\mathrm{q}}\right), 139.4\left(\mathrm{C}_{\mathrm{q}}\right), 133.2(\mathrm{CH}), 128.9$ $(\mathrm{CH}), 128.1(\mathrm{CH}), 127.9(\mathrm{CH}), 127.0(\mathrm{CH}), 125.1(\mathrm{CH}), 117.9\left(\mathrm{C}_{\mathrm{q}}\right), 51.2(\mathrm{CH}), 46.0(\mathrm{CH}), 20.9$ $\left(\mathrm{CH}_{3}\right), 20.7\left(\mathrm{CH}_{3}\right), 20.6\left(\mathrm{CH}_{3}\right), 20.1\left(\mathrm{CH}_{3}\right)$.

IR (ATR): $\tilde{V}=2931,2873,1631,1444,1369,1337,1039,786 \mathrm{~cm}^{-1}$.

MS (EI) $m / z$ (relative intensity): $361(8)\left[\mathrm{M}^{+}\right]\left({ }^{81} \mathrm{Br}\right), 359(8)\left[\mathrm{M}^{+}\right]\left({ }^{79} \mathrm{Br}\right), 318(38), 316(37), 261$ (98), 259 (100), 152 (85).

HR-MS (EI) $m / z$ calcd for $\mathrm{C}_{19} \mathrm{H}_{22} \mathrm{BrNO}^{+} 359.0885$, found 359.0882 .

The spectral data were in accordance with those reported in the literature. ${ }^{113 a}$

Synthesis of 4-bromo- $N, N$-diisopropyl-4'-methyl-[1,1'-biphenyl]-3-carboxamide (220I)

$\mathrm{O}_{Y} \mathrm{~N}(i-\mathrm{Pr})_{2}$ The general procedure $\mathbf{H}$ was followed using $N, N$-diisopropyl-4'-methyl-[1,1'-biphenyl]-3-carboxamide (219l) $(148 \mathrm{mg}$, $0.5 \mathrm{mmol}$ ) and NBS (178 $\mathrm{mg}, 1.0 \mathrm{mmol})$. After $22 \mathrm{~h}$, purification by column chromatography on silica gel ( $n$-hexane/EtOAc: $20 / 1 \rightarrow 10 / 1)$ yielded 2201 ( $88 \mathrm{mg}, 47 \%)$ as a white solid.

M.p. $=193-194^{\circ} \mathrm{C}$.

${ }^{1} \mathrm{H}-\mathrm{NMR}\left(300 \mathrm{MHz}, \mathrm{CDCl}_{3}\right): \delta=7.57(\mathrm{dd}, J=8.1,0.5 \mathrm{~Hz}, 1 \mathrm{H}), 7.44(\mathrm{dt}, J=8.1,0.5 \mathrm{~Hz}, 2 \mathrm{H})$, 7.37 (dd, $J=8.2,2.2 \mathrm{~Hz}, 1 \mathrm{H}), 7.34(\mathrm{~d}, J=2.0 \mathrm{~Hz}, 1 \mathrm{H}), 7.23(\mathrm{~d}, J=8.2 \mathrm{~Hz}, 2 \mathrm{H}), 3.67$ (sept, $J=$ $6.7 \mathrm{~Hz}, 1 \mathrm{H}), 3.52$ (sept, $J=6.7 \mathrm{~Hz}, 1 \mathrm{H}), 2.37$ (s, 3H), $1.59(\mathrm{~d}, J=6.7 \mathrm{~Hz}, 3 \mathrm{H}), 1.57$ (d, $J=6.7 \mathrm{~Hz}$, $3 \mathrm{H}), 1.24(\mathrm{~d}, J=6.7 \mathrm{~Hz}, 3 \mathrm{H}), 1.05(\mathrm{~d}, J=6.7 \mathrm{~Hz}, 3 \mathrm{H})$.

${ }^{13} \mathrm{C}-\mathrm{NMR}\left(75 \mathrm{MHz}, \mathrm{CDCl}_{3}\right): \delta=168.1\left(\mathrm{C}_{\mathrm{q}}\right), 140.7\left(\mathrm{C}_{\mathrm{q}}\right), 140.4\left(\mathrm{C}_{\mathrm{q}}\right), 137.8\left(\mathrm{C}_{\mathrm{q}}\right), 136.5\left(\mathrm{C}_{\mathrm{q}}\right), 133.1$ $(\mathrm{CH}), 129.6(\mathrm{CH}), 127.9(\mathrm{CH}), 126.8(\mathrm{CH}), 124.8(\mathrm{CH}), 117.5\left(\mathrm{C}_{\mathrm{q}}\right), 51.2(\mathrm{CH}), 46.0(\mathrm{CH}), 21.1$ $\left(\mathrm{CH}_{3}\right), 20.9\left(\mathrm{CH}_{3}\right), 20.7\left(\mathrm{CH}_{3}\right), 20.6\left(\mathrm{CH}_{3}\right), 20.1\left(\mathrm{CH}_{3}\right)$.

IR (ATR): $\tilde{V}=2969,2929,1631,1441,1336,1021,763,514 \mathrm{~cm}^{-1}$.

MS (ESI) $m / z$ (relative intensity): $396(28)\left[(\mathrm{M}+\mathrm{Na})^{+}\right], 749(100)\left[(2 \mathrm{M}+\mathrm{H})^{+}\right]$.

HR-MS (ESI) $m / z$ calcd for $\left[\left(\mathrm{C}_{20} \mathrm{H}_{24} \mathrm{BrNO}\right) \mathrm{H}\right]^{+} 374.1114$, found 374.1107 . 


\section{Synthesis of 4-bromo-4'-fluoro- $N, N$-diisopropyl-[1,1'-biphenyl]-3-carboxamide (220m)}

$\mathrm{O}^{\mathrm{N}(i-\mathrm{Pr})_{2}}$ The general procedure $\mathbf{H}$ was followed using 4'-fluoro- $N, N$-diisopropyl-[1,1'-biphenyl]-3-carboxamide (219m) (150 mg, $0.5 \mathrm{mmol}$ ) and NBS (178 $\mathrm{mg}, 1.0 \mathrm{mmol})$. After $22 \mathrm{~h}$, purification by column chromatography on silica gel ( $n$-hexane/EtOAc: $20 / 1 \rightarrow 10 / 1)$ yielded $220 m$ (102 $\mathrm{mg}, 54 \%)$ as a white solid.

M.p. $=156-157^{\circ} \mathrm{C}$.

${ }^{1} \mathrm{H}-\mathrm{NMR}\left(300 \mathrm{MHz}, \mathrm{CDCl}_{3}\right): \delta=7.59(\mathrm{~d}, J=8.2 \mathrm{~Hz}, 1 \mathrm{H}), 7.49(\mathrm{dd}, J=8.6,8.6 \mathrm{~Hz}, 2 \mathrm{H}), 7.33(\mathrm{dd}$, $J=8.2,2.3 \mathrm{~Hz}, 1 \mathrm{H}), 7.30(\mathrm{~d}, J=2.3 \mathrm{~Hz}, 1 \mathrm{H}), 7.11(\mathrm{dd}, J=8.6,8.6 \mathrm{~Hz}, 2 \mathrm{H}), 3.66(\mathrm{sept}, J=6.6 \mathrm{~Hz}$, $1 \mathrm{H}), 3.63(\mathrm{sept}, J=6.6 \mathrm{~Hz}, 1 \mathrm{H}), 1.58(\mathrm{~d}, J=6.6 \mathrm{~Hz}, 3 \mathrm{H}), 1.56(\mathrm{~d}, J=6.6 \mathrm{~Hz}, 3 \mathrm{H}), 1.25(\mathrm{~d}, J=6.6$ $\mathrm{Hz}, 3 \mathrm{H}), 1.07(\mathrm{~d}, J=6.6 \mathrm{~Hz}, 3 \mathrm{H})$.

${ }^{13} \mathrm{C}-\mathrm{NMR}\left(75 \mathrm{MHz}, \mathrm{CDCl}_{3}\right): \delta=167.9\left(\mathrm{C}_{\mathrm{q}}\right), 162.7\left(\mathrm{~d},{ }^{1} J_{\mathrm{C}-\mathrm{F}}=247 \mathrm{~Hz}, \mathrm{C}_{\mathrm{q}}\right), 140.5\left(\mathrm{C}_{\mathrm{q}}\right), 139.9$ $\left(\mathrm{C}_{\mathrm{q}}\right), 135.6\left(\mathrm{~d},{ }^{4} J_{\mathrm{C}-\mathrm{F}}=3 \mathrm{~Hz}, \mathrm{C}_{\mathrm{q}}\right), 133.2(\mathrm{CH}), 128.7\left(\mathrm{~d},{ }^{3} J_{\mathrm{C}-\mathrm{F}}=9 \mathrm{~Hz}, \mathrm{CH}\right), 128.0(\mathrm{CH}), 124.9(\mathrm{CH})$, $117.9\left(\mathrm{C}_{\mathrm{q}}\right), 111.9\left(\mathrm{~d},{ }^{2} J_{\mathrm{C}-\mathrm{F}}=22 \mathrm{~Hz}, \mathrm{CH}\right), 51.2(\mathrm{CH}), 46.1(\mathrm{CH}), 20.9\left(\mathrm{CH}_{3}\right), 20.7\left(\mathrm{CH}_{3}\right), 20.6$ $\left(\mathrm{CH}_{3}\right), 20.1\left(\mathrm{CH}_{3}\right)$.

${ }^{19} \mathrm{~F}-\mathrm{NMR}\left(283 \mathrm{MHz}, \mathrm{CDCl}_{3}\right): \delta=-(114.3-114.6)(\mathrm{m})$.

IR (ATR): $\tilde{V}=2966,2928,1631,1599,1438,1337,1226,849,813 \mathrm{~cm}^{-1}$.

MS (EI) $m / z$ (relative intensity): $379(9)\left[\mathrm{M}^{+}\right]\left({ }^{81} \mathrm{Br}\right), 377(9)\left[\mathrm{M}^{+}\right]\left({ }^{79} \mathrm{Br}\right), 336(35), 334(36), 279$ (99), 277 (100), 170 (75), 135 (60).

HR-MS (EI) $m / z$ calcd for $\mathrm{C}_{19} \mathrm{H}_{21} \mathrm{FBrNO}^{+} 377.0791$, found 377.0790.

Synthesis of methyl 4'-bromo-3'-(diisopropylcarbamoyl)-[1,1'-biphenyl]-4-carboxylate (220n)

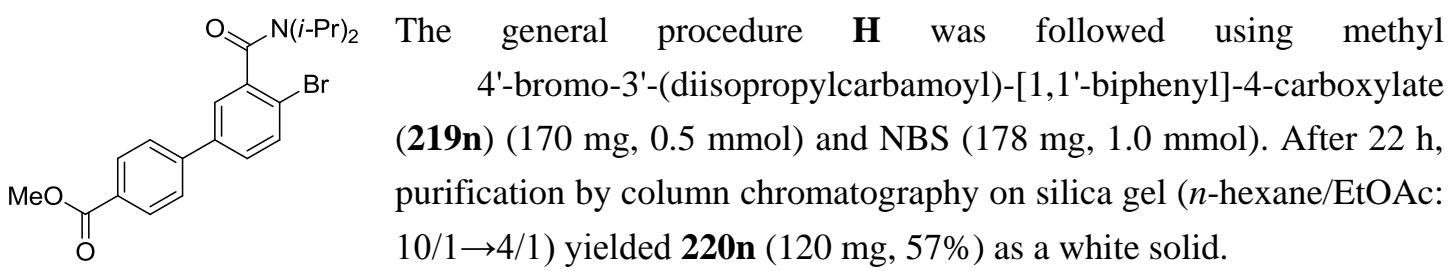

M.p. $=182-183^{\circ} \mathrm{C}$.

${ }^{1} \mathrm{H}-\mathrm{NMR}\left(300 \mathrm{MHz}, \mathrm{CDCl}_{3}\right): \delta=8.08(\mathrm{dt}, J=8.4,1.8 \mathrm{~Hz}, 2 \mathrm{H}), 7.62(\mathrm{~d}, J=8.2 \mathrm{~Hz}, 1 \mathrm{H}), 7.59(\mathrm{dt}$, $J=8.4,1.8 \mathrm{~Hz}, 2 \mathrm{H}), 7.41(\mathrm{dd}, J=8.2,2.2 \mathrm{~Hz}, 1 \mathrm{H}), 7.38(\mathrm{~d}, J=2.2 \mathrm{~Hz}, 1 \mathrm{H}), 3.94(\mathrm{~s}, 3 \mathrm{H}), 3.65$ (sept, $J=6.7 \mathrm{~Hz}, 1 \mathrm{H}), 3.53$ (sept, $J=6.7 \mathrm{~Hz}, 1 \mathrm{H}), 1.58(\mathrm{~d}, J=6.7 \mathrm{~Hz}, 3 \mathrm{H}), 1.57(\mathrm{~d}, J=6.7 \mathrm{~Hz}$, $3 \mathrm{H}), 1.25(\mathrm{~d}, J=6.7 \mathrm{~Hz}, 3 \mathrm{H}), 1.07(\mathrm{~d}, J=6.7 \mathrm{~Hz}, 3 \mathrm{H})$.

${ }^{13} \mathrm{C}-\mathrm{NMR}\left(75 \mathrm{MHz}, \mathrm{CDCl}_{3}\right): \delta=167.8\left(\mathrm{C}_{\mathrm{q}}\right), 166.7\left(\mathrm{C}_{\mathrm{q}}\right), 143.7\left(\mathrm{C}_{\mathrm{q}}\right), 140.7\left(\mathrm{C}_{\mathrm{q}}\right), 139.6\left(\mathrm{C}_{\mathrm{q}}\right), 133.4$ $(\mathrm{CH}), 130.2(\mathrm{CH}), 129.5\left(\mathrm{C}_{\mathrm{q}}\right), 128.2(\mathrm{CH}), 126.9(\mathrm{CH}), 125.1(\mathrm{CH}), 118.9\left(\mathrm{C}_{\mathrm{q}}\right), 52.2\left(\mathrm{CH}_{3}\right), 51.2$ $(\mathrm{CH}), 46.1(\mathrm{CH}), 20.9\left(\mathrm{CH}_{3}\right), 20.7\left(\mathrm{CH}_{3}\right), 20.6\left(\mathrm{CH}_{3}\right), 20.0\left(\mathrm{CH}_{3}\right)$.

IR (ATR): $\tilde{V}=2960,1719,1629,1435,1368,1340,1271,1102,769,710 \mathrm{~cm}^{-1}$.

MS (EI) $m / z$ (relative intensity): $419(10)\left[\mathrm{M}^{+}\right]\left({ }^{81} \mathrm{Br}\right), 417(10)\left[\mathrm{M}^{+}\right]\left({ }^{79} \mathrm{Br}\right), 376(38), 374(38)$, 319 (98), 317 (100), 151 (19).

HR-MS (EI) $m / z$ calcd for $\mathrm{C}_{21} \mathrm{H}_{24} \mathrm{BrNO}_{3}{ }^{+} 417.0940$, found 417.0934 . 
Synthesis of 4'-acetyl-4-bromo- $N, N$-diisopropyl-[1,1'-biphenyl]-3-carboxamide (220o)

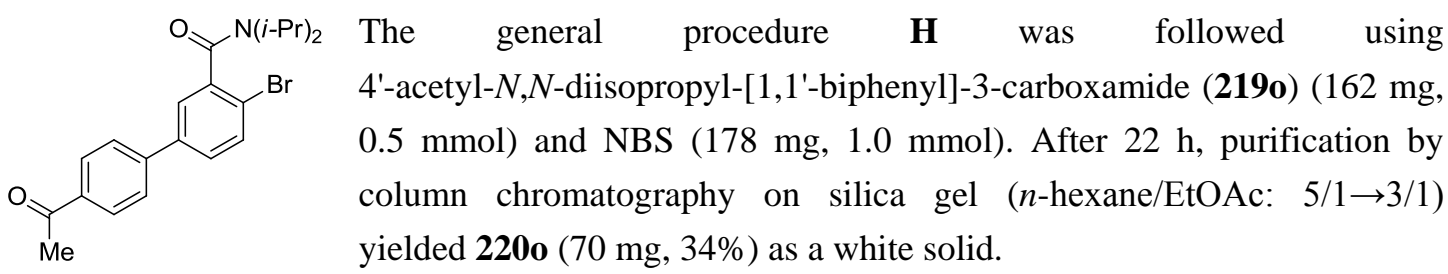

M.p. $=203-204^{\circ} \mathrm{C}$.

${ }^{1} \mathrm{H}-\mathrm{NMR}\left(300 \mathrm{MHz}, \mathrm{CDCl}_{3}\right): \delta=8.01(\mathrm{~d}, J=8.2 \mathrm{~Hz}, 2 \mathrm{H}), 7.66-7.58(\mathrm{~m}, 3 \mathrm{H}), 7.38(\mathrm{dd}, J=8.2$, $2.2 \mathrm{~Hz}, 1 \mathrm{H}), 7.38$ (d, $J=2.2 \mathrm{~Hz}, 1 \mathrm{H}), 3.65$ (sept, $J=6.7 \mathrm{~Hz}, 1 \mathrm{H}), 3.53$ (sept, $J=6.7 \mathrm{~Hz}, 1 \mathrm{H}$ ), 2.62 $(\mathrm{s}, 3 \mathrm{H}), 1.58(\mathrm{~d}, J=6.7 \mathrm{~Hz}, 3 \mathrm{H}), 1.57(\mathrm{~d}, J=6.7 \mathrm{~Hz}, 3 \mathrm{H}), 1.25(\mathrm{~d}, J=6.7 \mathrm{~Hz}, 3 \mathrm{H}), 1.07(\mathrm{~d}, J=$ $6.7 \mathrm{~Hz}, 3 \mathrm{H})$.

${ }^{13} \mathrm{C}-\mathrm{NMR}\left(75 \mathrm{MHz}, \mathrm{CDCl}_{3}\right): \delta=197.5\left(\mathrm{C}_{\mathrm{q}}\right), 167.8\left(\mathrm{C}_{\mathrm{q}}\right), 143.8\left(\mathrm{C}_{\mathrm{q}}\right), 140.7\left(\mathrm{C}_{\mathrm{q}}\right), 139.5\left(\mathrm{C}_{\mathrm{q}}\right), 136.3$ $\left(\mathrm{C}_{\mathrm{q}}\right), 133.4(\mathrm{CH}), 129.0(\mathrm{CH}), 128.2(\mathrm{CH}), 127.1(\mathrm{CH}), 125.1(\mathrm{CH}), 119.0\left(\mathrm{C}_{\mathrm{q}}\right), 51.3(\mathrm{CH}), 46.1$ $(\mathrm{CH}), 26.7\left(\mathrm{CH}_{3}\right), 20.9\left(\mathrm{CH}_{3}\right), 20.7\left(\mathrm{CH}_{3}\right), 20.6\left(\mathrm{CH}_{3}\right), 20.0\left(\mathrm{CH}_{3}\right)$.

IR (ATR): $\tilde{V}=2989,1681,1637,1603,1441,1337,1257,1016,813,604 \mathrm{~cm}^{-1}$.

MS (EI) $m / z$ (relative intensity): $403(11)\left[\mathrm{M}^{+}\right]\left({ }^{81} \mathrm{Br}\right), 401(11)\left[\mathrm{M}^{+}\right]\left({ }^{79} \mathrm{Br}\right), 360(43), 358(43)$, 303 (99), 301 (100), 151 (18), 43 (41).

HR-MS (EI) $m / z$ calcd for $\mathrm{C}_{21} \mathrm{H}_{24} \mathrm{BrNO}_{2}{ }^{+} 401.0990$, found 401.0990 .

\section{Synthesis of 3'-acetyl-4-bromo- $N, N$-diisopropyl-[1,1'-biphenyl]-3-carboxamide (220p)}

$\mathrm{O}^{\mathrm{N}(i-\mathrm{Pr})_{2}}$ The general procedure $\mathbf{H}$ was followed using $\mathrm{Me} B$ 3'-acetyl- $N, N$-diisopropyl-[1,1'-biphenyl]-3-carboxamide (219p) (162 mg, $0.5 \mathrm{mmol})$ and NBS (178 mg, $1.0 \mathrm{mmol})$. After $22 \mathrm{~h}$, purification by column chromatography on silica gel $(n$-hexane/EtOAc: $10 / 1 \rightarrow 4 / 1)$

yielded 220p (93 $\mathrm{mg}, 46 \%$ ) as a white solid.

M.p. $=159-160{ }^{\circ} \mathrm{C}$.

${ }^{1} \mathrm{H}-\mathrm{NMR}\left(300 \mathrm{MHz}, \mathrm{CDCl}_{3}\right): \delta=8.11(\mathrm{t}, J=1.6 \mathrm{~Hz}, 1 \mathrm{H}), 7.93(\mathrm{dt}, J=7.8,1.6 \mathrm{~Hz}, 1 \mathrm{H}), 7.72(\mathrm{dq}$, $J=7.6,1.1 \mathrm{~Hz}, 1 \mathrm{H}), 7.62(\mathrm{~d}, J=8.2 \mathrm{~Hz}, 1 \mathrm{H}), 7.52(\mathrm{dd}, J=7.8,7.6 \mathrm{~Hz}, 1 \mathrm{H}), 7.41(\mathrm{dd}, J=8.2,2.3$ $\mathrm{Hz}, 1 \mathrm{H}), 7.37(\mathrm{~d}, J=2.3 \mathrm{~Hz}, 1 \mathrm{H}), 3.65$ (sept, $J=6.7 \mathrm{~Hz}, 1 \mathrm{H}), 3.53$ (sept, $J=6.7 \mathrm{~Hz}, 1 \mathrm{H}), 2.63$ (s, $3 \mathrm{H}), 1.58(\mathrm{~d}, J=6.7 \mathrm{~Hz}, 3 \mathrm{H}), 1.57(\mathrm{~d}, J=6.7 \mathrm{~Hz}, 3 \mathrm{H}), 1.24(\mathrm{~d}, J=6.7 \mathrm{~Hz}, 3 \mathrm{H}), 1.06(\mathrm{~d}, J=$ $6.7 \mathrm{~Hz}, 3 \mathrm{H})$.

${ }^{13} \mathrm{C}-\mathrm{NMR}\left(75 \mathrm{MHz}, \mathrm{CDCl}_{3}\right): \delta=197.8\left(\mathrm{C}_{\mathrm{q}}\right), 167.8\left(\mathrm{C}_{\mathrm{q}}\right), 140.6\left(\mathrm{C}_{\mathrm{q}}\right), 140.0\left(\mathrm{C}_{\mathrm{q}}\right), 139.8\left(\mathrm{C}_{\mathrm{q}}\right), 137.7$ $\left(\mathrm{C}_{\mathrm{q}}\right), 133.4(\mathrm{CH}), 131.5(\mathrm{CH}), 129.2(\mathrm{CH}), 128.2(\mathrm{CH}), 127.8(\mathrm{CH}), 126.7(\mathrm{CH}), 125.1(\mathrm{CH})$, $118.7\left(\mathrm{C}_{\mathrm{q}}\right), 51.2(\mathrm{CH}), 46.1(\mathrm{CH}), 26.8\left(\mathrm{CH}_{3}\right), 20.9\left(\mathrm{CH}_{3}\right), 20.7\left(\mathrm{CH}_{3}\right), 20.6\left(\mathrm{CH}_{3}\right), 20.0\left(\mathrm{CH}_{3}\right)$. IR (ATR): $\tilde{V}=2982,2934,1677,1629,1451,1367,1397,1036,767,602 \mathrm{~cm}^{-1}$.

MS (EI) $m / z$ (relative intensity): $403(11)\left[\mathrm{M}^{+}\right]\left({ }^{81} \mathrm{Br}\right), 401(11)\left[\mathrm{M}^{+}\right]\left({ }^{79} \mathrm{Br}\right), 360(46), 358(46)$, 303 (98), 301 (100), 151 (15).

HR-MS (EI) $m / z$ calcd for $\mathrm{C}_{21} \mathrm{H}_{24} \mathrm{BrNO}_{2}{ }^{+} 401.0990$, found 401.0991 .

\section{Synthesis of 5-(5'-acetylthiophen-2-yl)-2-bromo- $N, N$-diisopropylbenzamide (220q)}

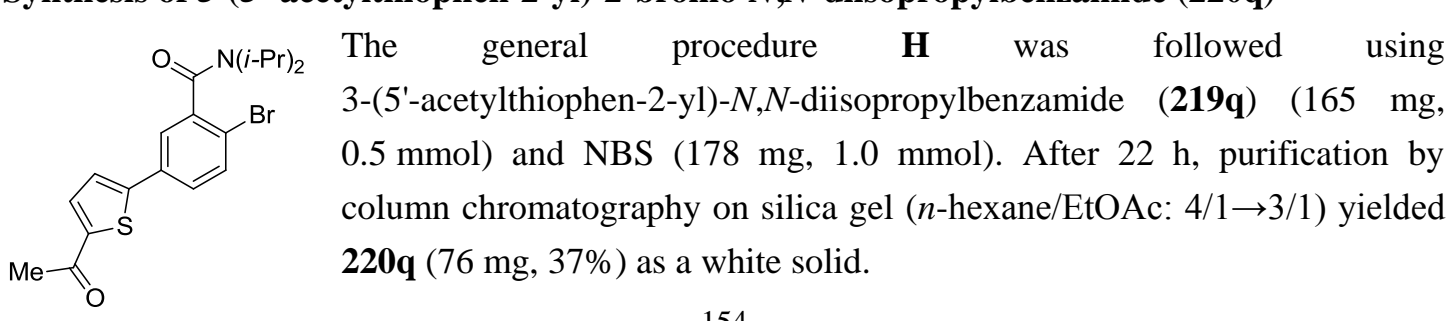


M.p. $=181-183^{\circ} \mathrm{C}$.

${ }^{1} \mathrm{H}-\mathrm{NMR}\left(300 \mathrm{MHz}, \mathrm{CDCl}_{3}\right): \delta=7.62(\mathrm{~d}, J=4.0 \mathrm{~Hz}, 1 \mathrm{H}), 7.58(\mathrm{~d}, J=8.2 \mathrm{~Hz}, 1 \mathrm{H}), 7.43(\mathrm{dd}, J=$ 8.2, $2.2 \mathrm{~Hz}, 1 \mathrm{H}), 7.40(\mathrm{~d}, J=2.2 \mathrm{~Hz}, 1 \mathrm{H}), 7.29(\mathrm{~d}, J=4.0 \mathrm{~Hz}, 1 \mathrm{H}), 3.62$ (sept, $J=6.7 \mathrm{~Hz}, 1 \mathrm{H}$ ), 3.53 (sept, $J=6.7 \mathrm{~Hz}, 1 \mathrm{H}), 2.54(\mathrm{~s}, 3 \mathrm{H}), 1.59(\mathrm{~d}, J=6.7 \mathrm{~Hz}, 3 \mathrm{H}), 1.55(\mathrm{~d}, J=6.7 \mathrm{~Hz}, 3 \mathrm{H}), 1.24(\mathrm{~d}$, $J=6.7 \mathrm{~Hz}, 3 \mathrm{H}), 1.07(\mathrm{~d}, J=6.7 \mathrm{~Hz}, 3 \mathrm{H})$.

${ }^{13} \mathrm{C}-\mathrm{NMR}\left(75 \mathrm{MHz}, \mathrm{CDCl}_{3}\right): \delta=190.5\left(\mathrm{C}_{\mathrm{q}}\right), 167.3\left(\mathrm{C}_{\mathrm{q}}\right), 150.3\left(\mathrm{C}_{\mathrm{q}}\right), 143.8\left(\mathrm{C}_{\mathrm{q}}\right), 140.9\left(\mathrm{C}_{\mathrm{q}}\right), 133.6$ $(\mathrm{CH}), 133.3(\mathrm{CH}), 133.0\left(\mathrm{C}_{\mathrm{q}}\right), 127.0(\mathrm{CH}), 124.6(\mathrm{CH}), 124.0(\mathrm{CH}), 119.5\left(\mathrm{C}_{\mathrm{q}}\right), 51.3(\mathrm{CH}), 46.1$ (CH), $26.5\left(\mathrm{CH}_{3}\right), 20.9\left(\mathrm{CH}_{3}\right), 20.6\left(\mathrm{CH}_{3}\right), 20.6\left(\mathrm{CH}_{3}\right), 20.0\left(\mathrm{CH}_{3}\right)$.

IR (ATR): $\tilde{V}=2977,2936,1653,1621,1435,1340,1281,1021,827,796,599 \mathrm{~cm}^{-1}$.

MS (EI) $\mathrm{m} / z$ (relative intensity): $409(10)\left[\mathrm{M}^{+}\right]\left({ }^{81} \mathrm{Br}\right), 407(10)\left[\mathrm{M}^{+}\right]\left({ }^{79} \mathrm{Br}\right), 366(40), 364(40)$, 309 (100), 307 (100), 185 (14).

HR-MS (ESI) $m / z$ calcd for $\left[\left(\mathrm{C}_{19} \mathrm{H}_{22} \mathrm{BrNO}_{2} \mathrm{~S}\right) \mathrm{H}\right]^{+} 408.0627$, found 408.0620 .

\section{Synthesis of 2-iodo- $N, N$-diisopropylbenzamide (221a)}

$\mathrm{O}^{\mathrm{N}(i-\mathrm{Pr})_{2}}$ The general procedure $\mathbf{H}$ was followed using $N, N$-diisopropylbenzamide (219a) (103 $\mathrm{mg}, 0.5 \mathrm{mmol})$ and NIS (225 mg, $1.0 \mathrm{mmol})$. After $22 \mathrm{~h}$, purification by column chromatography on silica gel ( $n$-hexane/EtOAc: $10 / 1 \rightarrow 5 / 1)$ and normal phase HPLC ( $n$-hexane/EtOAc: $19 / 1 \rightarrow 9 / 1)$ yielded 221a $(88 \mathrm{mg}, 53 \%$ ) as a white solid.

M.p. $=188-189^{\circ} \mathrm{C}$.

${ }^{1} \mathrm{H}-\mathrm{NMR}\left(300 \mathrm{MHz}, \mathrm{CDCl}_{3}\right): \delta=7.76(\mathrm{dd}, J=8.0,1.0 \mathrm{~Hz}, 1 \mathrm{H}), 7.34(\mathrm{ddd}, J=7.6,7.5,1.0 \mathrm{~Hz}$, $1 \mathrm{H}), 7.11(\mathrm{dd}, J=7.6,1.6 \mathrm{~Hz}, 1 \mathrm{H}), 7.00(\mathrm{ddd}, J=8.0,7.5,1.6 \mathrm{~Hz}, 1 \mathrm{H}), \quad 3.63-3.38(\mathrm{~m}, 2 \mathrm{H}), 1.58$ $(\mathrm{d}, J=6.8 \mathrm{~Hz}, 3 \mathrm{H}), 1.54(\mathrm{~d}, J=6.8 \mathrm{~Hz}, 3 \mathrm{H}), 1.25(\mathrm{~d}, J=6.8 \mathrm{~Hz}, 3 \mathrm{H}), 1.04(\mathrm{~d}, J=6.8 \mathrm{~Hz}, 3 \mathrm{H})$.

${ }^{13} \mathrm{C}-\mathrm{NMR}\left(75 \mathrm{MHz}, \mathrm{CDCl}_{3}\right): \delta=169.8\left(\mathrm{C}_{\mathrm{q}}\right), 144.2\left(\mathrm{C}_{\mathrm{q}}\right), 139.3(\mathrm{CH}), 129.4(\mathrm{CH}), 128.2(\mathrm{CH})$, $125.8(\mathrm{CH}), 92.2\left(\mathrm{C}_{\mathrm{q}}\right), 51.2(\mathrm{CH}), 46.0(\mathrm{CH}), 20.7\left(\mathrm{CH}_{3}\right), 20.7\left(\mathrm{CH}_{3}\right), 20.6\left(\mathrm{CH}_{3}\right), 20.0\left(\mathrm{CH}_{3}\right)$.

IR (neat): $\tilde{V}=2967,2929,1618,1581,1435,1339,1012,771 \mathrm{~cm}^{-1}$.

MS (EI) $\mathrm{m} / z$ (relative intensity): 331 (7) [ $\left.\mathrm{M}^{+}\right], 288$ (27), 230 (100), 202 (21), 43 (23).

HR-MS (EI) $\mathrm{m} / z$ calcd for $\mathrm{C}_{13} \mathrm{H}_{18} \mathrm{INO}^{+} 331.0433$, found 331.0414 .

The spectral data were in accordance with those reported in the literature. ${ }^{113 a}$

\section{Synthesis of 2-iodo- $N, N$-diisopropyl-5-methylbenzamide (221h)}

$\mathrm{O}_{Y^{N}(i-\mathrm{Pr})_{2}}$ The general procedure $\mathbf{H}$ was followed using $N, N$-diisopropyl-3-methylbenzamide (219h) $(217 \mathrm{mg}, 1.0 \mathrm{mmol})$ and NIS (450 mg, $2.0 \mathrm{mmol})$. After $22 \mathrm{~h}$, purification by column chromatography on silica gel ( $n$-hexane/EtOAc: 10/1) and normal phase HPLC ( $n$-hexane/EtOAc:

$19 / 1 \rightarrow 9 / 1)$ yielded 221h (219 $\mathrm{mg}, 64 \%)$ as a white solid.

M.p. $=161-162^{\circ} \mathrm{C}$.

${ }^{1} \mathrm{H}-\mathrm{NMR}\left(300 \mathrm{MHz}, \mathrm{CDCl}_{3}\right): \delta=7.63(\mathrm{~d}, J=8.0 \mathrm{~Hz}, 1 \mathrm{H}), 6.93(\mathrm{~d}, J=2.0 \mathrm{~Hz}, 1 \mathrm{H}), 6.82(\mathrm{dt}, J=$ 8.0, $0.7 \mathrm{~Hz}, 1 \mathrm{H}$ ), 3.58 (sept, $J=6.7 \mathrm{~Hz}, 1 \mathrm{H}$ ), 3.49 (sept, $J=6.7 \mathrm{~Hz}, 1 \mathrm{H}$ ), 2.27 (s, 3H), 1.57 (d, $J=$ $6.7 \mathrm{~Hz}, 3 \mathrm{H}), 1.54(\mathrm{~d}, J=6.7 \mathrm{~Hz}, 3 \mathrm{H}), 1.25(\mathrm{~d}, J=6.7 \mathrm{~Hz}, 3 \mathrm{H}), 1.05(\mathrm{~d}, J=6.7 \mathrm{~Hz}, 3 \mathrm{H})$.

${ }^{13} \mathrm{C}-\mathrm{NMR}\left(75 \mathrm{MHz}, \mathrm{CDCl}_{3}\right): \delta=169.9\left(\mathrm{C}_{\mathrm{q}}\right), 144.0\left(\mathrm{C}_{\mathrm{q}}\right), 139.0(\mathrm{CH}), 138.4\left(\mathrm{C}_{\mathrm{q}}\right), 130.4(\mathrm{CH})$, $126.5(\mathrm{CH}), 88.0\left(\mathrm{C}_{\mathrm{q}}\right), 51.2(\mathrm{CH}), 45.9(\mathrm{CH}), 20.9\left(\mathrm{CH}_{3}\right), 20.8\left(\mathrm{CH}_{3}\right), 20.7\left(\mathrm{CH}_{3}\right), 20.6\left(\mathrm{CH}_{3}\right)$, $20.0\left(\mathrm{CH}_{3}\right)$.

IR (ATR): $\tilde{V}=2966,2928,1621,1441,1337,1012,834,763,621,455 \mathrm{~cm}^{-1}$.

MS (EI) $m / z$ (relative intensity): 345 (11) $\left[\mathrm{M}^{+}\right], 302$ (23), 245 (100), 216 (16), 90 (22).

HR-MS (ESI) $m / z$ calcd for $\left[\left(\mathrm{C}_{14} \mathrm{H}_{20} \mathrm{INO}\right) \mathrm{H}\right]^{+} 346.0668$, found 346.0662 . 
The spectral data were in accordance with those reported in the literature. ${ }^{179}$

Synthesis of 2-iodo- $N, N$-diisopropyl-4,5-dimethylbenzamide (219v)

$\mathrm{O}^{\mathrm{N}(i-\mathrm{Pr})_{2}}$ The general procedure $\mathbf{H}$ was followed using $N, N$-diisopropyl-3,4-dimethylbenzamide (219v) (233 mg, $1.0 \mathrm{mmol}$ ) and NIS (450 mg, $2.0 \mathrm{mmol}$ ). After $22 \mathrm{~h}$, purification by column chromatography on silica gel ( $n$-hexane/EtOAc: $20 / 1 \rightarrow 10 / 1)$ yielded $221 \mathbf{v}(187 \mathrm{mg}, 52 \%)$ as a white solid.

M.p. $=106-107^{\circ} \mathrm{C}$.

${ }^{1} \mathrm{H}-\mathrm{NMR}\left(300 \mathrm{MHz}, \mathrm{CDCl}_{3}\right): \delta=7.55(\mathrm{~s}, 1 \mathrm{H}), 6.94(\mathrm{~s}, 1 \mathrm{H}), 3.62$ (sept, $\left.J=6.7 \mathrm{~Hz}, 1 \mathrm{H}\right), 3.49$ (sept, $J=6.7 \mathrm{~Hz}, 1 \mathrm{H}), 2.21(\mathrm{~s}, 3 \mathrm{H}), 2.17(\mathrm{~s}, 3 \mathrm{H}), 1.58(\mathrm{~d}, J=6.7 \mathrm{~Hz}, 3 \mathrm{H}), 1.56(\mathrm{~d}, J=6.7 \mathrm{~Hz}, 3 \mathrm{H}), 1.26$ $(\mathrm{d}, J=6.7 \mathrm{~Hz}, 3 \mathrm{H}), 1.06(\mathrm{~d}, J=6.7 \mathrm{~Hz}, 3 \mathrm{H})$.

${ }^{13} \mathrm{C}-\mathrm{NMR}\left(75 \mathrm{MHz}, \mathrm{CDCl}_{3}\right): \delta=170.0\left(\mathrm{C}_{\mathrm{q}}\right), 141.8\left(\mathrm{C}_{\mathrm{q}}\right), 139.7(\mathrm{CH}), 138.4\left(\mathrm{C}_{\mathrm{q}}\right), 137.0\left(\mathrm{C}_{\mathrm{q}}\right), 126.8$ $(\mathrm{CH}), 88.3\left(\mathrm{C}_{\mathrm{q}}\right), 51.1(\mathrm{CH}), 45.8(\mathrm{CH}), 20.8\left(\mathrm{CH}_{3}\right), 20.7\left(\mathrm{CH}_{3}\right), 20.6\left(\mathrm{CH}_{3}\right), 20.0\left(\mathrm{CH}_{3}\right), 19.3$ $\left(\mathrm{CH}_{3}\right), 19.1\left(\mathrm{CH}_{3}\right)$.

IR (ATR): $\tilde{V}=2970,2929,1623,1435,1359,1322,1043,817,609 \mathrm{~cm}^{-1}$.

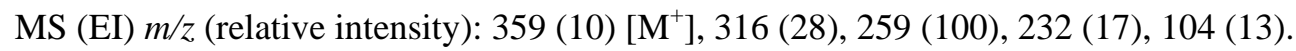

HR-MS (EI) $m / z$ calcd for $\mathrm{C}_{15} \mathrm{H}_{22} \mathrm{INO}^{+} 359.0746$, found 359.0745 .

\section{Synthesis of 3-fluoro-2-iodo- $N, N$-diisopropylbenzamide (219i)}

$\mathrm{O}^{\mathrm{N}(i-\mathrm{Pr})_{2}}$ The general procedure $\mathbf{H}$ was followed using 3-fluoro- $N, N$-diisopropylbenzamide (219i) $(219 \mathrm{mg}, 1.0 \mathrm{mmol})$ and NIS (450 $\mathrm{mg}, 2.0 \mathrm{mmol})$. After $22 \mathrm{~h}$, purification by column chromatography on silica gel ( $n$-hexane/EtOAc: $5 / 1)$ yielded $221 \mathbf{i}$ (128 mg, 36\%) as a white solid.

M.p. $=124-125^{\circ} \mathrm{C}$.

${ }^{1} \mathrm{H}-\mathrm{NMR}\left(300 \mathrm{MHz}, \mathrm{CDCl}_{3}\right.$ ): $\delta=7.32(\mathrm{ddd}, J=8.0,5.2,0.7 \mathrm{~Hz}, 1 \mathrm{H}), 7.00$ (ddd, $J=8.0,7.6$, $1.5 \mathrm{~Hz}, 1 \mathrm{H}), 6.93(\mathrm{dd}, J=7.6,1.0 \mathrm{~Hz}, 1 \mathrm{H}), 3.62-3.43(\mathrm{~m}, 2 \mathrm{H}), 1.60(\mathrm{~d}, J=6.6 \mathrm{~Hz}, 3 \mathrm{H}), 1.56(\mathrm{~d}$, $J=6.6 \mathrm{~Hz}, 3 \mathrm{H}), 1.26(\mathrm{~d}, J=6.6 \mathrm{~Hz}, 3 \mathrm{H}), 1.07(\mathrm{~d}, J=6.6 \mathrm{~Hz}, 3 \mathrm{H})$.

${ }^{13} \mathrm{C}-\mathrm{NMR}\left(75 \mathrm{MHz}, \mathrm{CDCl}_{3}\right): \delta=168.6\left(\mathrm{~d},{ }^{4} J_{\mathrm{C}-\mathrm{F}}=2 \mathrm{~Hz}, \mathrm{C}_{\mathrm{q}}\right), 161.8\left(\mathrm{~d},{ }^{1} J_{\mathrm{C}-\mathrm{F}}=246 \mathrm{~Hz}, \mathrm{C}_{\mathrm{q}}\right), 146.4$ $\left(\mathrm{d},{ }^{3} J_{\mathrm{C}-\mathrm{F}}=8 \mathrm{~Hz}, \mathrm{C}_{\mathrm{q}}\right), 130.3\left(\mathrm{~d},{ }^{3} J_{\mathrm{C}-\mathrm{F}}=8 \mathrm{~Hz}, \mathrm{CH}\right), 121.4\left(\mathrm{~d},{ }^{4} J_{\mathrm{C}-\mathrm{F}}=3 \mathrm{~Hz}, \mathrm{CH}\right), 114.8\left(\mathrm{~d},{ }^{2} J_{\mathrm{C}-\mathrm{F}}=\right.$ $24 \mathrm{~Hz}, \mathrm{CH}), 76.5\left(\mathrm{~d},{ }^{2} J_{\mathrm{C}-\mathrm{F}}=26 \mathrm{~Hz}, \mathrm{C}_{\mathrm{q}}\right), 51.3(\mathrm{CH}), 46.1(\mathrm{CH}), 20.8\left(\mathrm{CH}_{3}\right), 20.7\left(\mathrm{CH}_{3}\right), 20.6\left(\mathrm{CH}_{3}\right)$, $20.0\left(\mathrm{CH}_{3}\right)$.

${ }^{19} \mathrm{~F}-\mathrm{NMR}\left(283 \mathrm{MHz}, \mathrm{CDCl}_{3}\right): \delta=-(90.8-90.9)(\mathrm{m})$.

IR (ATR): $\tilde{V}=2967,2930,1620,1435,1340,1203,1041,788,604 \mathrm{~cm}^{-1}$.

MS (EI) $\mathrm{m} / z$ (relative intensity): 349 (10) [ $\left.\mathrm{M}^{+}\right], 306$ (28), 249 (100), 218 (18), 43 (16).

HR-MS (EI) $\mathrm{m} / z$ calcd for $\mathrm{C}_{13} \mathrm{H}_{17} \mathrm{FINO}^{+} 349.0339$, found 349.0339 .

\section{Synthesis of 4-iodo- $N, N$-diisopropylbenzo[ $[d][1,3]$ dioxole-5-carboxamide (221w)}

$\mathrm{O}^{\mathrm{N}(i-\mathrm{Pr})_{2}}$ The general procedure $\mathbf{H}$ was followed using 4-iodo- $N, N$-diisopropylbenzo[ $d][1,3]$ dioxole-5-carboxamide (219w) (249 $\mathrm{mg}$, $1.0 \mathrm{mmol}$ ) and NIS $(450 \mathrm{mg}, 2.0 \mathrm{mmol})$. After $22 \mathrm{~h}$, purification by column chromatography on silica gel ( $n$-hexane/EtOAc: $5 / 1$ ) yielded 221 w (277 mg, 73\%)

as a white solid.

M.p. $=149-150{ }^{\circ} \mathrm{C}$.

179 V. S. Chan, R. G. Bergman, F. D. Toste, J. Am. Chem. Soc. 2007, 129, 15122-15123. - 156 - 
${ }^{1} \mathrm{H}-\mathrm{NMR}\left(300 \mathrm{MHz}, \mathrm{CDCl}_{3}\right): \delta=6.73(\mathrm{~d}, J=7.8 \mathrm{~Hz}, 1 \mathrm{H}), 6.61(\mathrm{~d}, J=7.8 \mathrm{~Hz}, 1 \mathrm{H}), 6.02(\mathrm{dd}, J=$ 7.0, 1.2 Hz, 2H), 3.62 (sept, $J=6.7 \mathrm{~Hz}, 1 \mathrm{H}$ ), 3.47 (sept, $J=6.7 \mathrm{~Hz}, 1 \mathrm{H}), 1.55(\mathrm{~d}, J=6.7 \mathrm{~Hz}, 3 \mathrm{H}$ ), $1.52(\mathrm{~d}, J=6.7 \mathrm{~Hz}, 3 \mathrm{H}), 1.22(\mathrm{~d}, J=6.7 \mathrm{~Hz}, 3 \mathrm{H}), 1.04(\mathrm{~d}, J=6.7 \mathrm{~Hz}, 3 \mathrm{H})$.

${ }^{13} \mathrm{C}-\mathrm{NMR}\left(75 \mathrm{MHz}, \mathrm{CDCl}_{3}\right): \delta=169.1\left(\mathrm{C}_{\mathrm{q}}\right), 149.7\left(\mathrm{C}_{\mathrm{q}}\right), 145.5\left(\mathrm{C}_{\mathrm{q}}\right), 137.5\left(\mathrm{C}_{\mathrm{q}}\right), 119.1(\mathrm{CH}), 108.3$ $(\mathrm{CH}), 100.7\left(\mathrm{C}_{\mathrm{q}}\right), 70.0\left(\mathrm{CH}_{2}\right), 51.2(\mathrm{CH}), 46.0(\mathrm{CH}), 20.8\left(\mathrm{CH}_{3}\right), 20.7\left(\mathrm{CH}_{3}\right), 20.6\left(\mathrm{CH}_{3}\right), 20.2$ $\left(\mathrm{CH}_{3}\right)$.

IR (ATR): $\tilde{V}=2961,2927,1621,1445,1339,1238,1033,898,763,593 \mathrm{~cm}^{-1}$.

MS (EI) $m / z$ (relative intensity): 375 (13) $\left[\mathrm{M}^{+}\right], 332$ (20), 275 (100), 149 (12).

HR-MS (EI) $\mathrm{m} / z$ calcd for $\mathrm{C}_{14} \mathrm{H}_{18} \mathrm{INO}_{3}{ }^{+} 375.0331$, found 375.0329 .

\section{Synthesis of 4-iodo- $N, N$-diisopropyl-[1,1'-biphenyl]-3-carboxamide (221k)}

$\mathrm{O}_{Y} \mathrm{~N}(i-\mathrm{Pr})_{2}$ The general procedure $\mathbf{H}$ was followed using I,N-diisopropyl-[1,1'-biphenyl]-3-carboxamide (219k) $(141 \mathrm{mg}, 0.5 \mathrm{mmol})$ and NIS (338 mg, $1.5 \mathrm{mmol})$. After $22 \mathrm{~h}$, purification by column chromatography on silica gel ( $n$-hexane/EtOAc: $20 / 1 \rightarrow 10 / 1)$ yielded $221 \mathbf{k}(130 \mathrm{mg}, 64 \%)$ as a white

solid.

M.p. $=171-172{ }^{\circ} \mathrm{C}$.

${ }^{1} \mathrm{H}-\mathrm{NMR}\left(300 \mathrm{MHz}, \mathrm{CDCl}_{3}\right): \delta=7.84(\mathrm{~d}, J=8.2 \mathrm{~Hz}, 1 \mathrm{H}), 7.53(\mathrm{dt}, J=7.0,2.0 \mathrm{~Hz}, 2 \mathrm{H}), 7.43(\mathrm{dt}$, $J=7.0,2.0 \mathrm{~Hz}, 2 \mathrm{H}), 7.36(\mathrm{dt}, J=7.0,1.3 \mathrm{~Hz}, 1 \mathrm{H}), 7.32(\mathrm{~d}, J=2.2 \mathrm{~Hz}, 1 \mathrm{H}), 7.23(\mathrm{dd}, J=8.2$, $2.2 \mathrm{~Hz}, 1 \mathrm{H}), 3.65$ (sept, $J=6.7 \mathrm{~Hz}, 1 \mathrm{H}), 3.52$ (sept, $J=6.7 \mathrm{~Hz}, 1 \mathrm{H}), 1.60(\mathrm{~d}, J=6.7 \mathrm{~Hz}, 3 \mathrm{H}), 1.58$ $(\mathrm{d}, J=6.7 \mathrm{~Hz}, 3 \mathrm{H}), 1.28(\mathrm{~d}, J=6.7 \mathrm{~Hz}, 3 \mathrm{H}), 1.06(\mathrm{~d}, J=6.7 \mathrm{~Hz}, 3 \mathrm{H})$.

${ }^{13} \mathrm{C}-\mathrm{NMR}\left(75 \mathrm{MHz}, \mathrm{CDCl}_{3}\right): \delta=169.6\left(\mathrm{C}_{\mathrm{q}}\right), 144.5\left(\mathrm{C}_{\mathrm{q}}\right), 141.4\left(\mathrm{C}_{\mathrm{q}}\right), 139.6(\mathrm{CH}), 139.4\left(\mathrm{C}_{\mathrm{q}}\right), 128.9$ $(\mathrm{CH}), 128.1(\mathrm{CH}), 127.9(\mathrm{CH}), 126.9(\mathrm{CH}), 124.3(\mathrm{CH}), 90.8\left(\mathrm{C}_{\mathrm{q}}\right), 51.2(\mathrm{CH}), 46.0(\mathrm{CH}), 20.8$ $\left(\mathrm{CH}_{3}\right), 20.7\left(\mathrm{CH}_{3}\right), 20.6\left(\mathrm{CH}_{3}\right), 20.0\left(\mathrm{CH}_{3}\right)$.

IR (ATR): $\tilde{V}=2967,2930,1622,1444,1337,1207,785,608 \mathrm{~cm}^{-1}$.

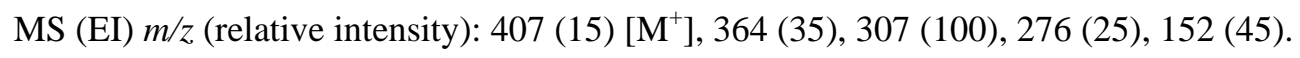

HR-MS (EI) $m / z$ calcd for $\mathrm{C}_{19} \mathrm{H}_{22} \mathrm{INO}^{+}$407.0746, found 407.0727.

Synthesis of 4-iodo- $N, N$-diisopropyl-4'-methyl-[1,1'-biphenyl]-3-carboxamide (2211)

$\mathrm{O}_{Y \mathrm{~N}(i-\mathrm{Pr})_{2}}$ The general procedure $\mathbf{H}$ was followed using - N,N-diisopropyl-4'-methyl-[1,1'-biphenyl]-3-carboxamide (219l) (148 mg,

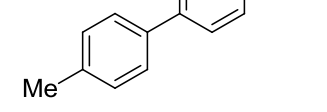
column chromatography on silica gel ( $n$-hexane/EtOAc: $20 / 1 \rightarrow 10 / 1$ ) yielded 2191 (145 $\mathrm{mg}, 68 \%$ ) as a white solid.

M.p. $=208-210^{\circ} \mathrm{C}$.

${ }^{1} \mathrm{H}-\mathrm{NMR}\left(300 \mathrm{MHz}, \mathrm{CDCl}_{3}\right): \delta=7.82(\mathrm{~d}, J=8.2 \mathrm{~Hz}, 1 \mathrm{H}), 7.43(\mathrm{dt}, J=8.1,1.8 \mathrm{~Hz}, 2 \mathrm{H}), 7.30(\mathrm{~d}$, $J=2.2 \mathrm{~Hz}, 1 \mathrm{H}$ ), $7.26-7.19$ (m, 3H), 3.65 (sept, $J=6.6 \mathrm{~Hz}, 1 \mathrm{H}$ ), 3.52 (sept, $J=6.6 \mathrm{~Hz}, 1 \mathrm{H}$ ), 2.37 $(\mathrm{s}, 3 \mathrm{H}), 1.60(\mathrm{~d}, J=6.6 \mathrm{~Hz}, 3 \mathrm{H}), 1.57(\mathrm{~d}, J=6.6 \mathrm{~Hz}, 3 \mathrm{H}), 1.27(\mathrm{~d}, J=6.6 \mathrm{~Hz}, 3 \mathrm{H}), 1.06(\mathrm{~d}, J=$ $6.6 \mathrm{~Hz}, 3 \mathrm{H})$.

${ }^{13} \mathrm{C}-\mathrm{NMR}\left(75 \mathrm{MHz}, \mathrm{CDCl}_{3}\right): \delta=169.8\left(\mathrm{C}_{\mathrm{q}}\right), 144.5\left(\mathrm{C}_{\mathrm{q}}\right), 141.4\left(\mathrm{C}_{\mathrm{q}}\right), 139.6(\mathrm{CH}), 137.8\left(\mathrm{C}_{\mathrm{q}}\right), 136.6$ $\left(\mathrm{C}_{\mathrm{q}}\right), 129.6(\mathrm{CH}), 128.0(\mathrm{CH}), 126.7(\mathrm{CH}), 124.1(\mathrm{CH}), 90.4\left(\mathrm{C}_{\mathrm{q}}\right), 51.2(\mathrm{CH}), 46.0(\mathrm{CH}), 21.1$ $\left(\mathrm{CH}_{3}\right), 20.8\left(\mathrm{CH}_{3}\right), 20.7\left(\mathrm{CH}_{3}\right), 20.7\left(\mathrm{CH}_{3}\right), 20.0\left(\mathrm{CH}_{3}\right)$.

IR (ATR): $\tilde{V}=2968,2929,1627,1440,1335,1034,762,515 \mathrm{~cm}^{-1}$.

MS (ESI) $m / z$ (relative intensity): $382(82)\left[(\mathrm{M}+\mathrm{H})^{+}\right], 444(37)\left[(\mathrm{M}+\mathrm{Na})^{+}\right], 843(100)\left[(2 \mathrm{M}+\mathrm{H})^{+}\right]$.

HR-MS (ESI) $m / z$ calcd for $\left[\left(\mathrm{C}_{20} \mathrm{H}_{24} \mathrm{INO}\right) \mathrm{H}\right]^{+} 382.0975$, found 382.0970 . 
Synthesis of 2-iodo- $N, N$-diisopropyl-5-(naphthalen-1-yl)benzamide (221x)

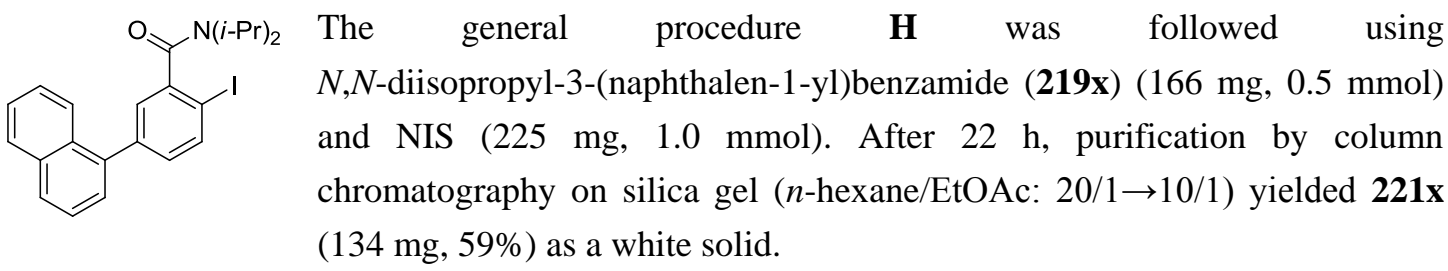

M.p. $=161-162^{\circ} \mathrm{C}$.

${ }^{1} \mathrm{H}-\mathrm{NMR}\left(300 \mathrm{MHz}, \mathrm{CDCl}_{3}\right): \delta=7.91(\mathrm{~d}, J=8.2 \mathrm{~Hz}, 1 \mathrm{H}), 7.89(\mathrm{~d}, J=8.2 \mathrm{~Hz}, 1 \mathrm{H}), 7.86(\mathrm{~d}, J=$ $8.6 \mathrm{~Hz}, 1 \mathrm{H}), 7.82(\mathrm{~d}, J=8.6 \mathrm{~Hz}, 1 \mathrm{H}), 7.50(\mathrm{dd}, J=8.2,7.0 \mathrm{~Hz}, 1 \mathrm{H}), 7.46(\mathrm{ddd}, J=8.0,7.0$, $1.5 \mathrm{~Hz}, 1 \mathrm{H}), 7.38(\mathrm{ddd}, J=7.6,7.5,1.5 \mathrm{~Hz}, 1 \mathrm{H}), 7.37(\mathrm{dd}, J=7.5,1.1 \mathrm{~Hz}, 1 \mathrm{H}), 7.25(\mathrm{dd}, J=2.2$, $2.1 \mathrm{~Hz}, 1 \mathrm{H}), 7.15(\mathrm{dd}, J=8.2,2.1 \mathrm{~Hz}, 1 \mathrm{H}), 3.77$ (sept, $J=6.6 \mathrm{~Hz}, 1 \mathrm{H}), 3.51$ (sept, $J=6.6 \mathrm{~Hz}, 1 \mathrm{H})$, $1.61(\mathrm{~d}, J=6.7 \mathrm{~Hz}, 3 \mathrm{H}), 1.51(\mathrm{~d}, J=6.7 \mathrm{~Hz}, 3 \mathrm{H}), 1.33(\mathrm{~d}, J=6.7 \mathrm{~Hz}, 3 \mathrm{H}), 1.09(\mathrm{~d}, J=6.7 \mathrm{~Hz}$, $3 \mathrm{H})$.

${ }^{13} \mathrm{C}-\mathrm{NMR}\left(75 \mathrm{MHz}, \mathrm{CDCl}_{3}\right): \delta=169.6\left(\mathrm{C}_{\mathrm{q}}\right), 144.2\left(\mathrm{C}_{\mathrm{q}}\right), 141.0\left(\mathrm{C}_{\mathrm{q}}\right), 139.3(\mathrm{CH}), 138.3\left(\mathrm{C}_{\mathrm{q}}\right), 133.7$ $\left(\mathrm{C}_{\mathrm{q}}\right), 131.1(\mathrm{CH}), 128.4(\mathrm{CH}), 128.2(\mathrm{CH}), 127.4(\mathrm{CH}), 126.9(\mathrm{CH}), 126.3(\mathrm{CH}), 126.0(\mathrm{CH})$, $125.5(\mathrm{CH}), 125.3(\mathrm{CH}), 91.0\left(\mathrm{C}_{\mathrm{q}}\right), 51.4(\mathrm{CH}), 46.0(\mathrm{CH}), 20.9\left(\mathrm{CH}_{3}\right), 20.7\left(\mathrm{CH}_{3}\right), 20.6\left(\mathrm{CH}_{3}\right)$, $20.1\left(\mathrm{CH}_{3}\right)\left(\right.$ One $\mathrm{C}_{\mathrm{q}}$ is invisible $)$.

IR (ATR): $\tilde{V}=2968,2933,1624,1439,1368,1331,1119,1038,1011,778 \mathrm{~cm}^{-1}$.

MS (ESI) $m / z$ (relative intensity): $458\left[(\mathrm{M}+\mathrm{H})^{+}\right](46), 915\left[(2 \mathrm{M}+\mathrm{H})^{+}\right](100)$.

HR-MS (ESI) $m / z$ calcd for $\left[\left(\mathrm{C}_{25} \mathrm{H}_{18} \mathrm{~F}_{3} \mathrm{NO}\right) \mathrm{H}\right]^{+} 458.0975$, found 458.0968.

Studies with isotopically labelled $[\mathrm{D}]_{4}-\mathrm{MeOH}$ (Scheme 90a)

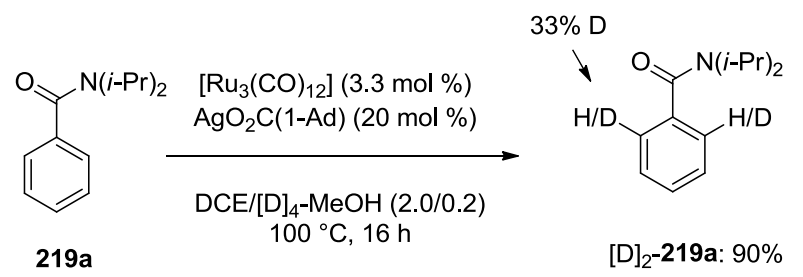

A mixture of $N, N$-diisopropylbenzamide (219a) (103 mg, $0.5 \mathrm{mmol}), \mathrm{Ru}_{3}(\mathrm{CO})_{12}(10.5 \mathrm{mg}$, $3.3 \mathrm{~mol} \mathrm{\%})$ and $\mathrm{AgO}_{2} \mathrm{C}(1-\mathrm{Ad})(28.7 \mathrm{mg}, 20 \mathrm{~mol} \%)$ in $\mathrm{DCE}(2.0 \mathrm{~mL})$ and [D] $]_{4} \mathrm{MeOH}(0.2 \mathrm{~mL})$ was stirred at $100{ }^{\circ} \mathrm{C}$ under $\mathrm{N}_{2}$ for $16 \mathrm{~h}$. The mixture was then allowed to cool to ambient temperature, diluted with EtOAc $(5 \mathrm{~mL})$, filtered through a short pad of silica gel and eluted with EtOAc $(50 \mathrm{~mL})$. After removing the solvent under reduced pressure, the product was purified by column chromatography on silica gel ( $n$-hexane/EtOAc: $4 / 1$ ) to yield a mixture 219a and $[\mathrm{D}]_{2}$-219a (93 mg, 90\%) as a white solid. The deuterium incorporation was estimated to be $33 \%$ by ${ }^{1} \mathrm{H}-\mathrm{NMR}$ spectroscopy.

\section{Studies with isotopically labelled compound $[D]_{1}-250$ (Scheme 90b)}

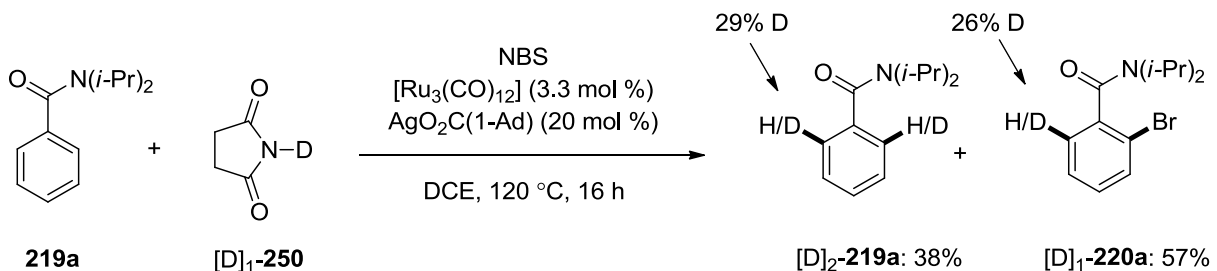

A mixture of $N, N$-diisopropylbenzamide (219a) $(205 \mathrm{mg}, 1.0 \mathrm{mmol}), \mathrm{NBS}(356 \mathrm{mg}, 2.0 \mathrm{mmol})$, -158 - 
$\mathrm{Ru}_{3}(\mathrm{CO})_{12}(21.1 \mathrm{mg}, 3.3 \mathrm{~mol} \%), \mathrm{AgO}_{2} \mathrm{C}(1-\mathrm{Ad})(57.4 \mathrm{mg}, 20 \mathrm{~mol} \mathrm{\%})$ and [D $]_{1}-250(200 \mathrm{mg}$, $2.0 \mathrm{mmol})$ in DCE $(3.0 \mathrm{~mL})$ was stirred at $120^{\circ} \mathrm{C}$ under $\mathrm{N}_{2}$ for $16 \mathrm{~h}$. The mixture was then allowed to cool down to ambient temperature, diluted with EtOAc $(5 \mathrm{~mL})$, filtered through a short pad of silica gel and eluted with EtOAc $(50 \mathrm{~mL})$. After removing the solvent under reduced pressure, the product was purified by column chromatography on silica gel ( $n$-hexane/EtOAc: $10 / 1 \rightarrow 5 / 1)$ to give $[\mathrm{D}]_{1}-\mathbf{2 2 0 a}(164 \mathrm{mg}, 57 \%)$ as a white solid and $[\mathrm{D}]_{2}-219 \mathbf{a}(79 \mathrm{mg}, 38 \%)$ as a white solid. The deuterium incorporation was estimated by ${ }^{1} \mathrm{H}-\mathrm{NMR}$ spectroscopy.

\section{Kinetic isotope effect studies by parallel experiments (Scheme 91)}

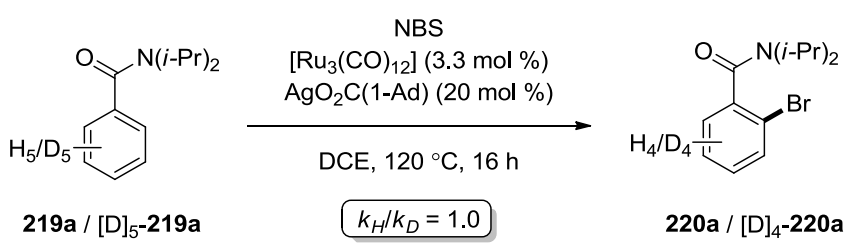

A mixture of benzamide $219 \mathrm{a}$ or $[\mathrm{D}]_{5}-\mathbf{2 1 9} \mathrm{a}(1.0 \mathrm{mmol})$, NBS $(356 \mathrm{mg}, 2.0 \mathrm{mmol}), \mathrm{Ru}_{3}(\mathrm{CO})_{12}$ $(21.1 \mathrm{mg}, 3.3 \mathrm{~mol} \%), \mathrm{AgO}_{2} \mathrm{C}(1-\mathrm{Ad})(57.4 \mathrm{mg}, 20 \mathrm{~mol} \%)$ and the internal standard 1,3,5-tri-tert-butylbenzene $(246 \mathrm{mg}, 1.0 \mathrm{mmol})$ in DCE $(8.0 \mathrm{~mL})$ was stirred at $120{ }^{\circ} \mathrm{C}$ under $\mathrm{N}_{2}$. For three hours, an aliquot $(0.2 \mathrm{~mL})$ was collected every fifteen minutes and submitted to GC analysis to determine the conversion.

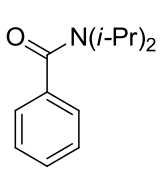

219a

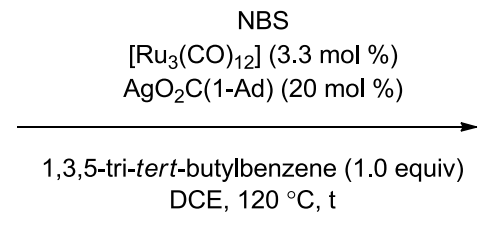

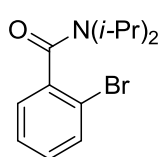

220a

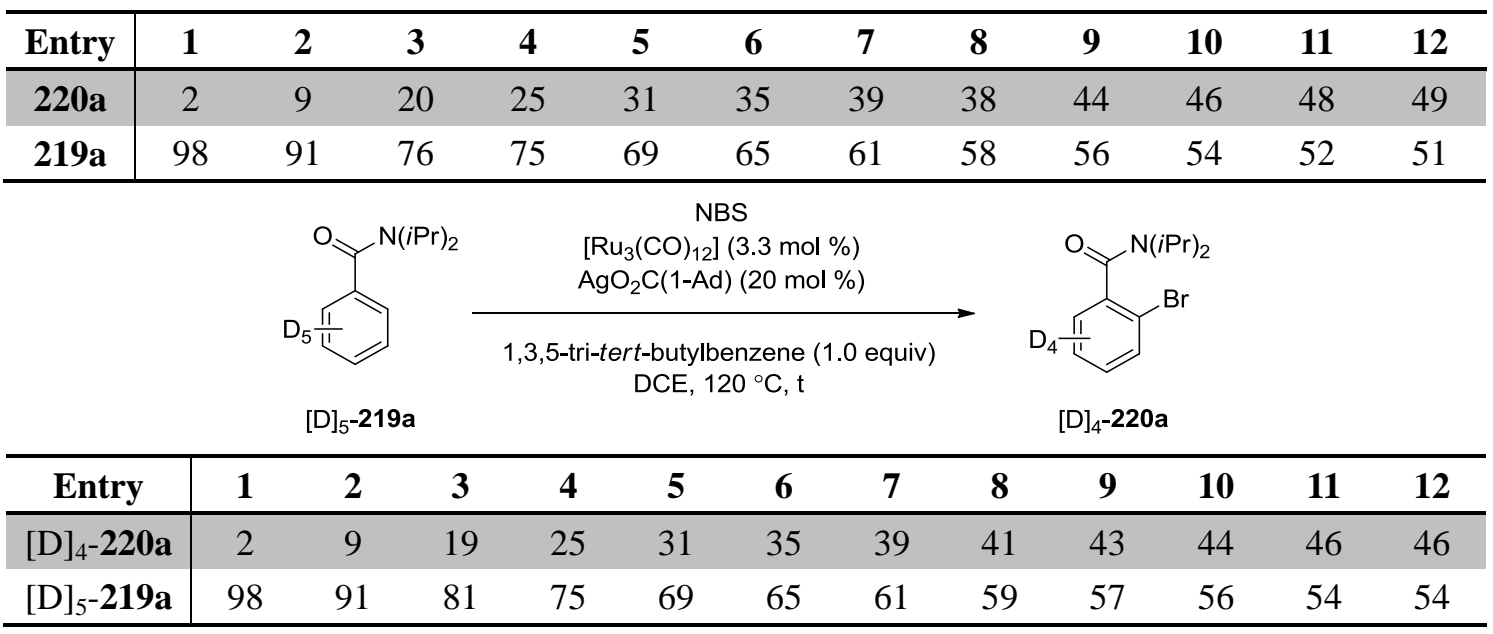




\section{List of Abbreviations}

\begin{tabular}{|c|c|c|c|}
\hline$\AA$ & Ångström & ESI & electronspray ionization \\
\hline Ac & acetyl & Et & ethyl \\
\hline Ad & adamantly & FG & functional group \\
\hline Alk & alkyl & $\mathrm{g}$ & gram \\
\hline AMLA & ambiphilic metal-ligand activation & GC & gas chromatography \\
\hline aq. & aqueous & $\mathrm{h}$ & hour \\
\hline $\mathrm{Ar}$ & aryl & Het & Hetero(aryl) \\
\hline APT & attached proton test & Hept & heptyl \\
\hline atm & atmospheric pressure & HPLC & high performance liquid chromatography \\
\hline ATR & attenuated total reflectance & HR-MS & high resolution mass spectrometry \\
\hline BHT & 2,6-di-tert-butyl-4-methylphenol & $\mathrm{Hz}$ & Hertz \\
\hline BINAP & 2,2'-bis(diphenylphosphino)-1,1'-binaphthyl & $i$ & iso \\
\hline $\mathrm{Bn}$ & benzyl & IES & internal electrophilic substitution \\
\hline Boc & tert-butyloxycarbonyl & IR & infrared spectroscopy \\
\hline $\mathrm{Bu}$ & Butyl & $J$ & coupling constant \\
\hline $\mathrm{Bz}$ & benzoyl & KIE & kinetic isotope effect \\
\hline calc. & calculated & $\mathrm{L}$ & ligand \\
\hline cat. & catalyst & Leu & leucine \\
\hline CMD & concerted-metalation-deprotonation & $m$ & meta \\
\hline $\operatorname{cod}$ & 1,5 -cyclooctadien & $\mathrm{m}$ & multiplet \\
\hline conv. & conversion & M & molar \\
\hline $\mathrm{Cp}$ & cyclopentadienyl & {$\left[\mathrm{M}^{+}\right]$} & molecular ion peak \\
\hline Cy & cyclohexyl & $\mathrm{Me}$ & methyl \\
\hline$\delta$ & chemical shift & Mes & mesityl \\
\hline d & doublet & $\mathrm{mg}$ & milligram \\
\hline DCE & 1,2-dichloroethane & $\mathrm{MHz}$ & megahertz \\
\hline DCM & dichloromethane & $\min$ & minute \\
\hline dd & doublet of doublet & $\mathrm{mL}$ & milliliter \\
\hline DFT & density functional theory & mmol & millimol \\
\hline DG & directing group & M. p. & melting point \\
\hline DMA & $N, N$-dimethylacetamide & MPV & membrane pump vacuum \\
\hline DME & dimethoxyethane & MS & mass spectrometry \\
\hline DMF & $N, N$-dimethylformamide & $m / z$ & mass-to-charge ratio \\
\hline DMSO & dimethyl sulfoxide & $n$ & normal \\
\hline DoM & directed ortho metalation & NBS & $N$-bromosuccinimide \\
\hline DPPH & 2,2-diphenyl-1-picrylhydrazyl & NHC & $N$ - heterocyclic carbene \\
\hline $\mathrm{dt}$ & doublet of triplet & NIS & $N$-iodosuccinimide \\
\hline Ed. & editor & NMP & $N$-methylpyrrolidinone \\
\hline EI & electron ionization & NMR & nuclear magnetic resonance \\
\hline equiv & equivalent & NXS & $N$-halosuccinimides \\
\hline
\end{tabular}




\begin{tabular}{|c|c|c|c|}
\hline$o$ & ortho & SPS & solvent purification system \\
\hline OPV & oil pump vacuum & $t$ & tert \\
\hline$p$ & para & $\mathrm{t}$ & triplet \\
\hline $\mathrm{Ph}$ & phenyl & $T$ & temperature \\
\hline Piv & pivaloyl & TEMPO & 2,2,6,6-tetramethylpiperidin-1-yloxy \\
\hline ppm & parts per million & $\mathrm{Tf}$ & trifluoromethanesulfonate \\
\hline $\operatorname{Pr}$ & propyl & TFA & trifluoroacetic acid \\
\hline PTSA & $p$-toluenesulfonic acid & TFAA & trifluoroacetic anhydride \\
\hline Py & pyridyl & THF & tetrahydrofuran \\
\hline PyDipSi & pyridyldiisopropylsilyl & TLC & thin layer chromatography \\
\hline pym & pyrimidyl & $\mathrm{TM}$ & transition metal \\
\hline $\mathrm{q}$ & quartet & TMS & trimethylsilyl \\
\hline $\mathrm{R}$ & rest & Ts & para-toluenesulfonyl \\
\hline rac & racemic & $\mathrm{TS}$ & transition state \\
\hline ref. & reference & $\tilde{V}$ & absorption \\
\hline s & singlet & $\mathrm{wt} \%$ & weight by volume \\
\hline sat. & saturated & $\mathrm{X}$ & (pseudo)halide \\
\hline $\sec$ & secondary & PyDipSi & pyridyldiisopropylsilyl \\
\hline $\mathrm{S}_{\mathrm{E}}^{\mathrm{Ar}}$ & electrophilic aromatic substitution & XPhos & 2-dicyclohexylphosphino-2', $4^{\prime}, 6^{\prime}$-tri- \\
\hline SET & single electron transfer & & isopropylbiphenyl \\
\hline SPO & secondary phosphine oxides & & \\
\hline
\end{tabular}




\section{Acknowledgements}

It is impossible for me to accurately represent how truly grateful I am to all of my family, friends, lab mates, professors, and, especially, my advisor, Prof. Dr. Lutz Ackermann. Nothing in this thesis would have been possible without every one of you. Thank you!

I have learned a tremendous amount about many different aspects of chemistry during my stay and for that I am indebted to my advisor Prof. Dr. Lutz Ackermann. I appreciate your persistent questioning of results, suggestions and discussions throughout this work. Your believing in me gives the confidence to go forward and peruse my highest ambitions.

I am also grateful to Prof. Dr. Dietmar Stalke for kindly accepting to be the second referee of this work, and for the work as second supervisor. His unending support provided me with a great deal of motivation.

I deeply thank Prof. Dr. Konrad Koszinowski, Prof. Dr. Franc Meyer, Dr. Alexander Breder and Prof. Dr. Guido Clever for their interest in this work and being on my review committee: I look forward to your questions at my defense and your input on my thesis.

I gratefully acknowledge China Scholarship Council (CSC) for the financial support during my research stay in Germany.

I thank Dr. Sergei Kozhuskhov for his concise correction of this manuscript, and Dr. Megha Joshi Yadav, Dr. Sudipta Roy, Jie Li, Wenbo Ma, Fanzhi Yang and Weiping Liu for their efficient advice to the thesis.

I admire the patience of Mrs. Gabriele Keil-Knepel for her listening and help with all the paper work. You really made me feel welcome when I first joined the lab and I really appreciate that.

I thank Mr. Stefan Beußhausen for the invaluable technical assistance with computer, software and else.

I also thank Mr. Karsten Rauch for his advices concerning problems from the lab.

Additionally, Dr. Alexander Breder, thank you for all the helpful comments and questions at the group seminars over the years. I really enjoyed having you there to ask probing questions to make me think that much harder, help us to discover new protocols.

Dr. Alexander V. Lygin, thank you for all of your help over my first year stay. As an excellent mentor, you are so easy to talk to and always willing to listen and give valuable advice and I truly appreciate that. Thank you for working together. I don't think I would be the chemist I am today if you were not in lab with me.

Dr. Nora Hofmann, thank you for inducing me into this new work environment and showing various techniques. Without your guidance and suggestions, I would not have the fortitude to make it through some difficult times.

I was also very lucky to have a smart lab mate Ratna Wolfram during my first year stay. You are such a generous and helpful friend and always willing to share german and indonesian cultures 
with others in the lab.

Dr. Marvin Schinkel, the first group member I met after arriving at Germany. I clearly remember that day that Weifeng and you picked me up on the Göttingen railway station. I felt very worm when touching a new world, even though it was a very bad weather. Thank you!

I truly thank Dr. Emelyne Diers, Karolina Graczyk, Darko Santrač and Svenja Warratz for their oboratively organized parties over the years, which makes our large group like a worm family. Ganbei!

I thank all my amazing lab mates-Dr. Thirunavukkarasu S. Vedhagiri, Jonathan Hubrich, Margherita Donati, Weiping Liu, Keshav Raghuvanshi in lab 309 and Darko Santrač, Phani Kumar Nekkanti, Carina Tirler, Stefano Cella in lab P123 for their help and encouragement at the past three years. Thank you for always being there for me to talk about chemistry and life.

I thank my colleagues in the Ackermann Lab, past and present: Dr. Harish Potukuchi, Dr. René Sandmann, Dr. Sebastian Barfüßer, Dr. Sabine Fenner, Dr. Atul Manvar, Dr. Benudhar Punji, Dr. Vaibhav Mehta, Dr. Hamad Hamdan Mohamed Al Mamari, Dr. Sudipta Roy, Dr. Megha Joshi Yadav, Dr. Emelyne Diers, Jola Pospech, Monica Dell'Acqua, Sittikorn Chancharoenrith, Monica Deponti, Christoph Kornhaaß, Karolina Graczyk, Svenja Warratz, Sachiyo Nakanowatari, Tobias Haven, Rajkumar Jeyachandran, Daniel Zell for the nice working atmosphere and the enjoyable times.

I would like particularly to thank all the members of the Analytical departments at the Institute for Organic and Biomolecular Chemistry: Mr. Reinhard Machinek and his team in the NMR department, Dr. Holm Frauendorf and Ms. Györgyi Sommer-Udvarnoki of the MS department.

During my stay in Göttingen I also enjoyed the friendship with my Chinese collegues and friends - Dr. Weifeng Song, Dr. Lixue Zhang, Dr. Qing Gu, Chunxiao Bao, Yingjun Zhu, Tongxun Guo, Muxin Han, Wenbo Ma, Jie Li, Jack Li, Fanzhi Yang, Weiping Liu, Zhixiong Ruan and Ruhuai Mei. Thank you all for the support during the hard times, and also the fun during the journeys.

My family- Mom, Dad, Fengqin, Hongmin and Fenghui have all been so supportive from the time I was a little kid to now. Their believing in me made all of this possible. My family has grown over the past few years, so welcome to Yonghao and Xibei thank you as well. I love you all.

Finally, I would like to thank all of my wonderful friends I have made over the past 30 years, and I don't think I would have made this journey if I didn't have every one of you!

Lianhui Wang (生连会) 


\section{Curriculum Vitae}

Date of birth: March $8^{\text {th }}, 1983$

Place of birth: Puyang (China)

Nationality: Chinese

\section{Education}

10/2010 - 02/2014 Studies for a doctorate under the supervision of Prof. Dr. Lutz Ackermann, Institute of Organic and Biomolecular Chemistry

Georg-August University of Göttingen, Göttingen, Germany

Research topic: "Carboxylate-Assisted Ruthenium-Catalyzed Direct $\mathrm{C}-\mathrm{H}$ Bond Functionalizations"

09/2007 - 07/2010 M. Sc. in Organic Chemistry

Supervisors: Prof. Dr. Xiuling Cui and Prof. Dr. Zhiwu Zhu

Department of Chemistry, Zhengzhou University, Zhengzhou, China

Research topic: "Application of Cyclopalladated Ferrocenylimine Complexes in the Synthesis of Arylboronate Esters and Suzuki-Miyaura Reaction"

09/2003-07/2007 B. Sc. in Chemistry

Department of Chemistry, Zhengzhou University, Zhengzhou, China

\section{Experience}

08/2011 - 03/2013 Teaching Assistant

Institute of Organic and Biomolecular Chemistry

Georg-August University of Göttingen, Göttingen, Germany

\section{Publications}

1. Lianhui Wang and Lutz Ackermann*: Ruthenium-catalyzed ortho-C-H halogenation of benzamides. Chem. Commun. 2014, 50, 1083-1085.

2. M. Schinkel, Lianhui Wang, K. Bielefeld, L. Ackermann*: Ruthenium(II)-Catalyzed C( $\left.\mathrm{sp}^{3}\right)^{3}$ $\mathrm{H} \alpha$-Alkylation of Pyrrolidines. Org. Lett. 2014, 16, Accepted for publication.

3. Lianhui Wang and Lutz Ackermann*: Versatile pyrrole synthesis through ruthenium(II)catalyzed alkene $\mathrm{C}-\mathrm{H}$ bond functionalization on enamines. Org. Lett. 2013, 15, 176-179.

4. Lutz Ackermann*, Lianhui Wang, Ratnakancana Wolfram and Alexander V. Lygin: Ruthenium-catalyzed oxidative $\mathrm{C}-\mathrm{H}$ alkenylations of anilides and benzamides in water. Org. Lett. 2012, 14, 728-731.

5. Lutz Ackermann*, Lianhui Wang and Alexander V. Lygin: Ruthenium-catalyzed aerobic oxidative coupling of alkynes with 2-aryl-substituted pyrroles. Chem. Sci. 2012, 3, 177-180. (highlighted by the Royal Society of Chemistry)

6. Lianhui Wang, Xiuling Cui*, Jingya $\mathrm{Li}$, Yusheng $\mathrm{Wu}$, Zhiwu Zhu and Yangjie $\mathrm{Wu}^{*}$ : Synthesis of biaryls through a one-pot tandem borylation/Suzuki-Miyaura cross-coupling reaction catalyzed by a palladacycle. Eur. J. Org. Chem. 2012, 595-603. 
7. Lianhui Wang, Jingya $\mathrm{Li}$, Xiuling Cui*, Yusheng $\mathrm{Wu}$, Zhiwu Zhu and Yangjie $\mathrm{Wu}^{*}$ : Cyclopalladated ferrocenylimines as efficient catalysts for the synthesis of arylboronate esters. Adv. Synth. Catal. 2010, 352, 2002-2010. 

